\title{
KUNST AUSSTELLEN
}

Nach den enttäuschenden Ergebnissen seiner Vereinstätigkeit in den 1820er und frühen 183oer Jahren kamen ganz neue Aufgaben auf Quandt zu. Sie gingen weit über seine privaten Tätigkeiten als reicher Mäzen und Kunstschriftsteller hinaus und erschlossen ihm neue und öffentlichkeitswirksame Felder. 1832 erhielt er den Auftrag zur Neueinrichtung eines Museums unter Zusammenführung der Kunst- und Rüstkammer in einem der Dresdener Zwingerpavillons. Daraus ging das Historische Museum hervor. Hierauf folgte 1836 der Eintritt in die Galeriekommission der Königlichen Kunstsammlungen, die ihm die Möglichkeit bot, in der Gemäldegalerie bei Neuhängungen mitzuarbeiten. Damit zeichnet sich ab Anfang der 183oer Jahre ein Tätigkeitsfeld ab, bei dem es weniger um die Förderung der Kunstproduktion, die Wiederentdeckung alter Kunst oder das Kunstsammeln ging, sondern in gewissem Sinn um den konsequenten nächsten Schritt: In Ausstellungen konnte Quandt seine Kunstansichten einem breiteren Publikum präsentieren.

Die Prozesse von Quandts Fördern und Ausstellen flossen ineinander und bedingten sich gegenseitig. Dies zeichnete sich in seiner Privatsammlung schon während der 1820er Jahre ab, wo er seine Bestände alter Meister und Zeitgenossen nicht gedankenlos an die Wände hing, sondern wohl überlegt präsentierte. Zugleich hatte er schon in den $1820 e r$ Jahren immer wieder Bilder seiner Sammlung in die Akademie- und Kunstvereinsausstellungen gegeben, um geförderte Künstler bekannter zu machen. ${ }^{1}$ Mit den königlichen Museen erhielt er nun die Gelegenheit, einem potentiell großen Publikum seine KunstAnschauungen im wahrsten Sinn des Wortes vor Augen zu führen. Quandts musealer Präsentation von Kunst sowohl im Privaten als auch im Öffentlichen und ihren Prämissen widmet sich der zweite Teil dieser Studie. 


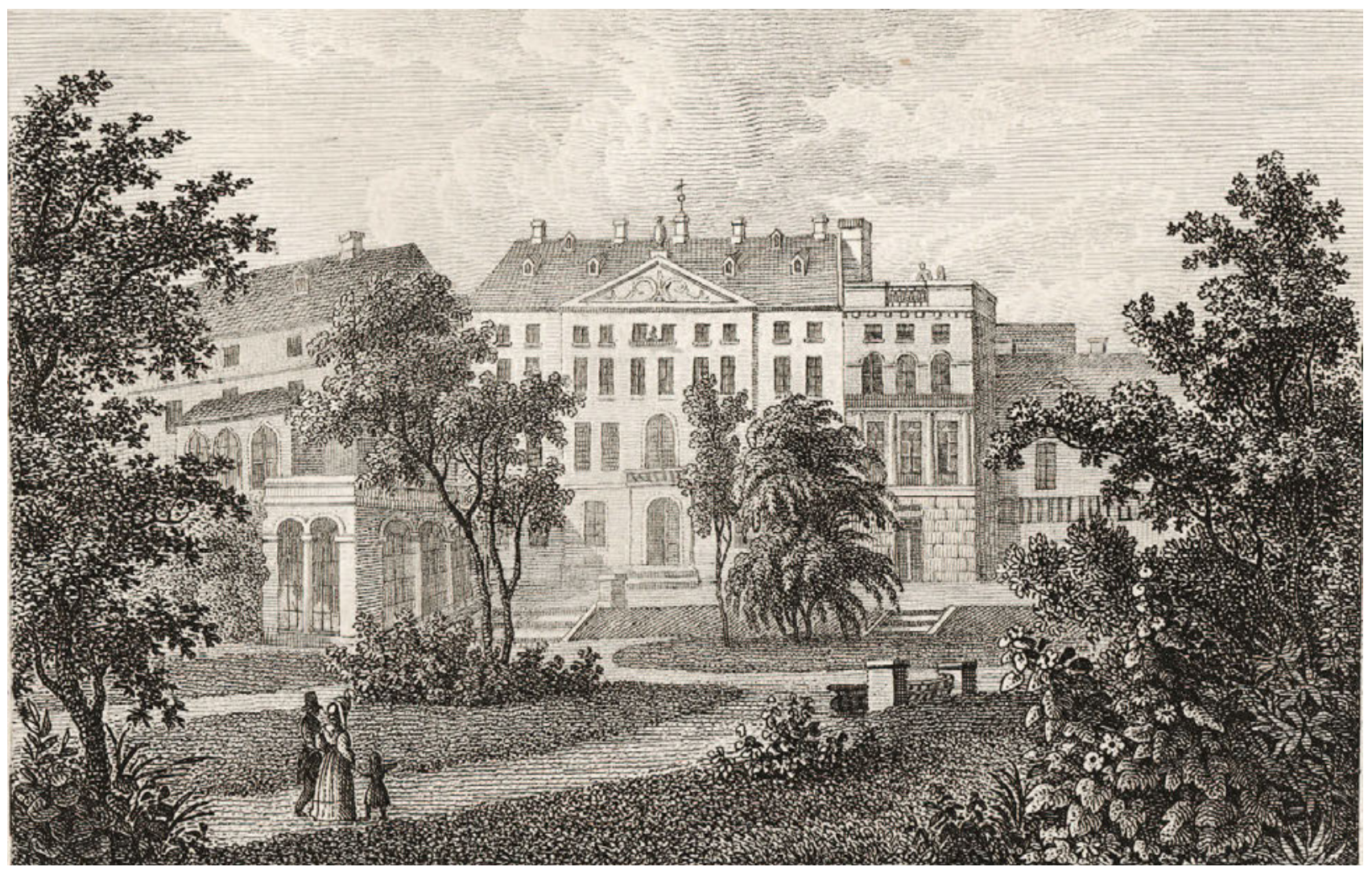

49 Johann Gottfried Abraham Frenzel, Haus und Garten des Herrn von Quandt zu Dresden, 1826, Radierung, $69 \times 107$ mm (Bild), Archiv des Autors 


\section{ALTE WERTE UND NEUE ERRUNGENSCHAFTEN: Aspekte der Privatsammlung}

\section{Ein offenes Haus für Kunst und Bildung}

Nach der Rückkehr aus Rom 1820 ließ sich das Ehepaar Quandt in Dresden nieder. Dort hatte der Kunstfreund auf der Neustädter Seite, angrenzend an die Elbwiesen und in unmittelbarer Nachbarschaft zur Augustusbrücke, an der Großen Klostergasse zwei Häuser gekauft, von denen er das kleinere gänzlich neu bauen und mit dem renovierten Haupthaus aus dem 18. Jahrhundert verbinden ließ (Abb. 49). Er richtete sich hier ein zusammenhängendes Anwesen mit Wohnungen, Garten und einem kleinen Museum ein. ${ }^{2}$ In den ersten Planungen hatte er vorgesehen, das angebaute Haus als Museum und Künstlerhaus mit Atelier einzurichten. Dieses Haus wäre im ersten Stock mit seiner Wohnung verbunden gewesen, im zweiten Stock mit einem Saal, der als Atelier hätte genutzt werden können, und im dritten Stock wäre die Künstlerwohnung eingerichtet worden. ${ }^{3}$ Das geplante Atelier wurde schließlich ein Ausstellungssaal für Teile der Gemäldesammlung. Die anderen Etagen vermietete Quandt teilweise an Leute aus der politischen Elite Sachsens. Zu ihnen gehörte, wohl nur bis 1824, Kriegskammerrat Anton von Carlowitz und ab 1830 Staatsminister Bernhard August von Lindenau. Damit beherbergte der Kunstfreund Leute aus dem Umfeld der reformorientierten Kräfte, die für die Begründung der ersten Sächsischen Verfassung von 1831 von großer Bedeutung waren. Besonders mit Lindenau, der den königlichen Sammlungen vorstand, ist auch ein gewisser Einfluss Quandts auf das Dresdener Kulturleben zu erklären. ${ }^{4}$

Pläne und tatsächliche Einrichtungen für die Sammlungen änderten sich in der ersten Hälfte der 1820er Jahre mehrfach. Nebst den Konzepten für die Gemäldesammlung lag ein Fokus

1 Zu den Dresdener Kunstvereinsausstellungen und Quandts Beteiligungen aktuell Marx 2014 (1). Zum Boom von Kunstvereinsausstellungen siehe Schmitz 2001, S. 253-264.

2 Im Dezember 1821 waren die Bauarbeiten zu Ende. Die Inneneinrichtung dauerte noch bis 1824. Brief von Clara Bianca von Quandt an Schnorr vom 14.12.1821, in: SLUB, Mscr. Dresd. n Inv. 15, Bd. 31, fol. 8ov. S. a. Hertzig 2011, S. 99; Briel 2002, S. 14; Lammel 1998, S. 470, Anm. 13; Bemmann 1925, S. 7-8; Schnorr 1886, S. 156; Seidemann 1860, S. 158; Becker/Frenzel 1826, S. XXVI-XXVIII. Grundrisse aus der Bauzeit des Haupthauses, sog. »Rudolphisches Haus« in Dresden, Sächsisches Landesamt für Denkmalpflege, Plansammlung, Inv.-Nr. M 21 A BI. 13-16, 51.

3 Die Künstlerwohnung war für Freund Schnorr gedacht, der 1827 jedoch von Rom direkt nach München ging; Briefe von Quandt an Schnorr auf der Vermehrung und Präsentation der Abgusssammlung antiker Werke. In einem Brief vom September 1849 an den Archäologen und Philologie-Professor Friedrich Gottlieb Welcker in Bonn wird zusammenfassend deutlich, welche Rolle Quandt der Antike zumaß. Die antike Kunst ließe die »ewiglebendige Schönheit des Alterthums« erkennen. Dadurch wirke sie in die Gegenwart und Zukunft:»Ihr[Welckers-AR] Werk giebt nicht blos Erklärungen sondern Aufschlüsse über die Antike und gewährt in Zeiten wie die unsern, eine Zuflucht vor der Gegenwart in das Altertum, welches uns durch seine unvergängliche Herrlichkeit auch Vertraun zu der Zukunft einflößt; denn das Menschengeschlecht kann aller Verblendung unerachtet doch nicht völlig ausarten, weil in der geistigen, wie in der materiellen Natur eine unerschöpfliche Reproductionskraft liegt [...]. $\kappa^{5}$ Mit der Flucht vor unsicheren Zeiten in die Betrachtung alter Kunstwerke meinte er die so genannten Märzrevolutionen, die Dresden im Mai 1849 erfasst hatten. Darüber hinaus zeigt sich das Ideal, dass Quandt nicht nur der antiken Kunst, sondern der Kunst überhaupt zumaß: Sie erschafft sich das Schöne aus der Natur und gibt dadurch dem Menschen immerwährende Inspiration. Durch die Präsentation von Abgüssen nach Antiken wollte er Künstlern das Studium dieser idealen Werke ermöglichen.

Zuerst wollte Quandt Gipsabgüsse der Ägineten beschaffen. Ein Teil der Giebelfiguren des Aphaia-Tempels auf der griechischen Insel Aegina war 1813 in die Münchner Glyptothek überführt worden. Für seine Nachbildungen beabsichtigte er einen Saal zu bauen und durch Julius Schnorr von Carolsfeld mit Fresken bemalen zu lassen. Nachdem er dem Künstler von seinen Plänen geschrieben hatte, zögerte er. Geprägt vom

vom 23.12.1820, 11.2., 13.6. und 14.10.1821, in: SLUB, Mscr. Dresd. n Inv. 15, Bd. 31, fol. 55v-56r, 62r-v, 68r-v, $73 r$.

4 Zu den Vermietungen an Carlowitz und Lindenau siehe den Brief von Quandt an Rochlitz vom 18.12.1822, in: SLUB, Mscr. Dresd., App. 26, Nr. 218. S. a. Rüfenacht 2011, S. 101. Anton von Carlowitz war der Bruder des Reformpolitikers und Nachfolgers von Lindenau, Hans Georg von Carlowitz.

5 Quandt an Welcker, [September] 1849, in: Bonn, Universitäts- und Landesbibliothek, Dezernat 5 / Abt. Handschriften und Rara, Autographensammlung, S 685 (NL Welcker), Brief 2. Das natürliche Schönheitsideal geht auf Johann Joachim Winckelmann zurück, »dessen Ziel die Erkenntnis der ewiglebendigen Schönheit des Alterthums ist«, wie Quandt Welcker erklärt. 


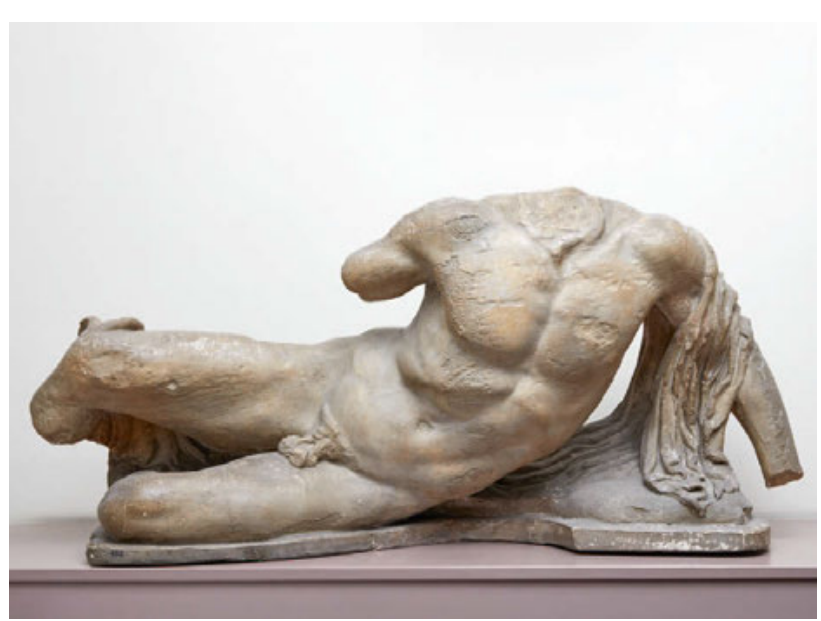

50 Flussgott, sog. Ilissos (Gipsabguss der Marmorstatue aus dem Westgiebel des Parthenon, Akropolis, Athen, Original in: London, British Museum, Inv.-Nr. 1816,0610.99), Gusswerkstatt: vermutlich D. Brucciani \& Co. Ltd., London, vor 1856, Gips, patiniert, 86,3×189 × 77 cm, Zürich, Archäologische Sammlung der Universität Zürich, Inv.-Nr. G 482

eigenen Erleben der Befreiungskriege gegen Napoleon in Leipzig wollte er wegen der drohenden Kriegsgefahr doch keine unbeweglichen Gemälde in Auftrag geben. ${ }^{6}$ Schließlich verzichtete er sogar auf die Beschaffung von Abgüssen der Ägineten.

Später kaufte er einige Abgüsse der Elgin-Marbles, die dem Fries des Parthenontempels in Athen entstammten. In einem Brief an den Altertumsforscher Carl August Böttiger aus dem Jahr 1821, in welchem er um Rat bei der Auswahl fragte, schrieb er: »Bey einer Auswahl wünschte ich besonders auf solche Gegenstände Rücksicht zu nehmen, welche für Künstler lehrreich $\mathrm{u}$ den Schönheitssinn bildend sind. Man kann dies wohl von allen den hier verzeichneten Kunstwerken erwarten, welche das Eigenthümliche u vor allen andern Antiken voraus haben, daß weit mehr schöne Natur als Stÿl an denselben zu schätzen ist, u daß sie deshalb für junge Künstler so höchst wichtig sind. Sie öffnen das Verständnis u den Sinn für reine, in keinen Styl, in keine Kunstform eingekleidete oder auch eingeengte Naturschönheit. Durch sie ist allein eine Vereinigung aller Künstler möglich, welche in unsern Tagen in zweÿ feindliche Lager zerfallen sind, in Anhänger des Mittelalters u der Schule des Mengs, weil in diesen Werken selbst Natur u Kunst sich völ-

6 Brief von Quandt an Schnorr vom 23.12.1820, 11.2., 1.4.1821 und 25.4.1822, in: SLUB, Mscr. Dresd. n Inv. 15, Bd. 31, fol. 55v-56r, 63r-64v, 85v.

7 Zitiert nach Bemmann 1925, S. 8 nach dem Brief in der SLUB, Mscr. Dresd. h 37 Korr. $4^{\circ}, 157$, Nr. 6.

8 Brief von Quandt an Schnorr vom 1.4.1821, in: SLUB, Mscr. Dresd. n Inv. 15, Bd. 31, fol. 63r-64v.

9 Quandt 1826 (1), S. 281-282.

10 Böttiger 1822, S. 62: „So bereitete er vor Kurzem eine zweckmäßige Sala terrena in seinem Garten, worin er drei Abgüsse aus den gerühmten Elgin Marbels im brittischen Museum, den Torso des Ilissus und The-

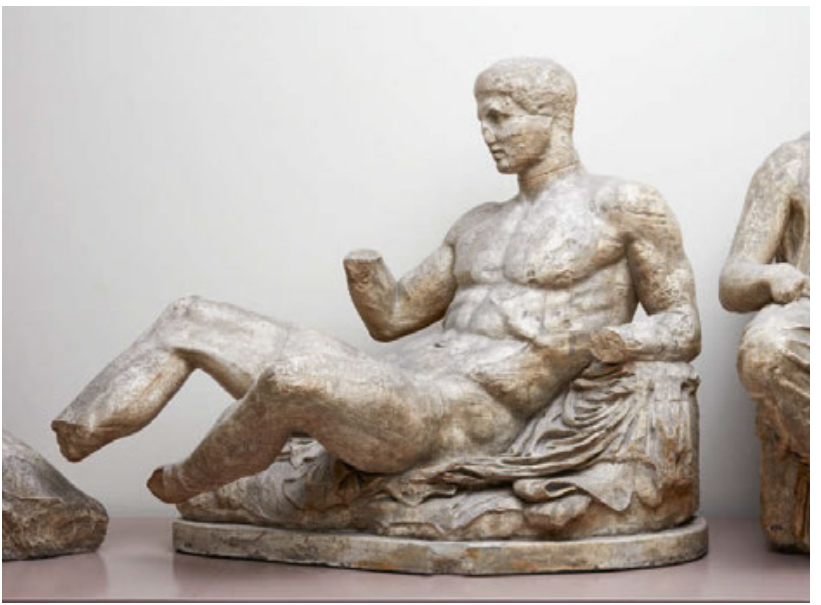

51 Dionysos, früher als »Theseus« (Gipsabguss der Marmorstatue aus dem Ostgiebel des Parthenon, Akropolis, Athen, Original in: London, British Museum, Inv.-Nr. 1816,0610.93), Gusswerkstatt: vermutlich D. Brucciani \& Co. Ltd., London, nach 1856, Gips, patiniert, $136 \times 177 \times 100($ ?) $\mathrm{cm}$, Zürich, Archäologische Sammlung der Universität Zürich, Inv.-Nr. G 475

lig ausgleicht. « Programmatisch war also die vereinigende Funktion, die Quandt den Elgin-Marbles zumaß. Bei Erhalt zweier liegender männlicher Gestalten aus der Elgin'schen Sammlung - des Flussgottes Illisos und des Helden Theseus (Abb. 5O-51) - sah er den Beweis seiner Vermutung erbracht, »daß das Schöne das vollkommen Naturgemäße ist, nicht aber jener sogenannte Idealstyl welcher von Natur u Wahrheit abweicht. $\kappa^{8}$ Der Kunstfreund glaubte, dass nur solche naturgemäßen, stillosen Statuen zum Abzeichnen während der Künstlerausbildung geeignet seien. ${ }^{9}$ Böttiger selbst lobte Quandt dafür, die Werke frei im Gartensaal aufgestellt zu haben. Dadurch könnten sie allseitig betrachtet und kopiert werden. In dem kleinen Ausstellungsraum für Antiken stellte Quandt den Wänden entlang weitere Parthenon-Abgüsse des Zentaurenkampfs und einer Prozession sowie einen Abguss der Venus von Milo aus..$^{10}$ Mit der Präsentation der Abgüsse erhoffte er sich einen Verdienst unter der Dresdener Künstlerschaft zu erwerben. Aus diesem Grund gewährte er während der Schließzeiten der königlichen Sammlungen Zutritt zu seinem Gartenpavillon, der auf dem Gemälde von Franz Wilhelm Leuteritz im Vordergrund zu sehen ist (Abb. 52). ${ }^{11}$

seus und den berühmten Pferdekopf so aufstellte, daß sie umgangen und von allen Seiten gezeichnet werden können, zur Freude aller hiesigen Kunstfreunde.« S. a. Anonym 1825, Sp. 828.

11 Als 1839 auch die königlichen Sammlungen Abgüsse der Elgin Marbles in den Zwingerpavillons ausstellen konnten, schrieb Quandt ein Vorwort an die Beschauer der Abgüsse von den Bildwerken vom Parthenon. Das Werk konnte weder in Bibliotheken noch Archiven ausfindig gemacht werden. Es ist erwähnt in Seidemann 1860, S. 159 und in KB 1839, Nr. 79, S. 316: „Die Abgüsse der Bildwerke vom Parthenon, der sogenannten Elgin marbles, sind nun seit einigen Wochen alle Freitage 


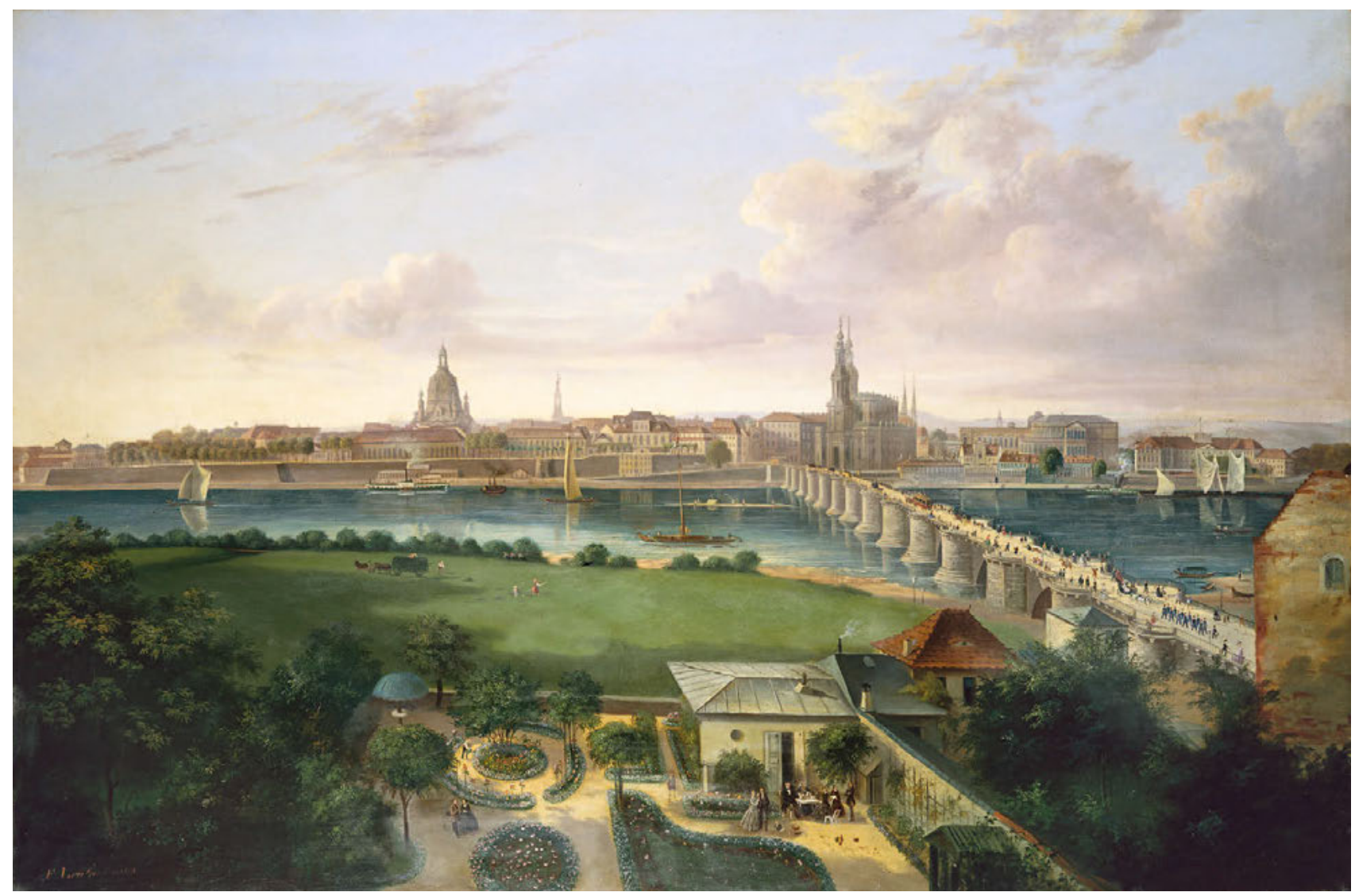

52 Franz Wilhelm Leuteritz, Blick vom Quandt’schen Garten aus, 1860, Öl auf Leinwand, 61,5× 92,5 cm, Dresden, Städtische Galerie, Inv.-Nr. 1979/k 191

Mit der Zeit trat das Sammeln von Antiken und Abgüssen in den Hintergrund. 1857 notierte Quandt: »Da ich selbst ein Alterthum geworden bin, so habe ich es aufgegeben Antiken zu sammlen, unerachtet solche den Vorzug haben, immer schön zu bleiben, was uns Menschen, die wir keine idealen Wesen, auch nicht von Stein, sondern individuelle, ephemere Ersch[e]inungen sind, nicht beschieden ist. $\ll^{12}$ Die Briefstelle macht deutlich, dass Quandts Hauptinteresse an den Antiken ihrer unvergänglichen Schönheit galt. Darin sollten sie den zeitgenössischen Künstlern vorbildlich sein. Gleichzeitig war die Antikensammlung für ihn immer sekundär, denn Vorbildhaftigkeit versprach er sich in erster Linie von Kunstwerken mittelalterlicher und frühneuzeitlicher Meister, wie noch darzulegen sein wird. Nach denselben Ansprüchen wie bei den Antiken im Gartensalon funktionierte daher auch die Präsentation der Gemäldesammlung im Wohnhaus.

in den Vormittagsstunden dem Publikum zugänglich. Die Anordnung des Lokals in einem der Zwingerpavillons ist geschmackvoll und zweckmäßig. Ritter von Quandt hat eine Erläuterung der Kunstwerke für die Bildhauer drucken lassen. Der Versuch ist nicht sehr zahlreich, was für die Berufenen umso vortheilhafter ist.« Zur Bedeutung von geregelten Öffnungszeiten für öffentliche Museen siehe Savoy 2006, S. 20-22.
Im ersten Stockwerk seiner Wohnung richtete Quandt in repräsentativen Wohnräumen auf der Gartenseite seine Gemäldesammlung ein. Alfred Meissner, Schriftsteller und Neffe seiner Frau beschrieb sie wie folgt: »Mein Onkel [...] hatte sich sein Haus auf der Neustadt mit prachtvoller Aussicht auf die Elbufer nach Art eines italienischen Palazzo eingerichtet und eine Enfilade von neun Zimmern im ersten Stockwerk ganz mit Gemälden angefüllt. Es waren theils Werke Alter Meister, die der erfahrene Bilderfreund in italienischen Klöstern und Villen aufgestöbert, theils moderne Bilder, die er bei noch lebenden Malern bestellt hatte. [...] Alle Zimmer der Belletage waren mit grünem Damast tapezirt oder mit Stuck bekleidet, aber völlig unbewohnt. $\ll^{13}$ Die Enfilade von neun Zimmern kann in den Quellen und den Katalogen nachvollzogen werden. Sein Hinweis auf das Unbewohnte deutet auf eine Trennung repräsentativer und eigentlicher Wohnräume hin. Ob Quandt sie wirklich

12 Brief von Quandt an Hermann Hettner vom 26.9.1857, in: Heidelberg, Universitätsbibliothek, Sign. Heid. Hs. 2751 C 85.

13 Meissner 1884, Bd. 1, S. 17. Eine Beschreibung der Innenausstattung aus unmittelbarer Hand im Brief von Quandt an Rochlitz am 18.12.1822, in: SLUB, Mscr. Dresd., App. 26, Nr. 218. S. a. Anonym 1825, Sp. 781-782, 788-791. 
gar nicht nutzte, kann nicht restlos geklärt werden. Immerhin betonte der Sammler, er lebe mit den Kunstwerken, und sehe Kunst als Mittelpunkt des Lebens an. ${ }^{14}$ So scheint eine gewisse Durchmischung von Wohn- und Sammlungsräumen naheliegend. Sicher ist, dass nur ein größerer Saal als reiner Museumsraum genutzt wurde. ${ }^{15}$ Eine ausführliche Beschreibung der elbseitigen Raumfolge eines anonymen Zeitgenossen zeugt davon, dass es sich hierbei eher um repräsentative Wohnräume handelte, die nur beschränkt alltagstauglich waren. Laut diesem Text lebte Quandt in dem sehr großen Haus an der Klostergasse gassenseitig in der Familienwohnung und nutzte den elbseitigen Gebäudeflügel vor allem zu besonderen Zwecken wie der Präsentation seiner Kunstsammlung. ${ }^{16}$

Dank des Katalogs von 1824, den Quandt für einen ungeschickten Hausdiener hatte drucken lassen, der Reisende durch die Sammlungen führen musste, einigen Briefpassagen und dem erwähnten anonymen Bericht über die Raumfolgen kann man sich eine recht gute Vorstellung der räumlichen Einrichtung machen. ${ }^{17}$ Im ersten Raum war Goethes Büste von Christian Daniel Rauch (vgl. Abb. 102) und eine Kopie nach Raffaels $G a^{-}$ latea aufgestellt. ${ }^{18}$ Der zweite Raum enthielt eine für Quandts Kunstverständnis bedeutende Anordnung zweier Landschaften von Caspar David Friedrich und Johann Martin von Rohden zusammen mit weiteren Gemälden, die sich im Laufe der Zeit wandelte. Diese beiden ersten Räume des Rundgangs werden Thema nachfolgender Kapitel sein. ${ }^{19}$

Zwei im Katalog erwähnte Räume mit Familienporträts und einem Seesturm von Franz Catel schien der anonyme Besucher

14 Quandt 1853, S. 1-2; Brief an Schnorr vom 7.8.1823, fol. 98r-99v, in: SLUB, Mscr. Dresd. n Inv. 15, Bd. 31, fol. 98r-99v.

15 Nebst den Quellen deuten die beiden Kataloge von 1824 und 1868 darauf hin, dass die Raumfunktionen über die Jahrzehnte unverändert blieben. Beide Kataloge verweisen auf einen Salon und auf Kunstwerke im Wohnzimmer der Frau.

16 Diese Vermutung ergibt sich aus der Lektüre von Anonym 1825, Sp. 781-828, zum Beispiel Sp. 781: »Wir steigen eine Treppe; der Vorsaal wird uns geöffnet, und wir gehen durch mehrere reich und geschmackvoll ausgeschmückte Zimmer in das Hinterhaus, welches auf die Elbe sieht. « Erst da beginnt die eigentliche Beschreibung der Kunstwerke, die auch mit Kat. Quandt 1824 übereinstimmt. S. a. Becker/Frenzel 1826, S. XXVI-XXVIII.

17 Kat. Quandt 1824. Über den Zweck dieses Führers siehe den Brief von Quandt an Rudolph Weigel vom 2.3.1844, in: SLUB, Mscr. Dresd. App. 1191, Nr. 583; Anonym 1825, Sp. 780-782, 788-791, 811-814. 817-820, 826-828. Rüfenacht 2018, S. 6-45 bietet einen Überblick der einzelnen Kunstwerke in Quandts Sammlung in Bezug zu den Präsentationsräumen gemäß Kat. Quandt 1824 und Kat. Quandt 1868.

18 Quandt plante hier anfänglich die Unterbringung der Vittoria Caldoni von Schnorr, die er aber erst 1825 erhielt und sie dann im Gemäldesaal des zweiten Geschosses ausstellte. Brief von Quandt an Schnorr vom 22.8.1823, in: SLUB, Mscr. Dresd. n Inv. 15, Bd. 31, fol. 101r. Zu den ausgestellten Werken siehe Rüfenacht 2018, SQ-1, SQ-2.

19 S. a. Brief von Quandt an Schnorr vom 22.8.1823, in: SLUB, Mscr. Dresd. n Inv. 15, Bd. 31, fol. 101r. von 1825 nicht gesehen zu haben, denn er ging direkt zur Beschreibung des Ambientes eines Salons über: »Der Salon [...] versetzt Dich in ein vornehmes italienisches Wohnhaus. Seine glänzenden, gelbmarmorirten Wände sind in Stuck gearbeitet; aus ihnen erheben sich en relief graumarmorirte ionische Säulen mit vergoldeten Basen und Kapitälen; die zwischen ihnen oben angebrachten Figuren sind von dem Bildhauer Matthäi, $[. .$.$] nach den Raphaelischen Figuren gearbeitet. Der Kamin$ ist von echtem carrarischen Marmor, die Säulen desselben werden durch Hermen gebildet, deren Köpfe von sehr zarter Arbeit sind. Auf demselben findest Du eine kleine antike Venus von pentelischem Marmor. $\mathrm{K}^{20}$ Es folgte das repräsentative Wohnzimmer der Frau mit verschiedenen Gemälden wie Maria mit dem Kinde von Julius Schnorr von Carolsfeld, auf die noch genauer einzugehen sein wird. ${ }^{21}$ Darauf trat man in einen Raum mit Sepiazeichnungen von Schnorr und einer Zeichnung von Caspar David Friedrich.22 Letztere wird von dem anonymen Besucher beschrieben: »In einem folgenden Zimmer findet man [...] eine von Friedrichs (in Dresden) besten Kompositionen: eine freie Ebene auf hohen mit Laub bewachsenen Bergen, in der Mitte ist ein Kreuz aufgerichtet und mit belaubten Bogen umgeben.« Es handelt sich dabei um eine verschollene Fassung des Kreuzes an der Ostsee, die bis anhin von Helmut Börsch-Supan und Karl Wilhelm Jähnig sowie aktuell im Werkkatalog der Zeichnungen von Christina Grummt nur aufgrund einer Beschreibung von 1807 bekannt und frageweise Quandts Sammlung zugeschrieben war, was hiermit bewiesen werden kann. ${ }^{23}$

20 Anonym 1825, Sp. 789; Kat. Quandt 1824, S. 7. Der Katalog erwähnt den Salon erst als fünften Raum - warum, bleibt ohne Grundrisse unklar. Gegenüber Schnorr nennt Quandt diesen Raum einen »Speisesaal«, der »gar keine Bilder [habe], sondern [...] mit Gÿpsmarmor ausgelegt« sei. Im Raum davor plante er ursprünglich die Hängung der Judith von Philipp Veit; siehe Rüfenacht 2018, SQ-77. Zum Porträtzimmer siehe Brief von Quandt an Schnorr vom 22.8.1823, in: SLUB, Mscr. Dresd. n Inv. 15, Bd. 31, fol. 101r; Rüfenacht 2018, SQ-8, SQ-9, SQ-10 (Porträts), SQ-64 (Catel). Zum Bildhauer Matthäi siehe unten Anm. 34.

21 »Meiner Frau ihr Wohnzimmer ist mit Eggers Bildern u Ihrer Madonna aus geschmückt, beÿ deren Anblick wir uns immer erfreun u Ihrer mit wahrer Liebe gedenken. "Brief von Quandt an Schnorr vom 22.8.1823, in: SLUB, Mscr. Dresd. n Inv. 15, Bd. 31, fol. 101r. Zu den Bildern dieses Raums siehe Rüfenacht 2018, SQ-70 bis 75 .

22 Anonym 1825, Sp. 790.

23 Kat. Quandt 1860 (2), Nr. 332. Börsch-Supan/Jähnig 1973, S. 293, Kat. Nr. 151; Grummt 2011, Bd. 1, S. 478, Kat. Nr. 507. Christina Grummt ordnet zwar die bekannte Fassung unter Kat. Nr. 506 Quandt zu, doch passt das abgebildete Blatt nicht zur zitierten Beschreibung von Anonym 1825. Vielmehr stimmt diese mit der bei Grummt wiedergegebenen Beschreibung im Journal des Luxus und der Moden von 1807 überein. Die Zeichnung auch erwähnt im Brief von Johann Caspar Schinz an Louise Seidler, in: ThULB, HSA, Aut. W. M. v. Goethe, Nr. 1166, J. C. Schinz an Louise Seidler, Dresden, o. Datum [1825], [S. 1-2]. 
Nach einem weiteren Nebenzimmer mit unterschiedlichen Werken wie zeitgenössischen Zeichnungen und einer mittelalterlichen Miniatur stieg man über eine Treppe in das zweite Stockwerk empor und trat in einen besonderen, kapellenartig eingerichteten Saal, der als Vorraum des großen Gemäldesaales diente. ${ }^{24}$ Auf Garten und Elbe ausgerichtet, war der Vorsaal in seiner Einrichtung symptomatisch für die Sammlungsräume, indem er mit verschiedenen Objekten aus Quandts vielseitiger Sammlung und Nachbildungen mittelalterlicher Kunst bestückt war. Der Düsseldorfer Schriftsteller Karl Leberecht Immermann beschrieb stimmungsvoll die Situation dieses historistischen Raumes im Gefüge der Sammlungsräume: »Durch abgeschloßne Treppengänge und Vorsäle, mit Zeichnungen und Gypsabgüssen bevölkert, von eingesetzten Glasgemälden dämmerhell, schreitend, fühlte ich, daß ein feiner Sinn sich hier die belebte Einsamkeit geschaffen habe, um welche es allein verlohnt, zu leben. Darnach wurde mir das Allerheiligste aufgethan, und ich fand den Herrn des Hauses unter seinen Schätzen. $\ll^{25}$ Dieses »Allerheiligste « war der eigentliche Gemäldesaal.

Hier präsentierte Quandt den Hauptteil seiner Gemälde Alter und Neuer Meister. Kunstfreunde, Künstler und Kopisten konnten darin ihrer Leidenschaft nachgehen. Der anonyme Besucher von 1825 berichtete hierüber: »Der liberale Besitzer verstattet Künstlern gern das Kopiren aus seiner Sammlung, und man findet daher häufig jüngere Maler in dem zuletzt genannten Saale emsig vor der Staffelei sitzend. $\aleph^{26}$ Auch Carl August Böttiger lobte in seinem Artikel über Quandts Sammlung im Artistischen Notizenblatt genau diese Offenheit und Gesprächsbereitschaft des Kunstfreundes: »Dabei darf seine unermüdete Bereitwilligkeit, alles, was er besitzt, Künstlern und Kunstfreunden zu jeder Stunde mitzutheilen und ihnen mit Rath und Belehrung aus seiner Kunstbibliothek zur Hand zu seyn nicht unerwähnt bleiben. $\ll^{27}$

Mit dem Ausstellen von Kunst erhoffte sich Quandt, beste Möglichkeiten zu schaffen, damit sich Künstler und Kunstpublikum bilden können. Er präsentierte seine Sammlungen daher nicht nur in seinen Privatgemächern, sondern auch an Akademieausstellungen in Dresden, München oder Berlin. Entsprechend unterstrich der Sammler, dass er »die Ausstellungen für eine der nützlichsten Kunstanstalten halte. Es wird durch diese das Band zwischen Künstlern u dem Publicum immer von neuem geknüpft, erregt in der Volksmasse eine große Theilnahme an der Kunst als die Eröffnung von Museen voll Werke verstorbener Meister und Zeiten welche selbst für den Gebildeten oft so fern liegen, dass er erst die Geschichte zu Hülfe nehmen und seine Einbildungskraft anregen muß, um sich in den Standpunkt zu versetzen aus welchen solche Werke betrachtet werden müßen. Endlich aber geben Ausstellungen den Lebenden die klarere Selbsterkenn[tnis] über den Werth der eignen Leistungen, als die Vergleichung mit Werken frührer Meister wo sich dann jeder junge Künstler immer einen uralten Meister aussucht den er erreicht zu haben glaubt. $\ll^{28}$

Quandts Sammlung mit ihrer Kombination aus Abgüssen von Antiken, Alten Meistern und zeitgenössischen Malern sollte einen Einblick in die Geschichte der Kunst bieten, die bis in die Gegenwart wirkte. Indem er selber Kunst seiner Zeitgenossen sammelte, zeigte er, dass er an diese umfassende Wirkung der Künste in der Geschichte glaubte. Dies attestierte ihm auch Carl August Böttiger: »Wie ganz anders ist es mit den Sammlungen der Werke lebender Meister, wenn nur ihr Besitzer das Rechte zu bestellen und zu wählen wußte. Man lebt da zweimal unter seinen Zeitgenossen; man kennt den Meister nach seiner Persönlichkeit; man würdigt ihn nach seiner Schule und sieht mit Freuden seine Fortschritte; Hoffnungen werden erweckt, noch Herrlicheres wird hervorgelockt; der rühmlichste Wetteifer entzündet und durchdringt die sich hier in derselben Sammlung freundlich begegnenden Künstler des Südens und des Nordens. ${ }^{29}$ Der polnische Graf und Kunstsammler altitalienischer und zeitgenössischer deutscher Kunst, Athanasius Raczyński, lobte Quandt in seiner Geschichte der neueren deutschen Kunst als unabhängigen Kunstkenner, dessen Sammlung »aus warmer Liebe und zartem Gefühle für die Kunst« entstanden sei..$^{30}$
24 Zum Vorzimmer an der Treppe im ersten Geschoss siehe Kat. Quandt 1824, S. 9; Anonym 1825, Sp. 790-791. S. a. Brief von Johann Caspar Schinz an Louise Seidler, in: ThULB, HSA, Aut. W. M. v. Goethe, Nr. 1166, J.C. Schinz an Louise Seidler, Dresden, o. Datum [1825], [S. 1-2]. Zu den Werken im Vorraum und Saal siehe Rüfenacht 2018, S. 29-4O, 43-45 (Raum 9 gemäß Kat. Quandt 1824, Raum 5 gemäß Kat. Quandt 1868).

25 Immermann 1833, S. 281-282; Anonym 1825, Sp. 811-812

26 Anonym 1825, Sp. 828. S. a. Brief von Quandt an Schnorr vom 22.8.1823, in: SLUB, Mscr. Dresd. n Inv. 15, Bd. 31, fol. 101 r.

27 Böttiger 1822, S. 62. S. a. Marx 2014 (2), S. 117.

28 Brief von Quandt an Johann Gottfried Schadow vom 29.8.1826, in: Berlin, Historisches Archiv der Preußischen Akademie der Künste, PrAdK 212a, fol. 45. S. a. Marx 2014 (1), S. 102-103.

29 Böttiger 1822, S. 61
30 »Wenn von der neueren Kunst in Dresden die Rede ist, so darf die Sammlung des Herrn von Quandt nicht übergangen werden: sie ist nicht die Frucht der Ostentation, der Mode und der stolz-pedantischen Ansprüche, sondern sie ist aus warmer Liebe und zartem Gefühle für die Kunst entstanden.« Raczyński 1836-1841, Bd. 3, S. 224-226 listet eine größere Anzahl Gemälde aus der Sammlung Quandt auf und äußert sich zu einzelnen ausführlicher, jedoch nicht zu der Hängung. S. a. Lammel 1998, S. 341. Zur Geschichte der neueren deutschen Kunst siehe aktuell die kenntnisreiche Monographie von Uta Kaiser; Kaiser 2017, S. 123-302. Quandt hat Raczyńskis Kapitel über Dresden unterstützt, indem er ihm Informationen zur älteren Dresdener Kunst mitteilte und das Manuskript des Kapitels durchsah. Es ist angesichts der besprochenen Künstler nicht zu übersehen, dass Quandts spezifische Interessen in Raczyńskis Ausführungen deutlich enthalten sind. Siehe Kaiser 2017, S. 231; Raczyński 1836-41, Bd. 3, S. 209-228, zu Quandt S. 211, 224-226. 


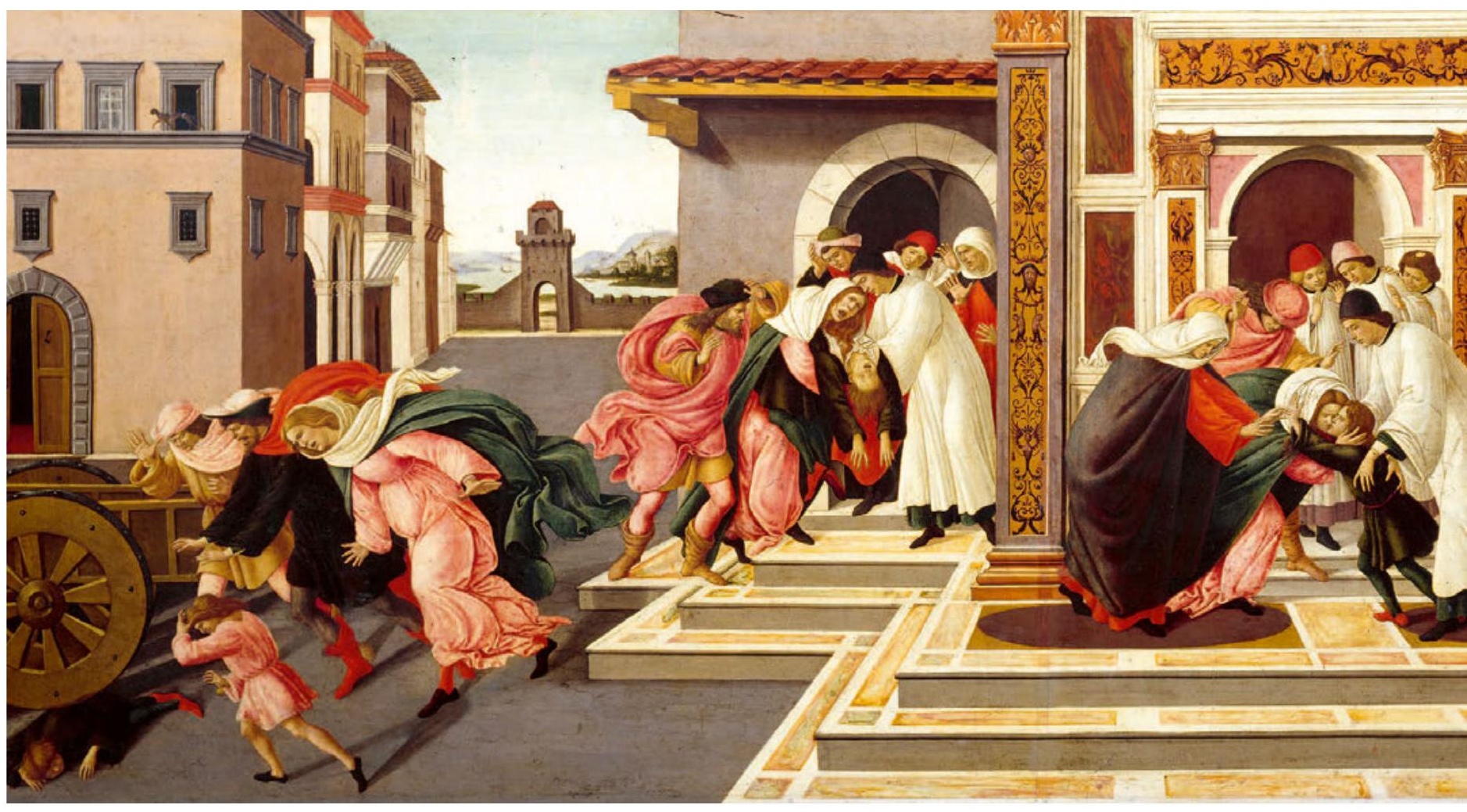

Schon bald galt Quandts Haus der Kunst mit seinem Anspruch auf öffentliche Wirkkraft als leicht zugänglich. Künstler wie Karl Friedrich Schinkel, Johann Gottfried Schadow oder Gottfried Semper besuchten die Sammlung genauso wie der Weimarer Kunstkenner und Goethe-Berater Johann Heinrich Meyer oder die Schriftstellerin Helmine von Chézy und viele andere mehr. ${ }^{31}$ So heißt es in der weit verbreiteten Tageszeitung Allgemeine Zeitung, der Kunstkenner habe sich durch seine »bedeutenden Kunstsammlungen, wovon er den liberalsten Gebrauch macht, sich bei seinen Mitbürgern große Achtung erworben $[\ldots] \cdot \ll^{32}$

\section{Vorbildliche Maler: Die Alten Meister in der Sammlung}

Die beachtliche Anzahl an Werken Alter Meister und ihr Verhältnis zu den Arbeiten Neuer Meister führte dazu, dass der Sammler sie in direktem Zusammenhang präsentierte. Welche Rolle er dabei den älteren Kunstwerken zumaß, deutete sich be- reits in seinen Tagebüchern der ersten Romreise an: »Wo aber sonst als in den Werken der ältern Kunst finden wir diese Fülle des Daseyns, diese Gesammtheit des innersten Lebens? [...] Zu dieser Totalität des Bewusstseyns kommen wir höchst selten, und so will es auch dem neuen Künstler nicht gelingen, den Menschen so aufzufassen und ihn in dieser Vollendung und Fülle darzustellen, als es die Alten vermochten. Immer sind die Darstellungen der Neuern charakteristisch und individualisirend, einseitig. Nie stehen die dargestellten Wesen so hoch, so mitten inne in dem erhabenen Mittelpuncte der Menschheit [...].«33 Quandt sah die Werke der Alten Meister vom menschlichen Geist durchdrungen. Dies war programmatisch für die Präsentation seiner Sammlung, wie der Vorsaal zum großen Ausstellungsraum im zweiten Obergeschoss seines Hauses in Dresden verdeutlicht.

Dieser Zugangsraum war als eine Art Kapelle eingerichtet. Altdeutsche und schweizerische Glasmalereien zierten die Fenster, kleine Säulchen mit kopierten Gipskapitälchen des Meißener Domes säumten die Wände. Dazwischen standen unter kleinen Baldachinen Abgüsse der zwölf Apostel von Peter
31 Quandt 1848, S. 239-240; Brief von Johann Gottfried an Henriette Schadow vom 21.8.1822, in: Berlin, SMB, Zentralarchiv, Nachlass Johann Gottfried Schadow, NL Sw 215, Bd. 2. Brief Quandts an Schnorr vom 29.8.1824, in: SLUB, Mscr. Dresd. n Inv. 15, Bd. 31, fol. 116v; Brief von Quandt an Helmine Chézy, undatiert [um 1821/22], in: Krakau, Biblio- teka Jagiellonska, Sammlung Varnhagen [vor 1945 Besitz der Preussischen Staatsbibliothek Berlin].

32 Beilage zur AZ, 1827, Nr. 138, S. 549. S. a. Böttiger 1820, S. 61-62.

33 Quandt 1819, Bd. 1, S. 27. 


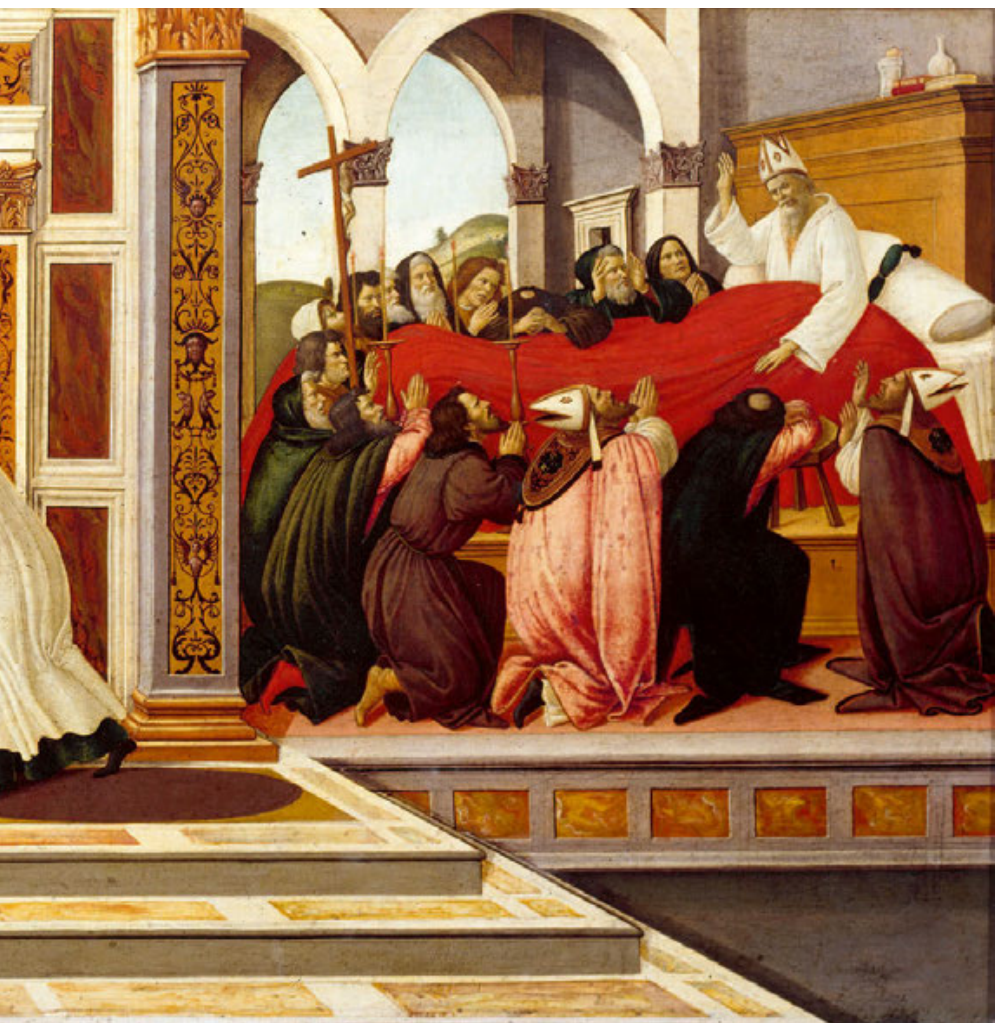

Vischer vom Sebaldusgrab in der Kirche St. Sebald in Nürnberg. Quandt hatte sie während der Reise nach Italien 1819/20 in Auftrag gegeben und nach Leipzig geschickt. ${ }^{34}$ Die Tür zum Gemäldesaal, die er entgegen seiner Idee nicht mit einem Spitzbogen ausführen konnte, war mit einem Vorhang behängt. Darauf war der Vers gestickt:

»Am Alten magst du dich erfreun,

Durch seine Mängel dich belehren,

Doch sollst du altes nicht erneun,

Durch's Bessermachen wirst du's ehren.«35

Der Spruch widerspiegelt die Diskussionen über die neue deutsche Kunst und warnte die jungen Künstler davor, andere blind nachzuahmen. ${ }^{36}$ In seinem Bericht über die Italienreise betonte Quandt: »Es kommt aber nun alles darauf an, ob diese Liebe zu dem Kunstgeist der ältern Schule sich rein ausbilden wird. Es ist so leicht, daß wir an dem Gegenstande unserer Neigung nicht blos das wahrhaft Liebenswürdige lieben, sondern auch das Mangelhafte an ihm liebgewinnen; [...
53 Sandro Botticelli, Aus dem Leben des heiligen Zenobius, um 1500 , Tempera auf Pappelholz, $66 \times 186 \mathrm{~cm}$, Dresden, Gemäldegalerie Alte Meister, Gal.-Nr. 9

Lieben die jungen Gemüther, welche sich der Kunst ergeben, die ältern Meisterwerke um dessen willen, wodurch diese sich der Vollkommenheit nähern, so sind wir des segenreichsten Erfolgs gewiß. [...] Ist es aber nur ein Verlieben, so werden die neuen Künstler, als unabänderliche Muster, die Werke des Mittelalters, mit allen den Unvollkommenheiten der Zeit, aus welcher sie abstammen, nachahmen. $[. .$.$] Die aus jener frühen$ Zeit vorhandenen Werke sind allerdings als belehrende Vorbilder zu betrachten, aber nicht blos als Beispiele dessen, was zu thun, sondern auch, was zu vermeiden ist.«37 Die Werke Alter Meister in seiner Sammlung dienten also als Beispiele für die jungen Künstler, die in seiner Sammlung Kopien anfertigten. Zugleich konnten Besucher diese alten und neuen Kunstwerke miteinander vergleichen. Dabei ging es nicht um stilistische Vergleiche, sondern um die Vergleichbarkeit der Wirkungen, welche die Gemälde auslösten. Damit spielten die Alten Meister in Quandts Sammlung als Vorbilder eine bedeutende Rolle für seine eigene Gegenwart. $3^{8}$
34 Brief von Quandt an Christian August Heinrich Clodius, nicht datiert [1819], in: SLUB, Mscr. Dresd. App. 204, Nr. 92. Quandt spricht beim Kopisten von einem Matthäi. Es handelt sich wahrscheinlich um Johann Gottlob Matthäi oder dessen Sohn Ernst Matthäi, Vater bzw. Bruder des bekannten Dresdener Malers Johann Friedrich Matthäi. Zu den Aposteln Vischers in St. Sebald zu Nürnberg siehe Quandt 1816 (3), S. 554-555.

35 Brief Quandts an Schnorr vom 29.8.1824, in: SLUB, Mscr. Dresd. n Inv.
15, Bd. 31, fol. 117r. Der kapellenartige Vorraum sehr genau beschrieben in: Anonym 1825, S. 811-812.

36 Anonym 1825, Sp. 812: »Eine gute Lehre für die malenden Altdeutschthümler [...].« S. a. Grewe 2015, S. 213-216.

37 Quandt 1819, S. 168-174.

38 S. a. Anonym 1825, Sp. 812: »Da er nämlich immer die Beförderung der Kunst in der Gegenwart im Auge hatte, die er durch blinde Verehrung und Nachahmung des Alten so sehr beeinträchtigt und verkümmert 
Entsprechend machte die Kunst des 15. und 16. Jahrhunderts einen beachtlichen Anteil seiner Sammlung aus. So sind im Katalog von 1824 elf Italiener verzeichnet, davon vier deutsche Kopien des 19. Jahrhunderts, sowie sieben Deutsche, davon eine Kopie, und drei Niederländer. Im Auktionskatalog von 1868 sind es gar sechsundzwanzig Italiener, davon zwei Kopien, neun Deutsche und acht Niederländer. Die Vergrößerung der Sammlung im Bereich der Alten Meister - ohne dass dabei die Künstler des 18. Jahrhunderts mitgezählt wären - war damit ein wichtiger Aspekt. ${ }^{39}$ Wie Quandt seine eigenen Werke beurteilte, soll nachfolgend erläutert werden.

Im 1824 erschienenen Katalog zur Sammlung fehlen Kommentare zu einzelnen Bildern gänzlich. Wo Quandt dennoch ausführlicher wurde, betraf es zwei Themenbereiche: einerseits führte er die Biographien der frühneuzeitlichen Maler auf, indem er gelegentlich Forschungsmeinungen kritisierte und seine eigenen Ergebnisse präsentierte. Diese Lebensgeschichten dienten dem Sammler in erster Linie dazu, die Eigentümlichkeiten des Seelenlebens eines Künstlers darzulegen, um nicht nur historisch überlieferte Fakten aneinander zu reihen. Entsprechend notierte er noch Jahre später:»[...] bei der Künstlerbiographie scheinen mir die Epochen innerer Entfaltung wichtiger, als die Angaben von Jahrzahlen. $\ll^{40}$ Andererseits beschrieb er umfassend die Glasmalereien des Vorraums zum Gemäldesaal im zweiten Obergeschoss. Er erläuterte den künstlerischen Aufstieg, Höhepunkt und Niedergang dieser Technik. Seine zahlreichen Notizen über Herstellung, Kolorit und Zeichnung sowie Verweise auf andere Forscher zeigen seine vertiefte Kenntnis und Belesenheit in Fragen der Glasmalereikunst. ${ }^{41}$

Diese beiden Schwerpunkte des Katalogs von 1824 fokussieren stark auf die Kunst im deutschen Raum. Sinnvoll war dies bei den Glasgemälden, denn sie stammten vorwiegend aus Süddeutschland und der Schweiz. Im Vergleich zu den Lebensbeschreibungen italienischer Künstler wie Fra Angelico, Botticelli, Pinturicchio und Francia waren die Biographien Cranachs und Vischers lang und ausführlich. Damit zeigt sich, dass ihm der Bestand an altdeutscher Kunst in seiner eigenen Sammlung sehr wichtig war. Er wollte sie in das Blickfeld des Interesses seiner Besucher rücken.

sah, so räumte er [...] vornehmlich ausgezeichneten und manierfreien Arbeiten jetzt lebender Maler in seiner Sammlung einen Platz ein.«

39 Die Werke des 18. Jahrhunderts stammen wahrscheinlich aus dem Erbe seiner Eltern. Siehe Briel 2002, S. 12.

40 Quandt in Bezug auf die Biographie von Adrian Ludwig Richter, in: Quandt 1848, S. 239. S. a. Quandt 1816 (2), S. 67: »Es ist also nicht leicht, das Zufällige vom Wesentlichen zu sondern, das Eigenthümliche von äußerer Mitwirkung zu unterscheiden und so durch eine Reihe sich zum Leben verkettender Begebenheiten in das Innere eines Menschen einzudringen. «

41 Kat. Quandt 1824, S. 11-16. S. a. Quandt 1840 (4).
Die Urteile, die Quandt über die Werke Alter Meister in seiner Sammlung schrieb, werden selten fassbar. Wo sie feststellbar sind, fallen sie unterschiedlich aus. So schrieb er nach der Anschaffung der Tafel mit Szenen aus dem Leben des Heiligen Zenobius von Sandro Botticelli, die sich heute in der Gemäldegalerie Alte Meister in Dresden befindet (Abb. 53):»[...] einiges darinnen [überschreitet] jene Grenzen des Ausdruck [...], über welche hinaus das Gebiet des Häßlichen liegt, welches kein Künstler betreten sollte, so wenig wie ein Sänger im Affect sich überschreÿen darf. Dennoch hat dieses Bild wieder andere Theile, welche es zu einem der vorzüglichsten Bilder der Florentinischen Schule erheben. $\ll^{42}$ Eine solche Aussage ist ganz im Sinne des gestickten Leitspruches am Eingang zur Sammlung zu verstehen und beschreibt Fehler und Vorzüge des Malers.

Von Lucas Cranach dem Älteren besaß der Sammler eine Fassung der Quellnymphe am Brunnen, heute im Museum der bildenden Künste Leipzig (Abb. 54). Dem »großen Coloristen« attestierte er einen bedeutenden Einfluss auf die Geschichte der Malerei und mit seinem Tod, »in welchem sich die Blüthe eines ganzen Jahrhunderts zeigt, blühte auch die deutsche Kunst ab.«\$3 Im Katalog von 1824 widmete er dem Maler die längste Biographie, in der er seinen Aufstieg und Niedergang zu erkennen glaubte. »Cranach genoss das Vertrauen aller Fürsten des sächsischen Hauses, und wurde in wichtigen Fällen zu Rathe gezogen, zu Ehrenämtern und wichtigen Aufträgen gebraucht. So edel diese nach außen wirkende Thätigkeit, diese Hof- und Weltverhältnisse, dieser Verkehr mit verschieden gesinnten Menschen in einer bewegten Zeit, unter gährenden Partheyen, Cranachs moralischen Charakter ausgebildet haben mag, so konnte er doch eben dadurch zu der Sammlung des Gemüths nicht kommen, welche dem Künstler unentbehrlich ist, und seine Kunst litt darunter, welche er fast nur noch wie ein Dilettant betrieb, das heißt ein solcher, der sich blos am Hervorbringen ergötzt, unabgesehn was er leistet.« Obschon er also diesen altdeutschen Maler durchaus schätzte und seine Bedeutung für die deutsche Kunstgeschichte verstand, fehlte ihm wenigstens in dessen Spätwerk der künstlerische Gehalt. Damit stand Cranach am Anfang eines Niedergangs der Künste, die in Manieriertheit und Realis-

42 Brief an Julius Schnorr von Carolsfeld vom 26.5.1824, in: SLUB, Mscr. Dresd. n Inv. 15, Bd. 31, fol. 115r. S. a. Bemmann 1925, S. 11-12. Quandt kaufte das Bild Mitte 1824 für 1400 Taler. Siehe Brief von Quandt an den Kunsthändler Gaspare Weiß in Berlin vom 20.11.1823, in: Mscr. Dresd., App. 204, Nr. 97z. S. a. Rüfenacht 2018, SQ-6; Skwirblies 2017, S. 98. Zum Kunsthandel Weiß siehe ebd., S. 377-379.

43 Quandt 1826 (1), S. 44; Quandt 1815, Sp. 995. Auch über die Leipziger Werke von Cranach schrieb er: „Die Farben sind von der lebhaftesten Frische, das Kolorit ist warm, natürlich und zart.« Quandt 1815, Sp. 989-990. S. a. Kat. Leipzig 1997, S. 155. Rüfenacht 2018, SQ-5. Zwei weitere Werke der Cranach-Schule ebd., SQ-42, SQ-43. 


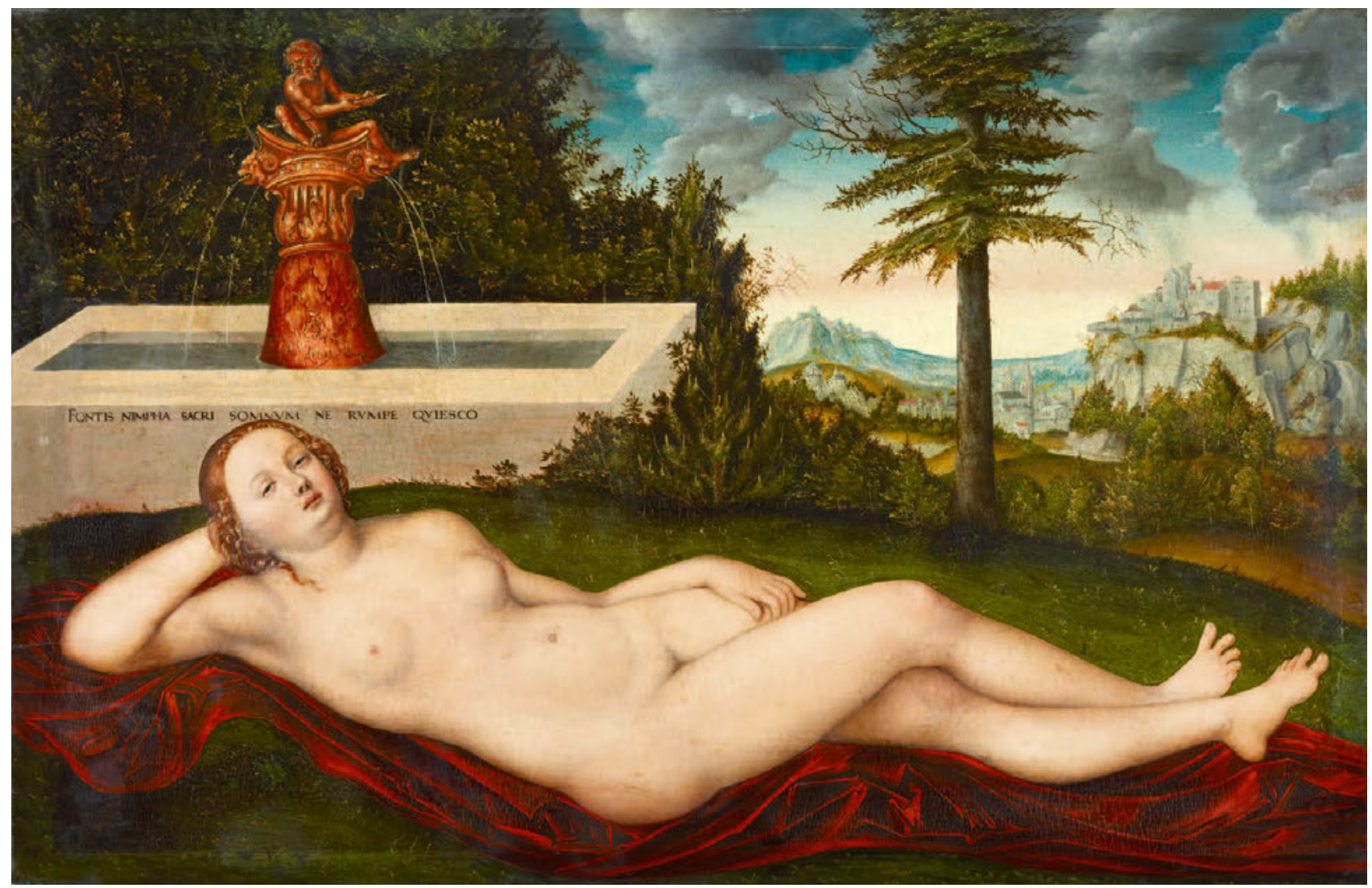

54 Lucas Cranach der Ältere, Quellnymphe am Brunnen, 1518, Öl auf Holz, 59 × 91,5 cm, Leipzig, Museum der bildenden Künste, Inv.-Nr. G 757

mus überzugehen drohten. ${ }^{4+}$ Seine Zeitgenossen sollten sich mit dieser Problematik auseinandersetzen und auf eine neue, bessere Kunst hinarbeiten. Zugleich verglich Quandt Cranach mit der italienischen Kunst. Dieser Vergleich führte doch zu hohen Weihen: »Lukas Kranachs Styl und Kolorit, wenn diese einmal mit denen eines andern Meisters verglichen werden sollen, haben noch die meiste Aehnlichkeit mit da Vincis Malerkarakter, welches jedoch mehr auf eine Gleichheit des Geistes bezogen werden muß, als daß Kranach ihn nachzuahmen gesucht habe. «\$5 Wahrscheinlich hatte Cranach gar nie ein Werk Leonardos gesehen, doch zeigt sich hier, wie sehr der Kunstfreund darum bemüht war, die Werke deutscher Kunst durch großartige Gegenüberstellungen aufzuwerten und auf eine Ebene mit der dominierenden Liebe zur italienischen Kunst zu stellen.

44 »Mit Kranach, in welchem sich die Blüthe eines ganzen Jahrhunderts zeigt, blühte auch die deutsche Kunst ab. Dürer, Schäufflein und Burgmayer waren schon früher gestorben, und Holbein hatte schon längst Deutschland verlassen, um jenseits des Meeres, in England, den Erinnerungen und Schmerzen einer unglücklichen Liebe zu entfliehn. Amberger lebte zwar in die andere Hälfte des sechszehnten Jahrhunderts weit hinüber, hatte aber als ein treuer Schüler des ältern Hollbein nicht genug Eigenthümlichkeit, um die deutsche Kunst aufrecht zu erhalten. Andere deutsche Künstler, z. B. Georg Penz, Sebaldus Böheim [Beham - AR] u. a., zogen nach Italien und nahmen den itali-
Ein anderer Italiener in seiner Sammlung, Fra Angelico da Fiesole, von dem Quandt eine Madonna mit Kind besaß, war im Licht seines Kunstverständnisses ein vorbildlicher Künstler, der mit Herz, Seele und vor allem Überzeugung malte (Abb. 55$){ }^{46}$ So schrieb der Sammler: »Deswegen änderte er nie etwas an seinen Werken ab, nicht etwa aus Künstlerstolz, sondern weil diese Bilder, wie sie ihm im Gebet vor die Seele traten, ihm zu heilig und lieb waren. [...] Uiberhaupt (sic!) haben Fiesole's Malereyen mehr eine subjective als objective Richtung, indem sie weit deutlicher Zustände eines frommen, beseligten Gemüths zur Anschauung bringen, als Begebenheiten darstellen, und wirklich war er in jenem Streben allen seinen Zeitgenossen und Vorgängern vorzuziehn. ${ }^{\star 7}$ Fra Angelico stelle sein inneres Leben dar, befördert durch seine Religiosi-

enischen Kunstcharakter an, in welchem sich mehr Temperament als Gemüthlichkeit äußert." Quandt 1815, Sp. 995-996.

45 Quandt 1815, Sp. 990.

46 Kat. New York 2005, S. 163. Über den Ankauf in Florenz siehe den Brief von Quandt an Schnorr vom 25.6.1820, in: SLUB, Mscr. Dresd. n Inv. 15, Bd. 31, fol. 31r-32v; Rüfenacht 2018, SQ-29.

47 Kat. Quandt 1824, S. 18-19; s. a. Quandt 1816 (2), S. 70-71. Das Gemälde wurde zu einem unbestimmten Zeitpunkt zersägt; siehe Kat. Oldenburg 2017, S. 77; Kat. New York 2005, S. 161-164. S. a. Brief an Schnorr vom 25.6.1820, in: SLUB, Mscr. Dresd. n Inv. 15, Bd. 31, fol. 31v-32r; Kat. 


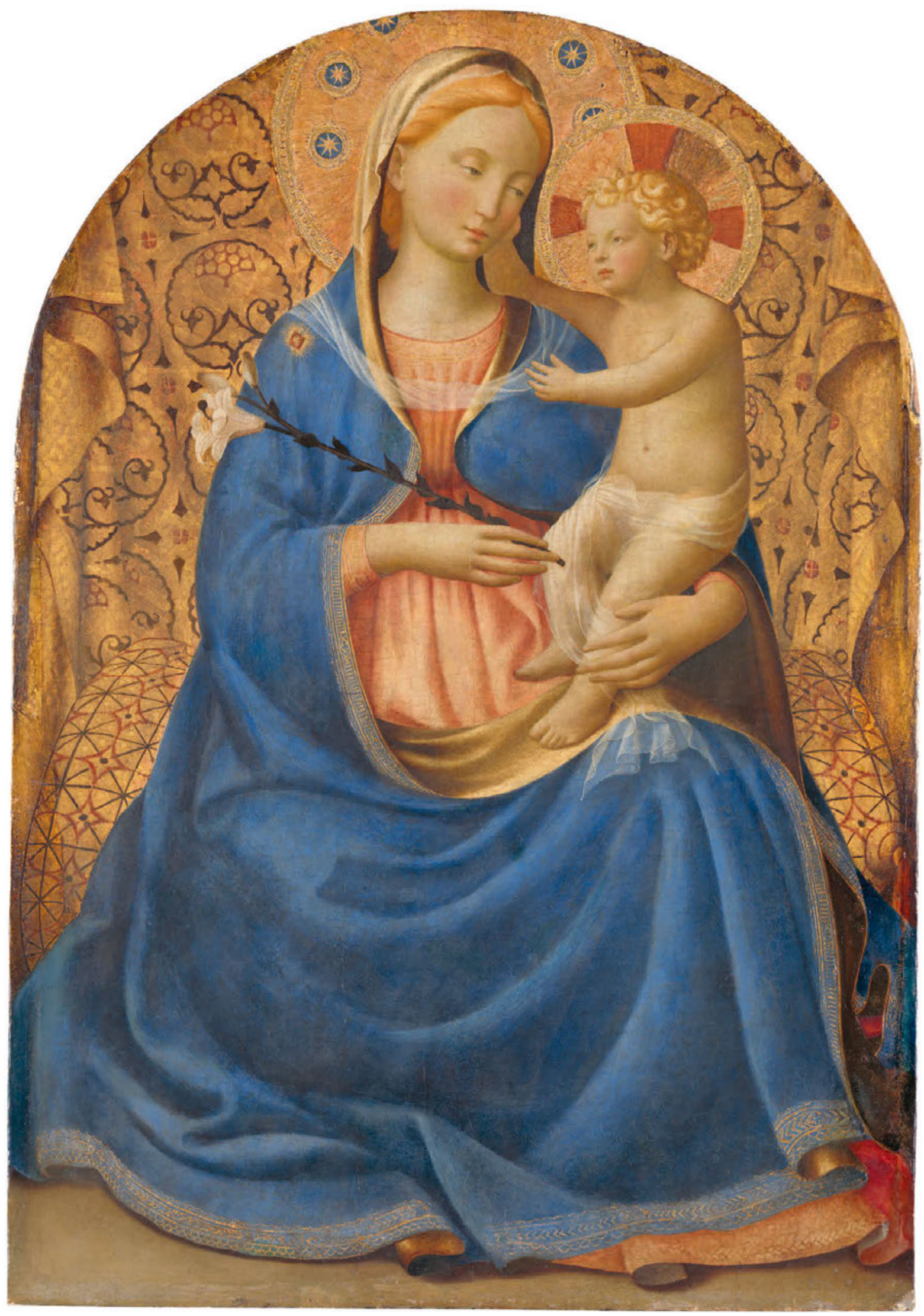

55 Giovanni da Fiesole gen. Fra Angelico, Madonna mit Kind, um 1430/31, Tempera auf Holz, $74 \times 61 \mathrm{~cm}$, Amsterdam, Rijksmuseum, Inv.-Nr. SK-A-3011 
tät. Damit galt er Quandt als ideales Vorbild für die zeitgenössischen Künstler. ${ }^{48}$

Quandts Sammlung Alter Meister gehörte zu den wenigen größeren Privatsammlungen dieser Art in Deutschland. ${ }^{49}$ Der Vorhang, der den Eingang zur Gemäldesammlung zierte, thematisierte die Rolle der alten Kunst für Quandts Geschichtsverständnis, so wie er es schon in seinen frühen Abhandlungen zu Werken Alter Meister erläutert hatte. In ihnen sah er eine ideale Verbindung von handwerksmäßiger und geistiger Tätigkeit. Nicht Nachahmung von Stilen war angebracht, sondern das Vermitteln einer Seelenwahrheit durch den Verstand, wozu die frühneuzeitlichen Künstler in seinen Augen besonders befähigt gewesen waren. ${ }^{50}$ Quandt maß den Alten Meistern vor allem einen pädagogischen Wert bei. Die jungen Künstler, denen er Zugang zu seinem Haus ermöglichte, sollten sich an den Alten Meistern schulen, sich ihre Errungen- schaften einverleiben und ihre Fehler kennen und vermeiden lernen. ${ }^{11}$ Damit würden sie die Geschichte der Kunst vorantreiben und durch ihre Bildung an der Fortentwicklung der Gesellschaft Anteil haben. ${ }^{52}$ Dies zu fördern, war der Anspruch seiner Sammlung Alter Meister, denn in dieser spiegelte sich nach seinem Kunstideal eine bessere Zeit wider: »Wir leben in einem papiernen Zeitalter; vor dem funfzehnten Jahrhundert war das goldne Zeitalter. Wir glauben schon etwas gethan zu haben, wenn die Sache zu Papier gebracht ist; jene stellten es ins Werk. «33 Mit solch hohen Absichten setzte sich Quandt intensiv für die Kunst der Alten Meister ein. Ihr Erhalt und ihre Ausstellung waren ihm zeit seines Lebens wichtig, wie über die Privatsammlung hinaus auch seine Tätigkeit im Sächsischen Altertumsverein gezeigt hat. Anhand einiger herausragender Präsentationssysteme kann dies nachfolgend weiter vertieft werden.
48 Quandt 1816 (2), S. 80: »Durch diese Bilder trat sein Inneres, welches ganz im Anschauen des göttlichen Wesens ausgelöst war, in die Außenwelt, und zog ihre einzelnen Erscheinungen, welche einander begränzen, in das geistige Gebiet hinüber, hauchte jeder den göttlichen Odem ein, der uns daraus anweht, und obschon auch Fiesole's Bilder nur einzelne Erscheinungen sind, so haben sie doch alle so vollen Antheil an seinem Gott geweihten Sinne, daß sie, darauf hinweisend, in der Gegenwart darstellen, was ewig ist und nur geistig sich anschauen darf."

49 S. a. Weddigen 2008, S. 220; Briel 2002, S. 12; Neidhardt 1976, S. 235

50 Quandt 1830 (1), S. 290: »[...] jene Maler der Seele, wie die Künstler des funfzehnten Jahrhunderts oft treffend genannt worden sind, legten es gar nicht auf Sinnenbetrug an. « Ausführlich über die Verbindung von Ideal und Realität in Quandt 1819, Bd. 2, S. 169-172.

51 Quandt 1819, Bd. 2, S. 173-174: »[...] der neuere Künstler [darf] doch nicht die Natur aus den Bildern der alten Meister wollen kennen lernen. Bey dem Nachahmer wird das zur Einseitigkeit, was bey dem Vorgänger Individualität ist. [...] Fehlerhaft würde es seyn, wenn die neuesten Künstler die Darstellung vernachlässigten und wohl gar, weil den Alten beym besten Willen, aus Mangel an Erfahrung und Kenntnissen, manches nicht gelang, dies zufällig Mißlungene nachahmten, und als einen wesentlichen Theil der ältern Schule betrachteten.«

52 S. a. Schmitz/Strobel 2001, S. LXIII.

53 Quandt 1826 (1), S. 2-4. 

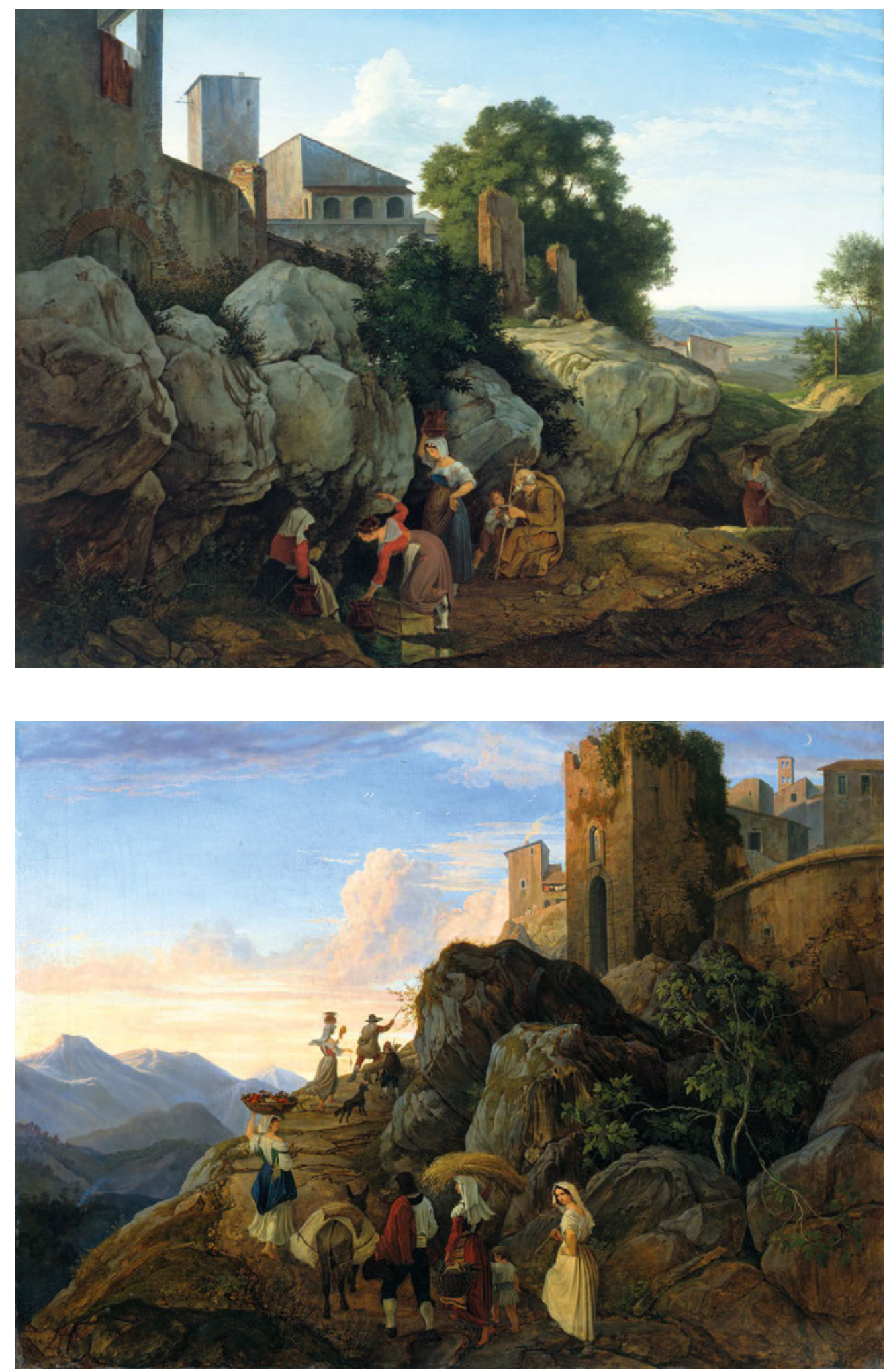

56 Adrian Ludwig Richter, Ariccia (Der Morgen), 1828, Öl auf Leinwand, 59,5×77,5 cm, Dresden, SKD, Albertinum | Galerie Neue Meister, Gal.-Nr. 2228

57 Adrian Ludwig Richter, Civitella (Der Abend), 1827/28, Öl auf Leinwand, 59,5 × 77,5 cm, Dresden, SKD, Albertinum | Galerie Neue Meister, Gal.-Nr. 2227 


\section{KUNSTTHEORIE MITTELS PRÄSENTATION: Assoziationsreiche Pendants}

Nach seinem Einzug in das Dresdener Stadthaus am 21. August 1823 schrieb Quandt an seinen Freund Schnorr: »Gestern habe ich meine neue Wohnung bezogen, an welcher ich nun zwei Jahre gebaut. Ich hoffe jetzt die Früchte so mancher Mühe zu genießen u eine meiner ersten Genüße war, meine Gemälde in den Zimmern zu vertheilen. $\ll^{1}$ Die Einrichtung seiner Sammlung ist im Detail zwar nicht mehr rekonstruierbar. Doch lassen sich mehrere spezifische Gemäldehängungen feststellen, die mit komplexen geschmackstheoretischen und ästhetischen Fragestellungen in Verbindung gebracht werden können. Eine besondere Rolle übernahmen dabei die Pendants. Sie bezeichnen einander gegenübergestellte, oft in ihrer Bildaussage antithetische Gemälde, mit denen eine bestimmte Aussage getroffen werden sollte. Derartige Präsentationen waren unter Dresdener Sammlern jener Zeit ausgesprochen beliebt. ${ }^{2}$ Nicht selten wurden gezielt Gegenstücke in Auftrag gegeben. Ein solches typisches Beispiel in Quandts Sammlung sind die als Pendants erarbeiteten Gemälde Ariccia (Der Morgen) und Civitella (Der Abend) von Adrian Ludwig Richter (Abb. 56-57). Das Antithetische ist gerade hier sehr deutlich. Der Morgen mit dem Schöpfen frischen Wassers aus dem Brunnen und der Abend mit dem Einbringen der Ernte lässt sich auf einer metaphorischen Ebene über den Tageskreis hinaus auf den Lebenskreis und dem Werden und Vergehen in Verbindung bringen. ${ }^{3}$ In der freien Konfrontation miteinander in Zusammenhang stehender Gemälde war Quandt oft besonders einfallsreich. Einigen solchen Gegenüberstellungen und ihren assoziationsreichen Kontexten wird nun vertieft nachgegangen.

\section{Ordnungsprobleme}

Die Prüfsteine der nachfolgend dargelegten Rekonstruktionsbeispiele der Sammlungspräsentation sind zwei Kataloge von

1 Brief von Quandt an Schnorr vom 22.8.1823, in: SLUB, Mscr. Dresd. n Inv. 15, Bd. 31, fol. 101r.

2 Büsing 2011, 15-17, 235-240

3 Rüfenacht 2018, SQ-67, SQ-68. S. a. Kap. Landschaftsmalerei als Metapher der menschlichen Vernunft.

4 Rüfenacht 2018, S. 6-45, siehe dort auch die Einleitung S. 2-5.

5 Brief von Quandt an Rudolph Weigel vom 2.3.1844, in: SLUB, Mscr. Dresd. App. 1191, Nr. 583
1824 und 1868 sowie schriftliche Quellen, die in Bezug zu Gemälden der Sammlung gebracht werden können. Die beiden Kataloge weisen gewichtige Unterschiede auf, da es sich beim älteren Büchlein um einen Sammlungs-, beim jüngeren um einen Auktionskatalog handelt. Eine Übersicht über die einzelnen Werke in Quandts Sammlung aufgrund dieser Kataloge und Quellen wurde 2018 publiziert. Sie bildet die Grundlage nachfolgender Überlegungen. ${ }^{4}$ Eine vollständige Sammlungsrekonstruktion und eine Rekonstruktion der Hängungssysteme ist indessen ohne Pläne von Quandts Wohnung nicht möglich. Beim Katalog von 1824 handelt es sich um eine frühe, von Quandt selbst verfasste Zusammenstellung seiner sich noch im Aufbau befindenden Sammlung. Dies bestätigte er in einem Brief von 1844: »Mit größtem Vergnügen würde ich Ihnen Verzeichnisse meiner Gemäldesammlung senden, allein ich selbst besitze kein einziges. Auch war es kein Verzeichniß zu nennen, was ich zum Behuf eines sehr unbeholfenen alten Bedienten vor fünfzehn Jahren hatte drucken lassen, wenn solcher in die Lage kam Fremden meine Gemälde zu zeigen. Auch hat sich meine Sammlung bedeutend seit dem vermehrt, es sind aber auch einige Bilder welche sich damals in der Stadt befanden nach Dittersbach gekommen u so wäre auch schon jenes Verzeichnis ganz unbrauchbar. « Dieser erste Katalog folgte zwar den Gemälden in Quandts Räumlichkeiten, war jedoch nur mit kryptischen Informationen wie Künstlernamen und Bildtitel versehen. Aus diesem Grund war die Identifikation der Gemälde nur bei knapp der Hälfte der Werke möglich, was wiederum direkten Einfluss auf die Interpretation der Ordnungen hat. ${ }^{6}$ Leider wurde ein zweiter Sammlungskatalog, den Quandt herzustellen beabsichtigt hatte und mit einigen Stichen illustrieren wollte, aufgrund seines Todes nicht mehr vollendet. Ein solcher hätte Aufschluss über viele dieser offenen Fragen geben können.?

6 Für rund ein Drittel der erwähnten Gemälde fanden sich über die Kataloginformationen hinaus keine weitergehenden Anhaltspunkte. Einige Informationen zum Verbleib der Kunstwerke gibt ein kurzer Bericht über die Verkäufe der Auktion von Clauss 1869, S. 49-50. Neue Ergebnisse zu den Ankäufen durch die Herzogliche Gemäldegalerie Oldenburg bietet Kat. Oldenburg 2017, S. 30. S. a. Rüfenacht 2018, S. 6-45.

7 Brief von Quandt an Rudolph Weigel, nicht datiert [um 1857/59], in: SLUB, Mscr. Dresd. App. 204, Nr. $97 \mathrm{~W}$. 
Der Katalog von 1868 ist ein Auktionskatalog, der neun Jahre nach dem Tod des Sammlers zur Orientierung der Kaufinteressenten hergestellt wurde. ${ }^{8}$ Dies führt zu mehreren Problemen: Die große zeitliche Distanz zwischen beiden Katalogen und ihre unterschiedliche Autorschaft verringern die Möglichkeit einer umfassenden Rekonstruktion und Charakterisierung. Womöglich hatte Quandts Sohn nach dessen Tod bereits Bilder veräußert oder umgehängt. Zudem kann aufgrund ihrer Entstehungsdaten in drei Fällen davon ausgegangen werden, dass Gustav von Quandt nachträglich Bilder angekauft hat. ${ }^{9}$ Des Weiteren kann ohne Quellen nicht festgestellt werden, wie häufig Johann Gottlob von Quandt seine über die Jahre bis zu seinem Ableben in der Größe sich nahezu verdoppelte Gemäldesammlung in Neuhängungen geordnet hat. Schließlich ist nicht bekannt, wie viele Bilder Quandt im Schloss Dittersbach gehängt hatte. Dort, wo der 1868er-Katalog Bilder nicht mehr erwähnt, die im 1824er-Katalog noch verzeichnet sind, könnte es sich um solche handeln, die auf Quandts Landgut präsentiert waren. Doch auch solche Aussagen können nur Mutmaßungen bleiben, da davon ausgegangen werden kann, dass Gustav von Quandt für den Gemäldeverkauf Bilder aus Dittersbach nach Dresden transferiert hat. All diese Probleme erklären die zahlreichen Unklarheiten, auf die man bei der Rekonstruktion trifft. Dennoch entpuppt sich der Auktionskatalog von 1868 als zentraler Bestandteil der Hängungsrekonstruktion. Der Herausgeber gab nämlich zu erkennen, dass »die Reihenfolge in der Aufführung derselben $[$ Gemälde - AR $][\ldots]$ durch die Vertheilung in den verschiedenen Räumen der Sammlung bedingt « sei. ${ }^{10}$

Sicherlich waren viele Wandabläufe von den Bedingungen des Bürgerhauses und den Dimensionen der Gemälde abhängig. Um diese zu kennen, wären mindestens Grundrisse unabdingbar, die jedoch nur aus der Bauzeit des Hauses im 18. Jahrhundert, jedoch nicht aus der Zeit von Quandts tiefgreifenden Umbauten 1820/21 überliefert sind. Dabei hatte er das neu errichtete Haus auf dem benachbarten Grundstück baulich ins
Haupthaus integriert und dieses umbauen lassen. ${ }^{11}$ Immerhin lässt sich einem Brief von Quandt an Friedrich Rochlitz entnehmen, dass die Räume, in denen die Gemälde präsentiert waren, 7.5 sächsische Ellen, also gut 4 Meter, hoch waren. ${ }^{12}$ Doch auch mit diesen Angaben können keine eindeutigen Ordnungskriterien erkannt werden, außer dass große Gemälde tendenziell höher, kleinere tief gehängt waren. Erschwert wird dieser Umstand dadurch, dass in einem Privathaus auch Möbel, Wandvertäfelungen, Kamine, Türen und Schränke die Hängeflächen einschränkten. Wegen dieser grundlegenden Lücken in den Quellen muss die umfassende, visuelle Sammlungsrekonstruktion fragmentarisch bleiben und kann nur in Einzelfällen und unter Heranziehung weiterer Quellen ansatzweise dargestellt und interpretiert werden. ${ }^{13}$

Die groben Züge der Ausstellung in Quandts Haus lassen sich dennoch von den beiden Katalogen ableiten. Ordnungen nach Alten und Neuen Meistern sind zu erkennen, die gelegentlich durchbrochen werden. Eine kunsttopographische Hängung nach Schulen konnte nicht festgestellt werden, was aber durch die beschränkte Sammlungsgröße bedingt sein könnte. Fruchtbarer erscheint der Fokus auf Bildgattungen. So sind Historien und Landschaften tendenziell gruppiert worden, wobei solche Zusammenstellungen eher von der erheblichen Anzahl dieser beiden Gattungen in der Sammlung abhängig waren. Entsprechende Anordnungen wurden auch immer wieder gebrochen. Gerade hinsichtlich der Gattungen sind zudem Unterschiede in den Hängungsprinzipien zwischen 1824 und 1868 erkennbar.

Im Gemäldesaal des zweiten Stockwerks, wo sich die größte Ansammlung an Gemälden in einem einzigen Raum befand, waren im Jahr 1824 die 45 präsentierten Bilder ihrer religiösen oder profanen Funktion entsprechend gruppiert. ${ }^{14}$ Zwar lässt sich aufgrund der geschilderten Lücken in den Quellen keine genaue Wandabfolge feststellen. Dennoch wird im Katalog von 1824 deutlich, dass gewisse Gemäldegruppen gebildet wurden. So beginnt der Raum 9 mit sieben altitalienischen Gemälden

Bemmann 1925, S. 7-8; Schnorr 1886, S. 156; Seidemann 1860, S. 158 Becker/Frenzel 1826, S. XXVI-XXVIII. 1869 verkaufte Quandts Sohn Gustav das Haus. Nach einem weiteren Umbau wurde das Dresdener Stadtkommando des sächsischen Kriegsministeriums dort untergebracht und eine Dienstwohnung für den Stadtkommandanten eingerichtet. Siehe dazu die Akten zum Umbau, die keine Pläne enthalten, in: 11248 Sächsisches Kriegsministerium, Nr. 5305, Acta den Umbau der Grundstücke No: 10 und 11 der Klostergasse zu Dresden sowie die Ausstattung der Dienstwohnung des Stadtcommandanten betreffend, 1869-1870. Die Klostergasse wurde im Februar 1945 während der englisch-amerikanischen Bombenangriffe zerstört. An ihrer Stelle liegt heute die Köpckestraße.

12 Brief von Quandt an Rochlitz vom 18.12.1822, in: SLUB, Mscr. Dresd., App. 26, Nr. 218.

13 Zur Methode der visuellen Rekonstruktion siehe Weddigen 2008, S. 10.

14 Kat. Quandt 1824, S. 18-40 (IXtes Zimmer). S. a. Rüfenacht 2018, S. 2940, 43-45 (Raum 9). 
von Madonnen und Heiligen, darunter Botticellis Aus dem Leben des Heiligen Zenobius (Abb. 53) und Fra Angelicos Madonna mit Kind (Abb. 55) ebenso wie zwei Perugino-Madonnen, wovon eine ein Werkstattbild des frühen 16. Jahrhunderts - bei Quandt noch als Umbrische Schule -, die andere eine Kopie von Eduard William Bienemann war. Quandt hatte dieses Gemälde wohl hier eingeordnet, weil es seiner Ansicht nach nicht die deutsche Kunst repräsentierte..$^{15}$

Im Katalog folgt hierauf eine etwas heterogene Gruppe nördlicher, kleinformatiger Bilder Alter und Neuer Meister mit Landschaften und Genreszenen. ${ }^{16}$ Erwähnt seien zwei Jan Brueghel dem Älteren zugeschriebene, nicht identifizierbare Landschaften, ein unbekanntes Seestück von Caspar David Friedrich sowie eine Fassung der Neapolitanischen Fischerfamilie von Franz Catel. Die nächste erkennbare Gruppe besteht aus vier altdeutschen Gemälden mit zwei Porträts von Christoph Amberger sowie der Quellnymphe Lucas Cranachs des Älteren (Abb. 54) und einem seiner zahlreichen Adam-undEva-Motive. Hierauf folgt erneut eine Gruppe kleiner Formate mit Genreszenen Neuer Meister. Danach schließen mittlere und große Formate, vor allem Landschaften und Architekturdarstellungen von Zeitgenossen, an. Sie können, durch ihre Größe bedingt, nicht mehr als eigentliche Gruppen bezeichnet werden. Eine italienische Landschaft des Stuttgarter Malers Gottlob Friedrich Steinkopf und eine Tiroler Vedute des in Dresden ansässigen Norwegers Johan Christian Claussen Dahl dürften dennoch als Gegenstücke anzusehen sein, obschon sechs weitere Gemälde dazwischen erwähnt sind. Die drei letzten, mächtigen Formate dieses Raums sind Friedrich Overbecks Kartonfragment aus dem Casino Massimo, Sophronia und Olindo auf dem Scheiterhaufen darstellend (Abb.13), Die Heilige Elisabeth verteilt Almosen auf der Wartburg von Gustav Heinrich Naeke (Abb. 37) sowie die verschollene Judith von Philipp Veit (Abb. $\left.5^{8}\right)$.

Selbst wenn in diesem Raum nur ein Drittel der Gemälde religiöse Motive darstellten, ist hier eine weitere Unterscheidung festzuhalten. So sind die katholischen, italienischen Kunstwerke von den protestantischen, altdeutschen Werken geschieden. Quandts Hängung von 1824 im Gemäldesaal des zweiten Stockwerks könnte somit als ein Kommentar auf die konfessionellen Aspekte in der Präsentation der königlichen Gemäldesammlung in Dresden gesehen werden. Tristan Weddigen hat in diesem Zusammenhang herausgearbeitet, dass das katho-

15 Die Aussage ist überliefert im Brief von Julius an Veit Schnorr vom 20.10.1820, in: SLUB, Mscr. Dresd. n Inv. 8, Bd. 1, fol. 184r. Das WerkstattBild von Perugino befindet sich heute im Städel-Museum, Frankfurt a/M, Inv.-Nr. 1379. S. a. Rüfenacht 2018, SQ-6 (Botticelli), SQ-29 (Fra Angelico), SQ-30, SQ-136 (Perugino). Des Weiteren SQ-16 (Francia), SQ-17 (Art des Cimabue), SQ-21 (Art des Alunno).

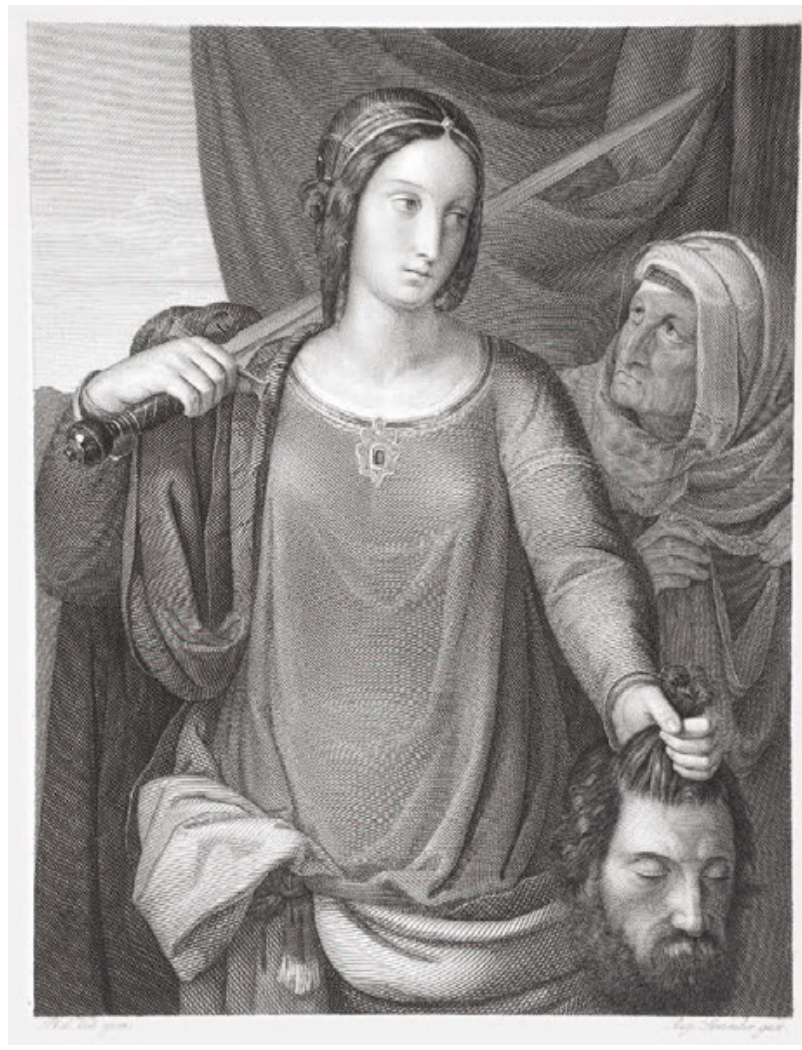

58 August Semmler nach Philipp Veit, Judith, o. J., Kupferstich, $324 \times 240$ mm, Mainz, Landesmuseum, Graphische Sammlung, Inv.-Nr. GS 2128

lische Königshaus aus Gründen des Dekorums ein Interesse an katholischen Bildern hatte. Diese vorwiegend italienischen Gemälde wurden durch ihre Präsentation in der inneren Galerie von der tendenziell profanen Malerei der Niederlande, wie sie in der äußeren Galerie gezeigt wurde, abgetrennt. Dadurch wurde die innere Galerie durch die Funktion der Kunstwerke in gewissem Sinn sakralisiert, wenn auch profane Themen durchaus präsent waren und zu sinnreichen, moralisch-religiösen Assoziationen führen konnten. ${ }^{17}$

Eine konfessionelle Komponente in Quandts Gemäldehängung dürfte jedoch aus ganz anderen Gründen Einzug gefunden haben. Noch 1824 galten seine Sympathien durchaus den katholischen Lukasbrüdern rund um Friedrich Overbeck oder Philipp Veit, die beide in diesem Raum gezeigt wurden. Gleichzeitig förderte er mit Julius Schnorr von Carolsfeld einen bekennenden protestantischen Nazarener, dessen katholische

16 Die einzelnen Bilder von »Raum 9 « in nachfolgender Aufzählung in der Spalte »Raum 1824/1868« in Rüfenacht 2018, S. 6-45.

17 Weddigen 2008, S. 107-122. 
Motive für Quandt weniger konfessionell als aufgrund der dargestellten Charaktere und Tugendbilder bedeutsam waren, wie noch gezeigt werden wird. Damit dürfte diese Präsentation im Gemäldesaal von 1824 vor allem dahingehend verstanden werden, dass Quandt einen Ausgleich nicht nur der Bildgattungen, sondern auch der Funktionen anstrebte sowie den Vergleich von Werken seiner Zeitgenossen, insbesondere der Nazarener, und ihren altmeisterlichen Vorbildern ermöglichen wollte. Allein durch den Einbezug zeitgenössischer Meister setzte er sich von den königlichen Sammlungen ab, wo solche noch bis 1840 überhaupt nicht vertreten waren. Er dagegen präsentierte sie zusammen mit den Alten Meistern im gleichen Sammlungsraum. ${ }^{18}$ Dadurch wurden bei Quandt Künstler und Kunstwerke über Zeit und Raum hinweg vergleichbar. Die auffallende Bildung von funktionsgetrennten Werkgruppen lässt sogar annehmen, dass Quandt mindestens in diesem Ausstellungssaal Scherwände eingezogen hatte. ${ }^{19}$ Die einzelnen Werkgruppen vermochten so möglicherweise direkt einander gegenübergestellt und so vergleichbar gewesen sein.

Im Katalog von 1868 hatte sich dieses die kunsthistorischen Epochen ausgleichende und durchmischende Prinzip aufgelöst. Im Gemäldesaal des zweiten Geschosses waren nur noch Gemälde zeitgenössischer Künstler präsentiert. Interessant ist nun, dass Quandt jetzt die Grenzen zwischen den Kunstgattungen vollends aufgelöst hatte, somit auch jegliche konfessionellen Aspekte aufgehoben wurden. So hingen Landschaften von Friedrich Helmsdorf und Pierre de la Rive zwischen Architekturdarstellungen von Domenico Quaglio und Maximilian Albert Hauschild, Genrebilder von Friedrich Gauermann folgten auf Gustav Heinrich Naekes Die Heilige Elisabeth verteilt Almosen auf der Wartburg (Abb. 37). Adrian Ludwig Richters Die Überfahrt am Schreckenstein (Abb. 10) und Ludwig Schnorrs Familie Johannes des Täufers bei der Familie Christi (Abb. 15) flankierten kleine Genrebildchen von Franz Catel, Johann Adam Klein und Peter von Hess, in unmittelbarem Anschluss waren zwei Landschaften von Joseph Anton Koch präsentiert (Abb. 46-47). ${ }^{20}$

Die größte Änderung gegenüber der Hängung von 1824 ist jedoch die Trennung Alter und Neuer Meister. Im Gemäldesaal

18 Spitzer 2010, S. 6-8.

19 Die große Menge an Gemälden scheint diese Vermutung zu erhärten. Selbst bei einer relativ dichten, mehrlagigen Hängung benötigten alle Gemälde um die 30 Meter fortlaufende Wand, um angemessen präsentiert zu werden. Dies bedürfte, ohne Scherwände, eines für ein Bürgerhaus gigantischen Raumes. 1868 waren hier nur noch $35 \mathrm{Ge}$ mälde ausgestellt, wobei die größten Formate eines Steinkopf, Dahl, Naeke und Overbeck fehlten. Die These der Scherwände scheint sich dadurch zu erhärten.

20 Rüfenacht 2018, SQ-95 (Naeke), SQ-96, SQ-97 (Gauermann); SQ-104, SQ-107 (Quaglio), SQ-105 (Hauschild), SQ-106 (Helmsdorf), SQ-108 (de la Rive); SQ-78 (Richter), SQ-79 (Schnorr), SQ-80 (Catel), SQ-81 (Klein) SQ-82 (Hess), SQ-83, SQ-84 (Koch). des zweiten Obergeschosses war am Ende von Quandts Leben kein Werk des späten Mittelalters und der Renaissance mehr ausgestellt. All diese Bilder hatte er in das zweite Zimmer der Raumfolge im ersten Stockwerk seiner Villa verfrachtet. Genau wie bei den Zeitgenossen zeigt sich auch hier eine Auflösung der Gattungsgrenzen, vor allem aber auch der alpinen Grenze nördlicher und südlicher Schulen. Da hingen neben Botticellis Aus dem Leben des Heiligen Zenobius (Abb. 53) Porträts des Flamen Pieter Pourbus und des Deutschen Georg Pencz sowie Brueghels Landschaften. Die vom Heiligen Johannes gehaltene trauernde Madonna aus dem Umkreis von Albrecht Bouts war zusammen mit Fra Angelicos Madonna mit Kind (Abb. 55) präsentiert. ${ }^{21}$ Zeichen der Verbindung nördlicher und südlicher Kunst sowie der Kunst der Alten und Neuen Meister bildeten indessen die beiden Landschaften von Jacob Ruisdael und Ernst Ferdinand Oehme. Dieses Pendant wird nachfolgend noch genau analysiert. ${ }^{22}$

Der Wille zu einem qualitativen Ausgleich der Bildgattungen, Funktionen, Schulen und selbst der Epochen schien sich bei Quandt über die Jahre hinweg noch stärker ausgeprägt zu haben. Welche weiteren Kriterien der Betrachtung sich in Quandts Gemäldehängungen niedergeschlagen haben könnten, vermag der Blick auf die zahlreichen Bildpaare aufzuzeigen. Diese sind aufgrund der Kataloge einfacher zu rekonstruieren. In Quandts Sammlung begegneten dem Betrachter einander unmittelbar gegenübergestellte Landschaften und Genredarstellungen eines Künstlers, um Vergleiche innerhalb des Werks eines Malers zu ermöglichen. ${ }^{23}$ Ähnliche Prinzipien lassen sich erweitern auf Meister und Schüler, Künstler einer Kunstschule oder Fachmaler zweier Generationen. So kann die Zusammenführung von Architekturdarstellungen der Maler Johann Theodor Goldstein und Carl Hasenpflug oder von Domenico Quaglio und Maximilian Albert Hauschild beobachtet werden. ${ }^{24}$ Ein wichtiges Pendant in der Gemäldehängung entpuppt sich in der Konfrontation von Joseph Anton Kochs Berner Oberland und Ideale Landschaft mit der Heimkehr Jakobs (Abb. 46-47). Die Heimkehr Jakobs hatte Koch in Zusammenarbeit mit Peter Cornelius, der die Figuren gemalt hatte, geschaffen. ${ }^{25}$ Auch das Pendant

21 Rüfenacht 2018, SQ-6 (Botticelli), SQ-8 (Pourbus), SQ-9 (Pencz), SQ-10, SQ-11 (Brueghel); SQ-28 (Bouts), SQ-29 (Fra Angelico).

22 Rüfenacht 2018, SQ-36 (Ruisdael), SQ-39 (Oehme). Siehe unten Kap. Erlebnis und Dichtung.

23 Rüfenacht 2018, SQ-46, SQ-47 (Rugendas), SQ-55, SQ-56 (Hasenpflug), SQ-70 bis 73 (Eggers), SQ-96, SQ-97 (Gauermann), SQ-101, SQ-102 (Wagenbauer), SQ-111 bis 114 (Graff und Klotz).

24 Rüfenacht 2018, SQ-55 bis 59 (Hasenpflug / Goldstein), SQ-104, SQ-105 (Quaglio / Hauschild).

25 Rüfenacht 2018, SQ-83, SQ-84. 
von Adrian Ludwig Richters Ariccia (Der Morgen) und Civitella (Der Abend) ist hier noch einmal zu nennen (Abb. 56-57).

Die genannten Beispiele ermöglichten in der Präsentation relativ einfache Vergleiche auf der Ebene der Kunstschulen, Gattungen, Motivik oder malerischen Qualität und waren, außer im Fall von Richters als Gegenstücke geplanten Gemälden, kaum als eigentliche Pendants in Auftrag gegeben worden. Sie wurden nur im Zuge der Gemäldepräsentation zusammengeführt. Doch darüber hinaus lassen sich in Quandts Sammlung einige Konfrontationen mit komplexen Bezugssystemen besonders im Kontext der Ausstellungsräume, in denen sie sich befanden, feststellen. Diese assoziationsreichen Pendants sind für das Kunstverständnis des Dresdener Sammlers wegweisend. Drei Varianten sollen nachfolgend genauer analysiert werden. Das erste Beispiel ist die Gegenüberstellung zweier Madonnenbilder von Louise Seidler und Julius Schnorr von Carolsfeld. Beim zweiten Exempel handelt es sich um die gemeinsame Präsentation der Landschaftsbilder Bewaldetes Tal von Jacob Ruisdael und Ernst Ferdinand Oehmes Dittersbacher Grund. Anhand des dritten Beispiels wird ein verzweigtes Bezugssystem ästhetischer Kategorien analysiert: Johann Martin von Rohdens Landschaft mit Einsiedler und Caspar David Friedrichs Die zertrümmerte Hoffnung. In diesem Fall können überaus vielschichtige Deutungsebenen herausgearbeitet werden, weil sich der Kontext des Sammlungsraumes über die Jahre gewandelt hat.

\section{Original und Kopie}

In der Gegenüberstellung zweier Madonnen mit Jesuskind von Louise Seidler nach Raffael und von Julius Schnorr von Carolsfeld lassen sich das Verhältnis von altem und neuen Meister und den Ansprüchen an die zeitgenössische Kunst erläutern (Abb. 59-60). ${ }^{26}$ Quandt hatte 1819 bei Schnorr in Rom eine Madonna mit Kind bestellt, die er seiner Frau als Geburtstagsgeschenk überreichte. Sie befindet sich heute im WallrafRichartz-Museum in Köln. ${ }^{27}$ Im Dankesbrief an den Maler schrieb Quandt: »Die meisten Beschauer werden noch mehr von dem Kinde angezogen, als von dem stillen in sich schauenden Blick der Mutter. Mich rührt nun weit mehr diese, ob wohl auch das Kind mir viel Freude macht. $\ll^{28}$ Selbst der Maler Franz Ludwig Catel, der laut Quandt ein Gegner der Nazarener war, bezeichnete die Madonna als das schönste Werk der neuen Kunst und Quandt betonte, dass das wahrhaft Schöne immer Recht behielte und selbst von Gegnern nicht verkannt würde. ${ }^{29}$

Im Katalog von 1824 ist das Gemälde als »eine Mutter in einer Landschaft« beschrieben. 1830 erklärte Quandt in seinen Briefen aus Italien, ein gutes Gemälde stelle eine ideale Welt der Erscheinungen aufgrund einer vernunftbestimmten Idee mit den Mitteln der Realität dar. Er verdeutlichte diese seine Ansicht anhand eines Beispiels: »Welcher Künstler z. B., der eine junge Frau, die ihr Kind in den Armen wiegte, sähe und sie abmalte, würde sagen können, daß dies ein Madonnenbild sei? [...] diese Erscheinung kann nicht seine Idee einer Madonna bestimmen, nicht zwingen, die hohe Mutterliebe sich so zu denken.«Quandt schien sich bei der Katalogisierung nicht sicher zu sein, ob Schnorr hier die künstlerische Idee einer Madonna oder einer idealen Mutter umgesetzt hatte. Aber anscheinend traf der Maler mit seiner Darstellung das, was der Sammler so oft mit »Idee bezeichnet hatte..$^{30}$

Die Auslegung von Madonnenbildern als Darstellung einer urtypischen Mutterliebe zeigt sich in einem Ankauf des Sächsischen Kunstvereins im Jahr 1830. Carl Gottlieb Peschel hatte ein Gemälde mit dem Titel Süße Mutter der Liebe geschaffen. Quandt schrieb daraufhin an Goethe: »Der Gegenstand ist eine Caritas, Mutter mit zwey Kindern, oder Madonna mit Christus u Johannes zu nennen, um dem Bilde einen Namen zu geben, damit die Leute, welche ohne Namen nicht wissen was sie aus einem Bilde machen sollen, doch etwas haben, woran sie sich halten können. $\ll^{31}$ Quandt ging es also nicht um einen ikonographischen Bildtitel, sondern um die Darstellung der grundsätzlichen Idee von Mutterliebe. Entsprechend präsentierte er Schnorrs Madonna in seinem Haus.

Das Bild hing im Wohnzimmer seiner Frau, Mutter seiner beiden Söhne, wie er Schnorr in einem Brief vom 22. August 1824 schrieb. Der Katalog von 1824 zeigt es als Gegenstück einer Kopie von Louise Seidler nach der Madonna di Casa Tempi von Raffael. Seidlers Kopie hatte für die junge Künstlerin den Zweck, sich am Original bilden zu können. ${ }^{32}$ Quandt verstand
26 Rüfenacht 2018, SQ-74 (Schnorr), SQ-75 (Seidler).

27 Brief von Julius an Veit Schnorr vom 30.10.1819, in: SLUB, Mscr. Dresd. n Inv. 8, Bd. 1, fol. 153v. S. a. Schnorr 1886, S. 154: »Die Aufgabe ist eine Madonna mit Jesuskinde zu malen, und das Bild ist zum Geschenk für seine Frau an ihrem Geburtstage bestimmt.« S. a. ebd., S. 164, 208, 359-360. Clara Bianca von Quandt war überglücklich über das Geschenk; Brief an Henriette Schnorr vom 1.12.1819, in: SLUB, Mscr. Dresd. n Inv. 8, Bd. 2, fol. 187r-188v. Maaz 1986, S. 35; Kat. Leipzig/ Bremen 1994, Nr. 60, S. 212-213; Teichmann 2001, S. 85-89.
28 Brief an Schnorr vom 21.4.1821, in der SLUB, Mscr. Dresd. n Inv. 15, Bd. 31, fol. 63r.

29 Brief von Quandt an Veit Schnorr vom 25.3.1820, in: SLUB, Mscr. Dresd. n Inv. 8, Bd. 2, fol. 194r-v.

30 Quandt 1830 (1), S.297-300; Kat. Quandt 1824, [Nr. 17], S. 8.

31 Brief von Quandt an Goethe vom 30.7.1829, in: Schmitz/Strobel 2001, S. $64,66$.

32 Das Bild befindet sich in österreichischem Privatbesitz. Zu seiner Entstehung siehe Seidler 2003, S. 291: »Der dritte Rafael, den ich in 


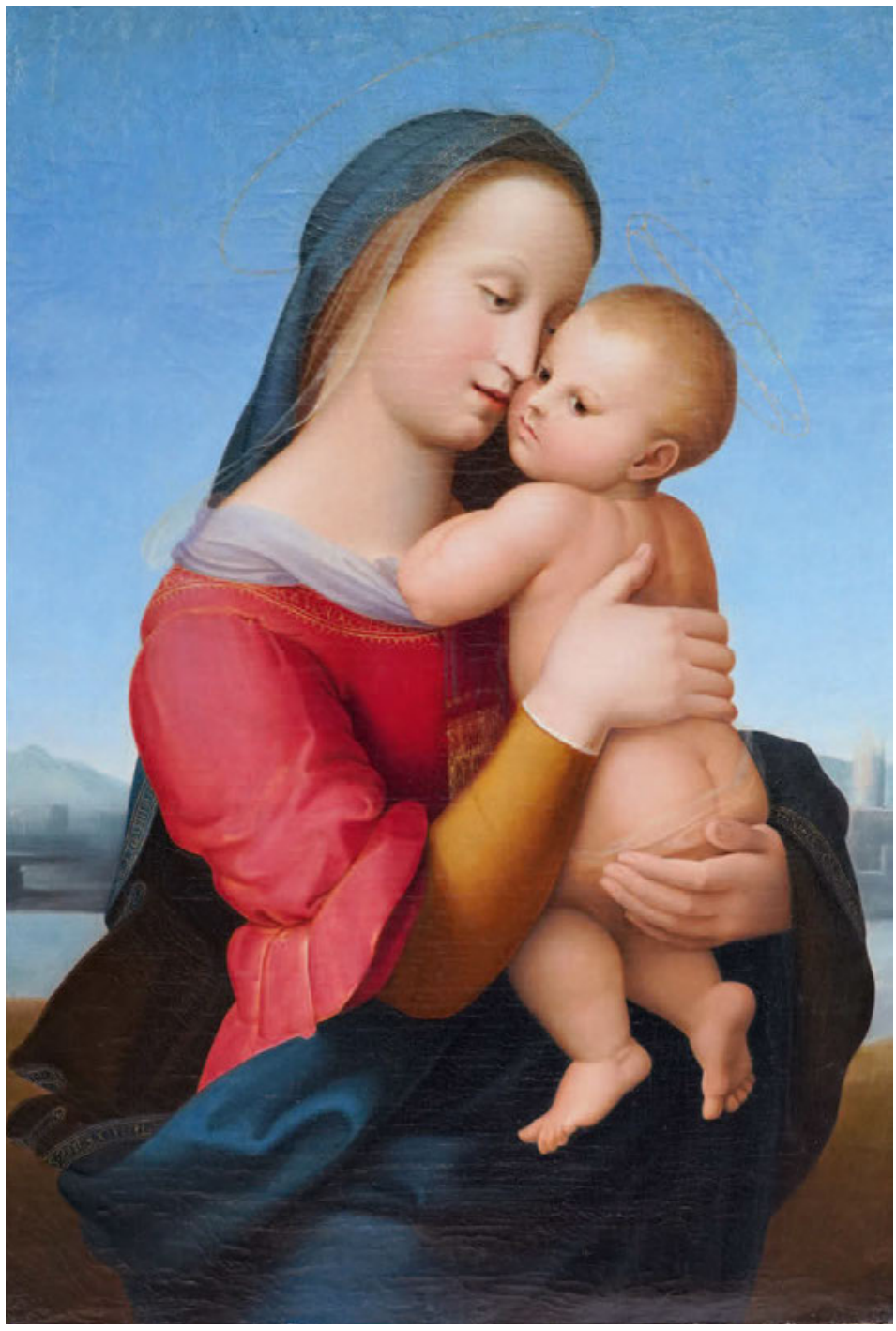

59 Louise Seidler nach Raffaello Santi gen. Raffael, Madonna di Casa Tempi, um 1820, Öl auf Leinwand, $75 \times 51$ cm, Privatbesitz das Kopieren so, wie es Johann Georg Sulzer unter dem Begriff des »Copierens« in der Allgemeinen Theorie der Schönen Künste, erschienen 1771/74, festgehalten hat: als einen Weg zur Aneignung des künstlerischen Charakters alter Meister. ${ }^{33}$ Dieses Verständnis geht auf Johann Joachim Winckelmanns Unterscheidung von Kopie und Imitation, Nachmachung und Nachahmung zurück. Nachmachung wurde als sinnlose Tätigkeit abgelehnt, Nachahmung als künstlerisch erstrebenswert angesehen. Gerade die Nazarener, zu denen Seidler zu zählen ist, erweiterten diesen Begriff der Nachahmung auf die mittelalterlichen Meister und die Künstler der Renaissance, denen sie nicht nur künstlerisch, sondern auch geistig nachstreben wollten. ${ }^{34}$ Seidler konnte durch ihre Kopie nach Raffael die künstlerische Umsetzung der Mutterliebe anhand einer Mariendarstellung erlernen. Ihre Gegenüberstellung mit Schnorrs Maria mit Kind ermöglichte den Vergleich künstlerischer Ideen. Original oder Kopie spielte darin keine Rolle, denn Quandt sah in guten Kopien sinnvollen Ersatz für Originale. ${ }^{35}$
Florenz copiren durfte, war die zarte Madonna Tempi: die jugendliche Mutter, das dem Beschauer zugewandte Kind an sich drückend; ein Gemälde, welches erst später recht bekannt und berühmt wurde. Es gehört in die mittlere Periode Rafaels und entzückt durch seine edle Einfachheit, Unschuld und Kindlichkeit. [...] eine meiner Copien kaufte Herr von Quandt, um sie der schönen Gallerie in seinem kunstgeweihten Wohnhause an der großen Elbbrücke in Dresden einzuverleiben.« S. a. Kovalevski 2006, S. 142, 151, 169. Zum Standort siehe auch Anonym 1825, S. 789-790.
33 »Man muß nicht suchen Copeyen zu machen, die alles Aeußerliche der Originale an sich haben, sondern fürnehmlich den Geist derselben auf eine uns eigene Art zu erreichen suchen.« Einträge »Copey« und „Copieren«, in: Sulzer 1771, Bd. 1, S. 230-232, Zitat S. 232. S. a. Quandt 1826 (1), S. 284-286.

34 Grewe 2015, S. 209-225 nennt dies »Epigonalität«. Zu Winckelmanns Verständnis im Verhältnis zu den Nazarenern ebd., S. 214, 218-219.

35 Quandt 1842, S. 9. Interessant hierzu auch Grewe 2015, S. 218-222 über Karl Leberecht Immermanns Theorie der Epigonalität, der Idee einer 
60 Julius Schnorr von Carolsfeld, Maria mit dem Kinde, 1820, Öl auf Leinwand, $74 \times 62 \mathrm{~cm}$, Köln, Wallraf-Richartz-Museum, Fondation Corboud, Inv.-Nr. WRM 1112

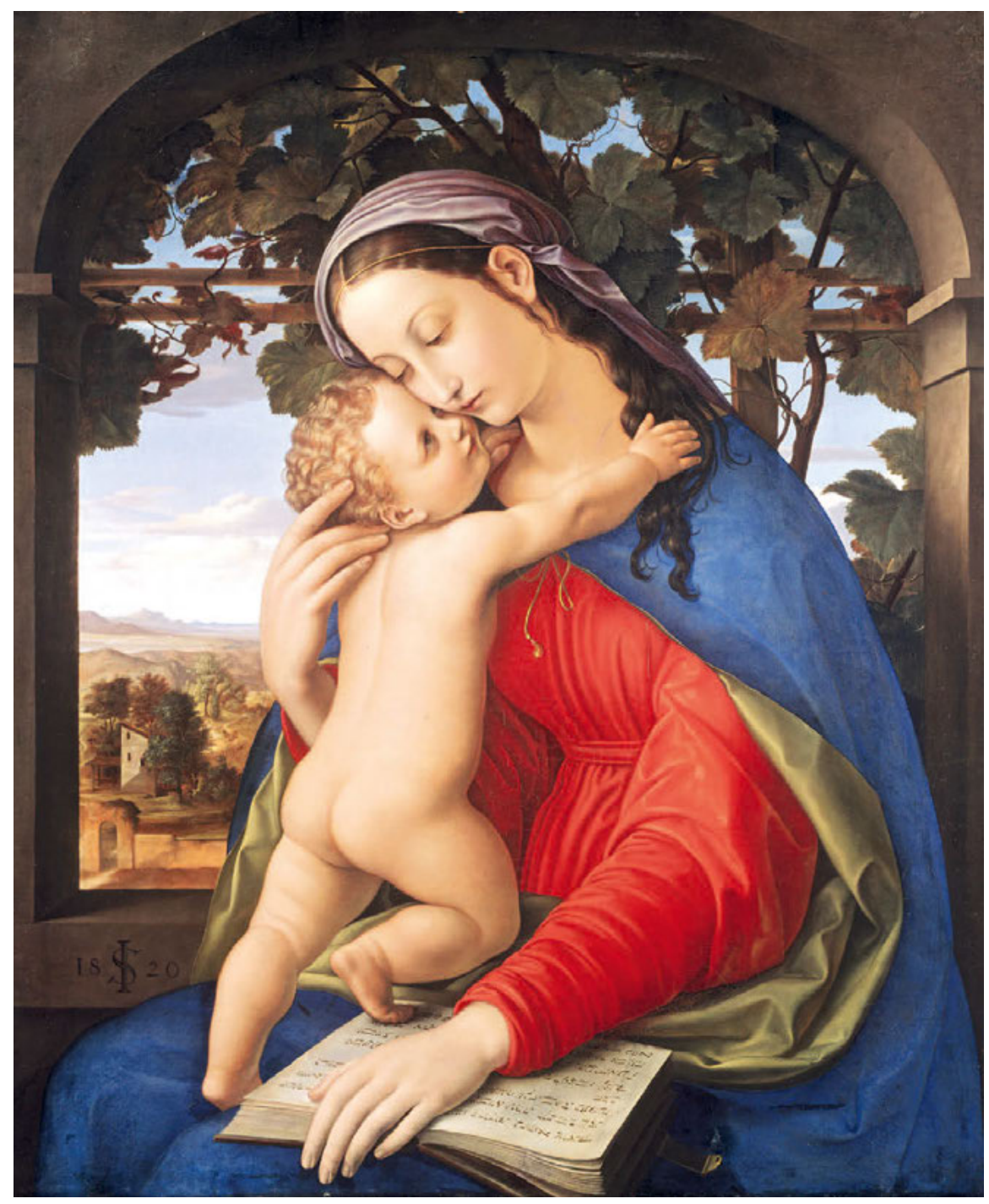

Durch die Gegenüberstellung von Seidlers Raffael-Kopie erfuhr Schnorrs Madonna eine Aufwertung. Sein Gemälde übertraf die Kopie der Zeitgenossin, weil er die Idee der Mutterliebe eigenständig erarbeitete. Gleichzeitig wurde der Bildgedanke der Mutterliebe durch die eigenständige Verarbeitung vergleichbar mit Raffaels originärer inventio, die Seidler durch die Kopie vermittelte. Diese Vergleichbarkeit von neuer und alter Kunst zu erreichen, war nicht zuletzt Ziel der Nazarener, denen Schnorr in zweiter Generation angehörte. Die Meister der Frührenaissance dienten als Vorbild für die Umsetzung der Forderung nach Wahrheit und Reinheit in der Kunst, denen sich die Lukasbrüder verpflichtet hatten. ${ }^{36}$ So erinnert auch
Schnorrs Maria mit Kind an Bilder der Frührenaissance. Diese Art der Nachahmung, die nicht als Kopistentum verurteilt werden kann, sondern versucht, durch hochstehende Technik und eigenständige Bildfindungen den Renaissance-Künstlern nachzueifern oder diese gar zu überbieten, erinnert an die positive Beschreibung der imitatio bei Sulzer. »Die allgemeine Nachahmung großer Meister besteht darin, daß man sich ihre Maximen, ihre Grundsäze, ihre Art zu verfahren, zueigne.«77 Seidler wendete diese Art der Nachahmung an, um zu lernen. Schnorr, zum Zeitpunkt der Entstehung des Werks schon zwei Jahre in Rom, übersetzte in seine eigene Bildsprache, was ihm an großartiger Kunst vor Augen stand. Quandt, indem er das Bild über alle künstlerischen Reproduktion als Befehlsgewalt über die Kunst mit dem positiven Effekt, aus der nie erreichbar perfekten Nachahmung der Alten immerzu Neues zu erschaffen.

36 Grewe 2015, S. 213-216; Thimann 2014, S. 33-68; Vignau-Wilberg 2011,
S. 12-22. S. a. Paul Eich, »Über das Verhältnis der Nazarener zum Mittelalter«, in: Kat. Frankfurt 1977, S. 27-35.

37 Sulzer 1774, Bd. 2, S. 797 


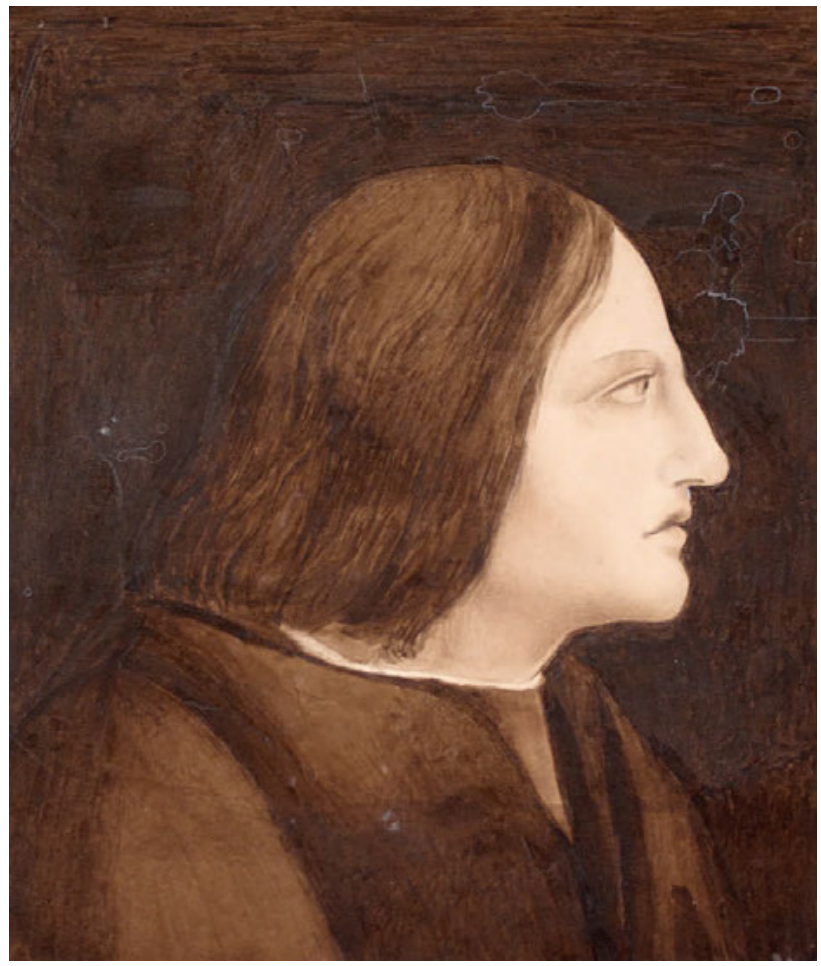

61 Erwin von Quandt, Profilbild einer jungen Person (wohl nach einer Bildniskopie von Louise Seidler nach Masolinos Fresken in der Katharinenkapelle von San Clemente, Rom), nicht datiert [vor 1857?], Sepia, $25,1 \times 21,3 \mathrm{~cm}$, Quandt-Verein Dittersbach

Maße rühmte, wertete es durch die Präsentation als Pendant einer Kopie nach Raffael auf. ${ }^{38}$ Damit präsentierte der Sammler ein dynamisches Wechselverhältnis zwischen ursprünglicher inventio, lernender imitatio und übertreffender aemulatio. ${ }^{39}$

Mit dem Einbezug einer qualitätsvollen Kopie schloss Quandt an Hängungsprinzipien an, wie sie in der Gemäldegalerie Alte Meister in Dresden zu sehen waren. Er verfolgte jedoch eine eigene Linie: In der königlichen Sammlung waren nur Originale gut genug, Nachahmer und Kopisten wurden in periphere Räume verbannt, eine Hängung nach kunstdidaktischen Kriterien war sekundär. Eine Ausnahme bildeten zwei Fassungen des Zinsgroschens von Tizian, von denen eine als eigenhän-

38 Die Deutungsschichten sind sogar noch komplexer: In Quandt 1819, S. 132 verbindet Quandt die altdeutschen Madonnenbilder als die echtesten Darstellungen der Mutterliebe überhaupt. Das Bild der Heiligen Jungfrau sei im Mittelalter ein Bild »Deutscher Jungfräulichkeit« gewesen und trage den Charakter der deutschen Nation in sich. So verstanden wäre Schnorrs Madonna mit Kind nur die konsequente Schlussfolgerung altdeutscher Großartigkeit und damit mindestens auf gleichem Niveau wie die italienischen Vorbilder.

39 S. a. Beiträge von Julian Blunck und Wolfgang Ullrich, in: Nida-Rümelin/Steinbrenner 2011, S. 11-20, 98-102, 104-110. Zur emulation [engl.] bei den Nazarenern kenntnisreich Grewe 2015, bes. S. 209-225.

40 Weddigen 2008, S. 99-106 mit weiteren Beispielen. dige Kopie angesehen wurde, mithin »Originalkopie« war und einer exquisiten Kunstkennerschaft diente..$^{\circ 0}$ Auch Quandt änderte in seinem Hängungskonzept für die königliche Galerie am Jüdenhofe von 1840/43 an diesem Prinzip einer Trennung von Originalen, Kopisten und Nachahmern nichts, obschon er den didaktischen Rundgang durch die Geschichte der Künste zu stärken suchte..$^{41}$ In seiner Privatsammlung indessen konnte die Kopie einerseits auf das fehlende oder nicht zugängliche Original verweisen, andererseits als Korrektiv desselbigen wirken, wie es später im Kontext des Streits um die Die Madonna des Basler Bürgermeisters Jakob Meyer zum Hasen von Hans Holbein formuliert werden sollte (vgl. Abb. 90-91). Damit versuchte man die qualitativen Unterschiede zwischen der unrestaurierten Darmstädter Version und der Dresdener Fassung zu erklären. Die Dresdener Kopie war demnach eine eigenhändige Verbesserung des als Erstfassung erkannten Darmstädter Gemäldes. ${ }^{42}$ Bei Quandt ging es freilich nicht darum, dass Seidlers Kopie Raffaels Original korrigiert hätte, sondern dass Raffael gleichsam mittelbar und nur im Auge des Betrachters durch die Wiederholung korrigierend auf Schnorrs Madonna einwirkte. Quandts Präsentation der beiden Gemälde reflektierte und interpretierte hier gewissermaßen seinen Wahlspruch am Eingang zu den Sammlungsräumen, die Mängel alter Kunst zu erkennen und zu verbessern, nicht aber nachzuahmen oder krampfhaft zu erneuern.

Der Zeit entsprechend übernahmen qualitativ gute Kopien, zumal nach großen Meistern wie Raffael, in Quandts Sammlung eine didaktische Rolle, vermittelten sie doch genauso wie die Kupferstiche etwas von der geistreichen Originalität des kopierten Meisters. ${ }^{43}$ In diesem Sinn besaß er fünf AltmeisterKopien von jungen deutschen Künstlern, darunter die erwähnte Raffael-Wiederholung von Seidler sowie die Kopie des Kopfes einer Figur im Profil aus der Katharinenkapelle von Masolino in San Clemente in Rom, ebenfalls von dieser Künstlerin. Dieses verschollene Bild ist möglicherweise in einer ungeschickten Wiederholung von Quandts Sohn Erwin zu erkennen (Abb. 61). ${ }^{44}$ Es flankierte Schnorrs Maria mit dem Kinde und Seidlers Raffael-Kopie. ${ }^{45}$ Eine programmatische Rolle in der Prä-

41 Quandt 1842, S.7-12. Siehe unten Kap. Quandts übersichtlicher Galerierundgang $1840-1843$.

42 Es handelt sich hierbei freilich nur um eine Argumentationsvariante im Rahmen des Holbein-Streits; Bader 2013, S. 243-251.

43 Kat. Quandt 1853, S. 134-138. S. a. Bader 2013, S. 310-321.

44 Kat. Quandt 1868, S. 21, Nr. 74.

45 Des weiteren eine Heilige Katharina von Carl Eggers. Siehe Kat. Quandt 1868, S. 20, Nr. 71. Brief von Quandt an Seidler vom 30.7.1841, in: Schmitz/Strobel 2001, S. 194; Seidler 2003, S. 236. Kovalevski 2006, S. 141, Abb. 119. Die Masolino-Kopie soll Kaiserin Faustina darstellen. Man ist gewagt zu mutmassen, dass Quandt mit dem Auftrag an Seidler »zu einem werthen Andenken« knapp zehn Jahre nach Goethes 
sentation übernahm Joseph Sutters verschollene Kreidekopie nach Raffaels Galathea, die er der Goethe-Büste von Christian Daniel Rauch gegenüberstellte und damit den großen Künstler der Renaissance und den verehrten Dichter der Gegenwart in einen Dialog brachte. ${ }^{46}$ Ferner präsentierte er im großen Gemäldesaal seiner Sammlung, also hinter dem Vorhang mit dem didaktischen Wahlspruch, zwei Nymphen von Adolf Senff nach der Diana von Domenichino in der Galleria Borghese in Rom. Die Kopie einer Perugino-Madonna von Eduard William Bienemann, die im Katalog von 1824 verzeichnet ist, missfiel ihm und schied später aus der Sammlung aus. ${ }^{47}$

Über schlechte Kopien hatte Quandt denn auch eine dezidierte Meinung: »Die Copisten, die ich zu den Wiederkäuern zähle [...], haben der Kunst außerordentlich geschadet, sie gewöhnten die Kunstliebhaber sich mit Mittelgut zu befriedigen, wenn es nur nach etwas aussah. $\ll^{48}$ Dass Quandt in jungen Jahren im Umkreis der Nazarener in Rom Kopien kaufte - nebst Seidler und Sutter gehörten auch Senff und Bienemann dazuist denn auch in erster Linie als Fördermaßnahme zu verstehen. Die guten Beispiele von Seidler und Sutter präsentierte er programmatisch, während er die minderwertigen Kopien im großen Gemäldesaal verteilte und dem vergleichenden Sehen anheimstellte - so hing Bienemanns Perugino-Kopie zwischen drei italienischen Madonnen des Quattro- und Cinquecento, während Senffs Nymphen nach Domenichino von italienischen und idyllischen Landschaften deutscher Zeitgenossen flankiert wurde. ${ }^{49}$ Trotz Quandts dezidierter Meinung zu Kopien ist festzuhalten, dass auch bei ihm Kopie und Original, ganz der Zeit entsprechend, nicht in strenger Hierarchie von- einander geschieden wurden, sondern vielmehr in einem sich befruchtenden Wechselverhältnis zueinanderstanden.50 Verständlich wird dies dann, wenn man sich vor Augen führt, wie schwierig zugänglich Originale überhaupt sein konnten. Eine gute Kopie vermochte eine Sammlung, wie das erläuterte Beispiel bei Quandt zeigt, über den didaktischen Charakter hinaus sogar sinnvoll und wünschenswert zu bereichern und die künstlerische Idee des Originals zu vermitteln. ${ }^{51}$ Daher war bei der Pendant-Präsentation von Schnorrs und Seidlers Madonnen nicht nur die künstlerische Umsetzung, sondern die Darstellung des idealen Gefühls der Mutterliebe selbst Gegenstand des Vergleichs - und genau hierin entsprach Quandt zentralen Anliegen der Lukasbrüder, welche nicht die alten Künstler unüberlegt nachahmen wollten, sondern ihre Geisteshaltung, insbesondere eine intendierte Frömmigkeit. $5^{2}$

Der Sammler verstand Mutterliebe als zeitlosen, allgemeinmenschlichen Begriff: »[...] das, was dem mittelalterlichen Christen das Mutterbild zur Madonna macht, macht es mir zum Bild der Liebe. Das ist aber auch ganz und gar nicht das Zeitliche an einem solchen Bilde, denn sich opfernde, hingebende Liebe, Glauben an Liebe, das Mysteriöse jeder Tiefe des Gemüths, ist eben auch etwas allgemein Menschliches. ${ }^{53}$ Mit dieser Sichtweise war Quandt nicht allein. August Wilhelm Schlegel ging in seinen Vorlesungen über schöne Literatur und Kunst, gehalten in Berlin zwischen 1801 und 1804, darauf ein. Im Kontext seiner Ausführungen über die Historienmalerei bezeichnete er Madonnenbilder als Darstellungen der Caritas. Die Jungfrau Maria sei auch für jemanden, der das »katholische Christentum« nicht kenne, als die liebende und fürsorgliche Mutter erkennbar.54
Tod einen weiteren Aspekt zu seiner Goethe-Verehrung hinzukommen ließ, indem er mit der bekehrten Faustina der ominösen GoetheGeliebten Faustina während dessen Rom-Aufenthaltes 1786-88 eine Reverenz erwies. Sie taucht in einigen Gedichten des Weimarers auf - so in den Römischen Elegien, die Quandt nachweisbar kannte; Quandt 1830 (1), S. 79. Die Hängung im Wohnzimmer seiner eigenen Frau entpuppte sich dann als erweiterter Arm der Goethe-Verehrung ins Liebes- und Eheleben; 18. Römische Elegie, in: FA 1987, Bd. I.1,

S. 429; 4. Venezianisches Epigramm, in: ebd., S. 444.

46 Siehe unten Kap. Ein erster Goethe-Raum in Dresden.

47 Brief von Julius an Veit Schnorr vom 20.10.1820, in: SLUB, Mscr. Dresd. n Inv. 8, Bd. 1, fol. 184r. Zu den hier erläuterten Kopien s. a. Rüfenacht 2018, SQ-2, SQ-75, SQ-76, SQ-93, SQ-136.

48 Brief von Quandt an Weigel(?) vom 23.9.1858, in SLUB, Mscr. Dresd. App. 204, Nr. $98 z$.

49 Kat. Quandt 1824, S. 23, 29.

50 Bader 2013, S. 244, 320-326.

51 Siehe hierzu Bader 2013, S. 276-280, hier S. 280 über die Bedeutung der Kopie im 19. Jahrhundert: »Die künstlerische Autorschaft [der Kopie - AR] sichert die kunsthistorische Autorität."

52 Hierzu ausführlich Grewe 2015, S. 213-216.

53 Quandt 1847, S. 138: »Das aber, was ein solches Bild zu einem mittelalterlichen Bilde stempeln würde, etwa die Königskrone, der Nimbus, die Mondsichel, auf der ein solches Bild steht, geben ihm in meinen
Augen, und nach meinem Gefühle, gar keinen höhern Werth und hätten als Aeußerlichkeiten wegbleiben können. « S. a. Quandt 1819, Bd. 1, S. 132: »Doch das Schönste und Höchste zu fühlen und darzustellen, des Weibes Weihe, Würde und Mutterglück, erreichte die Deutsche Kunst und Deutscher Frauen Herrlichkeit spiegelte sich in dem Bilde unserer Lieben Frau."

54 Schlegel 1801/O2, fol. 31v-32r: »[...] so wird in die Figuren und ihr Thun etwas Symbolisches gelegt werden müssen, sie werden eine Seite der menschlichen Natur u des Lebens anschaulich bezeichnen. Von dieser Art ist die Vorstellung welche man eine Caritas zu nennen pflegt, eine weibliche Figur mit einem Kinde auf dem Arm und im Schooß und ein paar andern um sich her, als Symbol der umfassenden mütterlichen Pflege und Sorgfalt. [...] So ist Maria das Bild der reinen Weiblichkeit, sie vereinigt im Geist $u$ in der Gesinnung, was materiell beleuchtet nur in verschiednen Epochen des Lebens stattfinden kann, Jungfräulichkeit u Mütterlichkeit; [...] Beyde Vorstellungen würden verständlich seyn, auch ohne alle Bekanntschaft mit dem katholischen Christenthum. «Schlegel richtet sich hier gegen die Interpretation der Madonnen durch Meyer/Goethe 1798, S. 23-25: »Was sind die übrigen anders als Mütter, welche ihre Kinder pflegen, tränken, ankleiden, zart und liebend in die Arme schließen? [...] es ist blos reine, treue Darstellung der reinsten Menschlichkeit. "Dies ist Schlegel zu wenig. S. a. Gaehtgens/Fleckner 1996, S. 303. 
Noch weiter ging Georg Wilhelm Friedrich Hegel: Der Philosoph nahm sich in seinen Vorlesungen über die Philosophie der Kunst von 1823 Madonnendarstellungen als Beispiel, um das Verhältnis vergangener und gegenwärtiger Kunst zu vertiefen. Maria und Kind seien Symbole des zeitlosen, immerwährenden menschlichen Bedürfnisses nach Liebe. Während fromme Andacht die Funktion mittelalterlicher Mariendarstellungen gewesen sei, vergegenwärtige die zeitgenössische Kunst einzig das Ideal der Liebe. Damit bleibe die Marienikonographie auch in der Gegenwart angemessen. ${ }^{55}$

Diese Interpretation der Madonna als Metapher der Mutterliebe war somit zu Beginn des 19. Jahrhunderts allgemein bekannt. In Quandts Pendant von Schnorrs Madonna und Seidlers Kopie nach Raffael schlug sich dies nieder. Raffaels $M a-$ donna di Casa Tempi repräsentierte eine Art phänomenologischen Urtyp dieser Liebe. Louise Seidler kopierte sie in die Gegenwart. Ihr Bild vergegenwärtigte die immerwährende Liebe nicht nur durch ihr Dasein in der Malerei, sondern auch durch die Überführung des raffaelischen Vorbildes. Schnorrs Gemälde wurde zum künstlerisch eigenständigen Beweis des dauerhaften Phänomens der Mutterliebe und seiner Aktualität in der Gegenwart. Quandt stellte mit der Bildung dieses Pendants den nazarenischen Anspruch nach Wahrheit und Reinheit der Kunst dar. Die Bilder waren, wie es Hegel formuliert hat, nicht mehr der Funktion der christlichen Andacht unterworfen. Die Andacht galt nun der Kunst. Damit sollte dieses Pendant die Eigenständigkeit der zeitgenössischen Kunst darlegen.

\section{Erlebnis und Dichtung}

Anhand des zweiten Beispiels eines herausragenden Pendants in Quandts Sammlung lässt sich die hier erläuterte Diskussion um die vielschichtige Frage nach dem Verhältnis alter und neuer Kunst weiterentwickeln. Doch wo im ersten Beispiel noch der

55 Hegel 1823 [2003], S. 253-255: »Das Bedürfnis solcher Darstellungen hat die Kirche. Sie verlangt solche Bilder, die verehrt werden sollen. Aber je höher die Kunst steigt, desto mehr werden solche Gegenstände in die Gegenwart herübergehoben. Die Malerei macht sie irdisch und gegenwärtig, gibt ihnen Vollkommenheit weltlichen Daseins, [...] so daß die Seite der sinnlichen Existenz zur Hauptsache und das Interesse der Andacht das Geringere wird. Die Kunst hat die Aufgabe, dies Ideale ganz zur Gegenwärtigkeit herauszuarbeiten, das dem Sinnlichen Entrückte sinnlich darstellig zu machen und die Gegenstände aus der fernen Szene in die Gegenwart herüberzubringen und zu vermenschlichen. Bei den Marienbildern ist z. B. das Verhältnis zum Kinde dargestellt wie das Verhältnis einer natürlichen menschlichen Mutter zu einem menschlichen Kinde. Dies wird uns zur Gegenwart gebracht, und das menschliche Verhältnis ist herausgehoben. Bei diesen religiösen Gegenständen ist ein objektives Bedürfnis, von dem ausgegangen wird.« S. a. Gethmann-Siefert 2005, S. 286-287.
Nachahmungsbegriff und die Ikonographie eine wichtige Rolle gespielt haben, rückt im Fall der Gegenüberstellung der Gemälde Bewaldetes Tal des holländischen Alten Meisters Jacob van Ruisdael und des Dittersbacher Grund des jungen sächsischen Künstlers Ernst Ferdinand Oehme die Frage nach dem Verhältnis von Betrachter und Motiv ins Zentrum des Interesses $\left(\right.$ Abb. 62-63)..$^{6}$

Ruisdaels Landschaft erstand Quandt durch Vermittlung seines ehemaligen Hauslehrers Friedrich Rochlitz. Das Gemälde des Niederländers war ihm ausgesprochen lieb. »Der Ruysdael war von jeher mein Liebling u wird es immer mehr, je einheimischer ich in dem engen, stillen Thale werde. Es fällt beÿ diesem Bilde mir immer Tiecks Lied ein: Rings von Bergen eingeschlossen, / Wo die klaren Bächlein gehen, / Wo die dunklen Weiden sprossen, / Wünscht ich bald mein Grab zu sehn. Lied u Bild haben eine zauberische hinreißende u übereinstimmende Trauer: $\ll{ }^{57}$ Quandt stellte zwischen dem Bild von Ruisdael und der Naturlandschaft in Dittersbach einen Bezug her. Als Betrachter erlebte er in Ruisdaels Bild ein ähnliches Gefühl wie beim Gang durch die Dittersbacher Hügel. Wenn Quandt sich durch die Landschaft des Niederländers an ein Gedicht von Tieck erinnert fühlte, dann drückte sich darin seine poetische Auffassung von Kunst aus. So wie er von der Historienmalerei eine poetische und nicht quellenkundige Wahrhaftigkeit forderte, erwartete er von der Landschaft nicht Naturnachahmung, sondern die Einbindung menschlichen Empfindens. Dieses Moment verstand Quandt als Poesie der Malerei..$^{8}$

Die Bedeutung der Poesie für das Kunstwerk kann am Ruisdael-Beispiel weiterverfolgt werden. Quandts Freund, der Dichter Ludwig Breuer, schrieb ein panegyrisches Gedicht auf Quandt mit dem Titel »Ruisdael an der Wesenitz«. Es entstand zum Huldigungsfest für Quandt bei seinem Einzug in Dittersbach, wo die Wesenitz floss. Breuer legte dem niederländischen Maler die Lobrede auf Quandt in den Mund. Ruisdael sprach in

56 Zu Ruisdael: Kat. Oldenburg 2017, S. 301; Slive 2001, Kat. Nr. 185 , S. 191. Zu Oehme: Kat. Dresden/Lübeck 1997, S. 84, S. 193, Kat. Nr. 90. Rüfenacht 2018, SQ-36 (Oehme), SQ-39 (Ruisdael); Kat. Quandt 1868, Nr. 34 (Oehme), Nr. 37 (Ruisdael). S. a. Rüfenacht 2017, S. 159-163; Bemmann 1925, S. 12.

57 Brief von Quandt an Rochlitz vom 24.8.1826, in: SLUB, Mscr. Dresd. App. 26, Nr. 219. Die Verse aus Ludwig Tiecks Gedicht »Der Trostlose«, 1. Strophe, in: Ludwig Tieck, Schriften in zwölf Bänden, Bd. 7. Gedichte, hrsg. v. Ruprecht Wimmer, Frankfurt a/M: Deutscher Klassikerverlag, 1995, S. 113. S. a. den Brief von Quandt an Schnorr vom 18.6.1826, in: SLUB, Mscr. Dresd. n Inv. 15, Bd. 31, fol. 132r: »Es ist eine Trauer über die ganze Natur in diesem Bilde verbreitet welche als genußreiche Schwermuth im Gemüth zum Bewusstseyn kommt.«S. a. Kat. Oldenburg 2017, S. 301.

58 Quandt 1830 (1), S. 176-177. »Die Poesie ist universelle Kunst. [...] die Kunst ist nichts anders, als Versinnlichung innerer Anschauung." 
den Versen, mit dem Einzug Quandts im Dittersbacher Rittergut würden seine Landschaftsgemälde nun endlich geschätzt:

»[...] Da endlich ist ein edler Mann gekommen,

Gleich mir entstammt er fernen Niederlanden ${ }^{59}$

Der meiner Kunst gewidmet treues Neigen.

Ihm reich ich, die ich einst geliebt zu schauen,

Bergstrom und Wald und saftig grüne Auen,

Mit einem Wort - mein Urbild selbst zu eigen.

Zur Huldigung war ich hierhergekommen

Dem nahenden Gebieter-Paar zum Frommen.

Was - dacht ich' - können Wünsche hier noch bieten,

Wo ernste Kunst, vereint mit heitrer Milde,

Die kräftige Natur zum Dienste zwingen? ${ }^{60}$

Breuer verlieh Ruisdael die dichterische Sprache, um ihn über seine eigenen Naturdarstellungen sprechen zu lassen. Es habe einen verständigen Kunstfreund gebraucht, der die natürliche Landschaft zu schätzen wisse, um überhaupt erst Verständnis für die Landschaftsmalerei aufbringen zu können.

Zu diesem Zeitpunkt war es nichts Neues, Ruisdaels Malerei die Sprache der Poesie anzudichten. Goethe hatte $1816 \mathrm{im}$ Morgenblatt für gebildete Stände unter dem Titel Ruysdael als Dichter einen Aufsatz veröffentlicht, der diese Interpretation vorzeichnete. Der Schriftsteller wollte anhand dreier Landschaften des Holländers aus der Dresdener Gemäldegalerie darlegen, dass die Betrachtung von dessen Gemälden über eine rein äußerliche, emotional bestimmte Befriedigung des Sehsinnes hinausgehe. ${ }^{61}$ Ruisdael sei ein denkender Künstler und verhelfe wie ein Dichter dem Betrachter zu einem sinnlichen Begriff der Natur. Die Kunstkenner wiederum würden diesen in eine adäquate Sprache übersetzen.

Mit seinem Artikel nahm Goethe dezidiert Stellung gegen die Idee von Landschaftsmalerei im Gespräch Die Gemählde der Gebrüder Schlegel von 1799 und gegen die Landschaften Caspar David Friedrichs. ${ }^{62}$ Alle Autoren erklärten zwar, Landschaftsmalerei ahme nicht nach, sondern stelle die sinnliche Erscheinung der Natur dar. Bei den Schlegels war es aber eine »Universalsprache des Gemüts«, bei Goethe ein Auffinden der

59 Anspielung auf Quandts Herkunft. Seine Vorfahren stammten aus Holland.

60 Breuer 1835, S. 133. S. a. Heinrich 2002, S. 45.

61 Es handelt sich um die Gemälde Das Kloster, Öl auf Leinwand, $75 \times 96 \mathrm{~cm}$, Der Wasserfall vor dem Schlossberg, Öl auf Leinwand, $99 \times 85 \mathrm{~cm}$ und Der Judenfriedhof, Öl auf Leinwand, $84 \times 95 \mathrm{~cm}$, alle in Dresden, Staatliche Kunstsammlungen, Gemäldegalerie Alte Meister, Gal.-Nr. 1494, 1495, 1502. Zum Aufsatz: Goethe 1816, S. 425-427; FA 1998, I.19, S. 632-636; Rudloff-Hille 1972-1975, S. 52-55.

62 Schlegel 1996, S. 24-39. Weddigen 2008, S. 181-185 setzt sich ausführlich mit dem Verhältnis von Goethes Essay und Schlegels Landschaftsidee auseinander; s. a. Grave 2003, S. 214-215; Bätschmann 2002, S. 22-23.

63 Weddigen 2008, S. 184-185; Rudloff-Hille 1972-1975, S. 52. rechten Worte, die des Künstlers Anliegen darlegen sollten. Goethe verband Anschauung und Denken miteinander, während die Gebrüder Schlegel Anschauung und Gemüt zu einer Einheit führten. ${ }^{63}$

In der Passage über die Dresdener Ruisdael-Gemälde im Begleiter durch die Gemälde-Säle des neu erstellten Galeriegebäudes von Gottfried Semper erwies Quandt noch 1856 Goethes Ruisdael-Aufsatz seine Reverenz. Er war vor allem an dessen Grundthese, dass Ruisdael ein Dichter sei, interessiert und weniger am Kerngehalt des Textes. Goethes Interpretation, Ruisdaels Landschaften seien Allegorien des menschlichen Daseins, deutete Quandt in seinem Sinn um. Er nannte den Zusammenhang zwischen den Landschaften und dem Betrachter »eine Wechselwirkung zwischen dem Leben des Menschen und der Natur «. ${ }^{64}$ Die Gemälde des Niederländer Malers seien ein »Wiederscheine aus den Tiefen der Seele«. Goethe blieb dagegen pragmatisch. Ruisdael erschaffe ein Kunstwerk, das zum Nachdenken anrege. Um Gefühle gehe es nicht, sondern um Verstandesbegriffe. ${ }^{65}$

Damit kam Quandt August Wilhelm Schlegel viel näher als Goethe. Schon Jahre zuvor, als der Kunstfreund dem Weimarer Dichter die Veduten von Dittersbach zugesandt hatte, zeigte sich dieser Unterschied (vgl. Abb. 8-9). Nachdem Quandt über die beiden Aquarelle von Traugott Faber geurteilt hatte, sie seien leblos und ohne Gefühl, antwortete Goethe lakonisch, er hoffe, »daß die liebe Natur auch zur Vernunft gekommen sey.« Quandt möge sich doch am Reellen, Fassbaren und Nützlichen erfreuen. Dieser bemerkte die unterschwellige Opposition gegen seine idealisierende Vorstellung von Landschaft und schrieb Jahre später in seinen Erinnerungen an Goethe, der Dichter habe seine »transcendente Kunstansicht« zurechtgewiesen. ${ }^{66}$ Trotzdem blieb es genau die Schlegel'sche, idealisierende Universalsprache der Poesie, die Quandt an der Landschaftsmalerei interessierte. Die Poesie half ihm, sich seiner Empfindungen bei der Landschaftswahrnehmung bewusst zu werden und sie auszudrücken. Quandts Beschreibungen der Dresdener Ruisdael-Bilder verdeutlichen dies umso mehr, als es

64 Quandt 1856, S. 117-118: »Göthe, der immer mit einem Worte mehr sagt, als alle andere mit vielen prächtigen Redensarten, nennt Ruysdael >Dichter. Die Bilder dieses Landschaftsmalers sind nicht sowohl Schilderungen der Natur an sich, als vielmehr der Gemüthsstimmungen, in welchen er Gegenstände auffasste, und Wiederscheine aus den Tiefen der Seele."

65 »Der Künstler hat bewundrungswürdig geistreich den Punkt gefasst, wo die Produktionskraft mit dem reinen Verstande zusammentrifft, und dem Beschauer ein Kunstwerk überliefert, welches, dem Auge an und für sich erfreulich, den innern Sinn aufruft, das Andenken anregt, und zuletzt einen Begriff ausspricht, ohne sich darin aufzulösen oder zu verkühlen.« Goethe 1816, S. 425.

66 Brief von Goethe an Quandt vom 18.12.1831, in: Schmitz/Strobel 2001, S. 152; Quandt 2001 [1870], S. 239. 


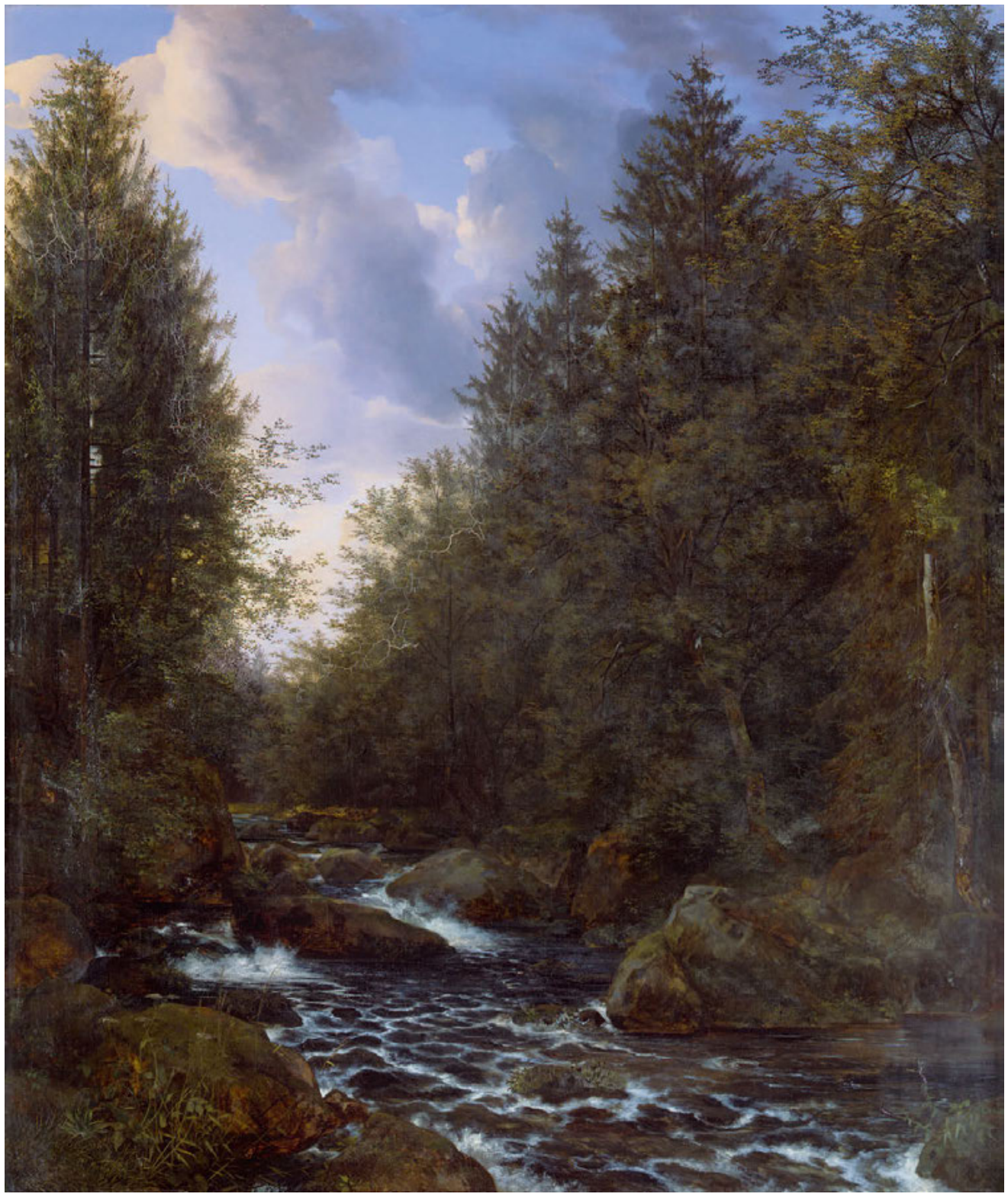

62 Ernst Ferdinand Oehme, Ein Bergstrom in waldiger Gegend (Dittersbacher Grund), 1831, Öl auf Leinwand, $80 \times 67 \mathrm{~cm}$, Dresden, Privatbesitz ihm nur um eine Übereinstimmung des Gefühls des Betrachters mit dem vermeintlichen Gefühl des Künstlers ging. ${ }^{67}$

Ruisdaels Bewaldetes Tal in Quandts Sammlung erhielt im Jahr 1830 ein Gegenstück: Ernst Ferdinand Oehmes Dittersbacher Grund. In diesem Pendant liegt Quandts Anspruch an die eigene Sammlung, gemäß dem die jungen Künstler der Gegenwart von den alten Meistern lernen, deren Fehler erkennen und sie übertreffen sollten. Der Spruch am Eingang zu seiner Gemäldeausstellung in Dresden verdeutlichte dies programmatisch. Er selber gab den jungen Künstlern die Möglichkeit, sich zu verbessern, indem er Aufträge vergab. Oehmes Dittersbacher Grund übernahm aber noch eine anspruchsvollere Rolle. Es veranschaulichte den Bezug zwischen der Landschaft Ruisdaels und der realen Natur im Rittergut Dittersbach, wo Quandt einen kleinen Landschaftspark gebaut hatte. ${ }^{68}$

Das neue Bild von Oehme ermöglichte es Quandt, sich vom vermittelnden Gedicht eines Tiecks oder Breuers - oder eben von »Ruisdael als Dichter« - loszulösen. Das Pendant veranschaulichte das, was Quandt bei der Betrachtung seiner RuisdaelLandschaft empfand - nämlich das gleiche Gefühl der Melancho-
67 »Der Grundton von Ruysdael's Gemüth ist eine genussreiche Wehmuth und den Gefühlen eines solchen Freundes sich hinzugeben, gewährt beseligende Uebereinstimmung."Quandt 1856, S. 118-120, hier S. 118.
68 Krause/Harnisch 2009, S. 4-17; Palm 2008, S. 12-58, 63-65; Heinrich 2002, S. 43-56, 95-103. 
63 Jacob van Ruisdael, Bewaldetes Tal mit Fluss und einer großen Fichte, um 1660, Öl auf Leinwand, 79,3 ×66,2 cm, Duisburg, Wilhelm-Lehmbruck-Museum, Inv.-Nr. $1404 / 1972$

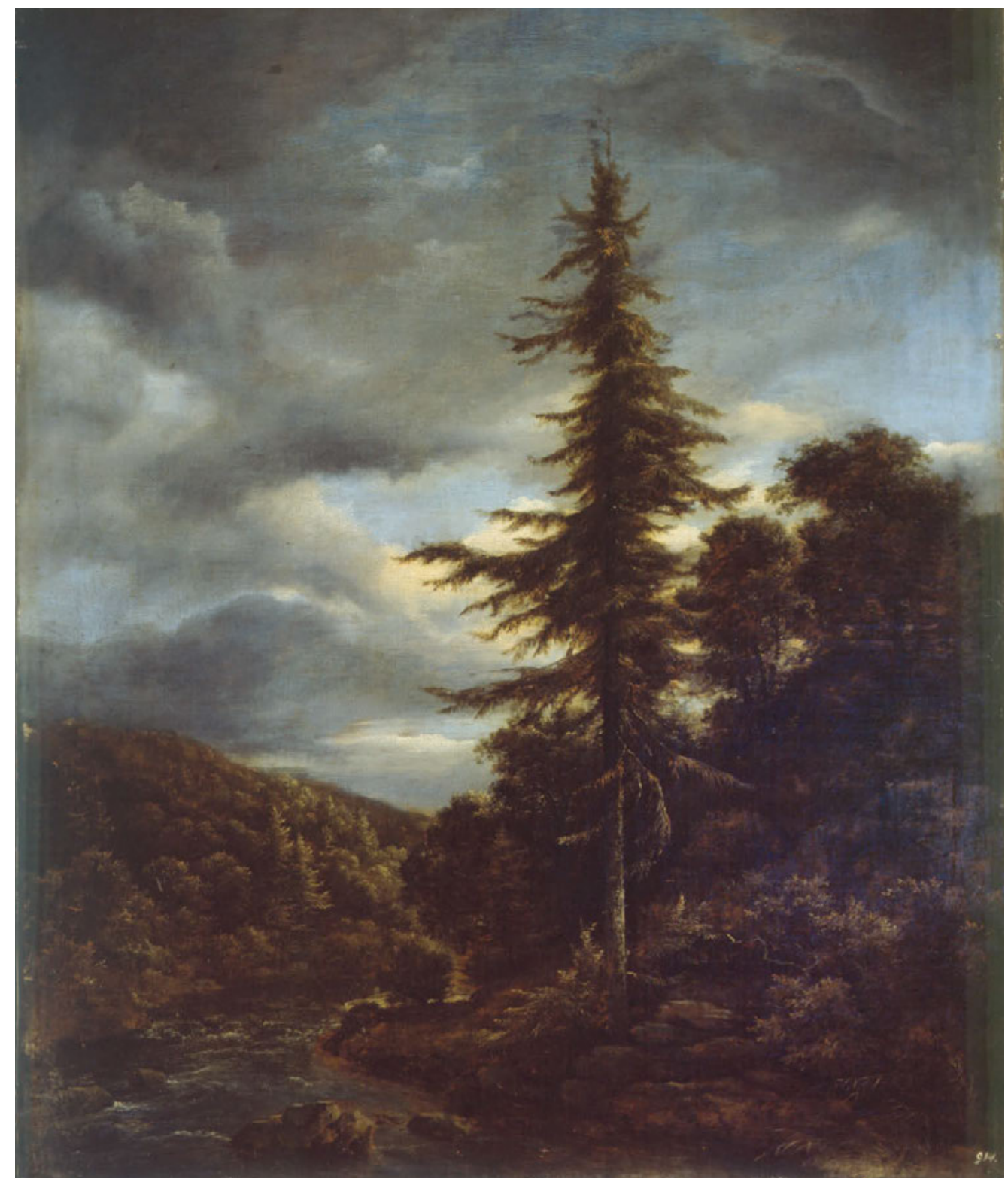

lie, in das ihn die Natur von Dittersbach versetzte. Oehmes Bild überführte die Naturerfahrung in eine Bilderfahrung. Gleichzeitig konnte die Bilderfahrung durch die Naturerfahrung überprüft werden, denn Oehmes Standort am Flüsschen Wesenitz, wo er sein Bild gemalt hatte, lag am Eingang des Landschaftsparks bei Schloss Dittersbach. Natur und Bild wurden so zum doppelten Spiegel des Gefühls des Betrachters. ${ }^{69}$ So vermochte Quandt

69 Quandt 1820 (1), S. 220: „Es findet aber oft zwischen dem Geist und der Natur ein ganz anderes Wechselverständniß, als zwischen dem Menschen und Menschen, statt. [...] Dieses Verhältniß des Menschen zur Natur, ist wie zwey einander gerade gegenüberstehende Spiegel, wovon der eine immer nur sein eigenes Bild aus dem gegenüberstehenden, als Object empfängt. Der Naturgenuß besteht recht eigentlich darin, daß wir nicht zum philosophischen Bewußtseyn gelangen, und dennoch mit dem Pendant die Naturerfahrung, die er in seinem meist im Sommer genutzten Dittersbacher Landsitz erleben konnte, ins Dresdener Stadthaus zu überführen. Die Gegenüberstellung von Ruisdaels Bewaldetes Tal und Oehmes Dittersbacher Grund entpuppt sich damit als Veranschaulichung von Quandts Landschaftsidee: Die ins Bewusstsein gerückte Empfindung der Naturanschauung interagiert zwischen realer Natur und Kunst. ${ }^{70}$

die doppelte Richtung der Thätigkeit der Seele angeregt wird, so daß die objective und subjective gegenseitig sich compensiren und in einer Anschauung zum Bewußtseyn gelangen. Durch dieses sich selbst beschauen, in der Wahrnehmung der Außenwelt, durch dieses Verwechseln des Bewußtseyns, enthält erst die Natur wahres geistiges Leben."

70 Im Kontext einer Übersendung zweier Veduten an Goethe - auf dessen eigenen Wunsch hin - formulierte er genau dies. Die Aussage 


\section{Ausgleich der nördlichen und südlichen} Kunstschulen

Mit den im Folgenden ausführlich zu beschreibenden, leider verschollenen Gegenstücken Landschaft mit einem Einsiedler von Johann Martin von Rohden und Die zertrümmerte Hoffnung von Caspar David Friedrich lassen sich die geschilderten Aspekte von Pendantbildungen nochmals erweitern. Neuerlich kommt die Frage nördlicher und südlicher Kunst hinzu. Gleichzeitig kann anhand dieses Pendants die über mehrere Jahre andauernde Konsolidierung von Quandts Kunstverständnis aufgezeigt werden. Die Präsentation der beiden Bilder im erweiterten Sammlungskontext gipfelt in der Manifestation eines zentralen Aspektes der Quandt'schen Ästhetik. Damit ist, wie nun aufzuzeigen sein wird, die Gegenüberstellung dieser beiden Bilder für seine Sammlung und sein Denken symptomatisch. ${ }^{11}$

Die nur noch in einer Radierung überlieferte, italienische Landschaft mit einem Einsiedler von Johann Martin von Rohden bestellte Quandt 1820 ursprünglich als Einzelbild (Abb. 64). Es sollte die »Pracht des Südens « darstellen..$^{72}$ Eine gegenüber Gemälde und Radierung leicht variierte Sepiazeichnung ist im Frankfurter Städel Museum erhalten. Vorbereitende Figurenzeichnungen stammen von Joseph Anton Koch..$^{73}$ Der Sammler fand rühmende Worte: »An Rohdens Landschaft glaube ich einen vorzüglichen Schatz zu besitzen [...]. Jede Einzelnheit ist im

scheint auf Oehmes Landschaft neben Ruysdaels Gemälde übertragbar zu sein: »[...] die Aufgabe des Landschafters scheint mir gerade die zu seyn, in seinem Bilde recht bewusst den Austausch des Gefühls wiederzugeben, welcher zwischen dem, der eine Gegend sieht und den Naturgegenständen, statt findet. Jede Gegend hat einen bestimmten Charakter, dieser versetzt uns in einen eignen Gemüthszustand und wir tragen diesen wieder auf die Gegenstände über und erblicken in diesen, gleichsam uns selbst in der Natur spiegelnd, was wir fühlen. "Brief von Quandt an Goethe vom 8.12.1831, in: Schmitz/ Strobel 2001, S. 150. S. a. Quandt 1830 (1), S. 56-57. Traugott Faber malte die Aquarelle, die in Quandts Augen viel zu vedutenhaft waren und eben gerade nicht das subjektive Gefühl der Landschaftsbetrachtung wiederzugeben verstanden. Immerhin gaben sie die örtlichen Bedingungen genau wieder. Doch des Übels nicht genug meinte er ironisch, dem Künstler noch einen »Injurienproceß« anhängen zu können, weil er die Reiterfigur, »unter dieser traurigen Gestalt, [er] meine Person gedacht«, so abscheulich ausgeführt hatte; siehe Quandt an Goethe am 11.12.1831, in: Schmitz/Strobel 2001, S. 151. S. a. Fernow 1806, S. 26-27.

71 Rüfenacht 2018, SQ-6 (Friedrich), SQ-69 (Rohden). S. a. Rüfenacht 2017, S. 163-171.

72 Quandt 1820 (1), S. 100, 263-264; Kat. Quandt 1868, Nr. 67. S. a. Pinnau 1965, Kat. Nr. VG 46, S. 142-144. Der Ankauf verlief nicht ohne Probleme: »Da Herr v. Rohden meint, daß sein für mich gefertigtes Gemälde mehr werth ist, als durch Contract zwischen uns bestimmt worden war u ein Käufer zu dem Bilde sich gefunden hat, von welchem sich $\mathrm{Hr}$. v. Rohden mehr Vortheil verspricht, so entlaße ich $\mathrm{Hr}$. v. Rohden seiner Verbindlichkeit gegen mich mir ein Gemälde zu liefern u gebe ihm hier mit seinen Contract zurück. Herr v. Rohden hat 220 Scudi
Geist des Ganzen gedacht u dargestellt [...]. Die Composition ist sehr geistreich $u$ alle Theile reihen sich organisch an einander. Der Strom der durch den Mittelgrund fließt, erklärt die ganze Anordnung der Landschaft [...]. Der Geognost o[der $]$ der Botanicker wird durch dies Bild beschäfftigt $\mathrm{u}$ der Kunstfreund er-

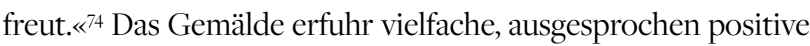
Rezensionen. ${ }^{75}$

1820 gab Quandt bei Friedrich eine nordische Landschaft als Gegenstück zu der in seinen Augen so geistreichen, südlichen in Auftrag. Im Katalog von 1824 ist sie als »Polar-Gegend « betitelt, im Auktionskatalog mit »Die zertrümmerte Hoffnung《 bezeichnet. ${ }^{76}$ Das verlorene Bild kann, wenn auch nicht in der Komposition, so doch in der Bildidee mit der Hamburger Fassung Das Eismeer (Die gescheiterte Hoffnung) von 1823-24 verglichen werden, dessen Provenienz bis in die 1960er Jahre fälschlicherweise in die Sammlung des Dresdener Kunstfreundes führte (Abb. 65): Der Landschafter Friedrich malt für mich ein großes Bild, welches ein Gegenstück zu Rohdens Landschaft werden soll. In Rohdens Bild ist alles vereint, was eine südliche Natur freundliches darbietet $\mathrm{u}$ in Friedrichs, was der Norden Ungeheures, und Erhabenes zeigt. Schroffe Felsen, oben mit Schnee bedeckt, an welchen kein armes Gräschen Nahrung findet, schließen einen Meerbusen ein, in welchem Stürme Schiffe verschlagen u durch ungeheure Eisschollen zerdrückt haben. Dieses graue Gemisch von Schiffstrümmern, Treibholz u Eismassen macht eine wunderbare u große Wirkung.《7

von mir auf dies Gemälde voraus erhalten, worüber ich die Quittung ebenfalls hier beylege, welche ich ihn jedoch nur gegen Empfang der 220 Scudi zurück zugeben bitte." Brief von Quandt an Schnorr vom 25.4.1822, in: SLUB, Mscr. Dresd. n Inv. 15, Bd. 31, fol. 85r. S. a. Kat. Kassel/Wuppertal 2000, S. 24-25. Overbeck, Catel und Rauch setzten sich schriftlich für Rohden ein, so dass Quandt die Sistierung aufhob. Rohdens Entschuldigungsbrief an Quandt vom 10.12.1822, in: ebd. Bd. 32, fol. 29r-v: »[...] Möchte doch selbes [Gemälde] Ew. H[och] w[ohl]g[eboren]. einiges Vergnügen gewähren, und ein Mitler seÿn die Unannehmlichkeiten welche ich Ew. Hwg. durch mein irriges Betragen verursachet habe doch einigermaßen wieder gut machen."

73 Johann Martin von Rohden, Studie (Landschaft mit Einsiedler und Pilger), 1818, Sepia über Graphit, $193 \times 265$ mm, Frankfurt a/M, Städel Museum, Inv. 6823; Pinnau 1965, Z 125. Zu den vorbereitenden Zeichnungen siehe Capitelli 2016, S.46-47. Die Autorin veröffentlichte zudem Zeichnungen von Julius Schnorr und Philipp Veit nach Staffagefiguren in Rohdens Gemälde; ebd., S. 48-53.

74 Brief an Schnorr vom 30.5.1823, in: SLUB, Mscr. Dresd. n Inv. 15, Bd. 31, fol. 96v. S. a. Anonym 1825, Sp. 782. Rohdens Gemälde sind gemäß Quandt die »Muster für alle Landschaftsmaler«; Quandt 1824, S. 366.

75 Beispielsweise KB 1822, Jg. 3, Nr. 63, S. 243: »Die Aufgabe war nicht geringe. Hr. Rohden hat sie auf eine Art gelöst, welche [...] höchst ehrenvoll erscheint."

76 Kat. Quandt 1824, S. 4; Kat. Quandt 1868, S. 18, Nr. 64.

77 Brief an Schnorr vom 4.3.1822, in: SLUB, Mscr. Dresd. n Inv. 15, Bd. 31, fol. 82r. Zur Abgrenzung von Quandts Version vom etwas späteren Eismeer siehe Börsch-Supan/Jähnig 1973, Kat. Nrn. 295, 311, S. 376-377, 386-387, basierend auf Stechow 1965, S. 241-246. S. a. Kat. Oslo/Dresden 2014, S. 94. 

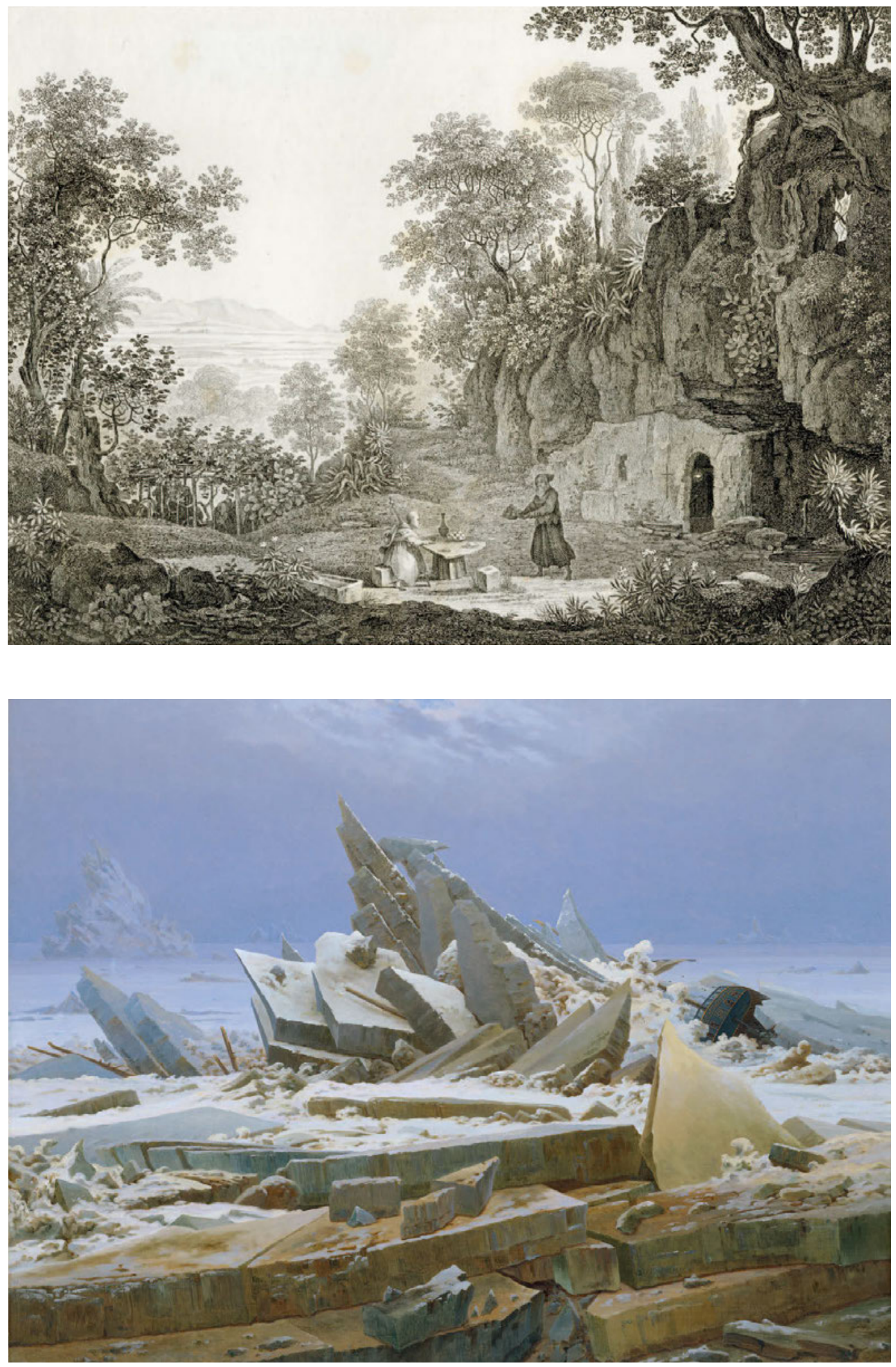

64 Johann Gottfried Abraham Frenzel nach Johann Martin von Rohden, Landschaft mit einem Einsiedler, 1827, Radierung, $19 \times 22,5 \mathrm{~cm}$, Nürnberg, Kunstsammlungen der Stadt Nürnberg, Inv.-Nr. St. N. 10607

65 Caspar David Friedrich, Das Eismeer (Die gescheiterte Hoffnung), 1823/24, Öl auf Leinwand, 96,7× 126,9 cm, Hamburg, Kunsthalle, Inv.-Nr. HK 1051 


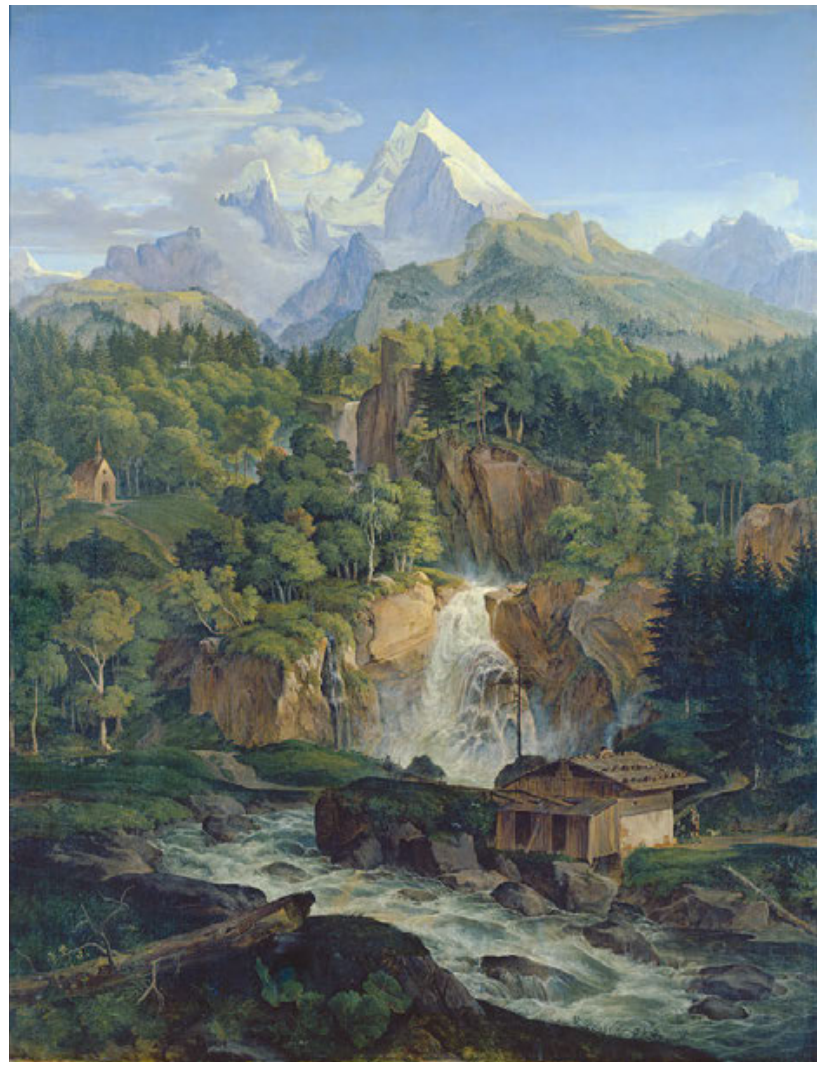

66 Adrian Ludwig Richter, Der Watzmann, 1824, Öl auf Leinwand, $121 \times 93,5 \mathrm{~cm}$, München, Bayerische Staatsgemäldesammlungen - Neue Pinakothek, Inv.-Nr. 8983

Friedrich erfüllte Quandts Auftrag einer nordischen Landschaft gemäß seiner künstlerischen Auffassung. ${ }^{78}$ Quandt attestierte ihm diese Selbstständigkeit. Sie führe ihn zu einem persönlichen Stil. Dennoch empfand er Friedrichs Kolorit in der nordischen Landschaft als ein »graues Gemisch«, was seiner eigenen Vorstellung des Erhabenen in der Malerei entgegenstand. 1830 schrieb er nämlich: »Erhabene Gegenstände fordern in der Malerei kräftige Farben, welche zwar nicht disharmonieren, aber große Gegensätze bilden müssen. «9 $^{79}$ Johannes Grave hat darauf hingewiesen, dass Quandt in seiner Beschreibung der Akademieausstellung in Dresden von 1824

78 Büsing 2011, S. 232; Busch 2003, S. 147; Grave 2001, S. 96-97. Busch und Grave, und mit innen Büsing, verweisen auf eine ironische Ebene, die dem alten Titel Ein gescheitertes Schiff auf Grönlands Küste im Wonne-Mond, der auf einer Vorzeichnung stand, inne liege. Man sehe ja keinen Mond. Quandt hat das vielleicht wirklich nicht verstanden: siehe -t. [Quandt] 1822, S. 372.

79 Quandt 1830 (1), S. 332 . S. a. -t. [Quandt] 1822, S. 372: »Man sagt, Hr. Friedrich habe die Grenze dieser Eigenthümlichkeit in jenem Gemälde überschritten [...]. Möglich, daß die allgemeine Stimme in diesem einzelnen Falle recht hat; gut aber ist es, daß sich $\mathrm{Hr}$. Friedrich in seinem eingeschlagenen Pfade nicht irren läßt und, wenn auch vielleicht noch in Manier befangen, doch nach einem und zwar nach seinem Style strebt.»

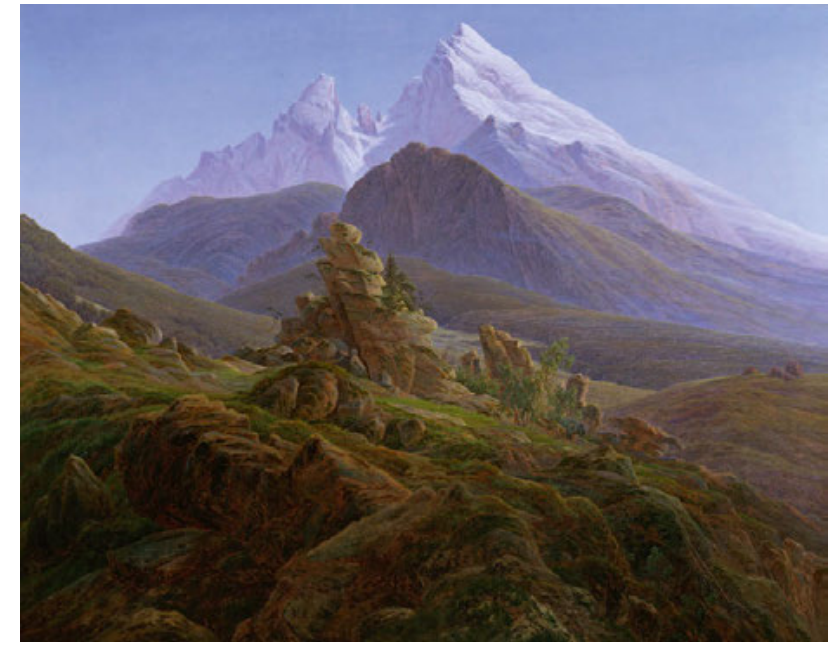

67 Caspar David Friedrich, Der Watzmann, 1824/1825, Öl auf Leinwand, $135 \times 170 \mathrm{~cm}$, Berlin, SMB, Alte Nationalgalerie, Inv.-Nr. F.V. 317, Leihgabe der DekaBank

zudem nicht eine Gebirgslandschaft Friedrichs als Beispiel des Erhabenen und diese überhaupt nur sehr knapp beschrieb, sondern eine Darstellung des Watzmanns des um Jahre jüngeren Künstlerkollegen Adrian Ludwig Richter. Jene verband er mit dem »Gefühl des Erhabenen [...], welches der Anblick im reinsten Sonnenlicht strahlender Gletscher, ungestümer Bäche und ernster Waldungen, welche als Landwehr den Bergstürzen und Lavinen sich entgegenstellen, einflößt. « ${ }^{80}$ Friedrich reagierte darauf mit einem eigenen Watzmann, der als Absage an die Ästhetik des Erhabenen gelten kann (Abb. 66-67). ${ }^{81}$

Der Maler schien mit seiner nordischen Landschaft nicht auf den Wunsch Quandts eingehen zu wollen, einen Gegensatz zum Schönen im Sinne des Erhabenen zu erschaffen. Um 1829/33 schrieb er im Manuskript Äußerungen bei Betrachtung einer Sammlung von Gemählden zu einer Ausstellung, wohl an der Kunstakademie: »Sich in Widersprüche aussprechen wollen ist eine gewöhnliche Sache bei Mahlern, sie nennen es Contrast. - Krum gegen gerade, kalt gegen warm, hell gegen dunkel, das sind die sauberen Krüken, an den sich die Erbärmlichkeit forthümpelt (sic!). $\ll^{82}$ Ein solch langweiliger,

80 Grave 2012, S. 196. Kritik von Richters Bild in Quandt 1824, S. 366 . Zu Friedrichs Bergbild schrieb er nur, immerhin im Superlativ: »Unter den Landschaften verdient vor allem Friedrichs großes Bild einer Gebirgsgegend rühmlichste Erwähnung." Es handelt sich um Hochgebirge, 1824, Lwd. $132 \times 167$ cm, ehemals Berlin, Nationalgalerie, zerstört 1945, Abb. in Grave 2012, S. 195.

81 Grave 2012, S. 187-199. Zeitgleich malte auch Dahl einen Watzmann; Kat. Oslo/Dresden 2014, S. 136, 140-141.

82 Friedrich 1999 [1829/33], S. 37. S. a. Büsing 2011, S. 231-232; Grave 2001, S. 97; Friedrich 1974, S. 93. 
mittelmäßig-ästhetischer Anspruch missfiel dem eigensinnigen Künstler. Friedrichs Schrift wurde pikanterweise von Quandt als Vorstand des Sächsischen Kunstvereins in Auftrag gegeben. ${ }^{83}$ Der Satz scheint daher, nur wenige Zeit nach der Vollendung der nordischen Landschaft, eine unterschwellige Boshaftigkeit auf seinen wegen des doppelten Beinbruchs am Stock gehenden Auftraggeber zu sein.

Die Äußerungen bei Betrachtung einer Sammlung von Gemählden verdeutlichen die Haltung des Künstlers gegenüber Quandt. In künstlerischen Fragen stimmte er überhaupt nicht mit seinem Mäzen überein. Im Manuskript strich er das Kürzel »H. v. Q« in einer Passage, in der er sich über die Vorschriften der Kunstkenner gegenüber den Malern aufhielt, um es durch ein X zu ersetzen. Es muss auf »Herrn von Quandt« bezogen werden. Friedrich kritisierte: »Wer unbesonnen genug von einer Naturerscheinung behauptet, sie sei der Bildenden Kunst unwürdig, verdient wohl keiner Beachtung [...]. Wohl jede Erscheinung in der Natur richtig und würdig und sinnig aufgefaßt kann ein Gegenstand der Kunst werden. [...] darum verramle man den Leuten nicht den Weg wie der X [H. v. Q. $]$ es will. $\ll^{84}$ Friedrichs Opposition zog sich noch weiter: »Willst du wissen was Schönheit sey? befrage die Herren Aesthetiker; beim Theetisch kann es dir nützen. Vor der Staffelei aber mußt du es fühlen was schön ist.« Das Originalmanuskript enthält hier den Zusatz »noch nicht an Q «. Damit ist wieder Quandt gemeint. ${ }^{85}$

Friedrichs wenig diplomatische Aussagen, die zwar nicht publiziert wurden und die Quandt nicht gesehen hat, erstaunen angesichts dreier Aufträge des Sammlers. ${ }^{86}$ Zeit seines Lebens war Quandt dem Maler gegenüber positiv eingestellt und dieser schien sich der Abhängigkeiten zwischen Künstler und Auftraggeber durchaus bewusst. Jedenfalls bedankte er sich 1835 artig für zehn Flaschen Wein, die ihm Quandt für einen unbekannten Auftrag zugesandt hatte. ${ }^{87}$ Mit seinem harten Urteil wurde Friedrich Quandts theoretischem Anspruch nicht gerecht. In seinen Schriften hatte der Kunstfreund geäußert, dass keine Re-

83 Hoch 1981, S. 229-230, Anm. 12; Büsing 2011, S. 227; Weddigen 2008, S. 225; Busch 2003, S. 148; Grave 2001, S. 99-100.

84 Friedrich 1999 [1829/33], S. 127, Anm. 760. S. a. Kat. Oslo/Dresden 2014, S. 91-95; Neidhardt 2005 (1), S. 81; Busch 2003, S. 148; Grave 2001, S. 98-99; Hoch 1981, S. 229; Friedrich 1974, S. 130.

85 Siehe Friedrich 1999 [1829/33], S. 37, Anm. 175.

86 Kat. Quandt 1868, Nrn. 50, 64, 90. S. a. Börsch-Supan/Jähnig 1973, Kat. Nrn. 268, 295, 416.

87 Brief von Friedrich an Quandt vom 16.10.1835, in: SLUB, Mscr. Dresd., App. 1191, Nr. 138.

88 Quandt 1830 (1), S. 167-169: »Wie viel vergebliche Versuche sind gemacht worden, das empirisch Schöne auf Principe zurückzuführen, Regeln dafür zu finden! [...] Alles, was sich in verständiger Weise thun läßt, ist ohngefähr, das Maas für die Erscheinungen anzugeben, über welche die Darstellungen der Erscheinungswelt nicht hinausgehen und unter welchem sie nicht zurückbleiben soll. [...] Dahingegen, wie vielen Andern ist es gelungen, Werke zu schaffen, in welchen die geln den Künstler zur Ausführung bestimmter Ideen zwingen können. ${ }^{8}$ In seiner Sammlung aber konnte er als Besitzer und Betrachter der Gemälde seine ästhetischen Gedanken assoziationsreich darlegen.

Die Präsentation von Friedrichs Bild und seinem Pendant, der südlichen Landschaft von Rohden, in den Sammlungsräumen an der Klostergasse weist eine gewisse Komplexität auf. Die beiden Bilder markierten »die südliche Natur in ihrer üppigen und majestätischen Pracht« und »die Natur des Nordens in der ganzen Schönheit ihrer Schrecken «. ${ }^{89}$ Johannes Grave sowie Werner Busch, und ihnen folgend Leander Büsing, haben vermutet, dass Quandt mit der Gegenüberstellung der beiden Bilder die zwei ästhetischen Kategorien des Schönen und Erhabenen, die das Gemüt zu erregen befähigt seien, effektvoll in Bezug zueinander gesetzt habe.90

Es stellt sich die Frage, ob Quandt die beiden Pendants überhaupt den ästhetischen Kategorien des Erhabenen und Schönen zuordnen wollte, als er sie anfangs der 1820er Jahre in Auftrag gab. Systematisch erarbeitete er sich diese Begriffe erst in den Briefen aus Italien, die 1830 erschienen. Zudem ging der Auftrag als Einzelbestellung noch während seines Aufenthaltes in Italien 1819/20 an Rohden, was das Konzept zweier Pendants vor dem Hintergrund des Schönen und Erhabenen eigentlich ausschließt. Noch 1824 befand sich Friedrichs Gemälde nicht in der Sammlung, wie die akribische Sammlungsbeschreibung eines anonymen Besuchers beweist. ${ }^{91}$ Schließlich wurde der ästhetische Charakter der Präsentation gemäß dem Katalog von 1824 durch zwei Architekturdarstellungen von Domenico Quaglio und einer Giovanni Battista Salvi genannt Sassoferrato zugeschriebenen Darstellung der Heiligen Familie gebrochen, die im Katalog zwischen den Gegenstücken beschrieben sind (Abb. 68). ${ }^{92}$ Gerade diese Gemälde verweisen auf andere Kategorien der Präsentation: einerseits die Gegenüberstellung unterschiedlicher Gattungen, andererseits eine Bezugnahme nördlicher und südlicher Kunst aufeinander. Damit eröffnet

Seele zur Seele spricht [...], in welchen der Geist sein Ebenbild und die Vernunftgemäsheit erkannte [...]!«

89 Brief des Russen Wassili Andrejewitsch Schukowski vom 23.6.1821, zitiert nach Grave 2001, S. 85 .

90 Grave 2012, S. 188-189; Büsing 2011, S. 231-232; Busch 2003, S. 147-148; Grave 2001, S. 85-99.

91 Die sehr genaue Beschreibung von Quandts Sammlung eines anonymen Besuchers erwähnt nur Rohdens Gemälde und zwei Architekturansichten von Domenico Quaglio. Sie erschien 1825. Der Autor musste 1824 bei Quandt gewesen sein, weil Quandts erster Katalog Friedrichs Gemälde bereits enthält. Dass der Autor das Bild unerwähnt ließ, kann nicht sein, da er sonst alle anderen Friedrich-Bilder, die Quandt 1824 besaß, beschreibt. Siehe Anonym 1825, Sp. 781-782, 790, 813; Kat. Kassel/Wuppertal 2000, S. 24-25; Pinnau 1965, S. 142.

92 Kat. Quandt 1824, S. 4; Kat. Quandt 1868, Nrn. 42 (als Schule von Bologna), 102, 105; Rüfenacht 2018, SQ-44 (Sassoferrato), SQ-104, SQ-107 (Quaglio). 

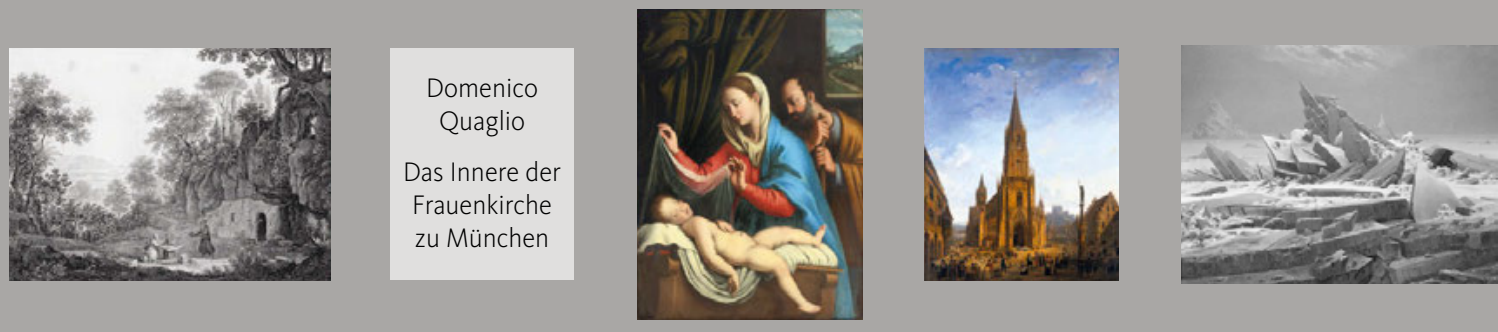

68 Rekonstruktion der Gemäldehängung im zweiten Zimmer von Quandts Sammlung (s. a. Abb. 64-65, 69-70), um 1824, nach Kat. Quandt 1824, S. 4

sich eine weitere Ebene, die in den vorangegangenen Zitaten bereits angeklungen ist. Der Süden bietet Freundlichkeit und Schönheit, der Norden Erhabenheit und Naturgewalt. Die beiden ästhetischen Kategorien nach Burke, Kant und Schiller mögen zwar mitschwingen, doch der Nord-Süd-Unterschied scheint überhand zu nehmen. Wenige Jahre nach der Fertigstellung der beiden Gemälde schrieb Quandt in der Kupferstecherkunst von 1826 zum Unterschied zwischen nördlicher und südlicher Kunst: »Wir sehen eine Auffassung der Gegenstände, der nach außen sich drängenden [...] Leidenschaften, in allem was die Italiener hervorbrachten, wogegen die Werke der Deutschen in seelenvoller Ruhe erscheinen. $\ll 33$ Damit werden Konnotationen deutlich, die Italien als irdischen Ort der sinnlichen Leidenschaften und Deutschland als geistig-religiöse Welt verstehen. ${ }^{94}$

Man kann das Gegenstück der südlichen Landschaft Rohdens und Friedrichs »Charakterbild des Nordens« als Überwindung der italienischen und deutschen Schulen und Stile ansehen. ${ }^{95}$ Es sind zwei deutsche Künstler, welche das Typische des Südlichen und des Nördlichen darzustellen vermögen. Dabei geht es nicht um einen Sieg der Deutschen über die Italiener, sondern um eine Abkehr von national konnotierten Stilen zugunsten der Erreichung des stilungebundenen Kunstideals. Die deutsche Kunst erträgt somit in der Hängung von 1824 den

93 Quandt 1826 (1), S. 20. S. a. Busch 2003, S. 147; Grave 2001, S. 93; Rautmann 1991, S. 48-49.

94 In der Landschaft Rohdens bewirtet dementsprechend der Einsiedler einen nordischen Pilger; Anonym 1825, Sp. 781. S. a. Locher 2001, S. 167; Weddigen 2008, S. 221-222; Rautmann 1991, S. 66-75.

95 Brief an Unbekannt vom 15.5.1858, in: SLUB, Mscr. Dresd., App. 278, Nr. $163 b$.

96 Raffael, Madonna di Loreto (Madonna del Velo), 1509/10, Öl auf Holz, $120 \times 90 \mathrm{~cm}$, Musée Condé, Chantilly, Inv. PE 40.

97 LOT 92 in der Auktion »Master Paintings: Part l«, 29.1.2015, versteigert für 305.000 USD. Internetressource: https://www.sothebys.com/ fr/auctions/ecatalogue/lot.92.html/2015/master-paintings-part-i-
Vergleich mit der italienischen Historie: der Heiligen Familie, angeblich von Sassoferrato, deren Motiv und Komposition auf Raffaels Madonna di Loreto, und somit auf den italienischen Künstler schlechthin, zurückgeht. ${ }^{96}$ Es könnte sich bei dem hier abgebildeten, den Dimensionen im Auktionskatalog 1868 exakt entsprechenden Gemälde um dasjenige aus Quandts Sammlung handeln. Das Bild wurde 2015 bei Sotheby's New York versteigert (Abb. 69).97 Mit den Architekturdarstellungen von gotischen Kirchen zeigt sich zudem eine in Quandts Augen genuin deutsche Kunst (Abb. 70): »Die deutschen Baumeister des 13. Jahrh. aber erkannten die Schönheit der Verhältnisse eines Baues, in welchem der Spitzbogen rein durchgeführt und Grundgesetz aller Formen ist. Diese Umgestaltung der Baukunst, diese neue Schöpfung, in der sich Gesetzmäßigkeit und Freiheit, Vernunft und Phantasie gegenseitig durchdringen, in der alle Theile harmonisch aus einer Grundform sich entwickeln, ist unbestreitbar das Werk der Deutschen. Wer den ersten Spitzbogen anwendete, um das Schieben zu vermeiden, hat so wenig das Spitzbogensystem der deutschen Baukunst erfunden, als der Biber die Baukunst. $\aleph^{98}$

Die Vorstellung einer Vereinigung nördlicher und südlicher Errungenschaften in der Kunst entfaltete sich über diese Präsentation von Gemälden in seiner Sammlung hinaus auch im Römer Auftrag an Julius Schnorr von Carolsfeld von 1819,

no9302\# [letzter Zugriff: 15.6.2018]. Quandt 1819, Bd. 1, S. 112-113; s. a. Weddigen 2008, S. 222. Zur zeichnerischen Vorlage des Motivs siehe Giovanni Battista Salvi gen. II Sassoferrato, Die Heilige Jungfrau deckt das Kind zu, o. J., Kreide auf Papier, $19 \times 17,3 \mathrm{~cm}$, Windsor Castle, Collection of Her Majesty the Queen, Inv.-Nr. 6083; Blunt/Cooke 1960, S. 106. Rüfenacht 2018, SQ-44.

98 Quandt 1846 (1), S. 82-83. S. a. den Brief von Quandt an Unbekannt vom 29.2.1848 mit Angaben zu seinen Quellen in dieser Thematik, in: SLUB, Mscr. Dresd. App. 204, Nr. 98p. Bei den Kirchendarstellungen handelt es sich um eine Innenansicht der Frauenkirche in München und um das Freiburger Münster von Nordwesten. Rüfenacht 2018, SQ-104, SQ-107. 
seine Gemahlin Clara Bianca in Öl zu malen. Bernhard Maaz vermochte dies für das hoch gelobte Nazarener Porträt in der Sammlung der Alten Nationalgalerie in Berlin überzeugend aufzuzeigen (Abb.18). Das Bildnis lehnt sich an Raffaels Porträt der Dona Isabel de Requesens, früher Johanna von Aragonien, an und zeigt die Dargestellte im Renaissance-Kostüm (Abb. 19). Der Blick geht in eine südliche Landschaft, in der die Orangenbäume wachsen. Gleichzeitig ist der Modus der Komposition altdeutsch motiviert. Die romanische Architektur erinnert an einen Kreuzgang, wie sie in der niederländischen Porträtmalerei des 16. Jahrhunderts bekannt ist.99 Quandts Anliegen einer Vereinigung der Künste zeigt sich auch in einem Auftrag an

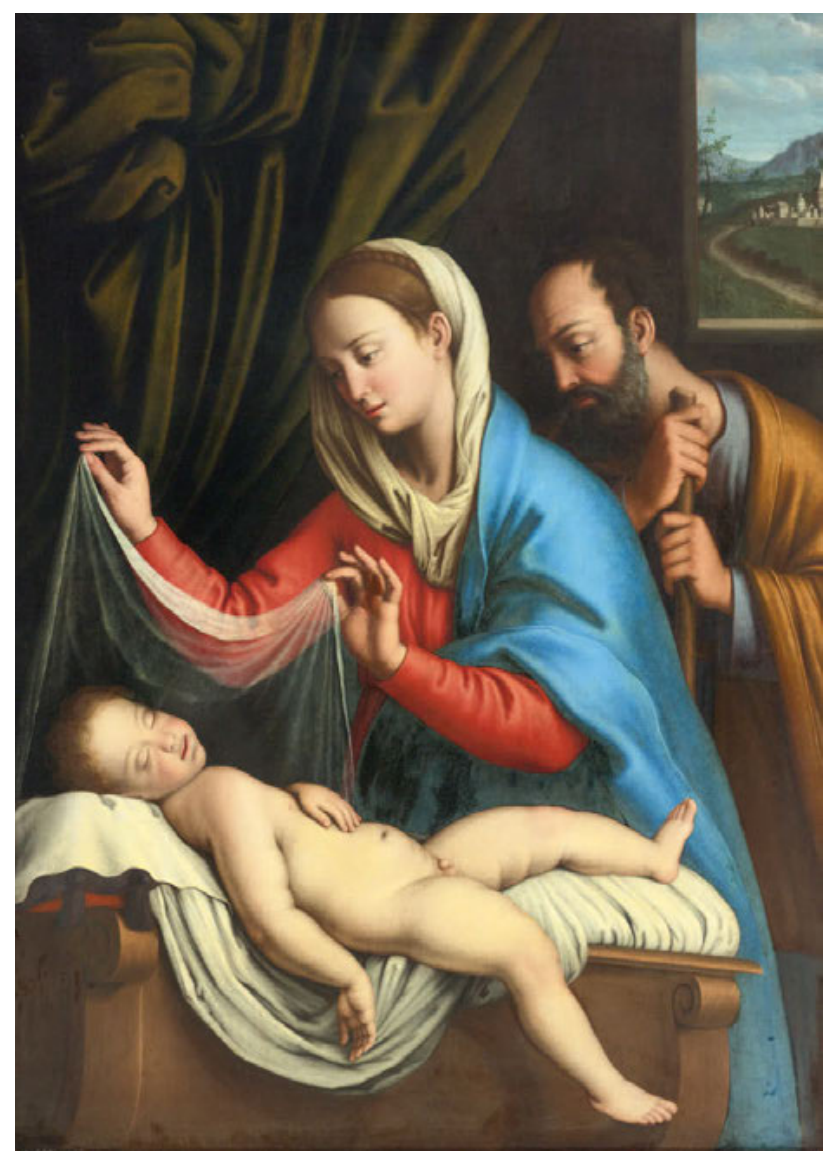

69 Giovanni Battista Salvi gen. Sassoferrato, Heilige Familie, nicht datiert, Öl auf Leinwand, 134,7 × 98,5 cm, Verbleib unbekannt

99 Maaz 1998, S. 141-144. Es wurde mehrmals vermutet, dass Schnorrs Vittoria Caldoni als Gegenstück seines berühmten Bildnisses der Clara Bianca von Quandt als Johanna von Aragonien, die Laute spielend, vorgesehen war. Der frappante Größenunterschied der beiden Gemälde lässt dies als unwahrscheinlich erscheinen. Wenn auch zu Recht auf die kompositorischen Übereinstimmungen hingewiesen wurde, so scheint die ähnliche Situation der Architekturelemente und des Hintergrundes eher auf ein Stilmerkmal des Künstlers als auf ein Pendant hinzudeuten. Quandts Sammlungskataloge von 1824 und 1868, wo das Porträt Clara Biancas gar fehlt, geben ebenfalls keine

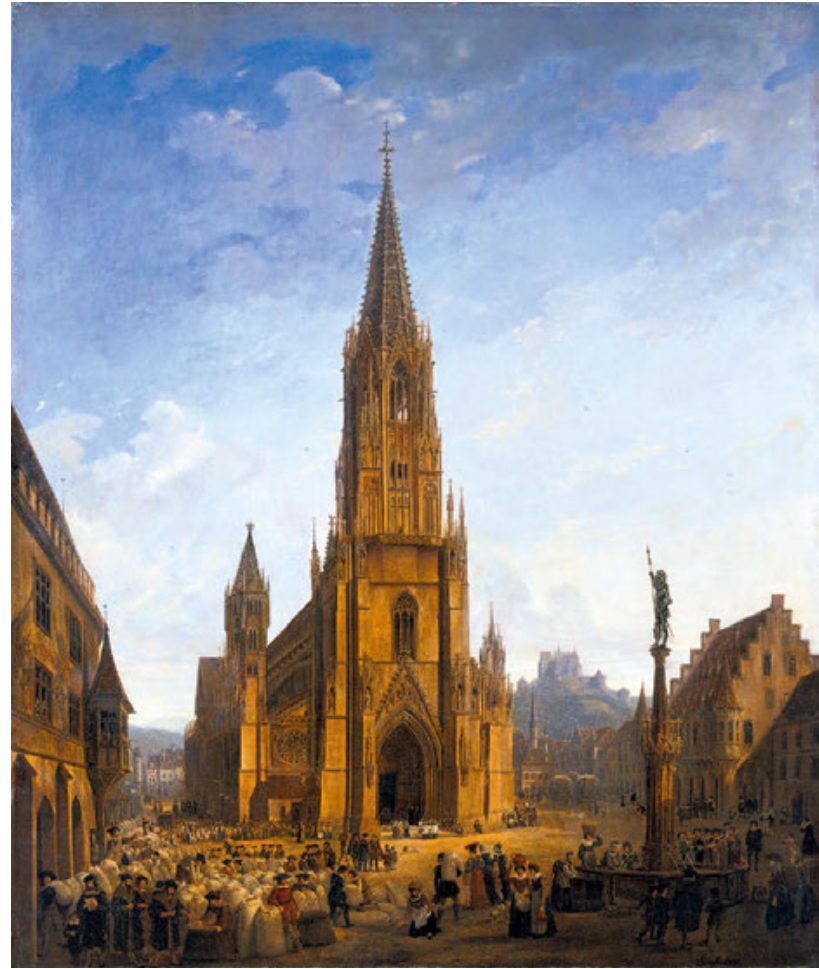

70 Domenico Quaglio, Ansicht des Freiburger Münsters von Nordwesten, 1821, Öl auf Leinwand, $102 \times 84,7$ cm, Freiburg i/Br, Augustinermuseum, Dauerleihgabe der Adelhausenstiftung, Freiburg i/Br, Inv.-Nr. A 1007

Philipp Veit. Dieser sollte eine Loreley nach dem Vorbild der Johanna von Aragonien von Raffael malen. Das nie vollendete Gemälde hätte ein typisch germanisches Motiv mit einer italienischen Komposition verbunden. ${ }^{100}$

Mit seinem die künstlerischen Unterschiede ausgleichenden Konzept stimmte Quandt mit Vorstellungen überein, wie sie Wilhelm Heinrich Wackenroder in seinen von Ludwig Tieck herausgegebenen und erweiterten Herzensergießungen eines kunstliebenden Klosterbruders von 1797 literarisch oder Overbeck in seinem Gemälde Italia und Germania, entstanden 1811-28, malerisch gelöst hatte. Wenn Wackenroder eine gleichberechtigte Kunst verlangte, in der er sich Dürer und Raffael als enge Freunde vorstellte, tat Quandt ähnliches, als er in seinen Streifereien in den Erläuterungen über die Pinakothek in München Dürer und Raffael einander gegenüberstellte. ${ }^{101}$ Auf

entsprechenden Hinweise. Vgl. Koeltz 2010, S. 107-109; Teichmann 2001, S. 122; Elke Spickernagel, »Vittoria Caldoni im Kreis der Nazarener«, in: Vogel 1996, S. 114-115. Rüfenacht 2018, SQ-142.

100 Veit malte für Quandt schließlich eine Judith. Rüfenacht 2018, SQ-77; Maaz 1998, S. 140-141; Suhr 1991, S. 66, 263; Maaz 1986, S. 40-41; Schlegel 1980, S. 230-231, 238; Schnorr 1886, S. 154; Raczyński 1836-1841, Bd. 3, S. 224.

101 Quandt 1819, Bd. 1, S. 112: »Wenn wir in Albrecht Dürers Bild den seelenvollen Deutschen erkennen, so zeigt uns Rafaels Portrait den begeisterten Italiener.« Wackenroder/Tieck 2005, S. 55-56. Zur Gene- 

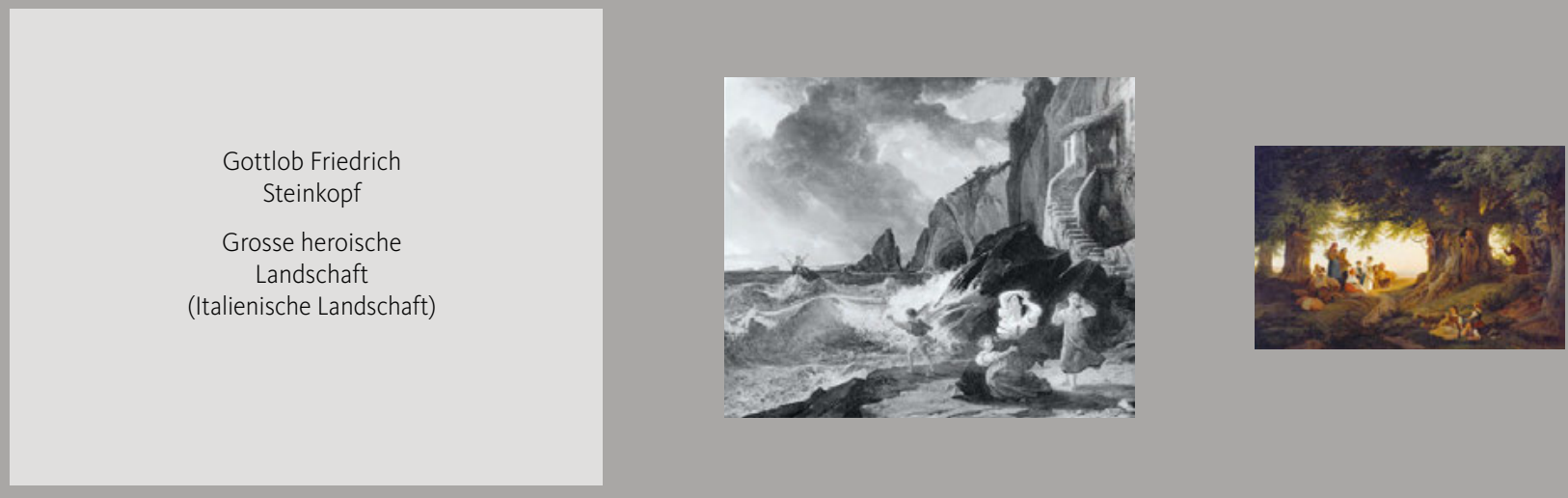

71 Rekonstruktion der Gemäldehängung im dritten Zimmer von Quandts Sammlung (s. a. Abb. 23, 56-57, 64-65, 72), vor 1868, nach Kat. Quandt 1868, S. $18-19$

praktischer Ebene bot sich Quandt zu Beginn der 1840er Jahre zudem bei der Neuhängung der königlichen Gemäldegalerie die Möglichkeit, die Präsentation und den Galerierundgang so zu gestalten, dass er zwischen den südlichen und nördlichen Kunstschulen ausgleichend vermittelte. So setzte er sich dafür ein, dass als Gegenstück zum isolierten Saal des Raffael, in dem die Sixtinische Madonna präsentiert war, ein Saal der altdeutschen Künstler eingerichtet wurde. Diese beiden Räume band er im Begleitkatalog in einen Galerierundgang ein, der einigermaßen konsequent chronologischen und kunsttopographischen Prinzipien folgte. ${ }^{102}$ Hierbei schloss er an Entwicklungen an, die, um dem aktuellen Kunstgeschmack zu entsprechen, Anfang des 19. Jahrhunderts in die Umgestaltung und Verbesserung der Präsentation nördlicher Kunst in der Äußeren Galerie der Dresdener Kunstsammlungen im Stallhof gemündet hatten. ${ }^{103}$ Literarisch vorbereitet hatten diese Aufwertung nördlicher Kunst Schriften Goethes oder der Gebrüder Schlegel. Goethe hatte sich bei mehreren Galeriebesuchen zwischen 1768 und 1816 immer wieder ausgesprochen positiv über niederländische Kunst geäußert, in der er eine Wahrheit der Naturdarstellung erfüllt sah. ${ }^{104}$ Die Gebrüder Schlegel wiederum formulierten

se des Topos einer Freundschaft Raffaels und Dürers siehe Thimann 2015, S. 9-10. S. a. Kat. Göttingen 2015, S. 307-341; Savoy 2006, S. 545; Büttner 2002, S. 29-32; Brücke 2001, S. 128-129. Friedrich Overbeck, Italia und Germania, 1811-28, Öl auf Leinwand, $95 \times 105$ cm, München, Bayerische Staatsgemäldesammlungen, Inv.-Nr. WAF 755. Zum Ausgleich deutscher und italienischer Kunst Thimann 2015, S. 30-36; Thimann 2014, S. 161-164; Grewe 2006, S. 401-424; Prange 2004,

S. 70; Locher 2001, S. 123-132. in dem fiktiven Gespräch Die Gemählde von 1799, in welchem sie ihre Galeriebesuche reflektierten, ihre hohe Wertschätzung der Kunst nördlich der Alpen. Vergleichend und ausgleichend setzten sie diese mit Werken der italienischen Malerei in Bezug, um, wie Goethe, die Naturwahrheit der Kunst zu bekräftigen. ${ }^{105}$ Quandt schuf mit seinen ausgleichenden Hängungsprinzipien in seiner Privatsammlung genauso wie in der Gemäldegalerie eine Präsentation, die sich auf der Höhe des Geschmacks seiner Zeit befand und auch jüngste Entwicklungen in Dresden reflektierte.

\section{Schön, erhaben, tragisch, rührend}

Über die Jahre hinweg wandelte sich die systematische Präsentation in seiner Sammlung. Der Auktionskatalog von 1868, gemäß dessen Vorwort nach Quandts Tod 1859 keine Änderungen in den Hängungen vorgenommen wurden, überliefert eine neue Kombination der Landschaften von Friedrich und Rohden mit anderen Gemälden im dritten Zimmer. Sie stehen nun im Kontext weiterer Landschaften von Adrian Ludwig

102 Siehe Kap. Eine Kunstgeschichte des Ausgleichs.

103 Weddigen 2008, S. 187-192.

104 Weddigen 2008, S. 176-185. Zu Goethes Ruysdael als Dichter von 1816 siehe oben Kap. Erlebnis und Dichtung.

105 Symptomatisch die Passagen über Landschaften von Salvatore Rosa, Claude Lorrain und Jacob van Ruisdael, oder über Holbein, Dürer und Leonardo da Vinci, in: Schlegel 1996, S. 26-31, 39-45. Zusammenfassend Weddigen 2008, S. 147-160. 

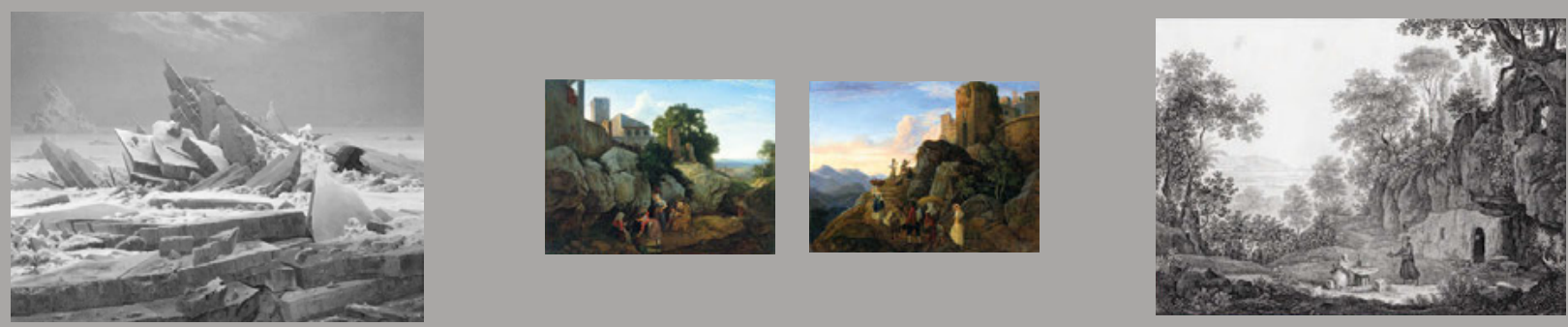

Richter, Gottlob Friedrich Steinkopf und Franz Ludwig Catel (Abb. 71). ${ }^{106}$ Die neue Hängung kann mit Quandts Kunsttheorie und seiner spezifischen Sichtweise der ästhetischen Kategorien interpretiert werden. Seine Ästhetik formulierte er ab 1830 in den Briefen aus Italien über das Geheimnisvolle der Schönheit und die Kunst. In dieser Publikation schrieb er, dass Kunstwerke durch ihre physische Präsenz Gemüt und Verstand anregten. Diese Erregung nannte er das »intellektuelle Wohlgefallen«. In den entsprechenden Passagen der Briefe reflektierte Quandt, weshalb der Anblick von Kunst beim Betrachter Gefühle auslösen könne.

Quandts Ausdruck »intellektuelles Wohlgefallen« ist ein Anklang an Immanuel Kants Schönheitsbegriff in der Kritik der Urteilskraft. Für den Philosophen war der Schönheitsbegriff kein Vernunftbegriff. Er charakterisierte Schönheit als die Fähigkeit des Menschen zu erkennen und zu urteilen - Schönheit aber nicht als eigentliche Erkenntnis. Daher war für Kant die Schönheit ein »interesseloses Wohlgefallen « ${ }^{107}$ Quandt rezipierte Kant in seinem eigenen Sinn und schrieb, Schönheit sei

106 Kat. Quandt 1868, S. 18-19. Rüfenacht 2018, SQ-63 (Steinkopf), SQ-64 (Catel), SQ-65, SQ-67, SQ-68 (Richter).

107 Kant 1790 [2009], S. 522-524. Der Schönheitsbegriff wird umfassend diskutiert ebd., S. 521-574; s. a. ÄGB 2010, S. 413; Prange 2004, S. 51-52; Frank 1989, S. 87-94.

108 Quandt 1830 (1), S. 44. Die Diskussion des Schönheitsbegriffs als Kernbegriff und Grundbedingung seiner Kunsttheorie, dessen Quintessenz hier nur postuliert wird, diskutiert er in den Briefen 1-5, ebd., S. 1-67.

109 Quandt war sich des Unterschieds seiner Ästhetik und Kants Philosophie bewusst. Er betonte denn auch, Kant diskutiere nicht den »das Vernunftgemäße in sinnenfälliger Form. $\ll^{108}$ Ein schönes Kunstwerk löse beim Betrachter ein Gefühl aus und dieses kategorisiere er mit seiner Vernunft. Damit wurde Kants »interesseloses Wohlgefallen« bei Quandt ein »intellektuelles Wohlgefallen $\ll .{ }^{109}$

Dieses »intellektuelle Wohlgefallen« unterteilt Quandt in den Briefen aus Italien in vier Hauptbegriffe. Es handelt sich um das Schöne, Erhabene, Tragische und Rührende. ${ }^{110}$ Dabei unterscheidet er zwei Formen des Schönen. Im Sinne eines Gedankens in anschaulicher Form könne ein Kunstwerk schön sein und gleichzeitig auch erhaben, tragisch oder rührend. ${ }^{11}$ Hingegen sei es als Gefühl der Schönheit, also als intellektuelles Wohlgefallen, den anderen Begriffen gleichgestellt. Dann sei das Schöne eine innere Befriedigung. ${ }^{112}$ In nächster Verwandtschaft stehe das Gefühl des Erhabenen. Wie das Schöne erhebe das Erhabene das Gemüt. Das betrachtete Objekt habe jedoch eine andere Wirkung: während beim Schönen das Dargestellte und das Gefühl des Betrachters übereinstimmten, sei das Erhabene »das freudige Gefühl der intellectuellen Ueberlegenheit«

Schönheitsbegriff, sondern das Urteil über Schönheit, also nur das Geschmacksurteil. Vergleiche Quandt 1844 (1), S. 96-97, 104 und Kant 1790 [2009], S. 531-532; Quandt 1830 (1), S. 50-52.

110 Briefe 7-10, Quandt 1830 (1), S. 80-146.

111 Quandt 1830 (1), S. 102: „Daß ein Kunstwerk schön seyn und auch das Gefühl der Erhabenheit in uns erwecken kann, geht aus dem Wesen des Schönen und Erhabenen hervor, welche zwar verschieden, aber nicht sich aufhebend entgegengesetzt sind."

112 Quandt 1830 (1), S.80. 


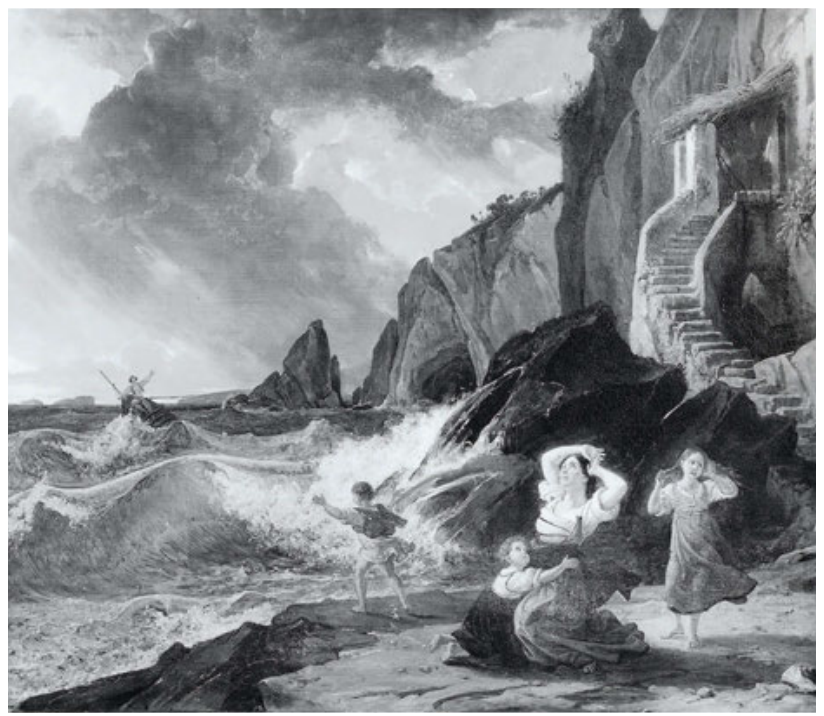

72 Franz Ludwig Catel, Eine Fischerfrau beklagt mit ihren Kindern am Strand den drohenden Tod ihres Gatten (Die unglückliche Heimkehr des Fischers), 1824, Öl auf Leinwand, $62 \times 74 \mathrm{~cm}$, Verbleib unbekannt (wohl ursprünglich aus der Sammlung Leo von Klenze München)

des Betrachters über das Dargestellte. ${ }^{113}$ Beim Rührenden erkenne der Betrachter den Schmerz des Dargestellten als seinen eigenen. ${ }^{114}$ Das Tragische wiederum empfinde man im Angesicht des Untergangs eines Individuums für bessere Zwecke. ${ }^{15}$ Der "philosophisch denkende Kunstforscher« solle, so Quandt, seine Gefühle bei der Betrachtung mit diesen vier Kategorien erklären. ${ }^{.16}$

Laut Quandt war es das Kolorit in der Malerei, das beim Betrachter Gefühle auslöste, die es zu kategorisieren galt. Daraus können Rückschlüsse auf die Hängung der Gemälde im dritten Zimmer gezogen werden, wie sie im Katalog von 1868 feststellbar ist. ${ }^{117}$ Caspar David Friedrichs Gemälde einer nordischen Landschaft erfüllte zwar hinsichtlich der Macht der Darstellung

113 Quandt 1830 (1), S. 82-83. Den Erhabenheitsbegriff diskutiert Quandt im 7. Brief, ebd., S. 80-103.

114 Quandt 1830 (1), S. 109-111. Ausführlich über das Rührende im 8. Brief, S. 107-113.

115 Quandt 1830 (1), S. 117: „Wir nennen es tragisch, wenn wir das Individuum untergehen und eine sittliche Idee siegreich hervorgehen sehen. « Detailliertere Beschreibung des Tragischen im 9. Brief, ebd., S. 116-120.

116 Siehe dazu Quandt 1842, S. 42: »Das ästhetische Urteil hingegen, da es nicht auf Verstandessätzen beruht, sondern von der Phantasie und dem Gefühl getragen wird, seinem Wesen nach subjectiv ist, lässt sich nicht wie ein mathematischer Satz beweisen."

117 21. Brief, Quandt 1830 (1), S. 316-339. S. a. Quandt 1844 (1), S. 1-8. Das Kolorit erscheint durch das Licht. Daher ist auch die Komposition untergeordnet, denn selbst sie erscheint in der Malerei durch das Licht bzw. Kolorit. Die ästhetischen Kategorien manifestieren sich in der Malerei daher hauptsächlich im Kolorit. die Kategorie des Erhabenen, wie Quandt es forderte, jedoch veranlassten die Dämpfung der Farben und die Grautöne den Kunstsammler dazu, den Künstler als Maler des Rührenden zu würdigen. »Ein getrübtes Licht und eine dunkle Färbung lassen uns die Natur in Trauer erscheinen und die sich dem Herzen einschmeichelnde Wehmuth lässt uns Alles in diesem Colorit erblicken. Einige nordische Künstler haben diesen Trauerton der Natur sehr gefühlvoll getroffen und in ihren Bildern wieder gegeben. [...] Unter den Neuern hat sich in dieser Hinsicht der Landschafter Friedrich ausgezeichnet. Die Werke dieser Künstler sind in Italien selten und würden hier auch kein Glück machen, weil hier in reicher Fülle die ungetrübte Schönheit in Farben und Formen sich offenbart. «118 Die »ungetrübte Schönheit« fand sich umgekehrt in der italienischen Landschaft Rohdens wieder, der selber bis zu seinem Tod in Rom lebte, auch wenn Quandt ihn nicht explizit nennt. Bemerkenswerterweise blieb der Kunstschriftsteller selbst bei der Beschreibung der ästhetischen Kategorien dem Vergleich deutscher und italienischer Kunst verhaftet, wie er 1824 augenscheinlich wurde: Schönheit war italienisch, Erhabenheit deutsch.

In der neuen Präsentation der Gemälde fand sich eine Genredarstellung, Die unglückliche Heimkehr des Fischers, von Franz Ludwig Catel, die Quandt dem Maler 1824 abgekauft hatte (Abb. 72). ${ }^{119}$ Mit der Umhängung in den Raum mit den Gegenstücken von Friedrich und Rohden erhielt es einen völlig neuen Kontext. Zusammen mit den Briefen aus Italien entpuppt es sich geradezu als Motiv zur Theorie: Quandt umgab seine langatmigen Ausführungen über das Erhabene, Rührende und Tragische mit der Geschichte einer Fischerfamilie, die als Ekphrasis zu Catels Gemälde erscheint. Die berichtartige Erzählung handelt von der rührenden Liebe eines schönen Fischerpaares. Die Beziehung endet mit dem tragischen Schiffbruch des Fischers auf der erhabenen Weite des Meeres. ${ }^{120}$ Offensichtlich versuchte Quandt die trockene Materie mit angeblich eigenen
118 Quandt 1830 (1), S. 333-334. S. a. Grave 2012, S. 188-189; Busch 2003, S. 147.

1191824 hing es noch völlig isoliert in Quandts Privatmuseum. Kat. Quandt 1824, S. 4. Rüfenacht 2018, SQ-64. Es ist davon auszugehen, dass es sich bei der hier abgebildeten Version um die Fassung aus der Sammlung Leo von Klenze, München handelt, die in ihren Dimensionen $(62 \times 74 \mathrm{~cm})$ kleiner als die Quandt'sche Version war (gemäß Kat. Quandt 1868, S. 18 umgerechnet 99,1 × 139,2 cm). Zudem schreibt Quandt in seiner Rezension im Artistischen Notizenblatt: »[...] des Gatten Nachen liegt zerschmettert am Gestade«, wohingegen auf dieser Version der Fischer noch im Boot ist. Auch wenn Quandt Handlungen gerne dramatisierend beschreibt, ist er in solchen Details doch präzise. Dennoch entspricht die Szenerie sonst weitgehend der Beschreibung von Quandt 1825, S. 75. Vgl. Kat. Hamburg 2015,

S. 390-391; Stolzenburg 2007, S. 69-70; Quandt 1825, S. 75.

120 Die ganze Erzählung in Quandt 1830 (1), S. 103-106, 113-115. 
Erlebnissen aus Italien aufzulockern, um Authentizität zu vermitteln. Nicht zuletzt deswegen wählte er als äußere Form seiner Ästhetik den Brief. Wichtiger war aber seine Intention, die abstrakte Materie anschaulich zu vermitteln. ${ }^{121}$

Analysiert man die verbleibenden Gemälde dieses dritten Zimmers im Katalog von 1868, lassen sich allenthalben Anbindungen an seine Version der ästhetischen Kategorien feststellen. Eine heute verschollene großformatige italienische Landschaft des Württemberger Malers Gottlob Friedrich Steinkopf befand sich neben dem Catel-Gemälde. Es zeigte Figuren bei der morgendlichen Weinlese. Quandt rühmte die freundliche, idyllische Stimmung, den Reichtum und die Milde des Südens. ${ }^{122}$ Sie stand somit in Bezug zur Landschaft Rohdens.

Nach dem Bild von Catel folgte die Abendandacht von Adrian Ludwig Richter, die Quandt dem Künstler 1842 abgekauft hatte (vgl. Abb. 23). In einem Brief schrieb Quandt: „Über Colorit, Composition u Halbdunkel des Gemäldes welches ich Ihnen zur Ansicht sende, sage ich kein Wort, denn dies alles sollte unbewusst im Gemüthe die ästhetische Wirkung hervorbringen, bei einem wahren Kunstwerke sollte davon gar nicht die Rede sein können, denn Farbe, Linien u Licht müssen im Gemüthe des Beschauers so Gedanke werden, wie der Gedanke des Künstlers im Kunstwerke ein sinnlich wahrnehmbarer Gegenstand geworden ist.« ${ }^{123}$ Explizit erwähnte Quandt hier die ästhetische Wirkung auf das Gemüt im Sinn seines intellektuellen Wohlgefallens. Zwar wollte er diese Wirkung nicht einordnen, doch womöglich kann sie mit dem Rührend-Erhabenen in Verbindung gebracht werden. Diese Mischform des intellektuellen Wohlgefallens beschrieb er als Übereinstimmung des Gemüts mit einer dynamischen Größe - nicht unpassend für eine Gottesdienstdarstellung. ${ }^{124}$ Zudem hingen die beiden bereits erwähnten Gegenstücke Ariccia (Der Morgen) und Civitella (Der Abend) von Adrian Ludwig Richter in diesem Raum (vgl. Abb. 56-57). Dass Quandt Richter vor dem Hintergrund seiner ästhetischen Kriterien beurteilte, zeigt sich in der Kritik der Dresdener Akademieausstellung von 1824, in der er dem Maler attestierte, dass er »das was in der Natur ans Unbegreifliche und in der Darstellung ans Unglaubliche reicht, ohne die Grenze des Möglichen und Wirklichen zu überschreiten $[. ..] \ll$, darstelle. Seine Bergbilder betrachtete der Kunstfreund mit dem Gefühl des Erhabenen. ${ }^{125}$

121 Tatsächlich können ein paar Motive der Geschichte in Briefen, die er von seiner Neapelreise 1820 abschickte, ansatzweise wiedererkannt werden. So berichtet er von einem Sturm auf einer Schifffahrt in einem Brief an Unbekannt vom 26.4.1820, in: Leipzig, Universitätsbibliothek, Sign. Nachlass 215 - Quandt, Johann Gottlob von.

122 Quandt 1821, S. 117-118. S. a. Schefold 1939, S. 146.

123 Brief an Georg Schöler vom 29.11.1845, in: München, Bayerische Staatsbibliothek, Autograph Quandt, Johann Gottlob von.
Quandts ästhetische Kategorien und die zeitgenössische Ästhetik

Worin unterscheidet sich nun aber die Feststellung, dass Rohdens südliche und Friedrichs nordische Landschaft mit Quandts Kunsttheorie in Verbindung gebracht werden können, von der These Graves und Buschs, die beiden Bilder würden das Schöne und Erhabene darstellen? Der Unterschied liegt in Quandts spezifischem Verständnis der ästhetischen Kategorien, das sich in erheblichen Punkten von der Ästhetik seiner Zeit unterscheidet. Zwar reflektierte er diese ausführlich, besonders Kants Kritik der Urteilskraft, doch anders als in der traditionellen Beurteilung der ästhetischen Kategorien setzte Quandt das Schöne und Erhabene einander nicht als Gegensätze gegenüber, sondern nur als ein Verschiedenes, das sich verbunden bleibt (Abb. 73). ${ }^{126}$ Ergänzt um das Rührende und Tragische, verteilte er die vier Kategorien auf einem Kreis, so dass jeweils zwei Begriffe einander polar gegenüber stehen. Sie bleiben im Rahmen des intellektuellen Wohlgefallens miteinander verbunden und können sich in unzähligen »Nüancen des Gefühls « mischen. ${ }^{127}$

Eine solche Verbindung der ästhetischen Kategorien fand in der zeitgenössischen Ästhetik nicht statt. Vielmehr argumentierten die Philosophen in Gegensatzpaaren. Das Schöne und das Erhabene bilden das bekannteste Paar. Kant unterteilte den ersten Abschnitt des ersten Teils der Kritik der Urteilskraft in die »Analytik des Schönen « und die »Analytik des Erhabenen«. Schönheit und Erhabenheit sind bei ihm keine vernunftgemäßen Begriffe und beinhalten deshalb keine objektive Erkenntnis. Schönheit sei »interesseloses Wohlgefallen« und charakterisiere sich durch die Freiheit und vermeintliche Allgemeingültigkeit des ästhetischen Urteils. Durch die Schönheit erkenne der Mensch sein eigenes Schaffen. Erhabenheit dagegen stelle die Natur als das Ungeordnete und Chaotische dieser Freiheit entgegen. Im Gegensatz zum Schönheitsurteil entziehe sich Erhabenheit dem sinnlichen Urteil, denn es gehe bei ihr nicht um das Urteil über einen Gegenstand des menschlichen Schaffens, sondern um einen Gegenstand der Natur. Dieser aber sei erhaben, er werde nicht als erhaben beurteilt. Kant unterscheidet das Erhabene als »Mathematisch-Erhabenes«, das alles Große in Bezug zu einem kleineren setze und in die Unendlichkeit fortführe, und als »Dynamisch-Erhabenes«, das

124 Quandt 1830 (1), S. 126, 333-334.

125 Quandt 1824, S. 366. S. a. Grave 2012, S. 196

126 Quandt 1830 (1), S. 102: »Daß ein Kunstwerk schön seyn und auch das Gefühl der Erhabenheit in uns erwecken kann, geht aus dem Wesen des Schönen und Erhabenen hervor, welche zwar verschieden, aber nicht sich aufhebend entgegengesetzt sind.«Zu Quandts Tendenz, philosophische Gegensätze auszugleichen s. a. Maaz 1986, S. 12.

127 Quandt 1830 (1), S. 123. 
die Macht der Natur zwar furchtbar erscheinen lasse, den Menschen aber nicht zu gefährden vermöge. ${ }^{128}$

Das Gegensatzpaar des Schönen und Erhabenen blieb auch bei Friedrich Schiller bestehen. Er verortete die Kategorien in einer unbestimmten Idealität und vermochte sie in der menschlichen Geschichte nicht zu erkennen. Hegel schloss sich dieser Historisierung an. ${ }^{129}$ Schelling bezog die Gegensätzlichkeit der beiden Begriffe nur auf das zu betrachtende Objekt. Der Unterschied des erhabenen und des schönen Gegenstandes ist auch bei ihm vorhanden. Die Wirkung auf den Betrachter ist jedoch die gleiche. Sowohl der schöne wie auch der erhabene Kunstgegenstand vermöchten den Betrachter zur ästhetischen Anschauung der eigenen Existenz führen. ${ }^{30}$

Kompilierend für die Hauptargumente der Ästheten des frühen 19. Jahrhunderts sind die Schriften von Friedrich Theodor Vischer. Mit ihm lassen sich die Hauptströmungen in der Diskussion um die ästhetischen Kategorien zusammenfassen und mit Quandt vergleichen. In seiner nur wenige Jahre nach den Briefen des Dresdener Kunstschriftstellers entstandenen Habilitationsschrift Ueber das Erhabene und Komische, ein Beitrag zu der Philosophie des Schönen von 1837 legte Vischer die Grundlage für seine umfassende Ästhetik, die in sechs Bänden ab 1857 erschien. Er beschrieb, wie Quandt auch, Schönheit als Einheit von Idee und sinnlicher Erscheinung. Dieser Begriff der Schönheit sei an einen Gegenstand im Hier und Jetzt gebunden. Ein erhabener Gegenstand zeige dagegen das Unendliche. Weil diese Idee des Unendlichen aber sinnlich erscheine, sei das Erhabene denselben Prinzipien wie die Schönheit unterworfen. Die vernünftige Idee sei also das gemeinsame Moment von Schönheit und Erhabenheit. ${ }^{31}$

128 Kant 1790 [2009], v. a. \$1-29, S. 521-619; siehe auch den Kommentar ebd., S. 1235-1247, zum Unterschied der beiden Begriffe besonders ebd., S. 1243-1245. Renate Reschke, »Schön/Schönheit«, in: ÄGB 2010, Bd. 5, S. 413; Jörg Heininger, »Erhaben«, in: ÄGB 2010, Bd. 2, S. 293-294. S. a. Frank 1989, S. 87-103. Quandt war mit dieser Unterscheidung gar nicht einverstanden: „Unbegreiflich ist es mir daher, wie viele Philosophen, und selbst der große Kant ein Erhabenes von zweierlei Art [...] unterscheiden wollen. « Zudem könne ein Gegenstand nicht erhaben sein, sondern nur das Gefühl der Erhabenheit auslösen. Quandt 1830 (1), S. 89-93, 99-102.

129 Jörg Heininger, »Erhaben«, in: ÄGB 2010, Bd. 2, S. 294-296; GethmannSiefert 2005, S. 54-56.

130 Schelling 2004, S. 113: »[...] so ist doch der Gegensatz zwischen Schönheit und Erhabenheit ein solcher, der nur in Ansehung des Objekts, nicht aber in Ansehung des Subjekts der Anschauung stattfindet [...]. Es läßt sich auch sehr leicht zeigen, daß die Erhabenheit auf demselben Widerspruch [der Unendlichkeit im Endlichen - AR] beruht, auf welchem auch die Schönheit beruht.« S. a. Quandt 1840 (3), Sp. 397-398.

131 Vischer 1837, S. 40-44. »Mit diesem Begriffe [des Erhabenen - AR] haben wir also nichts Fremdes vor uns, das zum Schönen äußerlich hinzukäme, sondern es treten nur die beiden Elemente des Schönen in eine neue Proportion, die Idee wächst über, Endliches und Unend-
Vischer erweiterte seinen Erhabenheitsbegriff um die Kategorie des Tragischen - ein Begriff, der schon im 18. Jahrhundert eine zentrale Rolle gespielt hatte und dessen Bedeutung bei Hegel um eine geschichtsphilosophische Ebene erweitert wurde. ${ }^{132}$ Das Tragische ist in Vischers Verständnis ein Aspekt des Erhabenen, und es beschreibt das Scheitern der nach dem Unendlichen strebenden Idee. ${ }^{133}$ Aus diesem Begriff des Tragischen heraus entwickelte er die Kategorie des Komischen. Im Gegensatz zum Tragischen sei das Komische der sinnlichen Erscheinung verpflichtet. Während das Tragische durch ein Scheitern jedweder Idee am Unendlichen definiert sei, erkläre sich das Komische aus der sinnlichen Erscheinung, welche »der Idee ein Bein stellen « wolle. ${ }^{134}$ Das Komische erwarte Erhabenheit, die sich plötzlich in Nichts auflöse. Dies geschehe bei der genauen Betrachtung einer sinnlichen Erscheinung, die vermeintlich eine Idee des Unendlichen in sich trage, also erhaben sein müsse. In den Details des komischen Gegenstandes zeige sich, dass dieses unendliche Moment gar nicht vorhanden sei, worauf die Erhabenheitserwartung verpuffe. ${ }^{35}$ Damit eröffnet sich bei Vischer ein Weg zurück zum Schönen, denn anstelle einer falschen Unendlichkeit entfalte sich die endliche, vernünftige Idee der sinnlichen Erscheinung. ${ }^{136}$

Für Quandt spielte zwar nebst dem Schönen und Erhabenen auch das Tragische in seinem Gefühlskreis des intellektuellen Wohlgefallens eine wichtige Rolle. Anders als Vischer stellte er dem Tragischen das Rührende entgegen. Dieser Begriff war den Philosophen wenig wichtig oder gar negativ konnotiert. Kant beschreibt in der Kritik der Urteilskraft, dass ein Geschmacksurteil nur dann ein Geschmacksurteil sei, wenn es nicht auf »Reiz und Rührung « beruhe. »Der Geschmack ist je-

liches decken sich nicht mehr, sondern dieses steht in seiner allem Endlichen überlegenen Größe vor uns. [...] Im Erhabenen steht die Idee in einem negativen Verhältniß zur Gegenständlichkeit, das Absolute erscheint über jede unmittelbare Existenz hinausgehoben, es ist (in der Kunst) der Versuch, das Unendliche auszudrücken, ohne in dem Bereich der Erscheinung einen adäquaten Gegenstand zu finden.«

132 Zum Beispiel in den Diskussionen um die Rolle der antiken Kunst bei den Weimarer Klassikern Goethe und Schiller. Vischer 1837, S. 83-94; Roland Galle, »Tragisch/Tragik«, in: ÄGB 2010, Bd. 6, S. 152-165.

133 Er folgt hierbei Karl Ferdinand Solgers Tragik-Begriff. Vischer 1837, S. 142

134 Vischer 1837, S. 155: »Hat nämlich im Erhabenen das eine der beiden Momente des Schönen, die Idee, das Uebergewicht bekommen, so wird das andere, die Erscheinung, nun auch sein Recht haben wollen, und, wo immer möglich, der Idee ein Bein stellen. Dies geht aus dem einfachen logischen Gesetze hervor, daß Gegensätze einander bedingen, und erweist sich in der Erfahrung durch den anerkannten Satz, daß vom Erhabenen zum Lächerlichen nur ein Schritt ist."

135 Vischer 1837, S. 155-156: »Das Komische sey ein deutlich gemachtes Erhabenes. Denn die Deutlichkeit besteht im Hervorheben der sinnlichen Einzelnheiten und diese sind es, die alsbald den Schein des Unendlichen aufheben. « Klaus Schwind, »Komisch«, in ÄGB 2010, Bd. 3, S. 363-371.

136 Vischer 1837, S. 225. 
derzeit noch barbarisch, wo er die Beimischung der Reize und Rührungen zum Wohlgefallen bedarf, ja wohl zum Maßstabe seines Beifalls macht. «137 Ein Geschmacksurteil sei nur dann möglich und unparteiisch, wenn es die Zweckmäßigkeit seiner Form zur Ausgangslage nehme. Vischer beschrieb das Rührende als Teil des Erhabenen, mit dem sorgsam umgegangen werden müsse. Der »weiche Affect« dürfe nicht »niedrig und gemein« werden..$^{138}$ Diese beiden Beispiele deuten an, dass das Rührende als Reiz oder Affekt angesehen wurde - eine Sichtweise also, die nicht gerade von intellektuellem Tiefgang zeugt.

Quandt räumte dem Rührenden dagegen einen intellektuell hohen Stellenwert ein und scheint damit in der Tradition der Frühromantiker und Nazarener zu liegen, welche das »aufrichtige Empfinden des Betrachters « geradezu einforderten. ${ }^{39}$ Das Rührende entspräche bei Quandt damit einem selbstbewussten, also vernünftig wahrgenommenen Empfinden der eigenen Gefühle beim Betrachten von Kunstwerken. Gerade die wichtige Rolle des »Rührenden« passt zu Quandt, der zu den großen Förderern der Nazarener gehörte. Umgekehrt war ihm das Komische eher fremd, weil es für ihn keinen ästhetischen, sondern einen moralischen Begriff bezeichnete: Dieser bewege sich zwar zwischen einem emotionalen Behagen oder Missbehagen, habe jedoch nicht unmittelbar mit dem betrachteten Gegenstand zu tun. ${ }^{140}$

Das Problem von Quandts Verteilung der Gefühlskategorien auf einem Kreis und der damit versuchte Ausgleich der philosophischen Gegensatzpaare liegt in einer Vermischung unterschiedlicher Begriffsebenen: Quandt ordnete das Schöne der Vernunft zu, während das Erhabene, Tragische und Rührende Gefühle bezeichnen. Doch Kant folgend, können Vernunftbegriffe und Gemütsregungen nicht auf der gleichen Begriffsebene verglichen werden. Aus dieser Erkenntnis heraus diskutierte der Philosoph Schönheit und Erhabenheit im Rahmen der Kritik der Urteilskraft, also auf einer gemeinsamen Begriffsebene. Damit gehört die Schönheit bei Kant nicht zur Vernunft. Auf der kantischen Kritik aufbauend erfolgte die Weiterentwicklung der ästhetischen Kategorien durch die Ästhetiker des frühen 19. Jahrhunderts. Die deutschen Idealisten um Schelling verbanden-ausgelöst durch Kants Philosophie-Objektivität und Sub-

137 Kant 1790 [2009], S. 547.

138 Vischer 1837, S. 78: „Sodann ist die Hauptsache, daß sich der weiche Affect des Leidens nie bis dahin verirre, daß man in diesem Zerfließen der Empfindung gar keine Willenskraft mehr unterscheiden könnte. In diesem lezteren Fall wird die Kunst niedrig und gemein, und ist nichts, als eine an unserem Thränensack arbeitende Pumpe."

139 Grave 2015, S. 105.

140 Quandt 1830 (1), S. 146-159.

141 Prange 2004, S. 48-52, 60-64. S. a. Dietzsch 2016, S. 41-54

142 Brief von Quandt an Schnorr vom 4.1.1830, in: SLUB, Mscr. Dresd. n Inv. 15, Bd. 31, fol. 166v. jektivität, Vernunft und Gefühl, in der Transzendentalphilosophie. Sie verstanden Kunst als Anschauung des Unendlichen. ${ }^{141}$

Doch das alles interessierte Quandt nur theoretisch. »Ich [habe] mir alle Mühe gegeben [...] darzuthun, daß eine Ästhetik als abstracte Schönheitslehre etwas ganz Unzulässiges ist«, schrieb er in einem Brief an Julius Schnorr von Carolsfeld. ${ }^{142} \mathrm{Er}$ wollte Kunst als etwas verstehen, was im Hier und Jetzt angeschaut wird. Für ihn war Kunstanschauung kein entferntes Unendliches, sondern ein Bild an der Wand, eine Statue auf dem Sockel oder der gotische Dom in der Stadt. So versuchte er, was die Philosophen längst als unmöglich erkannt hatten: nämlich das Geschmacksurteil als Vernunftbegriff herzuleiten und vernünftige Kunstbetrachtung zu betreiben.

\section{Ästhetik der Anschauung}

Doch selbst wenn Quandts Argumentation philosophisch gesehen nicht aufgeht, stellt sich die Frage nach ihrer Qualität. Worin könnte sie, entgegen aller Widersprüche zu den Lehrsätzen der philosophischen Ästhetik in der ersten Hälfte des 19. Jahrhunderts, liegen, da doch festgestellt werden kann, dass er die wichtigen Autoren seiner Zeit gelesen und interpretiert hat?

Seine genuin eigene Errungenschaft ist der Versuch einer Theoretisierung von Kunstbetrachtung durch die philosophische Ästhetik. Quandt argumentiert aus der sinnlichen Anschauung heraus, die intellektuelles Wahrnehmen erst zur Folge hat. Entgegen den frühromantischen Philosophen, für die der Begriff der Anschauung allgemein als ein intellektueller Akt der Existenzerfahrung eine wichtige Rolle spielt und Kunstanschauung speziell als bewusste oder unbewusste Existenzerfahrung angesehen wird, benützt ihn Quandt zuallererst im Sinn von Betrachtung mit den Augen- eben an-schauen.143 Damit ist die Ausgangslage jedoch eine völlig unterschiedliche. Anschauung vollzieht sich bei den Philosophen als Akt des Selbstbewusstseins. Kunstanschauung ist hierfür mögliches Mittel. Während das Selbstbewusstsein des denkenden Menschen am Anfang steht, beginnt Quandt mit dem Kunstwerk. Erst dessen Betrachtung

143 Anschauung im Wortgebrauch der frühromantischen Philosophie bedeutete ein intellektuelles Anschauen des eigenen Seins. »Um eine Anschauung handelt es sich [...], denn nur sie kann einerseits für die Unmittelbarkeit unserer Vertrautheit, andererseits aber für die im cogito sum besiegelte Existenz-Erfahrung aufkommen. Es geht nicht um eine sinnliche Anschauung, sondern um eine intellektuelle. Quandt wiederum verbindet sinnliche Anschauung mit intellektuellem Wahrnehmen. Zitat nach Funk 1989, S. 155. S. a. Dietzsch 2016, S. 49 . 
und die dabei ausgelösten Gefühle, damit einhergehend die vernünftige Erkenntnis des Geschmacksurteils als ein intellektuelles Wohlgefallen führen zu einer existenziellen Erfahrung. Erst hier lässt sich Quandts Anschauung an die Bedeutungen von Selbstbewusstsein Schelling'scher Transzendental-Philosophie anschließen. ${ }^{14}$ Dies subsumiert sich in seiner eigenwilligen Aufwertung des Begriffs des Rührenden als Selbsterkenntnis des Betrachters angesichts des Schmerzes des Dargestellten. Die emotionale Selbsterkenntnis geschieht erst im Prozess der Anschauung, sie ist nicht schon Selbsterkenntnis an sich. ${ }^{145}$

Das Problem von Quandts Ästhetik ist sein Credo des realen Kunstwerks, das von Anfang an vor Augen steht. Es ist in philosophischer Sicht gewissermaßen das Brett vor dem Kopf, das seine Theorie mit den ästhetischen Abhandlungen seiner Zeit, in denen (Kunst-) Anschauung rein philosophisch gedacht wird, unvereinbar macht. Diese Unvereinbarkeit darf jedoch nicht mit Unverständnis verwechselt werden, denn Quandt hatte, wenn auch keinen universitären, so doch Privatunterricht beim außerordentlichen Philosophieprofessor Karl Friedrich Richter in Leipzig genossen. Die philosophische Grundbildung diente ihm dazu, seine eigene Meinung theoretisch zu untermauern. So versuchte er die sinnliche Anschauung von Kunst mit der Ästhetik zu vereinbaren. Die Essenz von Quandts Ästhetik liegt daher vor allem in seinem Anliegen, zwischen Theorie und Praxis zu vermitteln.

Um die Unterschiede zu den Ästhetikern seiner Zeit erklärbar machen zu können, bedarf es eines Blicks auf Quandts argumentative Methodik. Einen Erklärungsansatz kann ein Vergleich seines intellektuellen Wohlgefallens und dessen Darstellung im Gefühlskreis mit Goethes Farbenlehre und dem berühmten Farbkreis bieten (Abb. 73-74). Eine Beschreibung der methodischen Gemeinsamkeiten beginnt beim Vokabular. Goethe spricht in Bezug auf den Farbkreis von Nuancen und Mischungen der Farben, Quandt von Mischungen der Gefühle. Dass hier Quandt eine von Goethe inspirierte Benennung verfolgt, vermögen seine Erläuterungen über die Erscheinungsform der ästhetischen Kategorien in der Malerei zu bestärken. Es sei »Farbenharmonie«, die beim Anblick von Malerei zur Erregung des Verstandes führe. In diesem Kontext verarbeitete er

144 Quandt 1840 (3), Sp. 397-398. Der Begriff der Anschauung ist ausgesprochen vielschichtig und schwer definierbar. Siehe Dietzsch 2016,

S. 47-54; Waltraud Naumann-Beyer, »Anschauung«, in: ÄGB 2010,

Bd. 1, S. 238-240; Prange 2004, S. 79.

145 Quandt 1830 (1), S. 109-111. Ausführlich über das Rührende im 8. Brief, S. 107-113. Vgl. Grave 2015, S. 103-105.

146 Quandt 1830 (1), S. 328; Goethe 1810, \$50-60, S. $19-26$.

147 Zur sittlichen Dimension der Farben siehe Goethe 1810, \$758-832,

S. 287-311; über das Kolorit, ebd., §871-899, S. 322-330. S. a. Gage 2001,

S. 204-205.

148 Quandt 1830 (1), S. 123. Der Vergleich mit Hegel wäre hier spannend: explizit Goethes Farbenlehre, und zwar spezifisch Goethes Verweis auf sich gegenseitig fordernde Farben. ${ }^{146}$

Wenn auch kein direkter Zusammenhang zwischen Goethes Farbkreis und Quandts Gefühlskreis feststellbar ist, sind die beiden Kreise gleichsam als Ergebnisse ähnlicher Methodik miteinander vergleichbar: Goethes Errungenschaft war das Aufbrechen der Polarität der Farben durch die Ergänzung der Komplementärfarben im Farbkreis. Zudem fügte er seinen physikalischen Erkenntnissen eine sittliche Dimension hinzu, indem er den einzelnen Farben die Temperamente zuordnete. So wie die Farben sich mischen können, fließen die Temperamente und Menschentypen ineinander über. ${ }^{147}$ Dieses verbindende Prinzip mochte für Quandts Überlegungen inspirierend wirken. So sind es nicht die klassischen Kriterien der Komposition oder Zeichnung, die beim Betrachter Gefühle auslösen. Es ist das Kolorit. Die vom Maler zusammengemischten Farben lösen bestimmte Gefühle aus, die Quandt mit seinen ästhetischen Kategorien beschreiben wollte. Genau wie die Farben können sie sich vermischen. ${ }^{148}$

Wie Goethes psychologische Interpretationen letztlich physikalischen Experimenten nicht standhalten konnten und kaum naturwissenschaftlichen, sondern vor allem kulturgeschichtlichen Mehrwert boten, so scheiterte Quandts Versuch einer Vereinbarung ästhetischer Theorie und praktischer Kunstbetrachtung. Immanuel Kant hatte den deutschen Idealisten zwar mit seiner These der »ästhetischen Idee« den Weg für eine neue Ästhetik geebnet und postuliert, nicht jeder Vernunftbegriff vermöge die Gedanken der Einbildungskraft auszudrücken. Auch Quandt versuchte mit Schelling, Solger und anderen hier anzuknüpfen. ${ }^{149}$ Doch während jene Kants These philosophisch weiterführten, versuchte dieser eine aus der Praxis der Kunstbetrachtung heraus gedachte Definition, die eben gerade die begrifflich nicht ausdrückbare »ästhetische Idee« zu bezeichnen versuchte. Dadurch musste er komplexe philosophische Begriffe vereinfachend behandeln.

Quandts Intention beim Verfassen seiner Briefe aus Italien könnte es also gewesen sein, die philosophischen Begriffe in eine gehobene Umgangssprache überführen zu wollen. Verschiedene Stellen erhärten diese Vermutung. So umschreibt

»Eine [...] Hauptsache ist die Farbe. Sie macht die Malerei zur Malerei. Zeichnung, Erfindung ist wesentlich, notwendig, doch die Farbe ist erst die Lebendigkeit, kein bloßes Kolorieren, sondern zugleich bezeichnender Ausdruck.« Hegel 1823 [2003], S. 258.

149 Kant 1790 [2009], \$49, S. 664: »Unter einer ästhetischen Idee aber verstehe ich diejenige Vorstellung der Einbildungskraft, die viel zu denken veranlaßt, ohne daß ihr doch irgend ein bestimmter Gedanke, d. i. Begriff, adäquat sein kann, die folglich keine Sprache völlig erreicht und verständlich machen kann.« S. a. Dietzsch 2016, S. 41-54; Waltraud Naumann-Beyer, »Anschauung«, in: ÄGB 2010, Bd. 1, S. 227228; Frank 1989, S. 102-103. 


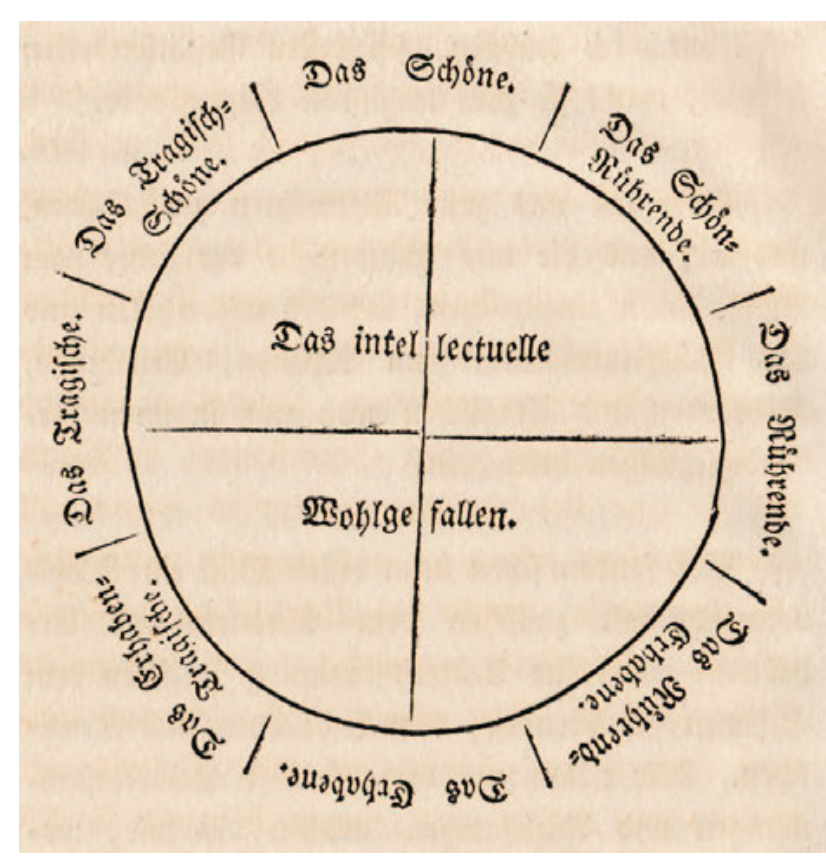

73 Johann Gottlob von Quandt, »Das intellectuelle Wohlgefallen«, in: Ders., Briefe aus Italien über das Geheimnisvolle der Schönheit und die Kunst, Gotha 1830, S. 124

er das Gefühl des Erhabenen mehrfach als »Erhebung des Gemüths« oder spricht in Beispielen von einem erhebenden Berg, Wasserfall, Farbton. ${ }^{150}$ Viel mehr als eine morphologische Verwandtschaft zwischen »erhebend« und »erhaben« besteht jedoch nicht, da »erhaben« spezifisch philosophisch ist und »erhebend « eher mit feierlicher Freude umschrieben werden muss. Dass genau diese Ungenauigkeiten in den Begriffen zu einer Unvereinbarkeit mit der philosophischen Ästhetik seiner Zeit führte, hat auch ein Rezensent der Briefe aus Italien festgestellt: »Aber die Begriffserklärung von >Schön< soll auf alles passen, was unsere Sprache möglicher Weise als schön bezeichnen kann. [...] Offenbar fehlt ein Wort in der Definition des V[er] $\mathrm{f}[$ asser $] \mathrm{s}$. Er meint das Kunstschöne allein. $\ll^{151}$

Doch genau diese vereinfachenden Begriffe und Umschreibungen haben einen didaktischen Charakter. Selbst die Briefform seiner Ästhetik und die zahlreichen erläuternden Beispiele und eingewobenen Geschichten deuten in diese Richtung. Quandts Schriften sind womöglich eine Art theoretisches Ma-

150 Quandt 1830 (1), S. 82, 96.

151 JALZ 1830, Jg. 26, Nr. 90, Sp. 235.

152 Schasler 1872, S. 872

153 Zum Galeriegespräch siehe Herding 1991, S. 261: »Mit der Wendung gegen Biographie, Inventar und Kritik agitieren [die Kunstfreunde] gegen verstandesmäßige Kälte im Umgang mit Kunstwerken und setzen dagegen die herausfordernde Subjektivität ihres Gefühls.« S. a. Weddigen 2008, S. 150-151.

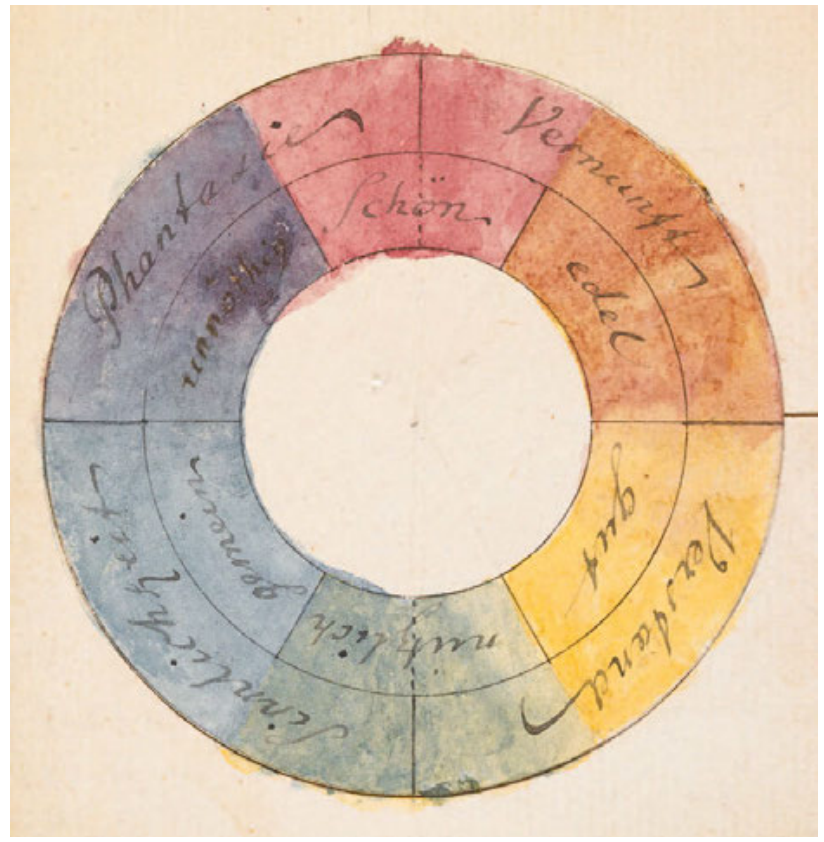

74 Johann Wolfgang von Goethe, Farbenkreis zur Symbolisierung des »menschlichen Geistes- und Seelenlebens", 1809, Feder in Schwarz, aquarelliert, auf Karton, $116 \times 78$ mm, Frankfurt a/M, Freies Deutsches Hochstift / Frankfurter Goethe-Museum, Inv.-Nr. III-14047

nifest des Galeriegesprächs. In diesen Gesprächen verwendeten die Kunstfreunde dilettierend die Begriffe der Philosophen. Quandts Briefe sollten in der Art eines Lehrbuchs Kunstfreunde zu einem wohlüberlegten Gebrauch ästhetischen Vokabulars führen. Max Schasler ordnete ihn in seiner Kritischen Geschichte der Aesthetik von 1872 dementsprechend denjenigen ästhetischen Schriftstellern zu, »welche theils die Aesthetik unter dem Gesichtspunkt der historischen Kunstforschung und als Einleitung zu dieser behandeln, theils in populärer Weise als gebildete Leute für gebildete Leute ästhetische Betrachtungen anstellen. $\ll^{152}$ Quandts Kunstfreunde konnten damit an ästhetischen Fragen teilhaben, ohne in die elitären Bereiche philosophischer Komplexität vorstoßen zu müssen. ${ }^{153}$ Quandt selber deutete dies vierzehn Jahre später in seinen Vorträgen über Ästhetik an: »Diejenigen, für welche diese Briefe geschrieben waren, $[$ waren $]$ die Kunst=Freunde und Liebhaber $[\ldots] . \ll 154$

Somit bleiben hinter Quandt als philosophischem Ästheten gewisse Fragezeichen stehen, denn die Materie blieb trotz

154 Quandt 1844 (1), S. 131: »Diejenigen, für welche diese Briefe geschrieben waren, die Kunst=Freunde und Liebhaber, fanden, daß durch den Ernst das Vergnügen an der Kunst geschmälert würde, weshalb denn ein vielgelesenes Literaturblatt [die JALZ 1830, Jg. 26, Nr. 90, Sp. 233240] gegen meine Aesthetik und für eine andere, die zu gleicher Zeit erschienen war, sich aussprach, in welcher das für schön erklärt wurde, was man zu sehen verlange.« 
rhetorischer Einschübe trocken. Sein Rezensent stellte fest: »Eine Reihe von glänzenden, aber unzusammenhängenden Kunstforderungen, Belehrungen und Urtheilen wird im besten Falle alles seyn, was wir als Ausbeute aus dieser gedankenreichen Arbeit mit hinwegnehmen.«155 Irgendwie scheint Quandts Ästhetik schon zu seiner Zeit als etwas unausgegoren wahrgenommen worden zu sein. Doch gerechter wird man ihm eher, wenn man ihn als Rezipient der ästhetischen Strömungen darstellt, und nicht als Philosoph, der er nicht war. Man sollte ihn als Vermittler zwischen der philosophischen Ästhetik und der Kunstkennerschaft darstellen. Besagter Rezensent verortete Quandts Briefe dementsprechend, auch wenn seine Kritik negativ war: »Hiermit haben wir jedoch nicht die Absicht, den besonderen Charakter dieses Buches anzugreifen, das in mehr als einer Beziehung dem Erwin [Vier Gespräche über das Schöne und die Kunst von Karl Wilhelm Ferdinand Solger] und allem, was sonst an geschmackvollen Kunstphilosophieen unter uns erschienen ist, an die Seite gesetzt zu werden verdient; es soll vielmehr nur unsere Meinung von der Ertraglosigkeit aller reinen Kunstspeculation andeuten. Die Periode der Systeme ist für Deutschland vorüber. [...] Die Philosophie, oder was sich dafür ausgiebt, ist allzu sehr Gemeingut der Deutschen geworden, als dass bey irgend einem neuen Lehrgebäude in den abstracten Wissenschaften noch auf einen bemerkbaren Erfolg zu rechnen wäre [...]. In der Kunstphilosophie aber ist es entschieden der eklektische Sinn, welcher dem Genius unserer Zeit entspricht. $\ll^{156}$

Der Rezensent zeigt deutlich das Problem von Quandt als Autor ästhetischer Schriften an: er war mit seinen ästhetischen Gedanken zu spät dran. Die großen Diskussionen im Umkreis der Frühromantiker und Deutschen Idealisten hatten Anfang des Jahrhunderts stattgefunden. Solgers Erwin, mit dem er verglichen wird, war 1815 erschienen. Schlegels, Schellings und Hegels wegweisende Vorlesungen über Kunst lagen viele Jahre zurück und waren längst publiziert. ${ }^{57}$ Quandts ästhetische Schriften wie die Briefe aus Italien oder die Vorträge über Ästhetik müssten daher mit ganz anderen Latten gemessen werden: nicht mit den Messlatten einer philosophischen Ästhetik, sondern mit denjenigen einer Rezeptionstheorie.

Dennoch ist Quandts Bemühen, zwischen philosophischer Ästhetik und Kunstbetrachtung zu vermitteln, nachvollziehbar. Der dritte Saal seiner Privatsammlung mit den Landschaftsbildern Rohdens, Friedrichs, Richters, Catels und Steinkopfs war

155 JALZ 1830, Jg. 26, Nr. 90, Sp. 233-234.

156 JALZ 1830, Jg. 26, Nr. 90, S. 234.

157 Frank 1989, S. 231-247: 14. Solger gilt selber bereits als »Spätling der romantischen Ästhetik«. Schasler 1872, S. 872 verortet Quandt als verspäteten Schelling-Anhänger.

158 Grave 2001, S. 93-95; s. a. Busch 2003, S. 146: »Pendants können auch der Versuch einer anschaulichen Präsentation ästhetischer Gedankengänge (vgl. Abb. 71). Anhand der seit vielen Jahrzehnten in den Gemäldesammlungen äußerst beliebten Pendanthängung, die zu künstlerischen, formalen, kunsttopographischen oder ikonographischen Vergleichen zwischen Bildern führen konnte, war hier eine Bild gewordene Ästhetik ausgestellt. ${ }^{158}$ Die Pendants vermittelten Quandts Sicht der ästhetischen Kategorien. Die durch die Kunstwerke ausgelösten Empfindungen der Betrachter sollten so vergleichbar gemacht werden.

Entgegen Leander Büsings Annahme, dass es Quandt »keinesfalls um die Gegenüberstellung hintergründiger Ideen gelegen war«, kann ihm eine ausgeprägt ästhetische und kunsttheoretisch unterfütterte Hängung attestiert werden.159 Die von Grave und Busch vermutete, polare Gegenüberstellung von Rohden und Friedrich im Sinne der Gegensätze des Schönen und Erhabenen greift ebenfalls zu kurz. Denn die beiden Bilder waren weder in der Frühzeit ihrer Präsentation noch später nach dem bipolaren Gegensatz des Schönen und Erhabenen präsentiert. Vielmehr wurden sie nun mit Gemälden ergänzt, die das Tragische und Rührende darstellen sollten. Der Sammler entpuppt sich damit vielleicht nicht als Ästhet auf der Höhe des philosophischen Diskurses, doch als engagierter Rezipient der philosophischen, ästhetischen und kunsttheoretischen Strömungen seiner Zeit. Als solcher hatte er die Praxis vor Augen und wollte die Kunstbetrachtung anregen.

Quandt betonte, dass das Ordnen seiner Sammlungen für ihn der Ästhetik naheliege. Kunst sammeln, ordnen und ausstellen stand also in einem engen Zusammenhang mit dem philosophischen Nachdenken über Kunst. Dies entsprach seiner »Vorliebe, in jedem Kunstwerke die Idee und in der Kunstgeschichte den Entwickelungsgang des Menschengeistes zu erkennen $[\ldots ..] \ll{ }^{160}$ Das Fortschreiten der Vernunft in der Menschheitsgeschichte sollte durch die sinnreiche Präsentation von Kunst sichtbar werden. Die Kenntnis der Kunstgeschichte würde die Gesellschaft nämlich zu »wahrer Cultur « führen. ${ }^{161}$ Mit der Öffnung seines Hauses für Künstler und Kunstfreunde hatte Quandts Sammlung eine bildende Funktion. In Bezug auf seine Kupferstichsammlung meinte der Kunstfreund: »[...] Es war für mich nicht etwa, diese Blätter mein zu nennen, das größte Vergnügen, wie dies bei Raritätenkrämern der Fall ist, sondern auch Anderen durch Betrachtung derselben einen Genuss zu bereiten; wie denn jede gemeinschaftliche Freude eine vielfältigere und größere ist, als die einsam egoistische. Der Be-

\footnotetext{
zur Demonstration unterschiedlicher kunsttheoretischer Positionen

benutzt werden [...]."

159 Büsing 2011, S. 231-232.

160 Kat. Quandt 1853, S. 2.

161 Quandt 1826 (1), S. 299-304.
} 
sitzer von Kunstschätzen hat noch immer vor anderen den Vorzug, der Verwahrer eines Gemeinguts zu seyn, denn ein solches sind Kunstwerke in der That. $\ll^{162}$

Wo konnte er dieses »Gemeingut « außerhalb seines privaten Rahmens besser fördern, als in den großen königlichen Kunstsammlungen, die mit der Reorganisation des sächsischen Staates zu Beginn der 183oer Jahre für die Allgemeinheit nach und nach einfacher zugänglich wurden? Ein erstes Engagement bot sich ihm in der Zusammenführung von Kunstkammer und Rüstkammer zwischen 1832 und 1834 zum Historischen Museum. Diese neue Dauerausstellung konzipierte er selber. Hier konnte er seine hehren Ziele und Ansprüche, wie sie im Kontext seiner privaten Sammlung verfolgt werden konnten, in einem öffentlichen Zusammenhang anwenden.

162 Kat. Quandt 1853, S. 1. 


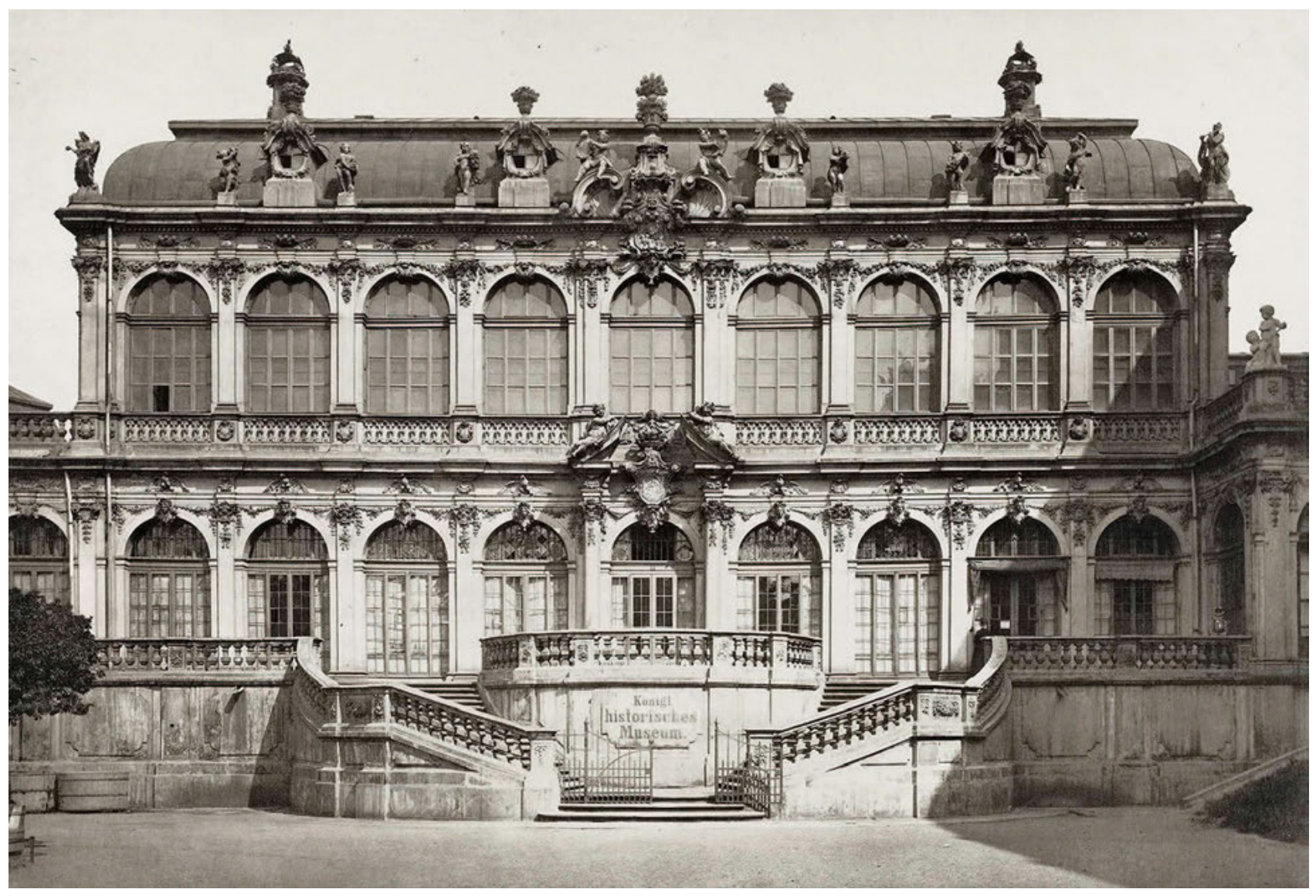

75 Das Königliche Historische Museum in Dresden, Eingangsbereich zum nordwestlichen Eckpavillon des Zwingers, um 1870 (Foto: Hermann Hettner, Der Zwinger in Dresden, Leipzig 1874, Tafel X) 


\section{GESCHICHTE UND GESELLSCHAFT: Das Historische Museum Dresden}

Mit dem Austritt aus dem Kunstverein begann im Leben Johann Gottlob von Quandts eine neue öffentliche Institution eine bedeutende Rolle einzunehmen: das Museum. Während er im Kunstverein seine Ansichten bei Aufträgen und Ankäufen eingebracht hatte, bot sich ihm nun die Möglichkeit, durch Ausstellungen seine Überzeugungen zu vermitteln. Im Gegensatz zu den sehr individuellen Möglichkeiten der Präsentation in seiner eigenen Sammlung war dieses Tätigkeitsfeld gewissen räumlichen und sammlungshistorischen Bedingungen unterworfen. Zudem musste er mit verschiedenen Personen zusammenarbeiten: Einerseits war er den Verantwortlichen des Ministeriums Rechenschaft schuldig, andererseits traf er auf Mitarbeiter in den königlichen Sammlungen, mit denen er sich arrangieren musste. Wie der wohlhabende Privatmann mit seinen weitreichenden Ideen und die Bedingtheiten einer öffentlichen Institution aufeinandertrafen, ist Thema der nachfolgenden Kapitel über das Historische Museum und die königliche Gemäldegalerie.

\section{Auftrag, Konzept und Einrichtung}

Quandts erstes großes Projekt war die Neuorganisation der Dresdener Rüstkammer unter Einbezug der ethnologischen Sammlung und der Kunstkammer in den Jahren 1832 bis 1834 im Zwinger (Abb. 75). ${ }^{1}$ Es ist sein frühestes offizielles Engagement für eine öffentliche Sammlungsinstitution, wenn man von sei-

1 Minning 2012, S. 153-165; Rüfenacht 2010, S. 110-119. Zur Geschichte der Rüstkammer aktuell Klatte 2017, S. 91-100.

2 Zum Museum als öffentliche Institution Savoy 2006, S. 9-26; Waidacher 1993, S. 73-75, 91, 283-288.

3 Über den Auftrag berichtet Quandt an Schnorr im Brief vom 1.1.1833, in: SLUB, Mscr. Dresd. n Inv. 15, Bd. 31, fol. 183v. S. a. Heres 2005/o6, S. 721; Neidhardt 2005 (1), S. 81; Titz-Matuszak 2000, Bd. 1, S. 120; Heres 1987, S. 45; Friesen 1880, S. 316, 320-321.

4 Magirius 1989, S. 54; Ermisch 1900, S. 11; Klemm 1835, S. VIII. Zum Mietverhältnis siehe den Brief Lindenaus an Quandt vom 13.5.1833, ThSA, FaL, Nr. 13, fol. 48r: »Ew. Hochwohlgebohren werden bereits davon unterrichtet seÿn, daß meine sehr bergab gegangene Gesundheit, mich in die traurige Nothwendigkeit versetzt hat, meine Entlaßung aus königl. Sächs. Diensten erbitten zu müßen; damit findet sich denn auch leider unser Miethverhaeltnis beendiget und ich habe bei deßen Schlus, meinen allerverbindlichsten Dank für die ausgezeichnete Güte und nen Aktivitäten als privater Kunstkenner und Artikeln über die Zustände der königlichen Gemäldegalerie absieht, die bereits in die Jahre vor seinem Umzug nach Dresden zurückreichen und von denen im nachfolgenden Kapitel zu berichten sein wird. Mit der Konzeptualisierung der neuen Ausstellung im Zwinger erhielt Quandt die Möglichkeit, Theorie und Praxis im Rahmen einer öffentlichen Institution zusammenzubringen, wie er es bis dahin nur in Kunstzeitschriften und Buchpublikationen formuliert und in seiner Privatsammlung umgesetzt hatte. ${ }^{2}$

Den Auftrag für die umfassende Reorganisation und die hieraus erfolgte Neueinrichtung der Rüstkammer erhielt Quandt vom Staatsminister Bernhard August von Lindenau im Jahr 1832. ${ }^{3}$ Eine wichtige Rolle spielte hierbei wohl auch Quandts erfolgreiche Tätigkeit als Leiter der zweiten Sektion für Malerei und Plastik im Sächsischen Altertumsverein. In die gleiche Zeit fiel die Restaurierung des Zwickauer Wolgemut-Altars, die Quandt mit viel Verve initiiert hatte. Zudem war er Gründungsmitglied dieses Vereins, der sich die Erhaltung sächsischer Altertümer zum Ziel gesetzt hatte. Die Rüstkammer konnte in gewissem Sinn zu diesen Landeskulturgütern gezählt werden. Lindenau, der zu dieser Zeit in Quandts Haus wohnte, war zudem seit 1830 Mitglied des engeren Ausschusses im Altertumsverein. ${ }^{4}$ Seit dem 4. Januar 1830 hatte der Minister die Aufsicht über die königlichen Sammlungen und Kunstakademien in Dresden und Leipzig von Detlev Graf von Einsiedel übernommen, der wegen seiner restaurativen Haltung gegenüber den Staatsreformen freigestellt worden war. ${ }^{5}$ In dieser Funktion

Wohlwollen zu sagen, die ich in den vergangenen drei Jahren, bei jeder Veranlaßung und bei jedem Wunsch, in Ihnen fand. "Der Rücktritt Lindenaus als Minister fand doch nicht statt. Ob auch das Mietverhältnis weitergeführt wurde, konnte nicht eruiert werden.

5 Einsiedels Gesuch um Entbindung vom Amt wurde von König Anton am 12.11.1829 gutgeheißen. Er wurde angewiesen, Lindenau in das Amt einzuführen. Am 29.12. erfuhren die Leiter der Sammlungen, dass Lindenau am 4.1.1830 die Aufsicht übernehme und wurden für ein Treffen mit diesem im Konferenzzimmer des Geheimen Kabinetts eingeladen; HStADD, 11125 Ministerium des Kultus und öffentlichen Unterrichts, Nachtrag, $\mathrm{N}$ 40, Acta die Oberaufsicht über die wissenschaftlichen u. Kunst Sammlungen betreffend. 1829-1933, fol. 1r-6v. S. a. die Abschrift des königlichen Befehls zur Einsetzung Lindenaus in: HStADD, 10025 Geheimes Konsilium, Loc. 4742, Die Oberaufsicht über die Kunst- und wissenschaftlichen Sammlungen betr. 1829, fol. 1-2. S. a. Bloh 2005, S. 61-62; Titz-Matuszak 2000, S. 101-119, 121; Heres 1988, p. 66-69; Heres 1987, S. 43. 
begann Lindenau die Sammlungen in verwaltungstechnischer und wissenschaftlicher Hinsicht umfassend zu reformieren. Er überzeugte König Anton und den Mitregenten Prinz Friedrich August davon, der Residenzstadt Dresden den Erhalt der königlichen Sammlungen in einem Hausfideikommiss zu garantieren, was 1831 durch einen Verfassungseintrag geschah. Zudem ordnete er die Herstellung neuer Inventare an. ${ }^{6} \mathrm{Ab} 1830$ verlangte Lindenau von den Kommissaren Jahresberichte über die Tätigkeiten in den einzelnen Sammlungen, die nach bestimmten Kriterien verfasst werden mussten. ${ }^{7} 1831$ setzte er bessere Öffnungszeiten durch, die ein breiteres Publikum zuließen, förderte und forderte die Nutzung der Museen durch Schüler der Kunstakademie, der medizinisch-chirurgischen Akademie und der 1828 gegründeten technischen Bildungsanstalt. ${ }^{8}$

Die Rüstkammer, die in einem Nachbargebäude des Stallhofs ungenügend untergebracht war, sollte im Rahmen der Reformen in den königlichen Sammlungen bessere Räumlichkeiten erhalten. ${ }^{9}$ Lindenau ließ den Sekretär und späteren Inspektor der Rüstkammer, Johann Gottlieb Brietze, am 10. Mai 1831 über die weiteren Pläne des Ministeriums mit der Rüstkammer in Kenntnis setzen: »Se. Königliche Majestät und Se. Königl. Hoheit wünschen, daß die Mengs'schen Gyps-Abgüße und die in der Rüstkammer aufbewahrten Gegenstände eine veränderte und solche Aufstellung erhalten mögen, welche der Schönheit und Eigenthümlichkeit dieser Sammlungen an-

6 Siehe die Inventare des Historischen Museums 1836-1838, HStADD, 13458 SKD, RK, Lieber-Nr.77-88, 90, 92-93. - Nach den alten fideikommissarischen Bestimmungen von 1737/47 hätten die königlichen Sammlungen bei fehlender männlicher Nachfolge im Haus Wettin verkauft und damit verloren gehen können; Heres 2004, S. 48-49; Bäumel 2004, S. 18; Titz-Matuszak 2000, S. 121-125; Vötsch 2000, S. 181-185.

7 Abschrift eines Zirkulars Lindenaus an die Vorsteher der Königlichen Sammlungen vom 4.2.1830, in: HStADD, 13458 SKD, RK, Nr. 6, fol. 14r-15V. Drei inhaltliche Kriterien waren zu berücksichtigen: 1. Bericht über die Zugänge von Objekten und deren Nachtrag in den Inventarien sowie Rechenschaft über allfällig herzustellende neue Sammlungskataloge. 2. Angaben zur Benutzung der neuerdings öffentlichen Sammlungen unter besonderer Berücksichtigung der Schüler der Kunstakademie und der technischen Bildungsanstalt. 3. Vorschläge zur »Bereicherung « der Ausstellungen anhand Restaurierungen oder Erwerbungen durch Verkauf von Doubletten oder Umtausch. Entwürfe der handschriftlichen Jahresberichte ab 1830 (für das Jahr 1829) bis 1838, ebd., Nr. 6, fol. 16-20, 42-47, 75-80 und Nr. 35, fol. 25-30, 42-44, 50-57, 59.

8 Abschrift des Zirkulars Lindenaus vom 2.4.1831 über Öffnungszeiten, Beschränkungen und Eintrittskosten in den königlichen Sammlungen in: HStADD, 13458 SKD, RK, Nr. 6, fol. 50-53. Dresdener Anzeiger 29.4.1831, Nr. 119. Zu den verbesserten Öffnungszeiten und freien Zutritte siehe Lindau 1829, S. 166 (noch kein freier Eintritt); ebd., 4. erw. Aufl., 1835, S. 258 (freier Eintritt montags und donnerstags vormittags); ebd., 6. erw. Aufl., 1845 (freier Eintritt donnerstags unter Beschränkung auf 36 Personen in ger-Gruppen). Die Angestellten der Rüstkammer verlangten umgehend bessere Besoldung aufgrund der Zusatzarbeiten wegen der neuen Öffnungszeiten: Briefe und Briefentwürfe von Brietze und Lindenau, in: HStADD, 13458 SKD, RK, Nr. 6, fol. 53V-55r, 57r-6or, April bis Juli 1831. Siehe hierzu auch Savoy 2006, S. 11-12, 20-22. gemeßener und den Anforderungen der Künstler und Liebhaber mehr als die gegenwärtige zu entsprechen vermag. $\ll^{10}$ Diese erste Planung sah vor, die Abgusssammlung in die ehemalige Brühl'sche Gemäldegalerie, die zu diesem Zeitpunkt als Ausstellungsgebäude von der Kunstakademie benutzt wurde, zu verlegen. Gleichzeitig sollte die Rüstkammer in die Räumlichkeiten der Abgusssammlung im Erdgeschoss des Stallhofes disloziert werden. Die Organisation des Umzugs wurde Quandt, dem Leiter der Abgusssammlung Carl August Böttiger, dem Direktoren der Antiken- und Münzsammlung Hofrat Heinrich Hase, dem Oberinspektor des Mathematisch-Physikalischen Salons und Vorstehers der Technischen Bildungsanstalt Wilhelm Gotthelf Lohrmann und dem Akademie-Professor für Baukunst Joseph Thürmer übertragen."

Nachdem dieses Konzept von Böttiger und dem Generaldirektoren der Kunstakademie Heinrich Graf Vitzthum von Eckstätt erfolgreich bekämpft und auch der noch in Betracht gezogene Umzug ins Zeughaus, dem heutigen Museum Albertinum, verworfen worden war, zeichnete sich eine Lösung in der Kunstkammer ab..$^{12} 1831$ wurde der Kunstkämmerer Rudolph Sigismund Blochmann beauftragt, die Bestände zu revidieren. ${ }^{13}$ Sein zusammen mit Oberkämmereisekretär Friedrich Nollain eingereichter Bericht mit Hinweisen zu einer verbesserten Erhaltung und Aufstellung der Kunstkammersammlung überschnitt sich mit einem Gutachten Quandts. Dieser

9 Beschwerden über die Zustände in den Jahresberichten für das Jahr 1829-31, in: HStADD, 13458 SKD, RK, Nr. 6, fol. 16v-17r, 42v-43r, 77r. Im Jahresbericht für das Jahr 1830 wird ein Neubau am noch unbebauten Standort der heutigen Sempergalerie gefordert. Lindenaus negative Antwort vom 22.3.1831, in: ebd., fol. 49r. S. a. Klatte 2017, S. 97; Heres 2006, S. 94-97; Friesen 1880, S. 321.

10 HStADD, 13458 SKD, RK, Nr. 6, fol. 56

11 Ebd.; s. a. Heres 1987, S. 45; Winzeler 2007, S. 192-193.

12 Quandt, Thürmer und Nollain setzten sich für die Aufstellung im Zwinger ein. Siehe HStADD, Akten der Generaldirektion der Königlichen Sammlungen, Cap. XV. Nr. 26a, D. Registranda die wißenschaftlichen u. Kunstsammlungen betr. aufs Jahr 1832 (Kriegsverlust), fol. 58. Abschrift in: HStADD, 13458 SKD, NL Posse, Nr. 29, Lage 3, fol. 12v. Das Konzept eines Umzugs der Rüstkammer in das Zeughaus bei gleichzeitiger Umnutzung der alten Rüstkammerräume durch die technische Bildungsanstalt wird in einem Briefentwurf Brietzes an Lindenau vom 13.2.1832 fassbar. Darin äußerte der Inspektor Vorbehalte gegenüber dem Zeughaus. Im Kriegsfall würden Zeughäuser als erste angegriffen und besetzt. Zudem gab er zu bedenken, dass Künstler und Liebhaber die kunstvolle Rüstkammer im militärischen Zeughaus vergessen könnten. HStADD, 13458 SKD, RK, Nr. 6, fol. 83-85. Quandt freute sich noch Mitte März 1832 über den Umzug der Rüstkammer ins Zeughaus. Siehe den Brief an Johann Georg Keil vom 19.3.1832, in: SLUB, Mscr. Dresd., App. 393, Nr. 2h. Einen Monat später erfolgte das Dekret zur Auflösung der Kunstkammer. Damit war das Zeughaus als Ausstellungsort bis zu dessen Aufhebung 1877 und Nutzung als Museum Albertinum ab 1891 aus dem Rennen gefallen. Siehe hierzu Heres 2004, S. 58-59.

13 Nagel 2012, S. 377 
war selbst von Lindenau beauftragt worden, die Kunstkammer zu begutachten. Sein Urteil war eher negativ. Quandt betrachtete die Kunstkammer nicht als historisch überliefertes Sammlungskonglomerat, aus deren Kernbeständen die königlichen Sammlungen entstanden waren, sondern beurteilte sie als ein Depot der anderen Sammlungen in schlechtem konservatorischem Zustand. Die Bestände seien sehr divergent und eine wissenschaftliche Beschreibung nicht möglich. Daher seien die Auflösung und die Verteilung aller Objekte auf die verschiedenen Sammlungen anzustreben. ${ }^{14}$ Aufgrund seines Gutachtens wurde sie im April 1832 per Dekret aufgelöst, die meisten Gegenstände auf Grünes Gewölbe, Kupferstichkabinett, Gemäldegalerie, Porzellansammlung und Rüstkammer verteilt und einige Stücke verkauft. ${ }^{15}$

Quandts Name wird in der Forschung oft mit der bedauerlichen Versteigerung einiger Kunstkammer-Objekte in Verbindung gebracht. Die bekannten Quellen und zeitgenössischen Berichte lassen diesen Schluss nicht zu. Im Gegenteil hatte der Kunstfreund sich in seinem Gutachten dafür eingesetzt, dass die mittelalterlichen Gegenstände und Tafelbilder der Kunstkammer in die Sammlung der Rüstkammer überführt würden, um dadurch den Überblick über die sächsische Geschichte zu vervollständigen. Einige der 1833 zum Verkauf freigegebenen Bildnisse sächsischer Kurfürsten finden sich denn auch dort wieder. ${ }^{16}$ Sein Hauptanliegen war es denn auch, die beiden Sammlungen sinnvoll miteinander zu verbinden. So berichtete

14 Rescript vom 6.4.1832, in: HStADD, Akten der Generaldirektion der Königlichen Sammlungen, Cap. X.23 Acta die königl. Kunstkammer betr. 1830, fol. 71 sowie Cap. XV. Nr. 26a, D. Registranda die wißenschaftlichen $\mathrm{u}$. Kunstsammlungen betr. aufs Jahr 1832 (beides Kriegsverlust), fol. 49. Teilweise Abschriften in: HStADD, 13458 SKD, NL Posse, Nr. 27, Lage 5.2, fol. 3r-v sowie Nr. 29, Lage 3, fol. 12V: „Vortrag des Herrn von Quandt über die Kunstkammer nach Anleitung der über die Revision dieser Sammlung von dem Oberkämmerei-Sekretair Nollain vorgelegten Protocolle und anderen Litteralien, mit dem Erachten, daß eine wissenschaftliche Beschreibung der fraglichen Sammlung wegen ihres gemischten Bestandes nicht ausführbar, daß solche von jeher als ein Depot für die anderen Cabinetten betrachtet worden sey und nunmehr, da vieles zu Grunde gegangen und zerstückelt, wohl aufzulösen und zum Theil mit der Rüstkammer zum Theil mit den übrigen Galerien zu vereinigen sein möchte.« S. a. Minning 2012, S. 165.

15 HStADD, Akten der Generaldirektion der Königlichen Sammlungen, Cap. X.23 Acta die königl. Kunstkammer betr. 1830, fol. 71. Rescript vom 29.5.1832, in: Cap. XV. Nr. 26a, D. Registranda die wißenschaftlichen u. Kunstsammlungen betr. aufs Jahr 1832 (beides Kriegsverlust), fol. 126. Teilweise Abschriften in: HStADD, 13458 SKD, NL Posse, Nr. 27, Lage 5.2, fol. 3r-v sowie Nr. 29, Lage 3, fol. 13r: »Der Herr von Quandt überreicht die von ihm erforderten Vorschläge über die Vertheilung der Gegenstände aus der Kunstkammer an die übrigen kgl. Sammlungen und fügt spezielle Verzeichniße darüber bei, unter Wiederholung des Antrags, daß die lange Gallerie im Zwinger, wo dermalen sich die Vögel befinden, ebenfalls mit den zu Aufstellung der Rüstkammer bestimmten Räumen zu vereinigen sein möchte.« - Zur Auflösung der Kunstkammer siehe Minning 2012, S. 153-165, Klatte 2017, S. 97; Berge 1933, S. 2-3. Berge scheint Quandts Gutachten noch gekannt zu ha- er in einem Brief an Julius Schnorr von Carolsfeld, er habe »die alte Rüstkammer u Kunstkammer mit einander verschmolzen $[. ..] \cdot \ll^{17}$

In den Verkäufen lag wohl eine staatspolitische Komponente, gewissermaßen eine Konzession an die Stände im Landtag für die umfassenden und kostspieligen Maßnahmen zur Reorganisation der königlichen Sammlungen generell, die Lindenau angestoßen hatte. So hatte der Minister in seinen Kriterien, über welche die Inspektoren der Sammlungen ab 1830 jährlich zu berichten hatten, bereits grundsätzlich verlangt, zur »Bereicherung« der Ausstellungen nebst Restaurierungen und Erwerbungen auch Verkäufe oder Umtausch in Betracht zu ziehen - eine Sammlungsbereinigung war also von oben her gewollt, auch durch Deakquisition. ${ }^{18}$ Quandt deutete diesen politischen Aspekt im Zusammenhang mit seiner Arbeit in der Galeriekommission an: »Die Stände laßen sich weit eher zur Unterstützung einer Actiengesellschaft geneigt finden, als zur Rettung eines Kunstschatzes, der als ein todtes Capital betrachtet wird. $\ll^{19}$ Und Wilhelm von Kügelgen schrieb die erfolgten Verkäufe der Kunstkammerobjekte finanziellen Engpässen zu, welche den Umzug gefährdet hätten: Man [...] stellte diese Waffen, etwa ein Drittel davon veräußernd, um die Kosten des Umzugs zu bestreiten, in den hohen, hellen Korridoren des Zwingers auf. $\ll^{20}$

Mit der Räumung der Kunstkammer und ihrer Aufteilung auf die verschiedenen Sammlungen wurden Räumlichkeiten in

ben. S. a. den Brief von Quandt an Schnorr vom 1.1.1833, in: SLUB, Mscr. Dresd. n Inv. 15, Bd. 31, fol. 183v. S. a. Schäfer 1860, S. 34; Nagel 2012,

S. 377. Der Bericht des Kunstkämmerers Blochmann war wohl zu spät eingegangen.

16 Brief von Quandt an Schnorr vom 1.1.1833, in: SLUB, Mscr. Dresd. n Inv. 15, Bd. 31, fol. 183v. S. a. den Brief von Quandt an Johann Georg Keil vom 19.3.1832, in: SLUB, Mscr. Dresd., App. 393, Nr. 2 h.

17 Vgl. Cap. X.a.52, Verzeichniß derjenigen unansehnlichen und unbrauchbaren Gegenstände der Kunstkammer, welche zur Vertheilung an die übrigen Gallerien sich nicht eigneten, und zu verkaufen seyn möchten, 1833 (Kriegsverlust). Teilweise Abschrift in: HStADD, 13458 SKD, NL Posse, Nr. 27, Lage 6, S. 1-4. Nachweislich nicht verkauft und in das historische Museum eingegliedert wurde ein Bildnis von Kurfürst August eines Malers Ciriacus von 1586 (Nr. 80 in der Verkaufsliste), ein gleiches von unbekannter Hand von 1561 (Nr. 81) und drei Bildnisse der Gemahlin und Kinder Annas (Nr. 82-85). Sie werden in Quandt 1834 (1), S. 42-44 erwähnt und als historisch wichtige Gemälde erkannt, was dagegenspricht, dass Quandt die Verkäufe selber vorgeschlagen hat.

18 Abschrift eines Zirkulars Lindenaus an die Vorsteher der Königlichen Sammlungen vom 4.2.1830, in: HStADD, 13458 SKD, RK, Nr. 6, fol. 14 r15V. Paraphrase der Kriterien oben Anm.7.

19 Brief an Unbekannt, [1837], in: ThSA, FaL, Nr. 15, fol. 9v. S. a. Bloh 2005, S. 62; Heres 2004, S. 49-50; Titz-Matuszak 2000, S. 119-121; Heres 1987, S. 44-46; Friesen 1880, S. 321.

20 Kügelgen 1959 [1870], S. 126; Friesen 1880, S. 321. S. a. Lindenau an das Ministerium des Königlichen Hauses vom 25.1.1833, in: HStADD, 10711 Ministerium des Kgl. Hauses, Loc. 19, Nr. 1, fol. 59r-6or. Für diesen Hinweis danke ich Christine Nagel. 

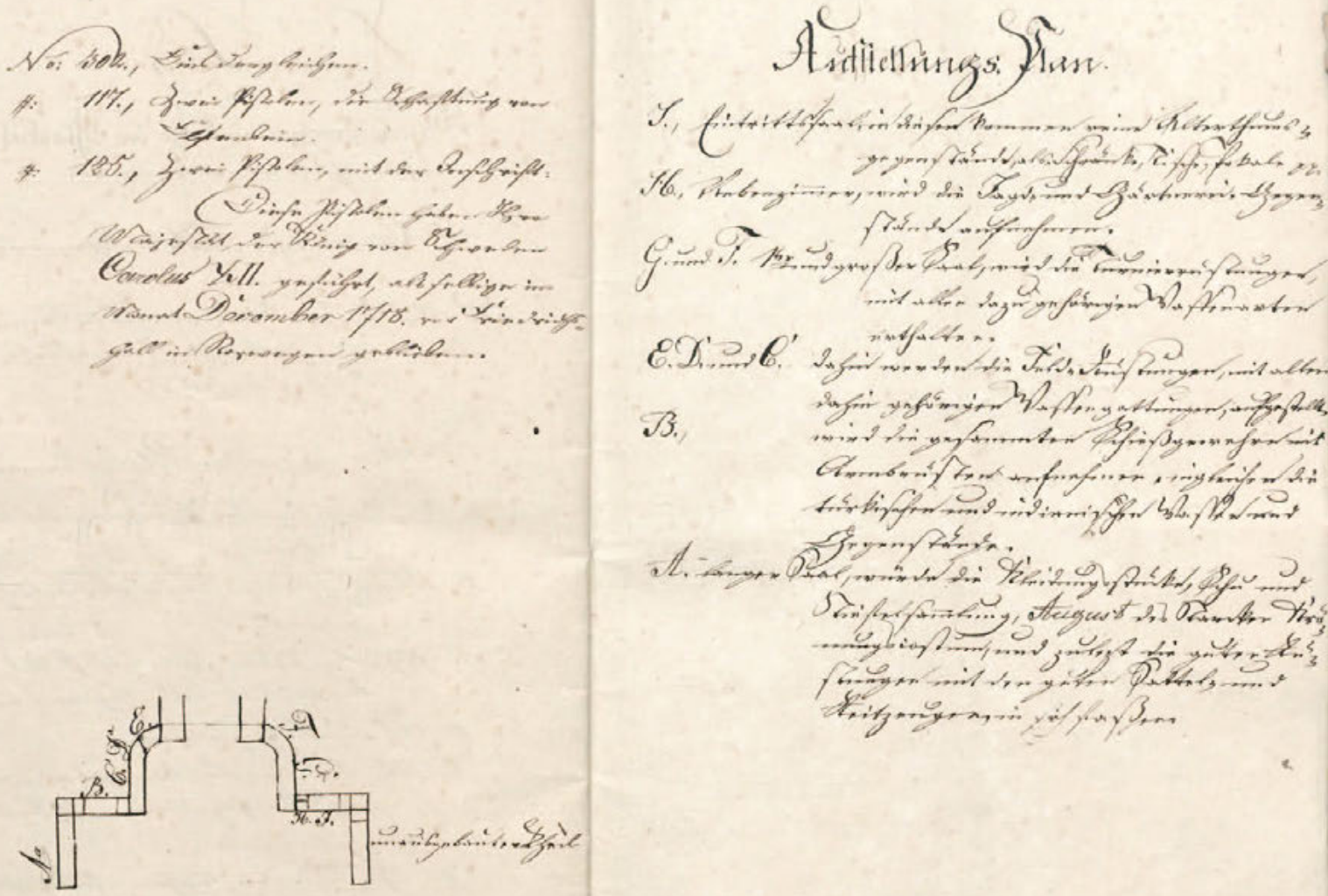

76 Johann Gottlob von Quandt und Johann Gottlieb Brietze, Ausstellungs. Plan, in: HStA, 13458 SKD, RK, Nr. 46, fol. 12V-13r

den nördlichen Galerien und Pavillons des Zwingers frei, in die nun die Rüstkammer ziehen sollte (Abb. 75). Am 30. April 1832 wurde Inspektor Brietze von Lindenau in Kenntnis gesetzt: $\gg$ Se. Königl: Majestät und des Prinzen Mitregenten Königl: Hoheit haben für gut befunden, die Verlegung der Rüstkammer in den an der Wallseite gelegenen Theil der Zwingergebäude unter Vereinigung mit einem Theile der jetzt in der Kunstkammer aufbewahrten Gegenstände, anzuordnen und mit der Leitung der deshalb erforderlichen Arbeiten den von Quandt, den Profeßor Thürmer und den Ober Kämmerei Secretair Nollain zu
beauftragen.«Brietze sollte die notwendigen Vorkehrungen für den Umzug aufgrund der Vorgaben des Komitees treffen. ${ }^{21}$

In einem Dokument im Archiv der Dresdener Rüstkammer konnte das Konzept von Quandt für die neu einzurichtenden Räume wiedererkannt werden. Das Schriftstück beschreibt in den Grundzügen die Aufstellung der Objekte in den Räumen, wie sie schließlich in seinem Führer Andeutungen für Beschauer des historischen Museums von 1834 erläutert ist und wie sie in den Inventaren nachvollzogen werden kann. ${ }^{22}$ Quandt sandte seinen Vorschlag im August 1832 an Staatsmi-
21 HStADD, 13458 SKD, RK, Nr. 6, fol. 97r. Am 24.6.1832 wurde Brietze angeordnet, die Gegenstände der aufgelösten Kunstkammer der Neuaufstellung sofort »einzuverleiben«. Brief Lindenaus, in: ebd., fol. 99 r. S. a. ebd., fol. 4r-5v. Die Einrichtung des neuen Museums war zu diesem Zeitpunkt noch kaum vorangeschritten; siehe Brietzes Brief vom 28.7.1832, in: HStADD, 13458 SKD, RK, Nr. 6, fol. 10or-101r. Klemm 1838, S. 288 .

22 Das Konzept in: HStADD, 13458 SKD, RK, Nr. 46, fol. 1-13. Das Schrift- bild zeigt nicht die Handschrift Quandts, sondern eher diejenige eines Kanzleischreibers. Eine Bleistiftnotiz schreibt es Brietze zu, was unwahrscheinlich ist. Das Dokument entspricht inhaltlich und sprachlich eindeutig Quandts Argumentation. Dass das Konzept aus Quandts Feder stammt, lässt sich mit einem Brief von Quandt an Schnorr vom 1.1.1833 beweisen, in dem er den Ablauf der Ausstellung zusammenfasst. Er entspricht exakt demjenigen des Konzepts. SLUB, Mscr. Dresd. n Inv. 15, Bd. 31, fol. 183v. S. a. Quandt 1834 (1), S. X, XII-XIII, XVI. 
nister Lindenau. ${ }^{23}$ Inhaltlich beschrieb das Konzept nur allgemeine Schwerpunkte und Themenfelder der geplanten Neuaufstellung: »Bei der großen Menge von Gegenständen dürfte es kaum möglich sein, einen ins Einzelne gehenden Plan zur Aufstellung eines geschichtlichen Museums zu entwerfen und uns reichen hier nur die Hauptabtheilungen anzugeben [...]. $\ll^{24}$ Die Grundzüge des Aufstellungsplanes notierte er in einen kleinen Situationsplan, den er mit Buchstaben und einer Legende versah (Abb. 76). Im Eingangssaal des Französischen Pavillons (J) sollten Hausratsgegenstände angeordnet werden. Diesem folgte ein Durchgangszimmer $(\mathrm{H})$ mit Garten- und Jagdgerät, woran in der Bogengalerie $(\mathrm{G}, \mathrm{F})$ die Abteilung für Turnierwesen anschließen würde. Darauf sollte man unter dem Wallpavillon hindurch in die gegenüberliegende Bogengalerie (E, D, C) eintreten, wo die Gerätschaften des Kriegswesens präsentiert würden. Zu dieser Abteilung zählte er auch die Gewehre, die im Parterre des heutigen Mathematisch-Physikalischen Salons (B) aufgestellt werden sollten. Darauf würden die Besucher über eine Kleiderkammer in die Langgalerie (A) treten, die bis hin zum Kronentor mit Prunkgerät angefüllt wäre. ${ }^{25}$ Für speziell wertvolle Objekte sah Quandt Glaskästen vor, die an den Fenstern zu platzieren wären, um die »ausgezeichnetsten Gegenstände $[\ldots]$ genau betrachten [zu können], ohne daß sie mit Händen begriffen würden. $\ll^{26}$

Zur Beaufsichtigung von Planung und Durchführung von Umzug und Einrichtung seines Ausstellungskonzepts war Quandt von Montag bis Mittwoch über die Mittagsstunden im Zwinger anwesend. Mit Inspektor Brietze stand ihm ein umtriebiger Mitarbeiter zur Seite, der die Arbeiten organisierte und umsetzte. Aufgrund der historisch-wissenschaftlichen Anforderungen der neuen Sammlungspräsentation wollte und konnte Brietze nicht die grob nach Gattungen geordneten Kammern eine nach der anderen aufheben und die Objekte zwischen-

23 Rescript vom 6.8.1832, in: HStADD, Akten der Generaldirektion der Königlichen Sammlungen, Cap. XV. Nr. 26a, D. Registranda die wißenschaftlichen u. Kunstsammlungen betr. aufs Jahr 1832 (Kriegsverlust), fol. 139. Abschrift in: HStADD, 13458 SKD, NL Posse, Nr. 29, Lage 3, fol. 13: »Der Herr von Quandt reicht einen Plan zu Aufstellung der Rüstkammer als ein Historisches Museum ein und beschreibt die Anordnung des Ganzen, wie aus der älteren in die neuere Zeit übergehend die Sachen in systematischer Reihenfolge unterzubringen sein möchten[...].."

24 Zitat in: HStADD, 13458 SKD, RK, Nr. 46, fol. 6v. Über seine Anwesenheit im Zwinger äußert sich Quandt in einem undatierten Brief an Böttiger von ca. 1833, in: Nürnberg, Historisches Archiv des Germanischen Nationalmuseums, Autographen Böttiger K. 21.

25 HStADD, 13458 SKD, RK, Nr. 46, fol. 2-7. Die den Sälen zugeordneten Buchstaben geben die Raumsituation der Kunstkammer wieder. Dies wird dort deutlich, wo Quandt die Entfernung von Scheidewänden fordert; Frenzel 1850, S. 2; Lindau 1845, S. 216.

26 HStADD, 13458 SKD, RK, Nr. 46, fol. 4r. Im Anschluss an das Konzept folgen zwei Beilagen mit allen Objekten, die für die Aufbewahrung in Glaskästen vorgesehen waren; ebd., fol. gr-12v. In den Andeutungen beschreibt Quandt die Objekte in den Glaskästen im Nachtrag; lagern, bis die definitive Aufstellung geklärt sein würde. Dies führte dazu, dass er bei den Umzugsarbeiten unter erheblichem Druck stand, weil die Direktion des Hoftheaters Teile der alten Räumlichkeiten der Rüstkammer beanspruchte. ${ }^{27}$ Sein Problem beschrieb er in einem Brief an die Kommission vom 28. Juli 1832: »Die bezweckt werdende beßere und systematischere Aufstellung dieser kostbaren und vielfältigen Sammlung erfordert dort [im Zwinger - AR $]$ demnach eine Zusammenstellung der Gegenstände nach ihren Geschlechtern, geschichtlichen, chronologischen und auch Kunstwerth. Diese Zusammenstellung aber kann, bei der großen Anzahl der Gegenstände und der großen Zerstreuung derselben in den vielen Zimmern [im alten Gebäude - AR], wenn schon[,] der genres nach vorher auf dem Papiere vorbereitet, doch den wißenschaftlichen Grundsätzen nach, erst bei der neuen Aufstellung bewerkstelliget werden. Aus diesem Grunde nun kann die Erneuerung des gegenwärtigen Locals nicht anders, als dem System der neuen Aufstellung gemäß geschehen.« Brietze verlangte also ein systematisches Vorgehen, um ein übereiltes und Verwirrung stiftendes Umräumen zu vermeiden. Er wollte den Umzug zudem auf nicht mehr als eine Genregruppe auf einmal beschränken und »nur soviel Stücke [bewegen], die in zwei Tagen aufgestellt und aufgehängt werden können, um möglichst Beschädigungen zu vermeiden. $\ll^{28}$ Die Kommission um Quandt reagierte umgehend und trug der Generaldirektion die Probleme und Vorschläge Brietzes vor. ${ }^{29}$

Brietze entpuppte sich während des Umzugs als ausgesprochen engagierter Konservator. So erklärte er dem Ministerium, dass zwar die augenfälligsten Reparaturen nach dem Transport der Objekte vorgenommen worden seien, dass aber noch zahlreiche weitere anfallen würden wie die Instandsetzung des Riemenzeugs der Harnische, der Postamente für die Rüstungen, der hölzernen Pferde sowie diverse Reinigungsarbeiten. Dazu

Quandt 1834 (1), S. 188-196.

27 Siehe dazu die 1821 revidierten Inventare der verschiedenen Kammern (Auswahl), in: HStADD, 13458 SKD, RK, Lieber-Nr. 138 (altdeutsche Gewehrkammer), 156 (Jägerkammer), 177 (Pistolenkammer), 220 (Sattelkammer), 248 (Türkenkammer), 259 (Kleiderkammer). S. a. Heres 2004, S. 96: Die Rüstkammer war nicht museal geordnet und hatte den Charakter eines »Magazins «.

28 Beide Zitate aus Brietzes Briefentwurf, in: HStADD, 13458 SKD, RK, Nr. 6, fol. 100r-101r.

29 Rescript vom 2.8.1832, in: HStADD, Akten der Generaldirektion der Königlichen Sammlungen, Cap. XV. Nr. 26a, D. Registranda die wißenschaftlichen u. Kunstsammlungen betr. aufs Jahr 1832 (Kriegsverlust), fol. 142. Abschrift in: HStADD, 13458 SKD, NL Posse, Nr. 29, Lage 3, fol. 13v: »Anzeige des Herrn v. Quandt, Prof. Thürmer und Secr. Nollain, daß die für die Hoftheater-Expedition gewünschte Abtheilung des Rüstkammergebäudes bis zum Michaelistermin a.c. nicht geräumt werden könne, indem das neue Local noch nicht fertig sey und die Tausende von Gegenständen nur nach und nach und nicht zimmerweise translocirt werden können.« Zu den Umzugsvorgängen s. a. Minning 2012, S. 160. 
forderte er eine gesonderte Finanzierung. ${ }^{30}$ Wohl im Auftrag Quandts, der dies schon im Konzept gefordert hatte, schlug Brietze dem Ministerium im März 1833 vor, alte Waffen aus dem Zeughaus in das neue Museum zu überführen. Dort seien sie nämlich dem Publikum verborgen, während sie im neuen Kontext in ihren historischen Zusammenhang gebracht werden könnten. ${ }^{31}$

Im Oktober 1833 waren die Umzugsarbeiten weitgehend abgeschlossen. Lindenau schrieb Brietze vor, seine Helfer umgehend zu entlassen, wogegen er sich in einem Brief wehrte. Er teilte Lindenau mit, er wolle vier von fünf Mann bis zur endgültigen Beendigung der Einrichtung des letzten Saales (A) behalten, um nicht rostige Degen aufstellen zu müssen. Dies würde nämlich »in auffallender Disharmonie zu dem schönen Saale selbst, so wie zum Ganzen stehen $[. ..] \times \ll^{2}$ Definitiv fertig gestellt waren die Arbeiten im Januar 1834 und im März wurden sie auch von Quandt persönlich als beendet erklärt.33

\section{Ein moralisch-didaktischer Rundgang zur Förderung der Vaterlandsliebe}

Mit dem Ende der Einrichtung und der Eröffnung des neuen Museums erschien Quandts Führer mit dem Titel Andeutungen für Beschauer des historischen Museums. Es war der erste gedruckte Katalog, den die neue Rüstkammer erhielt, wenn er auch nur eine Auswahl der ausgestellten Gegenstände beschrieb (Abb. 77). ${ }^{34}$

Der umstrittene Name Historisches Museum entsprang Quandts Geschichtsverständnis und seiner Vorstellung von Objektpräsentation. ${ }^{35}$ Er glaubte erkannt zu haben, dass sich das Kunstverständnis der Gesellschaft verändert hatte. In der

30 Briefentwurf vom 6.3.1833, in: ebd., fol. 114-116. S. a. HStADD, 10711 Ministerium des Kgl. Hauses, Loc. 19, Nr. 1, fol. 17r-32r. Zusammenstellung Brietzes über im 18. Jh. veräußerte Waffen, aus deren Erträgen die entsprechenden Sammlungen hätten finanziert werden sollen. Dieses Geld forderte Brietze ein, nachdem es die Rüstkammer nie erhalten hatte. Für diesen Hinweis bedanke ich mich bei Christine Nagel.

31 Briefentwurf vom 15.3.1833, in: HStADD, 13458 SKD, RK, Nr. 6, fol. 117v$118 v$. Zudem schlägt er vor, den Harnisch Kurfürst Moritz' im Dom zu Freiberg nach Dresden zu überführen, was nicht geschah. S. a. Quandt, in: HStADD, 13458 SKD, RK, Nr. 46, fol. 5V-6r: »Eine Vervollständigung dieser Abtheilung durch größere Schießgewehre [...] wäre sehr wünschenswerth und ohne Zweifel finden sich dergleichen noch im Zeughause, welche nicht dahin, sondern in eine Waffensammlung gehören.« Zur Musealisierung von Zeughäusern und Waffensammlungen Neumann 1991/92, S. 159-179.

32 Briefentwurf vom 7.10.1833, in: HStADD, 13458 SKD, RK, 6, fol. 129 r.

33 Briefentwürfe Brietzes vom 22.1. und 2.4.1834, in: ebd., fol. 132r, 138r139v. Brietze übersandte Lindenau gemäß diesen Briefen eine Liste nicht verwendeter Gegenstände und ordnete diese nach ihrem artistischen und materiellen Wert ein. Um sie vor einem Verkauf zu schützen, schlug er vor, sie noch in die Ausstellung einzubinden.
A ndeutungen

fiir

Beschauer

des

\section{historischen Museums}

von

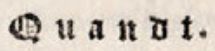

Dresden,

im Verlage der Walther'schen Fofbuchhanding.

1834.

77 Johann Gottlob von Quandt, Andeutungen für Beschauer des historischen Museums, Dresden 1834, Titelblatt

Damit deutet sich an, dass er als Inspektor wohl gelegentlich anderer Meinung war als Quandt und die anderen Kommissare. Siehe hierzu auch den Entwurf zum Jahresbericht auf das Jahr 1833 vom 4.2.1834, in: HStA, 13458 SKD, RK, Nr. 6, fol. 132V-133r: »Was die neue Aufstellung der Sammlung an sich und die Grundsätze nach welchen selbige bewerkstelliget worden, betrift, darüber enthalte glaube ich mich aller Bemerkungen enthalten zu müßen, wohl aber zu der Bitte veranlaßt, keine von darüber etwa zu machenden Ausstellungen mir zur Last zu tegen, da in dem mir dabei angewiesenen Wirkungskreise, ich nur das, zu den von den $\mathrm{H}[$ erren]. Comißarien zu treffenden Dispositionen Nöthige, vorzukehren hatte.« Die Streichungen entsprechen dem Originaldokument.

34 Quandt 1834 (1). Um keinen Katalog mit wissenschaftlichem Anspruch handelt es sich bei Friedrich Martin Reibischs Publikation einer subjektiven Selektion von Rüstkammergegenständen; Reibisch 1825-1827. S. a. Weddigen 2008, 216-219.

35 Möglicherweise handelt es sich um das erste deutsche Museum überhaupt, welches als Historisches Museum bezeichnet wurde. In Quandts Konzept von 1832 ist von einem »geschichtlichen Museum« die Rede, in: HStADD, 13458 SKD, RK, Nr. 46, fol. 1r, 6r. In den Dokumenten der Rüstkammer taucht der Begriff Historisches Museum 
Einleitung zu seinen Andeutungen begründete er damit die Art und Weise der Einrichtung des Historischen Museums. Den Beginn der Veränderung setzte er im Mittelalter an. Damals hätten alle Menschen in der Öffentlichkeit Zugang zu Kunst gehabt. Sie erblickten Kunst in Kirchen, auf öffentlichen Plätzen oder an den Fassaden von Rathäusern. Doch der Reichtum der Fürsten und Wohlhabenden habe die Kunst ihrem öffentlichen Publikum entzogen. Erst im ausgehenden 18. Jahrhundert sei sie durch Philosophen und Dichter wieder ins Zentrum eines allgemeinen Interesses gerückt worden. Damit habe sich ein neues Kunstverständnis entfaltet und ausgebreitet. Das Bedürfnis nach der Sichtbarkeit der Kunst manifestiere sich nun in den Museen. Diese seien »Zufluchtsorte der aus der Welt verstossenen Kunst geworden «. ${ }^{6}$ Um Quandts hier formulierten Entwicklungsgang des Kunstverständnisses im Museum darzustellen, bedurfte es historischer Kontexte. Diese konnten die ausgestellten Objekte vermitteln: »Die Museen mussten daher auch eine andere, der Zeit gemäßere, Gestalt bekommen und man sah sich genöthigt, sie wissenschaftlich zu ordnen und dafür zu sorgen, dass ihre Aufstellung selbst den Kunstsinn befriedige. $\ll^{37}$ Damit suchte er den wissenschaftlichen und ästhetischen Erfordernissen seiner Zeit Rechnung zu tragen. ${ }^{38}$

Die Ausstellung sollte den historischen Verwendungszweck der Objekte durch deren angemessene Präsentation erschließen: »[...] jeder Gegenstand [trägt] auch ohne besondere geschichtliche Merkwürdigkeit doch das Gepräge seiner Bestimmung und Zeit an sich [...] und [bezeichnet] die Gewohnheiten, Neigungen und so auch die Sinnesweise dessen [...], dem er zum Nutzen oder Vergnügen diente. «39 Indem er die Objekte kontextualisierte, historisierte und ästhetisch präsentierte, wollte er den Betrachtern

erstmals im Briefentwurf Brietzes vom 22.1.1834 sowie drei Tage später in einem Brief Lindenaus an Brietze vom 25.1.1834 auf, in: ebd., Nr. 6, fol. 131r-132r. - Quandt empfand den alten Namen Rüstkammer als unpassend. Es sei nur eine Vorratskammer oder eine »GardeMeubles« gewesen. Er verteidigte den neuen Namen des Museums in Quandt 1834 (1), S. VIII, XVII. Die Benennung stieß bei Gelehrten zum Teil auf Unmut, blieb aber mitsamt seiner Kritik bis 1992 erhalten. S. a. Schuckelt 2010, S. 334; Weddigen 2008, S. 218-219; Heres 2005/06,

S. 721-723; Briel 2002, S. 17; Heres 1987, S. 45-46; Koetschau 1905,

S. 92-93; Friesen 1880, S. 321; Frenzel 1850, S. 1.

36 Quandt 1834 (1), S. III-IX, hier S. IX.

37 Ebd., S.X. S. a. Quandt 1841, S. 433.

38 Ein zeitlich und inhaltlich vergleichbares Projekt zeigt sich in der Neueinrichtung der Berliner Kunstkammer durch Franz Kugler, der 1838 eine Begleitpublikation veröffentlichte. Kugler und Quandt waren auf ähnliche Ordnungsprobleme gestoßen. Während Quandt seine Einrichtung einer ästhetischen Kulturgeschichte mit Aufstieg und Niedergang der Schönheit verpflichtete, versuchte Kugler eine kunstwissenschaftliche Ordnung zu schaffen: die synchronistische Anordnung der Stücke stand im Mittelpunkt, indem diese den kunstgeschichtlichen Epochen zugeordnet wurden und nur in den Unterabteilungen nach Genres geordnet waren. Quandt ging in seiner Einteilung von den Genres (häusliches Gerät, Jagdwaffen, Ritter- und Kriegswaffen, vergangene Zeiten nahe bringen. Damit bewirkte er seiner Meinung nach genau das Gegenteil dessen, was er den Kunstliebhabern vorwarf: »[...] eine gewisse sammelnde und untersuchende Kunstalterthums-Liebhaberei, die in den heiligen Gräbern der Vorzeit wühlt, Kunstwerke vom heimischen Boden in Museen unter fremdartige Dinge versetzt, und aus dem bedeutungsvollen Zusammenhange und den passenden Umgebungen herausreißt, zerstörte oftmals jenes schöne Heimathsgefühl, welches der Grundton der Vaterlandsliebe ist, und mit tausend Wurzeln $[\ldots]$ sich an die heimathlichen Alterthümer anklammert. « ${ }^{40}$

Diesen Vorwurf an die Adresse der Kunst- und Raritätensammler hatte Quandt drei Jahre vor den Andeutungen in der programmatischen Schrift Hinweisungen auf Kunstwerke aus der Vorzeit formuliert. Das Sammeln um des Sammelns willen und das kontextlose Präsentieren von Kunstgegenständen widersprachen seiner Vorstellung von Kunst. Das historisch zusammenhangslose Kunstobjekt, wie es besonders in der alten Rüstkammer oder auch der aufgelösten Kunstkammer gezeigt worden war, konnte seine Wirkung nicht entfalten. Es entzog sich dem historischen Entwicklungsprozess, dem es eigentlich eingeschrieben war. Den Entwicklungsgang des Menschengeistes zu erkennen und zu verstehen, erforderte historisches Wissen, wie Quandt in zahlreichen Publikationen immer wieder artikulierte, denn »die Geschichte $[\ldots]$ zeigt sich $[. .$.$] in einem$ Lebensverbande, in einem Pulsiren ohne Stillstand, als ein beseeltes Ganzes, was nach vollem Bewusstseyn und Willen und in Erkenntniß und That sich darzuthun strebt. $\ll^{41}$ Solch lebendige Geschichte und damit auch die historische Dimension von Kunst klang in der Gegenwart nach und nahm so Einfluss auf die Gesellschaft, die eigene Kultur und die Nation.

Prunkgerät) aus, wobei er diese wiederum in einen synchronistischen Entwicklungsgang stellte. Häusliches Gerät, Jagd- und Ritterwaffen sind der ältesten Zeit zugeordnet, Kriegswaffen und Prunkgerät der jüngeren. Quandt führte thematische, Kugler epochale Abteilungen ein, die der Verortung der besichtigten Objekte dienen. Kugler verwies zudem auf die Schwierigkeit der synchronistischen Aufstellung und lieferte aus diesem Grund Tabellen der Objekte nach Genres geordnet mit. Kugler 1838, S. XV-XVI, 303-308. Karl Friedrich Schinkels 1830 eröffnetes neues Königliches Museum (heute Altes Museum) in Berlin und seine Vorstellungen, was ein Museum für die Öffentlichkeit bedeute, sind für das Verständnis von Quandt wichtig. Siehe Elsa van Wezel, Die Konzeptionen des Alten und Neuen Museums zu Berlin und das sich wandelnde historische Bewusstsein (Jahrbuch der Berliner Museen. Neue Folge 43, 2001, Beiheft), Berlin: SMB, 2003. Zur wissenschaftlichen Hängung von Gemälden in Wien, Paris und Dresden siehe Weddigen 2008, S. 197-208, 216-219. Zur Bedeutung von historischen Kontexten für Kunstwerke siehe Quatremère de Quincy 2010, S. 239-243. S. a. Stara 2013, S. 131-140; Brückle 2015, S. 19.

39 Quandt 1834 (1), S. XVI-XVII.

40 Quandt 1831 (1), S. 7-9, hier S. 7.

41 Quandt 1853, S. 2; Quandt 1826 (1), S. IX. S. a. Quandt 1841, S. 433-434: »Von dem Begriffe ıSammeln kann man keine andre Erklärung geben, als: das Einzelne in einen Zusammenhang bringen.« 
Durch diese Erkenntnis eröffnete sich Quandt der Blick auf die eigene, deutsche Kultur und deren Geschichte. Wie die Brüder Melchior und Sulpiz Boisserée oder der bayerische König Ludwig I. trat er als einer der ersten Sammler altdeutscher Kunst auf. Die Vergangenheit verstand er als Korrektiv der Gegenwart. Schon 1819 meinte er: »So tragen denn die altdeutschen Kunstwerke den Idealcharacter der Deutschen $\mathrm{Na}-$ tion. $\ll^{4^{2}}$ Das Streben nach dieser Nation war im Zuge der napoleonischen Besatzung und der Befreiungskriege zum Ideal der Bildungsbürger geworden. In den Revolutionen von 1830, wie sie auch Sachsen erlebte, wurde die Basis für Staatsgebilde mit nationalem Charakter gelegt. Lindenaus Verfassung von 1831 ebnete den Weg zu einem einheitlichen Staat mit konstitutioneller Monarchie, den es zu konsolidieren galt.

Quandts Einrichtung des Historischen Museums, die überhaupt erst durch die Verfassung und Lindenaus Reformpolitik möglich wurde, darf mit den realpolitischen Entwicklungen in Zusammenhang gesetzt werden. Nach 1830 herrschte Aufbruchsstimmung und konservativ-aufgeklärte Bürger wie Quandt und sein einflussreicher Freund und Minister Lindenau setzten ihre Hoffnungen in eine landständische Verfassung mit gestärkter Monarchie. ${ }^{43}$ Ein idealisiertes, nationalorientiertes Geschichtsverständnis nährte solche Hoffnungen. Im Falle Quandts wurde es Triebfeder des neuen Museums und erklärt die Benennung als »Historisches Museum«. Seine Grundlage, gerade in institutioneller Hinsicht, dürfte indes noch weiter zurückreichen. Das historische Interesse am Vaterland wurzelt im Trauma der napoleonischen Okkupation. Doch gerade die damit einhergehenden Demütigungen führten zu gewissen Entwicklungen, die unterschwellig geradezu von französischen Errungenschaften abhängig sind. Insbesondere die Folgen der weitreichenden Konfiskationen von Kunst in den von Napoleon eroberten Gebieten Europas und ihrer Präsentation im Musée Napoléon in Paris hallten nach den Restitutionen von 1814/15 in den deutschen Museen nach: denn die erbeuteten Kunstwerke waren nach wissenschaftlichen Kriterien und ordentlich konserviert zusammen mit den französischen Beständen im Louvre präsentiert worden. Die eindrücklichen Kunstsammlungen sollten laut der französischen Propaganda beweisen, welche Freiheit Frankreich den despotisch geführten Ländern Europas gebracht hatte. ${ }^{44}$ Das Musée Napoléon

42 Quandt 1819, Bd. 1, S. 131. S. a. Quandt 1826 (1), S. 132, 299-304; Quandt 1839 (1), S. 1-11; Quandt 1853, S. 2. Quandt stand mit Sulpiz Boisserée in Briefkontakt. Die Briefe in: Sammlung Autographa, Warschau, Biblioteka Jagiellonska (ehemals Berlin, Staatsbibliothek). S. a. Heckmann 2003, S. 111-118.

43 Gross 2001, S. 200-204; Titz-Matuszak 2000, S. 103-115.

44 Savoy 2011, S. 50-52, 71-73.

45 »Die Zerstörung der Elemente und Materialien einer Wissenschaft [ist] das wahre Mittel [...], die Wissenschaft zu zerstören und zu hatte also eine explizit pädagogische und implizit patriotische Funktion.

Bereits beim Bekunden des Willens der französischen Regierung, Kunstwerke aus Italien abzutransportieren - was ab August 1796 bekanntlich auch geschah - erwuchs gegen diese Pläne rasch Widerstand. Für den französischen Kunstgelehrten Antoine Chrysostôme Quatremère de Quincy, der die Meinung vieler Künstler vertrat, war dies politischer Diebstahl, die Konfiskationen eine Entseelung der Nationen und eine Zerstörung wissenschaftlicher Kenntnisse durch den Verlust des ursprünglichen Kontextes. Auf Italien bezogen schrieb der Franzose: »Dieß vorausgesetzt muß die Zerstückelung des Museums zu Rom der Tod aller Kenntnisse seyn, deren Grundlage ihre unzertrennliche Verbindung ist. «5 Auf deutscher Seite äußerte sich der Forscher über italienische Kunst, Carl Ludwig Fernow, ähnlich: „Eine Nation, die ihren Kunstsinn nicht aus sich selbst entwickelt und durch sich selbst ausbildet, wird ihn sich durch keine Eroberungen erwerben. $\ll^{46}$ Nach Napoleons endgültiger Niederlage 1815 argumentierten die alliierten Siegermächte mit rechtlichen und politischen, für den Kulturgüterschutz vor allem aber auch kulturellen Argumenten- die Kunstwerke sollten an ihre Ursprungsorte zurückkehren und der nationalen Erinnerung und Entwicklung ihrer Bürger dienen. Der Abwehrmechanismus gegen die Franzosen führte zu einem »Erwachen des nationalen Bewusstseins «.47

Solche Entwicklungen widerspiegeln sich in Quandts Historischem Museum in Dresden. Zeitgleich zu dessen Einrichtung schrieb er eine Rezension zu Aloys Hirts Kunstbemerkungen auf einer Reise über Wittenberg und Meißen nach Dresden und Prag. Hirt stellte einen Mangel an altdeutschen Bildern in der Dresdener Galerie fest. ${ }^{48} \mathrm{Um}$ dem abzuhelfen, schlug Quandt vor, die besten altdeutschen Bilder Sachsens im Tausch mit guten Werkstattbildern in Dresden zentral zu sammeln, um die königliche Kunstsammlung nach wissenschaftlichen Kriterien zu vervollständigen. Er begründete dies folgendermaßen: »Es wäre wohl nicht zu wünschen, dass eine Gallerie alle wichtigen Denkmale der Kunst eines ganzen Landes verschlingen, und dadurch ihre Lücken ausfüllen möchte, wodurch die Quellen des Sinnes für Kunst und Vaterlandsgeschichte den einzelnen Orten entzogen würde; wohl aber: dass man diese Denkmale vor Verderben und Vergessenheit sicherte. Da die meisten Städte,

tödten. "Dritter Brief aus den Lettres à Miranda von 1796 in der deutschen, im gleichen Jahr erschienenen Übersetzung; Quatremère de Quincy 2010, S. 239-244, hier S. 239. S. a. Stara 2013, S. 123-146; Savoy 2011, S. 200-201; Jourdan 2009, S.126-127.

46 Zitiert nach Savoy 2011, S. 203. Zum Widerstand allgemeine ebd., S. $199-235$

47 Savoy 2011, S. 16, zu den Restitutionen ebd., S. 151-193. S. a. Jourdan 2009, S. 130-134.

48 Hirt 1830, S. 15 


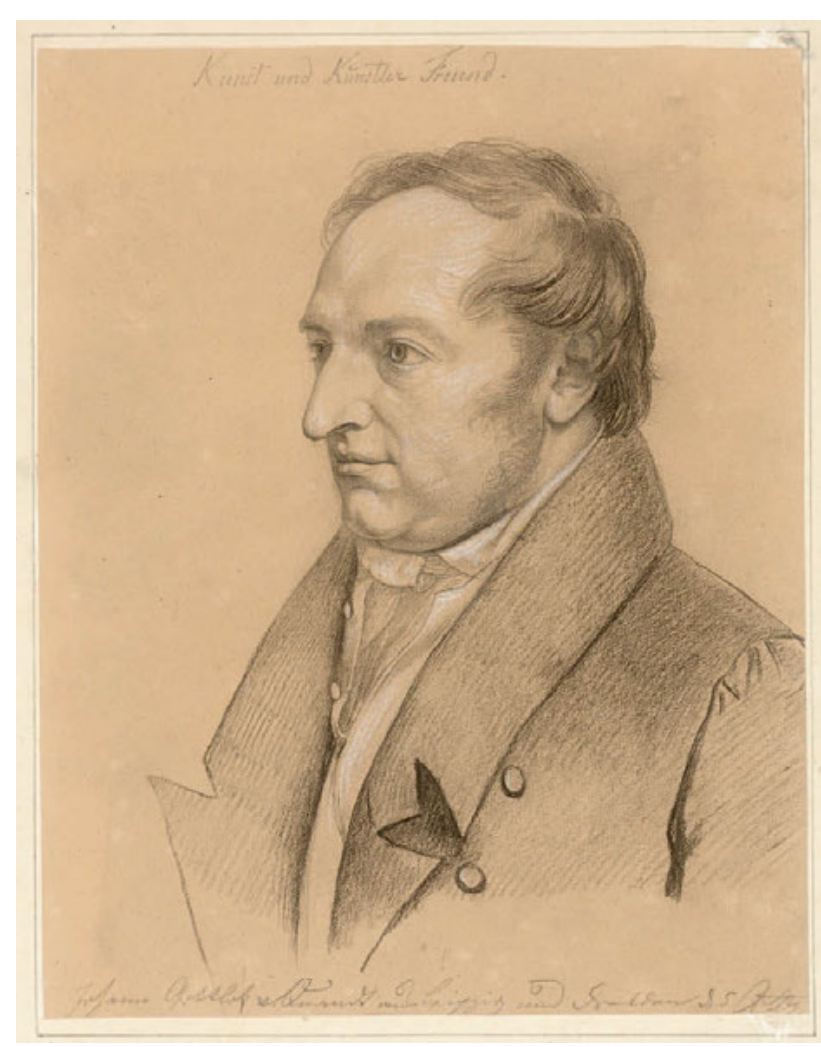

78 Carl Christian Vogel von Vogelstein, Bildnis Johann Gottlob von Quandt, 2. H. 19. Jh., schwarze Kreide, weiß gehöht, $262 \times 208$ mm (Blatt), Dresden, SKD, Kupferstichkabinett, Inv.-Nr. C 3311

wo diese Kunstschätze sich befinden, an bequemen Straßen liegen, welche sie mit der Hauptstadt in Verbindung setzen, so würden die im Lande vertheilten Kunstwerke, wären sie nur erst bekannter und in genießbarem Zustande, mit der CentralGallerie der Hauptstadt, ein für deutsche Kunstgeschichte herrliches Ganze $[\mathrm{s}]$ bilden, so wie etwa [die $]$ Toscana, durch seine an Kunstwerken reichen Städte und Klöster, gleichsam ein großes Museum ist $[. ..] \times{ }^{49}$ Das »Verschlingen der Kunst eines ganzen Landes« ist natürlich auf das Musée Napoleon zu beziehen, das erwähnte »Museum der Toscana« greift Quatremère de Quincys »Museum zu Rom«auf. Dennoch plädierte Quandt mit Argumenten des Denkmalschutzes, wie sie im revolutionären Frankreich vierzig Jahre zuvor zunehmend diskutiert worden waren, für eine Zentralisierung vaterländischer Künste in Dresden. Der revolutionäre Vandalismus im Zuge der Enteignungen kirchlicher Institutionen hatte die Franzosen in der Er-

49 Quandt 1830 (3), Sp. 570-571.

50 Kat. Bonn 2010, S. 93; Jourdan 2009, S. 125-128; Huse 2006, S. 19-64, insb. 19-20, 62-64. S. a. Savoy 2011, S. 50-52; Falser 2008, S. 22-27; Schmidt-Burkhardt 2005, S. 65; Magirius 1989, S. 52.

51 Savoy 2011, S. 216-226. Zu Quandts Haltung zur Revolution und Napoleon siehe Kap. Biographie eines Bildungsbürgers und Menschenfreundes, bes. Anm. 48; Quandt 1834 (1), S. 186-187. kenntnis bestärkt, historische Kulturgüter zu schützen, indem sie erschlossen, inventarisiert und zentral gesammelt wurden..$^{\circ}$ In einer bemerkenswerten Durchmischung von wissenschaftlichen und vaterländisch-politischen Aspekten der postrevolutionären Diskussionen um Kulturgüterschutz sah es Quandt als gerechtfertigt an, Objekte nach Dresden zu transferieren. Dort sollten sie die Sammlung nach wissenschaftlichen Kriterien stärken. Es zeigt sich hier die abgeschwächte und auf das eigene Vaterland bezogene Form eines Phänomens, das zu Zeiten der napoleonischen Vorherrschaft in deutschen Gelehrtenkreisen zu beobachten gewesen war: nämlich die für eine »Kunst- und Kulturgemeinschaft« positive Bewertung einer Zentralisierung von Kunstobjekten und ihrer ordentlichen Präsentationen, wie damals im Louvre zu Paris - freilich nicht mehr im Sinn eines gesamteuropäischen Kosmopolitismus, sondern nur noch auf die eigene Nation bezogen. ${ }^{11}$ Quandts Wille, im Historischen Museum Dresden Kontexte zu schaffen, die den vaterländischen Kulturwert historischer Objekte wahrnehmen ließen, widerspiegelt solche Entwicklungen, die in die Richtung eines vaterländischen oder »Nationalmuseums« zielten, wie noch zu diskutieren sein wird.

Doch in der Durchführung solcher Vorstellungen stieß er auf ein praktisches Problem (Abb. 78). Er hatte eine alte Sammlung zu ordnen, deren historische Kontexte längst verloren waren und die in den alten Gebäulichkeiten völlig disparat aufgestellt gewesen war. Eine historische Ordnung musste am Unwissen über viele Objekte kranken und eine chronologische Folge daran scheitern, dass die unterschiedlichsten Gegenstände beieinanderstehen würden. Sein Anspruch war es aber gemäß seinem Konzept von 1832, im neuen Museum ein »Bild des Lebens« zu zeigen..$^{2}$ Die Konsequenz war eine thematische Präsentation in Objektgruppen, die dem großen Gedanken des Entwicklungsganges der Kunst von ihrer mittelalterlichen Öffentlichkeit über die Dekadenz der barocken Luxusobjekte hin zum Wiedererwachen der Künste in den Museen folgen sollte. »In deren räumlichen Aufeinanderfolge [würde $][. .$.$] eine ge-$ schichtliche Folge [...] dargestellt, wie sich aus dem häuslichen Leben früherer Zeit, allmälig ein Uebergang zur Pracht der Höfe entwickelt hat und wir an die Stelle des Kunstfleißes und Geschmackes, mit welchem alles gearbeitet war, was einem bestimmten Zwecke sei es im Haus oder Felde diente, ein Luxus trat, der Schimmer und Schein beabsichtigte. «33

\footnotetext{
52 HStADD, 13458 SKD, RK, Nr. 46, fol. 1r-2r, 13r. Quandt 1834 (1), S. XIIXIII. Die Datierung der Objekte war in zahlreichen Fällen gar nicht möglich. S. a. Heres 2006, S. 94-97. Zu zeitgenössischen Diskussionen der chronologischen Präsentationsform siehe Weddigen 2008, S. 199-200. Die gleichen Probleme hatte Kugler in der Berliner Kunstkammer; Kugler 1838, S. XVI.

53 HStADD, 13458 SKD, RK, Nr. 46, fol. 6v-7r. Noch etwas polemischer
} 
Quandt strebte also eine Synthese von Chronologie und historischer Klassifikation an. Zusammen würden diese Ordnungsprinzipien »als zwei Correlate ein Resultat, nehmlich die Veranschaulichung der Sitten und Bildungsganges geben [...]. « S4 $^{5}$ Damit entstand eine kulturgeschichtliche Präsentation unter historisch-wissenschaftlichen und ästhetischen Prämissen: ein »geschichtliches Sittengemälde «.55 Die Komposition dieses Geschichtsbildes bestand aus den fünf Hauptabteilungen, wie er sie im Konzept beschrieben und in eine Raumfolge im Zwinger gebracht hatte (vgl. Abb. 76): Haushaltsgegenstände, Jagd- und Gartengerät, Turnierwaffen, Kriegswaffen und Luxusobjekte..$^{56}$

Die virtuelle Präsentation des Königlichen Historischen Museums in den Andeutungen führte den Besucher des Museums anhand eines ausgeklügelten argumentativen Schemas durch die realen Zwingerräume. Im Vorwort ordnete er jedem Saal ein zumeist moralisches Thema oder Schlagwort zu. Allgemeine historische Erklärungen gehen den Beschreibungen einzelner Objekte in den Kapiteln zu den Sälen und Räumen voran.

Für den Eingangssaal (J) mit den Hausratsgegenständen wählte er charakteristische Worte: »Tüchtigkeit und Sorgfalt« würden »das Familien- und das gesellige Leben der Vorzeit« beschreiben. Es sei die Zeit des treuen und sinnvollen Fleißes gewesen. ${ }^{57}$ Am Anfang der Ausführungen zum ersten Saal stehen Fragen der Epoche und der Nation, die er anhand der Geschichte der Glasmalerei als genuin deutscher Errungenschaft erläuterte. Präsentiert wurden die Glasmalereien in den Fenstern der Rückwand und den Bogenfenstern im Eingangsbereich..$^{8}$ Anhand zahlreicher Bildnisse, die an den Wänden

im Brief von Quandt an Schnorr vom 1.1.1833, in: SLUB, Mscr. Dresd. n Inv. 15, Bd. 31, fol. 183v: »Alles was dem häuslichen Leben u der bürgerlichen Kunstthätigkeit angehört, nimmt der erste Saal auf u giebt so durch alle Arten von altem Hausrath ein Bild der treufleißigen, sinnvollen Vorzeit. Der zweÿte Saal enthält Jagd u Gartengeräth u führt in das Gebiet der männlichen Thätigkeit. Der 3te sehr große Saal, wird mit ritterlichen Waffen u Rüstungen zu Schimpf u Ernst angefüllt. Der 4 u 5 Saal wird den Kriegsgeräthen eingeräumt u schließt sich mit den Schießgewehren, womit dem Ritterthum u der Heldenzeit ein Ende gemacht wurde. Im letzten Saale werden die Schaurüstungen u Prachtgeschirre aus der Zeit glänzender Hoffeste aufgestellt, welche einen starken Contrast zu dem Leben bilden, welches sich uns freundlich, gemüthlich u nahbar(?) in Kunsterzeugnißen u Hausgeräthen darstellt, die man im ersten Zimmer findet."

54 Ebd., fol. 1r.

55 Quandt 1834 (1), S. XIII. Hier unterscheidet sich Quandt von einem frühen Kunstwissenschaftler wie Franz Kugler. Beide versuchten zwar die Objekte in einen kulturgeschichtlichen Zusammenhang zu stellen, jedoch ist bei Quandt die übergeordnete Norm der ästhetischen Entwicklungsgeschichte, des Auf- und Niedergangs der Schönheit in der Kunstgeschichte viel ausgeprägter. Kugler geht in seinem Verzeichnis der Berliner Kunstkammer mit wissenschaftlichem Interesse an die einzelnen Objekte heran, die dann kulturgeschichtlich verortet werden; Kugler 1838, S. XVI.

56 Quandt 1834 (1), S. XIII-XVI; HStADD, 13458 SKD, RK, Nr. 46, fol. 13r. S. a. Klemm 1838, S. 288-289. verteilt waren, erklärte er den Besuchern die tugendhaften wettinischen Herrscher und beschrieb deren Errungenschaften in vergangenen Zeiten..$^{59}$ Damit rückte er sie als Schirmherren ins Blickfeld, wodurch die historische Qualität der präsentierten Gegenstände gleichsam verbürgt wurde. ${ }^{60}$ Er musste allerdings durch Ernst Rietschel Reliefbildnisse zweier Herzöge anfertigen lassen, weil ihm nicht eine komplette Ahnenreihe zur Verfügung stand. ${ }^{61}$ Doch auch sie verhalfen zusammen mit Quandts Ausführungen über Epoche, Nation und Herrschaft dem Betrachter zu einem Verständnis über die historischen Hintergründe der Kunstwerke in der Ausstellung.

Auf historischen Schenktischen, umgeben von Stühlen, standen Pokale und Trinkgefäße, auf Konsolen an den Pfeilern Gefäße, Toilettengegenstände, Reiseapotheken und Nähkästchen. ${ }^{62}$ Quandt schrieb: »Beim Eintritt in den ersten Saal fühlen wir, dass Gegenstände uns umgeben, die einer andern Zeit angehören, als die, in der wir leben. Es war und konnte nicht die Absicht seyn, eine scenische Täuschung, durch welche man in ein Hauswesen der Vorzeit versetzt würde, hervorzubringen, wohl aber Alles zu entfernen, was die Stimmung stören könnte $[. .$. und diese Gegenstände so aufzustellen, wie es ihre ursprüngliche Bestimmung fordert. $\ll^{63}$ Unter der $»$ Bestimmung $\ll$ der Gegenstände darf weniger ein praktischer als vielmehr ein metaphorisch-ideologischer Zweck verstanden werden. Die historisch eingeordneten Gegenstände ließen laut Quandt nämlich auf die Gesellschaft schließen. Indem im ersten Raum Gegenstände der »Vorzeit« - in Quandts Verständnis des Mittelalters - präsentiert wurden, verwiesen diese selbst auf eine

57 Quandt 1834 (1), S. XIV. Brief von Quandt an Schnorr vom 1.1.1833, in: SLUB, Mscr. Dresd. n Inv. 15, Bd. 31, fol. 183v.

58 HStADD, 13458 SKD, RK, Nr. 46, fol. 2r. Zur deutschen Herkunft der Glasmalerei siehe Quandt 1834 (1), S. 1-8. Die Glasfenster waren in stilistisch passende »Schirme«, also Rahmen, eingefügt.

59 Quandt 1834 (1), S. 17-44. Zudem dienten die Gemälde der Darstellung von »Trachten und Sitten der Vorzeit«: HStADD, 13458 SKD, RK, Nr. 46, fol. 2v-3r. Es handelt sich u. a. um Bildnisse von Lucas Cranach und Werkstatt. Siehe Kolb 2005, Kat. Nr. 34.1-2, S. 427, Nr. 47, S. 504, Nr. 48.1-2, S. 509, Nr. 49.1-4, S. 516

60 Diese Historisierung der herrschaftlichen Urheber der Sammlungen ließ sich ab 1834 auch in der Gemäldegalerie feststellen. Es handelt sich hier um ein neues Phänomen. Weddigen 2008, S. 208-212, 219-225 vermutet darin eine »bürgerlich-patriotische Verklärung des Landesherrn«, der in der konstitutionellen Monarchie politisch unbedeutend geworden war. Wahrscheinlich ging die genealogische Einrichtung der äußeren Galerie im Stallhof von 1834 auch auf Quandt zurück. S. a. Quandt 1834 (1), S. IV-V.

61 Georg der Bärtige, Herzog von Sachsen, 1833, Dresden, Skulpturensammlung, Abg. Inv. ZV 4116, ASN 116 sowie Ernst, Kurfürst von Sachsen, 1833, Dresden, SKD, Skulpturensammlung, Abg. Inv. ZV 4115, ASN 534; Wilmowsky 2017, S. 99, 278-279 (WVZ 29-30); Kat. Dresden 2004, Kat. Nr. 8-9.

62 HStADD, 13458 SKD, RK, Nr. 46, fol. 2; Quandt 1834 (1), S. 44-59.

63 Quandt 1834 (1), S. 1 
integre Gesellschaft. Diese bestand aus fähigen Künstlern und Handwerkern, die qualitativ hochstehende Kunstobjekte für die kunstfördernden Adelsschichten zum Vorteil der wohl regierten Nation herstellten. Dies war freilich ein Zirkelschluss. ${ }^{64}$

Das folgende Zimmer (H) führte Jagd-, Gärtnerei- und Drechslerwerkzeuge vor. Thematisch trat der Betrachter nun ins Freie hinaus, wo die Männer tätig waren. Vielsagend notierte Quandt: »Das edle Waidwerk [ist] Mittelglied zwischen Friedenslust und Kampfesernst; denn es galt, Bären und Wölfe zu erlegen. «5 Das gesellschaftliche Motiv blieb auch hier zentral. Die ausgestellten Objekte charakterisierten eine friedfertige, das Böse bekämpfende Männer-Gesellschaft. Doch ein Negativpunkt trübte die Sicht, wie Quandt monierte. Der Schmuck der Jagdgeräte habe in früheren Zeiten dem edlen Sinn des adligen Jägers entsprochen, heute aber seien die Gerätschaften von Zierde überladen und daher nicht mehr zweckmäßig. ${ }^{66}$ Damit war der Entwicklungsgang der Kunst und der Gesellschaft, wie ihn der Rundgang durch das Museum suggerierte, in diesem Saal schon angedeutet.

Der Übergang in die erste Bogengalerie $(\mathrm{G}, \mathrm{F})$ war fließend. Der Museumsbesucher wurde nun von den Feldarbeiten und Jagdvorgängen auf einen weiteren »Schauplatz der männlichen Beschäftigungen geführt, und es folgte nun was zu den Waffenthaten gehört. « ${ }^{67}$ Chronologisch angeordnet, wurden hier die Turnierrüstungen und Turnierwaffen präsentiert. In langen Ausführungen beschreibt Quandt die Entwicklung des Rittertums und Turniergeschehens. Seine Vorstellungen von »Volksleben verdeutlichen die Erklärungen zur Entstehung des Ritterstands. Zum Schutz der werktätigen Bevölkerung - dem bäuerlichen und handwerkenden »Nährstand « - seien die Ritter von den Königen auf ihrem Herrschaftsgebiet verteilt worden. Auch der »ehrstand « habe sich dank der Ritter »sorgenfrei den Wissenschaften und Künsten« widmen können. Das körperliche Training wiederum hätten sich die ritterlichen Beschützer in Turnieren angeeignet, um in ehrenvollem Kampf zu bestehen. ${ }^{68}$

Die Rüstungen und Waffen nahmen den größten Teil der Räumlichkeiten im Museum ein (Räume B-G). Umso enger gewoben war Quandts Argumentationsfaden. Nachdem man die Turnierwaffen-Galerie verlassen hatte, betrat man die zweite Galerie (E, D, C) mit Kriegswaffen für den Kampf im Heer.
»Beim Eintritte in diese Gallerie [...] zeigt sich nicht die heitere Pracht, die uns aus den ritterlichen Waffen anstrahlt.« Der ehrenvolle Ritter, der den direkten Zweikampf gesucht hatte, war nun den Söldnerheeren gewichen, deren Schlagkraft von der Masse, der Größe der Artillerie und der Potenz des Heerführers geprägt war. Der Entwicklungsgang erklärte sich ganz einfach: Kraft und Mut des einzelnen Ritters, wie man es in der Turniergalerie erleben konnte, stand nun im Kontrast zu den Waffenmassen der »Heereshaufen«. Auch Ritterspiele späterer Zeiten seien nur noch ein Abklatsch der alten Turniere gewesen. Dieser Niedergang sei sowohl an der Bewaffnung und Rüstung wie auch an den mangelnden Tugenden ersichtlich geworden: »Zuletzt verwandelten sich die glänzenden Harnische völlig in Goldbrocatwesten, die sich so zu den alten Harnischen verhielten, wie die welche sie trugen, an Tüchtigkeit und Kraft sich zu ihren Ahnherren verhalten mochten. $\ll^{69}$

Mit ausführlichen historischen Informationen zu den Besitzern von Rüstungen und Waffen bestückt, betraten die Besucher am Ende der Galerie im Parterre des heutigen MathematischPhysikalischen Salons einen Raum mit Gewehren (B). In den Andeutungen erläuterte Quandt die Herkunft des Schwarzpulvers und das erste Auftreten von Gewehren. Die Waffen gehörten angeblich Leibwachen und waren mehr verziert als benutzbar. Spöttisch bemerkte er: »Bei Beschauung dieser künstlich verzierten Gewehre, drängt sich uns unwillkührlich die Betrachtung auf, dass es eine Zeit gab, in der man das Kriegswesen und den Soldaten selbst, als einen Luxusgegenstand behandelte, wodurch er allerdings sehr an Brauchbarkeit verlor, die Leibwachen sehr vermehrt wurden und der ganze Stand des Militairs, mehr den Charakter einer bewaffneten Hofdienerschaft annahm. $\ll^{70}$

Damit war der Übergang zu den Räumen geschaffen, die dem letzten großen Thema gewidmet waren: den Luxusobjekten (B, A) des augusteischen Zeitalters in Sachsen. Die Räume hatten einen festlichen Charakter. Mit kritischem Unterton verglich Quandt die höfischen Feste des Königshauses mit den politischen Umbrüchen in Europas Osten während des Großen Nordischen Krieges von 1700 bis 1721: »In jener stürmischen Zeit, als [...] der Osten von Europa den Doppelkampf innerer Entwickelung und äußerer Machtvergrößerung bestand, glänzte Sachsen in prächtigen Festen. $\ll^{71}$ An das Gewehrkabi-
64 Zur »Vorzeit« und ihrer Rolle für die Gesellschaft siehe Quandt 1815, Sp. 961-973; Quandt 1819, Bd. 1, S. 27; Quandt 1831 (1), S. 9-48.

65 Quandt 1834 (1), S. XIV, 60. S. a. Brief von Quandt an Schnorr vom 1.1.1833, in: SLUB, Mscr. Dresd. n Inv. 15, Bd. 31, fol. $183 \mathrm{v}$.

66 Quandt 1834 (1), S. 68-69.

67 HStADD, 13458 SKD, RK, Nr. 46, fol. 3V.

68 Quandt 1834 (1), S. 70-96, hier S. 71. Noch ausführlicher ist die Turniergeschichte im nachfolgenden Katalog zum Historischen Museum von Frenzel 1850, S. 18-83.
69 Quandt 1834 (1), S. 84-86, 112-116, die Zitate S. 86, 112. Im Brief von Quandt an Schnorr vom 1.1.1833, in: SLUB, Mscr. Dresd. n Inv. 15, Bd. 31, fol. 183v: »mit ritterlichen Waffen u Rüstungen zu Schimpf u Ernst [...] dem Ritterthum u der Heldenzeit ein Ende gemacht wurde."

70 Quandt 1834 (1), S. 150-155, hier S. 155, S. a. S. XV: »[...] wenn in den ritterlichen Waffen sich ein Ernst im Kampfesspiel zeigt, so verräth sich hier ein Uebergang des Ernstes zum Spiele.«

71 Quandt 1834 (1), S. 163. Die geschichtlichen Ereignisse rund um den schwedischen König Karl XII., der wegen seines Hegemonialstrebens 
nett schloss ein Saal (B) mit »Prachtgeräth« an - hauptsächlich Pferdegeschirr und Zaumzeug. Verzierungen säumten die Decke, die den Ornamenten der ausgestellten Objekte entnommen waren. ${ }^{72}$ Dann folgte ein Zimmer mit »Waffen aus anderen Weltheilen, besonders aus dem Oriente «. Der mit historischen Zelttüchern ausgekleidete Raum erhielt ein morgenländisches Ambiente, und sollte an die »Türkenkammer« Augusts des Starken und dessen orientalische Zeremonien erinnern. ${ }^{73}$ Eigentlich wünschte sich Quandt, »dass gereiste Männer, welche die Trachten und Lebensweise fremder Völker kennen, uns über diese seltsamen und phantastisch gestalteten Waffen und Geräthschaften belehrten.« Doch weil er diese Kenner nicht zur Verfügung hatte, musste er sich in den Andeutungen auf die Abschrift und Übersetzung der Inschriften beschränken. Indem er überhaupt die Inschriften beachtete, ging er einen Schritt weiter als früher, als man die orientalischen Objekte nur als Requisiten und Trophäen behandelt hatte. Damit legte er eine Basis für weitere historische Untersuchungen. ${ }^{74}$

Bevor die Besucher in die letzte Galerie (A) eintraten, durchschritten sie die Kleiderkammer mit fürstlichen Textilien. ${ }^{75}$ Quandts Ausführungen zu den Luxusobjekten wurden immer kürzer und deuten an, dass er diese Gegenstände als unwichtig erachtete. Stücke aus der Sammlung des sächsischen Kurfürsten Friedrich August II. bezeichnete er als belanglos und führte stattdessen die königliche Gemäldesammlung an. »Den Geist dieses Regenten lernt man richtiger aus den von ihm gesammelten Kunstwerken beurtheilen, als aus einer Sammlung dieser Art, die ungleich weniger Belege zu seinem ausgebildeten Kunstsinne geben kann.«Und zu einem Paar Stiefel Napoleons, die im sächsischen Regen und Schlamm eingegangen und daher in Dresden verblieben seien, meinte er mit archivalischer Weitsicht, sie würden »im Laufe der Zeit und nach Jahrhunderten doch zu bedeutenden Merkwürdigkeiten werden « - aber nicht in seinen Augen. ${ }^{76}$

in Osteuropa in den Großen Nordischen Krieg verwickelt war, hatte Quandt im Kontext zweier Pistolen auf den vorangehenden Seiten beschrieben.

72 Quandt 1834 (1), S. 163-165. Dieser Saal kam wohl im Zuge der Umzugsarbeiten hinzu, ist er doch im Konzept von 1832 nicht erwähnt. Ursprünglich sollte Pferdegeschirr und Zaumzeug in der Langgalerie untergebracht werden; HStADD, 13458 SKD, RK, Nr. 46, fol. 5r-6v.

73 Quandt 1834 (1), S. 166; HStADD, 13458 SKD, RK, Nr. 46, fol. 6r. S. a. Schuckelt 2010, S. 14, 228-253; Lindau 1845, S. 231.

74 Quandt 1834 (1), S. 167-180, hier S. 167; Schuckelt 2010, S. 334. Die Abschriften wurden durch einen »Oberlehrer M. Fleischer« übersetzt.

75 Quandt 1834 (1), S. 181-182; HStADD, 13458 SKD, RK, Nr. 46, fol. 6r.

76 Quandt 1834 (1), S. 184-186.

77 HStADD, 13458 SKD, RK, Nr. 46, fol. 7r. Solche Aussagen erinnern an Quatremère de Quincy; vgl. Stara 2013, S. 132-134.

78 Quandt 1834 (1), S. XVI. Am deutlichsten im Brief an Schnorr vom 1.1.1833, in: SLUB, Mscr. Dresd. n Inv. 15, Bd. 31, fol. 183v: »Im letzten Saale werden die Schaurüstungen u Prachtgeschirre aus der Zeit
Quandts Rundgang durch das Museum hatte einen moralisch-didaktischen Anspruch. Das »Sittengemälde«stellte einen historischen Entwicklungsgang dar, den die Besucher entsprechend abschritten. Dies hatte er schon 1832 im Konzept klargestellt: »Es tritt dies in der Gegeneinanderstellung des Zimmers $\mathrm{J}$ und Saales A als Anfang und Endpunkt dieses Museums deutlich hervor, wo in jenem der kunstreiche Hausrath, in diesem die glänzenden Prachtpferde aufgestellt sind. $\ll 77$ In den $A n-$ deutungen erklärte er noch deutlicher, dass in der Abfolge der Säle »der Gegensatz älterer und neuerer Zeit, von Häuslichkeit und Festespracht, von eisernem Ritterthum und glänzendem Hofleben, die Umwandlung von Sitten und Lebensweise, sich anschaulich darstellt. $\ll^{88}$ In Quandts Historischem Museum erlebte der Besucher, die Kunstwerke betrachtend, den Verfall der Gesellschaft vom Mittelalter bis kurz vor die revolutionären Umbrüche - ein Niedergang von häuslich-gesitteter Arbeitsund Festfreude hin zu Luxus, Prunksucht und Dekadenz.

Diesen Vorwurf an die Adresse der deutschen, ja europäischen, absolutistischen Gesellschaft hatte Quandt schon in früheren Schriften formuliert. ${ }^{79}$ Wenn die Verbindung von Schönheit und Zweckmäßigkeit in den Kunstwerken verloren gehe, verliere sich in einer Gesellschaft auch der »wahre Kunstsinn $\ll^{80}$. Diesen Verlust verstand er als Fehler der Geschichte. $\mathrm{Ob}$ eine Gesellschaft diesen Fehler beging und sich vom Schönen entfernte, war eine Frage des Zeitgeistes. Quandt unterschied hiervon den »Geist der Zeit«: »Der Wahn, der Aberglaube, der Irrthum sind Bildungsstufen, Durchgangspunkte, bisweilen, wie man sagen möchte, die ironischen Formen der Erkenntniß, der Gewißheit, der Wahrheit in gewissen Zeiten. Mag man dies den Zeitgeist nennen, aber was diese Mißverständnisse löst, was verkannt zum Grunde liegt, was sich immer wieder zurechtfindet, ist der Geist der Zeit. Der Zeitgeist beherrscht den Geschmack, der Geist in der Zeit bestimmt den Sinn für das Schöne. $\aleph^{81}$ Die Kunst des 17. Jahrhunderts verfiel demzufolge den Fehlern des

glänzender Hoffeste aufgestellt, welche einen starken Contrast zu dem Leben bilden, welches sich uns freundlich, gemüthlich u nahbar in Kunsterzeugnißen u Hausgeräthen darstellt, die man im ersten Zimmer findet.«

79 Quandt 1826 (1), S. 304-306.

80 Quandt 1834 (1), S. XVI.

81 Quandt 1847, S. 140. Quandt reagiert in diesem Text auf einen nicht eruierten Aufsatz über Zeitgeist als Tradition bestimmter Zeiten und Gesellschaften. Für ihn bedeutet Zeitgeist Moden einer Zeit, die einmal positiv oder auch negativ ausfallen. Sie sind nicht konstant. Die Konstante ist der Geist der Zeit, wobei der Zeitbegriff hier zeitenübergreifend zu verstehen ist. Unter Geist versteht Quandt den nach Schönheit strebenden, vernünftigen Gedanken. Dieses Streben der Vernunft ist der Geschichte der Menschheit inhärent und somit zeitlos, je nachdem, ob eine bestimmte Gesellschaft ihrem Zeitgeist entsprechend darauf reagiert oder nicht. Je nach Bildungsstand einer Zeit erhält die zeitlose Schönheit mehr oder weniger Aufmerksamkeit. Die Kunst übernimmt in dieser Entwicklungsgeschichte der Schönheit eine zentrale Rolle. Sie 
Zeitgeistes, des Geschmäcklerischen, den Modeerscheinungen. ${ }^{82}$ Die Kunst des Mittelalters und der Renaissance jedoch, und ihr nachfolgend und von ihr lernend die Kunst seiner Gegenwart strebte nach tieferen Gründen. In Quandts Augen suchten diese Zeiten Schönheit umzusetzen. Der konstante Geist der Zeit oder einfacher gesagt, die immerzu positiv sich entwickelnde Menschheit, sollte über den Zeitgeist und seine Moden siegen.

Im Historischen Museum sollte die wissenschaftliche und ästhetische Präsentation hierbei helfen. Durch Betrachtung der Kunstwerke und Lektüre der historischen Zusammenhänge in den Andeutungen wurden die Besucher aufgeklärt. Sie sollten die Oberflächlichkeit der Barockzeit von der Tiefgründigkeit mittelalterlicher Gesellschaften unterscheiden lernen. Der Rundgang durch die Sammlung wurde zum sinnlichen und vergeistigten Kreislauf und die Erkenntnis der Entwicklung der Menschheit schloss direkt an die Vergangenheit an, »als noch ein Herzensschlag ein frisches Blut durch Kunst und Volksleben strömte. ${ }^{83}$ Das Museum war damit ein Ort der Bildung der Gesellschaft.

\section{Vaterländische Geschichte sichtbar machen}

Das Publikum des Historischen Museums nahm die neue Präsentation und Quandts Andeutungen positiv auf. So liest man im September 1834 in der Allgemeinen Forst-und Jagdzeitschrift, das Historische Museum sei »für den Jäger und Jagdfreund von

ist nämlich der sinnliche Ausdruck der Schönheit. Eine Gesellschaft ohne Sinn für Schönheit bringt auch keine gute Kunst hervor. Daher sollten Künstler idealerweise nur dem Geist der Schönheit dienen, nicht aber der Zeit. Ebd., S. 134. Siehe hierzu auch Quandt 1826 (1), S. 304-306 ; Quandt 1830-1833, Bd. 1, S. XIX; Quandt 1853, S. 36.

82 Quandt 1847, S. 138: »[...] das, was dem mittelalterlichen Christen das Mutterbild zur Madonna macht, macht es mir zum Bild der Liebe. [...] Denken Sie nur an die Kunstwerke, welche aus dem Zeitgeiste des 17. Jahrhunderts hervorgegangen und dadurch Bilder der Zeit sind! Was jedem Menschen an diesen Producten unausstehlich ist, liegt nicht in den Gegenständen oder den Aufgaben, sondern dem Zeitgeiste, dem sie angehören.« Ebd., S. 139: Watteau gefalle, nicht weil er den Zeitgeist darstellte, sondern weil er inn verspottete.

83 Quandt 1834 (1), S. IX. S. a. Waidacher 1993, S. 212-220.

84 Allgemeine Forst- und Jagd-Zeitung, 3./5.9.1834, Nr. 106, S. 420, 424. S. a. die Rezension von Karl Heinrich von Lang, in: Literarisch-historische Zeitschrift, 1835, Nr. 2, S. 44: »Daran gefällt uns [...] vornehmlich der Gedanke, bei allen Werken der Kunst das historische herauszuheben, und bei Bildnissen kurze Lebensumrisse der Vorgestellten zu geben."

85 Morgenblatt für gebildete Stände, 12.4.1836, Nr. 88, S. 352. S. a. die Ausgabe vom 14.4.1842, Nr. 89, S. 356: »[...] während v. Quandt bereits 1834 Andeutungen über das historische Museum schrieb. Dieß großartige Lehrbuch der Vorzeit erklärt sich übrigens dem nicht gelehrten Besucher mit Hülfe des Führers am besten von selbst, und eine bloße trockene Beschreibung würde dem Alterthumsforscher nur viel Roherz in die Hände liefern.«
Interesse«, die Präsentation der ritterlichen Rüstungen würde »eine heitere und kräftige Wirkung hervorbringen « und Quandt habe mit den Andeutungen »durch treffende historische Notizen durchgehends dem Leser ein erwünschtes Geschenk bereitet.. ${ }^{84}$ Das Morgenblatt für gebildete Stände rühmt 1836 die Optimierungsbestrebungen in den königlichen Kunstsammlungen Dresdens: »Besonders hat unter andern das vormals unter dem Namen der Rüstkammer bekannte historische Museum durch die lehrreiche und geschmackvolle Anordnung des Herrn von Quandt ungemein gewonnen. $\ll^{85}$ Auch in Reiseberichten, Memoiren und Führern durch Dresden liest man viel Positives:»Die Gebäude des Zwingers enthalten noch das [...] hauptsächlich unter Mitwirkung des, um die Kunst auf mannichfache Weise verdienten Kenners, von Quandt, so zweckmäßig als geschmackvoll zusammengesetzte historische Museum. ${ }^{86}$

Selbst der Name des Museums wurde so verstanden, wie ihn Quandt letztlich meinte: nämlich als Museum der Geschichte, vorwiegend Sachsens, in welchem die Menschen durch Anschauung belehrt wurden. Der Verleger und Buchhändler Paul Gottlob Hilscher betonte in seinem zweibändigen Werk zu den Dresdener Museen, das aus Anlass von Lindenaus Neuorganisation der königlichen Sammlungen 1835/36 erschienen war, dass die »Sammlung von Rüstungen, Waffen und andern geschichtlichen Merkwürdigkeiten [...] zur Kenntniss der Vorzeit, vorzüglich des sächsischen Volks [...] den Namen des historischen Museums « erhalten habe. ${ }^{87}$ Auch der nachfolgende Katalog Friedrich August Frenzels von 1850 lobte die Einrichtung und so blieb sie bis zum Umzug 1877 ins Johanneum bestehen. ${ }^{8}$

86 [Friedrich August Laun], Memoiren von Friedrich Laun, Bd. 3, Bunzlau: Appun's Buchhandlung, 1837, S. 128; Lindau 1845, S. 216. S. a. Friesen 1880 , S. 321.

87 Hilscher 1835/36, Bd. 2, [S. 13]. Ebenso Lindau 1845, S. 215: »Die im historischen Museum enthaltenen, in Beziehung auf Völkerkunde und Kenntniß der deutschen Vorzeit überhaupt, besonders aber der sächsischen, großentheils historisch und ethnologisch wichtigen oder anziehenden Gegenstände, vorzüglich aber die Erinnerung an denkwürdige Personen und Ereignisse [...] verdienen einer besonderen Aufmerksamkeit gewürdigt zu werden.« S. a. Koetschau 1905, S. 92-94.

88 Frenzel 1850, S.1-2. Frenzels Publikation schien nicht als offizieller Katalog gegolten zu haben. Gustav Klemm am 14.3.1859 und in dessen Nachfolge Wilhelm Schäfer am 22.5.1864 trugen dem Ministerium des Königlichen Hauses vor, Kataloge herzustellen. Schäfer machte geltend, dass seit Quandts Andeutungen von 1834 als offiziellem Katalog keine neue Publikation zum Historischen Museum erschienen sei; HStADD, 11125 Ministerium des Kultus und öffentlichen Unterrichts 1576-1945, 19243 Historisches Museum 1856-1866, fol. 46r-5or (Klemm); fol. 131r-132v (Schäfer). Das Ministerium des Königlichen Hauses lehnte das Angebot ab, da ein Umzug in neue Räumlichkeiten bereits in Planung war. Auch Grieben 1857, S. 119 bezeichnete Quandts und Frenzels Kataloge als ungenügend. Für Hinweise danke ich Christine Nagel. Zum Umzug ins Johanneum siehe Bloh 2005, S. 67. 


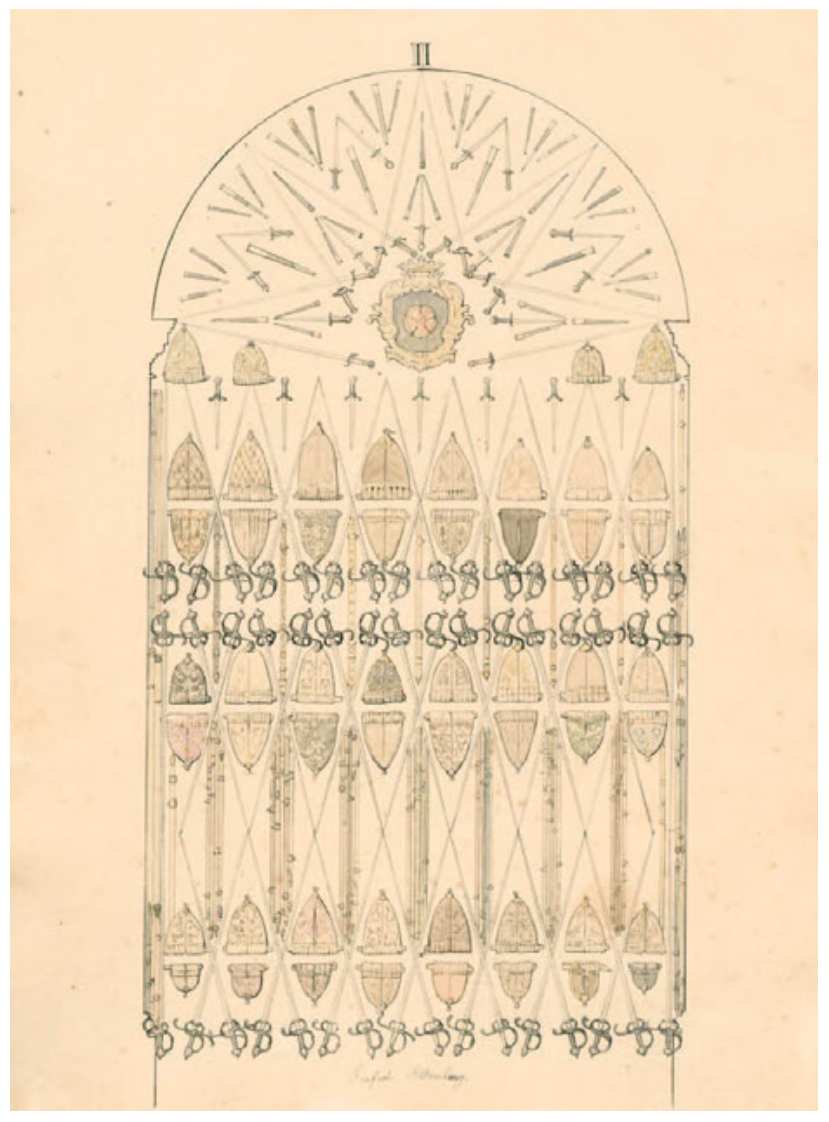

79 Unbekannt nach Joseph Thürmer und Johann Gottlob von Quandt, Wandaufriss mit der Hängung von Rapieren, Dolchen, Scheiden, Degentaschen und Wehrgehängen in der II. Bogennische des Paradesaales im ehemaligen Königlichen Historischen Museum Dresden, mit dem Wappen der Burggraphschaft Altenburg, 1836/77, Feder und Tusche, teilweise koloriert, $360 \times 263$ mm (Blatt), Dresden, Rüstkammer, Inv. -Nr. T 215/40

Besonderen Anklang aber fanden die ornamentalen Anordnungen großer Mengen von Waffen, Rüstungsteilen und einigen textilen Stücken in den von Säulen gebildeten Nischen der Galerien (Abb. 79-81). Hierzu hieß es in der sechsten Auflage des beliebten Reiseführers Merkwürdigkeiten Dresdens und der Umgegend von Wilhelm Adolph Lindau: »Die Nischen und Felder hinter der langen Reihe der Harnische sind mit Schwertern, Lanzen, Schilden, Helmen, kurz mit Waffen, Turnier $=$ und Paradegeräthe der verschiedensten Art ausgestattet, die [...] schön gruppirt in den manchfachsten und bewundernswürdig

89 Lindau 1845, S. 225-226. S. a. Frenzel 1850, S. 91, 98, 106-107. 90 Frenzel 1850 , S. 2. S. a. Heres 1987, S. 45-46. Als Vorlage sollen laut Frenzel die Dekorationen der Zeughäuser in London, Paris, Wien und Berlin gedient haben. Das Berliner Zeughaus wurde 1828 einem breiteren Publikum zugänglich gemacht, wobei eine Abbildung von Michael Carl Gregorovius der »Kunst-Rüstkammer« eine ganz anders geartete Präsentation zeigt als diejenige von Thürmer und Quandt. Der Magazincharakter scheint musealisiert worden zu sein, was in Dresden nicht der Fall war. Die Abbildung in: [s. n.], »Das Berliner

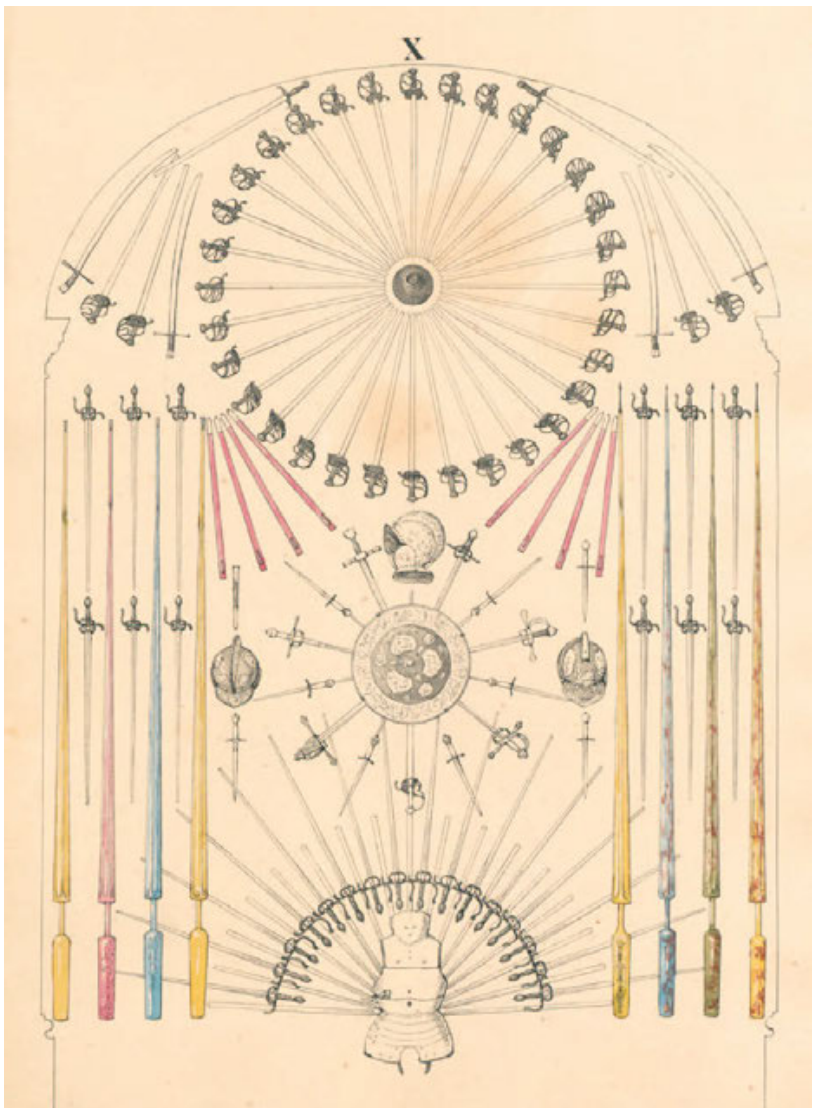

80 Unbekannt nach Joseph Thürmer und Johann Gottlob von Quandt, Wandaufriss mit der Hängung von Rennzeug, Prunksturmhauben, Prunkschild, Brechscheibe, Rapieren, Säbeln, Dolchen und Stechlanzen in der X. Bogennische des Turniersaales im ehemaligen Königlichen Historischen Museum Dresden, 1836/77, Feder, teilweise laviert, 359 × 262 mm (Blatt), Dresden, Rüstkammer, Inv.-Nr. T 215/40

abwechselnden Formen und Figuren dem Auge des Beschauers einen freundlichen Anblick gewähren. ${ }^{89}$ Friedrich August Frenzel erklärte, dass es der Professor für Baukunst, Joseph Thürmer, gewesen sei, der »mit großem Geschmacke die einzelnen Stücke symmetrisch und in gefällig architektonischen Formen an den Wänden und Pfeilern « angebracht habe. ${ }^{90}$

Dank einem über fünfzig Blatt umfassenden, undatierten Konvolut von Wandaufrissen, das im Archiv der Rüstkammer erhalten blieb, lässt sich von den ornamentalen Hängungen in den drei Zwingergalerien ein genaues Bild machen. ${ }^{91}$ Die darge-

Zeughaus«, in: Mitteilungen des Deutschen Historischen Museums 1992, Bd. 2, Nr. 6, Internetressource: www.dhm.de/magazine/zeughaus/Waffenarsenal.html [letzter Zugriff: 17.9.2018]. S. a. Neumann 1991/92, S. 159-179.

91 SKD, RK, Bibliothek, T 215/40, um 1845(?). S. a. Schuckelt 2010, S. 14; Bloh 2005, S. 62; Bäumel 2004, S. 18. Die Zeichnungen von unbekannter Hand lassen sich vielleicht mit der Antwort des Ministeriums des Innern auf ein Gesuch des Kunsthistorikers Ludwig Puttrich vom 4.11.1845 in Zusammenhang bringen, in: HStADD, 13458 SKD, 


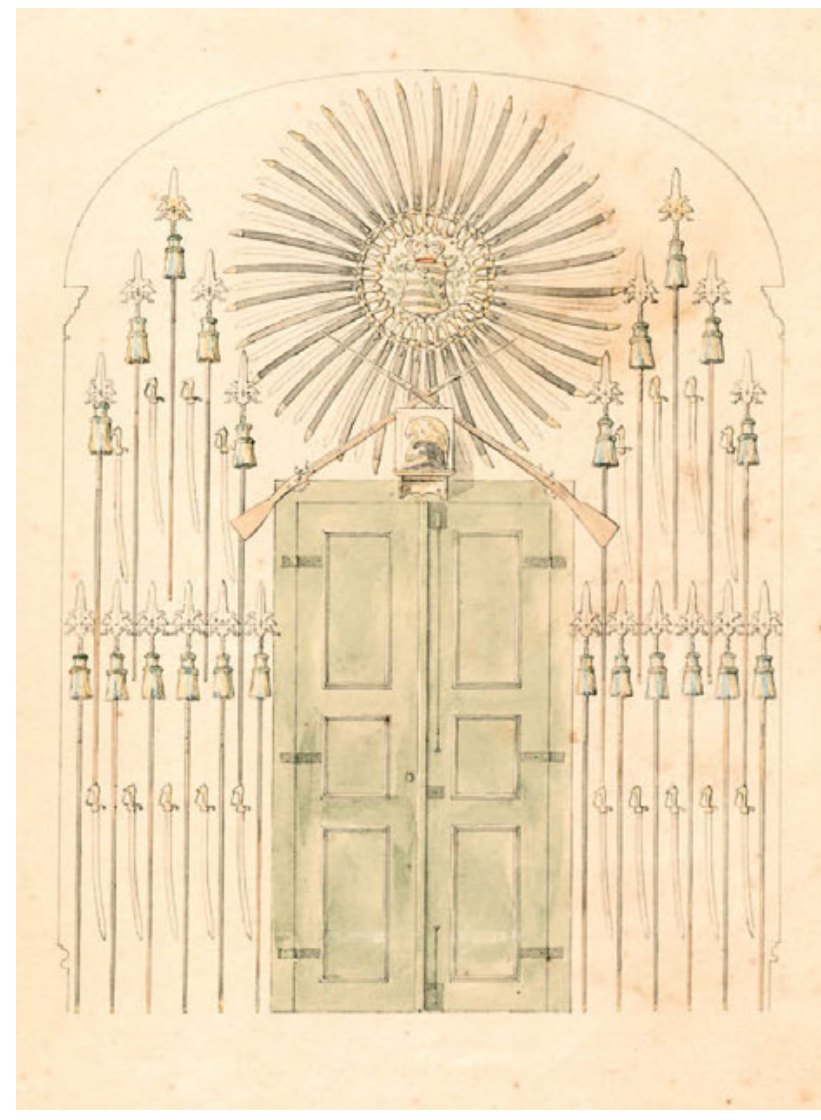

81 Unbekannt nach Joseph Thürmer und Johann Gottlob von Quandt, Wandaufriss mit der Hängung von kursächsischen und königlich-sächsischen Militär- und Gardewaffen sowie Raupenhelm in der Bogennische eines Zugangs zum Paradesaal im ehemaligen Königlichen Historischen Museum Dresden, mit dem königlich-sächsischen Wappen im Zentrum der Rosette, 1836/77, Feder und Tusche laviert, teilweise koloriert, $360 \times 263$ mm (Blatt), Dresden, Rüstkammer, Inv.-Nr. T 215/40

RK, Nr. 38b, [nicht paginiert]. Darin wird gutgeheißen, dass »Herr Frenzel die gewünschten Armaturen, im Locale der Sammlung selbst zeichne.« Beim möglichen Urheber könnte es sich also um Johann Gottfried Abraham Frenzel, der Schreiber beim Kupferstichkabinett war und als Vedutenstecher unter anderem Quandts Haus dargestellt hat, handeln. Die in der Rüstkammer überlieferte Zuschreibung an Friedrich Martin Reibisch oder Friedrich August Rahnfeld konnte dagegen nicht nachvollzogen werden. Gemäß mündlicher Mitteilung von Jutta von Bloh existiere in den Akten der Rüstkammer eine Notiz über ungenügende Zeichnungen im Zusammenhang mit einem Führerprojekt für das Historische Museum von Friedrich August Rahnfeld. Diese Notiz wurde mit dem Konvolut der Wandaufrisse in Verbindung gebracht, die jedoch qualitativ außerordentlich gut und detailgetreu sind. Zur Datierung siehe unten Anm. 93.

92 Die gesamthaft fünfzig Blätter mit Zeichnungen sind in drei Abteilungen unterteilt, denen ein Deckblatt vorangeht. Ein Titelblatt ist nicht vorhanden. Das Deckblatt ordnet die nachfolgenden Zeichnungen den Sälen zu und hält deren Anzahl fest: »1. Galerie. Turniersaal. 17. Blatt. 2. Galerie. Schlachtsaal. 16. Blatt. 3. Galerie. Paradesaal. 16. Blatt."

93 Inventare des Historischen Museums 1836-1838, in: HStADD, 13458 SKD, RK, Lieber-Nr. 77-88, 90, 92-93. Eine Stichprobe im Inventarium über die in dem Turnier=Saale des königl: historisch: Museums zu Dresden befindlichen Gegenstände, Lieber-Nr. 77 stimmt exakt mit den Zeichnungen überein. Für die Datierung der Zeichnungen von stellten Waffen sind so genau wiedergegeben, dass Kenner der Rüstkammer einzelne Objekte eruieren können. ${ }^{22}$ Zudem lässt sich feststellen, dass die Zeichnungen genau den Inventaren von $1836-38$ entsprechen. 93

Im Konzept von 1832 hatte Quandt vorgeschlagen, »die Wand selbst mit Degen, Schwertern, He $[1]$ men, Schildern zu bekleiden [...], aus welchen eine Art Mosaik gebildet werden könnte. «94 Mit einer solchen Präsentationsform ging ein Verlust des alten Magazincharakters der Rüstkammer einher. ${ }^{95}$ Am stärksten bedauerte dies wohl der Maler Wilhelm von Kügelgen in einer Schilderung der Stimmung in der alten Rüstkammer: »Die Waffen standen und hingen da sämtlich noch ohne Gepränge und Ostentation, wie zu der Zeit, da sie im Gebrauch gewesen, und auch die Luft schien noch dieselbe, die Johann Friedrich und Kurfürst Moritz schon geatmet, wenn sie durch diese Räume schritten. Aber gerade dieser Moderduft schien mir das beste: er war die Melodie des Heldenliedes, das die Wände sangen. Später, nach 1830, als der Fortschritt auch in Sachsen einbrach, wollte man es besser machen und stellte diese Waffen [...] in den hohen, hellen Korridoren des Zwingers auf. Man ordnete nun die alten Mordgewehre zu glänzenden Sonnen oder freundlichen Rosetten und Girlanden an den Wänden, verbannte jenen mysteriösen Geruch der Vorzeit und nahm der Sammlung endlich selbst den Namen, indem sie jetzt ganz elegant Historisches Museum heißt. Das ist der Fortschritt des Geschmackes. $\ll^{96}$

Doch Quandt ging es um mehr als Geschmack. Die großen Fenster im Zwinger fluteten die hohen Säle mit viel Licht und vertrieben den Muff der »alten landesherrlichen Rüstkammer« zugunsten der vielfach gelobten, neuen Aufstellung der Gegen-

Interesse ist ein Vorentwurf des Inventars zum Schlachtensaal in den Akten der Rüstkammer: HStADD, 13458 SKD, RK, o. Nr. [5], »B. Im 2ten Saale sind untergebracht«, datiert in Bleistift auf 1836. Hier stimmen nicht alle Details mit den Zeichnungen überein. Einer Notiz zu den Waffen im dritten Bogen ist zu entnehmen, dass erst später Streitäxte hinzugekommen seien. Dies würde Unstimmigkeiten erklären. Damit kann ausgeschlossen werden, dass es sich bei den Wandaufrissen um Entwurfszeichnungen von Joseph Thürmer selbst handelt, der schon 1833 verstorben war. Als terminus ante quem kann nur der Umzug von 1877 ins Johanneum gesetzt werden, da bis zu diesem Jahr weder ein genauer Katalog noch ein neues Inventar erstellt wurde, was für einen Vergleich unabdingbar wäre. Für zahlreiche Hinweise danke ich Gernot Klatte. Zur Zuschreibung siehe oben Anm. 91.

94 HStADD, 13458 SKD, RK, Nr. 46, fol. 3V-4r. Zu symmetrischer Präsentation von Glasmalereien s. a. Quandt 1834 (1), S. 16.

95 Heres 2006, S. 96. Ornamentale Präsentationen von Waffen zur Beförderung des Sinnes für Geschichte und Traditionen reichen bis in Zeughäuser und Rüstkammern des frühen 18. Jahrhunderts zurück. Traktate beschreiben zudem den Effekt von Kuriosität und Vergnügen, welchen entsprechende Einrichtungen auf das Publikum hatten; siehe Neumann 1991/92, S. 160. S. a. Friesen 1880, S. 321.

96 Kügelgen 1959 [1870], S. 126. S. a. Weddigen 2008, S. 216-219, Heres 1987 , S. 46. 
stände. ${ }^{97}$ Die »glänzenden Sonnen« und »freundlichen Rosetten« waren Mittel zum Zweck. Sie verhalfen dem aufzuklärenden Bürger zur geistigen Erleuchtung. Quandt selber versprach sich von der ornamentalen Aufstellung eine »heitere Laune «.$^{8}$ Sie sollte in vergangene Zeiten versetzen. Ernst Förster verstand das Anliegen und schrieb in seinem Handbuch für Reisende in Deutschland, im Historischen Museum sei »alles vollkommen anschaulich zusammengestellt, so dass man an Zeit und Ort der alten Ritterspiele sich versetzt sieht. « ${ }^{99}$

In den Andeutungen von 1834 versuchte Quandt aufzuzeigen, wie einstige Gesellschaften von Kunst durchdrungen gewesen waren. Dieses Anliegen konnte er nicht nur durch die Präsentation reinen historischen Wissens erzielen, da zu viele Informationen zu den Werken verloren gegangen waren. So zielte er durch die dekorative Gestaltung der Ausstellungsräume darauf ab, ein Gefühl für die Rolle der Kunst in historischen Zeiten zu vermitteln: »Geschichte und Dichtung einer Zeit [machen] ein Gesammtes [aus], das in der Anschauung zum Ganzen werden muss. Es würde ebenso einseitig seyn, sich blos an Thatsachen zu halten, ohne in die Idee einzudringen, als es einseitig wäre, die Begebenheiten nach dem idealen Gepräge der Dichtung sich vorzustellen. $\ll^{100}$ Quandt verstand unter Geschichte die realen Geschehnisse einer Zeit und unter Dichtung die Idealformen der Kunst, die auf einen tieferen, die Gesellschaft zusammenhaltenden Sinn referierte. Beide waren eng miteinander verschränkt und wurden besonders in den verschiedenen Kunstformen sinnlich wahrnehmbar.

Erste solche Authentizität vermittelnden Präsentationsformen waren bereits am Ende des 18. Jahrhunderts in Frankreich entstanden, als durch die revolutionären Enteignungen der Kirchen zahlreiche mittelalterliche Kunstwerke konfisziert und präsentiert worden waren. Gerade auch die französischen Konfiskationen im Rheinland und vor allem in Italien ab 1794/1796, die zu intensiven Diskussionen über die Wichtigkeit der ursprünglichen Entstehungskontexte von Kunstwerken geführt hatten, spielten hierfür eine wichtige Rolle..$^{101}$ So hatte Alexandre Lenoir, Gründer und erster Leiter des Musée des Monuments français in Paris, ab 1795 die Kunstobjekte nach ihrer Entstehungszeit geordnet und jedem Jahrhundert einen Raum gewidmet. Diese »Jahrhundert-Räume« gestaltete er gemäß dem

97 Friesen 1880, S. 321.

98 Quandt 1834 (1), S.XIV.

99 Förster 1847, S. 236. Siehe auch Quandt 1834 (1), S. 96: »[...] zu beiden Seiten desselben [Harnisches] sind zwei Heroldstäbe angebracht als Verkündiger des Ritterthums, welches unsere Phantasie in der eisernen Schaar, die sich den Saal entlang aufstellt, in vormaliger Kraft, Kühnheit und Herrlichkeit erblickt.« S. a. Kügelgen 1959, S. 126: »Gleich unten auf dem dunkeln Hausflur standen vor dem Treppeneingang als Schildwachen zwei schwer geharnischte Figuren, die einen schon im voraus in die erforderliche Stimmung brachten."
Charakter ihrer jeweiligen Zeit. So erhielt die Kunst des 13. Jahrhunderts spitzbogige Gewölbe und Durchgänge, Glasmalerei an den Fenstern und Totenleuchten als gedämpfte Lichtquellen. Anders als Quandt ging es Lenoir freilich nicht um eine Aufwertung mittelalterlicher Kunst, vielmehr diente die düster anmutende Präsentation einer Entwicklungsgeschichte, welche die Errungenschaften der nachfolgenden Kunstepochen in umso hellerem Licht darstellen sollte..$^{102}$ Ob Quandt vor der Schließung des Museums 1816 in Paris war, ist nicht bekannt. Dennoch waren ihm Beispiele kontextualisierender Präsentationen mittelalterlicher Kunstwerke wie in der Löwenburg in Kassel oder im Gotischen Haus in Wörlitz sicherlich bekannt. Zudem errichtete er selber in seinem Wohnhaus Anfang der 1820er Jahre einen neugotisch inszenierten Mittelalterraum für Skulpturen und Glasmalereien des 15. und 16. Jahrhunderts. ${ }^{103}$

Quandts Inszenierung im Historischen Museum Dresden diente ihm, im Gegensatz zu Lenoir in Paris, eben gerade dazu, ein leuchtendes Mittelalter zu zeigen, auf welches Niedergang und erneuter Aufstieg folgte. Quandt wertete mit szenographischen Techniken die spätmittelalterlichen Gegenstände der Kunst und des Kunsthandwerks auf und ging mit dieser Präsentation in einem öffentlichen Museum dieser Größe neue Wege. Die auf die Ausstellungsgegenstände Rücksicht nehmende Innenraumgestaltung, wie sie dann in den Nationalmuseen immer häufiger gepflegt wurde, breitete sich ab der Mitte des 19. Jahrhunderts rasant aus. Die architektonisch anmutenden Waffenornamente übernahmen dabei in gewisser Hinsicht jene Authentizität vermittelnde Rolle, welche später auch den eklektischen Kombinationen originaler Architekturteile mit historistischen Nachbauten in den Period Rooms der Nationalmuseen zugewiesen wurde..$^{104}$

Die gotische Formensprache der Waffenornamente zeugte zudem von einem patriotischen und quasi-religiösen Mittelalterideal mit Nachwirkungen bis in die Gegenwart. ${ }^{105}$ Sie waren visuelles Zeichen für die Verschränkung von Historizität und Ästhetizismus. Quandt wollte Geschichte über das geistige Erlebnis hinaus sichtbar machen - eine Sichtbarkeit von Geschichte, die durch ihren volksbildenden Charakter schließlich auch im Alltag, in der Gesellschaft und in der Nation, wie sie sich im Sachsen der 183oer Jahre auszubilden begann, evident

\footnotetext{
100 Quandt 1834 (1), S. 95-96.

101 Savoy 2011, S. 216-226.

102 Brückle 2015 S. 19-23; Thome 2015, S. 77-80.

103 Wörlitz, Kassel und weitere frühe Beispiele diskutiert bei Brückle 2015, S. 151-168. Zu Quandts Mittelalterraum siehe oben Kap. Vorbildliche

Maler. Die Alten Meister in der Sammlung.

104 Thome 2015, S. 82-86; Brückle 2015, S. 23-24, 168-169.

105 Quandt 1834 (1), S. IX-X. S. a. Waidacher 1993, S. 212-220, 231-239.
} 
würde. Mit seinem Geschichtsbild, das er im historischen $\mathrm{Mu}-$ seum entworfen hatte, verfolgte er letztlich weniger ein streng historisch-wissenschaftliches, sondern ein pädagogisches Ziel. Sein Publikum war breit gefächert und sein Ausstellungsführer ein Cicerone, der »nicht eher spricht, als man ihn befragt, und folglich den Beschauer in seinen eigenen Betrachtungen nicht stört. « ${ }^{106}$ Das präsentierte Objekt stand weniger im Mittelpunkt als dessen historischer Kontext und vertrat typologisch gewisse Tugenden und Gesellschaftsbilder. Die Präsentation hatte bewusst den Besucher vor Augen und wollte ihn zu Erkenntnissen führen. Geschichtswissenschaftler wurden auf Quellen und weiterführende Literatur verwiesen. Quandts Einrichtung des Historischen Museums hatte damit ein publikumsorientiertes Vermittlungsziel, das ganz im Sinn der ästhetischen Bildung seiner Zeit bestand und bis heute in den Anliegen der Museumspädagogik - heute diskret meist »Bildung und Vermittlung« genannt- nachhallt. ${ }^{107}$

Dass aus Quandts Ausstellung und seinen Andeutungen ein wissenschaftliches Problem folgte, formulierte bereits 1859 der Hofbibliothekar Gustav Klemm: »Die Aufstellung dieser Gegenstände fand in den Jahren 1834 ff. statt und war von dem damaligen Standpunkt der Wissenschaft aus betrachtet, durchaus nicht unzweckmäßig zu nennen. [...]. Die Alterthümer des europäischen Mittelalters waren nur sehr fragmentarisch bear- beitet worden und den verdienten Männern, welchen die neue Ausstellung jener Sammlung übergeben wurde, standen jene reichen Hülfsmittel noch nicht zu Gebote, welche seitdem die Culturgeschichte hervorgerufen hat. Gegenwärtig aber, wo die Culturgeschichte zur Culturwissenschaft sich auszubilden begonnen hat, wo reiche Hülfsmittel vorhanden sind, ist es wohl an der Zeit den außerordentlichen wissenschaftlichen Schatz, den das Königl. Museum darbietet, in eine den ernsten Kenner mehr befriedigende Form zu bringen. $\ll^{108}$

Dennoch hatte Quandt durch die ästhetische Präsentation einer historischen Entwicklung der Kultur in Sachsen eine museale »Visualisierungsmaschine« erschaffen, wie dies die ab der Mitte des 19. Jahrhunderts entstehenden Nationalmuseen werden sollten. Er hatte mit seinen Mitarbeitern eine Präsentation entwickelt, welche die Kunstgegenstände nicht nur durch die kulturgeschichtlichen Ausführungen in seinen Andeutungen, sondern vor allem auch mittels einer auf Eindrücklichkeit abzielenden Szenographie kontextualisierte. ${ }^{109}$ Sein Historisches Museum gehört in dieser Hinsicht zu den sehr frühen Versuchen einer nationalgeschichtlich-sächsischen Institution, welche von Anfang an kritisiert, aus wissenschaftlicher Perspektive ab der zweiten Hälfte des 19. Jahrhunderts überholt, namentlich aber erst 1992 mit der lange geforderten Rückbenennung in Rüstkammer gescheitert war.
106 Quandt 1834 (1), S. XVIII-XXI, hier S. XIX.

107 Zirfas 2016, S. 29; Vieregg 1991, S. 106-111. S. a. Waidacher 1993, S. 86$87,212-220$.
108 HStADD 11125 Ministerium des Kultus und öffentlichen Unterrichts 1576-1945, 19243 Historisches Museum 1856-1866, fol. 46r-5or. 109 Vedder 2010, S. 170. S. a. Brückle 2015, S. 168-169. 


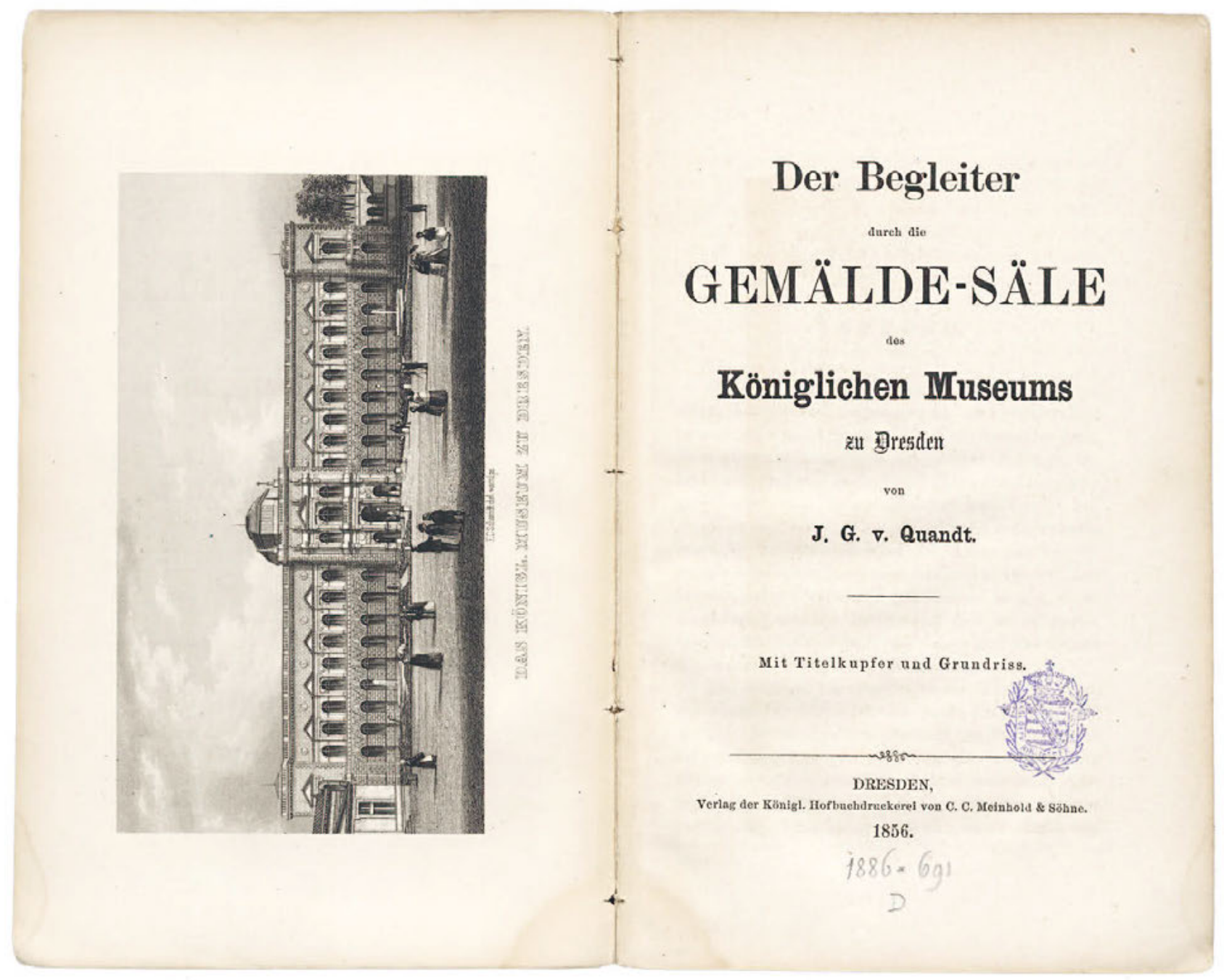

82 Johann Gottlob von Quandt, Der Begleiter durch die Gemälde-Säle des Königlichen Museums zu Dresden, Dresden 1856, Frontispiz und Titelblatt 


\section{ORDNUNG UND KONSERVIERUNG: Die Königlich-Sächsische Gemäldesammlung}

Zeitgleich mit der Einrichtung des Historischen Museums begann Quandt in offiziellem Auftrag für die Königlich-Sächsische Gemäldesammlung zu arbeiten. Auch diese Tätigkeit war eine Folge der Reformen des Staatsministers Bernhard August von Lindenau. Anfangs der 183 oer Jahre wurde Quandt als private Fachperson beigezogen. 1836 wurde er Mitglied der neu gegründeten Galeriekommission, die den Sammlungsinspektor unterstützte. Die Aufgaben, mit denen Quandt beschäftigt war, betrafen die Konservierung zahlreicher Gemälde sowie Neuhängungen gemäß den neusten Ordnungskriterien in der Gemäldegalerie. Eng damit zusammenhängend und von Quandt mit großem Engagement angegangen war die Frage eines Galerieneubaus, von dem man sich für Konservierung und Präsentation Besserungen erhoffte. Im Jahr nach der Eröffnung des neuen Museumsgebäudes von Gottfried Semper erschien Quandts Begleiter durch die Gemälde-Säle des Königlichen Museums zu Dresden (Abb. 82)

Christoph Schölzel hat in seiner Dissertation über die Restaurierungsgeschichte der Dresdener Gemäldegalerie detailliert auf Quandts Rolle in Restaurierungs- und Konservierungsfragen hingewiesen. ${ }^{1}$ Nachfolgende Ausführungen heben daher nur einige Aspekte dieser Beschäftigung hervor und fokussieren verstärkt auf die Hängungsproblematik, die für Quandts Kunstverständnis von zentralem Interesse sind.

\section{Konservierungsfragen}

Johann Gottlob von Quandt äußerte sich schon früh über die Königliche Gemäldegalerie in Dresden. 1816 schrieb er einen Bericht über die Neueinrichtung des Inspektors Karl Friedrich Demiani, die einige Bilder in gutes Licht gerückt habe. Dieser erste Text über die Dresdener Gemäldesammlung war weit- gehend positiv und verstand die Präsentation der Bilder vor dem Hintergrund der schwierigen räumlichen Bedingungen im Stallhofgebäude am Jüdenhof in Dresden (Abb. 83). ${ }^{2}$ Sechs Jahre später erschien im Kunstblatt ein anonymer Artikel, der wahrscheinlich von Quandt stammt, sich über den Zustand der Bilder empörte und zu sofortigen Konservierungsmaßnahmen aufrief: »Es ist Zeit, denjenigen, die der unschätzbaren Gallerie in Dresden vorstehen, öffentlich zuzurufen; [...]; Ihr seyd nicht allein Eurem König, dem Eigenthümer, der Euch diesen Kunstschatz zur Wahrung anvertraute; Ihr seyd es dem edeln Vaterlandsstolz aller Sachsen, aller Deutschen; ihr seyd es dem ganzen gebildeten Europa, der Vor- und Nachwelt, der Forschung und der Uebung, der Geschichte und dem Fortschreiten der Kunst schuldig, für die Erhaltung des Schönsten was die größten Meister entschwundner Jahrhunderte geleistet haben, werkthätig zu sorgen!«3 Dieser Aufruf im Kunstblatt war der Auftakt zu mehreren Artikeln über den Zustand der Gemäldegalerie. Während der $1820 e r$ Jahre war er hierin einer der federführenden Meinungsmacher.

Das alte Galeriegebäude am Stallhof war in Quandts Augen das größte Problem für den schlechten Zustand der Gemälde und ihre unvorteilhafte Präsentation (Abb. 84). Große jahreszeitlich bedingte Temperaturunterschiede in den ungeheizten Ausstellungssälen und der Ruß der Kohleheizungen der Stadt schadeten den Gemälden beträchtlich. ${ }^{4}$ Dies prangerte er über Jahrzehnte hin bis zum Baubeginn des neuen Museums durch Gottfried Semper im Jahr 1855 immer wieder an. Wilhelm Schäfer bezeichnete daher noch ein Jahr nach dessen Tod Quandt als »[...] namentlich unser[en] für die Gallerie seit 40 Jahren wahrhaft väterlich besorgte $[\mathrm{n}]$ Kunstkenner $[\ldots]$. «s $^{5}$

Ausgehend von der Kritik am alten Galeriegebäude beschäftigte sich Quandt mit Restaurierungsfragen. Er hatte viel darüber gelesen, wenn ihm auch die praktischen Erfahrungen fehl-
1 Schölzel hat zudem Quandts restaurierungstechnische Aufsätze erfasst und erläutert, weshalb sie hier nicht systematisch bearbeitet und nur punktuell erwähnt werden; Schölzel 2012, S. 45-56, 123-125, 140-148, 157-180, 195-239, 248-250, 262, 364-368.

2 »Daß durchgängig keine historische Folge in der Auffstellung der Gemälde beobachtet wurde, kann Keinen befremden, der das Local kennt.« Quandt 1816 (1), S. 831-843. Über Demianis Neuhängung siehe Schölzel 2012, S. 139.
3 Zitiert nach -t. [Quandt] 1822, S. 372; s. a. Friesen 1880, S. 322-324; Kat. Dresden 1856, S. 59; Schölzel 1994, S. 7; Rudloff-Hille 1972-1975, S. 59; vgl. Schölzel 2012, S. 146-147.

4 Kat. Dresden 1856, S. 58; Quandt 1842, S. 9-11, 25, 30-33, 47-50; Schäfer 1860, S. 98-99. Zum alten Galeriegebäude siehe Weddigen 2008, S. 4253; Pilz 2006, S. 145-150; Heres 2006, S. 124-128; Schäfer 1860, S. 44-47. 5 Schäfer 1860, S. 99. 


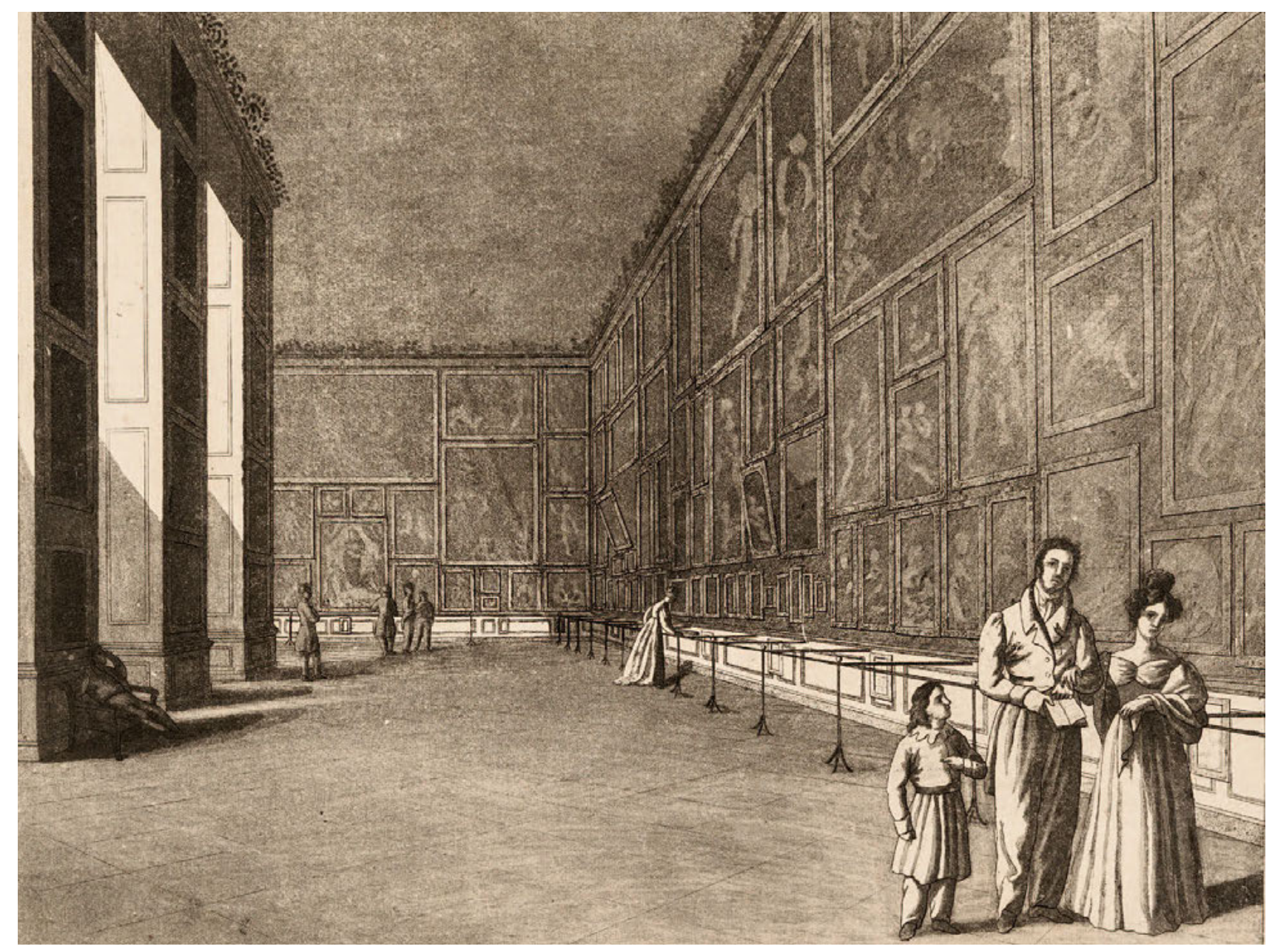

83 Anonym, Vue d'une partie de la galerie royale de Dresde (appellée galerie interieur ou italienne) comme elle était à l'an 1830, nach 1830, Aquatintaradierung, $298 \times 247$ mm (Platte), Dresden, SKD, Kupferstichkabinett, Inv.-Nr. A 1995-3216

ten. ${ }^{6}$ In seinem langen Kampf um eine bessere Erhaltung der Kunstwerke konnte er auf Schützenhilfe vieler Kunstkenner und Beamten zählen, welche die Dresdener Zustände ebenfalls anprangerten. ${ }^{7}$ Johann Georg Friedrich Freiherr von Friesen, der die Oberaufsicht über die Kunstsammlungen innehatte, überreichte dem König im Zuge der zahlreichen öffentlichen Angriffe auf die Zustände in der Gemäldegalerie im Jahr 1823 Forderungen zu verbesserten Konservierungsmaßnahmen. Er legte ein ausführliches Schreiben Quandts bei, in welchem dieser anhand von Vergleichen mit italienischen, französischen und deutschen Gemäldegalerien die Notwendigkeit verbesserter Konservierungsmaßnahmen erörterte. Quandt beschrieb die Gemäldegalerien aller Länder als »Sammlungen von Gemälden, $[. .$.$] welche über die Cultur u Sinnesweise verschie-$ dener Völker u Zeitalter oft die hellsten Blicke aufschließ $[\mathrm{en}] \mathrm{u}$ das klarste Verständnis eröffne $\lceil n]$. Auch benützte man Gemäldesammlungen als Mittel zur Volksbildung. Denn gewiß ist der Sinn für das Schöne die Blume aller geistigen Entwicklung.» Die Konservierung der Gemäldegalerie sei nichts weniger als die »Quelle der Belehrung für Künstler u der Geistescultur der
6 Quandt 1842, S. 11: »Ich bitte mir zu vergönnen, meine allgemeinen Ansichten über Wiederherstellung alter Gemälde hier aussprechen zu dürfen, wo sich dann die Anwendung auf das Einzelne leicht machen lässt. « Die dazugehörige Anm. 9, S. 20 verweist auf Lexika zur Restaurierung. Quandt hat aber anscheinend die Abnahme eines Gemäldes von einer Leinwand und Aufziehen auf eine neue Leinwand bei einem ihm bekannten Restaurator - wenigstens durch Anschauung - gelernt Er beschreibt sie ebd., S. 22-23. Zudem rezensierte er Restaurierungs- literatur; Quandt 1828 (1), S. 33; Quandt 1829 (3), Nr. 155, Sp. 593-600; Schölzel 2012, S. 177. Verschiedene Bücher über Restaurierung in seiner Bibliothek: Kat. Quandt 1860 (1), S. 193.

7 Zu den Diskussionen um die Restaurierung im frühen 19. Jahrhundert und weiteren Kritikern an den Zuständen der Gemälde siehe Schölzel 2012, S. 131-147. Goethe äußerte sich auch mehrfach über den Zustand in Dresden; siehe Rudloff-Hille 1972-1975, S. 55-62. 
Menschen im allgemeinen. $\ll^{8}$ Damit appellierte er an die Staatsverantwortung des Königs, sich der Probleme dieser volksbildenden Institution anzunehmen.

Quandt hegte jedoch erst nach dem Tod von Friesen echte Hoffnungen auf Veränderung, wie er in einem Brief an den Berliner Bildhauer Christian Daniel Rauch berichtete. Zu viele Künstler und Inspektoren hätten bis anhin versichert, es seien keine Maßnahmen zu treffen. Im Januar 1824 äußerte er gegenüber Rauch, der römische Restaurator Pietro Palmaroli würde nach Dresden berufen, um den Zustand der Gemälde in Dresden zu begutachten. Quandt hatte den Namen des Italieners in die Diskussion eingebracht, weil er ihn von seinen Italienreisen kannte und seine Restaurierungsarbeit wertschätzte. ${ }^{9}$ Mit guten Argumenten und einem starken Netzwerk vermochte er 1826 die Berufung dieses weithin gerühmten Restaurators nach Dresden durchzusetzen. ${ }^{10}$ Die Anstellung des Italieners war von einer Polemik in den Kunstzeitschriften begleitet und wurde sogar in der im ganzen deutschsprachigen Raum vertriebenen, täglich erscheinenden Allgemeinen Zeitung aufgegriffen. Besonders die Restaurierung der Sixtinischen Madonna von Raffael löste einen Expertenstreit aus. Der Dresdener Inspektor der Gemäldegalerie Johann Friedrich Matthäi, Karl Friedrich von Rumohr, einige Berliner Restauratoren und später auch Johann David Passavant äußerten sich gegen Palmaroli. Quandt verteidigte ihn vehement und erhielt Unterstützung von deutschen Künstlern in Rom, dem preußischen Hofmaler Karl Wilhelm Wach, dem Berliner Bildhauer Christian Daniel Rauch, dem
Sekretär der Königlichen Akademie der Künste, Ernst Heinrich Toelken, dem Verfasser der Geschichte der neueren deutschen Kunst, Athanasius Graf Raczyński und von Sulpiz Boisserée."

Quandts Aktivitäten im Restaurierungswesen gehen einher mit einer Aufwertung der Restaurierung als eigenständiger Disziplin. Ihre Techniken wurden bis anhin zumeist innerhalb der Ateliers weitergegeben, publik wurden die Arbeiten kaum. Die polemisch geführte Diskussion um die Restaurierung der Sixtinischen Madonna durch Palmaroli zeigt eine Verschiebung auf, die das restaurierte Kunstwerk in den Fokus öffentlichen Interesses rückt. Die Restauratoren traten in den Blickpunkt, weil sie als Konservatoren der bedeutenden Kunstwerke agierten. Dank ihrer Arbeiten erhielt Kunst Dauerhaftigkeit und somit dauerhafte Wirkmacht. Das Engagement Quandts ist in diesem Kontext zu verstehen. Entsprechend beschrieb es Julius Hübner in seinem einleitenden Rückblick auf die Galeriegeschichte im Galeriekatalog von 1856, wo er hervorhob, dass Quandts Aufsätze »mit all der Wärme geschrieben sind, welche den für die Galerie ächt patriotisch besorgten, trefflichen Mann bezeichnet. «² Ähnlich positiv äußerte sich Sulpiz Boisserée, der Quandts leidenschaftlichen Einsatz lobte und die neuste Publikation von Christian Köster, Über die Restauration alter Oelgemälde von 1827, kritisierte, weil sie ohne Kenntnis von Quandts Aufsätzen über Restaurierung geschrieben worden sei..'3 Quandt selber begrüßte die Entwicklungen im Restaurierungswesen und die Publizität der Konservierungspraxis. Dennoch gehörte seiner Ansicht nach nicht nur Kenntnis der

1842, S. 3, 12-16, 19-24; Quandt 1856, S. 82. S. a. den Bericht Matthäis vom 3.8.1831, in: HStADD, Akten der Generaldirektion der Königlichen Sammlungen, Cap. VII. Nr. 15, Acta die Gemälde-Gallerie betr., 18311833, fol. 70ff. (Kriegsverlust). Abschrift in: HStADD, 13458 SKD, NL Posse, Nr. 30, Lage 7, fol. 5v-6v; Raczyński 1836-1841, Bd. 2, S. 664, Bd. 3, S. 214-215; Kat. Dresden 1856, S. 59-61; Schäfer 1860, S. 99-103, 197-199; Schnorr 1898, Jg. 7, Nr. 1, S. 85. Rauchs Unterstützung geäußert in zwei Briefen an Quandt vom 25.3.1824, in: SLUB, Mscr. Dresd., App. 70 und 25.8.1827, in: Nürnberg, Historisches Archiv des Germanischen Nationalmuseums, Autographen K. 27. Zu Sulpiz Boiserée siehe seinen Brief an Quandt, nicht datiert [Poststempel: Stuttgart, 16.5.1827], in: Krakau, Biblioteka Jagiellonska, Autographen Sammlung, Boisserée [vor 1945 Sammlung Autographa der Preußischen Staatsbibliothek Berlin]. Ausführlich über den Expertenstreit Schölzel 2012, S. 172-177.

12 Kat. Dresden 1856, S. 59. S. a. Friesen 1880, S. 316.

13 Boisserée bat Quandt um Zusendung seines Aufsatzes über Palmaroli. Es handelt sich um Quandt 1827 (1): »Die mit Eigenthümlichkeit und Geist geschriebene kleine Schrift über Restauration alter Oelgemälde von Köster (Heidelberg 1827) wird Ihnen wohl schon zu Gesicht gekommen seÿn [...]. Es ist recht schade, daß er Ihre Nachricht nicht gekannt hat, er hätte Ihnen in den höchsten Ehren gedenken müßen.« Brief vom 16.5.1827, in: Krakau, Biblioteka Jagiellonska, Autographen Sammlung, Boisserée [vor 1945 Sammlung Autographa der Preußischen Staatsbibliothek Berlin]. Quandt rezensierte Kösters Arbeit: Quandt 1828 (1), Nr. 9, S. 33-34. Zur Aufwertung des Restaurierungswesens besonders in Dresden und zur erwähnten Schrift Kösters siehe Schölzel 2012, S. 177-180. 
Theorie und Erfahrung dazu, sondern auch künstlerisches Talent. »Der Restaurator muß wie der Maler Farbensinn haben, er muß Colorist u ein wahrer Künstler seÿn.« Wenn Schmutz und Dreck oder vergilbte Firnisse entfernt würden, müsse der Restaurator die Farben des Gemäldes wieder aufeinander abstimmen können. ${ }^{14}$

1842 publizierte Quandt mit der Schrift Über den Zustand der königlichen Gemäldegalerie zu Dresden eine programmatische Schrift »für wahre Freunde der Kunst «.5 Der Kunstfreund veröffentlichte hier einige wichtige Texte der Galeriekommission. Man kann darin eine Auswahl der aus seiner Sicht wichtigsten Errungenschaften sehen, die er persönlich in der Galerie angeregt oder durchgesetzt hatte. Sein Ziel dieser kleinen Quellenanthologie war es, den zögernden politischen Institutionen den Grund für einen Museumsneubau zu liefern. »Als der Landtag herannahte und ich die Unentschloßenheit sah, ob ein Antrag wegen Baus eines neuen Museums an die Stände gerichtet werden sollte, wovon doch die Erhaltung unserer Kunstschätze abhängt, trug ich aus den Acten des Oberkämmereiarchivs zusammen was sich auf diese Gegenstände bezieht u ließ es drucken. ${ }^{16}$

Rückblickend stellte Quandt fest, dass der Staat vor 1837 die Erhaltung der Gemäldegalerie sträflich vernachlässigt habe. Es sei erst der Staatsminister Bernhard August von Lindenau gewesen, der die staatliche Verantwortung wahrgenommen habe. Tatsächlich legte Lindenau mit einem umfassenden Plan zur Reorganisation der Gemäldegalerie im September 1830 die Grundlage für Veränderungen. Er beanstandete den fehlenden Raum für die zahlreichen Gemälde, ihre unsystematische Anordnung, verlangte die Hängung nach Schulen und eine bessere Beleuchtung der Räume. Für die Umsetzung dieser Forderungen stellte er sich eine Kommission vor, der unter anderen auch Quandt angehören sollte. Schließlich wollte er eine vaterländische Galerie einrichten und »statt der jetzt darinnen befindlichen ganz verschoßenen $\mathrm{u}$ abgenützten grün seidenen Tapezierung mit rothem Zeug [bespannen], da nach allen neueren Erfahrungen

14 Brief von Quandt an Schnorr vom 4.6.1846, in: SLUB, Mscr. Dresd. n Inv. 15 Bd. 31, fol. 257v-258r. Quandt setzte sich bei Restaurierungen dafür ein, dass Bilder möglichst den ursprünglichen Zustand eines Gemäldes zurückerhielten. Damit sprach er sich gegen den so genannten Galerieton aus, der durch die vergilbte Patina bedingt war und von einigen Kennern als ursprünglich angesehen wurde. Quandt jedoch wollte den Kunstgenuss nicht trüben; Quandt 1842, S. 6. S. a. Schölzel 2012, S. 201.

15 So lautet der Zusatztitel von Quandt 1842. S. a. Schölzel 2012, S. 238; Marx 1992 (2), S. 13-14.

16 Brief von Quandt an Schnorr vom 21.1.1843, in: SLUB, Mscr. Dresd. Inv. 15 Bd. 31, fol. 223r.

17 Vortrag des Ministers v. Lindenau über die Gemäldegalerie, 5.9.1830, in: HStADD, Akten der Generaldirektion der Königlichen Sammlungen, Cap. VII Nr. 14, Acta die Gemälde-Gallerie betr., 1825-1830 (Kriegsverlust). Abschrift in: HStADD, 13458 SKD, NL Posse, Nr. 30, Lage 6, fol. 7v-9r. diese Farbe für eine Bilder-Gallerie die geeignetste ist. $\ll^{17}$ Lindenau bezog mit diesen Vorschlägen Position als gerade erst neu angetretener Vorsteher der Kunstsammlungen. Der Minister zeigte sich offen gegenüber den Forderungen der Kunstkenner. Es ist anzunehmen, dass ihm einige von ihnen die besten Argumente zuspielten - wie Quandt, bei dem Lindenau zu diesem Zeitpunkt wohnte. Umgesetzt wurde nicht alles, doch die Reorganisationen nicht nur der Gemäldegalerie, sondern der gesamten Kunstsammlungen überhaupt, nahmen ihren Lauf. ${ }^{18}$

\section{Gründung und Arbeit der Galeriekommission}

Lindenau gründete 1834 eine Kommission, welche die Bilder aus dem so genannten »Vorrat« der königlichen Gemäldesammlung im Brühl'schen Palais, der Doublettengalerie, revidieren sollte. Quandt war Mitglied dieser Expertengruppe. Ihr Gutachten führte dazu, dass die Doublettengalerie aufgehoben, eine größere Anzahl an Gemälden restauriert und in das Stallgebäude überführt wurde.19 Aus dieser Expertengruppe erwuchs Ende 1836 die Galeriekommission. Entscheidend für ihre Gründung waren jedoch äußere Umstände. Zahlreiche Experten wie Quandt, die Berliner Aloys Hirt und Gustav Friedrich Waagen, Direktor der Berliner Gemäldegalerie, aber auch die Schriftsteller Ludwig Tieck und Athanasius Graf Raczyński hatten sich negativ über den Zustand der Bilder geäußert. Ausschlaggebend war schließlich ein Artikel von Waagen in der Leipziger Zeitung, nachdem Lindenau in der Ständeversammlung intensiv um Unterstützung geworben hatte. ${ }^{20}$ Die ersten Mitglieder waren die drei Künstler Ferdinand Hartmann, der den Vorsitz übernahm, Galeriedirektor Johann Friedrich Matthäi und Carl Ludwig Vogel von Vogelstein sowie die beiden Kunstkenner, der Literaturwissenschaftler und Oberhofmarschall Hermann Freiherr von Friesen und Quandt. Das Gremium, bestehend aus Künstlern und Kunstkennern befasste sich im weitesten Sinn mit konser-

18 In der Gemäldegalerie wurden 1831 bauliche Maßnahmen wie die neue Wandbespannung, Erhöhung der inneren Galerie, Aufstellen eiserner Abschrankungen und Abänderungen an den Bilderrahmen abgeschlossen. Vortrag an S. Kgl. Maj. über die in der Gemäldegallerie stattgefundenen Veränderungen u baulichen Einrichtungen, 8.11.1831, in: HStADD, Akten der Generaldirektion der Königlichen Sammlungen, Cap. VII. Nr. 15, Acta die Gemälde-Gallerie betr., 1831-1833 (Kriegsverlust). Abschrift in: HStADD, 13458 SKD, NL Posse, Nr. 30, Lage 7, fol. 1V-2r.

19 Johann Friedrich Matthäi, Jahresbericht 1835 vom 23.1.1836, in: HStADD, Akten der Generaldirektion der Königlichen Sammlungen, Cap. VII. Nr. 29, Acta die königl. Gemälde-Gallerie betr., 1836-1839 (Kriegsverlust). Abschrift in: HStADD, 13458 SKD, NL Posse, Nr. 30 , Lage 8, fol. 1v. Schölzel 2012, S. 187-193; Schäfer 1860, S. 104-105. Schäfer zitiert hier längere Passagen aus nicht identifizierten Schriften Quandts.

20 Kaiser 2017, S. 231; Schölzel 2012, S. 196-197; Friesen 1880, S. 323; Raczyński 1836-1841, Bd. 3, S. 214. 


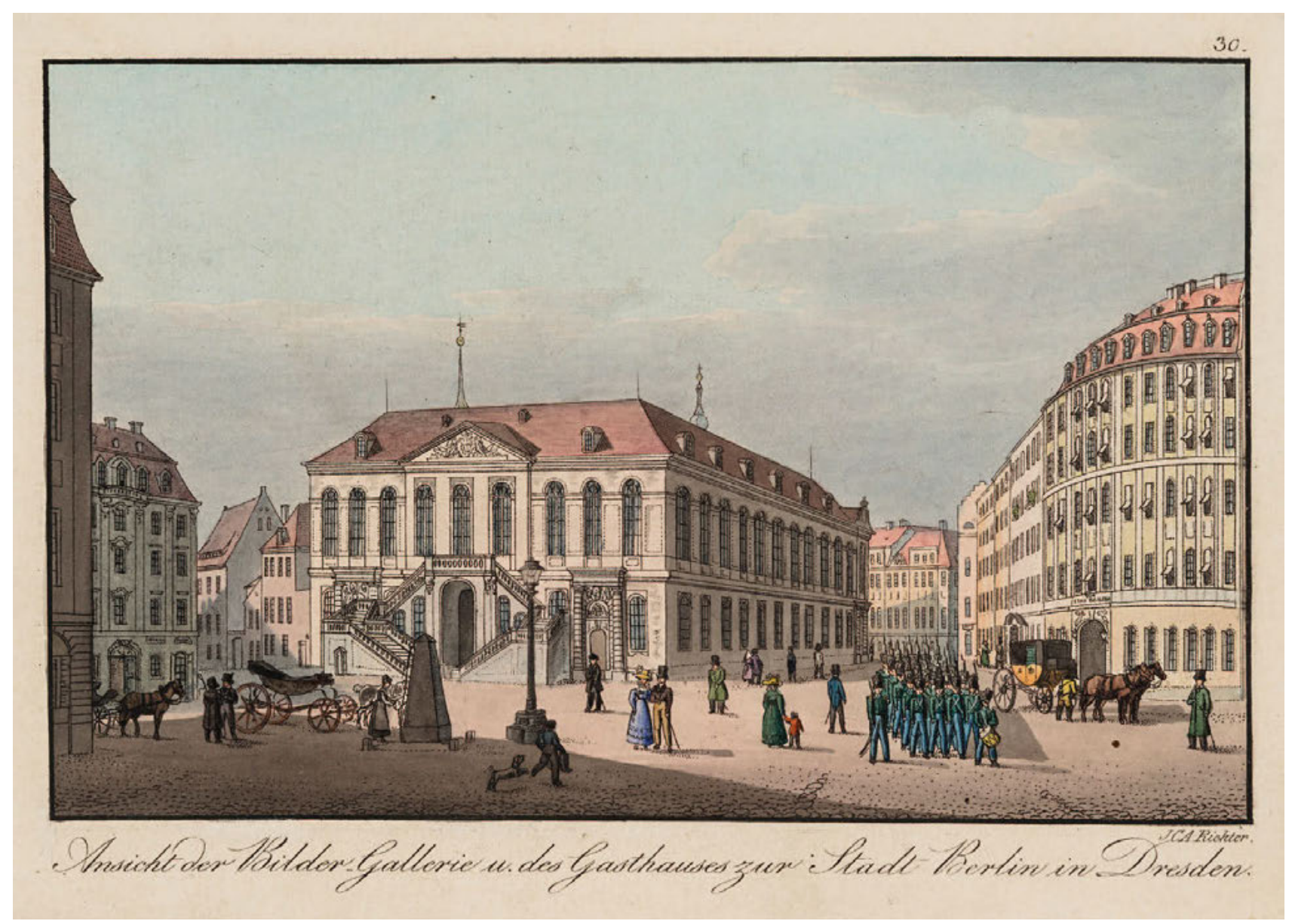

84 Johann Carl August Richter, Ansicht der Bilder-Gallerie u. des Gasthauses zur Stadt Berlin in Dresden, um 1840, Radierung, koloriert, $114 \times 167$ mm (Platte), Dresden, SKD, Kupferstichkabinett, Inv.-Nr. A 1995-4297

vatorischen Maßnahmen in der Gemäldesammlung, was hauptsächlich Restaurierungs- und Präsentationsmaßnahmen beinhaltete. Es traf die Auswahl der zu restaurierenden Gemälde, erstellte Protokolle über den Erhaltungszustand, begutachtete wöchentlich die laufende Tätigkeit des Restaurators und beurteilte schließlich das Ergebnis. Für die Erhaltung der Gemälde erhoffte man sich durch das »Zusammenwirken von Kunstkenner, Künstlern und Restaurateur eine bedeutende Bürgschaft «.2

In einer ersten Phase der Arbeiten wurden die klimatischen Verhältnisse im Gebäude beurteilt. Besonders Quandt und Friesen setzten sich von Anfang an vehement für den Bau eines

21 Laut einer Korrespondenz zwischen der Herzoglichen Galerie Gotha und der Dresdener Galerie über die Aufgaben der Restauratoren; zitiert nach Schölzel 2012, S. 209; Quandt 1842, S. 4-5. Ein undatiertes und unvollendetes Konzept über die Geschichte der Galeriekommission, wahrscheinlich von Friedrich Nollain, entstanden um 1846/47 befindet sich in Jahresbericht 1841 vom 14.2.1842, in: HStADD, Akten der Generaldirektion der Königlichen Sammlungen, Cap. VIIa, Nr. 5 , Jahresberichte 1837-1842 (Kriegsverlust). Abschrift in: HStADD, 13458 SKD, NL Posse, Nr. 30, Lage 10, fol. 8r-v. Zur Tätigkeit der Galeriekommission in ihren Anfängen siehe Schölzel 2012, S. 196-207. Über neuen Museums ein, denn sie glaubten, der Verbleib im alten Haus am Jüdenhof würde den Zustand der Gemälde nur verschlechtern. Doch »die nach damaligen Begriffen zaghafte Finanzverwaltung betrachtete ein solches Ansinnen ungefähr im Lichte eines utopischen Gedankens.« Der König schlug einen Kompromiss vor. Es sollte begutachtet werden, ob ein kleineres Museum für die besten Gemälde errichtet werden und die zweite Garde im alten Gebäude verbleiben könnte. Rasch entfernte man sich von diesem Gedanken, weil man die Sammlung nicht aufteilen wollte. ${ }^{22}$ Ein Neubau sollte bis auf weiteres nicht möglich sein. die Aufgabenteilung zwischen Kommission und Restauratoren ebd., S. 287-288. S. a. Marx 1992 (1), S. 93-94; Marx 1992 (2), S. 31. Vogel von Vogelstein trat schon 1840 wieder aus der Galeriekommission aus und vertraute Lindenau an, dass dies mit dem »übereilten willkürlichen Treiben und Anordnungen des HE v. Quandt« zu tun hatte. Zitiert nach Schölzel 2012, S. 210 nach einem Tagebucheintrag Vogel von Vogelsteins. Er wurde mit Julius Hübner ersetzt.

22 Friesen 1880, S. 323-325, hier S. 324. Zur Arbeit der Kommission und Quandts Berufung siehe auch Heres 2005/06, S. 721; Heinrich 2002, S. 9; Heres 1987, S. 45; Schnorr 1888, S. 12; Quandt 1842, S. 4-5. 
Vor diesem Hintergrund begutachteten die Kommissionsmitglieder die Sammlung. Im Januar und Februar 1837 wurden die Besichtigungen in der Gemäldegalerie protokolliert. Quandt - überzeugt von der Notwendigkeit von Veränderungen - lieferte das erste Protokoll schon Ende Januar. Er verwies auf die klimatischen Probleme und den Steinkohleruß im Galeriegebäude. Er diskutierte notwendige Restaurierungen und die hierfür geforderten Techniken und verlangte die Einstellung mehrerer Restauratoren. Der hohe Kostenaufwand könne gar nicht in Betracht gezogen werden, weil die Konservierung der Gemälde dringend notwendig sei. ${ }^{23}$ Quandts Expertise, die Einzelgutachten der anderen Kommissionsmitglieder sowie eine gemeinsame Stellungnahme des Gremiums flossen in die Entscheidungsfindung Lindenaus ein. Die Sammlungsrevision durch die Galeriekommission führte zwar trotz mehrfach geäußertem Wunsch zu keinen baulichen Veränderungen, doch Lindenau vermochte im Frühjahr 1837 erhebliche Verbesserungen durchzusetzen. ${ }^{24}$ Vor allem wurden weitere Restaurierungsgehilfen angestellt und damit die Anzahl gereinigter Bilder deutlich gesteigert. In der Folge entpuppte sich dieses Jahr für das Restaurierungswesen als derart erfolgreich, dass die Öffentlichkeit mit einem Artikel in der Leipziger Zeitung vom 16. Januar 1838 über die bearbeiteten Gemälde und die erfolgreiche Arbeit der nur ein Jahr zuvor gegründeten Galeriekommission informiert wurde. Hierauf folgte im April eine öffentliche Ausstellung der frisch bearbeiteten Werke. ${ }^{25}$

Die folgenden Jahre waren weiterhin von Restaurierungsarbeiten geprägt. ${ }^{26}$ Die Frage der Verbesserung des alten Galeriegebäudes blieb offen. Im Jahr 1839 begutachtete die Kommission die Gemälde noch einmal im Hinblick auf ein neues Gebäude. 1840 sollte sie prüfen, wie die Fenster besser abgedichtet werden könnten, um das Eindringen von Kohlestaub zu vermindern. Zudem sollten die mit Damast bezogenen Wände mit Papier abgedeckt werden, weil daran der Ruß weniger gut haften konnte. Quandt betonte im Protokoll zur beratenden Sitzung der Kommission vom 15. Februar 1840, die Versuche

23 Quandts Gutachten vom 29.1.1837, in: Quandt 1842, S. 10-12, 16. Teile des Gutachtens sind in einer Paraphrase von Hans Posse überliefert: HStADD, Akten der Generaldirektion der Königlichen Sammlungen, Cap. VII. Nr. 30, Acta die höchsten Orts anbefohlene commissarische Untersuchung des Zustandes der Gemälde in der königl. Galerie betr., 1837 (Kriegsverlust). Abschrift in: HStADD, 13458 SKD, NL Posse, Nr. 30, Lage 9, fol. 2v-3r.

24 HStADD, Akten der Generaldirektion der Königlichen Sammlungen, Cap. VII. Nr. 30, Acta die höchsten Orts anbefohlene commissarische Untersuchung des Zustandes der Gemälde in der königl. Galerie betr., 1837 (Kriegsverlust). Abschrift in: HStADD, 13458 SKD, NL Posse, Nr. 30, Lage 9, fol. 1r-8v. Schölzel 2012, S. 122-124, 199-207 liefert einen detaillierten Bericht über die verbesserten Möglichkeiten, die Lindenau anhand der Argumente in den Gutachten der Galeriekommission durchzusetzen vermocht hatte. jeglicher Optimierungen am alten Galeriegebäude seien reine Symptombekämpfung, es müsse ein neues Museum her. Zudem wiege man sich in falscher Sicherheit, wenn man auf ausbleibende Großbrände im vergangenen Jahrhundert verweise: »Es ist dies eine Beruhigung, wie die, durch welche sich Seiltänzer Muth einreden: da ich noch nicht den Hals gebrochen habe, so werde ich nicht verunglücken. $\ll^{27}$

Die Tätigkeiten der Galeriekommission fasste Quandt in seinem Zustandsbericht der Gemäldegalerie von 1842 zusammen. ${ }^{28}$ Kernpunkt ihrer Arbeit war die Restaurierung schadhafter Gemälde. Seit der Gründung der Kommission bis Ende 1841 waren 555 Gemälde konserviert worden. Dies sei zwar nur ein Viertel der Sammlung, so Quandt, »allein man wird so wohl mit der materiellen Thätigkeit der Restauratoren, als dem Eifer der Commission, der Galerie zu Hülfe zu kommen, sehr zufrieden seyn [...].« Zudem erscheine die Anzahl restaurierter Gemälde entsprechend höher, wenn man bedenke, dass »die Hälfte der jetzt vorhandenen Gemälde nur unbedeutende Bilder sind. $\ll^{29}$ Quandt sah die Arbeit der Kommission als Sisyphusarbeit an, da die Verunreinigungen durch Staub und Ruß sich bereits nach fünf Jahren auf gereinigten Werken sichtbar niederlasse. Er betonte den aufgeblähten Kostenaufwand, den die alle paar Jahre wiederkehrenden Reinigungen von Gemälden verursachen würden, nur weil kein gutes Galeriegebäude zur Verfügung stehe. Auch würden die Kunstwerke unter mehrfacher Restaurierung leiden, so dass man sich fragen müsse, wie viel Malerei nach fünfzig Jahren noch übrigbliebe. Man habe zum gröbsten Schutz der wichtigsten Stücke Glas, trotz aller Nachteile bei der Betrachtung, verwenden müssen: »Dies Verglasen ist immer nur in der traurigen Lage das einzige letzte Mittel. « $3^{\circ}$

Weil ein neues Gebäude vorerst nicht in Aussicht war, nahm man sich in der Kommission der optimalen Präsentation der Gemälde und verbesserten Galerierundgängen an. Quandt hatte dazu den Aufstellungsplan geliefert, den Direktor Matthäi mit seinen Gehilfen umzusetzen hatte. Diese neue Aufstellung manifestiert sich im Galeriekatalog von $1843^{31}$

25 Quandt 1842, S. 51; Schölzel 2012, S. 206-207. S. a. Marx 1992 (2), S. 12; Schäfer 1860, S. 106

26 Schölzel 2012, S. 207-227.

27 Quandt 1842, S. 48-50, Zitat S. 49. Jahresberichte 1840/41, in: HStADD, Akten der Generaldirektion der Königlichen Sammlungen, Cap. VIIa, Nr. 5, Jahresberichte 1837-1842 (Kriegsverlust). Abschrift in: HStADD, 13458 SKD, NL Posse, Nr. 30, Lage 10, fol. 5 r-v. S. a. Schölzel 2012, S. 207; Marx 1992 (2), S. 10; Schäfer 1860, S. 107-108.

28 Quandt 1842, S. 51-62. S. a. Schäfer 1860, S. 108.

29 Quandt 1842, S. 55.

30 Quandt 1842, S. 58-59. S. a. Kat. Dresden 1856, S. 61-62.

31 Quandt 1842, S. 60: „Da die Hoffnung zu einem neuen Museum verschwunden war, so fasste die Commission den Entschluss, sich zu einer bessern Aufstellung der Gemälde in dem zwar untauglichen alten Lokale zu bequemen und ich muss die Bereitwilligkeit anerken- 


\section{Gewonnene Wissenschaftlichkeit, verlorene Übersichtlichkeit}

Die Umhängung in der Gemäldegalerie am Jüdenhof anfangs der 1840er Jahre basierte auf wichtigen früheren Präsentationen der 183oer Jahre, an denen Quandt ebenfalls beteiligt gewesen war. Für das Verständnis der Ausstellung von 1843 ist ein Blick zurück unumgänglich. Eine erste Mitarbeit Quandts ist bereits für das Jahr 1830 nachweisbar. Die Generaldirektion der Kunstsammlungen hatte damals die Leitung der Gemäldesammlung beauftragt, in der inneren Galerie, in der die italienischen Gemälde ausgestellt waren, Trennwände einzuziehen und die Wände neu zu tapezieren. Durch die von Joseph Thürmer und dessen Nachfolger Gottfried Semper eingefügten Scherwände wurde neuer Raum geschaffen für Gemälde aus der Doublettengalerie im Brühl'schen Palais, die frisch restauriert in das Museum am Jüdenhof gekommen waren. Die gewonnene Hängefläche ermöglichte aber auch die wissenschaftliche Präsentation der Gemälde, die davor vor allem nach ästhetischen Kriterien präsentiert worden waren..$^{32}$ Auf Vorschlag Lindenaus sollten Friedrich Matthäi, der Maler und Akademieprofessor Ferdinand Hartmann und Quandt die italienischen Gemälde neu ordnen..$^{33}$ Damit entsprach man den Forderungen progressiver Kunstkenner, welche die unwissenschaftliche Ordnung

nen, mit welcher sich der Galeriedirector Herr Prof. Mattäi der großen Arbeit unterzog, die Gemälde nach den von mir aufgestellten Grundsätzen, umzuhängen.« Kat. Dresden 1843. Über diese maßgebliche Beteiligung berichtet Quandt in einem Brief an Schnorr am 1.1.1841, in: SLUB, Mscr. Dresd. n Inv. 15, Bd. 31, fol. 213r-214v. S. a. Quandt 1842, S. 20, 60-61. S. a. Schölzel 2012, S. 207.

32 Schölzel 2012, S. 191; Schäfer 1860, S. 104-105; Kat. Dresden 1856, S. 62 ; Quandt 1842, S. 60; s. a. ebd., S. 25-26, 48, 55. Der Galerieinspektor Johann Friedrich Matthäi begann schon mit den Neuhängungen von 1825 die Gemäldesammlung nach chronologischen und kunsttopographischen Kriterien zu ordnen; Schölzel 2012, S. 154; Marx 1992 (2), S. 12-13.

33 Rescript vom 22.9.1830, in: HStADD, Akten der Generaldirektion der Königlichen Sammlungen, Cap. XV. Nr. 18, Generaldirektion Kunstsammlungen (Kriegsverlust), fol. 120. Abschrift in: HStADD, 13458 SKD, NL Posse, Nr. 29, Lage 3, fol. 10r; Vortrag des Ministers v. Lindenau über die Gemäldegalerie, 5.9.1830, in: HStADD, Akten der Generaldirektion der Königlichen Sammlungen, Cap. VII Nr. 14, Acta die Gemälde-Gallerie betr., 1825-1830 (Kriegsverlust). Abschrift in: HStADD, 13458 SKD, NL Posse, Nr.30, Lage 6, fol. 7v-8r, 9r; Brief von Quandt an Schnorr vom 3.1. und 13.5.1831, in: SLUB, Mscr. Dresd. n Inv. 15, Bd. 31, fol. 175v, 178r; s. a. Schölzel 2012, S. 187-191; Weddigen 2008, S. 219; Briel 2002, S. 16; Quandt 1846 (1), S. 33; Quandt 1842, S. 60-62.

34 Quandt 1816 (1), S. 843 hatte schon betont, dass eine chronologische Hängung die Mannigfaltigkeit gleichzeitig schaffender Meister am besten darlegen würde. Diese Haltung relativierte sich bei ihm im Laufe der Jahre hin zu der Forderung einer kombinierten Präsentation nach Chronologie und Kunsttopographie. S. a. Weddigen 2008, S. 8698, 193-208; Penzel 2007, S. 34-48; Savoy 2006, S. 16-20. Zur Kritik an den Hängungen im 19. Jahrhundert siehe Pilz 2006, S. 154-157; Marx 1992 (2), S. 12-13.

35 Brief vom 13.5.1831, in: SLUB, Mscr. Dresd. n Inv. 15, Bd. 31, fol. 178r. 36 Brief von Quandt an Rochlitz vom 3.4.1832: „Was die Gallerie betrifft, so beanstandeten und eine Hängung nach chronologischen oder kunsttopographischen Kriterien forderten. ${ }^{34}$ Quandt schrieb hierüber seinem Freund Julius Schnorr von Carolsfeld: »Wenn man die Bilder zu ordnen anfängt, sieht man welche erstaunlichen Meisterwerke wir besitzen, fühlt aber auch, wie viele Meister uns ganz fehlen $\mathrm{u}$ darum ist eine sÿstematische Aufstellung ganz unmöglich, so sehr es auch zu wünschen wäre, daß in einer Gallerie der Entwicklungsgang der Kunst sich darstellen möchte. «35 Bereits 1832, wenn auch noch nicht in allen Belangen neu geordnet, waren die Sammlungsräume bereits wieder für Besucher zugänglich. ${ }^{36} 1833$ vollendete man die Hängung nach Schulen in der inneren Galerie und publizierte den neuen Katalog. ${ }^{37}$

Die Reorganisationen der ersten Hälfte der 1830er Jahre betrafen nicht nur die innere, sondern auch die äußere Galerie mit den Gemälden der deutschen und niederländischen Schule..$^{8}$ Quandt war auch daran beteiligt. ${ }^{39}$ Die Gemälde wurden ebenfalls nach Schulen präsentiert. Auch hier wurden Bilder aus der Doublettengalerie im Brühl'schen Palais integriert. Weil die insgesamt um 454 Kunstwerke angewachsene Sammlung mehr Raum benötigte, wurden Ende 1834 Scherwände in den nördlichen und südlichen Flügeln eingezogen, nicht aber in den westlichen und östlichen Langgalerien. ${ }^{40}$ In den so entstandenen Kabinetten wurden kleinere Formate präsentiert.

war solche, zwar noch in großer Unordnung, aber doch schon den Fremden voriges Jahr zugänglich. Es war unmöglich, alle italienische Gemälde, welche sich in Kammern u Winkeln vorfanden u zu den bereits bekannten Meisterwerken hinzukommen sollen, in einem Jahre, zu restauriren u einzuordnen, allein das Meiste $u$ Beste ist sichtbar $u$ Sie werden manche neue Bekanntschaft machen. Auch was nicht jedermann gezeigt werden kann soll Ihnen nicht vorenthalten werden, kommen Sie nur u genießen Sie in vollen Zügen. «SLUB, Mscr. Dresd. App. 1191, Nr. 577.

37 Johann Friedrich Matthäi, Jahresbericht für das Jahr 1833 vom 29.1.1834, in: HStADD, Akten der Generaldirektion der Königlichen Sammlungen, Cap. VII, Nr. 28, Acta die Gemälde-Gallerie betr. 1834-1835, fol. 8 (Kriegsverlust). Abschrift in: HStADD, 13458 SKD, NL Posse, Nr. 30 , Lage 7, fol. gr-v. Kat. Dresden 1833. S. a. Schölzel 2012, S. 188-191. Weddigen 2008, S. 203-206. S. a. Marx 1992 (1), S. 93.

38 Zur Einrichtung der inneren mit der italienischen, und der äußeren Galerie mit der deutschen und niederländischen Schule zum Zeitpunkt des Umbaus des alten Stallgebäudes 1744 bis 1746 siehe Weddigen 2008, S. 48-51; Heres 2006, S. 123-128.

39 Siehe dazu die Jahresberichte auf das Jahr 1835 und 1836, in: HStADD, Akten der Generaldirektion der Königlichen Sammlungen, Cap. VII. Nr. 29, Acta die königl. Gemälde-Gallerie betr., 1836-1839 (Kriegsverlust). Abschrift in: HStADD, 13458 SKD, NL Posse, Nr. 30, Lage 8, fol. 1 r2V (Jahresbericht 1835 vom 23.1.1836), fol. $3 \mathrm{r}-7 \mathrm{r}$ (Jahresbericht $1836 \mathrm{vom}$ 8/10.2.1837). S. a. das Gutachten von Matthäi zur Neuhängung vom 3.10.1833, in: ebd., fol. 9v-12r. S. a. Registratur über die Beratung zweckmäßigerer Aufstellung der Gemälde in der äußeren Abteilung der Gemäldegalerie, 17.9.1834, in: HStADD, Akten der Generaldirektion der Königlichen Sammlungen, Cap. VII, Nr. 28, Acta die Gemälde-Gallerie betr. 1834-1835, fol. 15 (Kriegsverlust). Abschrift in: HStADD, 13458 SKD, NL Posse, Nr. 30, Lage 7, fol. $9 v$.

40 In der zweiten Jahreshälfte 1834 waren die Gemälde aus der äußeren in die innere Galerie geräumt, die Wandbespannung erneuert und die 
Sofort wurde - nun von der konservativen Seite - Kritik laut, die den Verlust des alten Charakters der Galerie mit ihren mächtigen Sälen und symmetrisch geordneten Gemäldeflächen beklagte. Matthäi musste sich im Jahresbericht auf das Jahr 1835 entsprechend rechtfertigen und schrieb, wer »einen Beweis für die Zerstörung des imponirenden Eindrucks, welcher die Galerie früher machte, finden will: so darf man nur daran erinnern, daß drei Säle beibehalten worden sind, deren Eindruck gewiß nicht kleinlich genannt werden kann. $\ll^{41}$ Damit waren der lange Westund Ost-Saal der äußeren und der Saal mit den Venezianern der inneren Galerie gemeint. Weil die Forderung Lindenaus, einen Saal für die sächsischen Veduten Bernardo Bellottos und Alexander Thieles einzurichten, im Stallgebäude aus Platzgründen nicht umgesetzt werden konnte, eröffnete man eine Galerie der sächsischen Prospekte im Brühl'schen Palais. Die Umbauarbeiten dieser Phase dauerten bis zur Katalogpublikation $1837^{42}$

In diesem Jahr begannen die umfassenden Restaurierungsarbeiten an den Gemälden. Quandt kritisierte in seinem Gutachten zum Zustand des Galeriegebäudes nicht nur die klimatischen Bedingungen und Verschmutzungsprobleme, sondern auch die Art der Sammlungspräsentation. Die in den Neuordnungen von 1830 bis 1837 weiterhin angewendete, architektonisch-symmetrische Hängung beeinträchtige die wissenschaftliche Aufstellung nach Schulen und Chronologie.43 Trotz der Bemühungen um eine kunstwissenschaftliche Präsentation empfand er offenbar die althergebrachte Hängungsordnung, die in erster Linie die Einbindung nahezu aller Bilder der Sammlung zum Ziel hatte, als Problem.

Tristan Weddigen konnte diese Inkonsequenz der wissenschaftlichen Neuhängungen 1830 bis 1837, wie sie in den Katalogen von 1833,1835 und 1837 feststellbar werden, nachweisen. Man richtete sich weiterhin nach geschmacklichen Kriterien

Scherwände eingezogen worden; Jahresbericht auf das Jahr 1834 vom 31.1.1835 von Matthäi, in: HStADD, Akten der Generaldirektion der Königlichen Sammlungen, Cap. VII, Nr. 28, Acta die Gemälde-Gallerie betr. 1834-1835 (Kriegsverlust). Abschrift in: HStADD, 13458 SKD, NL Posse, Nr. 30, Lage 7, fol. 12r-v. Man hatte den benötigten Raum zuerst falsch berechnet und musste noch weitere Scherwände einbauen; Jahresbericht 1835 vom 23.1.1836 von Matthäi, in: HStADD, Akten der Generaldirektion der Königlichen Sammlungen, Cap. VII. Nr. 29, Acta die königl. Gemälde-Gallerie betr., 1836-1839 (Kriegsverlust). Abschrift in: HStADD, 13458 SKD, NL Posse, Nr. 30, Lage 8, fol. 1 r-2v.

41 Jahresbericht 1835 vom 23.1.1836, in: HStADD, Akten der Generaldirektion der Königlichen Sammlungen, Cap. VII. Nr. 29, Acta die königl. Gemälde-Gallerie betr., 1836-1839 (Kriegsverlust). Abschrift in: HStADD, 13458 SKD, NL Posse, Nr. 30, Lage 8, fol. 2 r.

42 Zur Einrichtung dieses Saales siehe HStADD, Akten der Generaldirektion der Königlichen Sammlungen, Cap. VII. Nr. 15, Acta die GemäldeGallerie betr., 1831-1833 (Kriegsverlust). Abschrift in: HStADD, 13458 SKD, NL Posse, Nr. 30, Lage 7, fol. 2r-v, 7v-8v; Gutachten Matthaeis, die Aufnahme von Werken vaterländischer Künstler bei der GemäldeGallerie betreffend, 6.10.1833, in: HStADD, Akten der Generaldirektion der Königlichen Sammlungen, Cap. VII, Nr. 28, Acta die Gemälde- des 18. Jahrhunderts und hängte die Gemälde symmetrisch in Abteilungen und Dimensionen. Eine Anzahl italienischer Gemälde verblieb in der äußeren Galerie, altbekannte, ästhetische oder inhaltliche Gegenstücke wurden weiterhin zusammengehalten, auch wenn sie einer Hängung nach Schulen entgegenwirkten. ${ }^{44}$ Matthäi hatte schon in einem Gutachten vom Oktober 1833 einschränkend beschrieben, dass in der inneren Galerie »der geistige u chronologische Zusammenhang der Werke nach der Periodenfolge uns zur Richtschnur diente, wir aber die geographische Beziehung nur in so weit berücksichtigten, als an einem oder dem anderen Orte in gleichem Sinn gearbeitet würde, gleichviel, wo die Künstler geboren waren, die hier wirkten.«45 Es war wohl dieser »geistige« Zusammenhang, der eine kunsthistorische Schulhängung erschwerte und die Beibehaltung alter Hängungsformen bedingte. Dennoch hatte man sich bemüht, einen kunsthistorischen Rundgang herzustellen, der dem roten Faden der Chronologie und Kunsttopographie zu folgen vermochte, wenn er sich auch nicht nach den Geburtsorten der Künstler richtete.

1835 trat man vom nordseitigen Stallhof her über eine Wendeltreppe in den ersten Saal (Raum A) der Franzosen ein (Abb. 85). Dieser war dem kunstgeschichtlichen Rundgang enthoben, weil er die Wettiner Kurfürsten und Könige von Polen, August den Starken und Friedrich August II., als Sammlungsgründer feierte. Das sächsische Königshaus hatte vornehmlich französische Hofkünstler des 18. Jahrhunderts angestellt, weshalb dieser eigentliche Wettiner Saal als Franzosensaal bezeichnet werden konnte. Erst dann begab man sich auf den kunsthistorischen Rundgang. Der Besucher konnte mit den älteren Deutschen und Niederländern (Raum B) beginnen und entweder den Flamen und Spaniern im Westflügel der äußeren (Räume G,H) oder, bei den Altitalienern (Raum Aa) beginnend,

Gallerie betr. 1834-1835 (Kriegsverlust). Abschrift in: ebd., fol. 11r-v; Die Jahresberichte auf das Jahr 1833 und 1834 von Matthäi, in: ebd., fol. $9 v$ (Jahresbericht 1833 vom 29.1.1834), fol. 11V-12r (Jahresbericht 1834 vom 31.1.1835) sowie den Jahresbericht auf das Jahr 1836 vom 8/10.2.1837, in: HStADD, Akten der Generaldirektion der Königlichen Sammlungen, Cap. VII. Nr. 29, Acta die königl. Gemälde-Gallerie betr., 1836-1839 (Kriegsverlust). Abschrift in: HStADD, 13458 SKD, NL Posse, Nr. 30 , Lage 8, fol. 5V-6r. S. a. Kat. Dresden 1837, S. VII-VIII. S. a. Schölzel 2012, S. 191-193; Weddigen 2008, S. 206-212.

43 HStADD, Akten der Generaldirektion der Königlichen Sammlungen, Cap. VII. Nr. 30, Acta die höchsten Orts anbefohlene commissarische Untersuchung des Zustandes der Gemälde in der königl. Galerie betr., 1837 (Kriegsverlust). Abschrift in: HStADD, 13458 SKD, NL Posse, Nr.30, Lage 9, fol. 2v. Zur architektonisch-symmetrischen Hängung siehe Weddigen 2008, S. 91-94.

44 Weddigen 2008, S. 207-208; Friesen 1880, S. 317.

45 Gutachten von Johann Friedrich Matthäi vom 3.10.1833, in: HStADD, Akten der Generaldirektion der Königlichen Sammlungen, Cap. VII, Nr. 28, Acta die Gemälde-Gallerie betr. 1834-1835, fol. 15 (Kriegsverlust). Abschrift in: HStADD, 13458 SKD, NL Posse, Nr. 30, Lage 7, fol. 10r. 


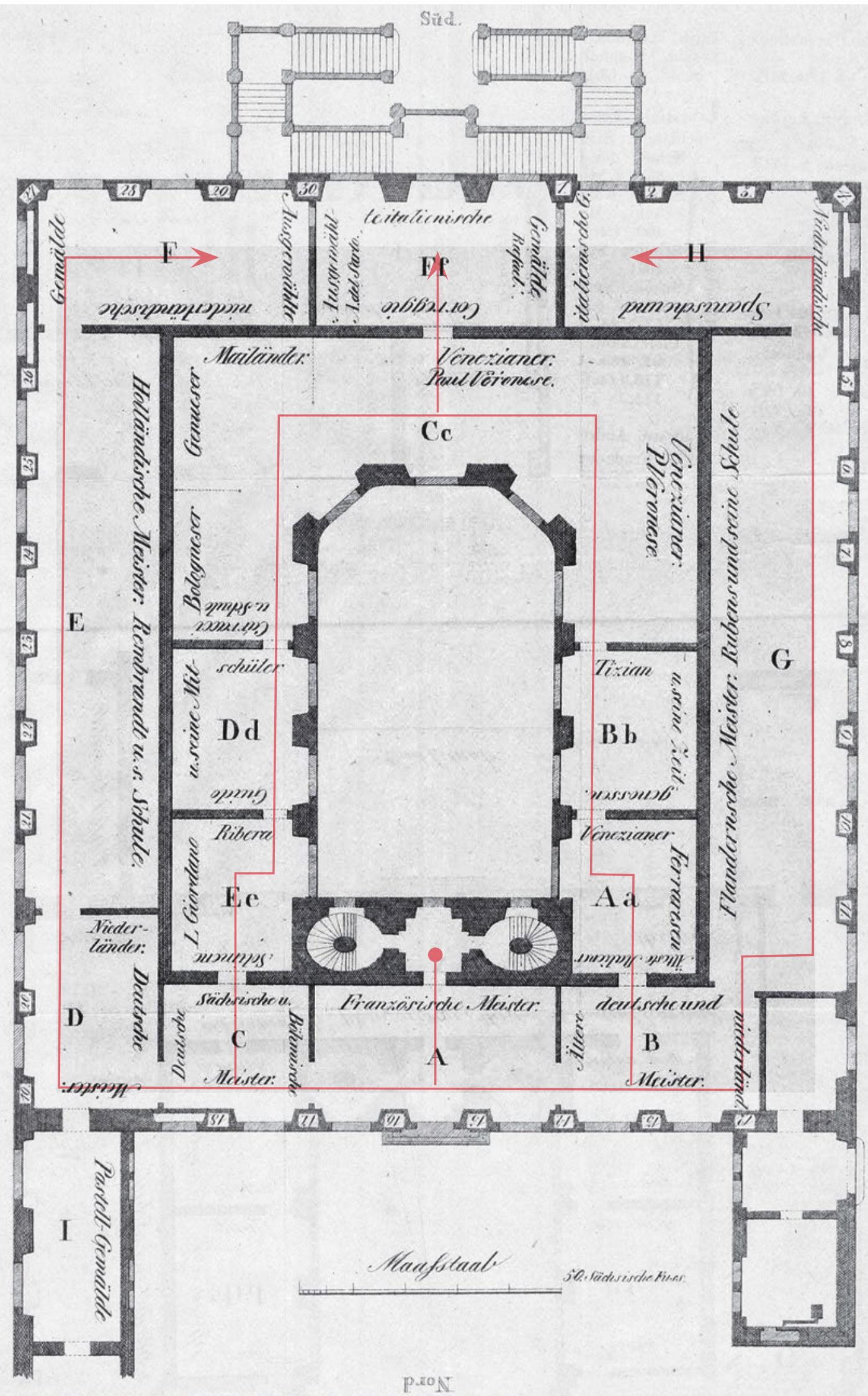

85 Schematische Darstellung des Rundgangs durch die Dresdener Gemäldegalerie, 1835 (Grundriss: Kat. Dresden 1835; Schema: Weddigen 2008, S. 527) 
der inneren Galerie entlang gehen. Eine dritte Variante war der Eintritt in den Ostflügel, wo die sächsischen und neueren deutschen Meister, sowie die holländischen Gemälde mit Schwerpunkt Rembrandt ausgestellt waren (Räume C-F), wobei der letzte Raum die besten holländischen und flämischen Bilder zusammenfasste. ${ }^{46}$

Der kunsthistorische Rundgang funktionierte in der inneren Galerie am besten, wenn man dem Buchstabensystem auf dem Plan im Katalog folgend von den älteren Italienern, Ferraresen und frühen Venezianer (Raum Aa) über den Tizian-Raum (Bb) zu den Venezianern des 17.Jahrhunderts, Mailänder und Bologneser schritt (Cc), danach an einer Wand mit Gemälden Annibale Caraccis vorbei in den Römer Raum mit Guido Reni (Dd) eintrat und mit dem Neapolitaner-Kabinett (Ee) einen Abschluss fand. Als Krönung des Rundgangs konnte man im von der inneren Galerie abgesonderten Südsaal (Ff) ausgewählte Italiener von Andrea del Sarto, Raffael und Correggio betrachten. Die Altarbilder Correggios bildeten hier den kostbaren Sammlungsschwerpunkt, Raffaels Sixtinische Madonna den geschmacklichen Höhepunkt. Dieser so genannte Raffaelsaal entzog sich allerdings durch seine herausgehobene Position im Grundriss und die vermischte Präsentation der Florentiner, Römer und Correggio-Schule dem kunsthistorischen Rundgang. ${ }^{47}$ Man verließ also entweder mitten in der Betrachtung von Veronese (Raum Cc) die Kunstgeschichte und vertiefte sich in die Betrachtung von Correggios »famosissima notte«, seiner berühmten Anbetung der Hirten, oder man schloss zu-

46 Kat. Dresden 1835, 1. Hauptabteilung, S. 123-150. Der Raum ausgewählter Niederländer war auf Wunsch des Prinzregenten eingerichtet worden; Gutachten von Matthäi zur Neuhängung vom 3.10.1833, in: HStADD, Akten der Generaldirektion der Königlichen Sammlungen, Cap. VII, Nr. 28, Acta die Gemälde-Gallerie betr. 1834-1835, fol. 28 (Kriegsverlust). Abschrift in: HStADD, 13458 SKD, NL Posse, Nr. 30, Lage 7, fol. 10r-v. Man schritt die Gemälde chronologisch rückwärts ab. Raum $F$ der ausgewählten Niederländer Gemälde lag unmittelbar neben dem Raffaelsaal Ff, was dem Anspruch des Ausgleichs der nördlichen und südlichen Kunst Rechnung trägt. Siehe hierzu Weddigen 2008, S. 213.

47 Da der Katalog nach den Neapolitanern zuerst allen Pfeilern (A-K) der Kunstgeschichte entlang zurückgeht, wird der kunsthistorische Rundgang etwas ad absurdum geführt, sofern man mit dem Buch der fortlaufenden Nummerierung folgt. Kat. Dresden 1835, 2. Hauptabteilung, S. 69-75 (Raum Ee), S. 76-84 (Pfeiler A-K der Räume Ee-Aa), S. 84-102 (Raum Ff). Der Grundriss ist dem Katalog am Ende beigegeben. S. a. Weddigen 2008, S. 212-213.

48 Zur »famosissima notte« siehe Kloppenburg/Weber 2000, S. 45-57, 81-88.

49 Jahresbericht 1837 vom 17.11.1837, unterzeichnet von Quandt, Friesen, Vogel und Matthäi, in: HStADD, Akten der Generaldirektion der Königlichen Sammlungen, Cap. VII. Nr. 29, Acta die königl. GemäldeGallerie betr., 1836-1839 (Kriegsverlust). Abschrift in: HStADD, 13458 SKD, NL Posse, Nr. 30, Lage 8, fol. 8v; Offizielle Beschlüsse vom März/ April 1837, in: HStADD, Akten der Generaldirektion der Königlichen Sammlungen, Cap. VII. Nr. 30, Acta die höchsten Orts anbefohlene commissarische Untersuchung des Zustandes der Gemälde in der erst den Rundgang ab und kehrte danach als Krönung zu Raffaels Sixtinischer Madonna zurück (vgl. Abb. 93-94).48

1837 wurde dieser Galerierundgang noch unübersichtlicher: Aus konservatorischen Gründen hatten Quandt und Friesen 1837 angeregt, den Raffaelsaal auf die Nordseite des Galeriegebäudes zu verlegen (Abb. 86). ${ }^{49}$ Der Saal mit ausgewählten italienischen Gemälden lag bis dahin im Südflügel am Jüdenhof, in welchem es durch die Mittagssonne sehr heiß werden konnte. So wurde der Raffaelsaal mit dem französischen Saal ausgetauscht. Zu diesem Zeitpunkt erhielten die Sixtinische $\mathrm{Ma}^{-}$ donna und andere empfindliche Gemälde gegen erheblichen Widerstand ein Schutzglas..$^{50}$

Doch weil dieser französische Saal vor allem Porträts der königlichen Begründer der Gemäldegalerie beinhaltete, sollte er weiterhin am Anfang des Parcours stehen und der Raffaelsaal weiterhin den Endpunkt des kunsthistorischen Sammlungsrundgangs darstellen..$^{51}$ Aus diesem Grund mussten die Eingänge vertauscht werden. Dies machte sich zwar bezahlt, denn der alte Eingang hatte über eine Treppe vom Stallhof her in die Galerie geführt, die »nach dem Zugang zu einem Keller glich $\ll .^{2}$ Der neue Eingang lag nun auf der Seite des Jüdenhofs und konnte durch eine zweiläufige Freitreppe erreicht werden.

Die Inspektoren der Galerie stellten prompt eine Zunahme der Besucherzahlen fest - ein wichtiges Argument für das Fernziel eines neuen Museumsbaus. ${ }^{53}$ Doch die Umänderung brachte den eigentlichen Parcours, der mehr oder weniger der kunsthistorischen Chronologie der Schulen gefolgt war, völlig durch-

königl. Galerie betr., 1837 (Kriegsverlust). Abschrift in: HStADD, 13458 SKD, NL Posse, Nr. 30, Lage 9, fol. 6r-7r; Quandt 1842, S. 11, 61; Friesen 1880, S. 330. S. a. Schölzel 2012, S. 200-201; Weddigen 2008, S. 213. Der Raffaelsaal in Kat. Dresden 1835, 2. Hauptabteilung, Saal Ff., S. 84-102 und Kat. Dresden 1837, 2. Hauptabteilung, Saal Ff, S. 84-102; Quandt 1842 [1837], S. 17-18 wünschte die Vergrößerung dieses Saals und eine zu ergänzende Vorhalle auf der Seite der Freitreppe, um die Hitze zu bändigen.

50 Friesen 1880, S. 330-331: »Dass einige Gemälde, unter ihnen die Sixtinische Madonna, behufs ihrer besseren Conservirung mit Glastafeln bedeckt wurden, war freilich ein Opfer, zu dem sich das Comité nach königlicher Genehmigung nicht ohne Widerstreben entschloss, und ich mache mir nur einen sehr geringen Ruhm daraus, den ersten Anstoss dazu gegeben zu haben.« Friesen sah Glas als gute Schutzmöglichkeit für Gemälde an, nachdem er im Auftrag des Königs Sammlungen in Holland, England, Frankreich und Belgien besucht hatte, um verschiedene konservatorische Maßnahmen kennenzulernen. Glas war in London sehr verbreitet. S. a. Kat. Dresden 1856, S. 61-62; Schölzel 2012, S. 208-209.

51 Zum Franzosensaal und den herrschaftlichen Sammlungsbegründern des Hauses Wettin siehe Weddigen 2008, S. 208-211.

52 Friesen 1880, S. 319.

53 Friesen 1880, S. 332: »Man darf mit Recht die Frage aufwerfen, ob es ohne alle diese Vorgänge wahrscheinlich gewesen wäre, in der Periode von 1837 bis 1847 die Finanzverwaltung und die Stände zu dem Beschluss der Erbauung eines neuen Museums zu bewegen.«S. a. Weddigen 2008, S. 213 




86 Schematische Darstellung des Rundgangs durch die Dresdener Gemäldegalerie, 1837 (Grundriss: Kat. Dresden 1837; Schema: Weddigen 2008 , S. 528) 
einander, da ausser dem Austausch des Franzosen- und Raffaelsaals keine Umhängungsmaßnahmen getroffen worden waren. Man trat in den französischen Saal ein und fand sich danach mitten in der venezianischen, mailändischen, genuesischen und bolognesischen Malerei des 17. Jahrhunderts wieder. Matthäi bemerkte hierzu in der Einführung zum Sammlungsrundgang: »Wir würden die Aufstellung mit den ältesten Gemälden begonnen haben, wenn wir es nicht vorgezogen hätten, die Besucher unserer Gemäldegalerie sogleich beim Eintritt A. auf die Begründer derselben hinzuweisen, und da ihre Bildnisse von französischen Künstlern gemalt sind, so reihen sich hier gleich die Gemälde der französischen Schule an, so dass wir den altteutschen und altniederländischen Gemälden erst in der Abtheilung B. begegnen, zu welcher man früher unmittelbar aus der ersten Abtheilung A. gelangte. Die Nothwendigkeit, den Eingang der Galerie auf die entgegengesetzte Seite zu verlegen, hat die Abtheilung B. von A. getrennt, und der Beschauer, welcher der Ordnung, in der die Gemälde verzeichnet sind, folgen will, hat die Abtheilung B. im dritten Zimmer links vom Eingange zu suchen. ${ }^{54}$

Mit dem Austausch des Raffaelsaales mit dem Franzosensaal war der sowieso schon auf wackligen Füßen stehende kunsthistorische Rundgang endgültig durcheinandergeraten. Man versuchte sich im Katalog von 1837 mit der Beibehaltung der fortlaufenden Nummerierung und Raumabfolge (A-H in der äußeren, und Aa-Ff in der inneren Galerie) zu behelfen. Dies hatte zur Folge, dass man nach dem Eintritt in den Franzosensaal und der Betrachtung der Galeriegründer durch drei Säle marschieren musste, um den Rundgang bei den alten Italienern (Aa) oder den Altdeutschen und Altniederländern (B) beginnen zu lassen oder aber man begnügte sich mit Blättern im Katalog und lief kreuz und quer in der Kunstgeschichte umher und folgte dabei nach Lust und Laune den Raumfolgen.

\section{Quandts übersichtlicher Galerierundgang}

Eine Möglichkeit zur Verbesserung der Unübersichtlichkeit des Galerierundgangs anerbot sich anfangs der 1840er Jahre. In der äußeren Galerie sollte die Hängung nach Schulen verfeinert werden. Im August 1840 unterbreitete Quandt dem Vorsteher der Königlichen Sammlungen, Bernhard August von Lindenau, Vorschläge, um den besten Bildern »ein beßeres Licht zu geben $\ll .55$ In einem Brief betonte er die Wichtigkeit der niederländischen und deutschen Gemälde in der Sammlung im Vergleich zu anderen europäischen Museen. Er bedauerte, dass die Meisterwerke von Hans Holbein dem Jüngeren nicht beieinander stünden und dessen Madonna des Basler Bürgermeisters Jakob Meyer zum Hasen - damals noch nicht als Fälschung erkannt zu hoch hinge..$^{56}$ Zudem monierte er, dass die vortrefflich restaurierten Bilder an ungünstige Plätze zurückgekehrt und schlecht sichtbar seien. Um das kunsthistorische Studium der Niederländer und Deutschen zu fördern, betonte er die Vorteile einer Schulhängung. Dass diese Arbeiten große Änderungen zur Folge haben und die 1833 bis 1837 im Zweijahrestakt erschienenen Kataloge, die Matthäi auf eigene Kosten hatte herausgeben müssen, für ungültig erklären würden, sollte nicht als Gegenargument dienen. ${ }^{57}$ Quandt argumentierte: »Auch ein zweiter Umstand, welcher der Umhängung der Gemälde sich entgegenstellte, des Director Matthäi Katalog Verkauf, könnte jetzt beseitigt werden, da die Stände Mittel bewilligt haben, welche es möglich machen, Matthäi für diese Accidenseinnahme zu entschädigen u dadurch kein Staatsdiener mehr auf zufällige Einnahmen angewiesen seyn soll. $\aleph^{8} \mathrm{Mit}$ diesem Vorgehen konnten die alten Kataloge aus dem Verkehr gezogen, die Neuhängung vorgenommen, die Gemälde teilweise neu zugeschrieben und ein neues Verzeichnis verfasst werden..$^{59}$

In der Folge erstellte Quandt ein auf den 24. September 1840 datiertes Gutachten, in dem er seine Vorschläge zur Neuhängung der äußeren Galerie genauer spezifizierte. Auszüge aus diesem Dokument veröffentlichte er zwei Jahre später in gedruckter Form. ${ }^{60}$ Drei Grundsätze sind in der Handschrift zentral: »A Zusammenhalten der Werke solcher Meister und ihrer Schüler, von welchen die Galerie in so bedeutender Anzahl und solcher Vortrefflichkeit Gemälde besitzt, daß man daraus dieser Künstler u ihrer Schüler wichtigste Entwicklungsmomente kann kennen lernen. B. Möglichste Berücksichtigung des Lichts, für die vorzüglichsten Gemälde. C, Ausscheiden solcher Bilder, deren Verfertiger mit Unrecht Meister genannt werden

54 Kat. Dresden 1837, S. VIII-IX. S. a. Weddigen 2008, S. 213. Der Grundriss von 1837 abgebildet bei Marx 1992 (1), S. 91, Abb. 71.

55 Brief von Quandt an Lindenau vom 27.8.1840, in: HStADD, Akten der Generaldirektion der Königlichen Sammlungen, Cap. VII. Nr. 35, Acta die kgl. Gemälde-Gallerie betr., 1840-1844, fol. 62ff. (Kriegsverlust). Abschrift in: HStADD, 13458 SKD, NL Posse, Nr. 30, Lage 3, fol. 11r-12r.

56 Protokoll der Galeriekommission vom 7.2.1846, in: HStADD, Cap. VII Nr. 39a, Akten der Generaldirektion der Königlichen Sammlungen, Protokolle von dem Gallerie Comité, 1843-1846, (Kriegsverlust). Abschrift in: HStADD, 13458 SKD, NL Posse, Nr. 30, Lage 3, fol. 3V.

57 S. a. Schäfer 1860, S. 14: »[...] und auch später sorgte der Gallerie-

director Matthäi vor jeder nothwendig gewordenen neuen Auflage seines Katalogs, dessen Verkauf zu seinen Revenuen gehörte, für eine neue wenigstens theilweise Umhängung."

58 Brief von Quandt an Lindenau vom 27.8.1840, in: HStADD, Akten der Generaldirektion der Königlichen Sammlungen, Cap. VII. Nr. 35, Acta die kgl. Gemälde-Gallerie betr., 1840-1844, fol. 62ff. (Kriegsverlust). Abschrift in: HStADD, 13458 SKD, NL Posse, Nr. 30, Lage 3, fol. 11V-12r.

59 Der Katalog erschien 1843. Siehe Kat. Dresden 1843.

60 Entwurf zu einer Aufstellung der königl: Gemäldegalerie in Dresden, in: SLUB, Mscr. Dresd. L 224, Bd. IV, Nr. 11, fol. 1r-5r. Zur Druckfassung siehe Quandt 1842, S. 7-12. 
u deren Gemälde ohne es bedauern zu müssen, an die Pfeiler gehängt werden können. « ${ }^{61}$ Später bemerkte Quandt hierzu, man habe aufgrund der aus geschmacklichen und nicht historischen Bedürfnissen zusammengeführten Sammlung keine Möglichkeit gehabt, eine konsequent chronologische Hängung nach Geburtsjahr der Künstler und nach Schulen herzustellen. ${ }^{62}$

Neu war nun, dass Quandt einen deutschen Saal mit Gemälden Holbeins, Dürers, deren Schulen und einigen Altniederländern vorschlug - einen Saal also, der dem Raffael- und Franzosensaal ebenbürtig war. Die deutsch- und altniederländischen Bilder sollten lichtoptimiert an die seitlichen Wände gehängt werden, während weniger wichtige Gemälde, »unter welche die Lucas Kranachs zu zählen sind«, den Fenstern gegenüber gezeigt werden könnten. Dann erstellte er Listen der präsentabelsten Holländer und Flamen und verteilte sie auf die verschiedenen Säle. Ihre Bilder sollten ebenfalls nach Schulen geordnet unter Berücksichtigung von Licht und Temperatur gemäß ihrer Wichtigkeit verteilt werden. Die klimatisch und lichttechnisch ungünstigsten Räume sollten für die Hängung der weniger wichtigen Kunstwerke, Kopien und Nachahmer dienen. ${ }^{63}$

Basierend auf Quandts Konzept wurde der kunsthistorische Rundgang optimiert. Die Aufteilung der Gebäudeflügel nach Schulen blieb zwar gleich wie vorher: Der Westflügel der äußeren Galerie war den Flamen gewidmet, die Nordseite den deutschen Meistern mit dem zwischengeschobenen Raffaelsaal, der Westflügel den Holländern, und die Südseite den Franzosen und Spaniern sowie Nachahmern und Kopien aller Schulen. Die innere Galerie blieb unverändert den Italienern vorbehalten. Doch in der Binnengestaltung der Räumlichkeiten wurden die kunsttopographischen Kriterien wesentlich konsequenter umgesetzt. ${ }^{64}$ Da diese Hängungssystematik mehr Raum erforderte, wurden 1841 auch in der westlichen und östlichen Langgalerie an den Fensterpfeilern Scherwände errichtet und Kabinette gebildet. ${ }^{65}$

Mit den Verbesserungen der frühen 1840er Jahre wurden vor allem der Katalog und die räumliche Situation aufeinander abgestimmt, was für die Besucher den Ablauf des kunsthistorischen Rundgangs deutlich vereinfachte. Die fortlaufende Nummerierung der Bilder und die Raumabfolgen $(\mathrm{A}-\mathrm{H}$ in der äußeren, Aa-Ff in der inneren Galerie) wurden neu zugeteilt. ${ }^{66}$ Der Rundgang begann auch 1843 im Franzosensaal (A). Hierauf folgte der Spaniersaal (B) - ein an ein Schaudepot erinnerndes Sammelsurium, welches auch Neueingänge italienischer Kunst, italienische Gemälde des 18. Jahrhunderts und einige Niederländer des 17. Jahrhunderts enthielt. ${ }^{67}$ Für die neue Raumabfolge wurden in die westliche und östliche Seitenwand des Eintrittsaales neue Türen gebrochen, wie dem Grundriss im Führer durch die Galerie von Julius Mosen entnommen werden kann (Abb. 87). ${ }^{68}$ Nach dem Spaniersaal trat man in die lange Galerie des Westflügels (C) ein, wo hauptsächlich Flamen gezeigt wurden. Hier lässt sich die Zusammenführung von Künstler und Schulen feststellen, wie sie Quandt zum Vorschlag gebracht hatte. So fanden sich an der ersten und zweiten Scheidewand am Fenster beispielsweise die Gemälde von Jacob Ruisdael oder an der sechsten und siebten Wand die Bilder der beiden David Teniers wieder. ${ }^{69}$

Der neue Rundgang zeigt gegenüber den Vorgängern eine überraschende Wendung. Die Besucher schritten zuerst die
61 Entwurf zu einer Aufstellung der königl: Gemäldegalerie in Dresden, in: SLUB, Mscr. Dresd. L 224, Bd. IV, Nr. 11, fol. 1r. Fast der gleiche Wortlaut in: Quandt 1842, S. 60. Quandt hatte 1840 offensichtlich einige Punkte dieses Schreibens an Lindenau betreffend Galeriehängungen von 1837 wieder aufgenommen. Siehe ebd., S.7-9.

62 Quandt 1846 (1), S. 33. S. a. Friesen 1880, S. 317-318

63 Entwurf zu einer Aufstellung der königl: Gemäldegalerie in Dresden, in: SLUB, Mscr. Dresd. L 224, Bd. IV, Nr. 11, fol. 1r-5r. Einen Saal für die altdeutschen und altniederländischen Gemälde hatte er sich schon 1816 gewünscht; siehe Quandt 1816 (1), S. 835: »Könnten die noch in der Gallerie zerstreut umher hängenden Altteutschen Bilder, welche eine abgeschiedene Welt für sich bilden, zusammen, in einem besonderen Zimmer aufgestellt werden, da sie Absonderung und Ruhe fordern, so hätten wir eine Cisalpinische Schule, welche sich gewiß, wenn auch nicht der Zahl, doch dem inneren Werthe nach, wohl jeder anderen an die Seite stellen könnte."

64 Um festzustellen, inwiefern die Schulbildung wirklich konsequent umgesetzt wurde, bedürfte es einer visuellen Rekonstruktion des Katalogs von 1843, wie sie Tristan Weddigen anhand der Inventare und Kataloge für die Jahre 1747, 1750, 1754, 1765, 1825 und 1835 vorgenommen hat. Siehe www.gallerycreator.uzh.ch/index.php?page=viewRooms [letzter Zugriff: 17.10.2018]. Die stichprobenartige Überprüfung des Kataloges zeigt zumindest, dass in der äußeren Galerie, außer im schaudepotartigen Raum B (früher H), keine Italiener mehr präsentiert waren. Eine restlos konsequente Schulhängung war schon aus dem Grund der massiven Größenunterschiede der Gemälde kaum möglich, so lange man nicht dazu überging, Gemälde in ein Depot zu überführen. Dies geschah 1843 weiterhin nicht. Zur Methodik der visuellen Rekonstruktion siehe Weddigen 2008, S. 10.

65 »Durch diese Raumerweiterung konnte überhaupt die systematische Zusammenstellung der Gemälde nach Meistern u. Schulen, auch in den übrigen Abtheilungen der Gallerie besser durchgeführt werden.« (Zitat nach Hans Posse); Jahresbericht 1841 vom 14.2.1842, in: HStADD, Akten der Generaldirektion der Königlichen Sammlungen, Cap. VIla, Nr. 5, Jahresberichte 1837-1842 (Kriegsverlust). Abschrift in: HStADD, 13458 SKD, NL Posse, Nr. 30 , Lage 10, fol. 5V-6r.

66 Nachfolgende Beschreibung des Rundgangs folgt den Abteilungen in Kat. Dresden 1843. Ein Grundriss findet sich in Mosen 1844, nach S. 203.

67 Zur damals noch wenig bekannten spanischen Malerei, ihres Eingangs in die Dresdener Gemäldegalerie und ihrer Präsentation siehe Weniger 2003, S. 341 .

68 Mosen 1844, nach S. 203. In diesem Grundriss sind die Scherwände der äußeren Galerie nicht eingezeichnet.

69 Entwurf zu einer Aufstellung der königl: Gemäldegalerie in Dresden, in: SLUB, Mscr. Dresd. L 224, Bd. IV, Nr. 11, fol. 3V. Die Angabe »Saal G« richtet sich noch nach dem Grundrissplan von 1837. S. a. Marx 1992 (1), S. 91, Abb. 71; Kat. Dresden 1843, S. 27-28 (Ruisdael), S. 32-35 (Teniers). 


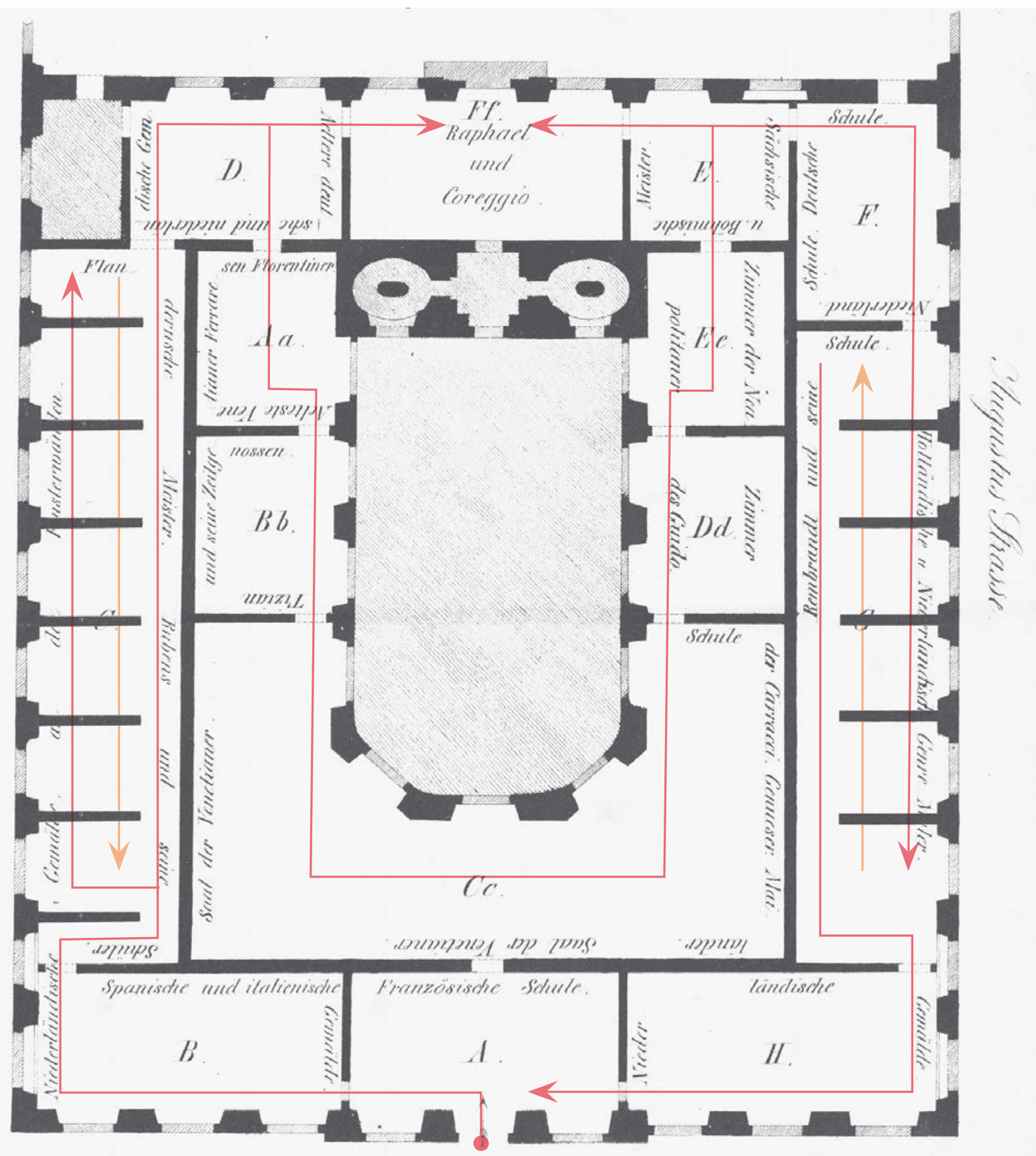

87 Schematische Darstellung des Rundgangs durch die Dresdener Gemäldegalerie, 1843 (Grundriss: Mosen 1844; Schema und digitale Rekonstruktion der Scherwände in der Äusseren Galerie: Andreas Rüfenacht)

sieben Vorderseiten der Trennwände an den Fensterpfeilern in Richtung Norden ab, wendeten sich dann den Rückseiten zu, gingen zurück zum Südeingang des Saales und beschlossen den Rundgang mit den Gemälden des Rubens und seiner Schü- ler an der langen Wand wiederum in Richtung Norden. ${ }^{70}$ Wo man heutzutage in den einzelnen Kabinetten die Hängung nach Schulen erwarten würde, wurde hier die Schulpräsentation dem fortschreitenden Rundgang angepasst. Am Beispiel Ja- 
cob Ruisdaels und David Teniers lässt sich dies nachvollziehen. Ruisdael wurde nicht im Kabinett, gebildet aus der Rückseite der ersten und der Vorderseite der zweiten Wand gezeigt, sondern auf den Vorderseiten der ersten, zweiten und sogar dritten Wand - also faktisch über drei Kabinette hinweg.71 Bei Teniers wird dieses Prinzip der Schulhängung noch verdeutlicht. So waren diese Gemälde an die Vorderseite der sechsten und der siebten Wand gehängt. Diese siebte Wand war aber zugleich die Ausgangswand, wo man sich umdrehte, um die Rückseiten der Scheidewände in Angriff zu nehmen. Konsequenterweise folgten die weiteren Bilder Teniers des Älteren und auch dessen Sohnes an den Rückseiten der sechsten und in einem Fall auch noch an der fünften Wand. ${ }^{22}$ Diese Anordnung war insofern originell, als sie es ermöglichte, jeder Wand entlang zu gehen, ohne auch nur ein Gemälde zweimal betrachten zu müssen. Man tat auf dem Rundgang also mit Sicherheit keinen Schritt zu viel und konnte der fortlaufenden Nummerierung im Katalog, und damit weitgehend dem kunsthistorischen Rundgang folgen.

Die Vorzüge dieser eigenwilligen Präsentation zeigten sich vor allem im Vergleich zur inneren Galerie. 1843 hatte man dort nichts geändert. Die italienischen Bilder waren nach Schulen in Kabinetten geordnet, die man entsprechend der Raumfolge abschritt. Angekommen im letzten Saal (Dd), musste man, dem Katalog folgend, die Gemälde an den Pfeilern beschauen. Dies hatte ein Abschreiten der Kunstgeschichte im Rückwärtsgang zur Folge und höchstens einen ungewollt didaktischen Sinn, weil die Besucher dann die Schulkabinette repetieren konnten. ${ }^{33}$

71 Kat. Dresden 1843, S. 27-28, wobei die dritte Wand zweimal auftaucht. Dies ist ein Druckfehler.

72 Kat. Dresden 1843, S. 32-35. An der fünften Wand vermerkt der Katalog eine Beteiligung David Teniers an einem Gemälde von Lucas van Uden.

73 Kat. Dresden 1843, S. 116-122 (I-X). Entsprechend: Kat. Dresden 1837, 2. Hauptabteilung, S. 76-84 (A-K). In der äußeren Galerie schritt man gemäß Kat. Dresden 1837, 1. Hauptabteilung, S. 210-241 alle dreißig Pfeiler am Ende des Rundgangs ab, nachdem man im letzten Raum $\mathrm{H}$ angekommen war. Wahrscheinlich waren mit den Pfeilern auch die Scherwände gemeint, da diese in der Beschreibung der entsprechenden Langgalerien nicht erwähnt sind. Dies ist ein Zeichen dafür, dass weniger wichtige Gemälde, Kopien und Nachahmer nicht konsequent in eine didaktische Schulhängung einbezogen waren.

74 An der dritten Wand; siehe Kat. Dresden 1843, S. 66-67. Entwurf zu einer Aufstellung der königl: Gemäldegalerie in Dresden, in: SLUB, Mscr. Dresd. L 224, Bd. IV, Nr. 11, fol. 1v. Im Anschluss an dieses Gutachten folgen zwei Bleistiftskizzen mit Hängungen: ebd., fol. $7 r$ (Gruppierung um Jan Gossaert gen. Mabuse), fol. 8 r (Gruppierung um Holbein). Sie stammen möglicherweise von Quandt selber und lassen sich in ihrer Struktur mit den Sälen in Kat. Dresden 1843, »Vierte Abteilung. D. Erste Wand «, Nrn. 446-453, S. 57-58, und »Dritte Wand «, Nrn. 518-547, S. 65-68 vergleichen. Die beiden Skizzen sind aber wohl eher ein Vorschlag, wie ein nach Schulen geordneter Wandaufriss aussehen könnte. Die Kataloge verzeichnen an diesen Wänden deutlich mehr Gemälde.

75 Im Katalogteil zur inneren Galerie waren die Bilder innerhalb des Fuvres eines Künstlers zwar nacheinander aufgeführt, nicht aber an
Nachdem man den Flamensaal (C) hinter sich gelassen hatte, trat man in den Saal mit altdeutschen und altniederländischen Gemälden ein (D). Sämtliche Bilder Holbeins hingen hier beieinander wie Quandt es gefordert hatte. ${ }^{74}$ Der Rundgang sah nun vor, in die innere Galerie einzutreten und dabei einer gewissen Chronologie Rechnung zu tragen: Der erste Raum zeigte altitalienische Gemälde, der weitere Rundgang folgte den italienischen Schulen (Aa-Ee) und unterschied sich nicht von der Präsentation von 1835. Die Räume, Kabinette und Wände waren den einzelnen Schulen gewidmet, die Hängung den räumlichen Gegebenheiten verpflichtet und der Katalog hielt die Euvres eines Künstlers zusammen, damit die Chronologie verständlich wurde. $^{75}$

Den auserwählten Saal (Ff) mit Raffaels und Correggios Bildern erreichte man dann nach Durchschreiten des Saales der deutschen Gemälde. Danach fand der Rundgang mit den neueren deutschen und besonders sächsischen Künstlern des 17. bis 19. Jahrhunderts in zwei Räumen (E-F) seine Fortsetzung, wobei mit zwei Landschaftsbildern Caspar David Friedrichs die einzigen Gemälde eines noch lebenden deutschen Zeitgenossens in die Sammlung gekommen waren. ${ }^{76}$ In der darauf folgenden langen Galerie $(G)$ befanden sich die holländischen Maler. Man ordnete dem Saal großzügig Rembrandt und seine Schule zu. Den Rundgang absolvierte man nach demselben Prinzip wie in der gegenüberliegenden Galerie der Flamen. Man schritt zuerst die Vorderseiten der fünf Scherwände, dann deren Rückseiten und schließlich die Längswand ab. So präsentierten sich

der Wand, wo sie in senkrechten, achsensymmetrischen Abschnitten nach einem Pendant-Prinzip und entsprechend ihren Dimensionen angeordnet waren. Römische Ziffern bei den einzelnen Bildern verwiesen auf diese so genannten Divisionen, die ebenfalls mit Ziffern bezeichnet waren. Das Auge des Betrachters musste also nach der geordneten Lektüre auf den Wänden oder aber nach einer fortlaufenden Betrachtung der Wände im Katalog hin und her springen. S. a. Weddigen 2008, S. 207.

76 Kat. Dresden 1843, S. 143, Nr. 1191, 1192. Es handelt sich um Zwei Männer in Betrachtung des Mondes, 1819/20, Lwd., 33×44,5 cm, Gal. Nr. 2194 und um Rast bei der Heuernte, 1834/35, Lwd., $72 \times 102$ cm, Gal. Nr. 2197 (verschollen). Die anderen »neueren« deutschen Gemälde waren von Künstlern wie Anton Graff oder Angelika Kauffmann. Friedrichs Gemälde kamen 1840 auf königlichen Wunsch hin in die Sammlung. Vermittler der Bilder war Quandt. Zuvor wehrte sich vor allem Friedrich Matthäi gegen einen Ankauf, so dass die Galeriekommission einen entsprechenden Vorschlag von Carl Gustav Carus noch abgelehnt hatte; Spitzer 2010, S. 6-8, 40. Im Raum F befanden sich auch niederländische Gemälde, die mit den deutschen an den drei Wänden gemischt gehängt zu sein schienen. Kat. Dresden 1843, S. 150-157. Erst in der Sempergalerie wurde im zweiten Stockwerk ein Kabinett mit »Werke[n] vaterländischer, zumeist noch lebender Künstler « eingerichtet, worunter sich 1856 Werke von Adrian Ludwig Richter, Caspar David Friedrich, Carl Peschel, Johan Christian Claussen Dahl oder Julius Hübner befanden. Kat. Dresden 1856, S. 331-334. S. a. Wilmowsky 2017, S. 425-426 zu einem Ankauf einer Pietà von Rietschel als zeitgenössische bildhauerische Position. 
die Leidener Feinmaler an den Vorderseiten der ersten bis dritten Wand, während an deren Rückseiten Landschaften aus dem Umkreis Jan Brueghels hingen. ${ }^{77}$ Die lange Galerie beendete man mit der Betrachtung der großen Wouwerman- und Rembrandt-CEuvres an der langen Wand. Der gesamte Rundgang wurde im südöstlichen Raum $(\mathrm{H})$, der weniger bedeutende Schulbilder aus dem Umkreis Rubens' sowie einzelne Holländer, Deutsche und Franzosen enthielt, beschlossen.

Die Errungenschaft des Rundgangs von 1843 war hauptsächlich eine neue Übersichtlichkeit, welche die Hängung, den schriftlichen Katalog und den Galeriebesuch auf praktische Weise miteinander zu verbinden vermochte. Quandt betonte, die Galerie habe »sehr wesentlich [...] durch diese Umstellung gewonnen, dass die vorzüglichsten Bilder $[. .$.$] in besseres Licht$ gebracht wurden, dass ihr Reichthum an den kostbaren kleinen Meistern hervortritt, der bei einer zerstreuten Aufstellung nicht bemerkbar war, und dass durch das Zusammenhalten von Meistern und Schülern Kunstkenntniss gefördert wird. ${ }^{\pi^{8}}$ Wenn auch der Kunstgeschichte weder chronologisch noch kunsttopogra- phisch bis ins letzte Detail streng wissenschaftlich Rechnung getragen wurde, und - bedingt durch Dimensionsunterschiede der Bilder - nicht in allen Fällen alle Bilder aus dem CEuvre eines Künstlers und dessen Umkreis beieinander hingen, so wurden doch die großen Bögen auf praktikable und didaktische Weise sichtbar. Man stimmte die Hängung und den Katalog so aufeinander ab, dass die Galeriebesucher einen einigermaßen logischen Ablauf abschreiten konnten. Die fortlaufende Nummerierung über alle Abteilungen hinweg ermöglichte einen vereinfachten Vergleich von Gemälde und Katalogeintrag.

\section{Van Eyck, Da Vinci, Holbein: Kunstgeschichte mittels Rahmenbeschriftungen}

Die neue Übersichtlichkeit des Rundgangs wurde durch direkt an die Rahmen angebrachte Informationsschilder gestärkt. Darauf standen die Katalognummer und der Künstlername mit Lebensdaten. Die Attribution diente dem Kunstverständnis

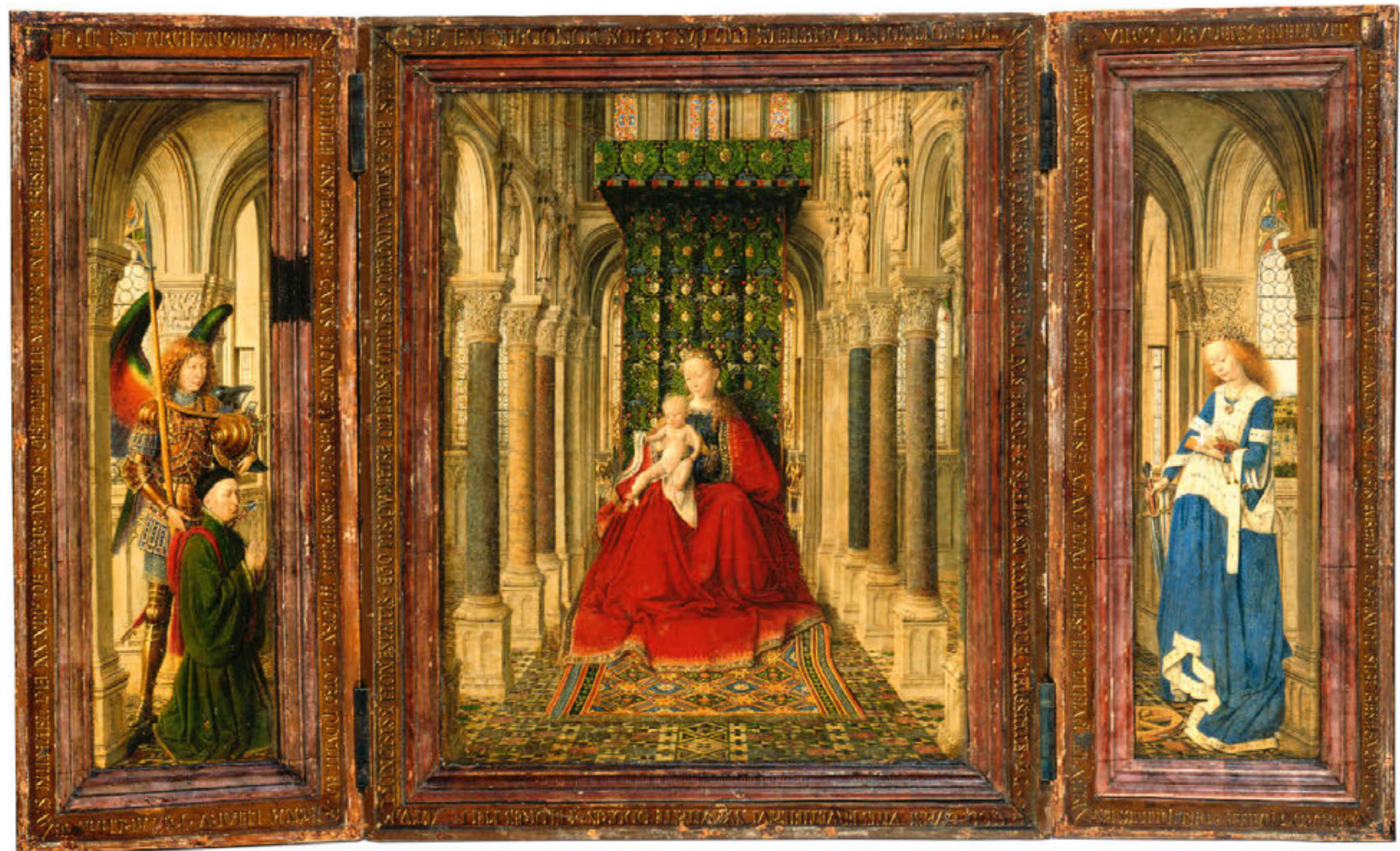

88 Jan van Eyck, Triptychon mit Maria und dem Kind, der Heiligen Katharina und dem Heiligen Michael mit Stifter, 1437, Öl auf Eichenholz, $33 \times 54,5 \mathrm{~cm}$, Dresden, Gemäldegalerie Alte Meister, Gal.-Nr. 799

77 Kat. Dresden 1843, S. 158-164 (Leidener Feinmaler); S. 170-175 (Jan Brueghel an den Rückseiten der zweiten bis vierten Wand). Immerhin entstand durch die Präsentation von Willem van Mieris an der Rückseite der ersten Wand im zweiten Kabinett ein Raum, der nur den
Leidener Feinmalern gewidmet war. Der Rundgang folgte hier jedoch der Chronologie, so dass das Leidener Kabinett eher zweitrangige Absicht und positiver Nebeneffekt zu sein scheint.

78 Quandt 1842, S.61. 
und half bei der chronologischen Einordnung der Gemälde in ihrem Hängungskontext. Quandt hatte die neue Beschilderung 1842 gefordert, worauf sie für die Neuhängung 1843 eingeführt wurde. ${ }^{79}$ Aus der Einführung der Namensschilder wollte er zudem Neuzuschreibungen bekannt machen. Dazu gehörte beispielsweise Jan van Eycks Triptychon mit Maria und dem Kind, der Heiligen Katharina und dem Heiligen Michael mit Stifter, ein kleiner Flügelaltar mit der Madonna in einer Kirche, das früher Albrecht Dürer zugeschrieben und von ihm schon 1816 dem flämischen Maler zuerkannt worden war (Abb. 88). ${ }^{80}$

Vier Jahre später musste er in einem Artikel im Kunstblatt »ueber die $[. .$.$] eingeführte Namenangabe« jedoch feststellen,$ dass längst nicht alle Beschriftungen auf dem aktuellsten Stand kunsthistorischer Forschung waren: »Es finden sich aber noch viele namenlose Gemälde in der königl. Galerie, was daher kommt, daß eine gründliche Kenntniß nicht durchdringen und nur einige irrthümliche Katalogbenennungen mit Mühe von den Bildern entfernen, aber selten von der richtigen Namenangabe überzeugen konnte. Gerade eine Sammlung wie die königliche, deren hoher Werth nicht in historischer Vollständigkeit, sondern im Besitz unübertrefflicher Werke einzelner großer Meister besteht, sollte durch eine richtige Angabe der Namen, wenigstens von dieser Seite, den Kunstgeschichtsforscher befriedigen. $\ll^{81}$ Nebst einigen italienischen Beispielen, darunter falsche Zuschreibungen an Giorgione, nennt er Hans Holbeins Bildnis Charles de Solier, Sieur de Morette, das trotz längst formulierter Zweifel immer noch Leonardo da Vinci zugewiesen wurde und entsprechend beschriftet war (Abb. 89): »Man muß freilich verstummen, so lange man uns den Vorwurf machen kann, daß wir eins der wichtigsten Werke Holbeins für ein Gemälde von Leonardo da Vinci halten und also verrathen, wie unbekannt uns zwei der größten Künstler sind. $\ll^{82}$ Doch trotz

79 Quandt 1842, S. 20: "[...] Antrag, an die Rahmen der Bilder Tafeln anzubringen, auf welchen die Namen der Meister zu finden sind. Der Vorschlag erhielt allerhöchste Genehmigung und wurde nach meinem Plane mit wenig Abänderungen ausgeführt.« Jahresbericht 1841 vom 14.2.1842, in: HStADD, Akten der Generaldirektion der Königlichen Sammlungen, Cap. VIla, Nr. 5, Jahresberichte 1837-1842 (Kriegsverlust). Abschrift in: HStADD, 13458 SKD, NL Posse, Nr. 30, Lage 10, fol. 6r. S. a. Schölzel 2012, S. 207-208. Die Rahmenbeschriftungen wurden schon in der Wiener Gemäldegalerie des Oberen Belvedere von Christian von Mechel erstmals eingeführt, stießen aber noch auf größeren Widerstand; Penzel 2007, S. 96-99, 271-274. Über die Herstellung von Bezügen zwischen Galeriekatalog und Hängung durch fortlaufende Nummerierung in Dresden siehe ebd., S. 100-102; Weddigen 2008, S. 194-199. Laut Martin Bernhard Lindaus Galeriebuch von 1856 sollen die Namensangaben von den Reorganisationen um 1832/34 herstammen; Weddigen 2008, S. 206. Dies trifft aber nicht zu, da die Quellen klar zeigen, dass die Namensschildchen nicht vor 1840 angebracht worden waren. S. a. Schölzel 2005 (2), S. 35 . Zu der Entwicklung der Kataloge, insbesondere hinsichtlich der Ausführlichkeit der Gemäldebeschriftungen siehe Hipp 2007, S. 56-64; Pilz 2006, S. 160-163.

80 »Dieses Bild, welches vormals A. Dürer zugeschrieben wurde, wahr-

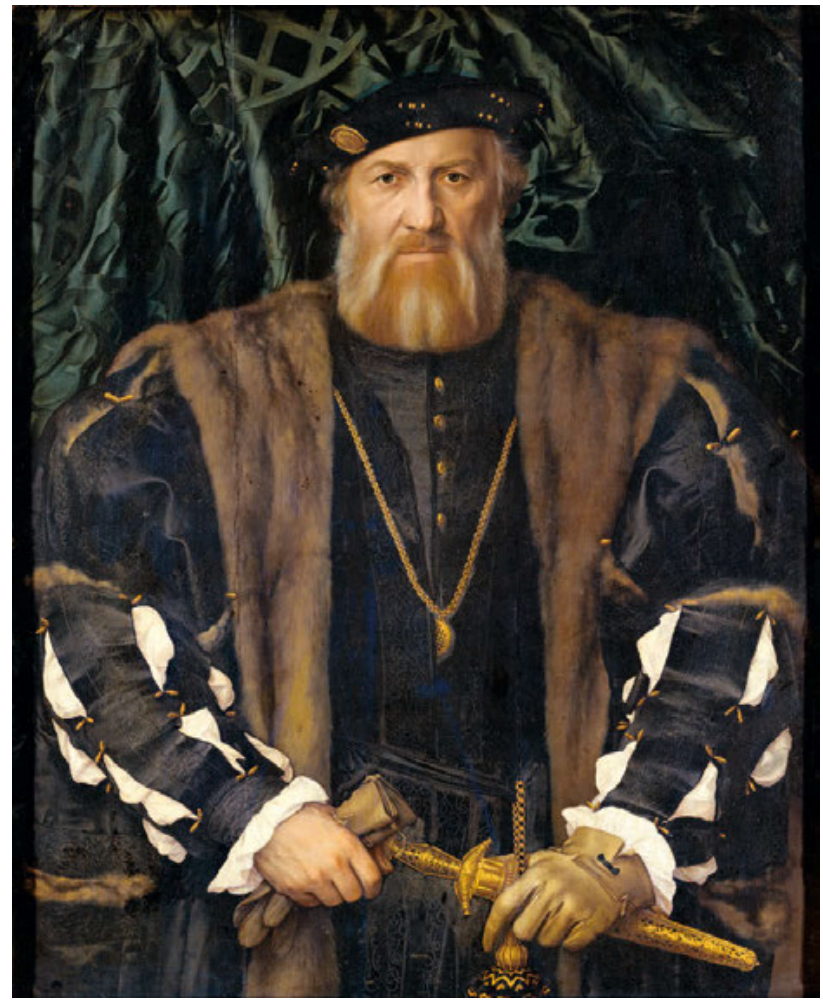

89 Hans Holbein der Jüngere, Charles de Solier, Sieur de Morette, 1534/35, Öl auf Eichenholz, 92,5×75,5 cm, Dresden, Gemäldegalerie Alte Meister, Gal.-Nr. 1890

seiner ausführlichen stil- und quellenkritischen Beweisführung sowie der Beilage eines Kupferstichs von Wenzel Hollar, anhand dessen er den Dargestellten identifizieren konnte, wurde das Bildnis erst 1856 in der neu erbauten Galerie von Gottfried Semper endgültig Holbein zugeschrieben und im entsprechenden Kontext präsentiert. ${ }^{83}$

scheinlicher aber ein Werk von Joh. von Eyk ist, - würde in einem kleinen abgesonderten Raume, wo alles beisammen wäre [...], erst vollkommen wirken können.« Quandt 1816 (1), S. 836. Quandts Zuschreibung datiert vierzehn Jahre vor Aloys Hirts bis heute anerkannten Attribution; Hirt 1830, S. 10-11. S. a. Neidhardt 2017, S. 351-352. Quandt 1846 (1), S. 33 schreibt nicht, die Zuschreibung stamme von Hirt, wie Schölzel 2012, S. 207, Anm. 269 vermerkt; Neidhardt 2005 (2), S. 14 .

81 Quandt 1846 (1), S. 33.

82 Quandt 1846 (1), S. 33

83 Die Zuschreibungsgeschichte des Bildnisses Charles de Solier, Sieur de Morette an Holbein ausführlich beschrieben bei Marx 1998, S. 265-268. Quandt schrieb es schon 1830 Holbein zu; siehe Quandt 1830(3), Sp. 575. Das Bild war 1843 immer noch im Raffaelsaal unter den Florentiner Meistern als Leonardo, Bildnis des Herzogs Sforza von Mailand, präsentiert; Kat. Dresden 1843, Nr. 1051, S. 127. Mosen 1844, S. 29 ebenfalls als Holbein. Im Kat. 1835/37, 2. Hauptabteilung, Nr. 472, S. 91 hatte man eine Anmerkung angebracht: »Man will seit einiger Zeit dieses Gemälde dem Holbein zuschreiben.«Zu Quandts Rolle bei dieser Zuschreibung siehe Quandt 1856, S. 149-150; Quandt 1853, S. 82, 85; Quandt 1846 (1), S. 33-36; Quandt 1842, S. 61-62. Julius Hübner 


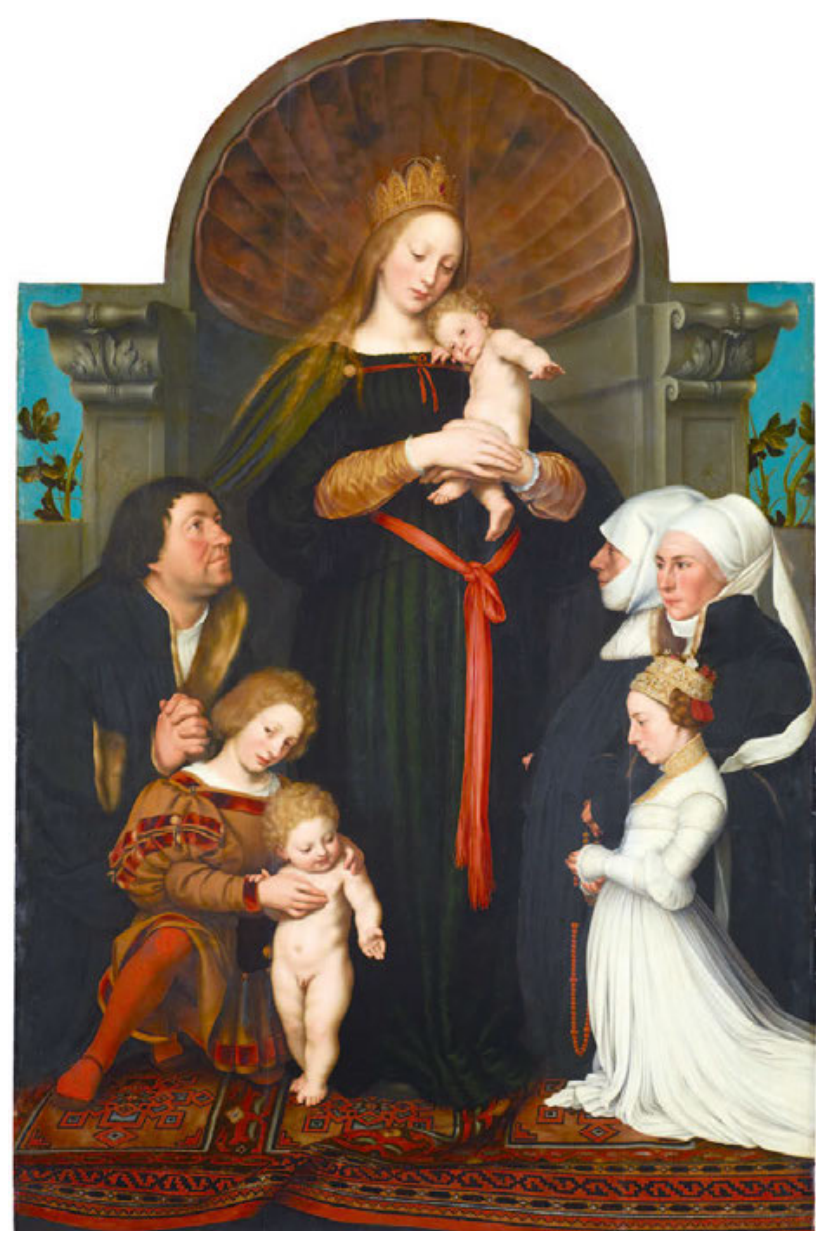

90 Bartholomäus Sarburgh nach Hans Holbein dem Jüngeren, Die Madonna des Basler Bürgermeisters Jakob Meyer zum Hasen, Öl auf Eichenholz, $159 \times 103$ cm, Dresden, Gemäldegalerie Alte Meister, Gal.-Nr. 1892

Im Fall der Dresdener Fassung der Madonna des Bürgermeisters Meyer von Hans Holbein dem Jüngeren, deren $\mathrm{Zu}-$ schreibung in jenen Jahren gelegentlich bezweifelt wurde, mochte Quandt seine Überzeugung nicht ändern. Trotz seiner nachweisbar guten Kennerschaft altdeutscher Kunst, die er durch Beobachtung, vergleichendes Sehen und Lektüre von primären Quellen und aktueller Literatur geschult hatte, hielt er an der nach wie vor verbreiteten Meinung fest, dass es sich um einen originalen Holbein handelte. In seinem Aufsatz über die neue Gemäldebeschilderung griff er das Thema auf, indem er die vielen fehlerhaften Zuschreibungen in der Dresdener Gemäldegalerie als Ursache aufführte, »daß durch diese Schwäche andere Kunstschriftsteller ermuthigt werden, auch die Aechtheit zuverlässiger Meisterwerke anzugreifen, da sie die Dresdner Kunstkennerschaft für unfähig halten müssen, die Ehre ihrer Kunstschätze zu vertheidigen. So hat es Dr. Kugler unlängst gewagt, das Bild der Familie Mayer von Holbein d. J. für eine Kopie öffentlich zu erklären. « ${ }^{84}$ Wie der Ausgang des HolbeinStreits 1871 zeigen sollte, lag hier Quandt, der sich als ein solcher Ehrverteidiger verstand, falsch.

Obschon der Dresdener Kunstkenner im Jahr 1859 ein gutes Jahrzehnt vor dem eigentlichen Holbein-Streit von 1871 starb, kann durch sein Beispiel der umfassenden Forschung über denjenigen Konflikt, der für die Genese der akademischen Kunstwissenschaft so bedeutend war, eine nuancierte Sichtweise hinzugefügt werden. ${ }^{85}$ Es ist gemeinhin anerkannt, dass die korrekte Zuschreibung der Darmstädter Version der Meyermadonna an Holbein und die als Kopie identifizierte, später dem niederländischen Maler Bartholomäus Sarburgh zugeschriebene Dresdener Variante einer Gruppe professionell arbeitender Kunstwissenschaftler gelang (Abb.90-91). Die Kunsthistoriker setzten sich gegen die Meinung von Künstlern und Laienpublikum durch und verhalfen so dem wissenschaftlich begründeten Kunsturteil zu einem Schlüsselmoment in der Entwicklung dieser Fachrichtung. ${ }^{86}$

Die Fehlbeurteilung des als einen frühen Kunsthistoriker zu bezeichnenden Quandt muss wenigstens teilweise von derjenigen der Künstler und des breiten Publikums abgehoben werden. Zwar vermuteten Fachkollegen wie der erwähnte Franz Kugler oder Aloys Hirt, der als erster die Originalität der sich zu dieser Zeit in Berlin befindenden Darmstädter Madonna in einem Aufsatz postulierte, in der Dresdener Fassung ebenfalls Anteile Holbeins. Sie schrieben das Bild seiner Werkstatt zu oder vermuteten darin eine eigenhändige Kopie. ${ }^{87}$ Andere drehten diese These der zwei Originale um und bezeichneten das Dresdener Bild als die Erstfassung.88 Doch Quandts beharrliches Verhaften an der Dresdener Tafel als alleiniges Original von der Hand Holbeins liegt vor allem in seiner Anschauungsmethodik sowie seiner Fixierung auf das Deutschtum Holbeins begründet. Er sah, ganz der verbreiteten Meinung entsprechend, die Meyer- hebt in der Einleitung zum ersten Katalog der Sempergalerie Quandts Rolle bei der Zuschreibung des Charles de Solier an Holbein hervor; Kat. Dresden 1856, S. 23f.. S. a. Bätschmann 2017, S. 44; Bader 2013 , S. 98-99.

84 Quandt 1846 (1), S. 33, Bezug nehmend auf Kugler 1845, S. 29-30. S. a. Maaz 2014, S. 21-22; Bader 2013, S. 51-52; Beyer 2010, S. 205-206; Bätschmann/Griener 1998, S. 13-15; Fechner 1871, S. 114-116.

85 Siehe Bader 2013, S. 18-28.

86 Aktuellste Literatur zum Holbein-Streit: Bätschmann 2017, S. 37-51; Maaz 2014, S. 26-40; Beyer 2010, S. 201-217; Bätschmann/Griener
1998, S. 11-18, 58-69. Lena Bader hat sich wissenschaftshistorisch und multiperspektivisch in ihrer umfassenden Studie Bild-Prozesse im 19. Jahrhundert mit dem Holbein-Streit auseinandergesetzt; siehe dazu Bader 2013, S. 8-13.

87 Hirt 1830, S. 14-15; Kugler 1845, S. 29-30. Zu Hirt und Kugler siehe Fechner 1871, S. 19-23, 28-29, 114-116; 2013, S. 49-54. Bader erwähnt weitere Kunsthistoriker, die an der Originalität des Dresdener Bildes festhielten, darunter Jacob Burckhardt; Bader 2013, S. 118-120, 139-140, 249-250.

88 Fechner 1871, S. 28-29. S. a. Bader 2013, S. 54-57. 


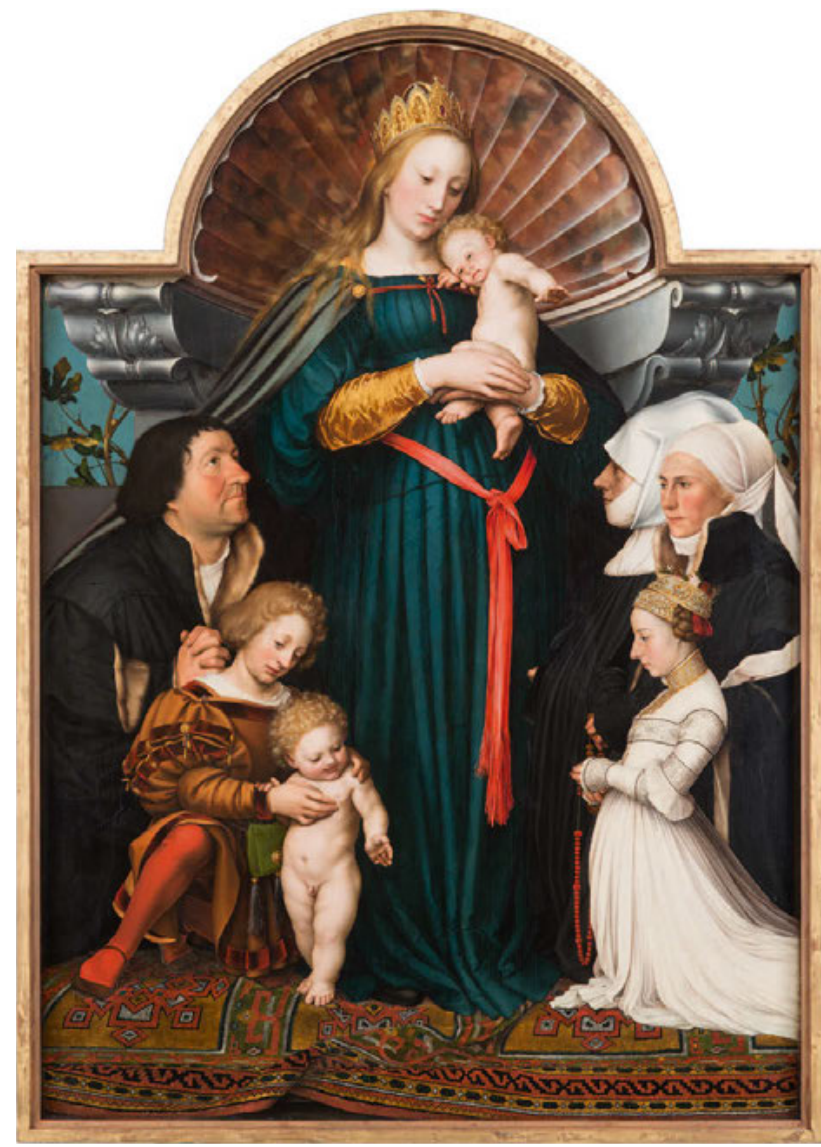

91 Hans Holbein der Jüngere, Madonna des Bürgermeisters Jacob Meyer zum Hasen, 1525/26 und 1528, Öl auf Nadelholz, 146,5 × 102 cm, Sammlung Würth, Schwäbisch Hall, Johanniterkirche

madonna als Höhepunkt der deutschen Kunst in der Dresdener Gemäldegalerie und damit Raffael und der Sixtinischen Madonna ebenbürtig: »[Das Bild ist es würdig], sich in einer Sammlung zu befinden, in der Raphaels Madonna di St. Sisto strahlt, ohne neben dieser Sonne wie der bleiche Mond zu verschwinden. ${ }^{89}$ Diese Quintessenz ist zwar ideologisch verklärt, in ihrem Charakter aber für die frühe Kunstgeschichte doch bedeutend: Zeit seines Lebens hat der Dresdener Kunstforscher sich für die Anerkennung altdeutscher Kunst, für Dürer und Holbein eingesetzt. Damit beabsichtigte er, das Antikeninteresse des Klassizismus, die Idealisierung der italienischen Kunst der Renaissance und das Primat Raffaels aufzuweichen und zu differenzieren..$^{\circ}$ Hierfür setzte er sich intensiv mit spätmittelalterlicher Kunst nördlich der Alpen auseinander, bereiste über die gewöhnlichen Destinationen eines Kunstliebhabers hinaus gehende Länder wie Spanien oder Schweden, sammelte Druckgraphik und Zeichnungen nach kunstgeographischen und chronologischen Kriterien. Sein kennerschaftlicher Blick auf die Geschichte der Künste in ihrer ganzen Breite ist demnach von einem kunsthistorischen Interesse im wissenschaftlichen Sinn geprägt. Dies zeigt sich auch darin, dass er lange die von den Künstlern in der Galeriedirektion gewünschte, räumliche Hervorhebung Holbeins und der altdeutschen Künstler ablehnte, wie nachfolgend noch zu zeigen sein wird.

Kennzeichnend für seine wissenschaftlichen Interessen ist gerade seine Beschäftigung mit Holbeins Meyermadonna. Auf der Rückreise aus Südfrankreich 1846 untersuchte er in der öffentlichen Bibliothek in Basel Holbeins Porträtstudien zu den Figuren des berühmten Bildes und äußerte sich zur Datierung (Abb. 92). ${ }^{91}$ Ihm fiel dabei eine Stilverschiedenheit zwischen Holbeins Zeichnungen und dem ausgeführten Gemälde auf. In der Distanz zwischen den Basler Porträtskizzen und einer »weniger unbefangenen Naturwahrheit« im Dresdener Bild sah er den Grund, eine Entstehung des Gemäldes nach Holbeins Abreise 1526 aus Basel im Zuge der schwierigen Auftragslage unmittelbar vor der Reformation zu vermuten: »Gerade diese Portraitköpfe in diesem Gemälde sind es, welche [...] eine Entschiedenheit vermissen lassen, die Holbein eigen war, und die Vermuthung begründen könnten, als hätte der Maler sich angestrengt, in der Erinnerung die Skizze zu vervollständigen. $\ll^{92}$ Im Bericht über seine Untersuchungen in Basel zeigt sich denn auch, weshalb Quandt zu diesem Schluss kam. Da ihm die historischen Quellen für sein Argument fehlten, begründete er seine Thesen in einer einfühlsamen Lektüre der Künstlerbiographie - mit anderen Worten: er psychologisierte, wofür er sich sogar rechtfertigte: »Da hierüber keine historischen Nachweisungen vorhanden sind, so ist es erlaubt, auf psychische Gründe Vermuthungen zu bauen. Wenn wir die unendliche Liebe und Frömmigkeit fühlen, welche das Bild beseelen und den Maler erfüllten [...], so möchten wir glauben, daß dieser Hausaltar von einem Katholiken in einer Zeit gemalt sei, wo seine Freunde und Glaubensgenossen wegen ihrer Ueberzeugung bedrängt wurden.«93 Da Quandt also nicht alle Quellen bekannt waren,
89 Quandt 1846 (2), S. 288; s. a. Quandt 1856, S. 146-147: »Dr. Mosen sagt zu bescheiden: $>$ Vielleicht bezeichnet dieses Bild den Höhenpunkt der deutschen Malerei, wie die sixtinische Madonna den Gipfel der römisch-christlichen Kunst - und wir bestätigen dieses Wort mit voller Ueberzeugung.« Quandt zitiert hier nach Mosen 1844, S. 28. Quandt 1853, S. 18. Zu den Vorläufern des Erfolgs von Holbeins Meyermadonna und der zahlreichen Kopien ab 1800 siehe Maaz 2014, S. 7-21. S. a. Bader 2013, S. 28-34
90 Vgl. Beyer 2010, S. 202

91 Die drei Kreidezeichnungen: Hans Holbein d. J., Bildnis des Jacob Meyer zum Hasen; Bildnis der Dorothea Meyer, geborene Kannengießer und Bildnis der Anna Meyer, um 1525/26, Kunstmuseum Basel, Kupferstichkabinett, Museum Faesch, Inv. 1823.140-142.

92 Quandt 1846 (2), S. 289

93 Quandt 1846 (2), S. 289 


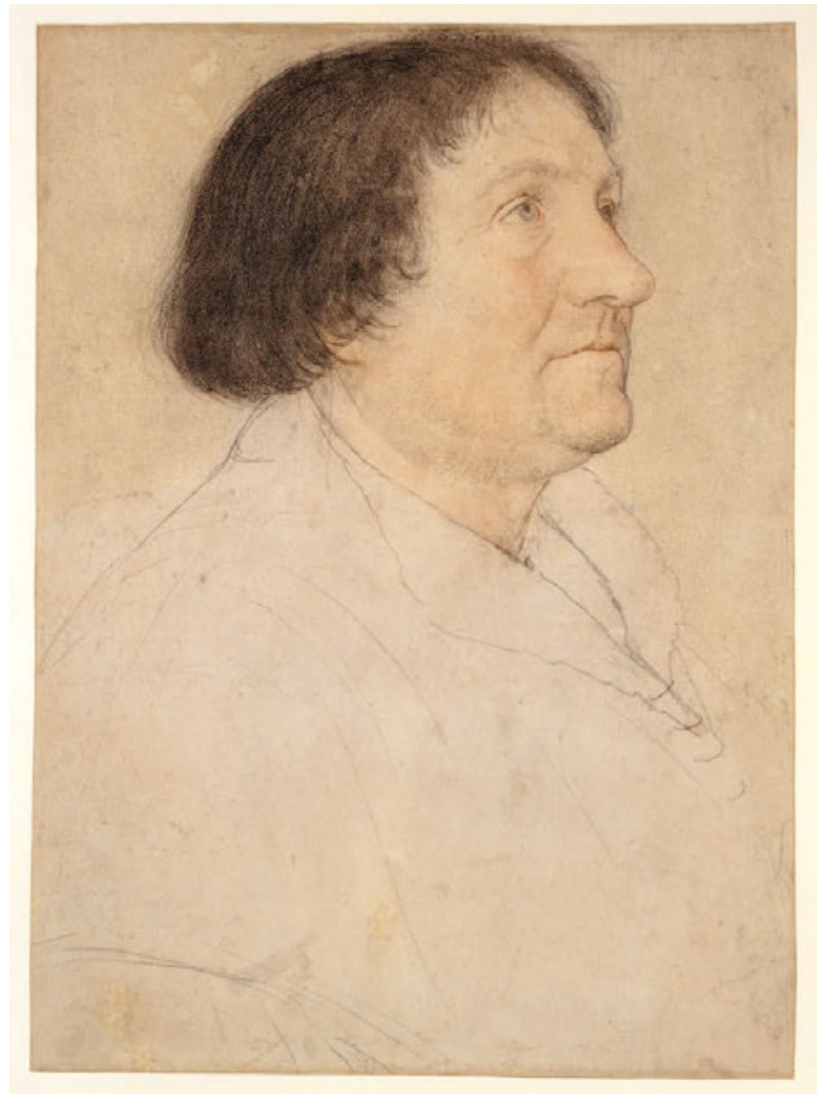

92 Hans Holbein der Jüngere, Bildnis des Jacob Meyer zum Hasen, um 1525/26, Kreidezeichnung, Kunstmuseum Basel, Kupferstichkabinett, Museum Faesch, Inv.-Nr. 1823.140

versuchte er in Kombination von Bildbetrachtung und Künstlerbiographik seine Schlüsse zu ziehen.

Vergleichendes Sehen wie das Abgleichen von Vorzeichnung und vermutetem Original von Quandt war nebst der quellenbasierten Provenienzprüfung einer jener Faktoren, der 1871 nach genauen Untersuchungen zur Neuzuschreibung führte.94 Die aktuelle Frage, ob es sich um eine Kopie handeln könnte, griff Quandt indes nicht auf und äußerte sich an anderen Stellen nur am Rande dazu oder hob die Originalität der Dresdener Fassung hervor. ${ }^{55}$ So ignorierte er 1830 in seiner Rezension von Aloys Hirts Kunstbemerkungen dessen angesichts der Darmstädter Madonna zum ersten Mal formulierte Zweifel an der Einordnung der Dresdener Madonna in Holbeins Werk. ${ }^{96} 1856$ kam

94 Quandt 1846 (2), S. 288-291. Zum vergleichenden Sehen siehe Bader 2013, S. 94-110. S. a. Bätschmann 2017, S. 37.

95 Zum Beispiel in Quandt 1853, S. 82 über ein druckgraphisches Blatt seiner Sammlung: »Lit. A. Die Familie Meyer zu den Füßen der Maria. Nach dem Originalgemälde von H. Holbein in der Königl. Gallerie zu Dresden.«S. a. Quandt/Schulz 1848, S. 58-60, zu einer Kopie nach Holbeins Meyermadonna in der Sammlung von Bernhard August von Lindenau in Altenburg. Dazu auch Maaz 2014, S. 19-21. er in seinem Begleiter durch die Gemälde-Säle bei der Beschreibung der bildimmanenten Divergenzen auf seine Beobachtungen zu den Basler Zeichnungen zurück und schrieb, einige Teile des Gemäldes seien wie die Porträtzeichnungen nach der Natur gemalt, andere Bereiche jedoch entsprängen Holbeins künstlerischem Geist und seien daher freier in der Darstellung. »G[e]rade diese Verschiedenheit, welche zu beobachten das Bild selbst Gelegenheit giebt, ist ein Beweis der Originalität, wenn solche noch zu beweisen nöthig wäre - ein Copist würde alles auf einerlei Weise behandelt haben. ${ }^{97}$ Diese Mutmaßung sollte noch viele Jahre von anderen geteilt werden, waren doch deutliche Unterschiede zwischen der unrestaurierten Originalfassung in Berlin und der qualitätsvollen Kopie in Dresden erkennbar. ${ }^{98}$

Es ist bemerkenswert, dass Quandt die stilistische Divergenz, die andere stutzig machte, recht früh erkannt hatte und dennoch bei einer Zuschreibung an Holbein blieb. Den Aspekt der Stilverschiedenheit innerhalb eines künstlerischen Werks griff der Basler Kunsthistoriker Jacob Burckhardt noch 1882 in einer Kritik am Mehrheitsentscheid der KunsthistorikerGruppe in Dresden 1871 auf, um zu zeigen, dass es in der Kunstwissenschaft nicht nur um dokumentarische Echtheit, sondern auch um ästhetische Schönheit der Bilder, mithin um Kunst und nicht um Namen, gehen müsse. ${ }^{99}$ In der Einordnung des Dresdener Holbein-Streits haben jüngste Untersuchungen hier anschließend eine Differenzierung vorgenommen, um das in der Forschung der letzten Jahrzehnte kolportierte Resultat dieses wissenschaftlichen Disputs zu relativieren. Laut diesem brach der Holbein-Streit dem begründeten Echtheitsurteil und damit der wissenschaftlichen Kunstgeschichte ihre Bahn, während das ästhetische Schönheitspostulat in die Schranken gewiesen wurde. Quandt gehört jedoch zu denjenigen Beispielen, anhand derer sich beschreiben lässt, dass die zeitgenössischen Positionen zu den beiden Holbein-Madonnen weitaus differenzierter waren als nur die beiden Extreme der Echtheit und Schönheit einander entgegenzusetzen. ${ }^{100}$

In diesem Sinn wäre es interessant zu wissen, ob Quandt das schwer zugängliche Original der Madonna des Bürgermeisters Meyer überhaupt je gesehen hatte. Das Bild war ab 1821 in Berlin beim königlich-preußischen Generalmusikdirektor Gaspare Spontini, Schwager des vorbesitzenden Kunsthändlers, präsentiert und zierte ab 1822 die Privaträume des Prinzenpaares
96 Quandt 1830 (3), Sp. 570-574; Hirt 1830, S. 15-16. S. a. Fechner 1871, S. 4, 114 97 Quandt 1856, S. 148. Zu Quandts ikonographischer Beurteilung des Christuskindes, das von vielen als kranker Sohn des Bürgermeisters Meyer angesehen wurde, siehe Bader 2013, S. 220, 223.

98 Bader 2013, S. 252-254.

99 Bätschmann 2017, S. 50; Bader 2013, S. 260-261; Beyer 2010, S. 213-214. 100 Zur Kritik an dieser Position jüngst Bader 2013, S. 118-121 259-263; Beyer 2010, S. 212-217. 
Wilhelm von Preußen und Marianne von Hessen-Homburg im königlichen Schloss zu Berlin. Ab 1836 kam es durch Heirat von deren Tochter nach Darmstadt. ${ }^{101}$ Es ist nicht nachweisbar, ob Quandt Kenntnis des Originals hatte. Doch die Art und Weise, wie er es ignoriert, lässt vermuten, dass er es nie studiert hatte. Er dürfte es in seine Argumentation einbezogen haben, wäre es ihm bekannt gewesen, gerade angesichts des Umstands, mit welcher Sicherheit er bereits 1816 das Dresdener Triptychon Albrecht Dürer ab- und Jan van Eyck zugeschrieben, und ohne jegliches Bedauern das Bildnis des Charles de Solier nicht mehr da Vinci, sondern Holbein zuerkannt hatte - im Gegensatz zum großen Widerstand gegen diese endgültige Zuschreibung im Jahr 1860. ${ }^{102}$ Zwar sind diese beiden Beispiele anders zu gewichten, ging es hier doch um zwei absolut gerechtfertigte Zuschreibungen an zwei der bekanntesten Künstler nördlich der Alpen. Dagegen wirkt die Aberkennung des einst originalen Holbeins in Dresden und die Feststellung, dass es sich nur um eine spätere Kopie handeln sollte, schwerwiegender. ${ }^{103}$ Dennoch war Quandt vergleichendes Sehen wichtig. Dies zeigt sich in der Gemäldegalerie am Beispiel von Holbeins Sieur de Morette, dessen Zuschreibung er nach ersten kennerschaftlichen Zweifeln unter Einbezug eines Kupferstichs, also durch Bildvergleiche, bewiesen hatte. ${ }^{104}$ Ebenso stellte er wiederholt Querbezüge auf unterschiedliche, ihm bekannte Gemälde während seiner zahlreichen Reisen her oder nutzte seine eigene graphische Sammlung vergleichend »als Leitfaden zur Geschichte der Kupferstecherei und Malerei $\ll .{ }^{105}$ Wie die oben zitierte Passage in seinem Aufsatz über die Rahmenbeschriftungen im Kunstblatt von 1846 zu erkennen gibt, hatte Quandt seine Ehre zu verteidigen. Gerade in Konkurrenz zu Franz Kugler und anderen jungen Kunsthistorikern wäre er bei einer Kenntnis des Originals zwar vielleicht immer noch nicht von einer Zuschreibung des Dresdener Gemäldes an Holbein abgekommen, er würde die Berliner Fassung aber mit größter Wahrscheinlichkeit diskutiert haben - vielleicht auch nur, um es wie die Dresdener Künstler, als verbessertes Original zu betrachten. ${ }^{106} \mathrm{Ob}$ sein starker Abwehrreflex gegen Kuglers Mutmaßung seine Unkenntnis des Originals vielleicht gar nachweist, bleibe dahingestellt - vielleicht hatte er es auch nicht sehen wollen, weil er möglicherweise das Dilemma erahnte, in das ihn seine eigene wissenschaftliche Kennerschaft augenblicklich gestürzt hätte.

101 Zur Zugänglichkeit siehe Maaz 2014, S. 20-21; Bader 2013, S. 50-51; Beyer 2010, S. 203. Das erste schriftliche Zeugnis zum Bild und zur Frage der Originalität könnte aus einem Brief von Hegel an seine Frau vom September 1821 stammen; Bader 2013, S. 305-307.

102 Zum Widerstand bei der Zuschreibung des Charles de Solier an Holbein siehe Marx 1998, S. 265-266.

103 Zu diesem langwierigen Prozess siehe Maaz 2014, S. 16-28.

104 Bader 2013, S. 98.
Quandt vertiefte sich im Sinn einer wissenschaftlichen Kunstgeschichte sicherlich zu wenig in historische Quellen und verließ sich oft auf seine Anschauung, womit ihm die korrekte Einordnung der Dresdener Madonna des Bürgermeisters Meyer verschlossen blieb. Doch gerade die vergleichende Kunstbetrachtung war ihm über eine umfassende Lektüre hinaus zentrales Instrument seiner Kunstkennerschaft. So sind auch die knappen Informationen auf den Galerierahmen der Gemälde zu verstehen. Dank ihnen konnten die umständlichen Beschreibungen im Katalog wegfallen. Die Besucher erschlossen sich die Geschichte der Dresdener Kunstwerke und damit eine Geschichte der Kunst mit dem dargebotenen Verweissystem durch die Anschauung. Künstlernamen und Lebensdaten auf den Schildern, knappe Informationen zu Bildinhalt und Herkunft eines Gemäldes im Katalog führten auf dem Galerierundgang zu vertieften Kenntnissen der Kunstgeschichte. ${ }^{107}$ Dies war der Weg zu einem Kunstverständnis, wie es Quandt zeit seines Lebens gewünscht hatte - nämlich einer Verbindung von kunsthistorischer Dokumentation und ästhetischer Anschauung.

\section{Didaktik der Anschauung}

Als Quandt im Spätsommer 1819 auf der Reise nach Rom war, formulierte er dieses Ideal: »Den [...] Zweck meiner Reise, hoffe ich noch zu erreichen, nehmlich Materialien zu einer psychologisch genetischen Kunstgeschichte zu sammeln. Vasari, Sandrart, Lanzi, u. a.m. haben Lebensbeschreibungen einzelner Künstler gegeben, wo jeder Einzelne für sich geschildert wird. Nicht blos jeden Einzelnen für sich betrachtet und nicht eine chronologische Aneinanderreihung, giebt eine wahre Kunstgeschichte, sondern eine Zusammenstellung, ein Aufsuchen der Ursachen u Wirkungen, woraus dann hervorgehn muß, wie die Kunst mit dem Zeitgeist Schritt gehalten hat und aus dem Vorhergehenden das Nachfolgende sich entwick $[\mathrm{el}] \mathrm{t}$. Der Einzelne wird hier nur als Glied des Ganzen, nicht als ein Ganzes erscheinen, die Kunstgeschichte in die der Menschheit eingreifen, ein zusammenhängendes Leben in dem der Individuen sich zeigen u die gesammte Geschichte, alles Seÿn, Wirken u Vorschreiten, einer in allen lebenden Weltseele, darstellen. $\ll^{108}$ Wenn Quandt nicht, wie später Kugler, Nagler, Schnaase oder Woermann, eine

\footnotetext{
105 Quandt 1853, Titelblatt.

106 Vgl. Beyer 2010, S. 208-209.

107 Schäfer 1860, S. X-XIII bedauerte den Verlust an Information in den Katalogen. Dies sei auf Wunsch der Kommission geschehen. S. a. Penzel 2007, S. 291; Prange 2004, S. 129-137.

108 Brief von Quandt an Unbekannt vom 21.8.1819, in: SLUB, Mscr. Dresd. App. 278, Nr. 163. Zum Zeitgeist siehe Quandt 1847, S. 134-140.
} 
umfassende Kunst- oder Künstlergeschichte geschrieben hat, so manifestiert sich in dieser Aussage doch ein kunstwissenschaftliches Verständnis, dass er in der neuen Galeriehängung und dem optimierten Rundgang ansatzweise umzusetzen versuchte.

Mit dem Genetischen meinte Quandt das Vererbte, gleichsam historisch Überlieferte. Er reihte nicht nur einzelne Künstler und ihre Schulen in chronologischer Reihenfolge aneinander, sondern versuchte die chronologische Kunsttopographie in eine übergeordnete Norm einzubinden, die sich über alle Zeiten forterbte. ${ }^{109}$ Diese Norm umschrieb er mit »Menschengeist« und meinte damit die Einheit von vernünftigem Denken und sinnlichem Wahrnehmen, von »Geist und Materie«, von »Wissen und Seyn.$^{.10}$ Diese Einheit verband er mit der naturgeschichtlichen Entwicklung des Menschen."I Ihr Äquivalent, die kulturgeschichtliche Entwicklung, manifestierte sich in der Geschichte der Ästhetik.12 Eine solche universale Ästhetik nährte sich aus dem Verständnis und der Anschauung eines konstanten Schönheitsbegriffs. Schönheit sei ein Akt der Vernunft. Sie sei der vernünftige Gedanke in sinnlich-anschaulicher Form, also die Einheit von Idee und Erscheinung - ein Gedanke, für den Quandt beanspruchte, ihn Jahre vor Hegel formuliert zu haben. ${ }^{113}$ Quandts »genetische« Kunstgeschichte war somit eine Geschichte der Schönheit.

109 Quandt 1826 (1), S. IX: »Wahre Geschichtserkenntnis ist nur das Erkennen einer Idee, welche sich in dem Zusammenhang aller und in den einzelnen Begebenheiten ausprägt, zu nennen, nicht aber das Aufzählen einzelner Begebenheiten nach einer Zeitfolge.« S. a. Quandt 1839 (1), S. 1: »[...] die Geschichte [ist auch nicht mehr] ein bloses (sic!) Aufzählen von Einzelnheiten, welche an und für sich betrachtet doch nichtig sind, so groß auch die Begebenheit für den Augenblick erscheint, und ihre Berichte über Vor- und Rückschritte in Wissenschaften, Künsten und Sitten sind nicht ein Wetterleuchten, wo Licht und Finsterniß wechseln; vielmehr zeigt sich Alles in einem Lebensverbande, in einem Pulsiren ohne Stillstand, als ein beseeltes Ganze, was nach vollem Bewusstseyn und Willen und in Erkenntniß und That sich darzuthun strebt."

110 Quandt 1844 (1), S. 105 (»Geist und Materie«); Quandt 1859 (1), S. 8 (»Wissen und Seyn«). Es handelt sich hierbei um die Grundthese von Quandts Briefe aus Italien über das Geheimnisvolle der Schönheit und die Kunst; Quandt 1830 (1), S. 7. S. a. Quandt 1844 (1), S. 6.

111 Quandt 1846 (2), S. 356-364. In der Senckenberg'schen Naturaliensammlung in Frankfurt am Main experimentierte Quandt anhand der Anschauung von Skeletten der Erdgeschichte mit dem Gedanken der Entwicklung des Menschengeistes, die an gewissen Stellen an die einige Jahre später durchschlagenden Erfolg feiernden Evolutionstheorie erinnern. So versteht er das menschliche Skelett als aus dem Affen hervorgehend, wenn auch diesen übertreffend. Er denkt die Naturgeschichte in einer pyramidalen Entwicklung, die auf den menschlichen Geist zuläuft. Der menschliche Schädel als dessen Gefäß erscheint als Höhepunkt der Evolution. Vischer 1837, S. 31-32 postuliert die Entstehung des Menschen als den Anfangspunkt der Schönheit.

112 Quandt 1844 (1), S. 6. Quandt hält die behandelten Philosophen - beginnend bei Platon, endend mit Hegel - vor dem Hintergrund seiner
Die Ästhetik des Kunstgelehrten schlug sich in einer Didaktik der Anschauung nieder. Durch Kunstanschauung sollte die Geschichte der Schönheit als Einheit von vernünftigem Denken und sinnlicher Erscheinung erkannt werden. Im Vor- und Nachwort zu seiner deutschen Übersetzung der 1792 erstmals erschienen Storia pittorica della Italia von Luigi Lanzi skizzierte Quandt die Hauptmomente der italienischen Malereigeschichte anhand der Ausprägungen und Wechselverhältnisse von Geist und Sinnlichkeit. Er warf Lanzi eine etwas emotionslose Sammelwut vor, die unterschiedlichste Dinge unkritisch zueinander führte. Damit lehnte er Lanzis naturwissenschaftlich-taxonomischen Blick auf die italienische Malerei ab, weil diese Methode keinen »Aufschluss über das Innere, das Geistige in den Malereien« gäbe. ${ }^{114}$ Nicht wie die Kunsttheorie des 18. Jahrhunderts auf dem vergleichenden Kunsturteil, basiert Quandts Kunstgeschichte auf einem normierten und historisierten Schönheitsbegriff. ${ }^{15}$ Diese Haltung verdeutlicht sich in einer Rezension eines Reiseberichts von Aloys Hirt, der bei der Betrachtung der Dresdener Gemäldegalerie allgemeine Gedanken zur Entwicklung des Menschengeistes erläuterte. Quandt schrieb: »Es ist dieß in unserer Zeit um so schätzbarer, weil die meisten Kunstgeschichtsforscher den Zusammenhang über einer Menge von unabsehbaren Einzelnheiten aus den Augen zu verlieren in Gefahr kommen und die beliebt gewordene geographische Eintheilung

ästhetischen Norm zusammen. Besonders verdichtet zeigt sich dieses »Fortschreiten des Menschengeistes « dort, wo er keine Philosophen zitiert. So beschreibt er die Ästhetik des Mittelalters und der frühen Neuzeit mit Künstlerbeispielen. Nach Platon und Aristoteles sind für Quandt erst wieder Giordano Bruno und Spinoza nennenswerte Beispiele, um über philosophische Ästhetik zu sprechen. Ebd., S. 69-86. S. a. Quandt 1853, S. 36.

113 Quandt 1830 (1), S. 44; Quandt 1844 (1), S. 4-10. Zum Anspruch, Hegel antizipiert zu haben: »[...] denn es ist die Idee, oder wie ich es ausgesprochen habe, das Vernunftgemäße in der sinnlichen Erscheinung, oder wie Hegel, fünf Jahre später als ich es sagte, das Vernünftige, worauf das Schöne beruht. « Brief von Quandt an Julius Schnorr vom 2.12.1843, in: SLUB, Mscr. Dresd. n Inv. 15, Bd. 31, fol. 234V. Ebenso Quandt. 1844, S. 141: „So spricht den Hegel deutlich aus, was ich vor zehn Jahren sagte und damals für leere Dialektik erklärt wurde. Indeß kommt immer eine Zeit, wo die Wahrheit Anerkennung findet.« Siehe dazu Hegel/Hotho 1835, S. 53: »Dieß ächte Produciren macht die Thätigkeit der künstlerischen Phantasie aus. Sie ist das Vernünftige, das [...] was es enthält, noch erst in sinnlicher Form vor sich hinstellt." S. a. Solger 1829, S. 58-66, hier S. 65: »Das Schöne muß die Idee als gegenwärtig in der Erscheinung darstellen, freilich nicht bloß sinnlich, sondern auch durch das Denken. «Ebenso Vischer 1837, S. 22: »Das Schöne ist das sinnliche Scheinen der Idee, die Idee in begränzter Erscheinung.« Vischer bezieht sich hauptsächlich auf Hegel.

114 Weddigen 2008, S. 214-215. Zu Quandts Einleitung »Ueber Lanzi's Kunstansicht « siehe Lanzi 1830-1833, Bd. 1, S. XVI-XXXVI und Bd. 3 , S. 337-348. Lanzis Storia pittorica della Italia markiert einen Wendepunkt in der kunsthistorischen Wissenschaft, indem sie als Ordnungssystem die Einteilung in Lokalschulen anwendet; Penzel 2007, S. 171.

115 Quandt 1830-1833, Bd. 1, S. XXVI-XXXII. 
der Schulen eine Verwirrung hervorgebracht hat, welche die Erkenntniß der Wechselwirkung, von Vorgängern, Zeitgenossen, Nachfolgern und Zeitverhältnissen, sehr erschwert. «16 $^{116}$ Das empirische Auflisten von Einzelheiten war Quandt ein Dorn im Auge. Gleichzeitig verlangte seine Ästhetik der Anschauung nach einer kunstgeschichtlichen Ordnung. Er plante aus diesem Grund, Lanzis Geschichte der Malerei eine »geistig genealogische Tabelle«beizufügen. Zu verwirrend sei die kunstgeographische Einteilung des italienischen Kunsthistoriographen.

Quandts synoptischer Überblick sollte auf der Kunstbiographik Vasaris und Baldinuccis fußen, wie er anmerkt. Jedoch wollte er nicht wie diese Gelehrten von Cimabue allein ausgehen, »sondern mehrere Kunstgeschlechter von verschiedenen Stammvätern nebeneinander fortlaufen [lassen], ihre Verzweigungen u Spaltungen, durch Zusammenlaufen $\mathrm{u}$ Trennen der Columnen andeute $[\mathrm{n}]$, das Durchgreifende eines großen Geistes durch viele Geschlechter u Zeiträume versinnlich[en] und das sich wieder Verliern u Abdämmern eines mächtigen, von einem hohen Meister ausgegangenen Einflußes, vor Augen [bringen]. « ${ }^{117}$ Um die Synopse anschaulich zu gestalten, gedachte er die Spalten der Tabelle nach kunsttopographischen Kriterien farbig zu gestalten. Seine »Hauptquellen« der Kunst wollte er mit den Primärfarben Gelb (Byzanz), Blau (Italiener) und Rot (Pisaner) unterlegen, ihre Überschneidungen wiederum mit den Sekundärfarben.. ${ }^{118}$ Für die Umsetzung plante er einen Kunstgelehrten zu gewinnen, »der viel gesehen hat « und die Wechselverhältnisse zwischen den Künstlern kenne. Er dachte an den Direktoren der Berliner Gemäldegalerie, Gustav Friedrich Waagen, den Dresdener Altertumsforscher Heinrich Hase oder an den Raffael-Forscher Johann David Passavant. ${ }^{119}$

Zur Ausführung kam der anschauliche Überblick nicht, was insofern bedauerlich ist, als Quandt mit diesem geradezu naturwissenschaftlichen Klassifikationsprinzip in tabellarischer Form auf der Höhe der Zeit gewesen wäre, wie verschiedene Beispiele aus der Historiographie anfangs des 19. Jahrhunderts zeigen. Selbst in Quandts engerem Umfeld entstand 1826 eine

116 Quandt 1831 (3), S. 65. Siehe Hirt 1830.

117 Brief von Quandt an Wilhelm Ambrosius Barth vom 14.1.1830, in: SLUB, Mscr. Dresd. App. 1191, Nr. 575-576. Barth selber hatte den synoptischen Überblick angeregt, wie aus dem Brief hervorgeht. S. a. Quandt/Schulz 1848, S. 2.

118 Die Kunstschulen mit den Hauptkünstlern, ihren Vorgängern und Nachfolgern sollten in die Spalten der Tabelle aufgeteilt werden, die einzelnen Künstler wiederum chronologisch in die Zeilen eingefügt. Quandt sah auch die Schwierigkeit, Meister, Schüler, Freunde und Gehilfen voneinander zu unterscheiden, weswegen er die Tabelle nur für die wichtigsten Künstler in Lanzis Werk erstellen wollte.

119 Siehe Schröter 1990, S. 352, Anm. 262.

120 Kat. Quandt 1860 (1), S. 156, Nr. 2408.

121 Schmidt-Burckhardt 2017, S. 15-19. S. a. Rössler 2017, S. 82-88.

122 Schmidt-Burckhardt 2005, S. 65-81, hier S. 72. Caumonts Flussdia- solche Tabelle, nämlich Johann Heinrich Meyers Uebersicht der Geschichte der Kunst bei den Griechen, die sich wohl in Quandts Bibliothek befand. ${ }^{120}$ In seiner frühen Art blieb Meyers Diagramm vorerst noch einzigartig, obschon Goethe persönlich das Produkt seines Kunstberaters als neues Instrumentarium zur Beschreibung der Künste sehr gelobt und zu dessen Verbreitung unter anderem Sulpiz Boisserée berichtet hatte - wohl um genau jenes Umfeld jüngerer Kunstkenner wie Quandt zu gewinnen, die sich mit der wissenschaftlichen Beschreibung der Alten Meister auseinandersetzten. Dort fiel es indes nicht auf fruchtbaren Boden. ${ }^{121}$ Ähnliche Tabellen entstanden in Frankreich, wo anfangs der 183oer Jahre der französische Kunstgelehrte, Archäologe und Geologe Arcisse de Caumont Diagramme zur Beschreibung des Laufs der Geschichte als Beigabe seines mehrbändigen Werks über die französische Architektur von ihren Anfängen bis ins 18. Jahrhundert veröffentlichte. Dabei unterteilte dieser, genauso wie Quandt es zu tun beabsichtigte, Epochen mit verschiedenen Farben. ${ }^{122}$

Quandts innovative Idee einer diagrammatischen Darstellung der italienischen Kunstgeschichte zeigt, wie er die Diskussionen um die richtige, historiographische Einordnung der Künstler und ihrer Werke verfolgt und mit seinen universalgeschichtlichen Kunstansichten zu vereinigen gesucht hat. Gerade in seiner eigenen Kupferstichsammlung spielte Chronologie und Kunsttopographie für die Einteilung eine zentrale Rolle. »Das Interesse am Geschichtlichen ist jedoch bei den meisten Kunstliebhabern das vorherrschende, wie ich oft zu bemerken Gelegenheit hatte, obwohl es bei mir dem ästhetischen Vergnügen nachsteht. Jener Neigung habe ich zu entsprechen gesucht und die Blätter meiner Sammlung historisch geordnet, jedoch dabei auch nicht völlig meine Vorliebe, in jedem Kunstwerke die Idee und in der Kunstgeschichte den Entwickelungsgang des Menschengeistes zu erkennen, verleugnet. $\ll^{123}$

Wie der Katalog von Quandts Kupferstichsammlung zeigt, ist diese nach Schulen geordnet. Die ersten Mappen beinhalteten deutsche Meister des 15. bis 19. Jahrhunderts, danach folg-

gramm wurde indes kaum rezipiert; vgl. Schmidt-Burckhardt 2017, S. 86-89.

123 Quandt 1853, S. 2; Quandt 1841, S. 433; Quandt 1826 (1), S. V-IX: »SOdann diente auch eine ziemlich reichhaltige Kupferstichsammlung, welche der Besitzer chronologisch und nach Schulen geordnet hat, [...] indem die Seltenheit oder Schönheit der Blätter unterhielt oder erfreute. [...] es wäre nicht einmal zu wünschen, daß nur einmal und von einem Standpuncte aus die Geschichte dieser Kunst construirt würde, indem vielseitigere und von Verschiedenen angestellte Betrachtung durchaus vorteilhaft ist. « Er beschreibt in dieser Schrift in elf Abhandlungen die Geschichte der Druckgraphik, indem er chronologisch den Künstlern Deutschlands, Italiens, der Niederlande, Frankreichs und Englands vom 15.-18. Jh. folgt. S. a. Kat. Quandt 1853. Zum Begriff der Universalgeschichte siehe Zwenger 2003, [s. p.]; Nipperdey 1976, S. 45 
ten die Niederländer und Holländer, Franzosen, Engländer und schließlich die Italiener. ${ }^{124}$ Tatsächlich lassen sich aber einige Eigenheiten in der Ordnung feststellen, die mit Quandts Kunstverständnis zusammenhängen. So führte er in der Mappe VIII oberdeutsche und altniederländische Blätter zusammen, weil darin der "germanische Nationalcharakter « erkennbar sei. ${ }^{125} \mathrm{An}$ einigen Stellen stellte er den Mappen einleitende Worte voran, die spezifische Vorstellungen des gegenseitigen Einflusses von Kupferstichkunst und Malerei darlegten. Zudem zieht sich die Frage des Ursprungs der Druckgraphik in Italien oder Deutschland als roter Faden durch die Ordnung und entpuppt sich ebenfalls als subjektiver Gedankengang. ${ }^{126}$ Trotz dieser eigenwilligen Ordnungskriterien benutzte Quandt für mehrere Mappen die aktuellste kunsthistorische Literatur. So richtete er sich für die Mappen XVII bis XIX, die Stiche nach Raffael enthielten und einen bedeutenden Anteil seiner Sammlung ausmachten, nach den Erkenntnissen aus der Raffael-Forschung von Passavant. ${ }^{127}$

Obschon Quandt eine chronologisch-topographische Kunstgeschichte mit seinem subjektiv-idealistischen Geschichtsbild verwebte, entstand keine Kunstgeschichte der Meisterwerke und Künstlergenies, wie man es eigentlich erwarten könnte. ${ }^{128}$ Quandt ging individuell auf einzelne Kunstwerke ein und verortete sie historisch. So konnte er auch Stücke, die stilistisch oder technisch weniger meisterhaft waren, als »schön« klassifizieren oder mindestens in einen wie auch immer gearteten Bezug zu seinem Schönheitsbegriff setzen.

Quandts Sichtweise der Ordnungskriterien wirft ein Licht auf seine Tätigkeit bei der Neuhängung der Gemäldegalerie von 1843. Natürlich hatte er diese in einem Kollegium bestehend aus Matthäi, Hartmann und Vogel von Vogelstein umzusetzen. Die gleichen subjektiven Kriterien wie in der eigenen Sammlung

124 Einen Überblick über die Ordnung bietet die kommentierte »Inhaltsanzeige« in: Quandt 1853, S. V-VIII.

125 Quandt 1853, S. 112.

126 Zum Zusammenhang von Malerei und Kupferstichkunst siehe die Einleitung zu Mappe X, Quandt 1853, S. 134-138. Zum Ursprung der Druckgraphik siehe ebd., S. 2-8, 191.

127 Nach Passavants Standardwerk Rafael von Urbino und sein Vater Giovanni Santi (1839). Quandt 1853, S. 248. S. a. Brief von Quandt an Passavant, nicht datiert (vor Okt. 1853): »Aus beifolgendem Verzeichniß werden Sie ersehen, wie oft ich Ihrer mit Verehrung und Zuneigung gedenke, denn jedes Blatt nach Raffael erinnert mich an Sie. Den Raffael habe ich nach Ihrer Angabe geordnet und konnte gewiß keine bessere Anleitung finden.« Frankfurt a/M, Universitätsbibliothek J.C. Senckenberg, Ms. Ff. J. D. Passavant A.II.e Nr. 588, fol. 1028 r

128 Quandt 1830-1833, S. 348: „Dies scheint uns der Faden zu seyn, der sich durch die Kunstgeschichte hindurchzieht, und an welchen sich die einzelnen Perlen leicht anreihen lassen. Unsere Absicht war, hierdurch [durch den kunsthistorischen Abriss] dem Leser den Faden der Ariadne zu geben, damit er sich in dem Labyrinthe einer Kunstgeschichte, welche nach Städten und Ländern eingetheilt ist, nicht verirre und nie vergesse, dass die Geschichte jeder Kunst zugleich die des Menschengeistes ist.« Vgl. Weddigen 2008, S. 216. konnten in der Königlichen Gemäldegalerie kaum angewandt werden. ${ }^{129}$ Entsprechend folgerte er bereits zwei Jahre früher: »Wenn nun die Frage entsteht, wie soll man eine Sammlung von Kunstwerken jetzt anlegen und ordnen? so glaube ich, nicht anders als nach einem historischen Plane: [...] weil in der Neigung, aus ihrem Lebensverbande herausgerissene Kunstwerke zu sammeln, sich die mehr wissenschaftliche als ästhetische Richtung unserer Zeit ausspricht, deren Anforderungen wir genügen müssen, da wir uns ihren Einflüssen nicht entziehen können. $\ll^{130}$ Wenn Quandt im Herbst 1840 im Brief an Lindenau und in seinem Gutachten für die Zusammenführung der wichtigsten Gemälde verschiedener Schulen plädierte, dann zeigt sich darin, dass er trotz seiner persönlichen Ansichten für die Darstellung historischer Entwicklungswege der Kunst die aktuellen Debatten der chronologischen oder der Schulhängung durchaus anzuwenden wusste und ihre Vorteile erkannte. ${ }^{31}$

\section{Eine Kunstgeschichte des Ausgleichs}

In der Diskussion um die Sammlungspräsentation der Dresdener Gemäldegalerie tritt Quandts spezifisches Kunstgeschichtsverständnis an einer Stelle besonders anschaulich hervor. Es betrifft die Säle auserlesener Gemälde. Im Brief an Lindenau von Ende August 1840 bemerkte Quandt in Bezug auf seine Änderungswünsche, »daß obige Allerunmaßgeblichsten Vorschläge den Saal des Raffael nicht berühren, in welchem die Gemälde nach dem Plane, der Sr. M. des Königs allerhöchste specielle Genehmigung erhielt, geordnet würden. Auch sind die Bilder in diesem Saale so gut aufgestellt, als es der beschränkte Raum zuließu die ungünstige Örtlichkeit gestattete. $\times^{1^{32}}$ Der Raf-

129 Zu den beteiligten Personen siehe SLUB, Mscr. Dresd. L 224, Bd. IV, Nr. 11, fol. 1v.

130 Quandt 1841, S. 433. Das Zitat entstammt einem kurzen Text über die Vorzüge der chronologischen Aufstellung von Gemälden in öffentlichen Museen in Raczyńskis Geschichte der neueren deutschen Malerei. Quandts Text geht ein Artikel zum gleichen Thema vom Berliner Hofmaler und Kunstprofessor Karl Wilhelm Wach voran. S. a. Kaiser 2017, S. 235.

131 Brief von Quandt an Lindenau vom 27.8.1840, in: HStADD, Akten der Generaldirektion der Königlichen Sammlungen, Cap. VII. Nr. 35, Acta die kgl. Gemälde-Gallerie betr., 1840-1844, fol. 62ff. (Kriegsverlust). Abschrift in: HStADD, 13458 SKD, NL Posse, Nr. 30, Lage 3, fol. 11r-12r. »Entwurf zu einer Aufstellung der königl: Gemäldegalerie u Dresden«, in: SLUB, Mscr. Dresd. L 224, Bd. IV, Nr. 11, fol. 1r-5r. Zur Druckfassung siehe Quandt 1842, S. 7-12. S. a. Weddigen 2008, S. 193-208; Penzel 2007, S. 282-299; Savoy 2006, S. 16-18; Prange 2004, S. 129-137.

132 Brief von Quandt an Lindenau vom 27.8.1840, in: HStADD, Akten der Generaldirektion der Königlichen Sammlungen, Cap. VII. Nr. 35, Acta die kgl. Gemälde-Gallerie betr., 1840-1844, fol. 62ff. (Kriegsverlust). Abschrift in: HStADD, 13458 SKD, NL Posse, Nr. 30, Lage 3, fol.12r. Zur Heraushebung der Sixtinischen Madonna s. a. Kat. Dresden 2012, S. $44-45$. 
faelsaal erschien Quandt als unantastbar, da er vom König selbst bewilligt und mitgestaltet worden war. Der Raum stand im Zeichen der besten Künstler und war geschmacklich-normativen und nicht kunsttopographischen, stilistischen oder chronologischen Kriterien unterworfen. Raffaels Sixtinische Madonna war der Höhepunkt des Saals und wurde im Katalog als erstes Gemälde aufgeführt. Die Nachahmer des römischen Künstlers und seine Kopisten kamen aus Gründen des vergleichenden Sehens und der Kunstbildung zu Ehren. Mit dem der Kunstgeschichte enthobenen Fokus auf Raffael wurde dem Geschmack der Zeit Rechnung getragen.

Die Längswand des Raums war Correggio gewidmet. Dass Correggio bei der Einrichtung des Raffaelsaals in den Jahren 1831/32 überhaupt einbezogen wurde, geht auf Quandt zurück. Die Kommission war zwar dagegen, weshalb Quandt seinen Vorschlag zurückzog. Es war schließlich der König, der die Einbindung der Gemälde dieses Künstlers verlangte. ${ }^{33}$ Man kann in Quandts Vorschlag die Abwehr eines reinen Saales der Auserlesenen erkennen. Weil der Kunstkenner von einer Sammlung erwartete, dass ihre Werke in historischen Kontexten gezeigt würden, musste er gegen eine isolierte Präsentation Raffaels ankämpfen. ${ }^{134}$ Die Einbindung Correggios konnte dadurch zum Kompromiss werden. Quandt wusste um die zentrale Rolle dieser Gemälde in der Königlichen Sammlung. Die vier großen und beliebten Altartafeln waren 1745 im Rahmen des Ankaufs der hundert besten Bilder aus der Sammlung Herzog Francesco III. von Modena in die Sammlung gekommen. Sowohl die Bilder Correggios wie auch Raffaels Sixtina waren von Kurfürst Friedrich August II. angekauft worden (Abb. 93-94). Ihre gemeinsame Präsentation hatte also einen sammlungshistorischen Wert. Die große Anzahl Correggio-Bilder widerspiegelte den gleichsam von oben diktierten und seit dem 18. Jahrhundert

133 Jahresbericht auf das Jahr 1836 vom 8./10.2.1837 von Matthäi, in: HStADD, Akten der Generaldirektion der Königlichen Sammlungen, Cap. VII. Nr. 29, Acta die königl. Gemälde-Gallerie betr., 1836-1839 (Kriegsverlust). Abschrift in: HStADD, 13458 SKD, NL Posse, Nr.30, Lage 8, fol. 5V: »Von 1831 bis 1832 wurde der Bau [der Scheidewände] u. die neue Aufstellung der Galerie, nachdem solches auf Höchsten Befehl unter Zuziehung des Herrn v. Quandt beraten war, ausgeführt. Hierbei muß ich bemerken, wie die erste Idee die Corregios (sic!) in den Saal zu den Gemälden des Rafael zu bringen von Herrn v. Quandt ausging, der jedoch nach gemeinsamer Beratung von inm aufgegeben, von Sr. Maj. dem jetzigen Könige jedoch wieder erfaßt u. in dem bestehenden Maaße ausgeführt wurde wie solches, durch die darüber vorhandenden Akten nachzuweisen ist.« Diese Akten konnten nicht mehr eruiert werden.

134 Quandt 1841, S. 433: „Wenn nun die Frage entsteht, wie soll man eine Sammlung von Kunstwerken jetzt anlegen und ordnen? so glaube ich, nicht anders als nach einem historischen Plane: 1) weil wir dadurch uns den Geist der Zeit [...] und die Zwecke, welche sie erfüllten, zurückrufen; den Lebensverband, in welchem einzig und allein die Kunstwerke einer frühern Zeit ihre volle Wirkung hervorbrachten, auf tradierten ästhetischen Kanon des wettinischen Königshauses, der sich neben der erstarkenden, neuen ästhetischen Normen verpflichteten Raffael-Mode noch zu behaupten vermochte. ${ }^{35}$

Wenn Quandt mit diesem Kniff eine sammlungshistorische Begründung für einen Raum auserlesener Gemälde herbeireden konnte, war die doch letztlich ahistorische Präsentation des Raffael-Saals nicht in seinem Interesse. Im Gutachten an Lindenau vom September 1840 äußerte sich der Kunstkenner hierüber deutlich: »Eilige Schaulustige«, notierte Quandt, würden das Wichtigste am liebsten schnell überblicken. Aus diesem Grund befürworteten im Gegensatz zu ihm einige Kommissionsmitglieder die Zimmer mit auserlesenen Gemälden, wie es neben dem Raffaelsaal bis 1837 auch noch einen Saal auserlesener Niederländer Gemälde gab (Saal F, vgl. Abb. 85-86). ${ }^{36}$ Er selber war für eine konsequente Hängung nach Schulen, denn diese hebe den unermesslichen Wert der Gemäldegalerie hervor und sei ausgesprochen lehrreich. Die Musterbilder herausragender Künstler würden, in ihren kunsthistorischen Kontexten präsentiert, den Betrachtern sofort auffallen. Darüber hinaus müsste alles »Treffliche was umher aufgestellt wäre, nicht für Ausschuss erklärt werden [...].« $\ll^{137}$ Dies geschehe aber, wenn man ein einzelnes Zimmer als Raum für die auserlesenen Gemälde bezeichnen würde.

Grundsätzlich war Quandt also gegen einen Raum der besten Werke. Er begründete dies mit der großen Anzahl qualitätsvoller Bilder in der Sammlung: »Dazu befinden wir uns in dem glücklichen embarras de richesse daß kein Zimmer groß genug ist, alle Schätze der Galerie in sich aufzunehmen u es also unmöglich wird, ein einziges Zimmer für das vorzüglichste zu bestimmen. $\ll^{138}$ Der Kunstkenner wollte auch die Meisterwerke in ihren kunsthistorischen Kontexten sehen. Es waren diese Kontexte, die ein Meisterwerk überhaupt erst zu einem solchen

dem Wege der Betrachtung vorstellen [...]; 2) weil in aller geistiger Entwickelung ein nothwendiger Zusammenhang stattfindet, der nur begriffen wird, wenn wir jedes Glied in seiner Verbindung mit dem Ganzen betrachten, was eben nur durch eine historische Ordnung geschieht."

135 Quandt verstand Friedrich August II., der den Ankauf der Modeneser Bilder getätigt hatte, als großen Kunstliebhaber, der aus reiner Liebe zur Kunst Gemälde angekauft und nicht wie August der Starke aus Prunksucht gehandelt habe. Vor allem standen ihm hervorragende Kunstkenner zur Seite; Quandt 1856, S. 6-7. S. a. Kat. Dresden 2007, S. 21-22; Kloppenburg/Weber 2000, S. 33-57. - Zum Raffaelsaal und seiner normativen Herauslösung aus dem kunstgeschichtlichen Rundgang in der Dresdener Gemäldegalerie siehe Weddigen 2008, S. 211-212. S. a. Brink 2005, S. 82-86.

136 Entwurf zu einer »Aufstellung der königl: Gemäldegalerie u Dresden«, in: SLUB, Mscr. Dresd. L 224, Bd. IV, Nr. 11, fol. 2v. Zum Niederländer Raum siehe Kat. Dresden 1835, S. 123-150 (Raum F). S. a. Weddigen 2008, S. 212.

137 SLUB, Mscr. Dresd. L 224, Bd. IV, Nr. 11, fol. 3r.

138 SLUB, Mscr. Dresd. L 224, Bd. IV, Nr. 11, fol. 3V. 


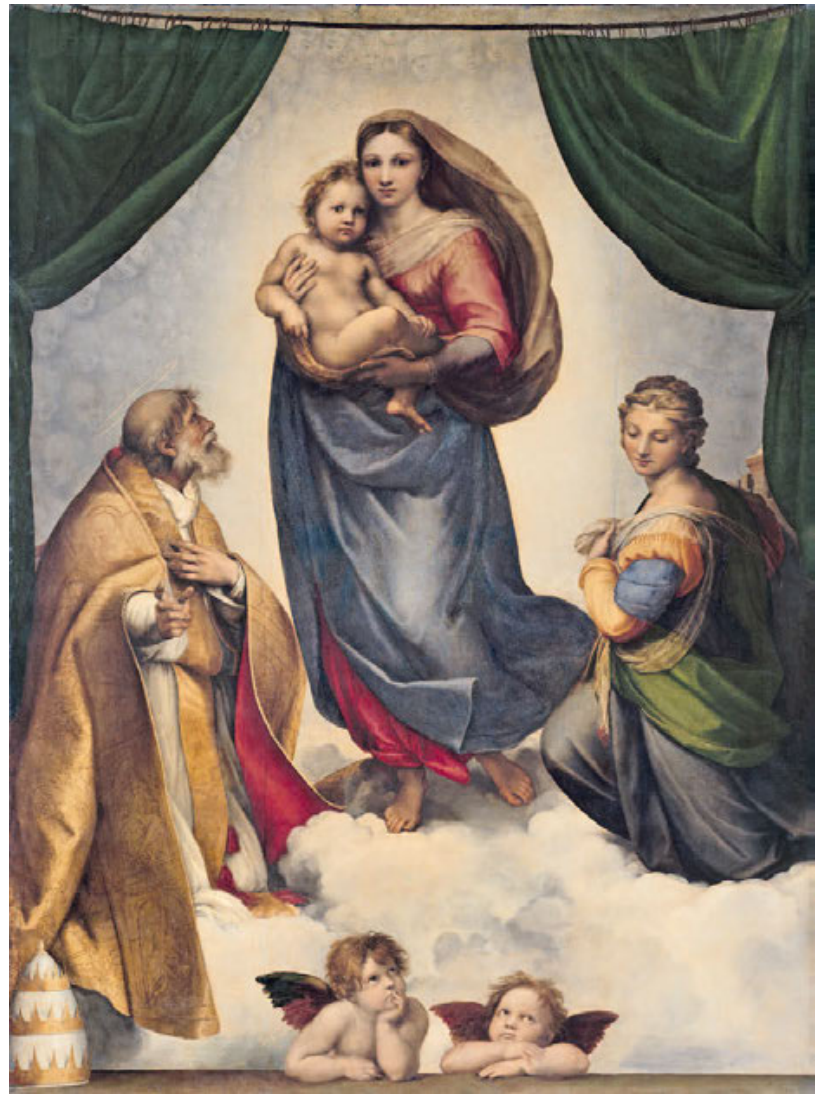

93 Raffaello Santi gen. Raffael, Die Sixtinische Madonna, 1512/13, Öl auf Leinwand, 269,5 × 201 cm, Dresden, Gemäldegalerie Alte Meister, Gal.Nr. 93

machten und nicht ihre Abkoppelung von der Kunstgeschichte. Das präsentierte Meisterwerk konnte dann nämlich als Vorbild inszeniert werden, sei es durch die Erkenntnis der historischen Vorbildfunktion, wenn Schulbilder um das Meisterwerk herum präsentiert waren, sei es durch die unmittelbare Vorbildfunktion für junge Künstler der Gegenwart. Die Kunststudierenden und lernbereiten Maler sollten durch Anschauung eines alten Meisters das Gute umsetzen und anhand der Fehler von Schülern und Nachahmern ihre eigenen Fehler ausmerzen lernen. ${ }^{139}$

In der Folge wurde wenigstens der Saal ausgewählter Niederländer aufgehoben. Im Katalog zur Hängung von 1843 ist er nicht mehr aufgeführt. Mit seinen Forderungen nach Schulbildung und Zurückweisung von Sälen auserlesener Meister in der

139 Zum Verhältnis von Meister und Schüler siehe Quandt 1826 (1), S. 264-266: »Für diese einzelnen Beispiele ließen sich tausend andere aus der Kunstgeschichte anführen, welche beweisen, daß an einzelne Meister hingegebene Schüler sclavische Nachahmer ihrer Lehrer blieben [...]. War dies nicht bei den meisten Schülern des Peter Perugino der Fall? Sieht man es nicht auffallend an den Anhängern des da Vinci? [...] Sind nicht Raphael's Jugendwerke selbst denen seines Lehrers sehr ähnlich? «Über das Kopieren Alter Meister ebd., S. $284-285$.

140 Siehe dazu Kat. Quandt 1824, S. 18-21.
Gemäldegalerie versuchte Quandt abzuschwächen, was er in seiner eigenen Sammlung konsequent umgesetzt hatte. Im Privatmuseum lässt sich nirgends die Isolierung eines einzelnen Kunstwerks oder einer bestimmten Gattung feststellen, obschon er Meisterwerke durchaus besaß und diese auch als solche bezeichnete. ${ }^{140}$ Vielmehr kombinierte er seine Gemälde nach ikonographischen Kriterien, vereinte unterschiedliche Gattungen, vollzog Hängungen nach ästhetischen Begrifflichkeiten, präsentierte alte und neue Meister als Gegenstücke, zeigte Kopien und Originale nebeneinander. Man darf davon ausgehen, dass er sich explizit gegen den Raffaelsaal ausgesprochen hätte, wenn er nicht vom König persönlich gewünscht worden wäre und für die Wettiner, gleichsam als Pendant des Franzosensaales mit den Bildnissen des königlichen Geschlechts, eine sammlungs- und geschmacksgeschichtliche Funktion innegehabt hätte. Im Rundgang von 1843, wie ihn der Katalog und die Umgestaltung der Hängung vorgeben, ist der Raffaelsaal mehr oder weniger konsequent in eine kunsttopographische Kunstgeschichte eingebunden. Man konnte ihn von der inneren Galerie her in wenigen Schritten durch die deutschen Zimmer erreichen. Sein Charakter der Auserlesenheit wurde damit wenigstens auf dem Katalogpapier und der damit vorgeschlagenen Abfolge des Galerierundgangs etwas relativiert (vgl. Abb. 87).

Dennoch lässt sich an seiner Lage in der äußeren Galerie ein Phänomen ablesen, das mit dem kunsttopographischen Rundgang kaum zusammenhängt: Seit seiner Verlegung an die Nordseite der Galerie im Jahr 1837 lag der Raffaelsaal in unmittelbarer und durch entsprechende Türen zugänglicher Nachbarschaft zu den beiden Räumen älterer und neuerer deutscher Malerei. Dieser Umstand wurde auch bei der Bereinigung der Hängung 1840/43 nicht verändert. Zwar konnte im Sinn des neuen Rundgangs chronologisch-kunsttopographisch vorgegangen werden, indem die altdeutsche und altniederländische Schule eines Holbeins oder van Eycks mit der RenaissanceMalerei Raffaels und Correggios verglichen werden konnte. Dies hatte einen ausgleichenden Effekt zwischen deutscher und italienischer Kunst zur Folge, wie er in den Diskussionen der Zeit eminent wichtig und auch für Quandt schon seit 1815 von Bedeutung war. ${ }^{141}$ Wenn man sich vor Augen hält, dass im altdeutschen Saal die später isoliert präsentierte Madonna des

141 Über einen Raum der Altdeutschen in der Gemäldegalerie und der Gemeinsamkeit nördlicher und südlicher Kunst siehe Quandt 1816 (1), S. 836-837. S. a. Quandt 1826 (1), S. 272: »Der Deutsche kann und soll weder Franzose noch Italiener, und eben so wenig Grieche werden, vielmehr das, wofür er geboren ist, rein und edel ausbilden. « Sehr zentral ist dieser Ausgleich bei den Nazarenern: Kat. Frankfurt 2005, S. 161-164; Kat. Rom 1981, S. 174-177; Kat. Frankfurt 1977, S. 45-46, 262-264. Hierbei wichtig ist die auf Friedrich Overbeck zurückgehende Italia und Germania-Ikonographie oder die Handreichung Dürers und Raffaels. S. a. Wackenroder/Tieck 2005, S. 43-47, 55-56; 
Basler Bürgermeisters Meyer, noch Holbein zugeschrieben, ausgestellt war, bestand plötzlich eine direkte Verbindung zwischen Holbein und Raffaels Sixtinischer Madonna. Das Meisterwerk deutscher Kunst wurde damit auf Augenhöhe mit der italienischen Kunst gebracht.

Dieser Anspruch einer Angleichung der deutschen und niederländischen Gemälde an die seit dem 18. Jahrhundert als künstlerisch bessere Kunstwerke beurteilten italienischen Gemälde zeigt sich noch auf einer weiteren Ebene. Zum ersten Mal überhaupt wurde die innere und äußere Galerie im Katalog nicht getrennt in zwei eigenen Kapiteln abgehandelt. Die innere Galerie wurde im Führer durch die Sammlung vielmehr in den Rundgang integriert. ${ }^{122}$ Dadurch wird die rhetorische und räumliche Trennung von italienischen und niederländischdeutschen Gemälden faktisch aufgehoben. 1843 entstand ein Rundgang, gemäß dem man zuerst den französischen und spanischen, dann den flämischen, altdeutschen und altniederländischen gefolgt von den italienischen Schulen entlangging, um den Galeriebesuch mit den neueren deutschen und den holländischen Schulen abzuschließen. Wenn er auch kunsttopographisch nicht restlos konsequent war, so hatte doch auf der geschmacklichen Ebene ein Ausgleich stattgefunden, der wenigstens gewisse kunsthistorische Kriterien beinhaltete.

Man kann dieses ausgleichende System der Kunstanschauung selbst im Blick auf die konservatorischen Bemühungen in der Galerie feststellen, die mindestens ebenso zentral waren wie die Bemühungen um eine kunsthistorische Präsentation. So kamen alle Bilder der deutschen Schule wie auch der Saal des Raffael auf der klimatisch günstigen Nordseite zu liegen. Die Säle der Flamen und Holländer waren auch nicht größter Hitze ausgesetzt, wie Quandt bemerkte. Hingegen präsentierte man die weniger wichtigen Schulen der Franzosen und Spanier sowie neueren Italiener, die Neuzugänge sowie Gemälde von Nachahmern und Kopisten in den sonnseitigen und lichtmäßig wenig günstigen Räumen der Südseite. ${ }^{143}$

Gleichzeitig beschränkte sich der propagierte Ausgleich auf bestimmte außerordentliche Künstler. In den einzelnen

Kat. Göttingen 2015, S. 307-341; Büttner 2002, S. 29-32; Locher 2001, S. 123-132; Schäfer 1860, S. IX-X; Quandt 1819, Bd. 1, S. 112.

142 Die Durchnummerierung aller Bilder von 1 bis 1857 im Kat. Dresden 1843 weist schon daraufhin.

143 SLUB, Mscr. Dresd. L 224, Bd. IV, Nr. 11, fol. 3r-5r: „Überdies ist das Zimmer [...] höchst unzweckmäßig, weil es auf der Mittagsseite liegt, und eine den Beschauern und den Gemälden höchst schädliche Hitze einschließt, welche selbst das Öffnen der Fenster wenig mäßigt.«

144 »Zugleich ist dabei auf B Rücksicht genommen, so da $\beta$ sämmtliche Holbeins, als die wichtigsten Gemälde in diesem Zimmer, dem Auge näher gebracht würden u Seitenlicht bekommen. Dieselben Vortheile kommen nach diesem Raum, auch den Gemählden der älteren Niederländer zu statten. Die weniger wichtigen Gemälde in diesem Zimmer, unter welche die Lucas Kranachs zu zählen sind, können den Fenstern

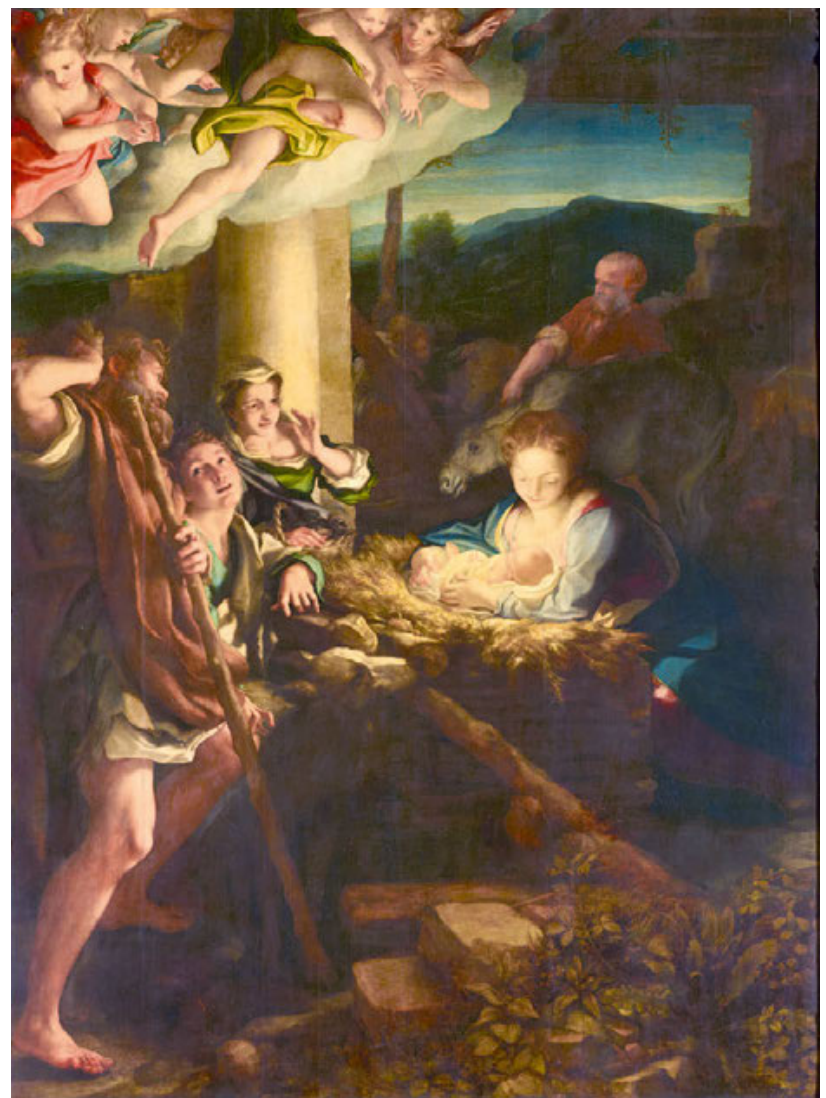

94 Antonio Allegri gen. Correggio, Anbetung der Hirten (Die Nacht), um 1528/30, Öl auf Pappelholz, 256,5 × 188 cm, Dresden, Gemäldegalerie Alte Meister, Gal.-Nr. 152

Räumen gab es weiterhin Qualitätsabstufungen. So verlangte Quandt, dass die Gemälde Holbeins an lichttechnisch günstigen Seitenwänden gezeigt wurden, während man Cranachs Bilder an den Wänden, den Fenstern gegenüber liegend und damit frontalem Lichteinfall ausgesetzt, hängte. Nach demselben Prinzip wurde mit dem beliebten David Teniers und dem weniger bedeutenden Nicolaes Berghem umgegangen. ${ }^{144}$

Allerdings hatte gerade im Fall des Raffael-und Holbein-Saals der ausgleichende Charakter des kunsttopographischen Rund- gegenüber und zum Theil auch höher aufgehängt werden. [...]. Dieser Saal hat eine Wand, welche an das Zimmer B anstößt, auf der kleinere Gemälde ein seitliches Licht haben $u$ auf dieser befinden sich bereits die meisten u vorzüglichsten Teniers, nur hängen solche viel zu hoch. Die Berghems sind mehr auf Massen berechnet, bedürfen weniger eines vorzüglichen Lichts u könnten daher auf der langen Wand aufgestellt werden. «SLUB, Mscr. Dresd. L 224, Bd. IV, Nr. 11, fol. 1V, 4r. Siehe Kat. Dresden 1843, S. 32-35, Nrn. 236-26o (Teniers), S. 45-46, Nrn. 338348 (Berghem); ebd., S. 63-67, Nrn. 503-514 (Cranach), Nrn. 526-535 (Holbein). Die »zweite Wand an der rechten Seite des Einganges« lag den Fenstern gegenüber. Einige Cranachs hingen auch an den Seitenwänden mit den Bildern Holbeins, Dürers und Ambergers; ebd., S. 68-69, Nrn. 545-554. Zu Cranach in der Dresdener Gemäldegalerie des frühen 19. Jahrhunderts, siehe Kolb 2005, S. 148-151. 
gangs ein Resultat zur Konsequenz, das Quandt kaum intendiert haben konnte. Die unveränderte Erhaltung des Raffaelsaales erhob den deutsch-niederländischen Saal selbst zu einem Saal auserwählter Malerei, wenn auch nicht explizit davon die Rede war. Dies zeigt deutlich der Galerieführer von Julius Mosen, der im Jahr nach der Vollendung des optimierten Galerierundgangs von 1843 veröffentlicht wurde. Mosen gab zwar den Plan mit der Raumabfolge gemäß dem Katalog von 1843 wieder, begann mit seiner Beschreibung aber im Raffael-Saal mit der Sixtinischen Madonna. Nach einigen weiteren Gemäldebeschreibungen dieses Raumes trat er in den deutschen Saal über und erläuterte dort nur Gemälde Holbeins, an erster Stelle die Madonna des Basler Bürgermeisters Jakob Meyer zum Hasen. Erst danach folgte er dem Rundgang in der inneren Galerie. ${ }^{145}$

Wenn die Präsentation der deutsch-niederländischen und italienischen Schulen in der Neuhängung von 1843 auch ein ungewolltes Resultat zur Folge hatte, so war der Ausgleich der Kunstschulen doch eine zentrale Forderung Quandts, die über die Frage des Ausgleichs Deutschlands und Italiens hinauswies. So wie sich Quandt seit jungen Jahren für die Aufwertung altdeutscher Kunst einsetzte, trat er 1846 als erster deutscher Kunstgelehrter überhaupt eine Spanienreise an. ${ }^{146}$ Gerade weil er davon ausging, dass »Nationalität etwas Geistiges und Angebornes sey«, richtete er seinen Blick auf spezifisch kulturelle Bedingungen. ${ }^{147}$ Zwar verglich er die spanische Malerei permanent mit der italienischen. ${ }^{148}$ Dennoch kann man ihm attestieren, überhaupt erst einen differenzierten Blick auf die spanische Kunst geworfen zu haben. Wie schon die italienische Kunst-

145 Mosen 1844, S. 5-30.

146 Lange 2007, S. 26-31. S. a. Karge 2007, S. 50; Kat. Frankfurt 1994, S. 22-23. Eigentlich hatte Quandt schon 1819 eine Reise nach Spanien geplant, stattdessen aber auf seine zweite Italienreise ging. Brief an Unbekannt vom 9.3.1819, in: Berlin, SMB, Zentralarchiv, Autographensammlung, Mappe 1133, Quandt, Johann Gottlob von, fol. 3v-4r: »Meine Reise nach Spanien habe ich aufgegeben, aus vielen Gründen, um so gewißer aber ist es, daß ich im Monath Maÿ nach Italien reise."

147 Quandt 1850 (1), S. 33-37: »ede Nation, worunter ich einen kräftigen Völkerstamm, Eingeborne eines Landes verstehe, die untereinander durch gleiche Naturgaben verbunden sind und gleichsam ein großes Individuum bilden, welches sich durch eigenthümliche Richtungen des Geistes von andern Nationen unterscheidet, wird gewiss eine Ursprache und eine eigenthümliche Kunst haben [...].«S. a. ebd., S. 197-199; Börner 2015, S. 129-136.

148 Quandt 1850 (1), S. 298: »Man kann jedoch die Epochen der spani schen Kunstgeschichte nur als Nachwirkungen der italienischen Betrachten. Die italienische Kunst ging im Steigen und Sinken der spanischen immer voraus. Ebenso im Brief von Quandt an Carl Lampe vom 30.9.1853, in: Leipzig, Universitätsbibliothek, 394, Quandt, von, (Rep. VI 25 zh 7): »Versprechen Sie sich jedoch nicht zuviel von diesen Bildern, denn selbst die vorzüglichsten spanischen Meister sind Nachahmer der Bolognieser(sic!) und nur Murillo hat, jedoch selten, seine Muster übertroffen. « S. a. Börner 2015, S. 115-117.

149 Brief von Quandt an die Cotta'sche Verlagsbuchhandlung (wahrscheinlich Johann Georg Cotta) vom 9.2.1848, in: Deutsches Litera- geschichte in seiner Lanzi-Übersetzung wollte er im Anhang des Reiseberichts auch die spanische Kunstgeschichte in einer großen Synopse darstellen und in einen europäischen Zusammenhang stellen. ${ }^{149}$ Als er in Sevilla eine Mondsichel-Madonna von Bartolomé Estebán Murillo erblickte, meinte er begeistert, er wolle weder Raffaels Schönheit, Tizians Wahrheit, Michelangelos Erhabenheit und Correggios Reiz herabsetzen, aber dieser spanische Maler fühle lebhafter als andere. ${ }^{150}$ Die spanischen Gemälde im Prado in Madrid beschrieb er ausführlich und rückte so Ribera, Velázquez, Murillo, Zurbarán und andere ins Licht. ${ }^{151}$ Für die deutschen Sammlungen forderte er, mit Kunstsinn zu sammeln und gute spanische Gemälde zu kaufen. Die Zusammenhänge und Wechselwirkungen in den Künsten würden nämlich nur mit einem »synchronistischen Überblick« deutlich - also mit einem vergleichenden Sehen, das in Museen nur unter bestimmten Ordnungskriterien wie der kunsttopographischen oder der chronologischen möglich war. Doch dieser Ausgleich der Kunstschulen, der auf eine kunsthistorische Präsentation von Kunstwerken abzielte, war in der Gemäldegalerie Dresden zu Quandts Lebzeiten schwierig zu erreichen. ${ }^{152}$

\section{Zwei Pole der Kunst}

Quandt publizierte den Bericht seiner Reise nach Spanien 1850 während des Neubaus der Dresdener Gemäldegalerie durch Gottfried Semper 1847 bis 1855. Mit einem Fernblick verglich er Madrid mit Dresden. Er beanstandete die Präsentation der

turarchiv Marbach, Cotta-Archiv (Stiftung der Stuttgarter Zeitung): »Noch muß ich bemerken daß am Schluß eine chronologische u zugleich sÿnchronistische Künstlertabelle gegeben wird, welche die spanischen Künstler mit denen andrer Nationen zusammenstellt u die Kunstgeschichte mit den wichtigsten Ereignissen in Verbindung darstellt. "Die Synopse kam nicht zur Publikation.

150 Quandt 1850 (1), S. 170. S. a. Börner 2015, S. 110-111, 118.

151 Quandt 1850 (1), S. 276-298. S. a. Börner 2015, S. 115-119.

152 Quandt 1850 (1), S. 153: »Leider füllt man jetzt auch in Deutschland Museen mit Bildern an, die man nur Gemälde nennen kann, und bezahlt die Werke der spanischen Schule, von welcher das beste nicht zu bekommen ist, als Raritäten sehr theuer. Wir sollten aber doch mit mehr Kunstsinn sammeln [...].« Ebd., S. 297f.: »Da aber Alles in einem unendlichen Zusammenhang von Wechselwirkungen steht, so wird uns die Kunstgeschichte eines Volks für sich abgesondert nie deutlich und wir müssen einen synchronistischen Ueberblick zu gewinnen suchen, von wo aus sich die Zustände der Kunst eines Volks mit den weltgeschichtlichen Umständen in Verbindung zeigen. « Über die Dresdener Ankäufe spanischer Gemälde war Quandt nicht glücklich: »Ich kann bei diesen Gemälden welche für die Gallerie gekauft wurden wie die Jungfrau von Orleans ausrufen: Ach es war nicht meine Wahl! - Wir haben zwar für eine kleine Summe viel Bilder bekommen, aber umgekehrt wäre es besser, wenig jedoch vorzügliche Bilder für viel Geld. « Brief von Quandt an Carl Lampe vom 30.9.1853, in: Leipzig, Universitätsbibliothek, 394, Quandt, von, (Rep. VI 25 zh 7). S. a. Weniger 2003 , S. 341. 
Zwinger.

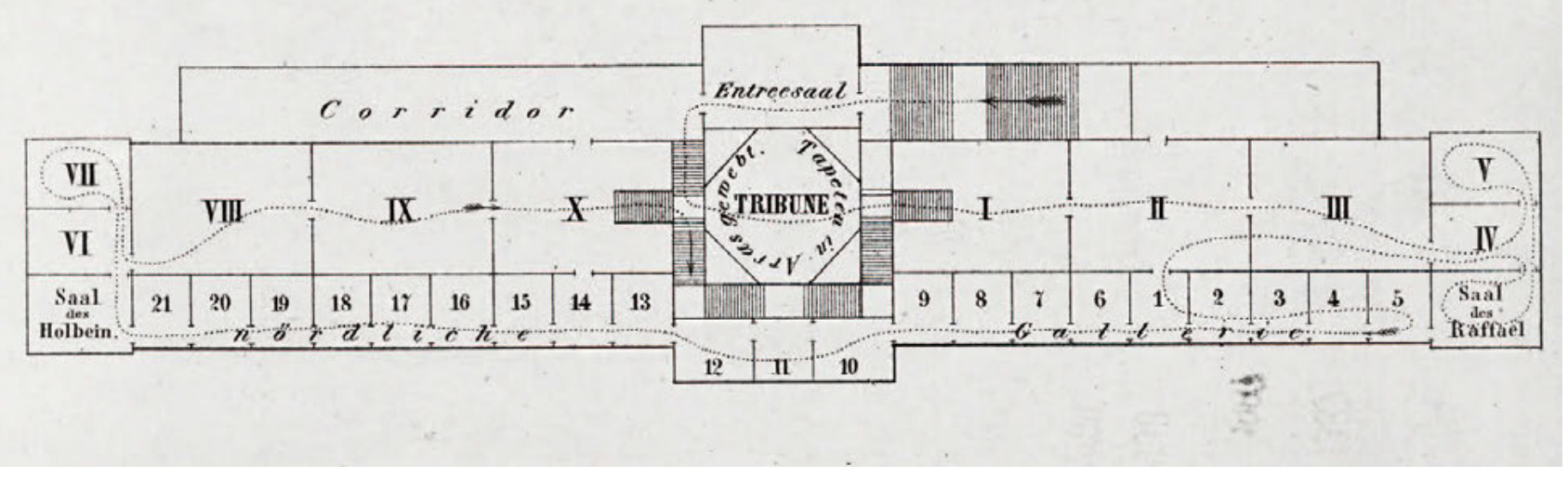

95 Grundriss der Gemäldegalerie Dresden, in: Quandt 1856, nach S. 8

Gemälde im Museo Real de Pintura y Escultura, dem heutigen Prado: Es fehle eine chronologische Anordnung, die »das $\mathrm{Zu}-$ sammensuchen der einem Zeitabschnitte angehörigen Werke äußerst beschwerlich [mache], und [es sei] ganz unmöglich, durch Vergleichung der Bilder einer Schule eine genetische kunstgeschichtliche Anschauung gewinnen zu können [...]«. Man könne aber dem Madrider Direktoren deswegen keinen Vorwurf machen, ebenso wenig ihm selber, »wenn das künftige Museum in Dresden dieselben Uebelstände bekommt, die das Museum in Madrid hat: $\ll^{153}$

Hierin versteckt sich ein Seitenhieb gegen die neue Gemäldegalerie in Dresden, für die Direktor Julius Schnorr von Carolsfeld in jener Zeit Hängungspläne entwarf. Nach Vollendung des Baus stellte Schnorr die Gemälde im Museumsneubau weiterhin den Kunstschulen entsprechend aus. Auch hatte Semper mit der Aufteilung des Gebäudes in große Oberlichtsäle und kleinere Kabinette einen Museumsbau entworfen, wie ihn Leo von Klenze in München mit der Pinakothek erfolgreich umgesetzt hatte. ${ }^{154}$ Doch die alte Unterteilung der inneren und äußeren Galerie in die italienischen und niederländischen Schulen blieb in den beiden Flügeln des Semperbaus erhalten. Die Zweiteilung war durch den erhöhten, zwischen den Ausstellungssälen liegenden Kuppelraum bedingt. Dadurch, dass der Zugang über diesen

153 Quandt 1850 (1), S. $265 f$.

154 Schölzel 2012, S. 258-261; Penzel 2007, S. 184-188; Laudel 2003, S. 187; Mallgrave 2001, S. 118; Magirius 1992 (1), S. 73 ; Magirius 1992 (2), S. 2930. Einen Überblick über die Hängung im Semperbau der zweiten Hälfte des 19. Jahrhunderts bietet Marx 1992 (1), S. 96-101. S. a. Marx 1992 (2), S. 17-18; Schäfer 1860, S. 145.

155 Mallgrave 2001, S. 122. Semper hatte sich in seinen ersten Plänen für einen wesentlich niedrigeren Baukörper eingesetzt, der die Dimensionen des Zwingers besser aufgenommen hätte. Weil man sich schließlich für einen hohen, rundbogigen Durchgang in der Mitte des zentralen Raum erfolgte, wurden die Flügel nur über Treppen erreichbar, so dass eine Seite der italienischen, die andere der deutsch-niederländischen Kunst gewidmet war (Abb. 95). ${ }^{55}$

Allerdings spitzte sich die Problematik eines Raums auserlesener Gemälde im neuen Gebäude deutlich zu. Die bereits im alten Stallhofgebäude beobachtete Tendenz einer isolierenden Exklusivität der Säle der deutschen Maler und Raffaels verstärkte sich mit der Einrichtung der neuen Sempergalerie. Der versuchte Ausgleich und die Einbindung der Räume deutscher und italienischer Gemälde in die Kunstgeschichte, wie sie der 1843 im Katalog vorgeschlagene Rundgang durch das alte Gebäude angeregt hatte, verlor sich im neuen Gebäude. Schnorr setzte hier nämlich um, was schon früher gefordert worden war: in einem isolierten Eckkabinett des westlichen Seitenflügels, abseits aller Besucherströme, wurde die Sixtinische Madonna in einem altarartigen Rahmen und als einziges Kunstwerk des Raums aufgestellt. Sie wurde so komplett der Vergleichbarkeit entzogen und verabsolutiert. Das äquivalente Kabinett des Ostflügels erhielt ebenfalls einen altarartigen Aufbau mit Holbeins Meyermadonna im Zentrum, umgeben vom Hausaltärchen van Eycks und einigen weiteren Gemälden Holbeins, Dürers und Rogier van der Weydens, womit immerhin ein kunsthistorischer Kontext beibehalten wurde. ${ }^{156}$

Gebäudes entschied, kam auch der zentrale Raum höher zu liegen. Zudem hatte man nach Baubeginn festgestellt, dass die Hängefläche für die Gemälde nicht ausreichen würde. 1848 wurde der Bauplan in Länge und Breite erweitert, die Kuppel erhöht und die beiden Eckfügel angefügt; S. a. Marx 1992 (2), S. 14-15; Schäfer 1860, S. 118-119.

156 Die Aufteilung wurde von vielen Zeitgenossen, darunter Carl Gustav Carus, Gustav Friedrich Waagen und Hermann Freiherr von Friesen begrüßt. Holbeins Meyermadonna wurde schon von August Wilhelm Schlegel zum Charakterbild des Deutschen erhoben und mit Raffael verglichen; siehe Schlegel 1996, S. 39-45 sowie Kommentar und Nach- 
Quandt war der isolierten Präsentation von Raffaels Sixtinischer Madonna und der Holbein zugeschriebenen Meyermadonna nicht abgeneigt. Er dachte die beiden Gemälde zusammen. Schon 1846 hatte er erklärt, Holbeins Bild sei würdig, sich in derselben Sammlung zu befinden wie Raphaels strahlendes Werk, ohne sich verstecken zu müssen. ${ }^{157}$ Gegenüber Schnorr hatte er im Herbst 1858 und Frühling 1859 die Meinung geäußert, Holbeins Meyermadonna müsse isoliert werden. Er war der Ansicht, dass sie, wie Raffaels Sixtinische Madonna auch, ohne jegliche begleitende Gemälde alleine präsentiert werden müsse. ${ }^{158}$ Diese Haltung mag zunächst überraschen. Warum verlangte Quandt plötzlich die totale Isolation der Meyermadonna, wo er vorher für die Kontextualisierung von Kunstwerken plädiert hatte? Es scheint hier weniger um die Isolation zweier Künstlergenies außerhalb der Kunstgeschichte zu gehen, als um Fragen charakteristischer Kunst einer Nation und um Vorbildrollen. ${ }^{159}$

Quandts Begleiter durch die Gemälde-Säle von 1856 gibt Aufschluss. Er verglich die Meyermadonna als Höhepunkt der deutschen Malerei mit der Sixtinische Madonna als Gipfel der italienischen Kunst. Der Kunstkenner verstand dabei die beiden Künstler als individuelle Ausprägungen der deutschen und italienischen Kunstauffassung. Die beiden Meisterwerke, so Quandt, machten bewusst, »worin die Eigenthümlichkeit des Characters der deutschen und der italienischen Kunst liegt. $\ll^{160}$ Nach der Besichtigung der Hauptsäle gemäß der Abfolge, wie

wort von Lothar Müller, ebd., S. 139f., 186f. Zum Prozess der Polarisierung von Raffael und Holbein siehe Schnorrs Tagebucheinträge, in: Schnorr 1896, Jg. 5, Nr. 2, S. 258; Schnorr 1897, Jg. 6, Nr. 3, S. 53f., 56; Schnorr 1899, Jg. 8, Nr. 3, S. 197-199. S. a. Bader 2013, S. 27-33; Schölzel 2012, S. 264; Kat. Dresden 2012, S. 45-46; Weddigen 2008, S. 224-225, 227-228; Brink 2005, S. 86-90; Laudel 2003, S. Magirius 1992 (1), S. 77; Plagemann 1967, S. 140; Friesen 1880, S. 333; Schäfer 1860, S. 172. Zur Konzeption der Rahmung für die Holbein-Madonna siehe Maaz 2014, S. 23-24; Bader 2013, S. 244-248.

157 Quandt 1846 (2), S. 288. S. a. Bader 2013, S. 53.

158 Schnorr 1901, Jg. 10, Nr. 3, S. 55, 68. Zur Sixtinischen Madonna s. a. Anonym [Quandt] 1826, S. 118-119.

159 Quandt 1844 (1), S. 112-113 definiert das Charakteristische als »das wesentliche Merkmal [...], woran ich etwas erkenne, was es ist, oder einen Begriff darunter denke.« Quandt hat den Begriff des Charakteristischen bei Hirt, Goethe und Hegel rezipiert und auf einen Nenner zu bringen versucht. Zum Begriff des Charakteristischen siehe Thomas Bremer, »Charakter/charakteristisch«, in: ÄGB 2010, S. 772-794, bes. $782-788$.

160 Quandt 1856, S. 146-148: »Das deutsche Kunstwerk gleicht einem tiefen, stillen See, in welchem sich der reine Himmel spiegelt und das italienische Kunstwerk einem Sterne, der seine Strahlen durch den unendlichen Weltraum aussendet. Dort verinnert sich alles, hier äußert sich alles Innere, dort ist alles Gesinnung, hier wird alles zur Handlung. Das deutsche Kunstwerk ist seinem Wesen nach lyrisch, das italienische dramatisch. Diese concentrische Richtung des deutschen Characters bewirkt einen harmonischen Gleichmuth, in welchem sich Tiefe und Wärme bei äußerer Stille vereinen und die Excentricität des italienischen Characters verbreitet eine höhere Be-
Quandt sie im beigefügten Grundriss des Begleiters festlegte, rundeten Raffael und Holbein die italienische beziehungsweise niederländisch-deutsche Kunstgeschichte ab. Die Bilder der beiden Künstler wurden so zu ebenbürtigen Zeichen einer nördlichen und südlichen Kunstgeschichte.

Mit dem Begleiter offerierte Quandt dem Galeriebesucher einen gedruckten Führer, der ausgewählte Werke herausgriff. Einerseits war es sein Ziel, dem eiligen Reisenden das Wichtigste zusammenzufassen, andererseits dem »ruhigen Beschauer« das »Ausgezeichnete vor Augen zu führen. Die Anschauung stand dabei im Mittelpunkt. Er wollte erklären und nicht beschreiben, wie es im offiziellen Galeriekatalog teilweise der Fall war. Darunter verstand der Autor natürlich Erklärungen im Sinne seines eigenen Kunstverständnisses. Demnach wollte er »in das Bewusstseyn des Beschauers die immanente Idee [...] rufen, welche der Künstler in einem Bilde vergegenwärtigte. ${ }^{161}$ Im Begleiter verfolgte Quandt eher eine ästhetischdidaktische denn eine wissenschaftliche Führung entlang der Geschichte der Kunst. ${ }^{162}$ Im Gegensatz zu seiner offiziellen Mitarbeit an der Galeriehängung von 1843, die gewissen Bedingungen unterworfen war, konnte er in seinem Führer durch die Sempergalerie, der kein Katalog war, den Betrachter nach seinen Vorstellungen von einem Gemälde zum nächsten leiten. Er konnte seine eigene Linie der Kunstgeschichte verfolgen. Dies ist die Geschichte des vernünftigen »Menschengeistes«, die sich in der Kunst niederschlägt. Es ist die Schönheit des Gedankens,

lebtheit über die äußere Erscheinung. Dies drückt sich nun auch, man könnte sagen, sprechend in den Physiognomien der Holbeinschen und der Raphaelschen Madonna aus. "Quandt bezieht sich hier auch auf das Büchlein über die Gemälde der Galerie von Julius Mosen; Mosen 1844, S. 28: »Vielleicht bezeichnet dieses Bild den Höhenpunct der deutschen Malerei, wie die Sixtinische Madonna den Gipfel der römisch-christlichen Kunst. « S. a. Penzel 2007, S. 314-317; Schäfer 1860, S. 15. S. a. Bader 2013, S. 28.

161 Quandt 1856, S. 3-4. Siehe dazu auch die Erklärung des Zwecks des Begleiters im Brief an Weigel vom 14.2.1856: „Von dem Begleiter muß ich wünschen, daß er nur den Gemälden gegenüber gelesen wird, er kann die Bilder nicht entbehren, diese aber den Erklärer [...] zu vergleichen seÿn. Ebenso im Brief an Hettner vom 6.6.1856, in: Heidelberg, Universitätsbibliothek, Sign. Heid. Hs. 2751 C85: »Der Zweck meines Buchs ist kein anderer, als dem geistig Blinden den Starr zu stechen und gerade im Gegensatz zu den modischen Kunstkennern, welche nur auf das Exotische an einem Kunstwerk hinweisen, das Innere hervorzuheben. Die von mir unerreichten Muster im Beschreiben und Betrachten von Gemälden sind Diderot, Göthe und Forster." Diese Vorbilder müssten noch genauer untersucht werden. S. a. Weddigen 2008, S. 228-230; Penzel 2007, S. 270-271, 317-326.

162 Penzel 2007, S. 308-310.S a. Schäfer 1860, S. XII: »[...] wiewohl nicht zu verkennen ist, dass von Quandt's >Begleiter ein erwünschtes Vademecum für dieselben [Kunstfreunde] ward [...]. Da fand der Verf[asser] [...] einen Herausgeber, und sofort ging er, noch außerdem von mehren Kunstfreunden ermuthigt und namentlich von dem als Kunstkenner rühmlichst bekannten von Quandt aufgemuntert, an die allerdings theilweise sehr schwierige Aufgabe [...].« 
die ein Kunstwerk hervorbringt. Damit konnte Quandt Raffael und Holbein als außerordentliche und vorbildliche Ausprägungen zweier Kunstrichtungen, die dasselbe anschaulich machten - nämlich Schönheit - in isolierter Aufstellung erklären.

\section{Hoffnungen und Enttäuschungen: Projekte für einen Galerieneubau}

Wenn Quandt auch Verständnis für die Isolation der Meisterwerke Holbeins und Raffaels aufzubringen vermochte, so war er doch mit der Präsentation der Gemälde in der neuen Sempergalerie nicht zufrieden. In einem Brief an den Leipziger Verleger Rudolph Weigel schrieb er, es sei nicht seine Schuld, dass »die Gemälde, ohne System aufgehangen wurden, wie es das Licht u die Größe der Zimmer zuließ, deren Eintheilung sehr unzweckmäßig ausgefallen ist. Die Aufstellung der Gemälde in der alten Galerie, die von mir angewendet, war nach Meistern u deren Schüler gruppirt. $\ll^{163}$ Hierin zeigt sich Quandts große
Enttäuschung über die Einrichtung des neuen Museumsbaus von Semper. Er verstand die Präsentation der Königlichen Gemäldesammlung als Rückschritt gegenüber dem, was er selber 1843 im alten Gebäude besser gemacht habe.

Um dieser Enttäuschung auf die Spur zu kommen, muss der Blick auf Quandts Rolle in der Genese des Galerieneubaus geworfen werden. Wie im Zusammenhang seines Engagements für die Restaurierung der Gemälde bereits erläutert wurde, hatte er schon seit den 1820er Jahren in seiner Kritik an den klimatischen Bedingungen der Galerie am Jüdenhof einen Neubau gefordert. Als sich Ende der $1830 e r$ Jahre echte Möglichkeiten für die Errichtung eines neuen Museums abzuzeichnen begannen, setzte er darauf große Hoffnungen, denn im »untauglichen alten Lokale« war keine wünschenswerte Präsentation mehr möglich. ${ }^{164}$

Mit den Gutachten der neu eingesetzten Galeriekommission vom Februar 1837 beauftragte Bernhard August von Lindenau Gottfried Semper mit der Ausarbeitung von Entwürfen zu einem neuen Museumsbau. ${ }^{165}$ Der Architekt legte 1838 erste Pläne für ein Gebäude auf der so genannten Stallwiese, gegen-

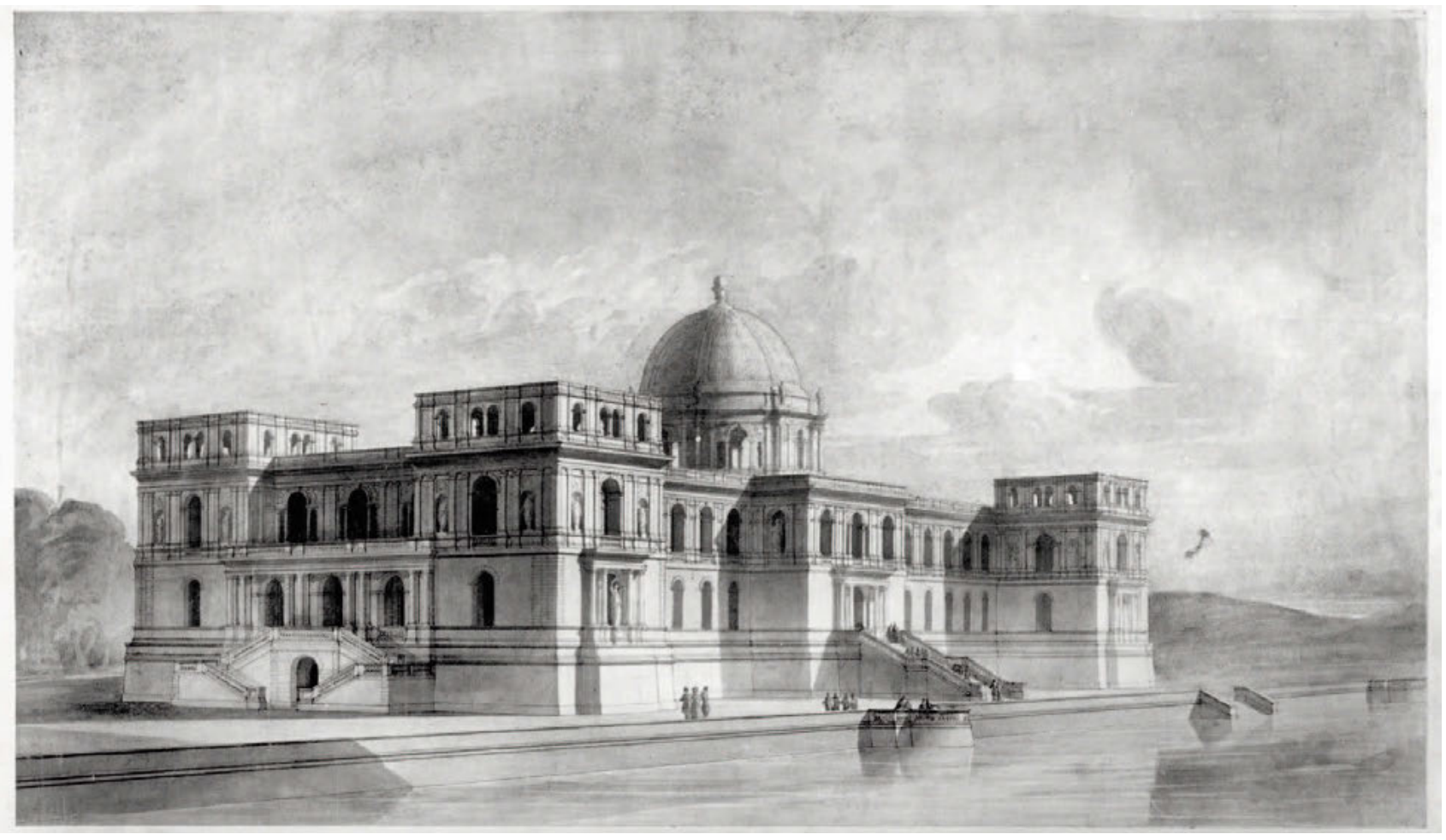

96 Gottfried Semper, Dresden, Gemäldegalerie, Stallwiesenprojekt II, Perspektive von der Elbseite, 1838/39, Dresden, Kunstakademie (Kriegsverlust)

163 Brief an Unbekannt [Weigel?] vom 27.4.1856, in: SLUB, Mscr. Dresd. App. 204, Nr. 97u.

164 Quandt 1842, S. 6o; s. a. ebd., S. 25-26, 48, 55. S. a. Kat. Dresden 1856, S. 62; Friesen 1880, S. 324-328; Magirius 1992 (2), S. 30.

165 Die Gutachten der Galeriekommission, in: HStADD, Akten der Generaldirektion der Königlichen Sammlungen, Cap. VII. Nr. 30, Acta die höchsten Orts anbefohlene commissarische Untersuchung des Zustandes der Gemälde in der königl. Galerie betr., 1837 (Kriegsverlust). Abschrift in: HStADD, 13458 SKD, NL Posse, Nr. 30, Lage 9, fol. 1r-8v. Mütterlein 1913, S. 357-399 lagen die im 2. Weltkrieg verlorenen Akten noch vor. Sein Aufsatz über die Genese des Semperbaus wirkt bis heute grundlegend. 


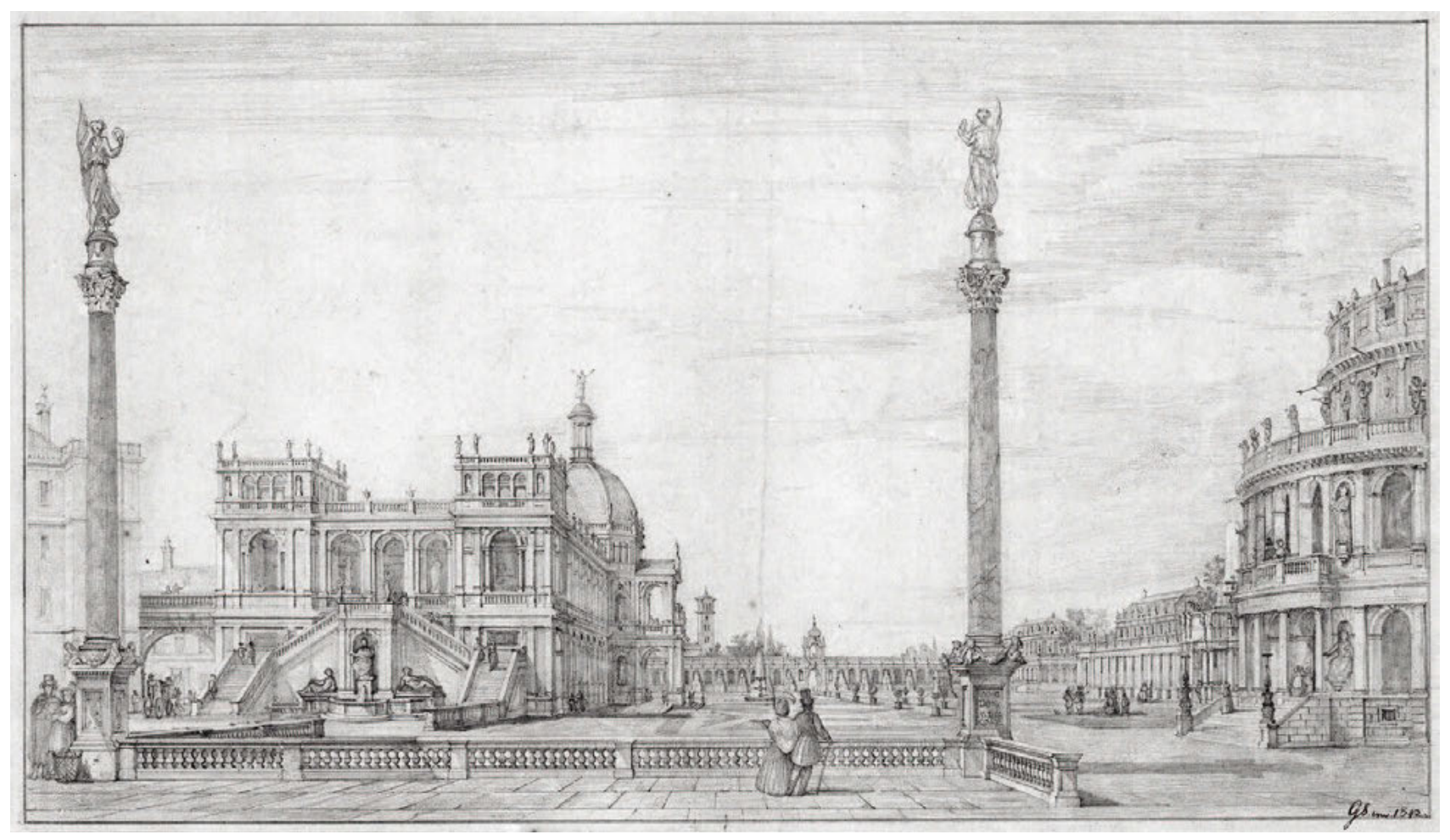

97 Gottfried Semper, Dresden, Zwingerforum mit Museum in Verlängerung des südöstlichen Zwingerflügels, Perspektive, 1842, Bleistift, $520 \times 332 \mathrm{~mm}$, Zürich, gta Archiv / ETH, Archiv-Nr. 20-0521-1

über der Brühlschen Terrasse auf der Neustädter Seite, vor (Abb. 96). ${ }^{166}$ Die Regierung beriet inzwischen mit dem akademischen Rat weitere Standorte, darunter einen am großen Garten und am Zwinger. Aber auch ein Umbau der alten Gemäldegalerie am Jüdenhof oder die Nutzung des Japanischen Palais wurden in Betracht gezogen. Aus Kostengründen wurden Sempers erste Pläne abgelehnt, der Große Garten wurde als zu weit weg vom Zentrum angesehen, das Japanische Palais als Chinoiserie ästhetisch als unpassend empfunden. ${ }^{167}$ Die Galeriekommission hatte sich schon im Februar 1837 nach intensiver Überzeugungsarbeit von Quandt gegen den Umbau des alten Gebäudes ausgesprochen, weil dadurch weder die Probleme des Stein-

166 Bericht der Galeriekommission vom 28.2.1837, in: Quandt 1842, S. 2829. S. a. Schölzel 2012, S. 227-228; Magirius 1992 (2), S. 31; Mütterlein 1913, S. 360-361.

167 Laudel 2003, S. 286-188; Magirius 1992 (2), S. 32; Plagemann 1967, S. 131-133; Mütterlein 1913, S. 361-364; Friesen 1880, S. 325-326, 331-332; Schäfer 1860, S. 108-113; Mitteilungen Landtag 1846, S. 2107; Quandt 1842, S. $33-36$.

168 Quandt 1842, S. 25-26. Bericht der Galeriekommission gegen einen Umbau vom 28.2.1837 publiziert ebd., S. 27-29. S. a. Schäfer 1860, S. 110-112.

169 Die Untersuchungen fanden von 1840/41 bis 1845 statt und umfassten zwei Ebenen: einerseits prüfte man Staub, Temperaturunterschiede und Licht direkt an den Gemälden, andererseits testete man besonders die Rückstände von Kohlestaub in und um die Galerie und an verschiedenen Orten der Stadt. So stellte man fest, dass sich vor der alten Galerie 60\% mehr Rückstände von Kohlestaub abgesetzt kohlerußes noch die Feuergefahr gelöst würden. ${ }^{168}$ Die Stände erwiesen sich für die nachfolgenden zehn Jahre bis zu Baubeginn als die größte Hürde: sie lehnten jegliche Pläne ab. Doch die Regierung blieb in der Frage des Museumsbaus aktiv. Hermann Freiherr von Friesen wurde auf eine Europa-Reise entsandt, um Gemäldegalerien zu studieren. 1841 veröffentlichte er seinen Bericht. Gleichzeitig berechnete die Galeriekommission die Hängeflächen. Eine chemische Kommission prüfte Lichtführung, Temperaturen, Luftqualität und Feuersicherheit. ${ }^{169}$

Quandt befasste sich intensiv mit den Vorschlägen Sempers. Sein Haus mutierte zur Diskussionsplattform Sempers und der Dresdener Kunstschaffenden. ${ }^{170}$ Zusammen mit Vogel von Vo-

hatte als am Zwinger. Dieser Test wurde mit Schnee vorgenommen, auf dem sich der Staub ablagerte. Die Ergebnisse wurden dem Landtag vorgelegt, dessen Verhandlungsergebnisse 1846 publiziert wurden; siehe Mitteilungen Landtag 1846, S. 2104-2106. S. a. Schölzel 2012, S. 229, 239-242. - Hermann Freiherr von Friesen, Hauptbericht über eine in allerhöchstem Auftrage zu Untersuchung von Gemäldesammlungen und Erforschung der Mittel, so zu Bewahrung und Erhaltung von Gemälden am Tauglichsten sind, vom 27. August 1840 bis zum 23. Januar 1841 nach Holland, England, Frankreich und Belgien unternommene Reise, Dresden: Gärtner, 1841. Ausführliche Paraphrase des Berichts in Schölzel 2012, S. 232-238. S. a. Mütterlein 1913, S. 369-370.

170 Brief von Quandt an Schnorr vom 4.6.1846, in: SLUB, Mscr. Dresd. n Inv. 15 Bd. 31, fol. 257r. Meissner 1884, Bd. 1, S. 164-165; s. a. Mallgrave 2001, S. 90; Magirius 1994, S. 482; Grossmann 1925-1928, S. 144. 


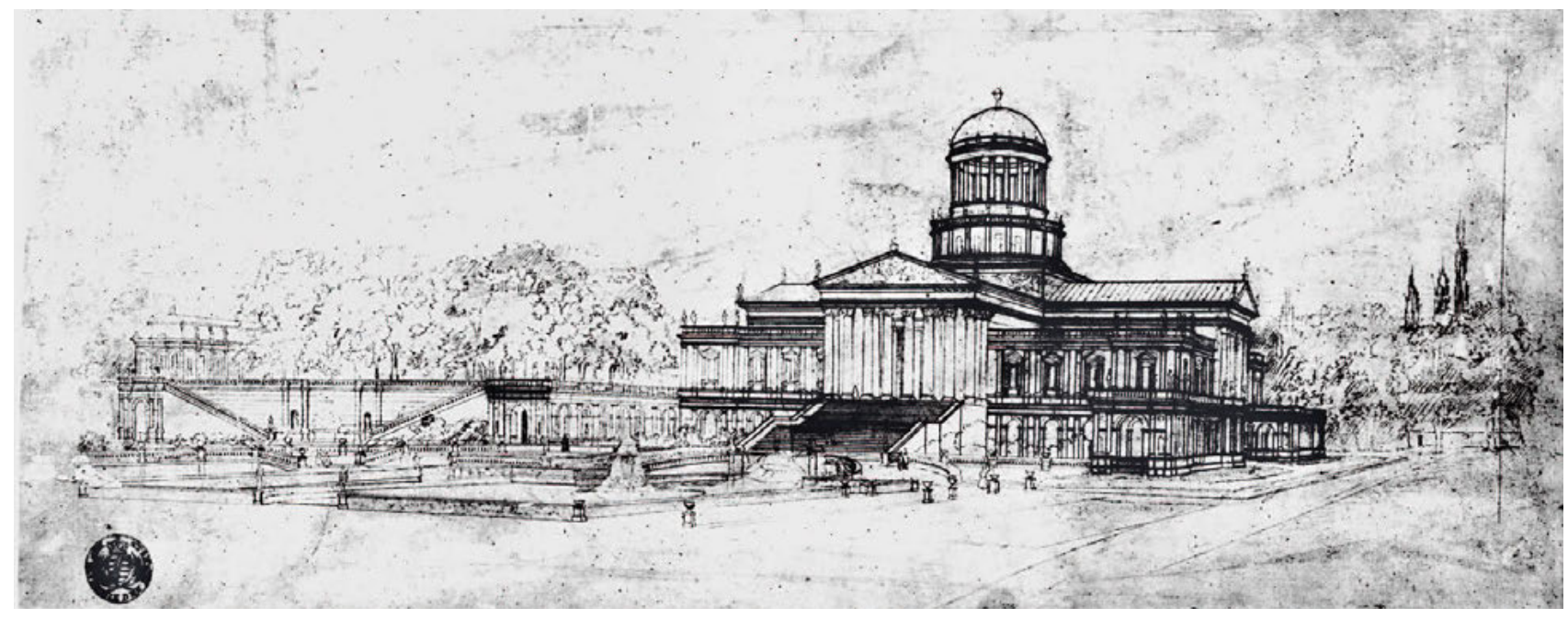

98 Gottfried Semper, Dresden, Gemäldegalerie, Projekt Zwinger-Wallanlagen, Perspektive, 1842, Dresden, Kunstakademie (Kriegsverlust)

gelstein, Friesen, dem König höchstpersönlich und anfänglich auch Semper selbst unterstützte er das Stallwiesen-Projekt. Sein eigenes Gutachten vom 31. Januar 1839 publizierte er im Jahr 1842. Ein Standort auf der Neustädter Seite an der Elbe erschien ihm vorteilhaft und er verglich ihn mit anderen Museumsbauten am Wasser wie dem Schinkelmuseum an der Spree in Berlin oder den holländischen und venezianischen Museen. Auch die praktische Seite zog er in Betracht. So erhoffte er sich eine Minderung der Baukosten, weil die Bausteine direkt von Schiffen aus verbaut werden könnten und damit geringere Transportkosten anfallen würden..$^{71}$ Eine Gruppe um den Bildhauer Ernst Rietschel setzte sich für einen Standort am Zwinger ein. Später kam auch Julius Schnorr als Befürworter dieser Lösung hinzu. Der König zog alle Meinungen zu Rate, so dass 1839 eine Mehrheit für den Standort am Zwinger zusammenkam. Doch die finanzielle Situation sollte das Projekt noch um mehrere Jahre verzögern..$^{72}$

Semper bettete inzwischen die Entwürfe für eine Gemäldegalerie am Zwinger in seinen Überbauungsplan eines großartigen Zwingerforums ein, das er ab 1835 zu planen begonnen und in dessen Rahmen er bis 1841 das Hoftheater errichtet hatte. Das Zwingerforum hätte - unter Abriss des Italienischen Dörf-

171 Quandt 1842, S. 30-43. Besonders die Aussicht von der Brühlschen Terrasse auf das Museum behagte ihm. Aus ästhetischer Sicht gefielen ihm die Entwürfe weniger als aus der Sicht der Zweckmäßigkeit. Die Diskussion über die Standorte wurde nicht nur in der Galeriekommission geführt. In die Gruppe, welche das Stallwiesenprojekt diskutierte, wurde Quandt nach 1839 nicht einbezogen; Quandt 1842, S. 47: »Aber eben darum glaube ich mir es schuldig zu seyn, darzulegen, welchen Antheil ich an dieser Angelegenheit hatte, es mag nun von andern beschlossen werden, was da will."

172 Zum Stallwiesen-Projekt siehe Schölzel 2012, S. 227-230; Laudel 2007, S. 130-131; Heres 2005/06, S. 724; Laudel 2003, S. 187-188; Mallgrave 2001, S. 117-118; Plagemann 1967, S. 373, Anm. 357. Friesen 1880, S. 326328, 332; Schäfer 1860, S. 109, 113-114. chens - einen großen Platz mit Randbebauung ergeben, der zur Elbe hin offen gewesen wäre. Mit dem Einbezug eines Museums in die Planungsarbeit ab 1840 entstanden verschiedene Vorschläge. Einmal war das Gebäude auf der Kronentorseite vorgesehen, ein anderes Mal sollte es am südöstlichen Flügel des Zwingers anschließen (Abb. 97). Ein weiterer gestalterisch anspruchsvoller Entwurf von 1842 wählte als Standort die Anhöhe des Zwingerwalls und entwarf einen prominenten Zentralbau mit Säulenarkaden, Tempelfronten und hoher Kuppel. Quandt bezeichnete diesen Entwurf als Krönung einer Gruppe von Prachtgebäuden, die aus Schloss, Hofkirche, Hauptwache, Theater und Zwinger bestand (Abb. 98). ${ }^{173}$ Selbst der König bedauerte die Unausführbarkeit dieses großen Planungswurfes. Mit dem Weggang Bernhard August von Lindenaus 1843 wurde unter seinem Nachfolger, Kultusminister Eduard von Wietersheim, wieder ein Umbau der alten Galerie in Betracht gezogen, jedoch aus Platzgründen und wegen zu hoher Kosten bald verworfen. Auch Semper hatte Entwürfe hierfür geliefert. ${ }^{174}$ Nach eingehenden Prüfungen wurde das Projekt an der Südostseite des Zwingers 1845 den Ständen zur Annahme empfohlen - und abgelehnt, weil die Nähe zum Schloss dem Brandschutz widersprach und die

173 Quandt 1842 [1839], S. 36: »Nicht zu läugnen ist, dass der Einfall etwas reitzendes hat, das Museum auf den Zwingerwall zu bauen, ein Gedanke, auf welchen Herr Prof. Semper selbst gekommen ist. Das Museum würde die Gruppe von Prachtgebäuden, als Krönung, vollenden, indem es auf diesem hohen Standorte die Kirche und das Theater überragte und eine imposante Wirkung hervorbrächte.« Quandts Originalgutachten vom 31.1.1839, in: HStADD, Ministerium für Volksbildung, Nr. 18909/1, Acta die Erbauung eines neuen Museums betr. Bd. 1, 1838-1839, fol. 21. S. a. Laudel 2007, S. 132; Heres 2005/06, S. 724

174 Das vorgelegte Umbauprojekt hätte entweder weniger Hängefläche oder den kostspieligen Abriss umliegender Gebäude zwecks VergröBerung des Stallgebäudes zur Folge gehabt; siehe dazu Mitteilungen Landtag 1846, S. 2106. Ausführlich hierzu auch Schölzel 2012, S. 230-232. 


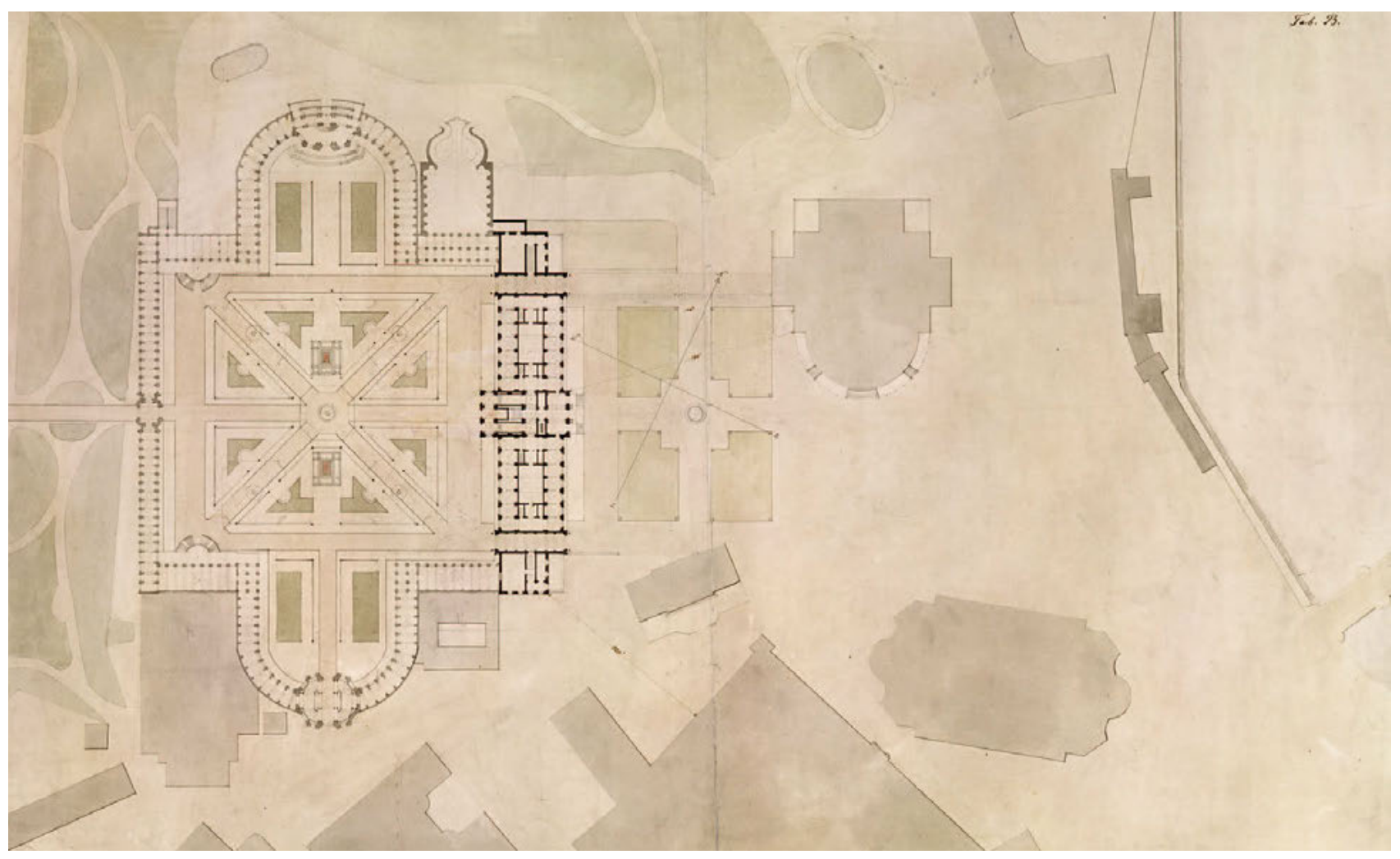

99 Gottfried Semper, Dresden, Zwingerforum mit Museum an der Nordostseite, 1846, Dresden, Landesamt für Denkmalpflege Sachsen, Sign. M 52.C., BI. X

Verlegung der Schinkelwache sowie der Abriss von Teilen des Italienischen Dörfchens zu kostspielig zu sein schienen.175

Schließlich wurde die offene Zwingerseite mit der Gemäldegalerie am heutigen Standort erschlossen, wie er von der Deputation der zweiten Kammer des Landtags zum Vorschlag gebracht worden war (Abb. 99). Ein Gremium um Quandt, Bendemann und Hübner beurteilten dieses Projekt und stimmten ihm zu. ${ }^{176}$ Daraufhin nahmen die Stände den Abschluss der Zwingerseite durch ein neues Museum an. $177 \mathrm{Im}$ Sinne einer Vollendung der historischen Pläne von Matthäus Daniel Pöppelmann, die Semper ausführlich studiert hatte, legte der Architekt neue Pläne vor. Er verstand den Zwingerhof nun als Prachthof des Museums.

175 Die Beratung über die Galerie fand am 18.2.1846 statt; siehe Mitteilungen Landtag 1846, S. 2107-2109; Schölzel 2012, S. 243; Mütterlein 1913, S. 379-386. Zu den verschiedenen Zwingerforum-Projekten zwischen 1835 und 1846 siehe Laudel 2007, S. 132-133; Laudel 2003, Kat. Nr. 12, S. 149-156 und Kat. Nr. 27, S. 188-191; Mallgrave 2001, S. 107-108; Magirius 1992 (2), S. 30-35; Fröhlich 1974, S. 35, 40-41. 52-55; Plagemann 1967, S. 135-138; Friesen 1880, S. 327. Die Pläne für das Zwingerforum standen in engem Zusammenhang mit dem Denkmalprojekt für König Friedrich August I.. Zu Sempers Dresdener Zeit siehe Laudel 2003, S. 125-132; Mallgrave 2001, S. 80-139 Magirius 1994, S. 480-511.

176 Brief von Quandt an Schnorr vom 4.6.1846, in: SLUB, Mscr. Dresd. n Inv. 15 Bd. 31, fol. 256v-257v. Zu den verschiedenen Plänen siehe Mütterlein 1913, S. 385-392.

177 Mitteilungen Landtag 1846, S. 2110-2112: »[...] so hat doch die Depu-
Ab Juli 1847 entstand Sempers Gemäldegalerie in additiver Bauweise und im starken Kontrast zum Rokoko-Zwinger (Abb. 100). Ernst Rietschel und Ernst Julius Hähnel zeichneten ab 1849 für die Ausführung des vom Architekten entworfenen Figurenprogramms verantwortlich. Es zeigte auf der Nordseite Statuen und Reliefs zur antiken, auf der Südseite zur christlichen Kunst. ${ }^{178}$ Der neue Museumsbau sollte hauptsächlich der Gemäldegalerie in den oberen Stockwerken dienen, aber auch Räumlichkeiten für die Gipsabgüsse, das Kupferstichkabinett, einen Saal für die Handzeichnungen, die Verwaltung und die Restaurierungswerkstätten enthalten. Der Kuppelsaal enthielt die englischen Versionen der Apostel-Tapisserien nach den

tation, ohne sich irgend als Bauverständige ansehen zu wollen, die Ansicht aussprechen zu müssen geglaubt, daß, da einmal der Platz an dem Zwinger gewählt werden soll und muß, man auf diesem Platze für das neue Gebäude diejenige Lage wählen müsse, welche die wenigsten Einwendungen in dieser Beziehung gegen sich hat und namentlich die weiteste Entfernung von bewohnten Gebäuden und den größten freien Raum vor und um den beabsichtigten Neubau darbietet, und glaubt sie, daß in dieser Hinsicht die Stellung des Gebäudes innerhalb der unausgebauten Seite des Zwingers nach der Elbbrücke zu den Vorzug vor der gewählten Lage verdiene [...].« Die Debatte ebd., S. 2112-2136. Annahme des Neubaus ebd., S. 2136. S. a. Schölzel 2012, S. 243.

178 Eine ausführliche Analyse bietet aktuell Wilmowsky 2017, WVZ 247, S. 562-610. 


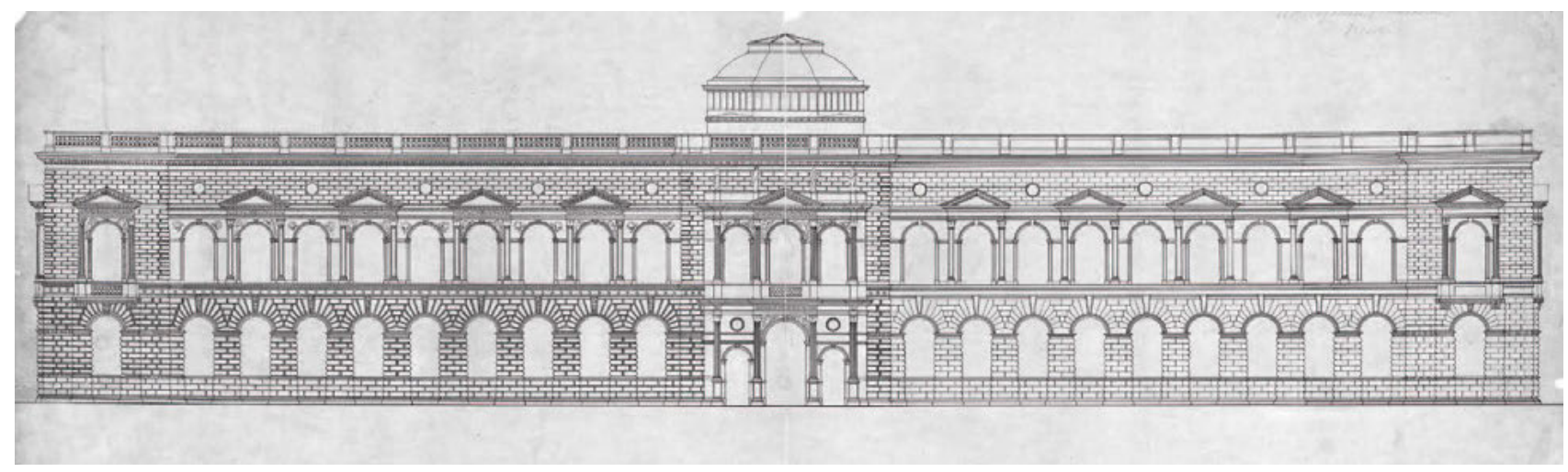

100 Gottfried Semper, Dresden, Gemäldegalerie, Ausführungsprojekt, Aufriss Fassade Elbseite, Nordseite, 1:125, 1846, Tinte, $1007 \times 352$ mm, Zürich, gta Archiv / ETH, Archiv-Nr. 20-089-17

Kartons von Raffael, die bis anhin im Brühl'schen Palais gelagert waren. ${ }^{179}$ Mit dem Galerieneubau entstand am Zwinger ein großer Museumskomplex, waren doch in den alten Zwingerpavillons bereits das Historische Museum, der MathematischPhysikalische Salon und das Naturalienkabinett untergebracht. Durch Sempers Neubau wurde der Zwinger »gleichsam zu einer Sammlung von Sammlungen « vereinigt. ${ }^{180}$

Semper hatte die Bauleitung nur anfänglich inne. Aufgrund seiner Unterstützung der Revolutionäre im Mai 1849 wurde ihm vorgeworfen, am Barrikadenbau in der Stadt teilgenommen zu haben. Semper wurde steckbrieflich gesucht und floh vor der angedrohten Verhaftung Hals über Kopf ins Pariser Exil. Hier sollte ihm sein ehemaliger Lehrer und Förderer Franz Christian Gau, den man nach dem Tod Joseph Thürmers gerne als Professor für Baukunst an die Dresden Akademie geholt hätte, helfen. ${ }^{181}$ Gau wandte sich Ende Juni 1849 an Quandt, der bei der Berufung Sempers an die Dresdener Kunstakademie 1833/34 eine wichtige Rolle gespielt und ihn mit kleinen Aufträgen in seinem Rittergut in Dittersbach und Eschdorf unterstützt hatte. ${ }^{182}$ Semper und sein Pariser Lehrer setzten ihre Hoffnungen in den Dresdener Kunstfreund und hofften auf schnelle Reaktion. ${ }^{183}$ Quandts ernüchternde Antwort erfolgte zehn Tage später. Aus seinem Brief spricht eine große Enttäuschung über

179 Darüber hinaus kamen weitere Bilder wie die Veduten Bellottos und Thieles aus dem Doublettensaal in das neue Museum. Zur Verortung der Sammlungen im Neubau siehe Kat. Dresden 1856, S. 64-65, 68 und die Grundrisspläne in Schäfer 1860, nach S. 144. Zu den Tapisserien siehe Kat. Dresden 2007, S. 678-679, Gal. Nrn. B 1-6; Kat. Dresden 1856, S. 68-72; Quandt 1856, S. 11-15. S. a. Schölzel 2012, S. 258-259.

180 Julius Hübner in Kat. Dresden 1856, S. 63. S. a. Heres 2006, S. 66-76, 105-119. Zu Baugeschichte, Stil und Ausstattung siehe Schölzel 2012, S. 243-248; Laudel 2003, Kat. Nr. 27, S. 191-195; Mallgrave 2001, S. 117128; Magirius 1992 (1), S. 73-83; Magirius 1992 (2), S. 35-62; Plagemann 1967, S. 131-144; Mütterlein 1913, S. 392-399; Schäfer 1860, S. VIII-IX, 15, $82-83,114-148$.

181 Semper war schon 1826 bis 1829 in Paris gewesen, wo ihn Gau unterrichtet und gefördert hatte. Gau empfahl Semper, nachdem er selbst den Architekten: »Sie wißen, wie sehr ich unsern Freund Semper geschätzt habe und werden daher überzeugt seÿn, daß mich der Verlust dieses Ausgezeichneten unter vielen Künstlern sehr geschmerzt hat.«Quandt, von großer Loyalität gegenüber dem Staat, warf Semper vor allem vor, dass er geflohen sei. Man verlasse nicht Frau und Kinder sowie Anstellung, Aufgaben und Lohn eines Staates, wenn man schuldlos sei. »Der Staat hat nicht mit Semper gebrochen, Semper aber mit dem Staate, der ihn auf alle Weise belohnte.«Zudem könne Semper, auch wenn er ein noch so guter Künstler sei, nicht über dem Gesetz stehen. Gau hatte in seinem Brief Quandt mit dem Argument zu gewinnen versucht, dass kein Vergehen Sempers künstlerische Leistungen mindern könne. Mit einem solchen Vorwand griff er bei Quandt gänzlich daneben. »Uebrigens kann man ja nur Gleiches gegeneinander abwägen, aber nicht Verschiedenes. Man kann nicht Genie und Verbrechen mit einander meßen. Sagen Sie selbst, verehrtester Herr! was sollte aus der menschlichen Gesellschaft werden, wenn die Genies sich alles erlauben dürften? «184 Dennoch wollte Quandt wenigstens den akademischen Rat über Sempers Anliegen unterrichten.

Semper antwortete selbst auf Quandts Vorwürfe. Er stritt zwar seine Teilnahme an den Revolutionskämpfen nicht ab, spielte aber seine Rolle beim Barrikadenbau herunter. Er ver-

das Dresdener Berufungsangebot abgelehnt hatte; siehe Kramp 2007, S. 101-120. Zur Flucht Sempers aus Dresden nach Paris siehe Mallgrave 2001, S. 178-187; Herrmann 1978, S. 10-31.

182 Zur Rolle Quandts bei der Berufung Sempers siehe Laudel 2003, Kat. Nr. 18, S. 163 und Kat. Nr. 23, S. 178-179; s. a. Seidemann 1860, S. 42, 163-165.

183 Brief von Gau an Semper am 11.7.1849, in: gta Archiv / ETH Zürich, Archiv-Nr. 20-K-1849-07-11. Gau habe den Brief am 28.6. abgeschickt. Gaus Brief an Quandt ist nicht erhalten. S. a. Mallgrave 2001, S. 186; Herrmann 1978, S. 15.

184 Kopie von Quandts Brief an Gau vom 7.7.1849, in: gta Archiv / ETH Zürich, Archiv-Nr. 20-K(DD)-1849-07-07:2. Vollständig abgedruckt in: Fröhlich 1974, S. 68-69. S. a. Brief von Gau an Semper am 12.7.1849, in: ebd., Archiv-Nr. 20-K-1849-07-12. 
langte von Quandt, gegen das Gerücht anzukämpfen, er habe eine leitende Funktion innegehabt. Zudem wollte er seine Flucht nicht als Selbstgericht verstanden wissen, sondern als Vermeidung einer Haft, während der er weder der Kunst noch der Familie noch dem Staat hätte dienen können. Schließlich betonte er, dass er überhaupt keinen Anspruch auf spezielle Behandlung hege und einzig auf eine Generalamnestie hoffe. ${ }^{185}$

Für die Hintergründe entscheidender sind weniger Sempers Rechtfertigungszeilen als seine Entwürfe des Briefes an Quandt, die in Zürich erhalten sind. Darin hatte er einiges formuliert, das im definitiven Schreiben nicht mehr vorhanden war. So bestritt er, dass Quandt sich beim König hätte einsetzen sollen. Er werde den Weg zum sächsischen Herrscher schon selber finden. Gau habe Quandt nur als Ratgeber und Freund gefragt und habe nicht gewollt, dass er sich mit einem solch persönlichen Anliegen an den akademischen Rat wende. Semper schrieb sich im Entwurf den Frust von der Seele: Er habe sich damit abgefunden, »daß Sie nur die schöne Gelegenheit in einem discours de procureur du roi [Staatsanwalt] Ihre Logik und Loÿalität glänzen zu laßen verführt habe. Sie wären sonst ein wohlwollender Mann, der aber den Parroxÿsmen [krankhaften Anfällen] der Eitelkeit unterworfen seÿ und dann Niemanden, als sich kennt. ${ }^{186}$ Glücklicherweise ließ Semper diese Passage im abgesendeten Brief aus. Es interessiert auch weniger die Bitterkeit des verständlicherweise sich für freie Rechte einsetzenden, republikanisch gesinnten Architekten, der gerne wieder nach Dresden zurückgekehrt wäre. Das Augenmerk gilt eher dem Bild, dass er von Quandt skizziert. In der Tat war der Kunstmäzen alles andere als ein republikanischer Revolutionär. Seine politischen Gesinnungen waren zwar nicht restaurativ. Vielmehr unterstützte er die 1830 eingerichtete sächsische Verfassung und die konstitutionelle Monarchie. Aber Quandt war selber als Besitzer eines Rittergutes Unsicherheiten unterworfen und hoffte auf einen gefestigten Staat. Sein Plädoyer gegen Semper kann vor diesem Hintergrund verstanden werden. Wenn der Architekt dies als staatsanwaltschaftliches Benehmen und königliche Loyalität empfand, lag er damit nicht daneben, denn Quandt

185 Eigenhändige Abschrift von Sempers Brief an Quandt vom 17.7.1849, in: gta Archiv / ETH Zürich, Archiv-Nr. 20-K-1849-07-17(S). Ein undatierter Briefentwurf an den sächsischen König ist enthalten in: ebd., ArchivNr. 20-K-1849(S):2. Aus den Akten im gta-Archiv wird nicht ersichtlich, ob er diesen Brief auch abgeschickt hat. S. a. Herrmann 1978, S. 14-16.

186 Vier Briefentwürfe von Semper an Quandt, undatiert [1849], in: gta Archiv / ETH Zürich, Archiv-Nr. 20-K-1849(S):1. Das Zitat ist dem wohl zuletzt entstandenen, am reinlichsten geschriebenen Brief (D) entnommen.

187 Hinsichtlich seiner politischen Gesinnungen ist die Parkgestaltung in Dittersbach von Interesse. So ließ er eine Konstitutionssäule und ein Denkmal für König Anton, der die sächsische Verfassung 1831 eingesetzt hatte, errichten. Krause/Harnisch 2009, S. 44-51; Palm 2008, S. 49-51. S. a. Quandt 2001 [1870], S. 242. hatte seine Position als Rittergutbesitzer zu verteidigen beziehungsweise wusste um die Gefahr, sie zu verlieren. ${ }^{187}$

Doch Sempers Bemühungen um Begnadigung fruchteten nichts. Noch im Juli 1849 wurde er in Dresden abgesetzt. Der Steckbrief wurde erst 1863 für ungültig erklärt, als man ihn für den Wiederaufbau seines niedergebrannten Hoftheaters gewinnen wollte. Nach Dresden kehrte er nie mehr zurück. Nachfolger an der Kunstakademie wurde Georg Hermann Nicolai, die Bauleitung der neuen Gemäldegalerie übernahm der Hofarchitekt Bernhard Krüger und der Landbaumeister Karl Moritz Hähnel unter der Anleitung einer Baukommission. Die offensichtlichste Konsequenz war eine niedrigere Kuppel, woraus Schwierigkeiten mit der Belichtung dieses von Semper als Saal der besten Kunstwerke vorgesehenen Gebäudeteils hervorgingen. ${ }^{188}$ Einige Probleme in der Disposition trugen jedoch schon die Pläne Sempers in sich. So war die Kuppel, welche Vestibül und Haupttreppe überwölben sollte und dabei die Fluchten der Gebäudeflügel zerschnitt, schon im Stallwiesenprojekt eingeplant. Ebenso lässt sich eine gewisse Distanz Sempers zu den Vorgaben feststellen. Weder wurde er mit der räumlichen Anordnung einer kunsthistorischen Entwicklungsgeschichte gerecht noch berechnete er sie nach der benötigten Hängefläche. Zudem waren die einzelnen Räume nicht von überall her zugänglich, was die Verbindung von Kabinetten und Hauptsälen zugunsten einer Schulhängung sehr erschwerte. ${ }^{189}$ Solche Eigenheiten mochten mit seiner Sicht des Museums zu tun haben. Er verstand es als »Caserne der Museumsgegenstände«, die keine Rücksicht auf den Ursprung der Kunstwerke nehme und ließ daher höchstens gewachsene Sammlungen wie diejenigen des Vatikans gelten. ${ }^{190}$

Zahlreiche zumeist positive Rezensionen folgten auf die Eröffnung im September 1855. ${ }^{191}$ Doch kritische Stimmen gab es auch. Quandts langjähriger Wegbegleiter in der Frage des Museumsbaus, Hermann Freiherr von Friesen, äußerte sich noch 1880 enttäuscht über den Standort: »Ich kann es nicht verschmerzen, dass man den Plan, das Museum gegenüber der Brühl'schen Terrasse [auf der Stallwiese, (vgl. Abb. 96)] am Elb-

188 Kramp 2007, S. 118-119; Heres 2005/06, S. 724-725; Laudel 2003, S. 193; Mallgrave 2001, S. 186; Magirius 1992 (1), S. 74; Magirius 1992 (2), S. 3840; Herrmann 1978, S. 16-17; Plagemann 1967, S. 135; Schäfer 1860, S. 120; Semper äußerte sich negativ über diese Kuppel in: Deutsches Kunstblatt 1855, Jg. 6, Nr. 42, S. 370-371.

189 Julius Hübner verweist darauf, dass man die Zusammenführung der Schulen in Hauptsälen und zugehörigen Kabinetten »möglichst» versucht habe. Es war offensichtlich nicht vollständig gelungen. Kat. Dresden 1856, S. 65-66. Ebenso Schäfer 1860, S. XIII. S. a. Marx 1992 (2), S. 7, 18.

190 Zitiert nach Laudel 2003, S. 187; Plagemann 1967, S. 140.

191 Kat. Dresden 1856, S. 66-67. S. a. die Literaturangaben bei Laudel 2003, S. 195 


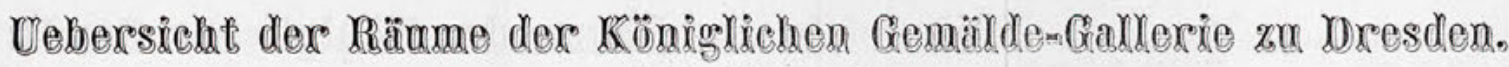 Erstes Stockwerk.}

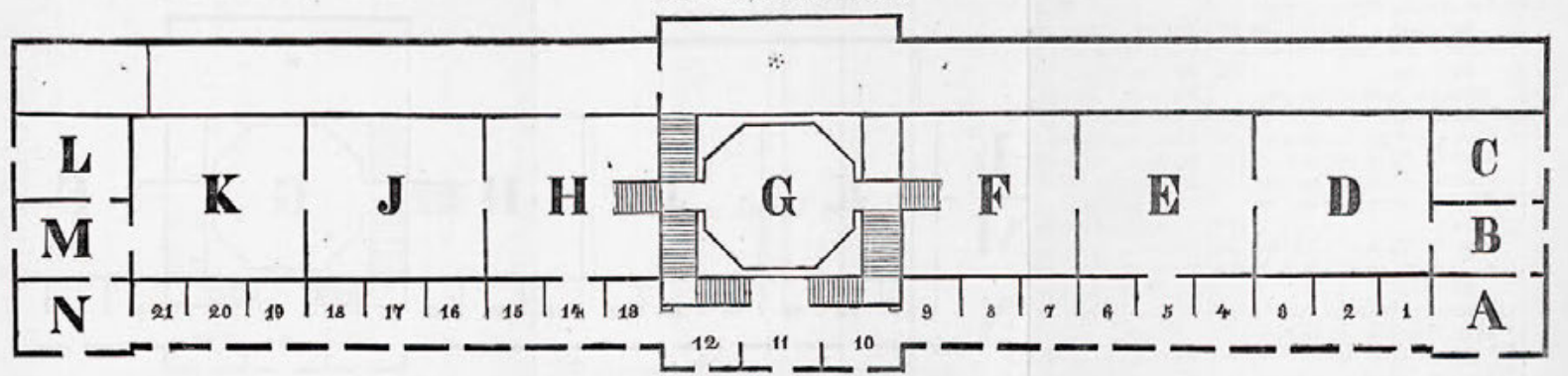

Der Entréesaal.* franjöfiffoje Scjufe: Bilder ron Louis Silvestre, yt

Die grösseren Säle, mit grossen Buchstaben von $\mathbf{A}$ bis mit $\mathbf{N}$ bezeichnet.
A. Madonna di S. Sisto von Raphael, os B. Rümị̧cje Scjute: Grullio Romano, Sassoferato, Carlo
Dolec ete. of
C. Copie der belle Jardinière des Rapharl. go
D. ferrarefiffje uno Lombaroifdje Stfufe: Francia,s"

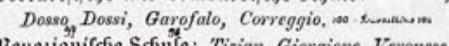 F. ßolognefiffie Scfinfe: Caracei, Cavanaggio, Guer-
cino, Guido Reni. 14s, sso
IK. Nièderfändifcje und fjoftändiffje Scfjufe: Rem- brandit, $\mathrm{Bal}$, Honthorst. aq
G. Die Raphaclischen und Altriederländischen Tapeten.
H. Ienuefifdje, Jeapofitanifdje tt. Spaniffoje Sdjufe:

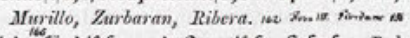
E. Venesiantifcje Sofjule: Tizim, Giorgione, Veroncse.

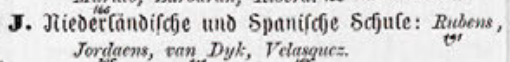

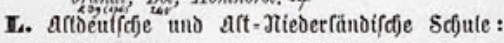 Burghmair.
MI. Desgl, Mabusc, Cranach. In Lierd
N. Desgl. Holbein's Maria, van ${ }_{\text {igt }}^{\text {Eych }}$, Rogier van der

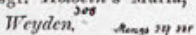

101 Uebersicht der Räume der Königlichen Gemälde-Gallerie zu Dresden. Erstes Stockwerk, in: Kat. Dresden 1856, nach S. 362

ufer zu erbauen, aufgegeben und dagegen, im Grunde nur des Kostenpunktes wegen, den jetzigen Platz am Zwinger gewählt hat. Mit der Ausführung jenes Projectes wäre ein Musterbau entstanden. Freiheit von den gefährlichsten atmosphärischen Einflüssen, Sicherheit vor Feuersgefahr von außen, und endlich eine repräsentative Stellung, wie sie nicht schöner gefunden werden konnte. Alle diese Vorzüge gehen dem jetzigen Gebäude mindestens zum Theil ab. $\ll^{192}$

Wilhelm Schäfer analysierte die Hauptprobleme der Disposition der Gemälde und ihrer Verarbeitung in Julius Hübners Katalog von 1856 (Abb. 101). ${ }^{193}$ Die Trennung der Säle und Kabinette hatte die konsequente Zusammenführung der Schulen nach chronologischen Kriterien nahezu verunmöglicht. Dies war zwar ein durch die unterschiedlichsten Formate der Gemälde bestimmtes Grundproblem einer jeder Sammlungspräsentation. Jedoch hatte man die Chance verpasst, wenigstens dem begleitenden Katalog einen kunsttopographisch-chronologischen Rundgang einzupassen, der die Schwierigkeiten der Hängung hätte abschwächen können. Stattdessen folgte er von 1856 an einer fortlaufenden Nummerierung, die nicht der Hängung entsprach und jeweils ein Umherblättern erforderte.

192 Friesen 1880, S. 332. Er beurteilt zudem die Schließung des Zwingers als unvorteilhaft und hätte sich wenigstens zum Zwingerhof hin offene Arkaden gewünscht, um die unterschiedlich hohen Gebäude nicht in Konkurrenz miteinander zu bringen. Auch Hübner in Kat. Dresden 1856, S. 63 betont, dass ein »eigentümlicher«, moderner Stil durch die Angleichung an die Zwingerpavillons nicht erreicht worden sei.

193 Schäfer 1860, S. IX-X, 16-17.

194 Quandt 1856, S. 7; Brief von Quandt an Unbekannt [Weigel?] vom 7.6.1856, in: SLUB, Mscr. Dresd. App. 204, Nr. 98s: Quandt widerspricht
Diese Vorwürfe offenbaren sich auch im Vorwort von Quandts Begleiter durch die Gemälde-Säle von 1856. Der Autor beklagte sich, dass die räumliche Disposition des Museumsbaus einer »genetischen« Hängung widersprach. Die Lichtführung und Raumdimensionen seien nicht überall gut und damit sei es unmöglich geworden, konsequent nach Schulen zu hängen. Dies sei doch die Hauptforderung an einen Museumsneubau, um die Verwandtschaften von Meistern und Schülern aufzuzeigen. Dadurch seien bei der Hängung der Sammlung, die durch ihren Schwerpunkt in der Kunst des 17. Jahrhunderts sowieso keinen kunsthistorischen Überblick zu geben vermöge, zahlreiche zusammengehörige Gemäldekonvolute auseinandergerissen und das Verfolgen einer allmählichen Entwicklung der schönen Künste gänzlich verhindert worden. ${ }^{194}$

Ganz gerecht wurde Quandt der neuen Präsentation mit seinem Vorwurf allerdings nicht, denn eine Schulhängung war vorhanden, ebenso wie ein Museumsneubau auf dem aktuellsten Stand der Erkenntnisse. Die angewendeten Prinzipien der Hängung entsprachen durchaus den neuen Gemäldegalerien in Berlin und München, wo man Schwerpunkte in der italienischen Renaissance und bei den Niederländern des 17. Jahrhun-

vehement einem Rezensenten seines Begleiters, der ihm vorwirft, keine chronologische Abfolge für die Beschreibung gewählt zu haben: »Daß ich keine genetische Ordnung beachtet habe, liegt theils an der Aufstellung der Gemälde, theils daran, daß der Sammlung kein chronologischer Plan zu Grunde liegt, was in der Vorrede schon auseinandergesetzt wird u ich hätte mit dem Beschauer schön herumspringen müssen, wenn ich ihn von den ältesten zu den neusten Werken führen wollte.«S. a. Weddigen 2008, S. 229-230. 
derts setzte. Die kunstgeschichtliche Präsentation orientierte sich in diesen Museen an ästhetisch-geschmacklichen Grundsätzen. ${ }^{195}$ In der etwas polemischen Anklage sah sich Quandt vor allem in seiner Forderung nach einer anschaulichen Kunstgeschichte der Schönheit enttäuscht. Mit dem Neubau der Galerie neigte sich Quandts langjährige Arbeit für die Königliche Sammlung ihrem Ende zu.

\section{Kompetenzstreitigkeiten: Quandts Rückzug aus der Galeriekommission}

In der Planungsphase für die Einrichtung des neuen Museums war die Galeriekommission einbezogen worden. Als sich abzuzeichnen begann, wie die Gemälde präsentiert würden, zog sich Quandt zwar noch nicht aus der Kommission, jedoch von der gestaltenden Mitwirkung zurück. ${ }^{196}$ Die Gründe hierfür werden in den Quellen nicht restlos klar. Einer scheint sich in der unterschiedlichen Auffassung der Hängung niedergeschlagen zu haben. Quandts boshafter Kommentar in der Spanienreise sowie die Worte in der Einleitung zu seinem Begleiter weisen in diese Richtung: »Unter solchen Umständen [der inkonsequenten Hängung - AR $]$ ward dem Beschauer nicht nur der Katalog als Wegweiser, sondern auch ein Begleiter nöthig, der durch allgemeinere Betrachtungen die vereinzelt aufgestellten Kunstwerke in Verbindung bringt [...]. «197 Gerade weil der neue Galerierundgang seiner Ansicht nach keine Kunstkennerschaft zu vermitteln vermochte, musste Quandt als erfahrener Kenner mit seinem Büchlein einspringen.

Ein anderer Grund waren die unklar verteilten Kompetenzen von Kommission und Direktor. Dieser latent schwelende Konflikt zeigte sich bei Veröffentlichung des neuen Galeriekatalogs von Julius Hübner. In seinem Manuskript erwähnte er die Mitwirkung der Galeriekommission. Dagegen wehrte sich Direktor Julius Schnorr von Carolsfeld beim Minister mit der

195 Man hat versucht, den großformatigen Bildern der Hauptsäle die zugehörigen Schulen möglichst in den anschließenden Kabinetten zuzuordnen; Kat. Dresden 1856, S. 65-66; Schäfer 1860, S. IX-X, 16-17. S. a. Penzel 2007, S. 178-188; Savoy 2006, S. 539-549.

196 Schäfer 1860, S. 145: »Die Disposition der Gemälde geschah durch den derzeitigen Gallerie-Director Schnorr von Carolsfeld unter Mitwirkung der Gallerie-Commission, zu der auch beim Beginn der Vorarbeiten Herr von Quandt, als Nestor, noch gehörte.«; s. a. Kat. Dresden 1856, S. 67; Schölzel 2012, S. 260-261.

197 Quandt 1856, S.7-8. Zur Publikation des Begleiters s. a. Brief von Quandt an Friedrich Gottlieb Welcker vom 2.2.1856, in: Bonn, Universitäts- und Landesbibliothek, Dezernat 5 / Abt. Handschriften und Rara, Autographensammlung, S 685 (NL Welcker), Brief 7.

198 Einträge Ende 1855/anfangs 1856, in: Schnorr 1897, Jg. 6, Nr. 3, S. 59; Schnorr 1898, Jg. 7, Nr. 1, S. 74, 75.

199 Kat. Dresden 1856, S. 66-67.
Begründung, Bendemann sei nicht anwesend gewesen und Quandt aus Prinzip von Anfang an jeglichen Beratungen ferngeblieben. ${ }^{198}$ In der gedruckten Fassung der Hübner'schen Einleitung zum Katalog von 1856 hieß es in der Folge nur noch, die Galeriekommission sei bei den Beschlüssen des Direktors zur Einrichtung der Galerie »mitwirkend « tätig gewesen. ${ }^{199}$

Die Gründe für diese Unstimmigkeiten lagen einige Jahre zurück. Mit dem Antritt Schnorrs als Direktor der Gemäldegalerie im Jahr 1846 war das Verhältnis zwischen Direktor und Galeriekommission zur Diskussion gestellt, aber nie geregelt worden. Die Kommission schien dem Direktor in vielerlei Hinsicht übergeordnet gewesen zu sein. Ein unvollendetes und undatiertes Konzept zur Geschichte der Galeriekommission von 1846/47 gibt Aufschluss. Es war wohl im Zuge der Kompetenzdiskussionen nach Schnorrs Antritt entstanden und beschrieb, dass nach der Gründung 1836 alle amtlichen Instruktionen direkt an die Galeriekommission gegangen seien. Anfänglich stand die Kommission nicht einmal unter dem Vorsitz des Direktors, sondern des Akademieprofessors Christian Ferdinand Hartmann. Erst 1838 habe man die Galeriekommission als mitwirkend und nicht leitend erklärt. ${ }^{200}$

Die unübersichtliche Situation reichte laut den Quellen in die Zeiten von Schnorrs Vorgänger Johann Friedrich Matthäi zurück. Hermann Freiherr von Friesen hatte Matthäi mit dem Vorwurf einer Bestechung des Lithographen Franz Seraph Hanfstaengl, der zahlreiche Meisterwerke der Gemäldegalerie lithographiert hatte, konfrontiert. Zudem hatte er ihm vorgeworfen, seine Aufgaben als Direktor der Gemäldegalerie nicht wahrnehmen zu können, weil er gleichzeitig ein Mandat als Professor der Akademie innehatte. Aus diesem Grund hatte Friesen seine Entlassung beantragt. Diese war von Lindenau abgelehnt worden, weil die Inspektoren Johann August Renner und Carl Heinrich Wilhelm Schmidt ein Fehlverhalten des Direktors nicht bestätigen wollten. Friesen hatte Lindenau in der Folge darauf hingewiesen, dass die Galeriekommission das Aufsichts-
200 »Der Galleriedirektor erscheint in dieser auch weiter bestehenden Galleriecommission dagegen in einer untergeordneten fast gedrückten Stellung. Alle Anordnungen erfolgen nicht an den Direktor sondern an die Galleriecommission. Da jedoch in neuerer Zeit das Bedürfnis einer gründlichen Abhülfe sich immer dringender fühlbar machte, so ist seit dem Anfang dieses Jahres (1838), ein schon vor mehrern Jahren vom Galleriedirector Matthäi gewünschtes Comité aus Kunstkennern und Künstlern eingesetzt worden, unter dessen Mitwirkung die Angelegenheiten der Gallerie beraten und ausgeführt werden. In dem Concept wurde der vom Commissionsrat Nollain herrührende Ausdruck >Mitwirkung vom Staatsminister v. Lindenau durch >Leitung u. Aufsicht « ersetzt, später jedoch wieder bestätigt.« Konzept zur Geschichte der Galeriekommission, undatiert [um 1846/47], in: HStADD, Akten der Generaldirektion der Königlichen Sammlungen, Cap. VIIa, Nr. 5, Jahresberichte 1837-1842 (Kriegsverlust). Abschrift in: HStADD, 13458 SKD, NL Posse, Nr. 30, Lage 10, fol. 8r-v. 
recht in Galerie-Angelegenheiten ausüben würde und somit dem Direktor vorstand. ${ }^{201}$ Im Konzept von 1846/47 hieß es dagegen, die Kompetenzfrage sei damals ungeregelt geblieben. ${ }^{202}$ Bis zu Schnorrs Antritt als Direktor wurde die Frage nicht geklärt.

Julius Schnorr wiederum hätte am liebsten ohne Kommission gearbeitet. Er notierte im August 1855 in sein Tagebuch, die Kommission könne aufgelöst werden. Sie habe keine Aufgaben mehr, seit die Restaurierungen durchgeführt seien und die Einrichtung der Galerie von den Galeriebeamten »und zwar zunächst von mir ausgeht $\ll^{203}$ Das Schicksal der Galeriekommission wurde jedoch auf höherer Ebene entschieden. Das Ministerium des Königlichen Hauses, in dessen Kompetenzen die Sammlungen lagen, erließ im Oktober 1855 ein neues Regulativ für die Galeriekommission. ${ }^{204}$ Die Entscheidungshoheit lag nun beim Direktor. Die Kommission sollte nur noch als beratende Behörde des Direktors tätig sein. Gutachten wurden auf Verlangen des Ministeriums oder des Galeriedirektors erstellt. Der Direktor hatte den Vorsitz und damit die alleinige Kompetenz, die Kommission überhaupt zu berufen. Die Verhandlungsergebnisse wurden vom Sitzungsleiter festgehalten, Protokolle nur dann erstellt, wenn dieser es für nötig hielt. Über Beschlüsse wurde nicht abgestimmt. Fand sich in den Beratungen keine einheitliche Meinung, »so ist jede abweichende Ansicht besonders zu motiviren ${ }^{205}$ Mit dem neuen Regulativ beschränkte sich die Wirkkraft der Kommission auf technische, nicht aber organisatorische Fragen. Ihre Aufgabenbereiche waren wie zuvor Konservierung und Restaurierung, Galeriehängungen, Ankäufe und Tauschgeschäfte, Zuschreibungsfragen und Kopierregeln.

Es verwundert nicht, dass Quandt mit seinen hehren Idealen und Hoffnungen, etwas ändern zu können, in dieser neuen
Galeriekommission nicht mehr Mitglied sein wollte. Mit Hermann von Friesen war der neben ihm einzige Kunstkenner schon 1842 aus dem Gremium ausgetreten. 1855 reichte Quandt frustiert seinen Rücktritt ein. Im Austrittsschreiben schrieb er: »Daß ich seit dem Einzuge der Gemälde in das neue Local keinen Antheil an den Versammlungen der Commission genommen habe, kommt daher, weil ich erkenne, wie vergeblich alles war, was ich für die Kunstschätze gethan, in dem der neue Bau an einem Orte steht, wo die Gemälde denselben Nachtheilen u Gefahren ausgesetzt sind wie im alten Galeriegebäude. Da es mir nicht gelungen Andere davon zu überzeugen, daß in Dresden zum Bau eines Museums die einzige passende Stelle der Platz ist, wo sich die Pontonschuppen befinden [auf der Stallwiese], so habe ich meine gute Absicht verfehlt u zu bereuen, daß die Erbauung eines neuen Museums von mir beantragt wurde. Ew. Excellenz [Eduard von Wietersheim] ersuche daher ganz ergebenst, mich von den Obliegenheiten eines Mitglieds der Galerie-Commission gnädigst zu dispensiren. $\ll^{206}$ Quandt sah sich als zentrale Figur des Neubaus. Das Projekt hatte mit dem Standort am Zwinger jedoch eine Wendung genommen, die für ihn nicht zufriedenstellend war.

Nach seinem Austritt bestand die Kommission nur noch aus Künstlern: Julius Hübner, Eduard Bendemann, Carl Gottlieb Peschel und Ernst Rietschel. ${ }^{207}$ Damit konnte Direktor Schnorr von Carolsfeld die Gemäldegalerie machtvoll leiten. Er hatte nur noch dem Ministerium Rechenschaft abzulegen. Mit dem Begleiter durch die Gemälde-Säle endete ein Jahr später schließlich Quandts öffentlich wirksame Tätigkeit in der Gemäldegalerie nach mehr als vierzig Jahren.

Jahresberichte 1837-1842 (Kriegsverlust). Abschrift in: HStADD, 13458 SKD, NL Posse, Nr. 30, Lage 10, fol. 8v.

203 Schnorr 1897, Jg. 6, Nr. 3, S. 53.

204 Brief und Regulativ des Ministeriums des Königlichen Hauses, signiert von Minister Heinrich Anton von Zeschau an Julius Schnorr vom 19.10.1855, in: HStADD, SKD, 01/GG Altbestand Gemäldegalerie Dresden 1846-1944 (1968), Nr. 8, Bd. 1, fol. 49r-51v. Seit 1853 waren die Kunstsammlungen dem Ministerium des königlichen Hauses untergeordnet; Heres 2005/06, S. 726. S. a. Schölzel 2012, S. 262-263.

205 Punkt VII. im Regulativ des Ministeriums des Königlichen Hauses vom 19.10.1855, in: HStADD, SKD, 01/GG Altbestand Gemäldegalerie Dresden 1846-1944 (1968), Nr. 8, Bd. 1, fol. 51r.

206 Brief von Quandt an Wietersheim vom 27.8.1855, in: HStADD, Akten der Generaldirektion der Königlichen Sammlungen, Cap. VII, Nr. 41, Acta die kgl. Gemälde-Gallerie betr., 1852-1856, fol. 59 (Kriegsverlust). Abschrift in: HStADD, 13458 SKD, NL Posse, Nr. 30, Lage 3, fol. 13v. S. a. Schölzel 2012, S. 262.

207 Brief des Ministeriums des Königlichen Hauses an Julius Schnorr vom 19.10.1855, in: HStADD, SKD, 01/GG Altbestand Gemäldegalerie Dresden 1846-1944 (1968), Nr. 8, Bd. 1, fol. 49r. S. a. ebd., Bd. 3, Acten, directorielle Aufzeichnungen über der Galerie-Commission gepflogene Verhandlungen und gefaßte Beschlüsse enthaltend. 1855-1869. S. a. Schölzel 2012, S. 262; Friesen 1880, S. 332. 


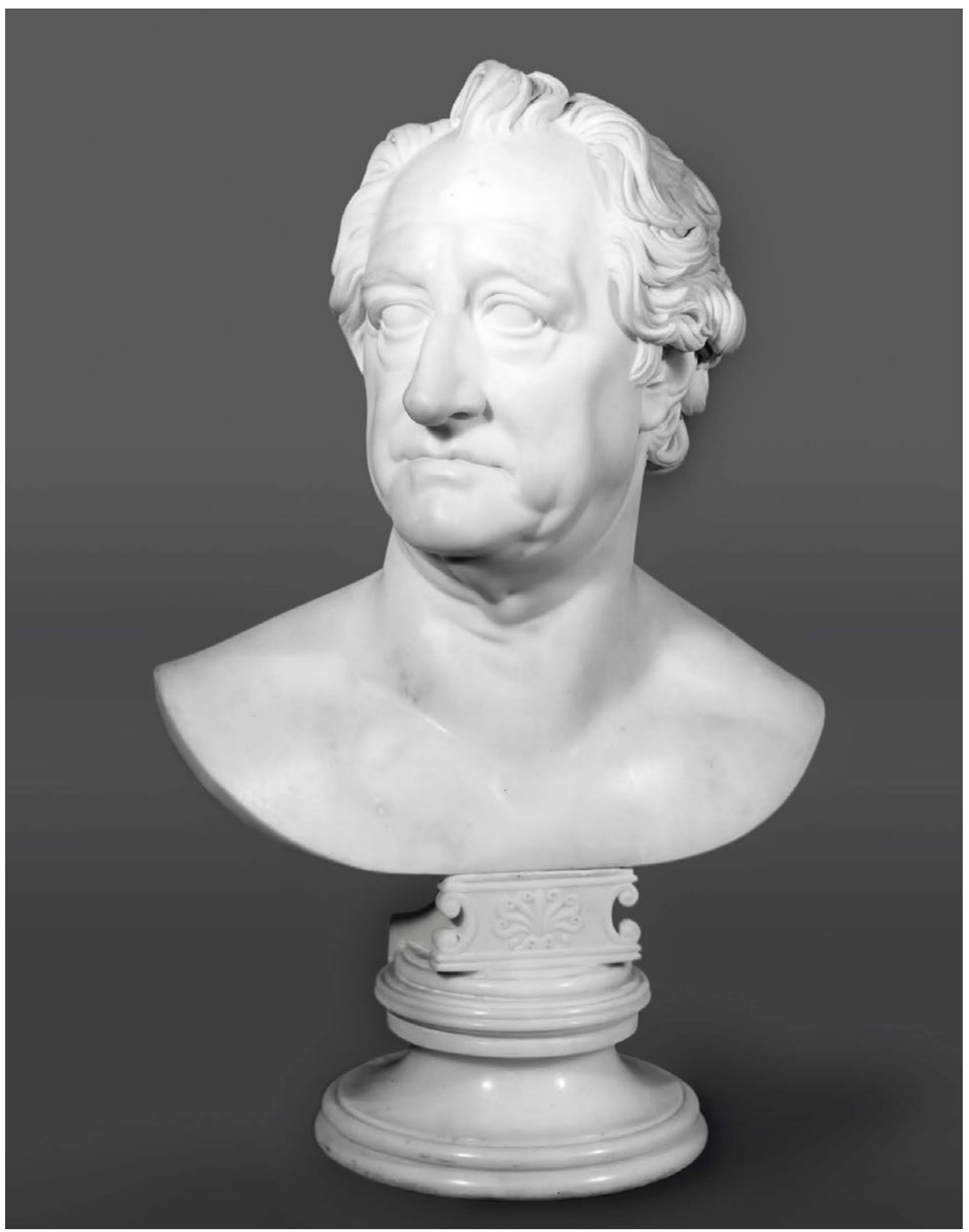

102 Christian Daniel Rauch, Goethe-Büste für Johann Gottlob von Quandt, 1820-23, Marmor, H. 44 cm, mit Sockel: 57 cm, Leipzig, Museum der bildenden Künste, Inv.-Nr. P 52 


\section{DER IDEALE MENSCH: Goethe-Inszenierungen in Dresden und Dittersbach}

Für die Umsetzung seiner Ideen mittels Kunstpräsentationen fand Johann Gottlob von Quandt im Privaten vielfältige Möglichkeiten. Im öffentlichen Rahmen stieß er auf größere Probleme, weil das Feld der Beteiligten und Betroffenen wesentlich komplexer war. Dennoch ging er in seinen Bemühungen um verständliche Ausstellungen immer von den Kunstwerken aus, die er anhand einer durchdachten Präsentation einem interessierten Publikum zugänglich machen wollte. Gelegentlich griff er dabei auf Künstlerbiographien zurück, um besondere Fähigkeiten und Überzeugungen zu erörtern. Abschließend soll ein Fallbeispiel diskutiert werden, das in seiner Grundidee Quandts Anspruch an das Ausstellen von Kunst zusammenfasst und sein Streben nach einer Synthese von Kunst, Künstler und Kultur aufzeigt.

Dieses Fallbeispiel verkörpert Johann Wolfgang von Goethe. Der Weimarer Dichter blieb für Quandt sein ganzes Leben lang vorbildlich. In Goethe zeigte sich dem Kunstkenner das Bild des idealen Menschen, der von den Künsten in allen Dingen durchdrungen war, ja selber zum Kunstwerk wurde. Als solches stand er Quandt in der Marmorbüste von Christian Daniel Rauch vor Augen (Abb. 102). Darum herum plante er in Dresden eine unausgeführte und eine umgesetzte Inszenierung. Auf seinem Rittergut Dittersbach errichtete er dem Künstler und seinem Werk den wohl ersten Erinnerungsort Deutschlands. Quandts Goethe-Inszenierungen zeugen von seiner hohen Meinung über den Dichter und vermitteln ein abschließendes Bild der bedeutenden Rolle, welche Quandt den Künsten und Künstlern in der Gesellschaft zumaß.

\section{Goethe als Bild des Lebens}

»Mein Onkel [Quandt - AR] war ein Goetheaner, wie es selten einen gab. Er besaß alle älteren Ausgaben Goethe'scher Schrif-

\footnotetext{
Rüfenacht 2012, S. 31-53.

2 Meissner 1884, Bd. 1, S. 17.

3 Quandt 1870, Nr. 19, Sp. 577-582, Nr. 20, Sp. 625-630. Quandt schrieb den Artikel, der nicht mehr zu seinen Lebzeiten publiziert wurde, nach 1848. Das Manuskript wurde 1869 in Leipzig versteigert; Kat. Leipzig 1869, S. 58, Nr. 1513: »Quandt, J. G. v., Meine Berührungen mit Goethe. Ungedrucktes Manuscript. 29 Seiten. Fol. «S. a. den Verweis »Literarischer Sprechsaal«, in: Magazin für die Literatur des Auslandes, 16.7.1870, Jg. 39, Nr. 29, S. 426-427. Laut diesem Artikel wurden Quandts Berührungen
}

ten, sowie alle Bücher über denselben. Goethe war ihm der Mittelpunkt einer Welt. Ein philosophischer Lebenskünstler und Epikuräer, im höchsten Grade gelehrt, geistreich, witzig, liebte er es auch wie Goethe jeden unangenehmen Eindruck von sich fern zu halten. $\ll^{2}$ Quandts Neffe Alfred Meissner charakterisierte auf diese Weise den Fokus des Kunstfreundes auf den großen Dichter. 1870 erschien in der Zeitschrift Europa. Chronik der gebildeten Welt eine biographische Schrift Quandts mit dem Titel Meine Berührungen mit Goethe. ${ }^{3}$ In den Berührungen erläuterte Quandt die erste Begegnung mit dem Dichter. Kennengelernt hatten sie sich 1808 im Kurort Karlsbad. Obschon Goethe zumeist alleine unterwegs war, forcierte der 21-jährige Quandt eine Begegnung: »Keine Bedenklichkeiten konnten die Sehnsucht, mich ihm zu nahen, stillen, ich folgte seinen Schritten und redete ihn an. Ich sprach es aus, wie seine Dichtungen mir mein eigenes Herz aufgeschlossen, mich erfüllt hätten und ich in meinem Innern nur von und durch ihn lebte. « ${ }^{4}$ Goethe referierte über Geognosie und wie sie in der Umgegend von Karlsbad studiert werden könne und fragte den jungen Verehrer nach dessen Verhältnissen.

Danach fanden bis zu Quandts Entdeckung der altdeutschen Gemälde in Leipzig im Jahr 1815, die ihm Goethe in einem Aufsatz attestierte, während mehrerer Jahre keine Kontakte mehr statt. Auf der Rückreise aus Italien im Jahr 1820 verblieb Quandt mit seiner frisch vermählten Gemahlin Clara Bianca einige Tage in Weimar, wo sie Goethe wiedersahen. Er beschreibt einen geselligen Abend, den Goethe für ihn organisiert habe..$^{5}$ Mit dem Umzug von Leipzig nach Dresden konnte der engagierte Kunstförderer durch die Vermittlung von Louise Seidler die Weimarischen Kunstfreunde für den Sächsischen Kunstverein gewinnen. Goethe vertrat deren Interessen. Daraus entstand ein bis zu Goethes Tod andauernder Briefwechsel. ${ }^{6}$ Obschon Quandt sehr stolz war, mit Goethe zu

erstmals im Beobachter am Hudson, dem deutschen Sonntagsblatt des New Yorker Democrat, veröffentlicht. Kommentierter Nachdruck, in: Schmitz/Strobel 2001, S. 230-242. S. a. Biedermann 1875, S. 133-140.

4 Quandt 2001 [1870], S. 233-234.

5 Quandt 2001 [1870], S. 236-238. S. a. Brief von Quandt an Schnorr vom 23.12.1820, in: SLUB, Mscr. Dresd. n Inv. 15, Bd. 31, fol. 54r-v; Schmitz/ Strobel 2001, S. 18-19.

6 Im ersten Brief an Goethe am 14.11.1828 schrieb Quandt: »Ew Excellenz danke ich zugleich auf das ergebenste dafür; daß Dieselben mir gestat- 
korrespondieren, verwehrte er die Publikation der Briefe zeit seines Lebens mit dem Argument, »eine wörtliche Veröffentlichung dieser Correspondenz würde nur die schon zu große Zahl der Briefe vermehren, die für einen Dritten gar kein Interesse haben können und aus welchen man Goethe durchaus nicht kennen lernt. «7

Mitte Mai 1830 reiste Quandt ein letztes Mal zu Goethe nach Weimar. ${ }^{8}$ Man sprach über Schopenhauers Abhandlung Die Welt als Wille und Vorstellung, witzelte über die dort aufgeworfene Frage der Rechtmäßigkeit von Notlügen und spottete über die Interpretation einer Sängerin von Franz Schuberts Vertonung des Erlkönig. Auch wenn Quandt die Gespräche dieses Besuchs als wenig bedeutungsvoll qualifizierte, sah er darin eine große Nähe zweier alter Freunde: »Das Wiedersehen zweier Personen, die einander lebhaft wohlwollen, hat an sich etwas so Befriedigendes, daß dabei gewiß keine Dinge von Wichtigkeit verhandelt werden. $\ll^{9}$ Er verglich diesen Umstand mit der Einsilbigkeit von Liebespaaren, die nicht zu reden brauchen, um sich zu verstehen.

»Er hat mich doch lieb gehabt! «, rief Quandt am 1. April 1832 - zehn Tage nach Goethes Tod - in einem Brief an Louise Seidler verunsichert und traurig aus. Wie der Zurückgebliebene hier selber zu erahnen schien, war das Verhältnis zu Goethe als Person keineswegs nur ein übereinstimmendes und freundschaftliches, wie verschiedene Beispiele vermuten lassen..$^{10}$ Doch Goethe stand als Mensch für einen Lebensentwurf. Er war für Quandt eine große Projektionsfläche. Gemäß eigener Aussage, kurz nach Goethes Tod, hatte Quandt sein Leben immer nach Goethe ausgerichtet. »Ich hatte mich ge- wöhnt, bey Allem was ich that, bey allem was mich erfreute an Göthe zu denken. [...] Immer sprach ich in Gedanken mit ihm. Das ist nun aus! Wir sind verwaist; sagte Tieck zu mir. Das ist das Wort, was mein Gefühl ganz ausspricht, ein Gefühl, was viele Tausende erfüllt. «" Mit Goethes Tod starb für Quandt die Metapher des idealen Lebens, »das Menschenleben in seinem Normalzustande. $\ll^{12}$ In seinen Hommagen, die in zwei Briefen an Ottilie von Goethe und Louise Seidler zur Geltung kommen, bediente er sich großer Worte. Sein Stern sei untergegangen, die Welt ohne diesen Sonnenschein verdunkelt, das Leben habe seinen Glanz und seine Wärme verloren. ${ }^{13}$ Dies macht vor allem eines deutlich: Es ging Quandt hinter der Person Goethe um eine Metapher des Lebens, um eine Idee, eine ideale Seinsweise. Goethe war für ihn nicht, anachronistisch gesprochen, ein Übermensch, der »Enorme«, sondern bedeutete ihm das Menschsein selbst. ${ }^{14}$

Goethes Person stand für ein Ideal der Vollständigkeit, der höchsten Form von Menschlichkeit, ihren Leiden und Freuden. Goethe verstand es, so Quandt, die dem Menschen immanente Endlichkeit in die Unsterblichkeit von Kunstwerken zu gießen.5 Damit wurde er selbst zum Kunstwerk, das für das Leben stand. Quandt schrieb an Seidler: »[...] er starb, ich sage: Er lebte, denn nur lebendig steht sein Bild vor mir.« ${ }^{16}$ So ließ der Verehrer eine Goethe-Stele des großherzoglichen Oberbaudirektors Clemens Wenzeslaus Coudray, die zum Begräbnis des Dichters aufgestellt worden war, auf seine Kosten in Kupfer stechen (Abb. 103) ${ }^{17}$ Gegenüber dem Großherzog Carl August von Sachsen-Weimar-Eisenach, Goethes Förderer, hatte Quandt sogar einmal gemeint, Goethe sei dessen Denkmal. ${ }^{18}$ Wenige ten mich unmittelbar an Hochdieselben schriftlich wenden zu dürfen, wodurch ich mich sehr beglückt fühle [...]«; Schmitz/Strobel 2001, S. 40. S. a. Jahresbericht des Sächsischen Kunstvereins von 1831 bis Ostern 1832: „Göthe schied von uns! Denn im Leben war er der Unsere, wie dieß unverkennbar aus den Briefen klar und gefühlvoll hervorleuchtet, die wir als Heiligthümer in unsern Vereinsacten aufbewahren." HStaDD, 12509 Sächsischer Kunstverein, Nr. 2, fol. 233v (S. 8).

7 Quandt 2001 [1870], S. 238. Quandts Sohn Gustav bemerkte, sein Vater habe alle Goethe-Briefe in seinem Nachlass verbrannt. Briefe von Gustav von Quandt an Karl Ludwig Schemann vom 12.10.1887 und 1.2.1889, in: Freiburg i/Br, Universitätsbibliothek, Schemann NL 12/2588.

8 Brief von Quandt an Goethe vom 16.5.1830. in: Schmitz/Strobel 2001, S. 91.

9 Quandt 2001 [1870], S. 241.

10 Zu den persönlichen Differenzen siehe Kap. Höhere Aufgaben: Der Sächsische Kunstverein.

11 Quandt an Louise Seidler am 1.4.1832, in: Schmitz/Strobel 2001, S. 165; ebenso im Brief an Friedrich Rochlitz, 3.4.1832, in: SLUB, Mscr. Dresd. App. 1191, Nr. 577. Sehr ähnlicher Wortlaut im Brief an Ottilie von Goethe vom 31.3.1832, in: ebd., S. 163-164.

12 Quandt an Louise Seidler am 1.4.1832, in: Schmitz/Strobel 2001, S. 165 S. a. Quandt 1846 (2), S. 389

13 Beide Briefe in: Schmitz/Strobel 2001, S. 163-166.

14 Quandt 1846 (2), S. 389: »Napoleon hat über Goethe, als er ihn zum ersten Mal sah, das treffendste Urtheil mit kurzen Worten ausgesprochen: Vous êtes un homme! [...] Das ist freilich denen nicht genug, die das Enorme verlangen."

15 Quandt 2001 [1870], S. 230-231.

16 Quandt an Louise Seidler am 1.4.1832, in: Schmitz/Strobel 2001, S. 165. S. a. Quandt an Ottilie von Goethe vom 31.3.1832, in: Schmitz/Strobel 2001, S. 164: "Göthe starb! - Göthe lebte - sind die Worte, mit welchen ich nur von seinem Hinscheiden sprechen kann; denn die Idee Leben, ist mit allen Gedanken an ihn so innig verknüpft, daß wir immer, wenn wir an ihn denken, zuerst fühlen; er lebte in der vollsten, naturgemäsesten, schönsten Bedeutung dieses Worts."

17 Brief an Coudray vom 8.6.1832, in: Schmitz/Strobel 2001, S. 167-168. Lorbeerkranz und Lyra verweisen auf Apoll, eine Verbindung, die nach Goethes Tod immer wieder hergestellt wurde; Heckenbücker 2008, S. 177-180. Quandt wollte auch Coudrays Manuskript von Goethes letzten Lebenstagen in der Waltherschen Hofbuchhandlung in Dresden veröffentlichen, was abgelehnt wurde. Brief an Coudray vom 12.4.1832 sowie die Antwort der Waltherschen Hofbuchhandlung, [nicht datiert], Düsseldorf, Goethe-Museum, Inv. O. S. a. WentzlaffEggebert 2009, S. 228; Schmidt-Funke 2006, S. 170.

18 Diese Aussage gegenüber dem Großherzog erwähnte er in seinem Trauerbrief an Seidler vom 1.4.1832, in: Schmitz/Strobel 2001, S. 165 Die Herausgeber glauben, dass Quandt das Gespräch imaginiert hat; ebd., S. LIII. 


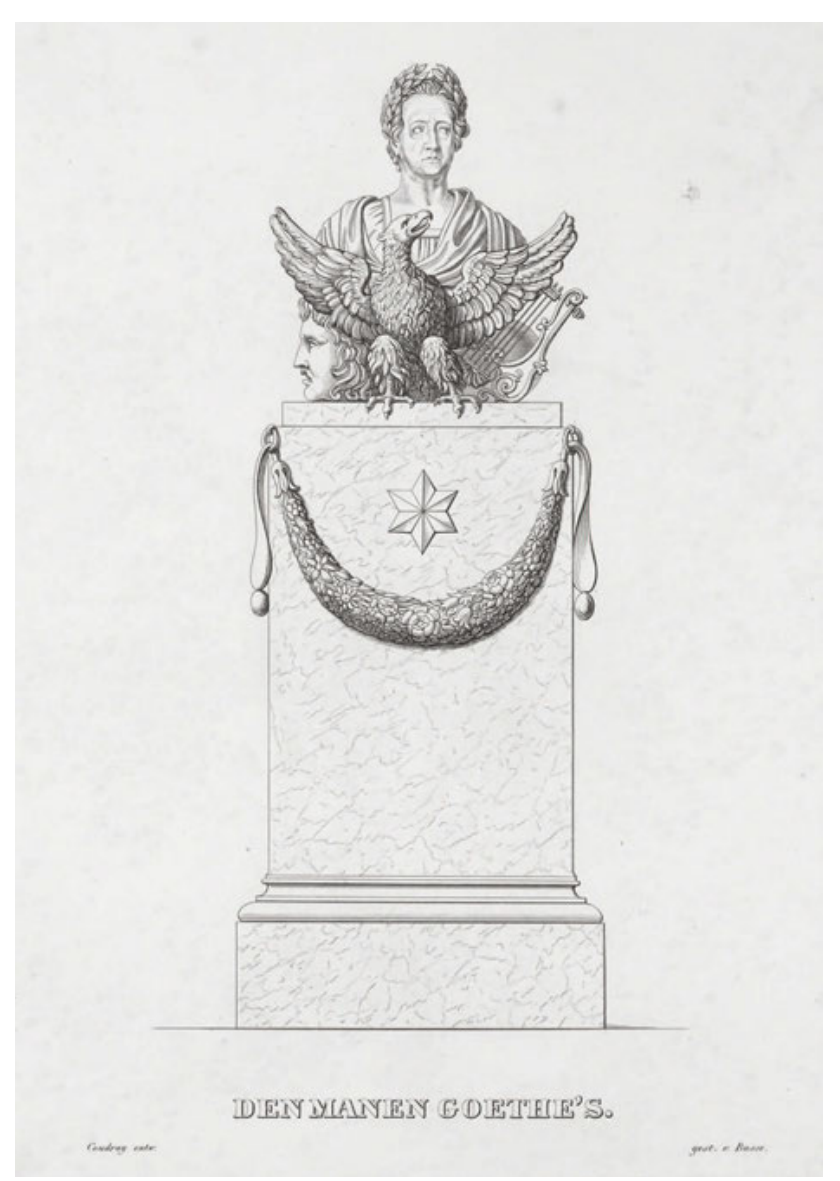

103 Georg Heinrich Busse nach Clemens Wenzeslaus Coudray, Den Manen Goethes, 1832, Kupferstich, $223 \times 303$ mm (Platte), Weimar, Klassik Stiftung Weimar, Graphische Sammlungen, Inv.-Nr. KGr/AK1589

Jahre vor seinem eigenen Tod schrieb Quandt in einem Brief an Arthur Schopenhauer, Goethe sei »ein Normalmensch [...], ein vollständiges Menschenexemplar« gewesen und jeder, der ihn betrachte, erkenne sich selbst: »Das ist der Mensch von Natur und auch ich bin ein Mensch. $\ll^{19}$ Goethe als Bild des Lebens bedurfte also der bildlichen Umsetzung - schon zeit seines Lebens. In diesem metaphorischen Zusammenhang dürfen Quandts Inszenierungen von Goethe verstanden werden.

19 Brief an Schopenhauer vom 19.11.1853, in: Schmitz/Strobel 2001, S. 243 f. S. a. Quandt 1846 (2), S. 389: »Zweierlei gehört dazu, Goethe zu ergründen: Hingebung und Selbsterkenntniß.»

20 Quandt berichtete Goethe, dass er nur für diese Aufführung seinen Badeaufenthalt in Teplitz unterbreche und zwei Tage nach Dresden komme; Brief an Goethe vom 16.8.1829, in: Schmitz/Strobel 2001, S. 62; s. a. den Geburtstagsgruß vom 28.8.1829, »tief erschüttert von den zermalmenden Eindrücken dieses unerschöpflichen Gedichts [Faust I - AR], das die höchsten Freuden und tiefsten Schmerzen der Menschheit [...] umfaßt«, in: ebd., S. 67.

21 Tieck 1841, S. 582. S. a. Jäckel 2002, S. 161-162.

22 Brief an Tieck vom 12.10.1829, in: Holtei 1864, Bd. 3, S. 82.

23 Rüfenacht 2018, SQ-1; Simson 1996, S. 177-178.

24 Siehe dazu den Brief an Schnorr vom 23.12.1820, in: Schmitz/Strobel

\section{Pläne für einen Goethe-Raum}

Als Ludwig Tieck am 27. August 1829, am Vorabend von Goethes achtzigstem Geburtstag, in Dresden den Faust aufführte, saß Quandt gerührt im Publikum. ${ }^{20}$ Einige Wochen später richtete er einen Brief an den Spielleiter, in dem er sich für dessen »Prolog zur Aufführung von Göthes Faust an Göthe's Geburtstage « bedankte. Tieck hatte eine Vorrede gedichtet, in der eine Personifikation der Poesie auf der Bühne einen panegyrischen Monolog rezitiert hatte. Er hatte geradezu ein gedichtetes Denkmal erschaffen: »Ja, diese edle Stirn, die ruhmumglänzte, / Mit ew'gem Lorbeer grün bekränzte, / das hohe Haupt, umspielt von Abendröthe: / Es ist der Musen Liebling, Deutschlands Göthe! $\ll^{21}$ Quandt war über das Gedicht beglückt, denn es habe das Publikum belehrend auf die Aufführung vorbereitet und den Dichter anschaulich in seiner ganzen Größe vorgeführt. Und so war es ihm sinnigerweise zumute, »wie es einem großen plastischen Künstler seyn muß, denn in mir gestaltete sich Göthes Bild zu einer colosalen Statue. «22 Was sich hier Quandt kolossal vor dem inneren Auge aufrichtete, besaß er selber in Form einer Büste bei sich zu Hause (Abb. 102). ${ }^{23}$ Er hatte 1821 den Berliner Bildhauer Christian Daniel Rauch mit der Erschaffung des Dichters in Marmor beauftragt. ${ }^{24}$ Vorausgegangen war ein Erlebnis in Weimar im November 1820, als er zusammen mit Goethe dessen Rauch-Bildnis betrachtet hatte.

Quandts Marmorversion war eine Wiederholung der GipsBüste aus dem Besitz Goethes (Abb. 104). Im Beisein von Karl Friedrich Schinkel und im Wettstreit mit Christian Friedrich Tieck hatte Rauch diese bei einem Treffen mit Goethe in Jena im August 1820 erschaffen. Die dabei geführten Gespräche über Kunst hatten für Goethe zu den schönsten Tagen des Jahres gezählt. ${ }^{25}$ Geradezu echohaft und doch überbietend formulierte Quandt in der posthum erschienen Schrift Meine Berührungen mit Goethe, die Betrachtung der Büste zusammen mit dem Dichter in Weimar habe zu den bedeutendsten Momenten seines Lebens gehört. Quandt bewunderte das lebendige Naturideal des Abbildes, das Rauch gezeigt hatte. ${ }^{26}$ Im Gegensatz

2001, S. 19. S. a. Wentzlaff-Eggebert 2009, S. 317, Anm. 5; Bemmann 1925, S. 9.

25 »Herr Staatsrath Schulz brachte mir drei würdige Berliner Künstler nach Jena, wo ich gegen Ende des Sommers in der gewöhnlichen Garten Wohnung mich aufhielt. [...] Die Herren Tieck und Rauch modellirten meine Büste [...]. Eine lebhafte, ja leidenschaftliche Kunstunterhaltung ergab sich dabei, und ich durfte diese Tage unter die schönsten des Jahres rechnen. « Zitiert nach: Simson 1996, S. 176. S. a. FA II.36, S. 88, 92.

26 »[...] die Natur bringt immer durch ihr höchst folgerechtes Verfahren die zufällig entstandenen Ungleichheiten der Theile in einen solchen nothwendigen Zusammenhang, daß ihre Werke stets einen übereinstimmenden Eindruck auf uns machen.« Quandt 2001 [1870], S. 237. 


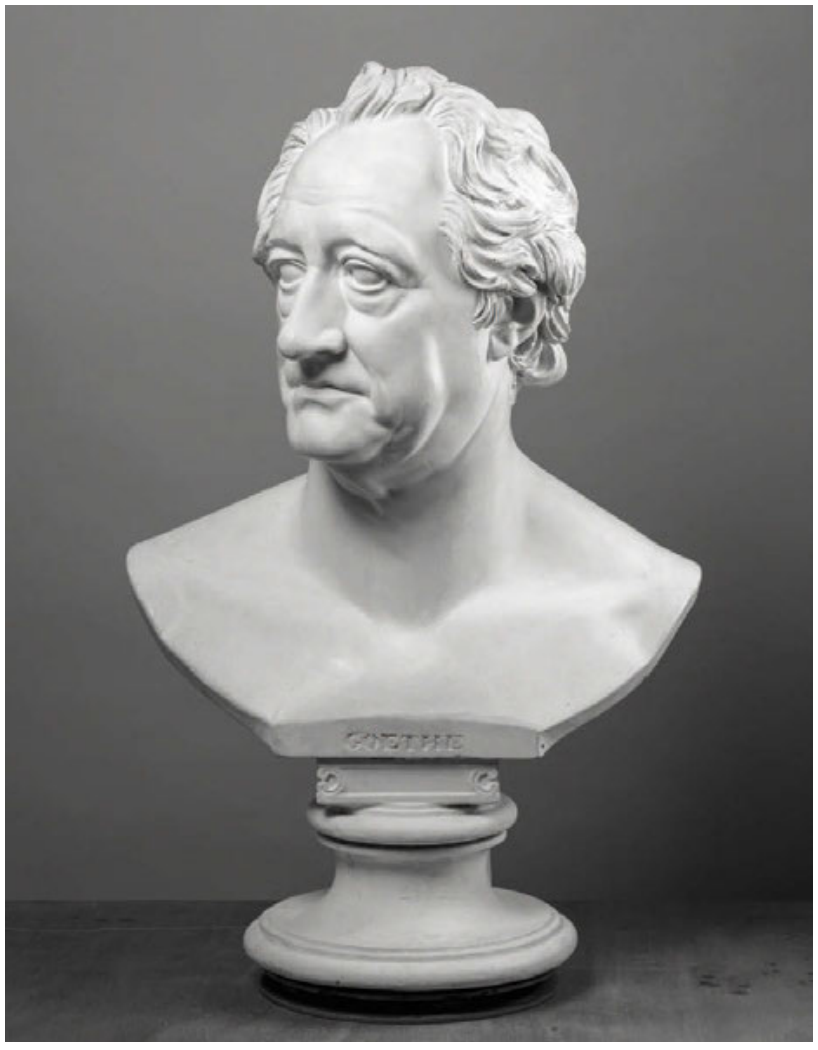

104 Christian Daniel Rauch, Johann Wolfgang von Goethe (sog. A-tempoBüste), 1820 , Gips, überstrichen, $58 \times 40 \times 26 \mathrm{~cm}$, Berlin, SMB, Alte Nationalgalerie, Inv.-Nr. RM 147

zu einem Gipsabguss nach der Natur habe der Bildhauer »den Ausdruck seines Geistes, seines Wesens, die Idee von ihm, das Ewige in ihm« dargestellt. »Dies ist der wahre Göthe!«, rief er aus und bestellte die Büste in Marmor. ${ }^{27}$

Quandt erhielt die fertige Goethe-Büste von Rauch im Mai 1823 und damit noch ein gutes Jahr vor dem Bezug der Dresdener Wohnung. ${ }^{28}$ Die Skulptur formte jedoch seine Einrichtungsentwürfe, die bis dahin noch wenig präzis waren, zu einem genauen Konzept. Einen vom Garten her zugänglichen Saal wollte er allein Goethes Bildnis widmen. Wie dieser genau aussehen sollte, schilderte er am 5. Mai 1823 Johann Heinrich

27 Die Charakterisierung der Büste als wahren Goethe äußerte Quandt 1844 (1), S. 33-35, um in seinen Vorlesungen über Ästhetik an der Dresdener Kunstakademie den Unterschied zwischen Naturnachahmung durch Kopien oder Abgüsse und wahrer Kunst zu erläutern; dasselbe erläuterte er auch anhand einer Zeus-(Jupiter-)Statue von Phidias. Dieses rhetorische Nebeneinander scheint mir bemerkenswert, zumal Rauchs Goethe-Büste gerne mit dem griechischen Gott in Verbindung gebracht wurde; Heckenbücker 2008, S. 136. Zum Auftrag an Rauch siehe Brief an Schnorr vom 23.12.1821, Auszüge in: Schmitz/ Strobel 2001, S. 19; Goethe/Rauch 2011, S. 117; Simson 1996, S. 177. S. a. Bemmann 1925, S. 9 .

28 Am 7.8.1823 schrieb Quandt an Schnorr, sein Haus in Dresden sei
Meyer, der Goethe persönlich Quandts Plan vorlegen sollte: »Zu diesem Zweck habe ich einen Gartensaal einrichten laßen, welcher durch ein Fenster über der Hauptthüre erhellt wird, so daß das Licht gedrängt auf die in der Mitte des Saals, auf einen dreyseitigen Altar gestellte, Büste fällt. Neben der Thür befinden sich zwey $\mathrm{Ni}[\mathrm{s}]$ chen in welche Candelaber kommen [...]. Die Form des Saals ist ein reiner Halbzirkel, weshalb die Decke fächerartig gemalt werden soll. Von dem Mittelpunkte nach dem Halbkreis würden sich laufende Arabesken ausbreiten u an kleinen Feldern enden, wo auf dunkelblauem Grunde, grau in grau, Scenen aus Göthens Romanzen u Anspielungen auf seine Lieder in basreliefartigen Bildern dargestellt würden. Statt des Simses wird unter der Decke ein gemalter Lorbeerkranz hinlaufen. Der Halbzirkel welchen die Rückwand bildet zerfällt in zwey Felder und einen Raum über der Ausgangsthüre. Diese Felder könnten durch steigende Arabesken eingeschlossen werden und da es vier Arabesken dazu bedarf, so veranlaßt diese Zahl auf die vier Epochen des Lebens hinzudeuten und leicht ließen sich in diese Verzierungen, wie in den Raffaelschen Arabesken Fabeln verwebt sind, Scenen aus Göthes Wahrheit und Dichtung (sic!) zu seinem Leben, einflechten. Die beyden großen Felder u das Thürstück zwischen diesen beyden, geben dem Maler Gelegenheit zur bildlichen Darstellung von Scenen aus Iphigenie, Tasso u Faust. Diese Malereyen würden bunt auf weißen Grund aufgetragen, wie die des Giulio Romano in der Villa Madama $\left[\ldots . . . \ll^{29}\right.$

Quandts Ehrensaal für Goethe sollte ein Denkmal für den idealen Menschen werden. Die Einrichtung, wie er sie im Brief an Meyer beschrieb, enthielt entsprechende Assoziationen. Folgt man Quandts Beschreibung, steht ganz am Anfang die Beleuchtung: Die Goethe-Büste sollte exakt im Licht der Sonne ruhen, der Dichter als Erleuchteter und Erleuchtender inszeniert werden. Man kann diese Präsentation als Inszenierung eines aufgeklärten Menschen lesen. Der Subtext hingegen ist apollinisch: Der Sonnengott Apoll und Gott der Musen ist dem Dichter hold. Ein Zeitgenosse schrieb bei Anblick der GoetheBüste in Quandts Haus denn auch: »Der schöne Ernst dieser Züge, die klare, sich leicht emporwölbende Stirn, von der man

vollendet und mit Kunstwerken eingerichtet, am 22.8. berichtete er vom Einzug. SLUB, Mscr. Dresd. n Inv. 15, Bd. 31, fol. $98 \mathrm{v}, 101$ r.

29 Brief an Johann Heinrich Meyer vom 5.5.1823, in: Schmitz/Strobel 2001, S. 22-24. Eine kurze Schilderung auch in einem Brief an Schnorr vom 22.8.1823, in: SLUB, Mscr. Dresd. n Inv. 15, Bd. 31, fol. $101 r$ und an Rauch vom 22.1.1824, in: Berlin, SMB, Zentralarchiv, Nachlass Rauch XI.3. Briefe von: Böttiger, 1822-1832, fol. 30r-32r. S. a. Richter 2002, S. 36; Vogel 1999, S. 192; Bemmann 1925, S. 10. Der halbrunde Saal wurde eben gerade nicht ausgeführt, wie Tausch 2010, S. 91 meint. Bei den erwähnten Goethe-Werken, die gemalt werden sollten, handelt es sich um die Dramen Iphigenie auf Tauris (1787), Torquato Tasso (1790) und Faust. Eine Tragödie (1808) sowie um Dichtung und Wahrheit (1811). 
fast annehmen möchte, daß sie ein heiterer, klar in die Welt blickender Geist sich selbst zu seinem Obdach gewölbt habe, läßt auch im Alter noch die Spur der ewigen Jugend und die Verwandtschaft mit dem Apoll erkennen. «30

Wenn er vor der Büste stand, fühlte Quandt als sonnte er sich. ${ }^{31}$ Durch die Lichtinszenierung sollte der verehrte Dichter erhöht werden. Mit Mitteln, die aus dem Sakralraum bekannt sind, unterstreichen das Kerzenlicht in zwei Nischen neben der Eingangstür genauso wie das altarartige Postament die bedeutungsvolle Aufstellung - ein Plan für einen Tempel mit Goethe als verehrtem Idol auf dem Licht-Altar, bekrönt vom Lorbeerkranz an der Decke.32 Mit dieser Inszenierung hätte Goethe bei Quandt schon zu Lebzeiten den Parnass erreicht.

Prägend für die Strukturierung des harmonischen Halbrundes des Dichterzimmers gemäß Quandts Beschreibung waren die Arabesken. Ein umfassender ästhetischer Diskurs um 1800 wertete diese als Kunstform deutlich auf. Ihr Charakter einer deutungsfreien Ornamentkunst verband sich mit einer poetischen Aufladung. ${ }^{33}$ Dieser Diskurs manifestiert sich in Quandts Plan, den vier Arabesken an den Wänden Szenen aus Goethes Dichtung und Wahrheit beizufügen, die auf die vier Lebensalter hinweisen. Unweigerlich verbindet man dieses Konzept mit Philipp Otto Runges Blättern der vier Tageszeiten, von denen Quandt eine Fassung besaß.34 Doch Runges Arabesken wurden in ihren vielschichtigen Bedeutungen zur Hieroglyphe und stießen an die Grenze der Verständlichkeit. Quandt kritisierte sie daher als »allegorisch-mystische Bilder«. Sie würden den Sinn nur andeuten, nicht aber veranschaulichen. ${ }^{35}$

30 Anonym 1825, Sp. 781. Die Verbindung von Goethe mit Apoll und ganz besonders mit der Statue des Apollo von Belvedere wurde durch die Iphigenie-Dichtung hergestellt, da sich der Dichter hier auf einen griechischen Sagenstoff eingelassen hatte. Seit Winckelmann den Apollo von Belvedere beschrieben habe, sei dieser Gott für die Deutschen typisch altgriechisch. August Wilhelm Schlegel prägte die Assoziation Goethes als strahlender Apoll, für Tieck steht der Apoll als Symbol dieses Dichters. Laut Heckenbücker wurde die Rauch-Büste Goethes dagegen eher mit Zeus in Verbindung gebracht. Heckenbücker 2008, S. 92-97, 103, 136, 176-177.

31 Quandt 2001 [1870], S. 232, sich beziehend auf Sokrates, der auf die Ähnlichkeit von Auge und Licht verweise.

32 Die Assoziationen mit Apoll wurden besonders nach Goethes Tod immer wieder bemüht; Heckenbücker 2008, S. 177-180.

33 Zusammenfassend Günter Oesterle, »Arabeske«, in: ÄGB 2010, S. 279-281; Busch 1985, S. 44-49. Siehe dazu auch Quandt 1854 (1), S. 60; Quandt 1822, S. 8-9.

34 Quandt 1853, S. 100-101; zu Runges Tageszeiten siehe Grewe 2015, S. 140-143; Busch 1985, S. 49-55.

35 Er sprach ihnen daher gleich ab, Kunstwerk zu sein; Quandt 1853, S. 101. Eine Kritik der Allegorie als abzulehnendes künstlerisches Mittel in: Quandt 1830 (1), S. 306-314. Zur Kritik an Runge siehe zusammenfassend Günter Oesterle, »Arabeske«, in: ÄGB 2010, S. 281; S. 55-56; Werner Busch erläutert Goethes zwiespältiges Verhältnis zur Arabeske besonders im Zusammenhang mit Runge und Eugen Napoleon Neureuther; Busch 1985, S. 55-68.
Wohl aus diesem Grund verband Quandt in seinem Gestaltungsplan die Arabesken mit Raffael. Er dachte dabei an Fresken der Raffael-Schule in der angeblichen Villa des Künstlers im Garten der Villa Borghese auf dem Römer Hügel Pincio (Abb. 105). ${ }^{36}$ In einem Artikel, den er 1822 über dieses Haus verfasst hatte, schrieb Quandt, der Charakter der Arabeske sei mit dem Märchen vergleichbar. Diese Kunstformen reizten »den Scharfsinn gleichsam neckend «. Der Betrachter sei versucht, in einer spielerischen und scherzhaften Darstellungsform einen tieferen Sinn zu suchen, wo gar keiner zu finden sei. Dabei habe die Arabeske als Verzierungsform nur Harmonie an einem bestimmten Ort zu erzeugen. ${ }^{37}$

Der Bezug auf den Künstlergenius der Renaissance ist die herausragende Referenz für Quandts erste Goethe-Inszenierung. In seinem Aufsatz über die Raffael-Villa schrieb Quandt: »So muß Raffael Sanzio’s Gartenhaus für jeden Fühlenden und Denkenden von der größten Wichtigkeit seyn, weil wir hier die Spuren, nicht eines untergegangenen Daseyns, sondern eines unsterblichen Geistes in seinen Werken, Spuren von Raffaels innerm Leben in den heitersten Farben und Bildern erblicken. $\ll^{8}$ Quandt führte hier Raffaels künstlerische Arbeit mit dessen Künstlerbiographie zusammen - ein Aspekt, der in seinem Goetheraum ebenfalls erkennbar wird: Vier Szenen aus Goethes autobiographischem Werk Dichtung und Wahrheit sollten in die Arabesken verwoben werden.

Für die spätere Präsentation der Goethe-Büste spielt die Verbindung des italienischen Raffaels mit dem deutschen Dichter eine eminent wichtige Rolle. Diese Analogie geht zudem noch

36 Auch Villa Nelli oder Olgiati. Kat. Göttingen 2015, S. 176-179; Weber 1997, S. 57; Schreiner 1973, S. 271-272. Das Haus wurde während der französischen Belagerung 1849 zerstört.

37 Quandt 1822, S. 6-10: »Es würde schwer, vielleicht unmöglich seyn, alle diese in einander spielenden, sich umrankenden, in Arabeskenstyl angeordneten Verzierungen [der Villa des Raffael] zu deuten; denn es ist ja eben dieß der Charakter der Arabeske, wie der des Mährchens unter den poetischen Producten, daß beide den Scharfsinn gleichsam neckend reizen, eine Bedeutung im bloßen Spiel und Scherz der Phantasie zu suchen. [...] Doch noch tausend andere Auslegungen wären im Einzeln möglich, und wer könnte sagen; diese ist die richtige, da die Arabeske kein Bild von etwas Wirklichem, nicht Andeutung eines in Worte zu fassenden Satzes, wie die Allegorie noch Versinnlichung eines Begriffs, wie das Symbol, sondern ein heiteres, freies Spiel mit Gestalten, Ausschmückung eines Raumes ist; jede Verzierung mit der Bestimmung des Orts, in welchem sie angebracht wird, nur in einer allgemeinen Harmonie stehen muß.«Quandt verwirft zudem die Ansicht, Raffael habe die Arabeske erfunden. Er habe sie vielmehr den antiken Thermen des Titus entnommen, welche man angeblich verschüttet habe, um Raffael als Erfinder und nicht Nachahmer der Arabeske darzustellen. Schließlich verweist er sogar auf das Verhältnis von Benutzung und Nachahmung von verschiedenen Vorbildern bei Raffael selbst.

38 Quandt 1822, S. 3. S. a. Weber 1997, S. 57. Die Fresken aus der Villa Raffaels wurden 1834 abgelöst und befinden sich in der Villa Borghese. Sie wurden mit dem Liebesleben des Künstlers in Verbindung gebracht, da sie Liebeslegenden darstellen. S. a. Schreiner 1973, S. 272. 


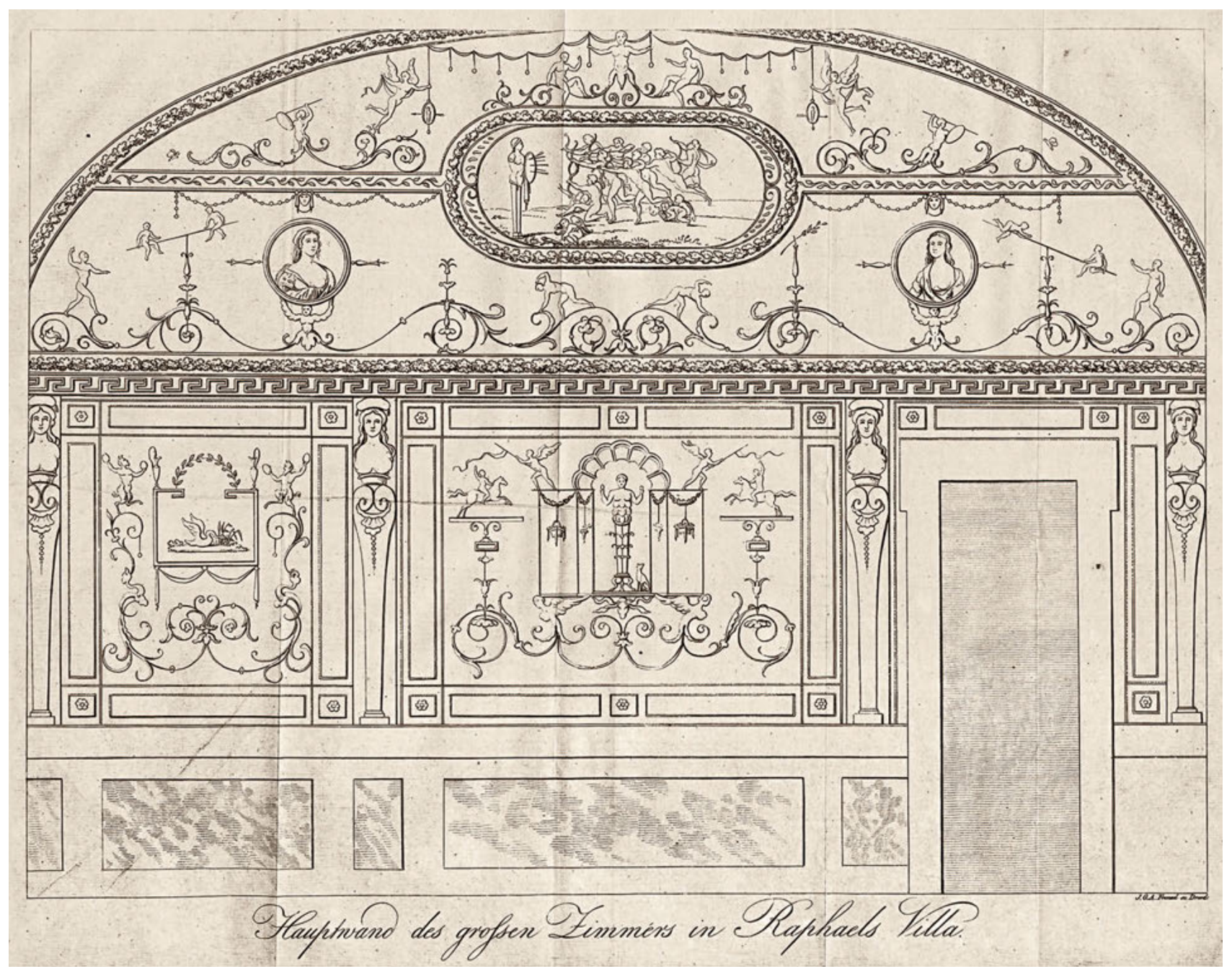

105 »Hauptwand des großen Zimmers in Raphaels Villa«, in: Die Muse. Monatsschrift für Freunde der Poesie und der mit ihr verschwisterten Künste, hrsg. v. Friedrich Kind, 1822, Jg. 1, Nr. 1, Tafel II

weiter. Für die Darstellung dreier Szenen aus Goethes Dramen Iphigenie, Faust und Tasso wollte Quandt eine stilistische Verbindung mit der Innenausstattung der Villa Madama herstellen, die für die Medici-Familie ab 1516 bei Raffael zur Planung in Auftrag gegeben worden war. Die legendäre Innenausstattung der mit Antiken, komplexen Stuckaturen und - für Quandt hier relevant - Grotesken umrahmten Wandbildern ausgestatteten antikischen Villa wurde im frühen 19. Jahrhundert noch allein Raffaels Schüler Giulio Romano zugeschrieben. ${ }^{39}$

Mit dem Hinweis auf die Dramen-Bilder zwischen den Arabesken und den Lebensaltern Goethes erreicht Quandts ekphrastische Beschreibung des Ehrensaales für Goethe ihren assoziativen Höhepunkt. Iphigenie steht für die Antike. Dieses Schauspiel charakterisiert sich durch die Humanität der Hauptfigur. Faust, der Suchende - »Zu groß, ein Mensch, zu klein, ein Gott zu werden $\ll^{40}-$ kann man dem deutschen Mittelalter zuordnen und Tasso als verkanntes Genie unter den Augen des unverständigen Protektors entspringt der italienischen Renaissance. Verfasser dieser Werke, die für Antike, Mittelalter und Renaissance stehen, ist Goethe. Der zum Zeitpunkt von Quandts Entwurf noch lebende Dichter vereinigt in seinem Werk Geschichte und Gegenwart.
39 Frommel 1987, S. 311-322. Die Bauarbeiten wurden ab 1518 unter der Leitung von Antonio da Sangallo d. J. ausgeführt, der bei der Planung mitwirkte. Nur das Sockelgeschoss entspringt Raffaels Entwürfen. Giulio Romano arbeitete nach Raffaels Tod 1521 mit Sangallo zusammen, vor allem in der Innenausstattung, wurde aber aufgrund von
Zwistigkeiten mit dem ebenfalls beteiligten Giovanni da Udine durch Baldassare Peruzzi abgelöst. Einige Raumausstattungen dürften dennoch auf ihn zurückgehen. Ebd., S. 319. Für Beispiele der Grotesken siehe die Abbildungen ebd., S. 352-354.

40 Tieck 1841, S. 590. 
Indem Quandts Bildprogramm Goethes historische Dramen mit dessen Biographie aus Dichtung und Wahrheit verbinden sollte, wurde der große Weimarer Dichter zur Metapher des Menschen, der Menschlichkeit und der Menschheitsgeschichte. Nach Goethes Tod lieferte Quandt den Hinweis zu dieser Interpretation: »Göthe[,] Kind, Jüngling, Mann und Greis, stellt das Menschenleben in seinem Normalzustande dar. Er war ein vollständiger Mensch [...]. Alle Leiden u Freuden der Menschheit fühlte sein großes Herz u schuf aus diesem edelsten Stoffe, unsterbliche Kunstwerke, in welchen die Welt sich spiegelt u im Gewande der Zeit, das Ewige erscheint. «t1

Durchgeführt wurde dieses assoziationsreiche Programm leider nicht. Eine Antwort auf Quandts Beschreibung ist weder von Meyer noch von Goethe bekannt. Drei Monate nach dem Brief an Meyer hatte Quandt kaum noch Hoffnung, dass der Saal bemalt würde. Es fehlte ihm in erster Linie der Künstler, ein zeitgenössischer Raffael, der die Freskenmalerei zur Umsetzung des gescheiten Programms beherrscht hätte. Der einzige in Dresden, dem er dies zutraute, war Carl Vogel von Vogelstein. Dieser bemalte zu dem Zeitpunkt die Wände der Pillnitzer Schlosskapelle. Doch Vogel, so der Verdacht Quandts, schien sich zu gut für einen Privatauftrag, seit er für den sächsischen König malte und würde »Göthen für ein Weltkind und es darum für eine Sünde halten, etwas zu dessen Ehre zu thun.« ${ }^{2}$ Die fehlende Möglichkeit, einen al fresco bemalten Raum in Auftrag zu geben, schien einer der Hauptgründe zu sein, weswegen der Ehrensaal für Goethe nicht vollendet wurde. Zu lange hätte es gedauert, bis sich überhaupt eine Möglichkeit dazu ergeben hätte, bemerkte er noch $1831 .{ }^{43}$

\section{Ein erster Goethe-Raum in Dresden}

So vereinfachte Quandt die programmatische Präsentation der Goethe-Büste. Einige Elemente wie der ideologisch-ästhe-

41 Quandt an Louise Seidler, 1.4.1832. in: Schmitz/Strobel 2001, S. 165 42 Brief an Schnorr vom 22.8.1823, in: SLUB, Mscr. Dresd. n Inv. 15, Bd. 31 , fol. 101r. Richter 2002, S. 36; Neidhardt 1976, S. 237. Zu Vogel und Pillnitz siehe Welich 1996, S. 112-114.

43 Brief an Schnorr vom 12.9.1831, SLUB, Mscr. Dresd. n Inv. 15, Bd. 31, fol. 181r-182v. S. a. Bertsch 2011, S. 259-260; Maaz 2002, S. 78.

44 Kat. Quandt 1824, S. 3. S. a. Anonym 1825, »Des Hrn. v. Quandt Kunstsammlung«, Sp. 781: »In dem ersten dieser Zimmer blickt dem Eintretenden Göthe's Büste von Rauch in cararischem Marmor gearbeitet, bedeutsam entgegen. [...] In demselben Zimmer finden wir eine sehr brave Kreidezeichnung von Raphaels Galatea, in der Größe des Originals von Suter gearbeitet. « Sutters Kopie nach: Raffael, Triumph der Galatea, 1512-20, Fresko, Rom, Villa Farnesina. Der Auftrag ist bei Schnorr 1886, S. 445, 451, 454-455, 461, 474 mehrfach erwähnt. Joseph Sutter war einer der Mitbegründer des Lukasbundes in Rom. Siehe Vignau-Wilberg 2011, S. 9-12. tische Zusammenhang zwischen Raffael und Goethe sollten zwar erhalten bleiben, doch unterschied sich das Resultat in der Tat frappant vom geschilderten Plan von 1823. Der Katalog von 1824 beschreibt die Inszenierung. Im ersten Zimmer der Gemäldesammlung sind Rauchs Skulptur und eine verschollene Kreidezeichnung in Originalgröße nach Raffaels Galatea in der Villa Farnesina von Joseph Sutter verzeichnet. ${ }^{44}$ Die marmorne Büste hob sich von einer roten Tapete ab, mit der die Wände bespannt waren. Der Neffe Alfred Meissner schildert die Situation: »Hinten, in einem unermeßlichen Bibliothekszimmer, seinem Sanctuar, hauste mein Onkel unter Tausenden von Büchern. Man kam, wenn man zu ihm wollte, an einer auf hohem Postamente ragenden Büste Goethe's vorüber [...]. Sie hatte hier eine symbolische Bedeutung. «45

Das Zimmer mit Goethes Büste lag zwischen einer auch für Besucher zugänglichen Raumfolge mit Gemälden und der Hausbibliothek. ${ }^{46}$ Die Inszenierung des Dichters fungierte somit als Schnittstelle zwischen privatem und öffentlichem Bereich. Vor dem Eintritt in sein Arbeitszimmer konnte sich Quandt vom Bildnis inspirieren lassen, wie er 1828 an Goethe schrieb: »[...] in vielen Fällen meines Lebens, wenn ich etwas bey mir selbst recht ernst erwog, so schaute ich Ew Excellenz lebensvolles Marmorbild an, welches ich von Rauch gearbeitet, zu besitzen glücklich bin, und oft war es, als gäbe eine Orakelstimme, dem Gemüthe nur vernehmbar, mir Antwort, immer aber fühlte ich mich dann innig erheitert und gestärkt. « ${ }^{77}$ In die andere Richtung aber trat man in die Gemäldesammlung ein und die Inszenierung erhielt eine andere Konnotation. Hier war sie Einladung und Programm zum beginnenden Sammlungsrundgang.

Als Sammler von Kunst übernahm Quandt eine gesellschaftliche Verantwortung. Er verstand sich als »Verwahrer eines Gemeingutes $\ll^{4}{ }^{4}$ Kunst sollte die Gesellschaft bilden. Damit ließen sich, so glaubte er, die Probleme der Gesellschaft im Staat lösen. Kunst könne die Bevölkerung zu »wahrer Cultur« führen. Eine

45 Meissner 1884, Bd. 1, S. 17. Zur Raumgestaltung: Brief von Quandt an Rauch vom 22.1.1824, fol. 3or-32r, in: Berlin, SMB, Zentralarchiv, Nachlass Rauch XI.3. Briefe von: Böttiger, 1822-1832. »[...] wo sie [die Büste $-A R]$ sich, gegen den hochrothen Hintergrund der Tapeten, auch vortrefflich ausnimmt."

46 Brief an Schnorr vom 22.7.1833, in: Mscr. Dresd. n Inv. 15, Bd. 31, fol. 186v: »lch habe in meinem Arbeitszimmer, solche Bilder aufgehangen, welche außer ihrem Kunstwerk [eine Darstellung des Todes Kaiser Barbarossas - AR], noch eine nähere Beziehung auf mich selbst haben. [...] Es kommen an dieser Wand Andenken von Personen zusammen, welche im Leben einander nicht begegnen möchten, wie z. B. Göthe u Rumohr u Sie selbst."

47 Brief an Goethe vom 6.12.1828, in: Schmitz/Strobel 2001, S. 43. 48 Kat. Quandt 1853, S. 1 
seiner Aufgaben war es also, diejenigen zu fördern, die Kunst herstellten: die Künstler. Denn als Erschaffer von Kunst übernahmen sie eine eminent wichtige Rolle in der Gesellschaft. ${ }^{9}$

Ausgehend von diesem Kunstideal war Quandt immer auf der Suche nach dem idealen Künstler. Unter den lebenden Zeitgenossen erfüllte Goethe diese Kriterien. Als Dichter diente er der Dichtkunst und diese war universell..$^{\circ \circ}$ Dem Gedicht attestierte Quandt wie auch dem Werk der bildenden Kunst Sinnlichkeit:»[...] ein Gedicht [ist] also eine innere Anschauung, welche sinnlich wahrnehmbar ausgeprägt ist und daher der Dichter ein Künstler. $\ll^{51}$ Mit solchen Aussagen rezipierte Quandt verbreitetes Gedankengut der Romantik, übernahm doch gerade die Poesie als Meta-Kunst die Rolle einer »Leitkunst «.52 Warum aber war Goethe für Quandt ein idealer Künstler? In seinen ästhetischen Anschauungen kam Quandt zum Schluss, dass der Gedanke als Grundbedingung der schönen Kunst eng mit der Sprache zusammenhängt. »Denken und Sprechen ist dem Menschengeist innig verbunden. [...] Die Sprache ist daher als eine Offenbarung des höchsten Geistes zu betrachten. ${ }^{53}$ Goethe war ganz besonders sprachlich befähigt: »Die Welt umher drang mächtig in ihn ein und ging gestaltet aus ihm in wunderbarer Schönheit heraus. «\$4 Der Weimarer Dichter vermochte mittels der Sprache seine Gedanken darzustellen. Goethes Kunst war in diesem Sinn sprachliche Manifestation dessen, was Quandt in Bezug auf die bildenden Künste als Gedanken in anschaulicher Form bezeichnete. 55 Damit definiert Quandts Kunstverständnis die Vorbildrolle Goethes. Seine Büste wurde zur Metapher seines Kunstideals am Eingang der Sammlung.

Eine ähnliche Rolle ist der Kreidezeichnung nach Raffaels Galatea in der Villa Farnesina in Rom zuzuschreiben, die in einem kommunikativen Bezug zu Goethes Büste stand. Über Raffael äußerte sich Quandt in einer Beschreibung der Sixtinischen Madonna in der Dresdener Gemäldegalerie folgendermaßen: »Sie können die Begriffe, die Ihnen dies Bild darstellt, einander logisch, als einer Sphäre der Idee der Menschheit angehörend,

49 Quandt 1826 (1), S. 307; Quandt 1857, S. 1133-1134.

50 Quandt 1830 (1), S. 316

51 Quandt 1830 (1), S. 177.

52 Scholl 2015, S. 93-101, hier S. 98

53 Quandt 1830 (1), S. 182-183.

54 Quandt 2001 [1870], S. 230.

55 Siehe hierzu Quandt 1830 (1), wo er Kunst als Gedanke in anschaulicher Form mit dem Schönheitsbegriff verbindet, besonders in folgenden Briefen: Im dritten ist die Rede von drei Klassen der Schönheit: Einheit in der Mannigfaltigkeit, Gefallen um ihrer selbst willen und Vollkommenheit. Im fünften Brief heisst es: »Schönheit ist das Vernunftgemäße in sinnenfälliger Form «. Im elften Brief wird der Künstler aufgefordert, Schönheit darzustellen, ebenso im 16. Brief: »Der Künstler muss [...] nach Schönheit streben, jedes Kunstwerk muss ideal seyn«. Der 24. Brief erörtert den Nutzen der Kunst.

56 Quandt 1844 (1), S. 23-24. Quandt war etwas enttäuscht, als er entdeckte, dass Raffael die Engel später auf die Wolken aufgesetzt hatte. beiordnen [...]: Das Kind an der passiven Empfänglichkeit, die Jungfrau an der hohen Anmuth, den Mann [Papst Sixtus - AR] an der Festigkeit, das Weib [die heilige Barbara - AR] an der erhabnen Liebe. Sie können auch logisch diese Begriffe [...] in eine höhere Einheit, die Idee der Menschheit aufnehmen [...]. $\kappa^{5^{6}}$ Wie Goethe war auch Raffael ganz besonders befähigt, große Gedanken in seine Kunstwerke einzuarbeiten. Zur Vermittlung dieser inventio genügte eine Kopie. ${ }^{57}$ Dem eintretenden Betrachter wurde somit auch Raffael als Vorbild zur Erreichung des Kunstideals anempfohlen.

Doch in der Gegenüberstellung von Goethe und Raffael kann noch eine weitere Bedeutungsebene festgestellt werden: da beziehen sich eine nördliche und südliche Kunstauffassung aufeinander. Dieser Vergleich zweier Kunstrichtungen entspringt einem Bedürfnis der Zeit, die deutsch-niederländische Kunst gegenüber der italienischen aufzuwerten. Gerade in der Dresdener Gemäldegalerie lässt sich in der ersten Hälfte des 19. Jahrhunderts beobachten, wie die nördliche Kunst durch veränderte Präsentation aufgewertet wird. An den Neuhängungen der 183oer und frühen 1840er Jahre war Quandt als Mitglied der Galeriekommission mitbeteiligt. Auch in seiner Sammlung verdeutlicht sich dieser Ausgleich in der Präsentation deutscher, niederländischer und italienischer Kunst in denselben Räumlichkeiten, die er zum Teil mit zeitgenössischen Künstlern kombinierte.

Warum es gerade Goethe und Raffael waren, die den Wettstreit der Künste am Anfang von Quandts Sammlungsrundgang zu einem gleichberechtigten Nebeneinander führen konnten, erklärte Quandt im Begleiter durch die Gemälde-Säle von 1856. Dort löste er die beiden Künstler vom Stilbegriff. Stil sei nur eine eigentümliche »Schreibart« des einzelnen Künstlers. Bei Raffael und Goethe trete er in den Hintergrund: »der große Künstler beherrscht sich und seinen Gegenstand, und so kann man von Raffael wie von Goethe sagen, dass darin, was sie schaffen, kein Styl bemerkbar ist [...], dass sie unbefangen und universell sind..$\aleph^{8}$ In der Inszenierung von Raffael und Goethe
»Ich gestehe, dass diese Entdeckung mir nicht lieb ist: denn sie stört meinen Glauben, dieses Bild sei in seiner Gesammtheit, als himmlische Erscheinung, aus Raffael's Phantasie hervorgetreten.« Zitiert nach Weber 1997, S. 60. S. a. die Beschreibung der Sixtinischen Madonna in: Quandt 1856, S. 83-85. Zu Quandt und die Restaurierung der Sixtinischen Madonna siehe Schölzel 2005 (1), S. 98, 100, 102.

57 »Gute Copieen sind wenigstens ein Ersatz für Originale [...].« Quandt 1842, S. 9. S. a. Anonym 1825, Sp. 781: »Doch erkennst Du den Raphael auffallend in den edeln Zügen des Geniuskopfs wieder, welcher unten an der Muschel zieht.

58 Quandt 1856, S. 54. Stil sei durchaus eine »beifallswürdige Eigenschaft«, sofern sie eine »große Lebensansicht« habe und über dem Niederen und Kleinlichen stehe. Der Charakter eines Künstlers zeige sich in seinem Stil. Der ideale Künstler aber überführe Gedanke und Erscheinung als Einheit ins Kunstwerk. Dadurch stehe er über dem Stil und das Hervortreten des Künstlercharakters im Bild trete in den Hintergrund; Quandt 1844 (1), S. 78-79. 
am Eingang der Gemäldesammlung zeigen sich daher die ganz großen Vorbilder der Kunst. Unabhängig von Nation und Gattung leuchtet Raffael aus der Renaissance in die Gegenwart, Goethe ist der Stern der Jetztzeit.

Mit der Gegenüberstellung von Goethe und Raffael konnte Quandt Vergangenheit und Gegenwart über die Grenzen künstlerischer Gattungen hinweg miteinander verbinden. Poesie und Malerei reichten sich die Hand. Durch Rauchs Büste präsentierte sich selbst die Skulptur als Teil dieser Kunstauffassung. Die Granitsäule, auf dem die Marmorbüste stand, unterstrich zudem auf der materiellen Ebene das Zusammengehen nördlicher Festigkeit und südlicher Lieblichkeit. ${ }^{99}$

\section{In Szene gesetzt: Goethe in Dittersbach}

Die bedeutende Rolle von Goethe als Vorbild lässt sich in einem Freskenprojekt zu Ehren des Dichters weiterverfolgen. Auf seinem Rittergut in Dittersbach, das er 1830 gekauft hatte, plante Quandt den Bau eines Belvedere auf dem benachbarten Hügel Schönhöhe. Gottfried Sempers Vorgänger, der Professor für Baukunst in Dresden Joseph Thürmer, führte es 1831-33 im Rundbogenstil aus (Abb. 106). Die Goethe-Fresken malte Carl Gottlieb Peschel in den Jahren 1836-38 (vgl. Abb. 111-116). Nach Thürmers Tod 1833 entwarf Semper die dekorative Architekturmalerei, die Peschels Fresken begleitete. ${ }^{60}$

Der Kauf des Rittergutes fiel noch in die letzten Lebensjahre Goethes. Dieser nahm regen Anteil daran. Er bat ihn um Ansichten der Gegend, damit er Quandt »von Zeit zu Zeit in Gedanken besuchen « könne. ${ }^{61}$ Der Dittersbacher Gutsbesitzer war überglücklich über diese Anfrage und gab zwei Aquarelle in Auftrag (vgl. Abb. 8-9). ${ }^{62}$ Als er die Veduten von Dittersbach im Dezember 1831 schließlich abschicken konnte, war er höchst unzufrieden mit deren Gestaltung. Er sah seinen Anspruch nicht erfüllt, demgemäß der Landschaftsmaler das Naturerleb-

59 Quandt bat Rauch persönlich um eine Marmorsäule. Der Bildhauer schlug ihm den »vaterländischen « Granit vor. Brief von Quandt an Rauch vom 22.1.1824, in: Berlin, SMB, Zentralarchiv, Nachlass Rauch XI.3. Briefe von: Böttiger, 1822-1832, fol. 30r-32r. Brief von Rauch an Quandt vom 25.3.1824, in: Dresden, SLUB, Mscr. Dresd. App. 70.

60 Da das Schloss Dittersbach und dessen Park- und Landschaftsgestaltung mehrfach Diskussion in der wissenschaftlichen Literatur war, sollen hier nur spezifische Fragestellungen zur Inszenierung Goethes zum Ausdruck kommen. Eine kunsthistorische Einordnung von Bauten und Fresken werden nur da vorgenommen, wo es aufgrund der Argumentation nötig wird. Weiterführende Literatur: Bertsch 2011, S. 260261; Tausch 2010, S. 89-97; Winzeler 2007, S. 192-193; Laudel 2003, Kat. Nr. 23, S. 178-179; Heinrich 2002, S. 43-56; Maaz 2002, S. 73-92; Glaser 2002, S. 70-72; Vogel 1999, S. 192-195; Magirius 1994, S. 483; Maaz 1987 (1), S. 44-66; Maaz 1987 (2), S. 30-42; Maaz 1986, S. 19-28; Bemmann 1925, S. 25-34; Seidemann 1860, S. 166-168; Raczyński 1836-1841, Bd. 3, S. 220. Quandt veröffentlichte seine Reden zur Grundsteinlegung und

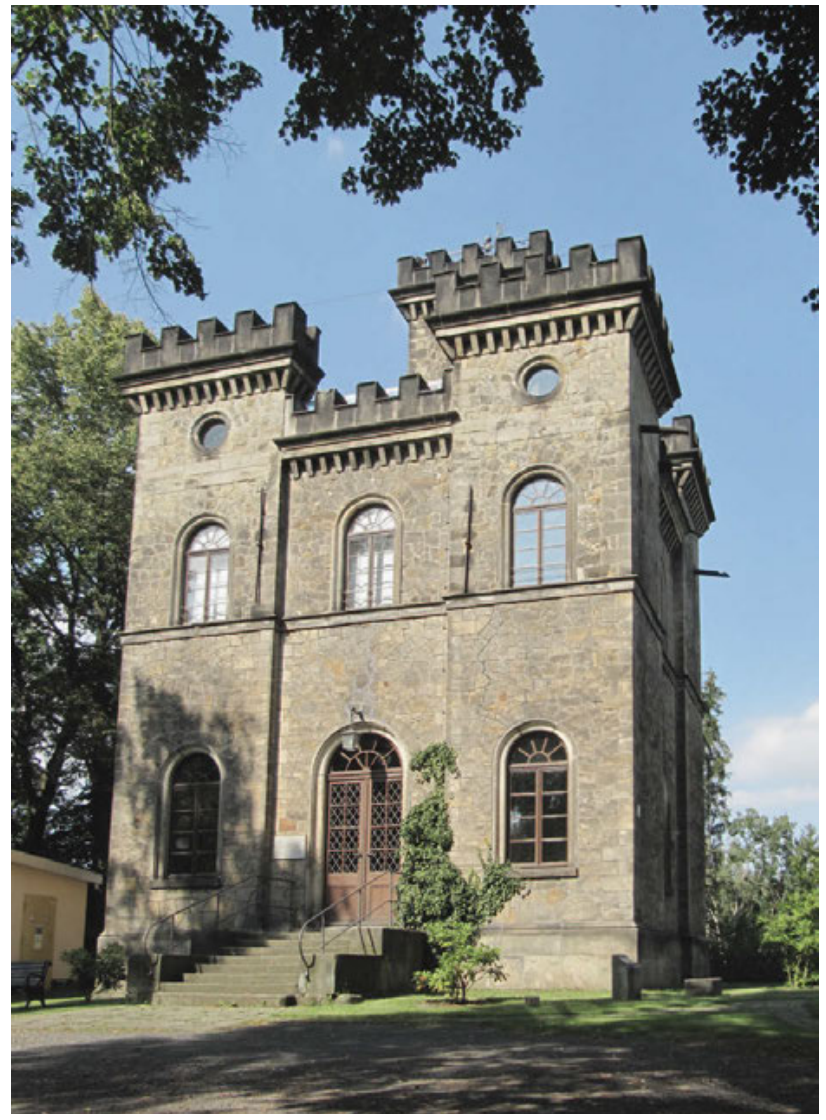

106 Joseph Thürmer, Belvedere, 1831-1833, Dittersbach, Schönhöhe

nis darstellen solle. ${ }^{63}$ Goethe reagierte in einer Art, welche die Unterschiede in den Kunstansichten der beiden Kenner zeigt: »Ew: Hochwohlgeboren von den herrlichsten Kunstwerken umgeben, [... fühlen sich freylich zu den höchsten Forderungen berechtigt, indessen wir andern uns schon mit dem begnügen, was ein wackerer Künstler geleistet hat. ${ }^{64}$ Dem Dichter gefielen die Ansichten in ihrer »Sorgfalt, Klarheit und Reinlichkeit« sehr gut. Einen Monat vor seinem Tod bat er Quandt noch um

Einweihung des Belvedere; Quandt 1840 (1), S. 3-11; Quandt 1838 (1), S. 253 .

61 Brief an Quandt vom 10.10.1831, in: Schmitz/Strobel 2001, S. 141.

62 Er beschrieb die Gegend schon einmal schriftlich im Brief an Goethe vom 6.11.1831, in: Schmitz/Strobel 2001, S. 142-146.

63 Brief an Goethe vom 8.12.1831, in: Schmitz/Strobel 2001, S. 150. Zudem bemerkte er schalkhaft, er könnte dem Künstler einen Prozess anhängen, weil dieser ihn als derart »traurige Gestalt« zu Pferd dargestellt habe. Brief an Goethe vom 11.12.1831, in: ebd., S. 151.

64 Brief an Quandt vom 18.12.1831, in: Schmitz/Strobel 2001, S. 152. Quandt hatte diese Meinungsdifferenz erkannt, als er in Meine Berührungen mit Goethe schrieb, »daß das [...] eine verdiente Zurechtweisung meiner transcendenten Kunstansichten sein sollte.«Quandt 2001 [1870], S. 239. Die Differenzen in der Landschaftsmalerei wurden wenige Monate zuvor offensichtlich, als Goethe die Aufnahme von Landschaften Friedrich Prellers d. Ä. durch den Sächsischen Kunstverein wünschte. Ebd., S. XXXII, 125, 130, 135-136, 313-314. 


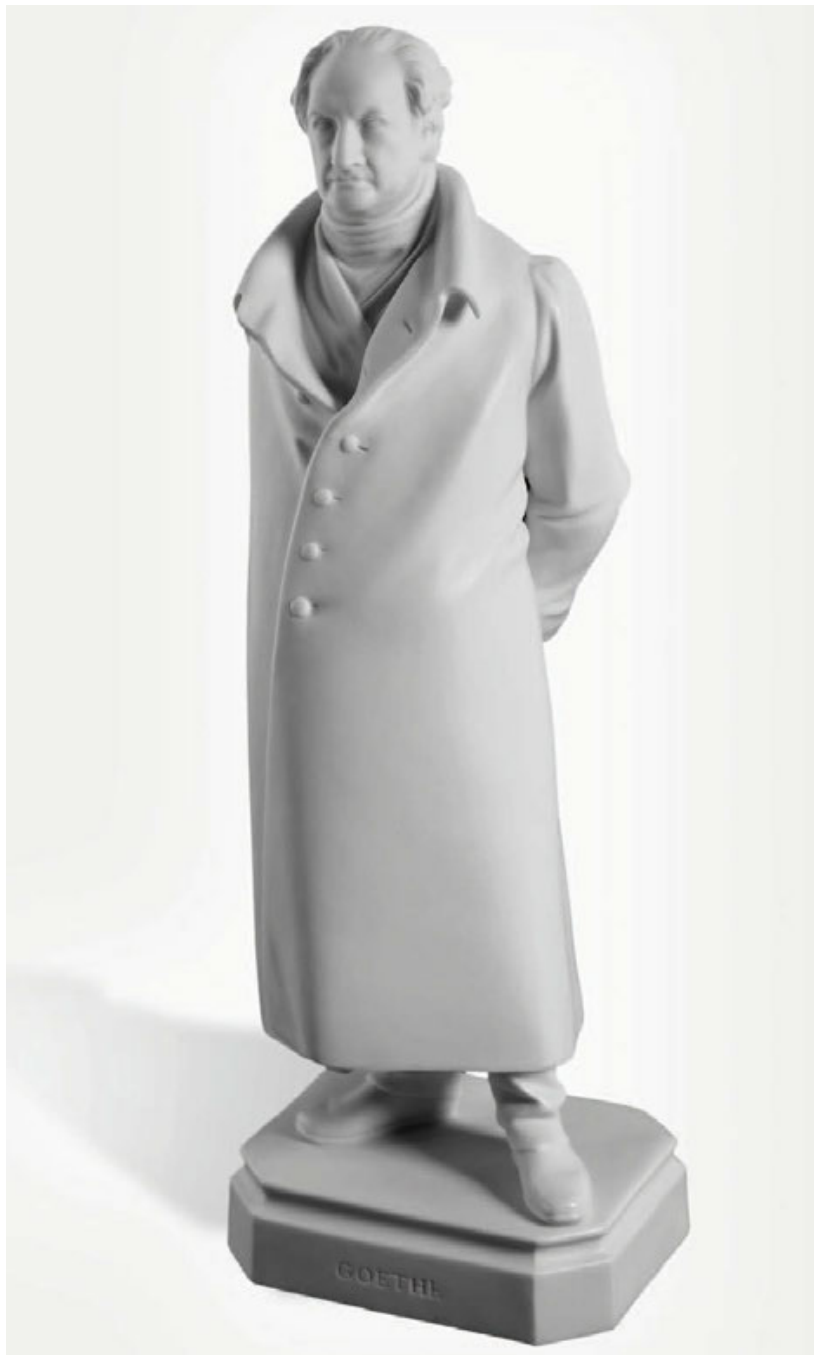

107 Unbekannt nach Christian Daniel Rauch, Goethe im Hausrock, um 1830, Porzellan, H. 29,8 cm, Meißen, Porzellan-Stiftung

65 Brief vom 27.2.1832, in: Schmitz/Strobel 2001, S. 159 und Brief von Quandt an den Weimarer Bibliothekar Johann Georg Keil vom 7.3.1832, in: SLUB, Mscr. Dresd. App. 393, Nr. 2g: »lch würde nicht über diese Erscheinung erschrecken, da er mir sie als noch beÿ seinem Leben sich ereignend, $\mathrm{u}$ als ein Lebens $\mathrm{u}$ Liebeszeichen ankündigt.« Quandt hatte dem Brief vom 6.11.1831 eine Versteinerung beigelegt und inn darauf aufmerksam gemacht, dass ihn vor allem Vulkanisten besuchten. Er wusste, dass Goethe den Neptunisten anhing, weswegen diese Stelle auch die implizite Darstellung seiner eigenen Meinung darstellt. Diese Meinungsdifferenz in geognostischen Fragen griff er in seiner Schrift Meine Berührungen mit Goethe noch einmal auf. Es handelt sich hierbei um ein kleines Beispiel, welches zeigt, dass sich Quandts Verehrung nicht in epigonenhafter Angleichung seiner Vorstellungen an diejenigen des Dichters ausdrückte; Schmitz/Strobel 2001, S. 145-146, 239-240, 317, 319. Zur geologischen Beschaffenheit der Gegend siehe Palm 2008, S. 72-76.

66 Das Turmschlösschen als Goethe-Denkmal und -Tempel bei: Schmitz/ Strobel 2001, S. XL-XLI; Maaz 2002, S. 90-91; 1987a, S. 65; Maaz 1987 (2), S. 30-42; Bemmann 1925, S. 40.

67 Goethe $1827-1842$, Bd. 44, S. 39-40. Zu dieser Schrift siehe auch Selbmann 1988, S. 46-47.

68 Ein Gipsabguss nach Rauchs erster Goethe-Büste, die heute im Fres- die Zusendung von Versteinerungen, sollten sich welche im Elbsandstein von Schönhöhe finden. Er ergötzte Quandt mit der Aussage, er spuke wohl in Dittersbach herum, so oft sei er in Gedanken dort am Spazieren. ${ }^{65}$

Dieses letzte Lebenszeichen des Weimarer Dichters fiel in die Zeit der Ausgestaltung des Rittergutes und des Turmschlösschens. Der Zeitpunkt von Goethes Tod lässt daher vermuten, dass Quandt dem Dichter ein Ehrendenkmal setzen wollte. Diese in der Forschung mehrfach diskutierte Sichtweise wird hier einer Neubeurteilung unterzogen. ${ }^{66}$

Goethe selbst hatte 1804 einen kurzen Text zur Denkmalfrage geschrieben, der 1833 in der Ausgabe letzter Hand erschien: »Das beste Monument des Menschen aber ist der Mensch. Eine gute Büste in Marmor ist mehr werth als alles Architektonische, was man jemanden zu Ehren und Andenken aufstellen kann. $\ll^{67}$ Goethe wollte mit dem Denkmal die Erinnerung an einen Menschen garantieren. Quandt als Kenner von Goethes Schriften wird sich besonders mit dem ersten Teil der Aussage identifiziert haben: dass der Mensch selbst das beste Denkmal sei.

Eine Goethe-Büste, wie er sie im Dresdener Stadthaus präsentiert hatte, befand sich zwar nie im Turm auf Schönhöhe. ${ }^{68}$ Dahingegen besaß er in seinem Dittersbacher Herrenhaus eine Version von Rauchs Statuette Goethe im Hausrock (Abb. 107) in Biskuitporzellan. Darüber schrieb er: »Einstweilen steht Göthe hier in Dittersbach in Porzellan vor mir u gewiß ist noch nie in diesem Stoffe eine edlere Gestalt gesehen worden, in welchem man sonst nur, dem Göthe ganz entgegengesetzte Wesen, Schäfer, Schäferinnen u Pagoden formte. Dieser Stoff ist dadurch zu Ehren gekommen, daß die vollständigste Menschennatur darinn abgebildet worden ist. ${ }^{69}$ In dieser Aussage zeigt sich wie auch in der Inszenierung von Rauchs Büste in Dresden die zwei-

kensaal auf Schönhöhe steht, wurde vom Freundeskreis des GoetheNationalmuseums in Weimar dem Quandt-Verein bei Einweihung der restaurierten Wandbilder im Jahr 2001 übergeben. Bildhauerische Arbeiten sind in der historischen Einrichtung keine belegt. Siehe die Abbildung in: Luzens 2002, S. 76.

69 Brief von Quandt an Johann Georg Keil vom 7.3.1832, in: SLUB, Mscr. Dresd. App. 393, Nr. 2g. Es handelt sich um eine Kopie nach Christian Daniel Rauch, Goethe im Hausrock, 1829, Biskuit, hergestellt in der Königlichen Porzellanmanufaktur Meißen; siehe Luzens 2002, S. 124. Quandt schrieb in einem Brief an Goethe vom 29.4.1829, er habe einen Abguss einer Statue von Rauch erhalten; Schmitz/Strobel 2001, S. 56. Bei der Vorlage handelt es sich um die erste Fassung von Goethe im Hausrock, 1828-29, Gips, H. 34 cm, heute Berlin, SMB, Skulpturengalerie, Inv.-Nr. RM 5000/51. Siehe die Briefe von Rauch an Goethe vom 1./11.2.1829, in: Goethe/Rauch 2011, S. 92, 95; Simson 1996, S. 266-68, Kat. Nr. 164. S. a. Kunst-Blatt, 1829, Nr. 73, S. 289-290: „So hat man [...] den Menschen und den Dichter, in einem Zustande, wo er selbst König ist im Reiche seiner Ideen und Träume [vor sich].« Laut dem Artikel hat Rauch die Statuette einzelnen Freunden als Gipsabguss geschenkt. Sie wurde in der Folge in Bronze, Gips, Elfenbein und Biskuit verbreitet und ist noch heute erhältlich. S. a. Quandt 1850 (2), S. $61-62$. 
seitige Rolle, die Goethe bei Quandt spielte. Einerseits war er seine Quelle der Inspiration und musste ihm überall vor Augen stehen. Andererseits betont Quandt auch hier die Vollständigkeit des Menschen Goethe, die über die Person des Weimarers hinausweist. Selbst das unwürdige Material, also die gebrannte Erde, wird durch den Menschen Goethe veredelt. Im Umkehrschluss enthüllt sich eine weitere Bedeutungsebene: Porzellan werde, so Quandt, normalerweise für die Darstellung ländlicher Figuren benutzt. Damit passte sie perfekt nach Dittersbach, wo sich Quandt umfassend für die Landbevölkerung einsetzte.

Das Kernthema des Menschen und seines Lebens, das Quandt auf Goethe bezogen immer wieder erwähnte, spielte auch beim Bau des Turmschlösschens auf Schönhöhe eine wichtige Rolle. Zum Fest der Grundsteinlegung am 12. September 1831 blickte Quandt in die ferne Zukunft, in der das Bauwerk an nichts mehr erinnern würde. ${ }^{70}$ Die Geschichte eines jeden Gebäudes sei an das Schicksal des Menschen geknüpft. Im Angesicht des Baus würden »Kinder spielen, Mädchen blühn, Jünglinge das Leben proben, Männer schaffen, Frau’n vollbringen, und Greise unter Enkeln sich der Jugend erinnern, und das Leben wird sich im Kreislauf wiederholen [...].« Der Turm war Symbol des werdenden und vergehenden Daseins. Der Mensch errichte sich in jeder Zeit Gebäude, die wieder zugrunde gingen. Damit thematisierte Quandt Werden und Vergehen der Natur und des schaffenden Menschen: »Aus dem Schoos der Vergangenheit entspringe die heitre Gegenwart, die wieder Mutter der Zukunft wird, und so steht die große Weltuhr und der Pulsschlag nimmer still.«

Zwei Jahre später stand man vor dem vollendeten Gebäude und Quandt sprach wieder zu seiner Festgemeinde.71 Gebaut war das Türmchen aus Quadern eines Steinbruchs der Schönhöhe, im Vordergrund sichtbar auf dem Gemälde des Belvedere (Abb. 108). Der Mensch hatte den natürlichen Felsenmassen sinnvolle Form gegeben. Die kleine Burg stehe für die lebenden Menschen, die sie errichtet haben, ja für die Menschheit selbst: »[..] alle Menschen vereint der Gedanke: >Menschheit<, der in

70 Paraphrase und Zitate in: Quandt 1840 (1), S. 3-4

71 Paraphrase und Zitate in: Quandt 1840 (1), S. 9-11.

72 Quandt, »Schönhöhe«, in: Friesen 1838, S. 253; Quandt 1834(2), [nicht paginiert]. S. a. Briefe an Schnorr vom 12.9.1831, in: SLUB, Mscr. Dresd. n Inv. 15, Bd. 31, fol. 181r-182v und Schorn am 12.11.1835, in: Weimar, GSA, Nr. 85/24,11, [fol. 3r].

73 Hirschfeld 1782, Bd. 4, S. 33-35

74 Gross 2005/06, S. 530-538. Dies lässt sich auch in der Rede zur Grundsteinlegung nachvollziehen.

75 Brief vom 6.11.1831, in: Schmitz/Strobel 2001, S. 144-145.

76 Der Brief ist in einem Entwurf erhalten in: Schmitz/Strobel 2001, S. 102

77 Brief vom 26.9.1830, in: Schmitz/Strobel 2001, S. 103-106. Er war vor allem über die Gewalteskapaden irritiert und wünschte eigentlich, dass die »erwachte Intelligenz«, unter die er sich selber wohl auch zählte, Verbesserungen durchführen würde. Durch nahen Kontakt zu unbeschränkter, unendlich wechselnder Mannigfaltigkeit durch alle Einzelne Daseyn hat [...].*

Der Rundbogenstil, in welchem das Belvedere erbaut war, sollte Sicherheit und Würde ausstrahlen. In seiner mittelalterlichen Art erinnerte es an das »Gepräge des Ernstes der Vorzeit «.$^{72}$ Schon Christian Hirschfeld hatte 1782 in seiner Theorie der Gartenkunst für schroffe Berggärten gotische Festungen gefordert, weil das Rohe an die Vorzeit erinnere und der Wildnis der Natur angepasst sei. Die Abbildung eines mittelalterlichen Turms war wohl auch Vorbild für Quandts Bergschlösschen (Abb. 109). ${ }^{73}$ Das vermittelte Bild eines standhaften Mittelalters verdeutlichte aber auch den Wunsch nach Sicherheit, die durch die Turbulenzen der revolutionären Unruhen und politischen Umbrüche in Dresden von 1830/31 erschüttert worden war. ${ }^{74}$ Quandt hatte denn auch Goethe gegenüber erklärt, er habe den Bau deswegen errichtet, weil ihn »Gegenwärtiges und Zukünftiges« beschäftigte, weil ihm das Vertrauen in die Zukunft über schlimme Zeiten hinweghalf und weil es in diesen turbulenten Zeiten ratsam sei, die Bevölkerung mit Arbeit zu beschäftigen. ${ }^{75}$

Diese Zeit der historischen Umbrüche, Goethe als Bild des Idealmenschen und der Bau des Belvedere als Symbol für die Kontinuität der menschlichen Existenz bündeln sich in einem erstaunlichen Akt bei der Grundsteinlegung von 1831. Quandt vergrub in einer Aushöhlung des Grundsteins zusammen mit anderen Gegenständen einen Brief von Goethe, den er am 18. September 1830 erhalten hatte. Nach den Dresdener Unruhen hatte der Dichter ihn gefragt, ob er und seine Besitztümer unangetastet geblieben seien und ihm seine »aufrichtige Besorgniß $\ll$ mitgeteilt. ${ }^{6}{ }^{6}$ Quandt antwortete mit einer langen Schilderung der Ereignisse und ließ durchblicken, dass er Verständnis für die gesellschaftlichen Verbesserungsbedürfnisse hatte. 77 In Erinnerung an die politischen Veränderungen, die er durchaus befürwortet hatte, beauftragte er einige Jahre später Ernst Rietschel mit der Ausführung einer Konstitutionssäule zu Ehren der sächsischen Verfassung und einer Büste für König Anton, unter dessen Regierung sie durchgesetzt worden war. ${ }^{78}$

seiner Dittersbacher Landbevölkerung schien er die Ereignisse im Griff behalten zu haben und betonte sein »Gefühl für die wichtigsten Angelegenheiten des Vaterlandes «. In den Berührungen analysierte er das Vorgehen aus der Distanz und ordnete es klar in die Unsicherheiten der Zeit ein. Dabei war er sich nicht mehr sicher, ob er »diese Reliquie der Gegenwart« hätte entziehen sollen. Quandt 2001 [1870], S. 242.

78 Büste und Säule entstanden 1840, wobei die Büste eine verkleinerte Umsetzung einer Festarchitektur Sempers und Rietschels zu Ehren des achtzigsten Geburtstages von König Anton 1835 war. Sie konnte trotz vielseitigem Wunsch in der Stadt nicht als Denkmal umgesetzt werden. Büste und Säule sind nicht im Original erhalten, wurden aber auf Veranlassung des Quandt-Vereins Dittersbach 2007 frei nach anderen Vorlagen rekonstruiert. Die Inschrift auf dem Sockel der Büste lautete: »Nicht um die Krone, Dein Volk zu beglücken wurdest Du König. « Wilmowsky 2017, WVZ 41.1, S. 287-289 und WVZ 42.2, 


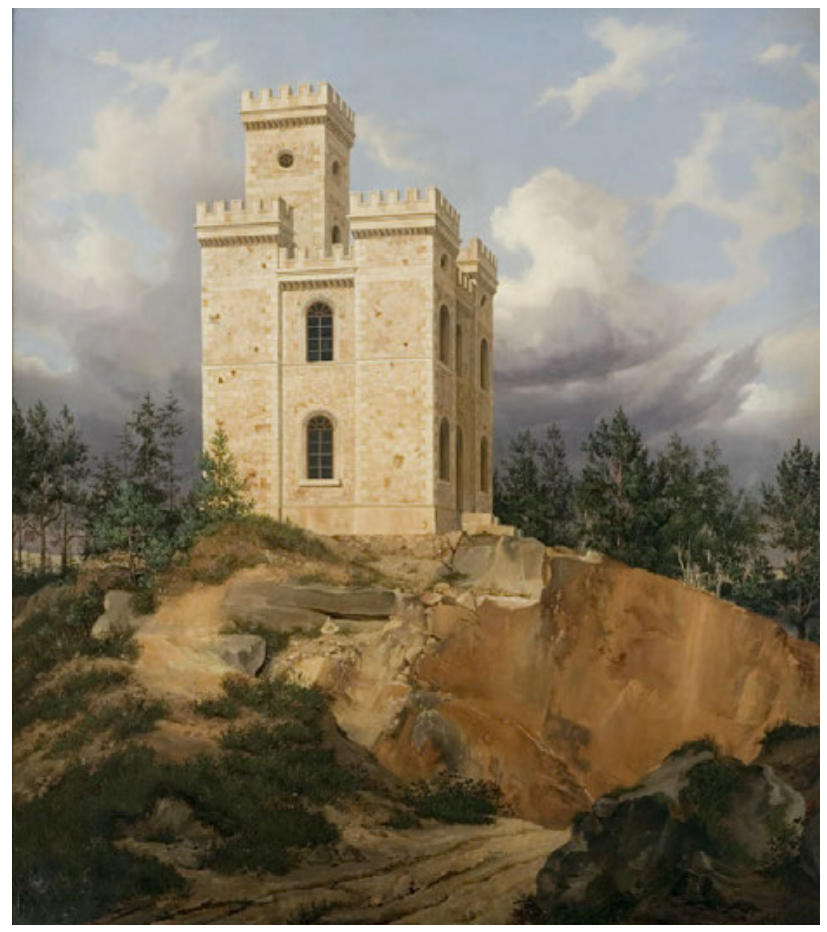

108 Johann Gottfried Pulian oder Otto Wagner, Schöne Höhe bei Dittersbach, um 1845, Öl auf Leinwand, 74,6 × 66,7 cm, Dresden, Städtische Galerie, Inv.-Nr. 1980/k 304

Bernhard Maaz legte den vergrabenen Brief als Zeichen einer vergötternden Verehrung Goethes aus. ${ }^{79}$ Diese Sichtweise muss relativiert werden. Quandt empfand den Brief als eine Urkunde einer Person, die aus reiner Menschlichkeit Anteil nahm am Schicksal des Einzelnen und des Vaterlandes. Diese Anteilnahme wollte er für die Zukunft bewahren, indem er sie in einem Glaszylinder in der Erde versenkte. ${ }^{80}$ Noch neun Jahre später wiederholte er ein ähnliches Ritual. Bei der Grundsteinlegung des Gutshauses von Rossendorf - ein Dorf, das zum Rittergut gehörte - vergrub er im Frühjahr 1840 dreißig Medaillen von bekannten toten und noch lebenden Zeitgenossen. Einige Münzen erhoffte er sich durch die Vermittlung von Julius Schnorr von Carolsfeld zu beschaffen und orderte bei ihm solche von Schnorr selbst, des Weiteren Ehrenzeichen des Malers Peter Cornelius, des Dichters Friedrich Rückert, des Philologen Friedrich Wilhelm von Thiersch, der Komponisten Ludwig van Beethoven und Wolfgang Amadeus Mozart und des Philoso- phen Friedrich Wilhelm Joseph Schelling. Diese illustren Personen waren Vorbilder und nicht Verehrte - analog zu Goethe in Dittersbach. Selbstironisch spöttelte Quandt, er würde eine unterirdische Walhalla einrichten - ein Tempel deutscher Vorbilder also - und für Schelling habe es leider nicht mehr gereicht. ${ }^{{ }_{1}}$ Von reliquienhafter Verehrung kann bei Quandts kleinem Ritual also gar nicht die Rede sein. So diente auch der im Grundstein versenkte Brief Goethes vielmehr dem Fokus auf dessen Empathie. Exemplarisch vom Dichter vorgelebt, wurde diese zur Tugend. Die Menschlichkeit Goethes stand in Quandts Verständnis für die Kontinuität der Menschheit und war daher nachahmenswert für alle, denn: »Ein Jeder [ist] Ergänzung der Menschheit [...] und die kommenden Geschlechter Fortsetzung eines gesammten Lebens [...], das unendlich seyn muß.« ${ }^{82}$ Damit entsprach selbst Goethes Tod im April 1832 der Grundidee des natürlichen Lebenszyklus. ${ }^{83}$

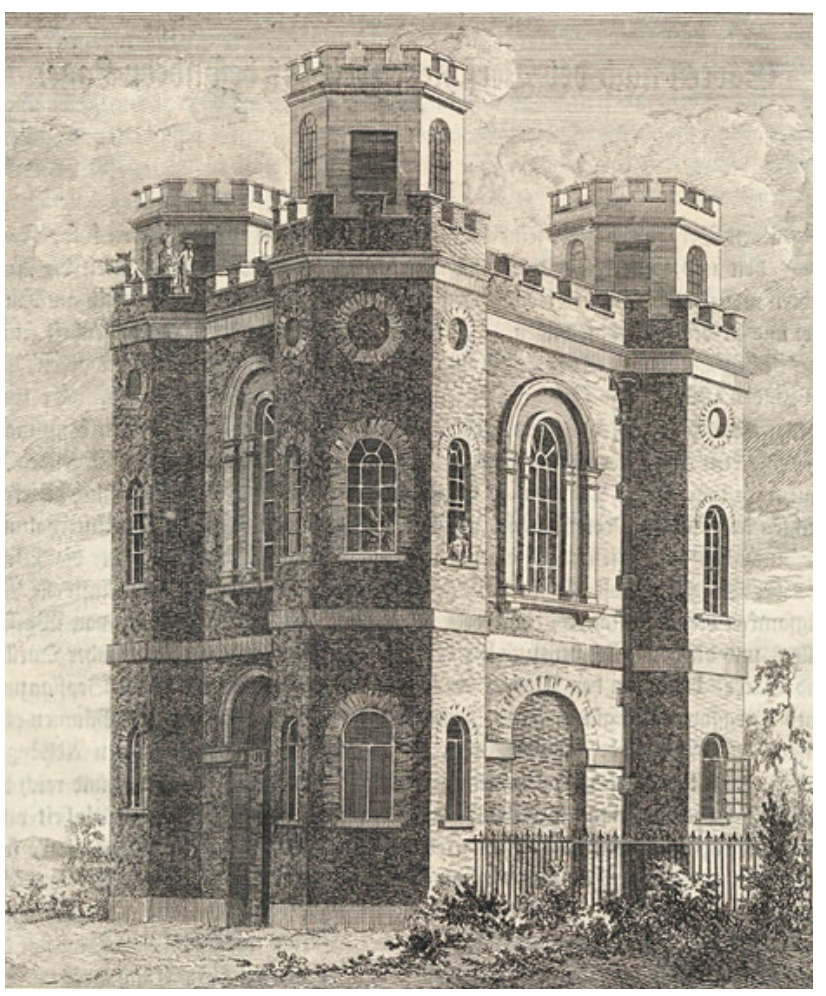

109 Christian Hirschfeld, Mittelalterlicher Turm in einem Berggarten, in: Hirschfeld 1782, Bd. 4, S. 34
S. 291; Palm 2008, S. 49-51; Krause/Harnisch 2009, S. 34-51. Wenn Quandt auch für politische Veränderungen war, wundert es nicht, dass der geadelte Bürger gerade dem alten König Anton ein Denkmal errichtete. Auf öffentlichen Druck hin musste der konservative König in der Phase der revolutionären Unruhen 1830 seinen Neffen Friedrich August zum Mitregenten küren. Die sächsische Verfassung gehörte schließlich zu den konservativeren in Deutschland. Hahn/Berding 2010, S. 430-433; Gross 2001, S. 203-204.
79 Maaz 2002, S. 77; Maaz 1987 (1), S. 47

80 Quandt 2001 [1870], S. 242.

81 Briefe von Quandt an Schnorr vom 16.3. und 26.4.1840, in: SLUB, Mscr. Dresd. n Inv. 15, Bd. 31, fol. 208r-212r.

82 Quandt 1840 (1), S. 10.

83 Brief an Seidler vom 1.4.1832, in: Schmitz/Strobel 2001, S. 165: »Nun ist er auch gestorben, wie es die Natur in ihrer Grundidee fordert.« 


\section{Zurück in die Zukunft: Der Freskenzyklus zu} Goethes Balladen

Dieses zyklische Menschenbild zog sich schließlich in den Fresken Peschels weiter, deren Entstehung und Inhalt Bernhard Maaz ausführlich beschrieben hat. Sie sollen hier nur anhand einer Quellenlektüre betrachtet und in einen erweiterten Kontext gestellt werden (Abb. 110). ${ }^{84}$ Quandt nahm den lang gehegten Plan wieder auf, einen Raum mit einem Bildprogramm al fresco ausschmücken zu lassen. Er hatte dies schon am Tag der Grundsteinlegung seinem Freund Schnorr mitgeteilt. ${ }^{85}$ In Peschel hatte er einen Maler gefunden, der in der Pillnitzer Schlosskapelle als Gehilfe von Vogel von Vogelstein sowie im Römischen Haus in Leipzig, erbaut 1832-1834 vom Musikverleger Hermann Härtel, zusammen mit Bonaventura Genelli Erfahrungen im Malen al fresco gesammelt hatte. ${ }^{86}$ Durch diese Verbindung erhielt Quandt zudem guten Kalk für die Fresken von Härtel aus Leipzig. In einem Dankesbrief betonte Quandt die Dauerhaftigkeit dieser Technik, die noch seine »späten Nachkommen« erfreuen würden. ${ }^{87}$ Quandt erhoffte sich nämlich durch die Gattung des Freskos anhaltende und öffentliche Wirkung, was den hohen inhaltlichen Anspruch des Bildprogramms in Dittersbach verdeutlicht. ${ }^{88}$

In einem Brief vom 12. November 1835 an den Redaktoren des Kunstblatt, Ludwig Schorn, erläuterte Quandt das geplante Bildprogramm und die erhoffte Bedeutung der Fresken: »Das Gebäude hat durch seine Lage u Thürme u Zinnen, etwas romantisches u damit es ganz der Romantik würdig geweihet werde, soll der Künstler diesen Saal, mit Bildern zu Göthes Romanzen, schmücken. $\ll^{89}$ An der Hauptwand kam das Bild nach der Ballade Der Sänger zur Ausführung, zu dessen Linken und Rechten in den Schmalseiten der König in Thule und GeistesGruß. Die drei Bilder sollten das »Leben in der Vorzeit« mit Tugenden wie Liebe und Treue, dem Gefühl der Heiterkeit und der ritterlichen Lebensart zeigen. An den Seitenwänden einander gegenüber liegend entstanden Bilder der »romantischen Naturanschauungen«. Der Fischer sollte auf die Sehnsucht nach der ewigen Verbindung mit der Natur, der Erlkönig auf die unnahbare, überwältigende und schauerliche Natur hinweisen..$^{90}$ Diese fünf Bilder führte Peschel aus (Abb. 111-115).

An der Längswand über dem Eingang wechselten die Konzepte bis zur Ausführung. Wie er Schorn im erwähnten Brief berichtete, sollte erst ein Medaillon des Dichters über dem Haupteingang angebracht werden und in den beiden Schmalseiten allegorische Figuren der Volkssage und der romantischen Dichtung gemalt werden: Eine Mutter sollte ihrem Kind verfallene Gemäuer zeigen und damit der Sage als traditionelle Überlieferungsform Reverenz erweisen. Ein Sänger wiederum würde genau diese alten Geschichten in einer Ruine mit Romanzen besingen. Die romantische Dichtung würde dabei die Volkssage verherrlichen..$^{11}$

In den Briefen aus Italien von 1830 erklärte Quandt das Verhältnis von romantischer Dichtkunst und Malerei. Beider größter Vorteil sei die Schrankenlosigkeit der Phantasie. Der Mensch sei weder an »historische Wahrheit« noch »physische Möglichkeit « gebunden. ${ }^{92}$ Diese Freiheit der Phantasie und des
84 Maaz 2002, S. 83-91; Maaz 1987 (2), S. 57-66; 1987b, S. 35-40; Bemmann 1925, S. 28-31.

85 Brief vom 12.9.1831, in: SLUB, Mscr. Dresd. n Inv. 15, Bd. 31, fol. 181r-182v. S. a. Bemmann 1925, S. 28. Der Saal sollte zu diesem Zeitpunkt noch überwölbt werden und wurde schließlich nur mit einer Balkendecke abgeschlossen. Es handelt sich um einen der ersten Goethe-Räume. Früher waren nur Wilhelm von Kaulbachs 36 Szenen zu GoetheWerken im Schlafzimmer der Königin im Königsbau der Münchner Residenz. Sie waren jedoch nie der Öffentlichkeit zugänglich und entsprechend wenig rezipiert; Maaz 2002, S. 90; Maaz 1987 (2), S. 65.

86 Richter 2002, S. 32-34; Maaz 2002, S. 78. Zum Römischen Haus von Härtel siehe Naumann 2007. Härtel sandte Quandt Kalk für seine Fresken in Dittersbach zu; Dankesbrief von Quandt an Härtel vom 24.5.1836, in: Berlin, StaBi, Handschriftenabteilung, Sammlung Härtel, Quandt, (Johann) Gottlob.

87 Brief von Quandt an Härtel vom 24.5.1836, in: Berlin, StaBi, Handschriftenabteilung, Sammlung Härtel, Quandt, (Johann) Gottlob: »Ew. Wohgebohren, haben mich durch Zusendung eines Fäßchen mit ausgelagertem Kalche aufrichtig verbunden u dadurch die Frescomalereÿ in meiner kleinen Burg sehr gefördert. [...] Wenn nun der Künstler mit Freuden hoffen darf, daß sein schönes Werk für die Zukunft durchaus gesichert ist u noch meine späten Nachkommen sich des Besitzes der trefflichen Malereÿen erfreun werden, so verdanken wir es Ihnen.«

88 Eine Idee, die Peter Cornelius 1814 propagierte und die auf reges Interesse stieß. Durch die Freskenmalerei erhofften sich die Lukasbrüder in Rom, Öffentlichkeit zu erlangen. Ihre Kunst sollte dadurch bekannt werden; Büttner 1980/99, Bd. 1, S. 70-76. Die Hoffnung wurde noch geschürt durch die Freskenaufträge in der Casa Bartholdy und dem Casino Massimo in Rom. Siehe Grewe 2017, S. 30-37; Vignau-Wilberg 2011, S. 42-46; Grewe 2009, S. 52-57; Schmitz 2008, S. 174; Locher 2005, S. 52-54; Schmitz/Strobel 2001, S. XXXV; Maaz 2002, S. 73; Maaz 1987 (2), S. 32-33.

89 Weimar, GSA, Nr. 85/24,11, [fol. 3 r-v]. Vollständig wiedergegeben bei Maaz 2002, S. 83-91; Maaz 1987 (1), S. 57-66; 1987b, S. 35-40. S. a. den Brief von Quandt an Schnorr vom 21.1.1836, in: SLUB, Mscr. Dresd. n Inv. 15, Bd. 31, fol. 195r: »Da der Saal eine mäsige Größe hat, die Lage u die Bauart des Gebäudes in Übereinstimmung einen romantischen Charakter haben u dieser Ort mehr zur Erholung, als ernsterer Thätig keit bestimmt ist, so habe ich zu dem Gegenstand für die Malereÿen, kein Epos, sondern Romanzen von Göthe gewählt. Dreÿ Bildern schildern das Menschenleben in der Vorzeit, durch den Sänger, den König in Thule u den Heldengeist u zweÿ Bilder die romantisch poetische Naturanschauung, in dem Fischer u dem Erlkönig.« S. a. Bertsch 2011, S. 260.

90 Die fünf Gedichte in zeitgenössischer Ausgabe in: Goethe 1821, S. 62, 108, 111-114.

91 Brief vom 12.11.1835, in: Weimar, GSA, Nr. 85/24,11, [fol. 3v]. S. a. Maaz 2002, S. 90; Maaz 1987 (1), S. 65 ohne Nachweis. Mit solchen Allegorien hätte er in typisch romantischer Tradition gestanden, die sich auf Raffaels Allegorie der Poesie in der Stanza della Segnatura berief. Siehe Scholl 2015, S. 93-94.

92 Quandt 1830 (1), S. 227-228. Siehe hierzu auch Scholl 2015, S. 93-101. 

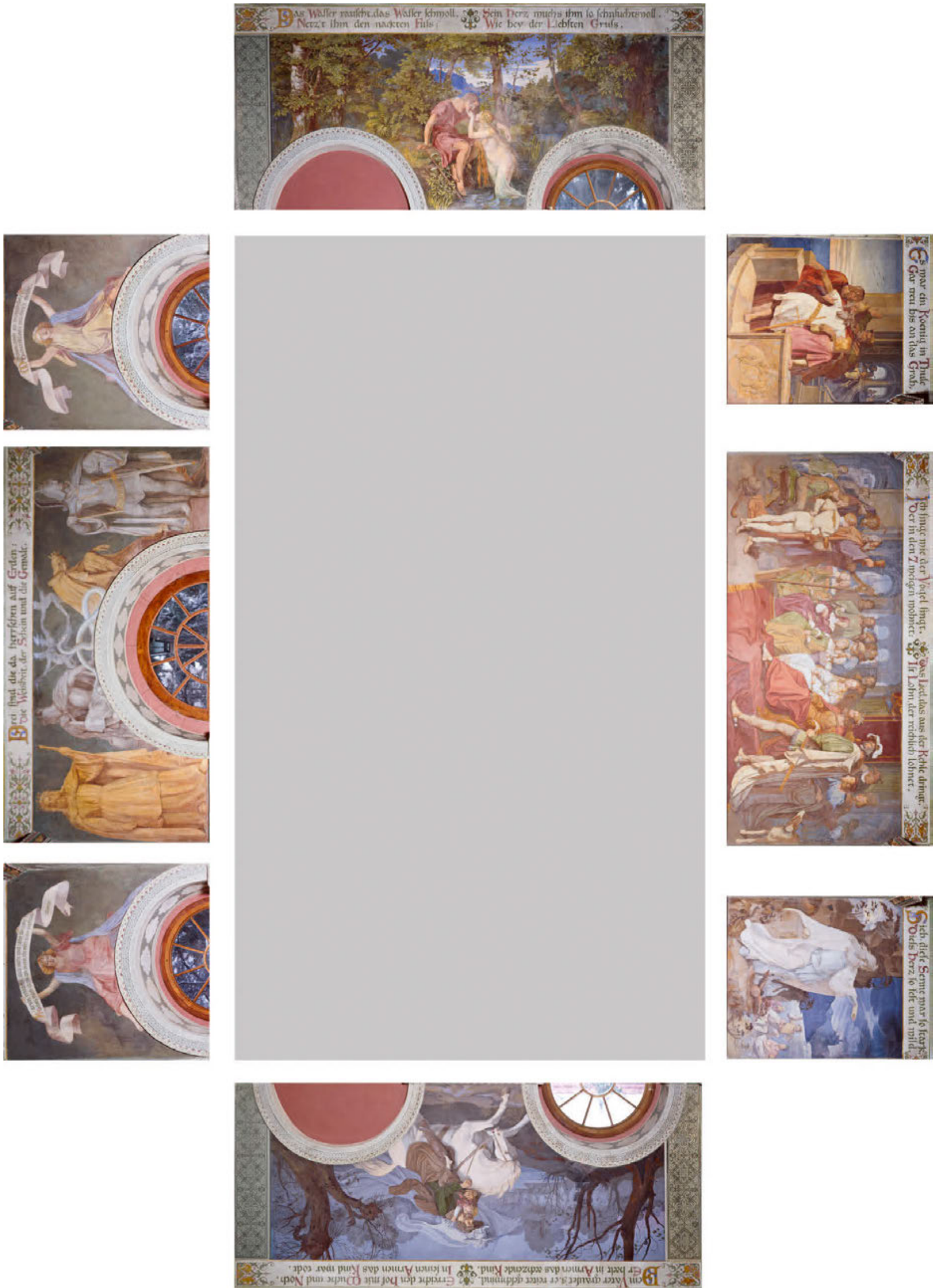

110 Schema des Wandbildprogramms im Freskensaal des Belvedere, Dittersbach, Schönhöhe 
Denkens war zeittypisch. Bereits die Zeitgenossen bezeichneten sie als »romantisch«. Die eigenen Bedingungen des Individuums wurden in Beziehung gesetzt zu allgemeinen und universellen Gesetzlichkeiten. Bei Quandt dürfte der vielschichtige Begriff kaum - wie bei den Gebrüdern Schlegel oder bei Novalis - enggeführt worden sein. Vielmehr kann man den Wortgebrauch mit dem Diktum seines Freundes Ludwig Tieck umschreiben. Dieser wollte dem Begriff keine besondere Bedeutung zumessen und »nahm es so, wie es damals allgemein genommen wurde. Höchstens wollte ich damit andeuten, daß hier das Wunderbare in der Poesie mehr hervorgehoben werden solle. «33 $^{93}$

Interessant ist nun die Einbindung Goethes: weil seine Poesie in den Augen der Romantiker genau diese uneingeschränkte Phantasie zum Ausdruck brachte, konnte er für ihre Zielsetzungen adaptiert werden. Der deutsche Schriftsteller Jean Paul - von Quandt sehr bewundert - beschrieb 1804 in seiner Vorschule der Aesthetik einige Beispiele romantischer Poesie, nachdem er ihre Triebfeder in der christlichen Sinnenwelt, dem völkischen Aberglauben und der Dämonologie der Vergangenheit festgemacht hatte.»Die weite Nacht des Unendlichen« und die Phantasie der romantischen Dichtkunst erkannte Jean Paul auch bei Goethe und darin zeigt sich die Adaption von Goethes Werken für verschiedene Zwecke: »Durch den romantischen Meister von Göthe zieht sich wie durch einen angehörten Traum, ein besonderes Gefühl, als walte ein gefährlicher Geist über den Zufällen darin [...], kurz vor einer Katastrophe der Natur. ${ }^{94}$ Wenn Quandt nun in seinem ersten Plan der Raumgestaltung auf Schönhöhe vorsah, ein Medaillon des Dichters zwischen der Volkssage und der romantischen Dichtung einzubinden, dann verschränkte er hier die Phantastik der alten Überlieferungen mit den Dichtungen seiner Zeitgenossen, für die der Weimarer vorbildlich stand. Für Quandts Zeitgenossen war Goethe der Sänger, der »das Vaterland $[. .$.$] wiederbe-$ lebt, alte Zeiten verjüngt, die Vorzeit zurückgerufen, die Liebe in herzdurchdringenden Tönen verkündigt, vom Wunder der Natur prophezeit und Allen da Gedicht, Phantasie, Herrlichkeit und Kraft gewiesen.«95

Der Subtext des Bildprogramms wird an dieser geplanten Eingangswand offengelegt. Es geht um die Suche der deutschen Bildungselite nach der eigenständigen Nation in Kunst und Ge-

93 Tieck 1855, Bd. 2, S. 172. Zum »oszillierenden« Begriff der Romantik im frühen 19. Jahrhundert siehe Ernst Müller, »Romantisch/Romantik«, in: ÄGB 2010, Bd. 5, S. 323-332. Vgl. hierzu auch Quandt 1846 (2), S. 375.

94 Jean Paul 1804, S. 137. Zu den Ursprüngen der romantischen Poesie siehe ebd., §21-22, S. 121-132. Quandt über Jean Paul im Brief an die Schillerstiftung in Dresden am 12.12.1855, in: Dresden, Stadtarchiv, Acta die Schillerstiftung betreffend, 1855, B.XI.b.3, Vol. II, fol. 232r: »Dichter [meint] einen Mann, welcher die Kraft hat, das Innere des Menschenlebens in der Sprache abzuspiegeln [...], denn weder die Reime noch Knallwörter beweisen den Dichtergeist u Jean Paul war ein ächter sellschaft. Die Allegorie der Volkssage stand für die vergangene, das Sinnbild der romantischen Dichtung für die gegenwärtige deutsche Dichtung. Goethe erschien als das aktuellste Beispiel dieser Verbindung von Vergangenheit und Gegenwart und wurde zwischen den beiden Allegorien zum Vorbild für Künftiges.

Dass sich das Bildprogramm des Belvedere-Sälchens auf dem Höhepunkt der zeitgenössischen Debatten befand, zeigt sich fast weniger in der Wahl von Werken des Weimarer Dichters, sondern in der Wahl der darzustellenden poetischen Gattung: der Ballade. Quandt selber betonte, dass die Ballade der Vergangenheit und der Gegenwart angehöre. ${ }^{96}$ Der Philosoph und Literaturprofessor Friedrich Theodor Vischer besprach im dritten Teil seiner Ästhetik, erschienen 1857, den Balladenbegriff in der Bedeutung seiner Zeit. ${ }^{77}$ Vischer bezeichnete die Ballade als »elementarische Form« der Poesie, die das Lyrische und Epische miteinander verbinden würde. Episch sei vor allem das Moment der Vergangenheit. Lyrisch aber bedeute, dass der eigenständige Stoff durch den Dichter aus der Vergangenheit in die Gegenwart verlegt würde. Besonders das Märchen- und Geisterhafte würde hierbei thematisiert, da darin »tiefer und rein menschlicher Sinn eingehüllt« sei. Die Ballade charakterisiere sich dabei in ihrer Mischung aus Epos und Lyrik als malerisches Helldunkel. Während das klassische Altertum solche Mischformen nicht gekannt habe, entwickelte sich die Ballade aus dem in Schottland entstandenen »epischen Lied«. Die Ballade sei also eine nordische Kunst: »Es ist die nordische Stimmung mit ihrem bewegteren, ahnungsvolleren, mehr andeutenden, als zeichnenden Ton, ihrem stoßweisen, Mittelglieder überspringenden Gange, es ist, was Göthe die mysteriöse Behandlung nennt, welche der Ballade zukomme. $\ll^{98}$ Vischer bezeichnete dieses Charakteristikum des nicht restlos Bestimmbaren als dramatisch. Handlung und Reden seien miteinander verwoben, gleichzeitig aber auch verschwiegen. In der Ballade zeige sich dadurch das Innere des Menschen im vielseitigen Ausdruck der Sprache. Die Komplexität des Begriffs, so Vischer, der den Gebrauch des Wortes auch bei seinen Zeitgenossen klärte, habe zur Folge, dass der Sprachgebrauch »locker und schwankend « sei. ${ }^{99}$ Dies alles zeigt sich bei Quandt, der von Romanzen und Balladen sprach und das gleiche meinte.

Dichter, unerachtet er keine Verse machen konnte.« Dieses Bonmot ist in Quandts Korrespondenz mehrfach feststellbar.

95 Tieck 1848 [1828], S. 248-249. Tieck charakterisiert in dieser Schrift unterschiedliche Ausprägungen von Goethe-Verehrern. Zur Poesie bei den Romantikern siehe Scholl 2007, S. 239-250.

96 Quandt, in: Friesen 1838, S. 253.

97 Vischer 1857, S. 1358-1367.

98 Vischer 1857, S. 1362.

99 Vischer 1857, S. 1364 


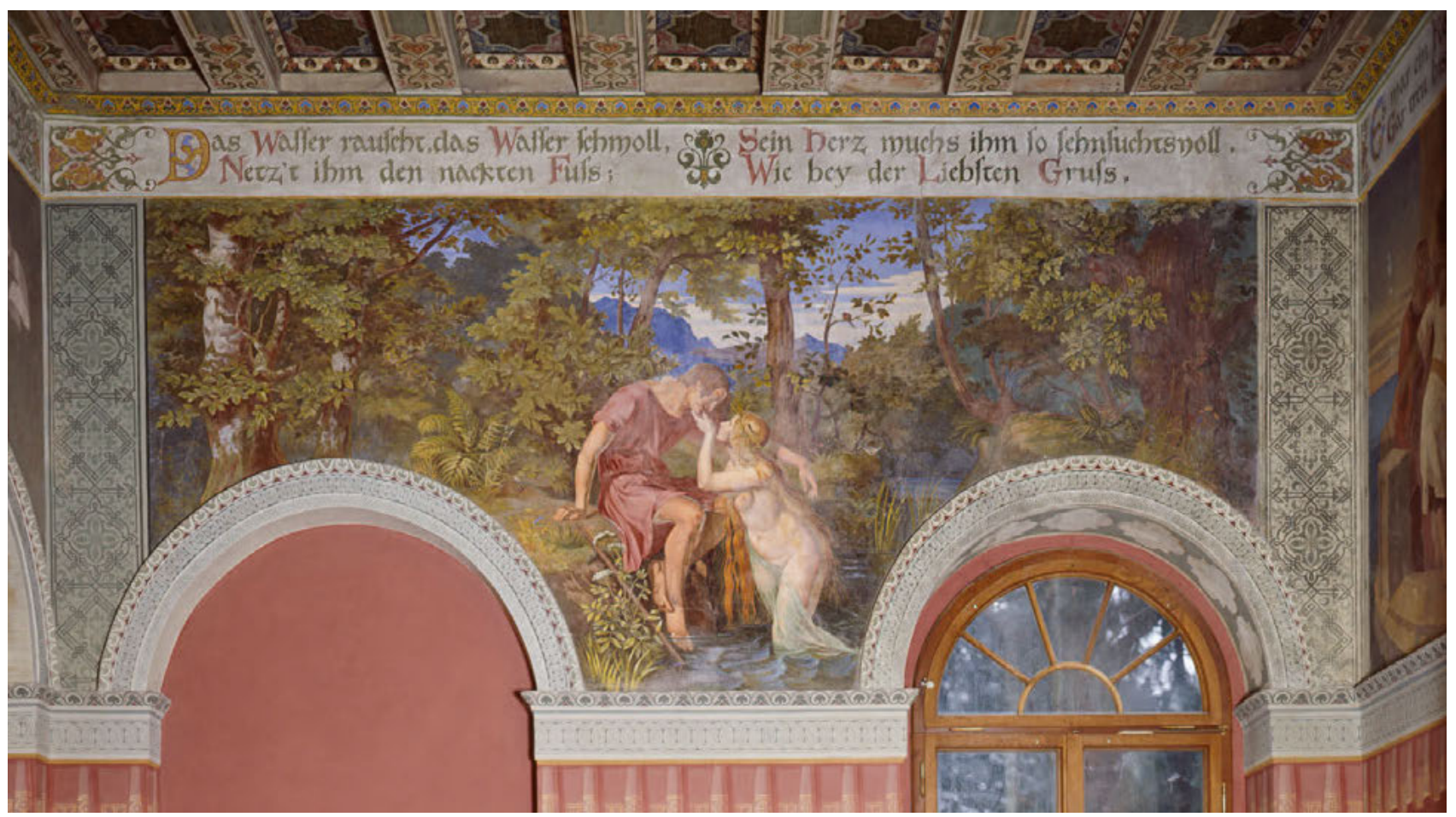

111 Carl Gottlieb Peschel, Der Fischer, 1836-38, Fresko, 180 × 450 cm, Dittersbach, Schönhöhe, Belvedere, Westwand

Dass Quandt für das Bildprogramm im Belvedere auf Schönhöhe Goethe-Balladen wählte, war folgerichtig. ${ }^{100}$ Goethe vermochte vorbildhafte Balladen zu dichten. In ihm verbanden sich in idealer Form vergangene mit gegenwärtigen Errungenschaften deutscher Dichtung. Damit war Goethe weniger Verehrter als Vorbild. Durch seine Arbeiten wurden die vielseitigsten Bedürfnisse der Gebildeten seiner Zeit gedeckt.101 In Quandts Bildprogramm wurde der Dichter zur Personifikation der zyklischen Menschheitsentwicklung und vereinte Vergangenheit, Gegenwart und Zukunft in seinem literarischen Werk. Wie Quandt in der Rede zur Einweihung von Schönhöhe formuliert hatte, reihte sich die künstlerische Gestaltungskraft des Menschen in die Schöpfungskraft der Natur ein..$^{102}$ Das Men-

100 »Die bedeutendsten Producte der neueren erzählenden Poesie sind Balladen, vor Allem die Göthe'schen. « Vischer 1857, S. 1366.

101 Mandelkow 1975-1984, Bd. 1, S. LXVI; Tieck 1848 [1828], S. 239.

102 Quandt 1840 (1), S. 9.

103 Quandt an Louise Seidler am 1.4.1832 nach Goethes Tod, in: Schmitz/ Strobel 2001, S. 165: »[...] nur lebendig steht sein Bild vor mir.« Goethes Roman Wahlverwandtschaften, der für das Belvedere in Dittersbach eine gewisse Rolle spielte, enthält im 1. Kapitel des 2. Teils eine interessante Passage, die vielleicht auf das Weglassen des BildnisMedaillons hinweisen könnte. Die Romanfigur Charlotte will den Kirchhof neu ordnen. Ähnlich Goethes Aussagen über das Denkmal in Goethe 1827-1842, Bd. 44, S. 39-40 betont ihr Architekt, das schönste Denkmal des Menschen sei dessen eigenes Bildnis. Charlotte entgegnet, Bildnissen würde man mit der Zeit ohne echte Erinnerung begegnen. Das Andenken an eine Person sei vielmehr als »heiliger Ernst« zu schenbild wurde zum Naturbild, die Vernunft Teil der Natur. Hierauf baut der Freskenzyklus von Schönhöhe.

Der bildliche Bezug mit dem Goethe-Medaillon fiel schließlich weg. Quandt wollte den Dichter womöglich »lebendig« in Erinnerung halten. ${ }^{103}$ Ebenso verzichtete er auf die Personifikationen von Volkssage und romantischer Dichtung. Ausschlaggebend hierfür war wohl eine Unsicherheit gegenüber allegorischen Darstellungen. ${ }^{104}$ Anstatt einer solchen sollte eine eigenwillige Darstellung aus Goethes Das Märchen gemalt werden (Abb. 116).

Doch bevor 1838 die Eingangswand fertig gestellt war, veröffentlichte Hermann von Friesen eine Beschreibung der fünf Fresken zu den Balladen ${ }^{105}$ Friesen erkannte in Quandts Bild-

betrachten und entsprechend lebendig zu halten. Zum Bezug auf die Wahlverwandtschaften siehe den Brief von Quandt an Goethe vom 6.11.1831, in: Schmitz/Strobel 2001, S. 144

104 Brief vom 12.11.1835, in: Weimar, GSA, Nr. 85/24,11, [fol. 3v]. S. a. Maaz 2002, S. 89. Die abzulehnende Allegorie steht im Kontrast zum Symbol, das er bevorzugt. Jede anschaulich dargestellte Idee werde in der Kunst zum Symbol. Dieses Symbol steht für einen vernünftigen Gedankengang. Im Gegensatz hierzu sei die Allegorie rein assoziativ und deute nur auf die Idee hin; siehe Quandt 1830 (1), S. 306-315. S. a. Grewe 2015, S. 134-136.

105 Friesen 1838, S. 253-254, 259-260. Die fehlende Erwähnung des Märchens deutet darauf hin, dass Friesen es noch nicht gesehen hatte. Quandt hingegen erwähnt es in der einleitenden Anmerkung; ebd., S. 253. Das Märchen erschien zuerst 1795 in Schillers Horen als letzte Erzählung im Novellenzyklus der Unterhaltungen deutscher Ausge- 


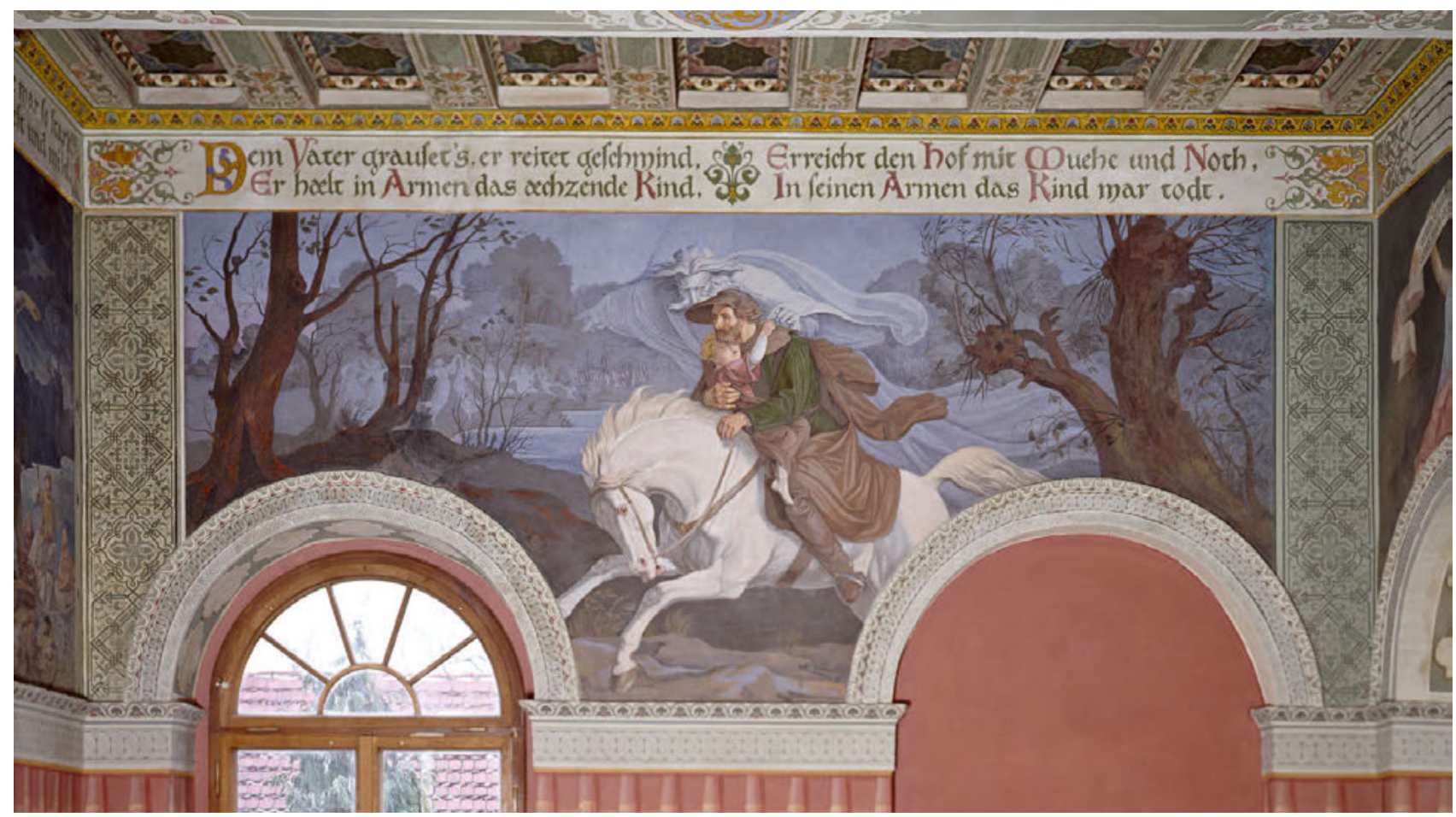

112 Carl Gottlieb Peschel, Der Erlkönig, 1836-38, Fresko, 180 × 450 cm, Dittersbach, Schönhöhe, Belvedere, Ostwand

programm, dass sich der Zyklus, vom Hauptbild des Sängers ausgehend, in zwei Richtungen des spoetischen Denkens und Lebens« bewegte. Die romantische Poesie, die gefördert werde und sich entfalte, strebe einerseits in die Richtung des Geheimnisvollen der Natur. Dieses dumpfe Erahnen steigere sich über den Geistes-Gruß hin zur schauerlich-ungeheuren Klimax im Erlkönig. Andererseits neige sie sich der Sehnsucht und der Liebe $\mathrm{zu}$ - auch hier spannungsreich potenziert. Der König in Thule werde durch den Drang zur Selbstauflösung des Individuums in der Natur im Fischer noch gesteigert. ${ }^{106}$

Die einzelnen Szenen sind mit Spruchbändern überschrieben, die nicht direkt mit der Darstellung zu tun haben. Quandt wollte die Bilder nicht erklären, sondern ergänzen: »Überhaupt habe ich bei den Überschriften auf der Wand, wo diese Bilder sich befinden, solche Stellen aus den Romanzen gewählt [...], welche allein der Poesie angehören, denn was bildlich darstellbar an einer Romanze ist, soll in dem Bilde zu sehen seÿn u keiner erklärenden Worte bedürfen.«107

Die Binnenbezüge der Fresken stehen, über Quandts zyklisches Gesamtkonzept hinausgehend, auf einem hohen $\mathrm{Ni}$ -

wanderten. S. a. Goethe 1827-1842, Bd. 15, S. 213-262; siehe Bluhm 2004 [2000], S. 3-4.

106 Friesen 1838, S. 253-254. S. a. den Brief von Quandt an Rochlitz vom 12.12.1841, in: SLUB, Mscr. Dresd. App. 26, Nr. 246.

107 Brief von Quandt an Rochlitz am 12.12.1841, in: SLUB, Mscr. Dresd. App. 26, Nr. 246. veau. ${ }^{108}$ So entpuppen sich nicht nur der Fischer und der Erlkönig als räumliche Pendants. Man kann auf mehreren Ebenen auch den König in Thule und den Geistes-Gruß aufeinander beziehen. In der Figurengestaltung zeigt sich der sterbende König als Pendant zum weisenden Geist, ebenso die Vorder- und Hintergründe. Obschon Quandt der Geistes-Gruß 3 als zu wenig heldenhaft erschien, hat Peschel hier einen wirkungsvollen ikonographischen Witz eingebaut: Mit dem Becher, den der König von Thule ins Meer geworfen hat, scheint eine der Figuren im Boot den Gruß des auffallend königsähnlichen Geistes ihm zuprostend zu erwidern. ${ }^{109}$ Man kann ihn damit als Symbol der romantischen Poesie bezeichnen. Folgerichtig wird der Sänger im entsprechenden Fresko mit einem Becher entlohnt. Als wiederkehrendes Motiv verbindet der Goldbecher die drei Bilder der Hauptwand und garantiert, künstlerisch phantasievoll umgesetzt, den inneren Zusammenhang des Zyklus.

Der goldene Becher weist schließlich auf Das Märchen weiter. Der Sänger und die gesamte Hauptwand seien der Vorzeit gewidmet, wie Quandt erklärte. Die Wahl der Gattung der Ballade erscheint vor dem Hintergrund von Vischers Erläute-

108 Vgl. hingegen Hecht 2000, S. 45: Quandts Schönhöhe von Peschel sei »auf wesentlich niedrigerem künstlerischen Niveau«. Zu den innerbildlichen Bezügen sei verwiesen auf Maaz 2002, S. 83-91; Maaz 1987 (1), S. 57-66; Maaz 1987 (2), S. 35-40.

109 Quandt äußerte sich Rochlitz gegenüber negativ über den GeistesGruß. Brief vom 12.12.1841, in: SLUB, Mscr. Dresd. App. 26, Nr. 246. 


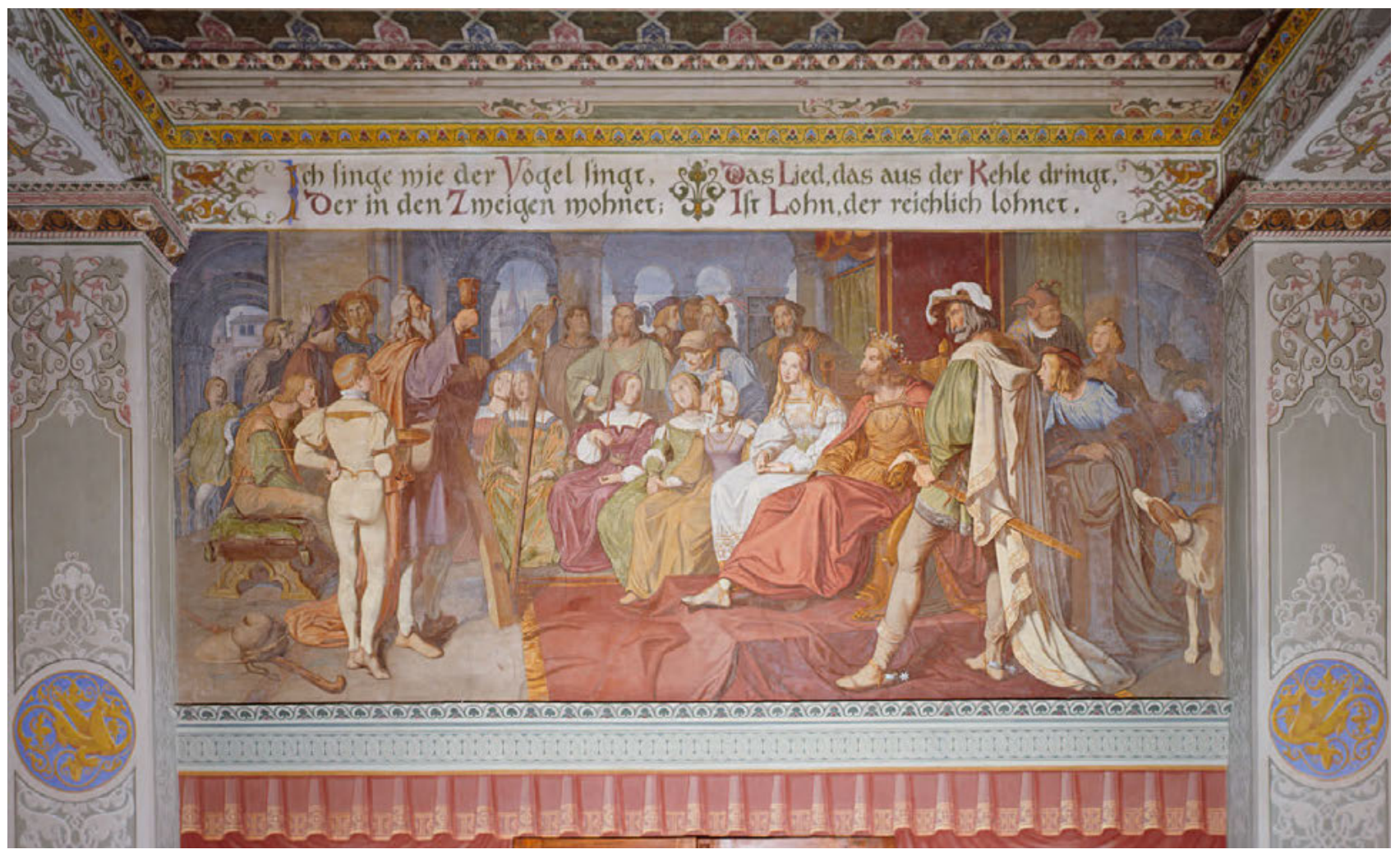

113 Carl Gottlieb Peschel, Der Sänger, 1836-38, Fresko, 180 × 400 cm, Dittersbach, Schönhöhe, Belvedere, Nordwand

rungen daher sinnig. Geschichten des Vergangenen wurden an die Gegenwart adaptiert. Ihnen stellte Quandt nun die Zukunft gegenüber, indem er mit dem Märchen nicht eine Ballade, sondern eine Erzählung Goethes aufnahm. Er interpretierte den Sinngehalt der Geschichte als neue Ordnung im goldenen Zeitalter. ${ }^{110}$ Diese zeitliche Ebene, die das utopische Fernziel einer besseren Welt beinhaltet, lässt die Fresken einen Teil von Quandts Grundidee des Rittergutes Dittersbach werden.

Sinnigerweise über dem Haupteingang angebracht, wies das Bild den Hinaustretenden in eine optimistische Zukunft. Hier eröffnete sich ihm die Natur des Dittersbacher Landschaftsparks, den Quandt gestalten ließ. Vielleicht raunte ihm der Gutsbesitzer ins Ohr: »Nicht nur auf Haus, Hof und Garten beschränkt der sinnige Mensch seine ordnende Thätigkeit, die Kunst ist ihm Rathgeberin für Alles und er verbreitet sie

110 Quandt, in: Friesen 1838, S. 253. Bluhm 2004 [2000], S. 16-18 hat darauf aufmerksam gemacht, dass der Subtext des Märchens eine Skepsis gegenüber der Hoffnung einer Bildung des Menschen durch die Kunst sei. Quandt scheint diese Ebene - genauso wie schon Schiller als Herausgeber der Erzählung in Die Horen - nicht erkannt zu haben. Ihm fiel einzig die Auflösung der vielschichtig gespaltenen Welt, symbolisiert durch die vier metallenen Könige, auf. Diese Auflösung geschah durch die Liebe. Dieses menschlichste aller Gefühle musste Quandt dazu bewogen haben, das schwer verständliche Märchen als Zielpunkt seines Freskenzyklus zu erwählen. Siehe Goethe 1827-1842, Bd. 15, S. 256-257. über Feld, Wiese und Wald.«"'1" Diese Tätigkeit des gestaltenden Menschen führt zur Rede bei der Grundsteinlegung zurück. Alle menschlichen Taten reihen sich in den Lebenszyklus der Menschheit ein. Gegenwärtiges vergeht und Neues kommt. Die einzige Kontinuität der Menschheit ist ihre Existenz, die eine schöpferische ist. In der Figur des wasserschöpfenden Mädchens, der so genannten Nymphe, welche Quandt 1835 als freien Auftrag an Ernst Rietschel gegeben hatte, scheint dieser Aspekt mitzuschwingen (Abb. 117). Quandt stellte diese Statue eines »heiteren Lebensmoment [es] $]$ am Bachlauf der Wesenitz in einer Nische auf."12 Dort verwies sie wie die anderen bildhauerischen Arbeiten und Kleinarchitekturen und das Belvedere auf die schöpferische Tätigkeit des Menschen. Kunst, so die Botschaft, konnte durch ihre Beständigkeit Individuen überdauern. Im Wissen um diese Möglichkeit ließ Quandt Gegenstände und

111 Quandt 1830 (1), S. 367-368 über den Sinn der Gartengestaltung. 112 Wilmowksy 2017, WVZ 44, S. 295-299. Der Auftrag erging 1835. Rietschel kämpfte mit dem Motiv, Quandt zögerte mit dem Material, schließlich wurde nach dem Gipsmodell des Bildhauers 1840 ein wetterbeständiger, weiß gefasster Zinkguss produziert, der in einer grottenartigen Nische aus rohen Felsquadern unmittelbar am Bach Wesenitz aufgestellt wurde. Die seit 1945 verschollene Skulptur wur de 2012 in einem neuen Marmorguss wiederhergestellt; siehe dazu Peter Große, »Bericht zur ordentlichen Mitgliederversammlung am 23.2.2013", Archiv des Autors. 


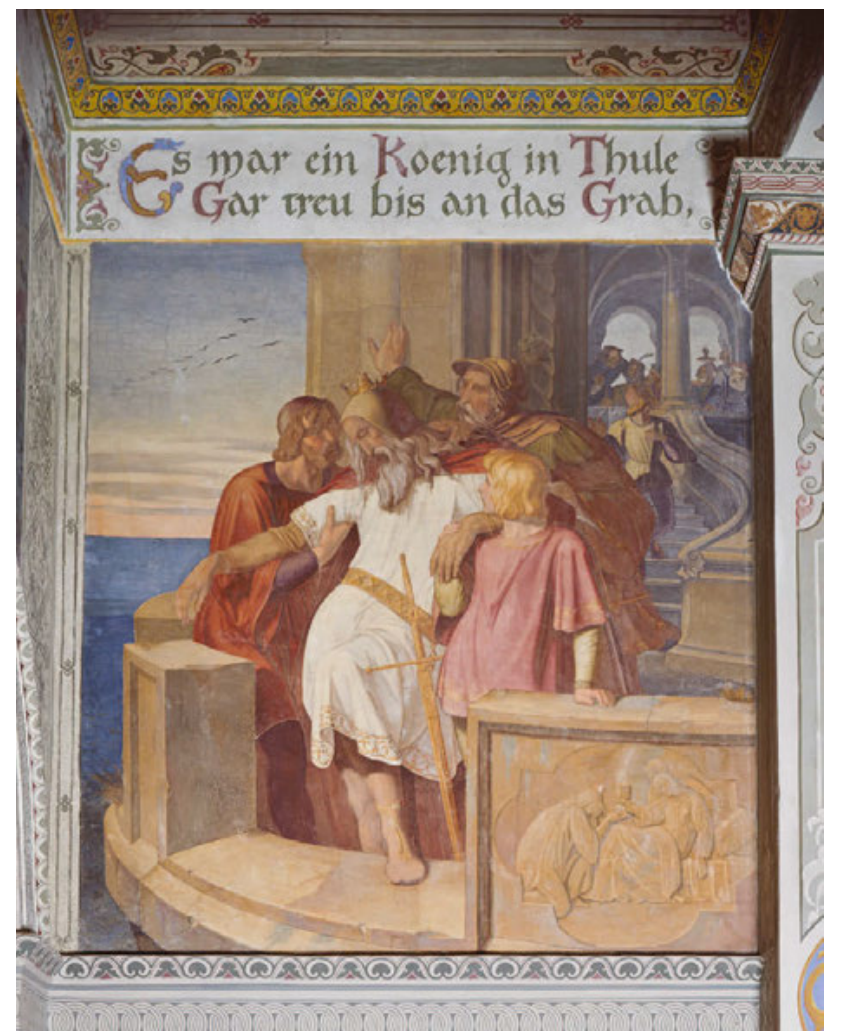

114 Carl Gottlieb Peschel, König in Thule, 1836-38, Fresko, $180 \times 165$ cm, Dittersbach, Schönhöhe, Belvedere, Nordwand

den erwähnten Brief Goethes im Grundstein ein und richtete sein Wort an einen zukünftigen Archäologen: »Und Du, geliebter, unbekannter, später Nachkomme, der einst den Schutt von diesem Orte abräumt und zu neuem Anbau ebnet, wenn Du dieses Blatt [die Rede zur Grundsteinlegung - AR] mit unsern Namen und Nachrichten findest; denk fröhlichen Muths an uns $\left[\ldots . . . \ll^{113}\right.$

In der Forschung wurde das Versenken von Gegenständen als Analogie zur Grundsteinlegung für das Haus auf der Höhe in Goethes Wahlverwandtschaften erkannt. Quandt hatte sie selber in einem Brief an Goethe erwähnt: »Die anwesenden Freunde [...] folgten dem Beyspiele in den Wahlverwandtschaften, kleine Andenken in die Höhlung des Steines legend. $\ll^{114}$ Die Übereinstimmung von Quandts Beschreibung dieses Aktes ist in der Tat der Szene in den Wahlverwandtschaften frappierend ähnlich. Auch die Begründung des Rituals ähnelt Quandts Anliegen: Der Maurer im Roman weiß wie Quandt auch, dass in der Zukunft alles Versteckte durch den Verfall des Baus wieder zum Vorschein kommen wird. ${ }^{15}$

113 Quandt 1840 (1), S. 4.

114 Brief vom 6.11.1831, in: Schmitz/Strobel 2001, S. 144; Maaz 1987 (2), S. 34 machte als erster auf den damals noch unpublizierten Brief aufmerksam. S. a. Tausch 2010, S. 89-94.
Doch der Subtext der Szene in den Wahlverwandtschaften stimmt nicht mit Quandts Grundsteinlegung überein. Der Maurer in Goethes Roman erwähnt in seiner Rede drei Dinge, die bei einem Neubau zu beachten seien: der rechte Bauplatz, ein starkes Fundament und die Vollkommenheit in der Ausführung. Das neue Haus im Roman steht für die adlige Familie, für deren Erhalt und Nachkommenschaft gesorgt werden soll. Aber genau diese althergekommene Ordnung bricht im Laufe der Erzählung vollständig auseinander. Keines der drei Elemente, die dem Maurer sinnbildlich in den Mund gelegt worden sind, würde zutreffen. Der Adel als Garant für Stabilität war untergegangen. Diese gesellschaftskritische Deutungsebene bezog sich auf den in die Krise gekommenen Landadel zur Zeit von Napoleons Machtübernahme in Deutschland anfangs des 19. Jahrhunderts. In diesen Jahren entstanden die Wahlverwandtschaften. Es stellte sich die Frage nach gesellschaftlichen Neuerungen, doch die Antwort dazu lässt der Roman offen. ${ }^{116}$

Quandt scheint Goethes Hinterfragen des althergekommenen Systems erkannt zu haben. Seiner Rede zur Grundstein-

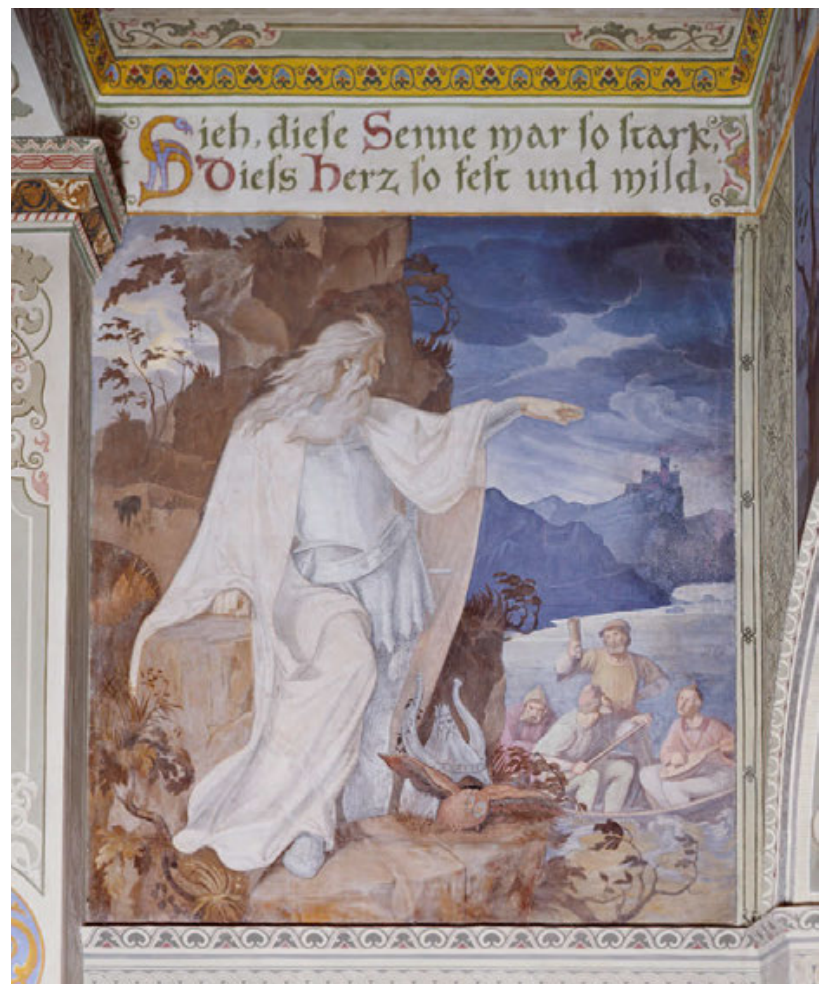

115 Carl Gottlieb Peschel, Geistes-Gruß, 1836-38, Fresko, $180 \times 165$ cm, Dittersbach, Schönhöhe, Belvedere, Nordwand

115 Die entsprechende Szene findet sich im 9. Kapitel des Romans.

116 Kreutzmann 2010, S. 334-339, 346-347 mit weiterführender Literatur. S. a. Bolz 1997, S. 156-157, 169. 


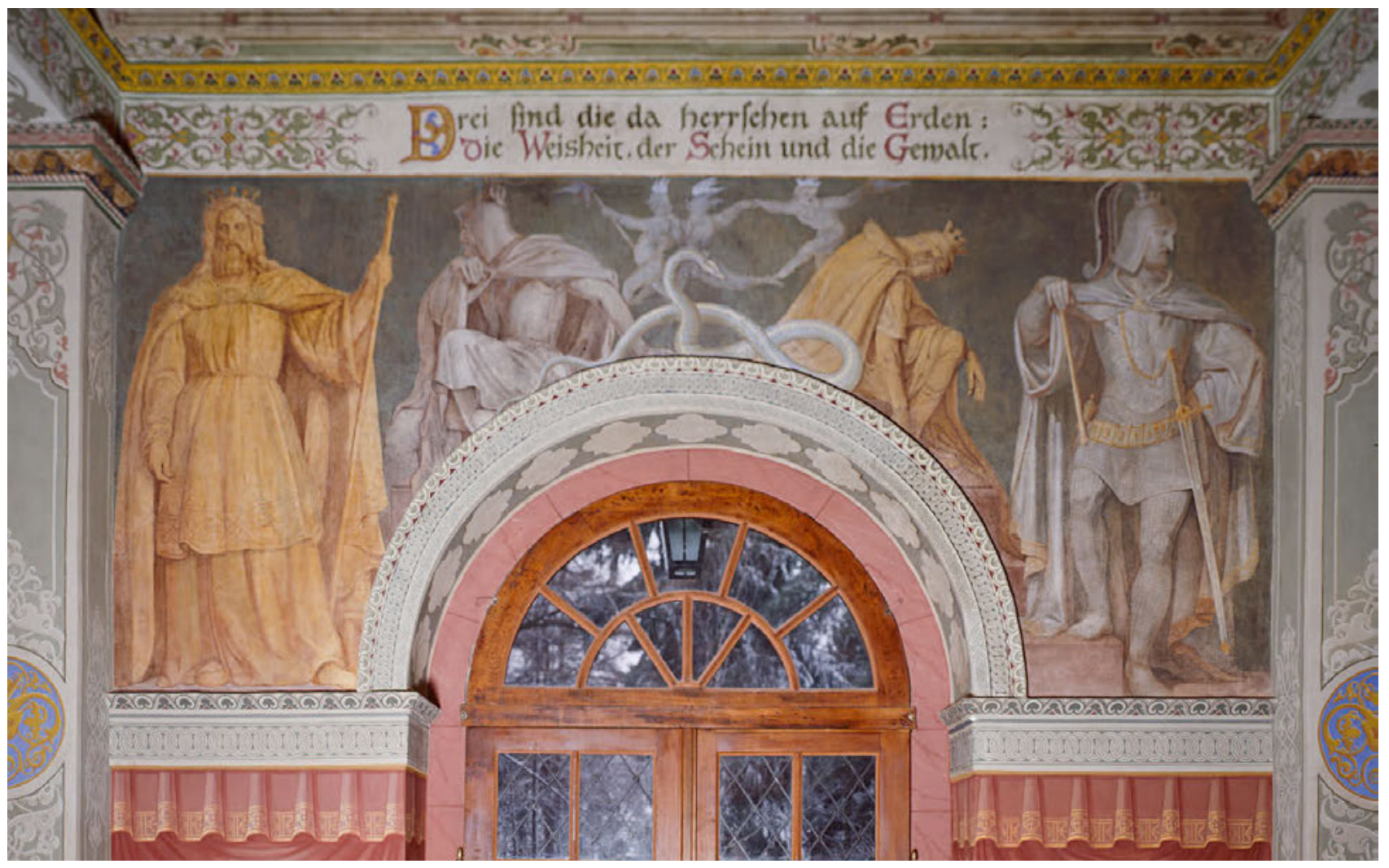

116 Carl Gottlieb Peschel, Das Märchen, 1836-38, Fresko, $180 \times 400$ cm, Dittersbach, Schönhöhe, Belvedere, Südwand

legung entgeht jeglicher Bruch, den man in der analogen Szene der Wahlverwandtschaften erkennen kann. ${ }^{117}$ Der Rittergutsbesitzer und neuadlige Bürger wollte im kleinen Dittersbach eine Gesellschaft bauen, in der eine klare Ordnung herrschte-keine demokratische, aber auch keine absolutistische, wie er selber sagte. ${ }^{118}$ Quandts adlig geprägte Landherrschaft hatte dementsprechend eine bildungsbürgerlich-idealistische Ordnung, in der die Kinder das Alphabet lernten, eine genossenschaftliche
Sparkasse eingerichtet wurde, Feste für die Bevölkerung stattfanden, Turnunterricht eingeführt werden sollte und die Landwirtschaft reformiert wurde. ${ }^{119}$ Nach den Wirren der Revolution musste sein Ziel Stabilität in Gesellschaft und Staat sein. In der Zukunft lag die Hoffnung und am Grundstein des Belvedere auf Schönhöhe sprach er: »[...] denn die Welt liegt im Großen und Ganzen als ein Paradies vor uns. $\ll^{120}$ Quandt schien also dort anzusetzen, wo Goethe die Lösung offen gelassen hatte.
117 Das Haus im Roman ist zum Einsturz verurteilt: der Grundstein liegt nicht auf ebener Erde, eine erste Mauer wurde schon vor der Grundsteinlegung errichtet und der hier agierende Maurer ist nur ein Geselle; Tausch 2010, S. 94-96. S. a. Bolz 1997, S. 178-179.

118 Quandt 2001 [1870], S. 242.

119 Diese Ordnung war ständisch und Quandt ihr Grundherr. Sein Selbstverständnis wird in einem Brief an Rochlitz vom 12.12.1841 deutlich. Quandt berichtete ihm über den Neubau des Gutshauses in Rossendorf - ein Dorf, das zu seinem Rittergut gehörte. Das herrschaftliche Haus wurde von vier runden Ecktürmen dominiert. »Der Roßendorfer Hof, den ich an eine neue Stelle versetzt habe, wo er wie eine große Burg sich ausbreitet, war noch ein weit umfassenderes Unternehmen. Ich gestehe, daß mich meine aristokratische Denkungsweise zum mittelalterlichen Baustÿl hinneigt; außer dem aber, muß auch ein Gebäude nicht als fremde Pflanze, sondern einheimisch in einer Gegend erscheinen u da passt sich denn in einen Föhrenwald, auf einem Berge, an dessen Fuß sich ein großer Teich ausbreitet u unter unsern meist trüben nordischen Himmel kein anderes Gebäude, als mit Mauern, Thoren Thürmen u Warten. Meine aristokratischen Gesinnungen habe ich durch die Überschrift des Burgthors, zu rechtfertigen gesucht, welche also lautet. Domus Domini est Subjectorum Refugium.« SLUB, Mscr. Dresd. App. 26, Nr. 246.

120 Quandt 1840 (1), S. 4. Daher kann beileibe nicht von einem Versuch Quandts gesprochen werden, die Wahlverwandtschaften modellhaft nachzuahmen; vgl. Tausch 2010, S. 92. Das zweistöckige Gebäude ist für Tausch ein Beweis hierzu. Ob Goethe nicht vielmehr selbst auf eine Schrift wie Hirschfelds Theorie der Gartenkunst von 1782 referiert, in der ein ebenfalls zweistöckiges Gebäude abgebildet ist? Siehe Hirschfeld 1782, Bd. 4, S. 33-35. Immerhin war dies das populäre Standardwerk der Gartenbaukunst jener Zeit und ein wichtiges Argument für die These von Tauschs Artikel; ebd., S. 98-103. S. a. Mandelkow 1975-1984, S. LXIV über Nachahmung und Eklektizismus bei den Goetheanern. 
Der »Goetheaner« Quandt hatte mit seinem Denkmal für Goethe mehr als die Erinnerung an den großen Weimarer Dichter zum Ziel gehabt. Goethe war für ihn Vorbild, um den Blick auf das Leben der Menschen und das menschliche Wirken zu wenden. Damit ist das Belvedere weniger Ort des GoetheGedenkens als vielmehr Denkmal des idealen Menschenlebens. Goethe steht am Anfang von Quandts Inszenierung. Vom Dichter ausgehend führt der Gedankengang weiter und zeugt von ei-

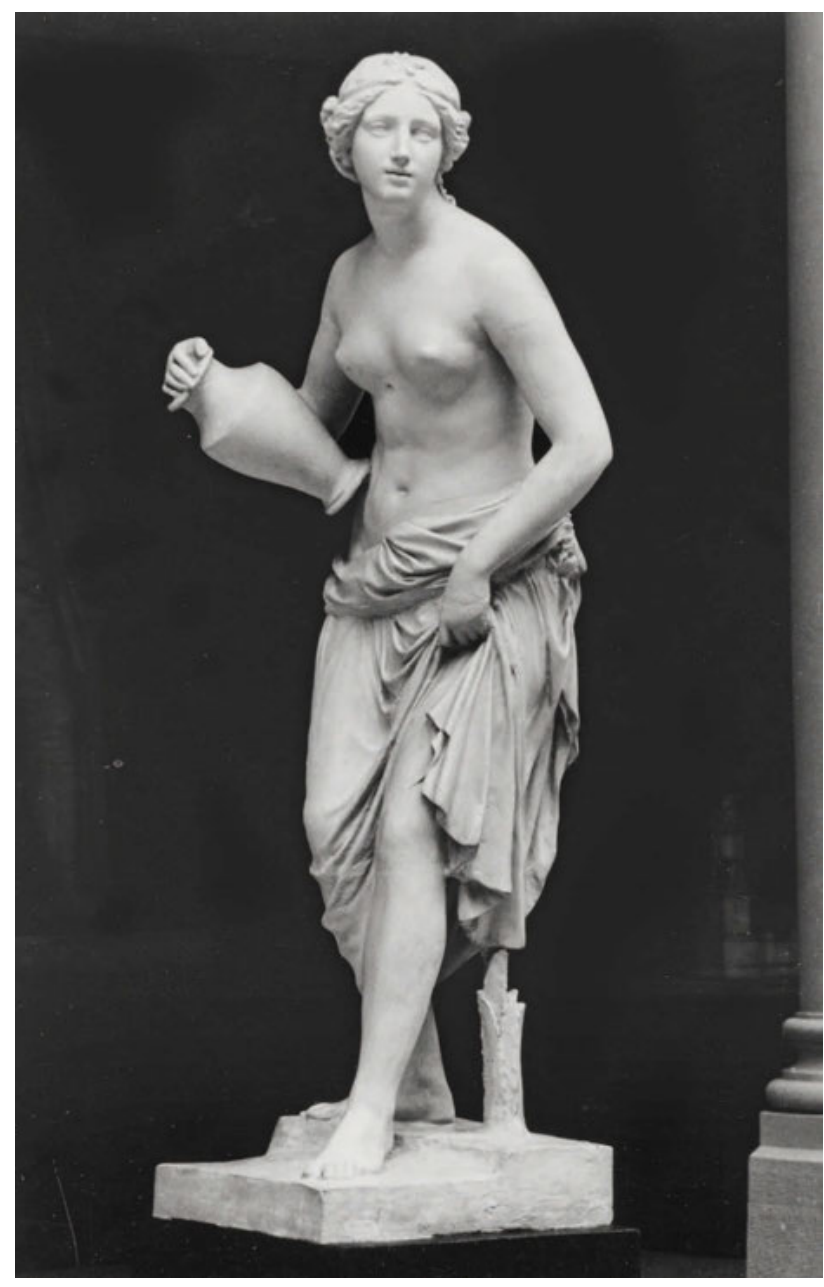

117 Ernst Rietschel, Nymphe, 1836/37, Gips, ehemals Dresden, RietschelMuseum, Verbleib unbekannt

121 Brief an Gustav Schüler vom 28.7.1841, Karlsruhe, Badische Landesbibliothek, Autographen, K 703, [fol. 1v].

122 Kunst-Blatt 1841, Nr. 99, S. 412. Die Goethe-Galerie ist eines der vier Dichterzimmer für Schiller, Wieland, Herder und Goethe. Schorn berichtete im Kunst-Blatt der Jahrgänge 1836-1842 regelmäßig vom Projekt. Das Schiller-Zimmer wurde ab 1835 als erstes ausgeführt; s. a. Hecht 2012, S. 13-30; Bertsch 2011, S. 255-261; Hecht 2000, S. 36-115.

123 S. a. Hecht 2000, S. 45, 91. ner Komplexität, die nicht einfach als epigonenhafte Verehrung des großen Weimarers bezeichnet werden kann.

Quandt war sich dennoch des Denkmalcharakters seines Freskensaals bewusst: »Das Unternehmen Göthen dadurch [durch die Fresken im Belvedere in Dittersbach - AR] ein Denkmal zu errichten, darf sich wohl dem in Weimar zur Seite stellen. ${ }^{121}$ Bescheiden stellt Quandt sein Dittersbacher Türmchen neben die Goethe-Galerie im Westflügel des Weimarer Schlosses, deren Ausgestaltung unter der Leitung von Ludwig Schorn nach Plänen von Schinkel 1841 in vollem Gang war (Abb. 118).122 Doch in diesem Fall hätte Quandt sein Projekt durchaus etwas mehr in den Vordergrund rücken dürfen. Der Erlkönig, Der König in Thule und Der Fischer der Goethegalerie, die Bernhard Neher Ende 1841 vollendet hatte, weisen bei allen Unterschieden einige Übereinstimmungen in Komposition, Haltung und Ausdruck der Figuren mit denjenigen von Peschel in Dittersbach auf. Sicherlich übernehmen die Darstellungen nach den drei Balladen in der Goethegalerie keine Hauptrolle, überfassen sie doch jeweils in kleineren Bildfeldern die monumentalen Hauptszenen. Dennoch erscheint es gerade in diesen Nebenszenen nachvollziehbar, dass Neher angesichts der Auftragsgröße Inspirationsquellen zuließ, um auf verwandte Bildfindungen zu kommen. So ist es beim Erlkönig vor allem die Figurengruppe des Reiters mit dem Kind und dem Erlkönig, die miteinander verwandt sind. Auch der Ausdruck des gehetzten Pferdes und der weisende Arm des schwebenden Geistes ähneln Peschels Interpretation (Abb. 119-120). ${ }^{123}$ Beim König in Thule sind es Architektur und Figurengruppe im rechten Bildvordergrund, die auf Peschels Fresko referieren, wenn auch das Darstellungsmoment ein anderes ist (Abb. 121-122). Ebenso offenbart sich im Fischer die weitgehend gleich komponierte Figurengruppe (Abb. 123-124). Besonders frappant zeigt sich die Kongruenz bei der Figur des Jünglings: Seine sehnsüchtige Reaktion auf die Nixe wirkt genau gleich wie diejenige des Fischers auf Schönhöhe.

Quandt ließ zwischen 1839 und 1841 bei Anton Krüger alle Fresken außer dem Märchen in Kupfer stechen und versandte diese unter anderem auch nach Weimar. ${ }^{124}$ Da Neher ab 1841 in Leipzig tätig und dadurch nicht mehr häufig im Weimarer Schloss anwesend war, um am umfassenden Bildprogramm zu arbeiten, könnte er die Stiche als Ideenvorlage benutzt haben. ${ }^{125}$

124 Brief von Quandt an Schnorr vom 17.2.1839, in: SLUB, Mscr. Dresd. n Inv. 15, Bd. 31, fol. 205r; Brief von Quandt an Louise Seidler vom 30.7.1841, in: Schmitz/Strobel 2001, S. 196. S. a. Kunst-Blatt 1839, Nr. 29 , S. 115 und ebd. 1841, Nr. 68, S. 288.

125 Im Dezember 1841 waren der Fischer und der König in Thule vollendet; siehe Kunst-Blatt 1841, Nr. 99, S. 412. Im Kunst-Blatt 1842, Nr. 72, S. 288 wird erwähnt, dass Neher an den Balladen arbeite. S. a. Bertsch 2011, S. 261 


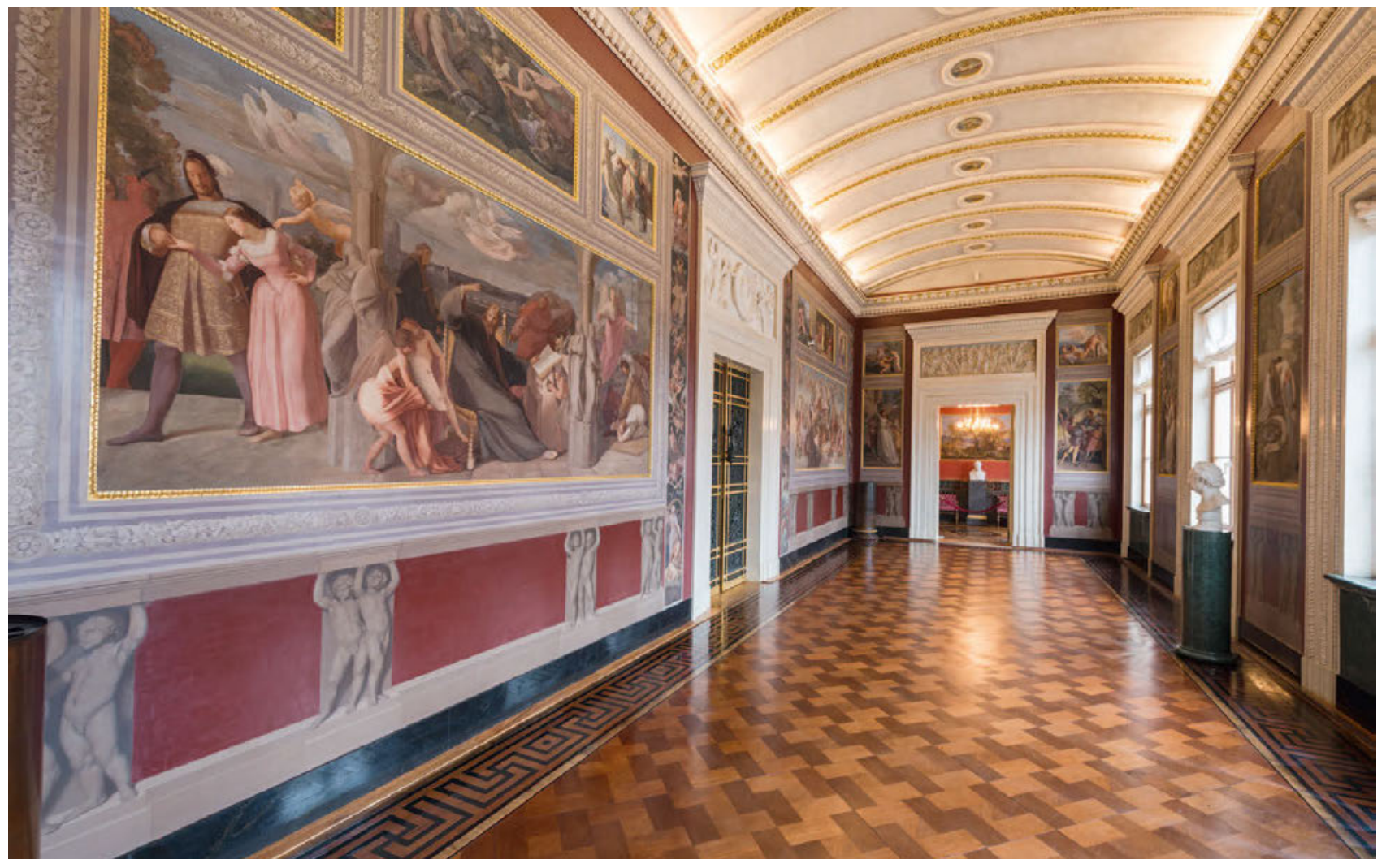

118 Goethegalerie, Weimar, Residenzschloss, Westflügel, 1. Obergeschoss, Raum 14.3

Zudem kann eine persönliche Bekanntschaft anhand eines Briefes von Quandt an Neher nachgewiesen werden. Neher war am 29. Oktober 1841 in Dresden und Quandt arrangierte ein Treffen mit dem Staatsminister von Lindenau. ${ }^{126}$ Die Ausmalung der Weimarer Dichterzimmer war zu diesem Zeitpunkt hochaktuell, so dass ein Austausch über die Frage zwischen Neher und Quandt angenommen werden darf. Neher wird Quandt in seinem offenen Haus in Dresden besucht haben und man hat mindestens die Kupferstiche oder die Vorzeichnungen von Peschel zusammen diskutiert. Dass Neher ins wenig weit entfernte Dittersbach gereist ist, erscheint als wahrscheinlich.

Möglicherweise hatte Quandts Idee eines konsequenten Bildprogramms schon Jahre zuvor vorbildlich gewirkt. Immerhin war Schorn 1835 von Quandt selbst darüber unterrichtet worden - im Jahr des Planungsbeginns für ein Goethe-Zimmer in Weimar. ${ }^{127}$ Hier hatte Schinkel zwar noch versucht, dem
Raum ein einheitliches Programm zu geben, doch in einem Dichterzimmer, das zur Verehrung gedacht war, mussten vor allem zahlreiche Referenzen zu möglichst vielen Werken gegeben werden. ${ }^{128}$ Quandts Bilderzyklus als Sinnbild für das Menschenleben und die schöpferische Kraft des Menschen in allen Zeiten war in diesem Sinn zielgerichteter und nicht allein auf die Verehrung Goethes ausgerichtet. Er wollte damit die Gesellschaft bilden und glaubte durch die Gattung des Freskos hierbei einen ersten Schritt getan zu haben. Er hoffte, dass er vorbildhaft für die staatlichen Akteure wirken würde. Seiner Meinung nach waren sie verpflichtet, Aufträge an Künstler zu vergeben, um mit öffentlichen Kunstwerken die Volksbildung zu fördern. Als König Friedrich August II. den Freskensaal in Dittersbach sah, sagte er zu Quandt, es sei gut, dass jemand den Anfang gemacht habe, al fresco malen zu lassen. Quandt habe darauf geantwortet: Und noch besser ist es Ew Maj:, wenn es nicht beÿm
126 Brief von Quandt an Neher vom 29.10.1841, in: SLUB, Mscr. Dresd., App. 204, Nr. 97tm.

127 Zudem war Schorn im September 1839 bei Quandt auf Schönhöhe: »[...] Tiek [sic!], Carus, Quandt, Hrn. Min. v. Lindenau suchte ich in ihren Wohnungen auf. Den Sonntag verbrachte ich in Dittersbach zu, es war das herrlichste Wetter und ich erfreute mich recht an den schönen Parkanlagen, auch die Fresken gefielen mir im Ganzen sehr wohl [...]. « Brief von Schorn an Johann Georg Keil vom 10.10.1839, in: SLUB, Mscr. Dresd. D.410, I, (Sammlung »Briefe an Familie Keil«), Nr. 143, vollständig abgedruckt in: Wentzlaff-Eggebert 2009, S. 312-314 128 Hecht 2012, S. 29-30. Anstelle von Schinkels antikisierendem Entwurf des Bildprogramms entstand ein historistisches. Mit Prellers vaterländischen Prospekten im Conseil-Saal bestand eine Verbindung der Goethe-Galerie mit den anderen Dichterzimmern für Schiller, Wieland und Herder. Das Dichtergedächtnis war damit national konnotiert. Zum Programm s. Hecht 2012, S. 15-17; Hecht 2000, S. 42-47. 


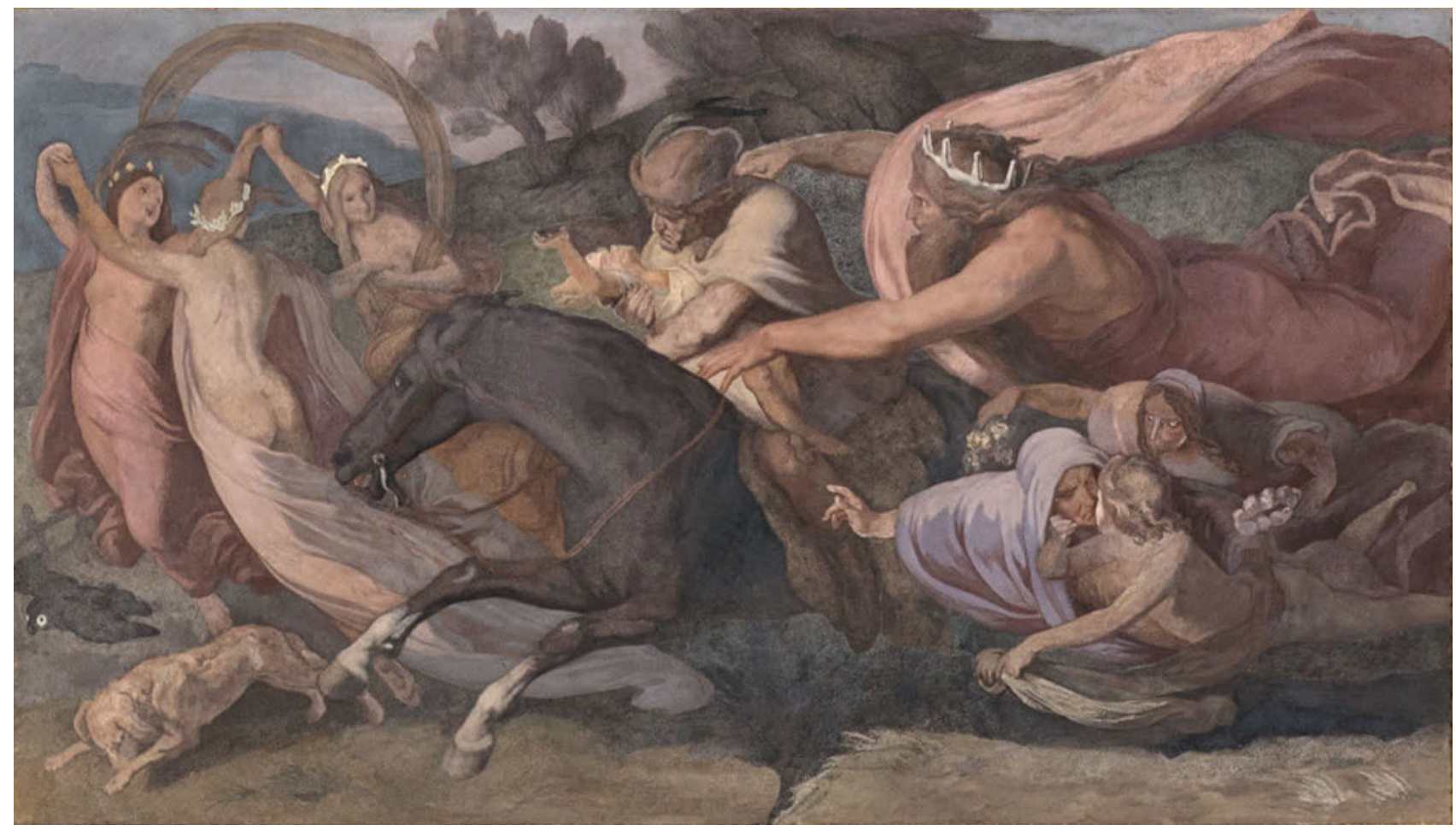

119 Bernhard Neher, Der Erlkönig, 1841, Fresko, Weimar, Residenzschloss, Westflügel, 1. Obergeschoss, Raum 14.3. Goethegalerie

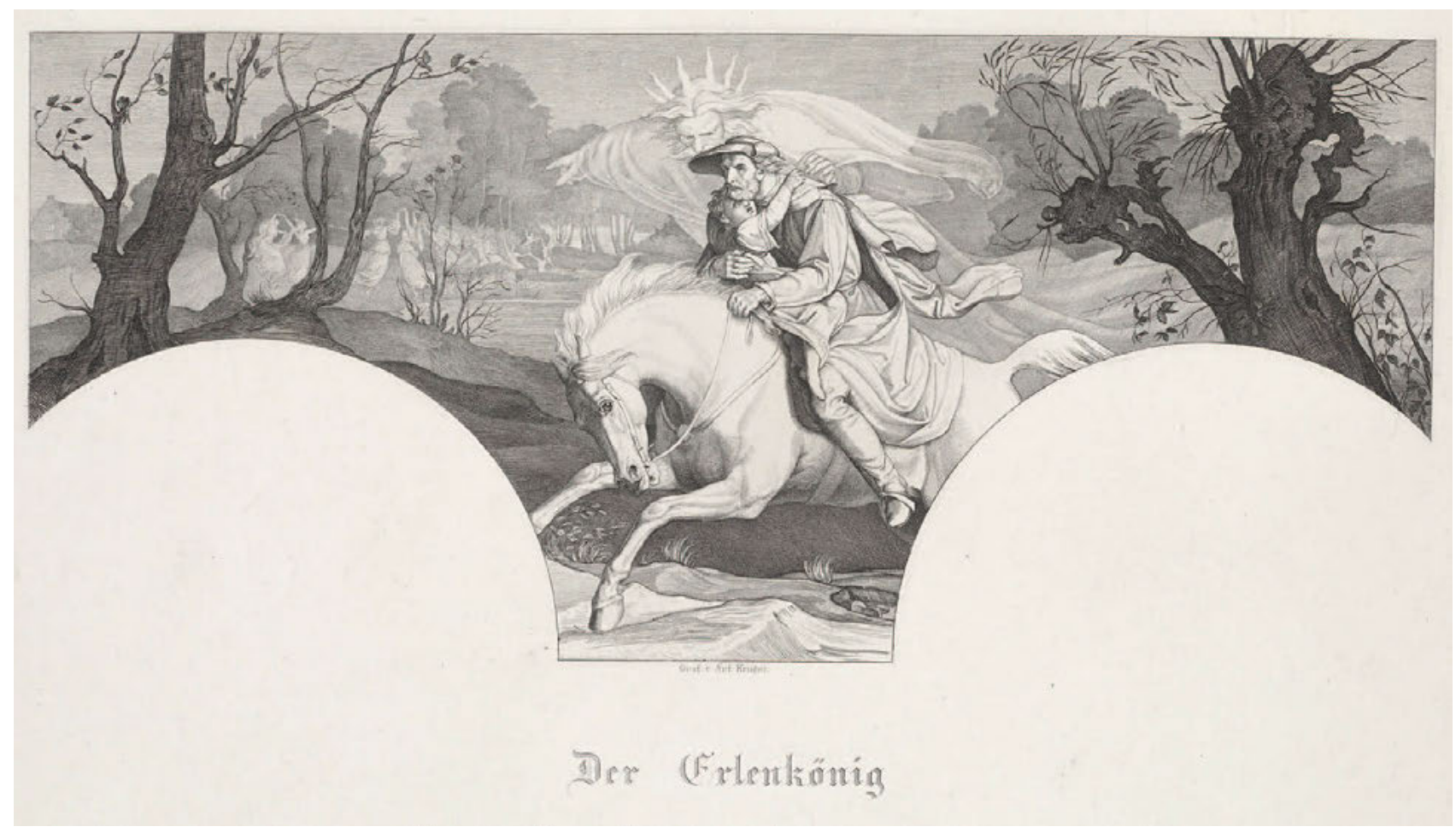

120 Ferdinand Anton Krüger nach Carl Gottlieb Peschel, Der Erlkönig, um 1839, Stahlstich und Radierung, $296 \times 410$ mm (Blatt), Weimar, Klassik Stiftung Weimar, Graphische Sammlungen, Inv.-Nr. KGr/O4017 


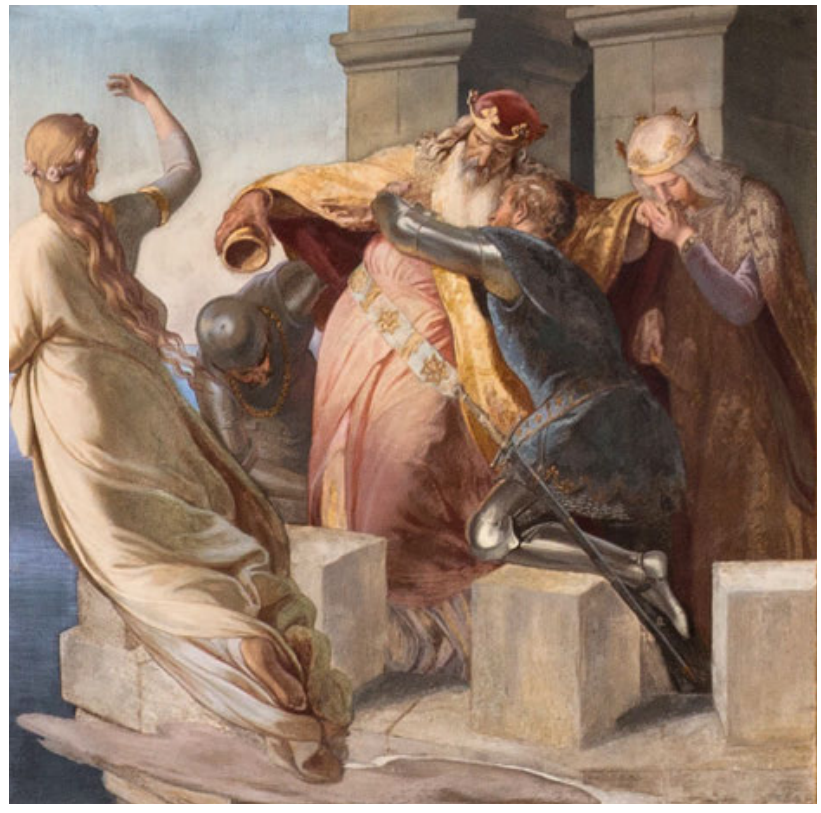

121 Bernhard Neher, Der König in Thule, 1841, Fresko, Weimar, Residenzschloss, Westflügel, 1. Obergeschoss, Raum 14.3. Goethegalerie

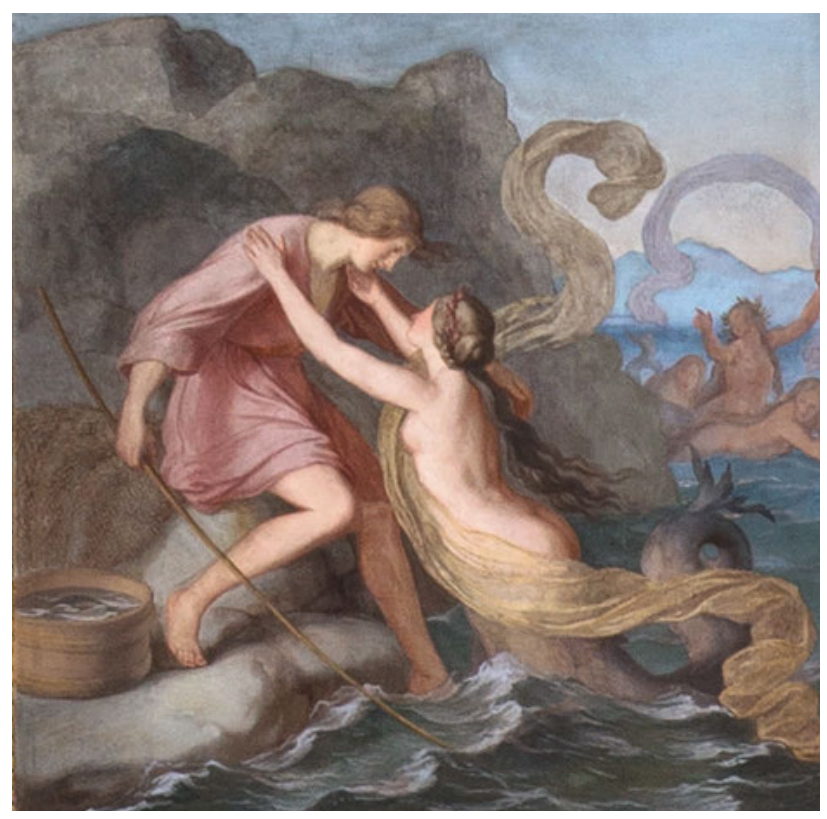

123 Bernhard Neher, Der Fischer, 1841, Fresko, Weimar, Residenzschloss, Westflügel, 1. Obergeschoss, Raum 14.3. Goethegalerie

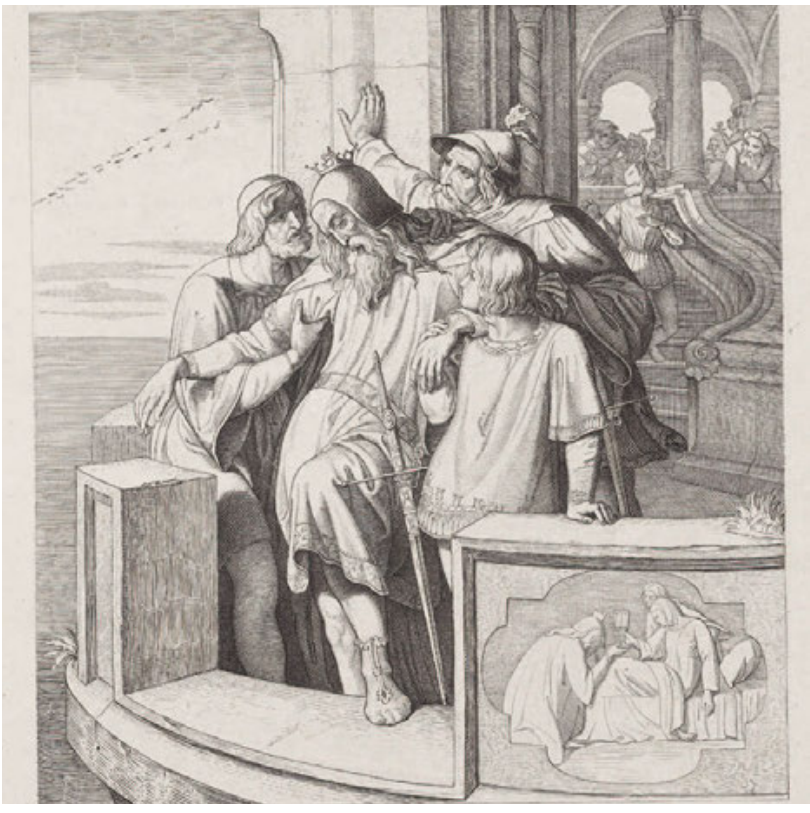

122 Ferdinand Anton Krüger nach Carl Gottlieb Peschel, Der König in Thule, um 1839, Stahlstich und Radierung, $221 \times 174$ mm (Blatt), Weimar, Klassik Stiftung Weimar, Graphische Sammlungen, Inv.-Nr. KGr/05132

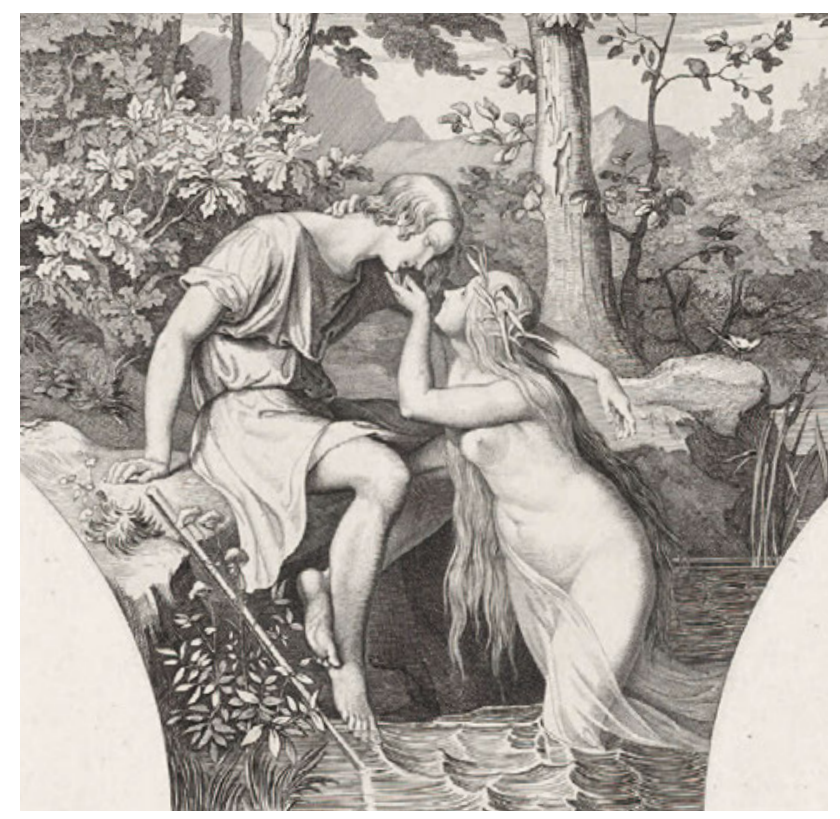

124 Ferdinand Anton Krüger nach Carl Gottlieb Peschel, Der Fischer (Ausschnitt), um 1839, Stahlstich und Radierung, $334 \times 483$ mm (Blatt), Weimar, Klassik Stiftung Weimar, Graphische Sammlungen, Inv.-Nr. KGr 03562 


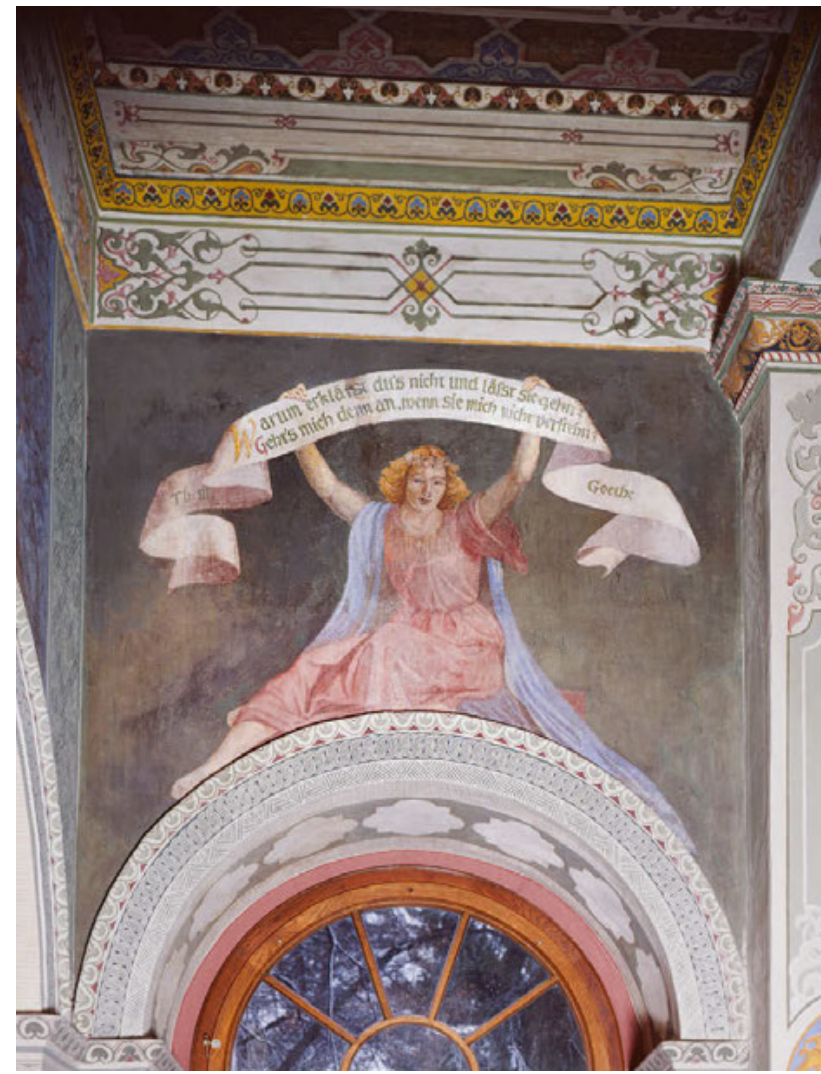

125 Carl Gottlieb Peschel, Figur mit Inschrift „Warum erklärst du's nicht und läßt sie gehn? Geht's mich denn an, wenn sie mich nicht verstehn? Goethe«, 1836-38, Fresko, Maße unklar, Dittersbach, Schönhöhe, Belvedere, Südwand

Anfang bleibt. «129 Nach der Berufung Eduard Bendemanns nach Dresden im Jahr 1837, um im Schloss Fresken mythologischen, historischen und allegorischen Inhaltes zu malen, war Quandt hocherfreut: »Ein helles Morgenroth geht an unserm Himmel auf $[\ldots] \cdot \ll 30$

Sein eigenes Bildungsprogramm mit Goethe als Vorbild vor Augen entfernte sich mit der später eingebetteten Darstellung des Märchens von einer konzisen Schlüssigkeit. Dass es mit dem Dittersbacher Rittergut trotz öffentlichen Anspruchs halt doch

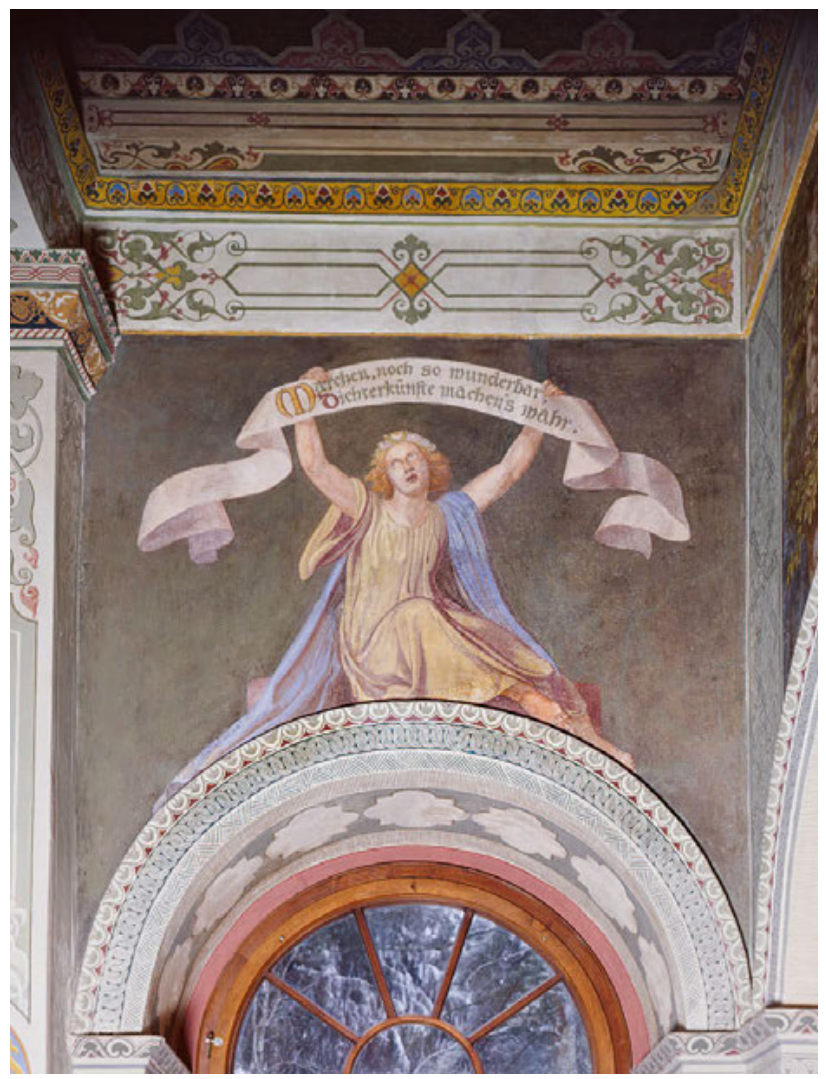

126 Carl Gottlieb Peschel, Figur mit Inschrift »Märchen, noch so wunderbar, Dichterkünste machen's wahr«, 1836-38, Fresko, Maße unklar, Dittersbach, Schönhöhe, Belvedere, Südwand

ein Privatprojekt blieb, war Quandt bewusst - auch wenn es in den elitären Kreisen Sachsens durchaus seine Wirkung zeigte. Die flankierenden Figuren links und rechts des Märchens scheinen mit ihren Schriftbändern denn auch die Grenzen des komplexen Bildprogramms zu kommentieren (Abb. 125-126). So heißt es einmal mit leiser Ironie: »Märchen, noch so wunderbar, Dichterkünste machen's wahr. «31' Die Pendant-Figur brachte es schließlich auf den Punkt: »Warum erklärst du's nicht und läßt sie gehn? Geht's mich denn an, wenn sie mich nicht verstehn? Goethe. ${ }^{132}$
129 Brief von Quandt an Schnorr vom 3./6.1.1837, in: SLUB, Mscr. Dresd. n Inv. 15, Bd. 31, fol. 197r. Quandt 1826 (1), S. 288-289. S. a. Schmitz 2008, S. 174; Schmitz/Strobel 2001, S. LI.

130 Brief von Quandt an Winkler vom 5.10.1837, in: SLUB, Mscr. Dresd. App. 204, Nr. 98e.

131 Goethe 1827-1842, Bd. 1, S. 174.

132 Zitat gemäß der Inschrift. Goethe 1827-1842, Bd. 3, S. 234. Die Verse hatten für Quandts Goethe-Verständnis eine tiefere Bedeutung. So schrieb er 1846 am Ende seiner Frankreichreise vor dem Geburtshaus des Dichters in Frankfurt, man müsse Goethe lieben, um ihn zu verstehen, und die Goethe-Kommentatoren sollten sich doch an ebendiese zwei Verse erinnern: »Da uns hiermit Alles gesagt zu sein scheint, was sich über die größte Erscheinung unsers Zeitalters sagen läßt, so will ich weiter keine Worte verlieren, mich in meinen ungarischen Pelz einhüllen und nicht eher entpuppen, als bis ich wieder in meinem von Bergen umschirmten Hause angelangt bin.»Quandt 1846 (2), S. 389. 


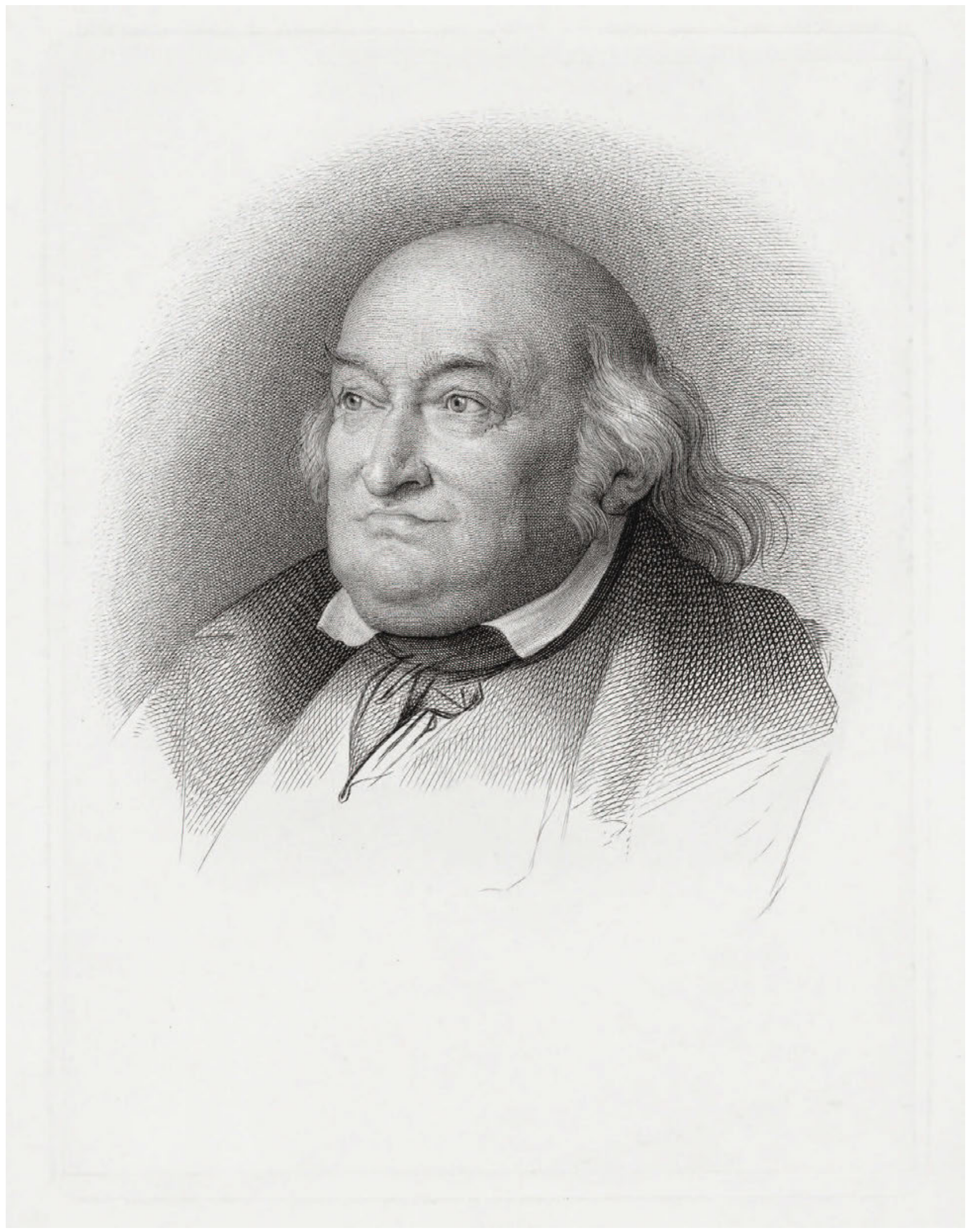

127 Carl Wilhelm Overbeck nach Eduard Bendemann, Bildnis Johann Gottlob von Quandt, 1850, Kupferstich, Maße unklar, Dresden, SKD, Kupferstichkabinett, Inv.-Nr. A 1897-309 


\section{JOHANN GOTTLOB VON QUANDT - EIN FRÜHER KUNSTHISTORIKER?}

Als Johann Gottlob von Quandt 1859 starb, erschienen zahlreiche Nachrufe in deutschen, ja selbst französischen und belgischen Zeitungen und Zeitschriften. ${ }^{1}$ Hervorgehoben wurden seine fundierten Kenntnisse der Kunst, die Förderung der Künstler, seine Einsichten über das Schöne, sein lebenslanges Engagement für die Künste und seine internationale Bekanntheit als Kenner und Kunstfreund (Abb. 127): »Am 19. Juni starb in Dittersbach der bekannte Forscher und Kenner der Kunst [...]. In allen seinen Werken offenbaren sich gründliche Kenntnisse, feiner Geschmack und geläuterter Sinn für das Schöne. Seinen persönlichen Werth bezeugen die vielen freundschaftlichen Verhältnisse, die für die ganze Dauer seines Lebens Leute aus allen Ständen, namentlich auch unsere berühmtesten Künstler mit ihm unterhielten. Als er starb, nahm er das Bewußtsein mit sich weg, das Wesen der Kunst in ihren Tiefen erkannt, sie auf geistreiche Weise studiert und ihre Pflege in der Gegenwart in sehr erheblichem Maße gefördert zu haben. $\ll^{2}$

\section{Quandt und die Konstituierung der Kunstgeschichte}

Sein Mäzenatentum ist bis heute bekannt geblieben. Doch darüber hinaus enthüllt das vertiefte Studium von Quandts Publikationen und seiner Korrespondenz einen ausgesprochen vielseitigen Kunstgelehrten. Nicht nur unterstützte er durch private Ankäufe zahlreiche Maler, sondern bemühte sich in öffentlichen Institutionen um Verständnis und Interesse für die Künste, die für ihn eine wichtige Errungenschaft menschlicher Gesellschaften war. Als Gründungsmitglied des Königlichen Altertumsvereins und Vorsitzender des Sächsischen Kunstvereins boten sich ihm viele Möglichkeiten. Mit seiner Kunstschriftstellerei verbreitete er die Erwartungen und Anforderungen, die ihm zur Erschaffung guter Kunst unentbehrlich erschienen. Darüber hinaus engagierte er sich in Museen wie der Gemäldegalerie und dem Historischen Museum für wissenschaftliche und didaktische Ausstellungen und öffnete seine eigenen, kenntnisreich präsentierten Sammlungen einem breiten Publikum.

Wenn Quandt als Mäzen und Förderer von Malern wie Julius Schnorr von Carolsfeld, Caspar David Friedrich und Adrian Ludwig Richter zwar nie ganz in Vergessenheit geraten ist, so fällt doch auf, dass er als früher Kunsthistoriker oder doch zumindest wichtige Persönlichkeit für die Genese des Faches Kunstgeschichte nie wirklich in Betracht gezogen wurde. ${ }^{3}$ Verschiedene Publikationen wie die Geschichte der Kupferstecherkunst von 1826 oder die Übersetzung von Lanzis Storia pittorica 1830 bis 1833 und seine wissenschaftlichen Präsentationen in den Dresdener Museen lassen Aspekte erkennen, die für die Konstituierung des Faches wichtig waren. Davon zeugt auch die zeitgenössische Sichtweise. In mehreren Nachrufen wurde er »unser berühmter
1 »[...] quelques mots de la perte que l'art vient de faire dans la personne de M. de Quandt, un des hommes qui ont le plus fait pour son développement dans notre pays depuis quarante ans. [...] En Allemagne il est honoré de tous ceux qui cultivent les beaux-arts, qui s'intéressent à leur histoire, qui espèrent les voir progresser encore." Gazette des Beaux-Arts, [Paris] 1859, 3. Bd., S. 191-192. »[...] un sincère ami des arts, connu aussi à l'étranger par ses nombreux écrits artistiques. Sa carrière fut des plus méritoires par la réorganisation de l'administration des Beaux-Arts à Dresde. L'académie des Beaux-Arts et le musée royal lui doivent, entre autres, ainsi qu'à son digne ami l'excellent ministre Bernhard Von Lindenau, leur organisation actuelle, et la mémoire de ces deux hommes vivra réunie dans leurs souvenirs reconnaissants." Journal des Beaux-Arts et de la Littérature, [Brüssel] 1859, Jg. 1, Nr. 13, S. 100.

2 Europa. Chronik der gebildeten Welt, 1859, Nr. 28, p. 1001-1002. Gleicher Artikel in Männer der Zeit. Biographisches Lexikon der Gegenwart, 1. Serie, Leipzig: Karl. S. Lorck, 1860, Sp. 913. »[...] den Tod des den Kunstfreunden, wohlbekannten, als Kunstschriftsteller geachteten Sammlers." Die Dioskuren. Zeitschrift für Kunst, Kunstindustrie und künstlerisches Leben. Hauptorgan der deutschen Kunstvereine, 1859, Jg. 4, Nr. 61, S. 114. "Sein ganzes Leben gehörte der Kunst und dem Wohlthun und beides gehörte zu seinem Leben.« Deutsche Allgemeine Zeitung, 23.6.1859, Nr. 143, S. 1266. »Heute früh verschied unser berühmter Kunsthistoriker Johann Gottlob v. Quandt im 73sten Lebensjahr. [...] Insbesondere für Dresdens Kunstzustände hat Quandt außerordentlich eingreifend und segensreich gewirkt. [...] Ebenso wenig ist zu vergessen dass besonders sein unermüdlicher Kampf gegen die Uebelstände des alten Galleriegebäudes es war welchem wir die Erbauung des neuen Museums verdanken. « Augsburger Allgemeine Zeitung, 23.6.1859, Nr. 174, S. 2843.

3 Vergleiche Prange/Locher 2007; Prange 2004; Locher 2001, S. 175, Anm. 140 erwähnt Quandt nur am Rande; MKL 2007; Dictionary of Art Historians. A Biographical Dictionary of Historic Scholars, Museum Professionals and Academic Historians of Art, hrsg. v. Lee R. Sorensen, Durham; Duke University [Internetressource: www.dictionaryofarthistorians.org, letzter Zugriff: 17.9.2018]; Kultermann 1966; Wilhelm Waetzold, Deutsche Kunsthistoriker, Leipzig: E. A. Seemann, 1924. 
Kunsthistoriker« genannt. ${ }^{4}$ Bereits zu Lebzeiten tauchte dieser Begriff auf und noch zwei Jahrzehnte nach seinem Tod hieß es, er sei der »Nestor der Kunstwissenschaft « gewesen..$^{5}$ In der Tat wurde er noch bis zu Beginn des 2O. Jahrhunderts in den bekannten Konversationslexika als Kunsthistoriker aufgeführt, ehe die Artikel über ihn nach und nach verschwanden. ${ }^{6}$

Nachfolgend sei Quandt in die Geschichte der Kunstgeschichte eingeordnet. Dies geschieht anhand einiger für die Konstituierung des Faches wichtiger Faktoren, die bei Quandt mehr oder weniger sichtbar werden. Dazu gehören nach Henrik Karge die Verfestigung des Begriffs »Kunstgeschichte«, Überblicksdarstellungen zwecks Absteckung des Gegenstandsbereichs, die Ablösung von der philosophischen Ästhetik, die Ausbildung einer diversifizierten Methodik und die Zuordnung von Kunst zu Epochenstilen, die Etablierung der Kunstgeschichte als Universitätsfach, die sich ausdifferenzierenden Publikationsmedien der Kunstgeschichte, schließlich die Transformation der Bildmedien, mit denen Kunst verbreitet wurde: von der Zeichnung über die Druckgraphik zur Fotografie.? Nicht alle diese Faktoren werden gleich tief behandelt, manche nur gestreift. Vor allem aber wird gezeigt, wie Quandt teilweise völlig mit diesen Entwicklungen einherging und manchmal dagegen anlief. Aus diesem Grund muss, Lena Bader folgend, für nachfolgende Einordnung Quandts in der Disziplingeschichte postuliert werden: »[Die] Vielzahl und Vielfalt der Positionen zeigen deutlich, dass die Konturen dessen, was Kunstgeschichte im 19. Jahrhundert ist, sowohl methodisch als auch personell, strukturell und selbst institutionell weder eindeutig noch selbstverständlich sind [...]. Eine großzügige Mehrstimmigkeit kennzeichnet jene Jahre; sie provoziert Methodenpluralismus, aus dem das Fach vielfältige Anstöße zur Entwicklung kritischer Instrumentarien schöpfen wird. ${ }^{8}$

Zuerst ist grundsätzlich festzuhalten, dass Quandts Name im Kontext der Verfestigung des Begriffs »Kunstgeschichte«

4 Augsburger Allgemeine Zeitung, 23.6.1859, Nr. 174, S. 2843. S. a. Neue Würzburger Zeitung, 25.6.1859, Jg. 60, Nr. 174, [s. p.] und die Landshuter Zeitung, 26.6.1859, Jg. 11, Nr. 143, S. 576.

5 »Es lacht uns daraus, wie von Quandt, der berühmte Kunsthistoriker bemerkt, mehr eine Ironie auf die Herrlichkeit alles irdischen Glanzes und Glückes an, als daß uns die Schauer des Todes anwehten. « August Lewald, »Über Todtentänze«, in: Abendblatt zur Neuen Münchener Zeitung, 14.1.1857, Nr. 12, S. 46. »In einem höchst interessanten, kürzlich an die Oeffentlichkeit gelangten Essay des Nestors der deutschen Kunstwissenschaft, J. G. v. Quandt: >Meine Berührungen mit Goethe heißt es am Schlusse [...]. M Magazin für die Literatur des Auslandes, 16.7.1870, Jg. 39, Nr. 29, S. 426.

6 Zu den Lexikoneinträgen über Quandt siehe Kap. Forschungsstand und Quellen in der Einführung.

7 Karge 2009, [S. 1].

8 Bader 2013, S. 27.

9 Herders Conversations-Lexikon, hrsg. v. Bartholomae Herder, Freiburg i/Br: Herder'sche Verlagshandlung, 1854-1857, S. 673. In Jacob Burck- als Disziplin bis ins frühe 20. Jahrhundert Erwähnung fand. Beispielhaft sei hier der knappe Eintrag im Herder-Lexikon von 1854/57 genannt: »Kunstgeschichte, nennt man vorzugsweise die Geschichte der Entwickelung der bildenden Künste; einen solchen Versuch über die alte Kunst haben wir von Plinius, der eigentliche Schöpfer der alten K. aber ist Winkelmann. Was die neuere Kunst betrifft, so hatte man über einzelne Theile derselben gute Schriften (Vasari, Waagen, Passavant, Quandt u.s.w.), doch erst Kugler (s. d.) lieferte die erste allgemeine K., Schnaase eine Geschichte der bildenden Künste (1.-4. Bd., Düsseldorf 1843 bis 55 ), ein Künstlerlexikon Nagler in 22 Bdn. (München 1835-53) « $\ll^{9}$ Immerhin wird hier Quandt als Verfasser kunsthistorischer Studien zusammen mit dem Berliner Gustav Friedrich Waagen und dem Frankfurter Johann David Passavant genannt, die heute unter anderen als frühe Vertreter des Faches in der ersten Hälfte des 19. Jahrhunderts anerkannt sind. ${ }^{10}$ Derselbe Lexikoneintrag nennt mit Franz Kugler und Carl Schnaase zwei Urheber großer kunsthistorischer Überblickswerke. Diese waren für die Etablierung des Faches von eminenter Wichtigkeit." In der Tat beabsichtigte Quandt selber zu Beginn seiner Karriere als Kunstgelehrter, eine kunsthistorische Gesamtdarstellung europäischer Kunst zu schreiben. Auf seiner Italienreise von 1819/20 wollte er »Materialien zu einer psychologisch genetischen Kunstgeschichte sammeln. ${ }^{12}$ Sein Opus magnum sollte Ursache und Wirkung künstlerischer Entwicklungen erklären, Zusammenhänge von Kunst und »Zeitgeist « erkennen lassen, durch die Beschreibung der Individuen die ganze Geschichte, »alles Seÿn, Wirken u Vorschreiten, einer in allen lebenden Weltseele, darstellen. $\ll^{13}$ Leider kam das Werk nie zur Vollendung. Ob Entwürfe entstanden waren, lässt sich wegen des verschollenen Nachlasses nicht sagen.

Trotz dieses fehlenden kunsthistorischen Hauptwerks lassen sich in Quandts zahlreichen Büchern, Artikeln und Rezensionen Ansätze zu einer »allgemeinen Kunstgeschichte« erken-

hardts Eintrag zur »Kunstgeschichte« in der 9. Aufl. des Brockhaus' Konversationslexikon von 1845 wird Quandt nicht erwähnt, hingegen in der 14. Auflage von 1892-1896: »In Deutschland nahmen diese Studien [der mittelalterlichen Baukunst - AR], die sich hier alsbald auch auf altdeutsche Malerei erstreckten, die Brüder Boisserée, J. G. von Quandt, Franz Kugler, Ernst Förster, Heidelhoff u. a. auf [...].« Brockhaus' Konversationslexikon, 10. Bd. (16 Bde.), 14. Aufl., Leipzig/Berlin/Wien: Brockhaus, 1892-1896, S. 803. Weitere Hinweise auf Quandt in Artikeln wie »Bildergalerie« und »Kunstgeschichte«; siehe 4. Auflage von Pierer's Universal-Lexikon der Vergangenheit und Gegenwart, Ausgabe von 1857.

10 Prange 2004, S. 124-129; Locher 2001, S. 187-190; Schröter 1990, S. 362-377; Kultermann 1966, S. 161-164.

11 Karge 2010 (1), S. 41-42; Karge 2010 (2), S. 86-104; Locher 2001, S. 209212, 244-254.

12 Brief von Quandt an Unbekannt vom 21.8.1819, in: SLUB, Mscr. Dresd. App. 278, Nr. 163.

13 Zum Zeitgeist siehe Quandt 1847, S. 134-140. 
nen. ${ }^{14}$ So erläuterte er seinen Hörern an den Winterabenden der Jahre 1824/25 die künstlerischen Entwicklungslinien, indem er seine umfassende Graphiksammlung präsentierte. Der in der Folge publizierte schmale Band Entwurf zu einer Geschichte der Kupferstecherkunst und deren Wechselwirkungen mit anderen bildenden Künsten von 1826 ist in diesem Sinn als Prolegomena zu der nie erschienenen großen Kunstgeschichte zu bezeichnen. Er selber schrieb im Vorwort:»Denn es haben sich wirklich die schätzbaren Notizen über einzelne Kunstwerke und Künstler [...] so gehäuft, daß sie unübersehbar zu werden beginnen, und es ein wahres Bedürfniß wird, sie nach Grund und Folge aneinander gereiht und zu einer Geschichte verarbeitet zu sehen. Wenn fast schon jetzt der Materialien zu einem so großen Baue zu viele sind, um von Einem Individuum verarbeitet werden zu können, so dürfte der Grundriß, nach welchem man das große Gebäude ausführen könnte, um so dringender nothwendig werden. $\ll^{15}$ Quandt verstand seine Arbeit also schon in den 1820er Jahren als Teil einer Kunstgeschichte, deren Aufgabe es sein sollte, das Wissen über die Geschichte der Kunst zu erweitern. Franz Kugler, der als Erster mit seinem Handbuch der Kunstgeschichte 1842 ein monumentales Überblickswerk veröffentlichte, bezog sich für seine Ausführungen über die Geschichte des Kupferstichs auf Quandts Geschichte der Kupferstecherkunst. ${ }^{16}$ Auch Quandts Übersetzung von Luigi Lanzis Geschichte der Malerei zwischen 1830 und 1833 bezeugt sein Interesse an einer allgemeinen Kunstgeschichte, indem er der Publikation eine tabellarische Übersicht über die italienische Kunstgeschichte mit komplexen Bezügen und farbigen Hervorhebungen beizulegen beabsichtigte. ${ }^{17}$ Diese kam zwar nicht zur Ausführung, zeigt aber, dass Quandt mit solchen Ideen der Entwicklung hin zu einer wissenschaftlichen Klassifizierung der

14 Zum Begriff der »allgemeinen Kunstgeschichte« siehe Karge 2010 (2), S. 88-89, 100-101; Locher 2010, S. 210-212.

15 Quandt 1826 (1), S. VIII: »Keineswegs wird behauptet, daß diese die alleinige Idee sey, nach welcher das Gebäude ausgeführt werden müßte; vielmehr müssen Plane entworfen werden, ehe ein großer Bau nur begonnen wird, und jede Idee kann ihr eigenes Gute haben, ja es wäre nicht einmal zu wünschen, daß nur einmal und von einem Standpuncte aus die Geschichte dieser Kunst construirt würde, indem vielseitigere und von Verschiedenen angestellte Betrachtung durchaus vorteilhaft ist."

16 Kugler 1842, S. 843-852, Anm. 1.

17 Brief von Quandt an Wilhelm Ambrosius Barth vom 14.1.1830, in: SLUB, Mscr. Dresd. App. 1191, Nr. 575-576.

18 S. a. Schmidt-Burckhardt 2017, S. 15-19, 86-90; Schmidt-Burkhardt 2005, S. 65-81.

19 Kugler 1842, S. IX-XIV. S. a. Karge 2013, S. 5-7; Karge 2010 (1), S. 42; Prange 2004, S. 145; Kultermann 1966, S. 168.

20 Quandt 1843 (3), Sp. 266. S. a. ebd., Sp. 257-258: „Schon dem Plane nach kann und soll man keine Vollständigkeit verlangen [...]. Diese Einheit hätte aber nur in einer Idee erreicht werden können, deren Evolution und Ausgeburt die Geschichte ist, und der Vf. wäre der Schöpfer einer Kunstphilosophie geworden, welche so aus der Kunstgeschichte
Kunst und ihrer Werke völlig entsprach und somit - wenigstens in den 1820er und frühen 183oer Jahren - auf der Höhe der Zeit dachte. $^{18}$

Als anerkannter Kunstgelehrter der älteren Generation rezensierte Quandt 1843 Kuglers wegweisendes Handbuch der Kunstgeschichte. Darin zeigen sich deutliche Unterschiede im Denken des älteren und jüngeren Forschers, die sich als generationelle Differenzen entpuppen. Bereits das Vorwort widerstrebte dem alten Kunstkenner. Kugler wollte durch die Beschreibung zahlreicher Kunstwerke deren Eigenheiten nebeneinanderstellen und verstand diesen Zugang als denjenigen eines Praktikers. ${ }^{19}$ Quandt jedoch war nie an einer Auflistung von Einzelwissen interessiert, sondern suchte diese durch einen großen Gedanken miteinander zu verbinden. Dementsprechend kritisierte er: »Das Werk geht von keiner obersten Idee aus, noch führt es zu einer solchen am Schlusse. $\ll^{20}$ Auf den weiteren Seiten der Rezension bemängelte er die oft ungenaue Wortwahl und beanstandete den geographischen Aufbau des Buches, der im Gegensatz zur Chronologie einen ganzheitlichen Ansatz verunmögliche. ${ }^{21}$ Quandt war mit Kuglers Werk überhaupt nicht zufrieden, wie ein Brief an seinen Verleger in Halle zeigt: »Eine Vervollständigung oder hie $\mathrm{u}$ da auch Beschäftigung des Einzelnen vorzunehmen, ist bei der Ausdehnung des Werks u der Beschränkung des gegebenen Raumes einer lit[erarischen]: Z[ei]tt[ung]: unmöglich u schon die Absicht es zuthun, würde so anmaaßend, wie das Unternehmen des V[er]f[assers], der eine universelle Kunstgeschichte zu schreiben gedachte, da doch das Studium einer Kunst, schon ein ganzes Menschenleben erfordert. Ich habe in der Anzeige mein Urtheil nicht so schonungslos, wie im Vertrauen zu Ihnen, ausgesprochen, aber auch nicht verschwiegen wo meine Überzeugung, die ich aber eben

hervorgehen musste, wie die Naturphilosophie aus der Naturkunde. Eine solche Idee [...] habe ich nicht darin gefunden; wir werden also wol auch hier nur unter Ganzem so viel als Zusammenhang verstehen und diesen Begriff wieder nur mit Aneinanderreihung erklären müssen."

21 Kritik an der Wortwahl: »[...] Ideal und Stil kommen ebenfalls nicht selten in ihren schwankenden Bedeutungen vor.« Quandt 1843 (3), Sp. 267. Kritik am Aufbau: »Das erste Kapitel der eigentlichen Kunstgeschichte [...], die Denkmäler des nordeuropäischen Alterthums als Zeugnisse für die ersten Entwickelungsmomente der Kunst, lässt den Plan vermuthen, dass an den Werken der Kunst, abgesehen von Raum und Zeit, die Grade geistiger Entwickelung dargelegt werden sollen. Wenn wir nun aber in dieser Meinung an der Hand des Vf's von Stufe zu Stufe bis zu den Indiern hinangestiegen und auf dem Gipfel angelangt zu seyn glauben, stürzt er uns dann unerwartet jenseits der Höhe zu den Chinesen hinab. "Quandt sieht sich getäuscht, weil er eine chronologische Abfolge erwartete, welche die Entwicklung der Menschheit darlegen würde. Vom vierten Kapitel an habe er dann »den schlichten geographischen Weg« eingeschlagen, der einen »Entwicklungsgang" nicht ermögliche. Ebd., Sp. 267-268. Vgl. Kugler 1842, S. 3, 96-128. S. a. Locher 2010, S. 77-78; Karge 2010 (2) S. 91-94. 
so wenig für untrüglich ausgebe, in Widerspruch mit den Behauptungen des Verfassers steht. Er will viel sagen, Welttheile u Jahrtausende in einen so kleinen Raum zusammenquetschen und doch nicht alles bis zur Unkenntlichkeit zerdrücken. Mühe habe ich nicht gespart u noch viele Studien gemacht, obwohl mir die Gegenstände nicht fremd waren [...]. $\ll^{22}$

Quandt verstand seine Aufgabe als Rezensent dahingehend, dass er Aspekte des kritisierten Werks vertiefen, ergänzen oder allenfalls berichtigen wollte. Gleichzeitig widersprach ihm der Kuglersche Anspruch, die gesamte Geschichte der Kunst aller Menschen in einem einzigen Buch zusammenzufassen. Genau dies, glaubte er, wäre nicht zu verwirklichen. Sein vernichtendes Fazit lässt sich einem Brief an Julius Schnorr von Carolsfeld entnehmen: »[...] ein Weiserer als ich, hätte Kuglers Buch in einen Winkel geschleudert, welches eines der wortreichsten u gedankenlosesten Bücher ist, [...], weil es ohne eigene Überzeugung und Urtheil vom Verfasser zusammengelesen $\mathrm{u}$ das Gelesene, aber nicht Auserlesene, niedergeschrieben wurde. $\ll^{23}$ Für Quandt war Kuglers Handbuch nur eine Kompilation von Vorhandenem, aber nichts Eigenständiges und Neues.

Bereits im Jahr danach veröffentlichte Quandt 1844 eine Rezension zum zweiten großen Überblickswerk der frühen Kunstgeschichte. Darin befasste er sich mit Carl Schnaases erstem Band der Geschichte der bildenden Künste. ${ }^{24}$ Der Anspruch des Werks, das bis 1864 in sieben Bänden erscheinen sollte, ließ ihn hoffen. ${ }^{25}$ Anders als Kugler beabsichtigte Schnaase, eine Kunstgeschichte zu schreiben, die einer alles vereinenden Idee folgte. ${ }^{26}$ Aus diesem Grund stellte er dem Werk ein einleitendes Kapitel voran, in das Aspekte der philosophischen Ästhetik einflossen. Auf diesem Gebiet fühlte sich Quandt zu Hause. So kritisierte er zwar zahlreiche begriffliche Probleme der knap-

22 Brief vom 25.10.1842, in: Berlin, SMB, Zentralarchiv, Autographensammlung, Mappe 1133, Quandt, Johann Gottlob von, fol. 15r-16v.

23 Brief vom 21.1.1843, in: SLUB, Mscr. Dresd. n Inv. 15, Bd. 31, fol. $222 \mathrm{v}$.

24 Quandt 1844 (3), Sp. 689-694, 697-728. Der erste Band handelt von altorientalischer Kunst. S. a. Brief von Quandt an Unbekannt vom 28.1.1844, in: Berlin, SMB, Zentralarchiv, Autographensammlung, Mappe 1133, Quandt, Johann Gottlob von, fol. 17r-v: "Sie erhalten hier die Recension über Schnaases Kunstgeschichte I. Theil, so gedrängt u so bald, als mir beides möglich war und doch weiß ich nicht, ob Ihnen die Abfassung und die Zeit nicht zu lang scheinen mögen. Ich habe es aber nicht kürzer machen können, denn ein Buch ist leichter geschrieben als gewissenhaft beurtheilt [...].«

25 Quandt 1844 (3), Sp. 689 über das »Zueignungsschreiben als Vorrede«, in: Schnaase 1843, Bd. 1, S. IX.

26 Schnaase 1843, Bd. 1, S. IX: »Mir stand eine andere Aufgabe vor Augen. Dass die Kunst einer jeden Zeit der Ausdruck der physischen und geistigen, sittlichen und intellectualen Eigenthümlichkeiten des Volkes sei [...].« S. a. Kugler 1842, S. X-XI; Kultermann 1966, S. 173-174; Locher 2001, S. 238-240; Karge 2013, S. 9-10.

27 Zum Beispiel Quandt 1844 (3), Sp. 716 über Ägypten: »Der geschichtliche Umriss, welchen der Vf. gibt, ist mit so sicherer Hand gezeichnet, dass die Epochen der ägyptischen Cultur deutlich, und in großen pen Einführung, war aber grundsätzlich positiv eingestellt und schätzte die Ausführungen zu Sitten und Charakter, Religion und Nation, Geographie und Geschichte, die der Autor des monumentalen Werks in seine geographisch geordneten Kapitel einfließen ließ. ${ }^{27}$ Er kam zum Schluss: »Wenn der Vf. uns auch nicht immer überzeugt, so geschieht es doch in den meisten Fällen und man könnte sagen, dass seine Aussprüche richtiger sind, als seine Theoreme. Das Dankenswertheste eines solchen gedankenreichen Buches ist, dass es anregt uns selbst über vieles zu fragen und unsere eignen Ansichten zu prüfen. $\ll^{28}$

Quandt nahm sich auch des zweiten Bandes an. ${ }^{29}$ In dieser Rezension wurde der Ton zunehmend negativ und gipfelte in der Ablehnung einer nebensächlichen Aussage Schnaases über Winckelmann: »Schlimmer scheint mir noch das, was der Vf. (S.30O u. 301.) über Winckelmann ausspricht. Er erklärt dessen Urtheile für veraltet und ungültig und sagt spöttisch: dass der Begründer der Kunstgeschichte sich oft als Dichter zeige u. s. w. [...]. « $\aleph^{30}$ Was Quandt hier dermaßen erzürnte, war Schnaases Kritik an einer charakteristischen Eigenschaft Winckelmanns. Dieser hatte durch seinen begeistert-subjektiven Schreibstil die trockene Gelehrtensprache der Kunstkenner des 17. und frühen 18. Jahrhunderts überholt. ${ }^{31}$ Schnaase verortete den so genannten Begründer der Kunstgeschichte in seiner Zeit und hob umso mehr die Errungenschaften der neuen Kunstgeschichte hervor. Quandt empfand dies als Affront, so dass er die Lektüre kurzerhand abbrach und die Rezension in der Hälfte des 533 Seiten starken Buches abrupt beendete: »Von hieraus lassen wir den Vf. allein seinen Weg gehen und ziehn uns still zurück, denn ohne Poesie hat die Kunst und ihre Geschichte kein Interesse für uns, sie würde, um mit Plato zu reden, ein bloßes Nachbilden von Nachbildern der Urbilder
Maßen gehalten, vor uns liegen." Siehe Schnaase 1843, Bd. 1, S. 289333. S. a. Karge. 2010, S. 48; Karge 2010 (2), S. 94-96. Zur Kritik an den ästhetischen Kapiteln »Das Schöne und die Kunst《 und »Die Idee des Kunstwerks « siehe Quandt 1844 (3), Sp. 689-694, 697-699. Schnaase 1843, Bd. 1, S. 3-36.

28 Quandt 1844 (3), Sp. 728.

29 Quandt 1844 (3), Sp. 1165-1184, 1189-1192. Darin ging es um griechische und römische Kunst. 1846 folgte die Rezension des dritten Bandes über altchristliche und muslimische Kunst. Quandt 1846 (3).

30 Quandt 1844 (3), Sp. 1192: »Aber noch Eines möchten wir dem Vf. ans Herz legen: - dass keiner die höchsten Meisterwerke ohne dichterische Begeisterung verstehn und ein Kunstkenner werden kann. Der wahre Dichter ist der geborne Kunstkenner.« Vgl. Schnaase 1843, Bd. 2, S. 300-301, wenn auch ohne Spott: „Seit Winkelmanns Zeit hat sich unsere Kenntniss des Alterthums [...] bedeutend erweitert und in gleichem Maaße das Kunstgefühl verändert [...]. Der Begründer der Kunstgeschichte hat auch hier wieder, wie so oft, sich selbst als Dichter gezeigt, indem er mit seiner liebenswürdigen Begeisterung dem Werke einen Gedanken unterlegte, der es so viel wie möglich zugänglich machte."

31 Prange 2004, S. 35-36. 
seyn, wenn sie nicht, wie viele andere Weise gesagt haben, eine stumme Poesie wäre. « $3^{2}$

In dieser emotionalen Reaktion tritt das Generationenproblem zwischen dem älteren Quandt und den jüngeren Schnaase und Kugler deutlich zu Tage. Die Poesie war gemäß Quandts Meinung für die Geschichtsschreibung besser geeignet als eine auf Quellen basierte Methode. Autoren wie Winckelmann waren hierin vorbildlich. Die Poesie als eigenständiges Erzeugnis menschlicher Vernunft sollte die divergenten Entwicklungen der Geschichte optimaler beschreiben können als historische Dokumente. So bemerkte Quandt in Bezug auf Schnaases Widmung an Franz Kugler: »In der an Herrn Dr. und Professor Franz Kugler gerichteten Zueignung, spricht der Verf. die Aufgabe aus, welche die Kunstgeschichte lösen soll. Es ist diese aber eine Fo $[\mathrm{r}]$ derung, welche nicht nur an die Geschichte, sondern überhaupt an alles vernünftige Denken gemacht werden kann, dass der Geist, in allem was er betrachtet, sich selbst in seiner Entfaltung erkenne. Es wäre ein eben so vergebliches Bestreben die Welt aus Einzelnheiten, aus Sonnenstäubchen aufzubauen, als eine Kunstgeschichte, welche die des Menschengeistes zugleich seyn soll, aus Notizen zu Stande zu bringen. «33

Quandt war sich des Unterschiedes zwischen einer jüngeren Generation von Kunsthistorikern, die vermehrt nach historisch-wissenschaftlichen Kriterien agierte, und der älteren durchaus bewusst. In einem kurzen Aufsatz über das Verhältnis von bildender Kunst und Kunstliteratur, Der Parallelismus zwischen ausübender Kunst und deren Literatur, schrieb er 1850: »Man muss bewundern und verehren, was gelehrte Männer hinsichtlich der Verbreitung der Alterthumskunde und besonders deren mythologischen Theils, Chronologie und Nomenclatur, gethan haben. Ebenso ist von Kennern der neuern Kunst deren Geschichte überaus erweitert und berichtigt worden. Vergleicht man diese neusten Werke mit Winkelmanns und Lessings archäologischen Untersuchungen, mit Goethe's jugendlicher Begeisterung für den Münster in Straßburg, den Propyläen und seiner Schilderung Ruisdaelscher Landschaft [...], oder mit Heinse's Briefen aus Düsseldorf, Forsters Ansichten vom Niederrhein, und selbst Fernow's römischen Studien, so zeigt sich eine auffallende Verschiedenheit der Richtungen [...]. Wenn diese letztgenannten Schriften auf die im Kunstwerke

32 Quandt 1844 (3), Sp. 1192. Es wären noch weitere Kapitel über griechische Kunst und über die römische Antike gefolgt. Siehe Schnaase 1843, S. VII-X.

33 Quandt 1844 (3), Sp. 689 über das »Zueignungsschreiben als Vorrede«, in: Schnaase 1843, Bd. 1, S. IX

34 Quandt 1850 (2), S. 61.

35 Zum Begriff Universalgeschichte siehe Zwenger 2003, [s. p.]; Locher 2001, S. 203-212; Nipperdey 1976, S. 42-46 in Abgrenzung zum Begriff der Kulturgeschichte als Geistesgeschichte. gleichsam latenten Ideen gerichtet sind und deren Entwickelung bezwecken, so zeigen die neueren Untersuchungen über Kunstwerke mehr von einem Eifer für das Sammeln geschichtlicher Nachrichten. Dieser Heißhunger nach Notizen, diese Scheu vor dem Eindringen und die Lust am Auslegen von Kunstwerken, wobei man mehr auf richtige Benennung der Gegenstände, welche vorgestellt wurden, als das Anschauen der Ideen, welche die vorgestellten Gegenstände umfassen, ausging, ist daran Schuld [...], wenn sich nun diese factische und historische Richtung auch in der ausübenden Kunst zeigt. So ist es ein sichrer Beweis, daß der materielle Stoff jetzt ein überwiegendes Interesse hat, welches diese Sphäre des Geistes ganz beherrscht. $\ll^{34}$

Es wird hier deutlich, dass sich Quandt zu der älteren Generation zählte. Er vertrat mit ihnen eine universalgeschichtliche Richtung. Kunstgeschichte sollte die Geschichte der menschlichen Vernunft, und wie sich diese in der Kunst manifestierte, ermitteln. Damit unterschied er sich von den kulturgeschichtlichen Zielen der jungen Kunsthistoriker. ${ }^{35}$ Ihre empiristische Herangehensweise, die bei Kugler stärker ausgeprägt war als bei Schnaase, war für Quandt uninteressant, weil Quellen seiner Ansicht nach im Gegensatz zur poetischen Vernunft keine umfassende Geistesgeschichte erzählen konnten. Doch dieser Ansatz wurde immer unbedeutender. Henrik Karge charakterisiert diesen Wandel in der Methodik als die verlustreiche Ablösung der sich konstituierenden Disziplin von der philosophischen Ästhetik zugunsten einer historischen Analyse der Kunstwerke. ${ }^{36}$

Dies lässt sich in einer Polemik, die Quandt mit seiner Rezension des ersten Bandes von Carl Friedrich von Rumohrs Italienischen Forschungen 1827 bereits ausgelöst hatte, nachvollziehen. Rumohr war einer der ersten, der in italienischen Archiven Quellen zu Künstlern studierte. In der umfassenden Kritik widersprach Quandt zahlreichen ästhetischen Aussagen zum Schönheitsbegriff oder dem Begriff des Kunstwerks. ${ }^{37}$ Rumohr reagierte pikiert und nahm in mehreren Publikationen und Briefen Stellung. Gegen seinen Rezensenten stichelte er: »Einwendungen dieser Art habe ich jederzeit als erfreuliche und tröstliche Zeugnisse für die Zweckmäßigkeit und Nützlichkeit meiner Bemühung angesehn, mit den ästhetischen Seifenblasen einen Krieg ganz neuer Art zu führen. $\ll^{38}$ Auch andere

36 Karge 2009, [S. 1]; Prange 2004, S. 95. S. a. Karge 2010 (1), S. 44-46; Karge 2010 (2), S. 89-94.

37 Quandt 1827 (2).

38 Rumohr 1832, S. 53-54; Rumohr 1831, S. 8-11. S. a. Stock 1933, S. 29-30, Anm. 34 und den Brief von Rumohr an Otfried Müller vom 9.1.1835, in: ebd., S. 4. Sehr ungehalten auch in einem Brief an Ludwig Tieck, in: Tieck 1864, Bd. 3, S. 194: »Ein Dienstfertiger [...] hat mir vier Blätter der Literaturzeitung, welche ich sonst nicht lese, zugesandt, worin Quandt (ob unser lieber, guter, viel rauchschmauchender Quandt zu 
reagierten erstaunt. Nicolaus Heinrich Julius, ein Berliner Arzt, wunderte sich: »Sollte die mit Quandt unterzeichnete Recension von Rumohr's Italienischen Forschungen in der Hall. Lit. Zeit. wirklich von demselben ganz seyn, so thäte es mir gar sehr leid um die Kunsteinsicht des Hr. v. Q. Obgleich die Künstler schon fühlen, daß es mit dem schwächlichen Wesen der bisherigen Zeit nicht mehr geht, so wird dennoch, vielleicht erst in einem Jahrhunderte, eine Zeit kommen, wo dieses Werk den Kenner der neuen Kunst abgeben wird, wie Winkelmann den der alten. $\ll^{39}$

Rumohrs Arbeiten wurden demnach schon früh als zukunftsweisend verstanden. Es wäre nicht einmal das Problem gewesen, dass Quandt dies nicht eingesehen hätte. Schon 1831 sprach er von seinem »sehr guten Freund «, den er immer mehr schätzte, und hängte dessen Porträt in seinem Arbeitszimmer zusammen mit Goethe und Schnorr an eine Wand, weil es »eine nähere Beziehung « zu ihm hatte. ${ }^{40}$ Dennoch verbiss sich der Dresdener in die ästhetischen Ausführungen des Berliner Gelehrten, weil dies sein ureigenes Gebiet war. Die Errungenschaft Rumohrs lag jedoch vor allem darin, ältere Traditionen einer von der Ästhetik geprägten Kunstgeschichtsschreibung mit den neuen empirischen Methoden der Quellenkunde, mithin Anschauung und Methodik miteinander verbunden $\mathrm{zu}$ haben. ${ }^{41}$

Diese Verbindung suchte Quandt indes kaum. Vielmehr beschäftigte er sich ab den 183 oer Jahren zunehmend mit der philosophischen Ästhetik und versuchte sie für Kunstfreunde verständlich zu erklären und für die Kunstbetrachtung zu adaptieren. Dieser alleinige Fokus auf die Ästhetik war jedoch etwas altmodisch. Wie ein Rezensent seiner Briefe aus Italien bereits 1830 erkannt hatte, war die Zeit der »reinen

Dresden?) mir nicht ein Quäntchen Verdienst läßt. Die Absicht, mich mißzuverstehen, hat darin der Unfähigkeit, mich zu verstehen, so treulich die Hand geboten, daß wirklich Harmonie darin ist [...].« S. a. Kat. Lübeck 2010, S. 176; Götz Pochat, »Carl Friedrich von Rumohrs ästhetische Theorie und kunsthistorische Praxis«, in: ebd., S. 225-233.

39 Brief an Johann Georg Keil vom 25.9.1827, zitiert nach Wentzlaff-Eggebert 2009, S. 492.

40 »lch unterhalte mich jetzt recht viel mit Rumohr [...] u wir sind sehr gute Freunde geworden. Ich schätze den Mann immer mehr.« Brief von Quandt an Louise Seidler vom 17.9.1831, in: Schmitz/Strobel 2001, S. 187 (SLUB, Mscr. Dresd. h 41, Nr. 4). »lch habe in meinem Arbeitszimmer, solche Bilder aufgehangen, welche [...] eine nähere Beziehung auf mich selbst haben. [...] Es kommen an dieser Wand Andenken von Personen zusammen, welche im Leben einander nicht begegnen möchten, wie z. B. Göthe u Rumohr u Sie selbst.« Brief von Quandt an Schnorr vom 22.7.1833, in: SLUB, Mscr. Dresd. n Inv. 15, Bd. 31, fol. 186v. Diese Aussagen fallen in eine Zeit, als Rumohr in Berlin wegen des dritten Bandes seiner Italienischen Forschungen über Raffael massiv kritisiert wurde. Quandt hat sie offenbar nicht rezensiert. Siehe dazu Kat. Lübeck 2010, S. 199-201.

41 Kat. Lübeck 2010, S. 218; Prange 2004, S. 111-112.

42 JALZ 1830, Jg. 26, Nr. 90, S. 234.
Kunstspeculation« vorüber und neue Erfolge nicht zu erwarten. ${ }^{42}$ Doch Quandts universalgeschichtlicher Ansatz, der ihn nach bestimmten grundlegenden Ideen in der Geschichte der Menschheit suchen ließ, war immerzu auf die Kunst bezogen, eine kritische Abgrenzung von Ästhetik und Kunstgeschichte mithin nicht vorhanden. Für eine kunsthistorische Methodik wäre dies jedoch von großer Wichtigkeit gewesen, denn diese stellte Quellenkritik, Kunstkennerschaft und Ästhetik in ein neues Verhältnis zueinander, wie es sich bei Rumohr bereits abgezeichnet hatte.

Obschon Quandt von der Anschauung des Kunstwerks ausging, war seine philosophisch-ästhetisch geprägte Herangehensweise nicht mehr entwicklungsfähig. Er interessierte sich nicht allzu sehr für Details wie sie Stilkunde und Formanalyse verlangt hätten. Regte ihn ein betrachtetes Kunstwerk zu anschaulichen Gedanken an, spielten künstlerische Details kaum eine Rolle.43 Dennoch war er gerade als Kenner der altdeutschen Kunst sehr anerkannt und sich stilistischer Unterschiede durchaus bewusst. Ikonographische Analysen stellte er immer wieder an. ${ }^{44}$ Umgekehrt war er kaum an textlicher Quellenarbeit interessiert. In seinen Schriften zog er höchstens publizierte historische Dokumente zu Rate. Er setzte sich nie in ein Archiv, wie es Carl Friedrich von Rumohr oder Johann David Passavant taten.45 Durch Quandts Anspruch, Kunstgeschichte als Universalgeschichte der Menschheit zu verstehen, spielten auch die wichtig werdenden Epochenstile eine untergeordnete Rolle. ${ }^{46}$ Anstatt des Verhältnisses künstlerischer Stile und Eigenheiten einer Epoche interessierten ihn vielmehr Aufschwung, Höhepunkt und Niedergang von Kunstepochen, weil sich darin die Geschichte menschlicher Vernunft manifestierte. $^{47}$

43 Quandt 1840 (2), S. 319: »[...] Denn der geometrischen Messung und mathematischen Demonstration entgeht sehr Vieles, was das künstlerisch geübte und geistig gebildete Auge wahrnimmt."

44 Ein spätes Beispiel, in seiner Fehlinterpretation symptomatisch, in Quandt 1856, S. 57-58 über Poseidon und Athene von Garofalo, Gemäldegalerie Alte Meister, Gal. Nr. 132: »Es bedarf also für uns keiner Auslegung, was das Bild vorstellt, denn die Schönheit, wo und wie sie sich offenbaret, ist ohne Weiteres bedeutend. Wer denn nun durchaus eines Namens bedarf, um bei der schönen Nymphe sich einen bestimmten Gegenstand zu denken, mag sie Kirke nennen, bei welcher Poseidon den Odysseus verklagt [...].« Die Ästhetik der Schönheit steht auch hier vor der Ikonographie. S. a. Brief von Quandt an Julius Hübner vom 3.8.1855, in: Hansestadt Lübeck, Bibliothek der Hansestadt Lübeck, Autographensammlung Hennings: Blaue Kartons. Die Rückweisung von Quandts Vorschlag bei Schäfer 1860, Bd. 1, S. 93.

45 Locher 2001, S. 187-190, 227-233; MKL 2007, S. 320-321, 353-355; Schröter 1990, S. 362-370, 374-377; Kultermann 1966, S. 155-156, 161-164.

46 Karge 2010 (1), S. 49-53 Karge 2010 (2), S. 94-96; Schlink 2002 [1997], S. 3-4. S. a. Prange 2004, S. 161, 210-215; Locher 2001, S. 203-212; Nipperdey 1976, S. 42-46.

47 Locher 2010, S. 71 weist auch bei Kugler dieses dreigliedrige Modell in der Tradition Vasaris nach. 


\section{Gelehrter Protagonist einer jungen Disziplin}

Quandts Schriften und Briefe zeigen, dass sich der Dresdener Kunstgelehrte trotz Fragezeichen vor allem in Bezug auf seine Methodik den grundlegenden Aspekten, die für die Konstituierung des Faches Kunstgeschichte wichtig waren, gut zuordnen lässt: Seine Zeitgenossen rechneten ihn, bezogen auf die Bezeichnung der Kunstgeschichte als Disziplin, dazu. Seine Rezensionen der kunsthistorischen Publikationen Rumohrs, Kuglers, Schnaases und anderer verweisen auf seine hohe Anerkennung als Kunstgelehrter, der die neuen Werke der Kunstgeschichte zu beurteilen wusste. Seine zahlreichen Bücher und Artikel zu kunsthistorischen Themen, Künstlern und Kunstwerken verdeutlichen, dass er die zeitgenössischen Diskussionen wahrnahm und rezipierte. Darüberhinaus sind bei ihm Ansätze zu einer »allgemeinen Kunstgeschichte « zu erkennen, auch wenn er kein Überblickswerk geschrieben hat. ${ }^{48}$ Wie Carl Friedrich von Rumohr stritt er für ein »anschauliches Denken«, das Bestrebungen in der Geschichte der Kunst nicht als formalisierte »Künstlersprache«, sondern nach dem Vorbild der Natur zu erklären beabsichtigte. ${ }^{49}$ Wie Gustav Friedrich Waagen in Berlin verfolgte er mit seinen Hängungen in der Dresdener Gemäldegalerie eine »sichtbare Geschichte der Kunst«, welche die aktuellsten Diskussionen um chronologische und kunsttopographische Hängungen aufgriff. $5^{\circ}$ Gerade hier, aber auch in seiner Konzeptarbeit für das Historische Museum in Dresden, zeigt sich eine frühe Professionalisierung in den Museen, wo mit Quandt nicht ein Künstler, sondern ein Gelehrter die Federführung innehatte..$^{51}$ Abschließend seien daher noch einige Faktoren erläutert, die für Quandts Biographie sehr typisch, für eine bleibende Anerkennung als früher Kunsthistoriker wohl aber abträglich waren.

48 Zum Begriff der »allgemeinen Kunstgeschichte« siehe Karge 2010 (2), S. 88-89, 100-101; Locher 2010, S. 210-212.

49 Prange 2004, S. 111-118. S. a. Locher 2001, S. 227-233.

50 Prange 2004, S. 129-137.

51 Bis 1882 mit Karl Woermann ein erster Kunsthistoriker anstelle eines Künstlers die Direktion der Dresdener Gemäldegalerie übernahm, sollte es indes noch Jahrzehnte dauern. Zur Professionalisierung der Museen siehe Weddigen 2008, S. 54-65; Kat. Frankfurt 1994, S. 29-34.

52 Zitiert nach Kat. Leipzig 1997, S. 17.

53 AZ 1826, Beilagen Nr. 119-121, S. 473-482, hier S. 477. Die Künstler hatten Quandt eine Rezension der Dresdener Akademieausstellung von 1825 zugeschrieben. Brief von Schnorr an Quandt vom 2.11.1826, in: München, Bayerische Staatsbibliothek, Autograph Schnorr von Carolsfeld, Julius; Schnorr 1886, S. 519-520. Quandt reagierte nicht auf das Pamphlet und nahm nur in einer Antwort an Schnorr Stellung: »Dabey fällt mir eben ein, daß d[ie] Künstler in Rom uns verbothen haben über Kunstgegenstände zu sprechen u da nun das Sprechen nichts anders ist als laut oder schriftlich zu denken, so ist also das Denken darüber auch verbothen. In der allgemeinen Zeitung haben sich diese Herren mit eigner Machtherrlichkeit zu ihren eignen Rich-
Quandt war ein Kunstkenner mit unsystematischer Bildung. Sie war von Privatlehrern und Selbststudium geprägt, jedoch nie an einer Universität vertieft worden. Adele Schopenhauer formulierte diese Eigenschaft recht offen: »[...] wir fühlen beide [Adele und Arthur Schopenhauer - AR] das Peinliche einer ganz unvollkommen gebliebenen Ausbildung und Richtung seines Wesens, es ist etwas ganz Ungeordnetes, Wildes in seiner Phantasie wie in seinem ganzen Leben. $\ll^{2}$ Ähnlicher Meinung waren noch andere. 1826 unterschrieben in Rom die Künstler Catel, Koch, Riepenhausen, Rohden, Thorvaldsen, Reinhart und Veit die Streitschrift Betrachtungen und Meynungen über die jezt in Deutschland herrschende Kunstschreiberei, von Künstlern in Rom von 1826, die der Architekt Adolf Weissenburg verfasst hatte. Egozentrismus und Unwissenheit, ja »Lüsternheit nach dem Richteramt« wurde den Kunstschriftstellern darin vorgeworfen. Mit fehlerfreier Sprache, aber dürftiger Bildung glaubten sie den Künstlern Vorgaben machen zu dürfen. Dass Kunstschriftsteller wie Quandt hier angesprochen waren, ist deutlich: »Werfen wir noch einen kurzen Blik auf die Bildung der heutigen Kunstschreiber, so geht aus ihren Arbeiten genugsam hervor, daß sie größtentheils aus Leuten bestehen, welche sich eine kurze Zeit in Italien aufgehalten, (wir kennen diese Herren meist persönlich, und wissen sehr gut, wie viel sie auf der Geisteswage wiegen,) oder die in ihrer Vaterstadt Gelegenheit haben, einigen Umgang mit Künstlern zu unterhalten, in keinem Fach aber, weder in der Kunst, noch in der Wissenschaft etwas tüchtiges Selbstständiges geleistet haben. ${ }^{53}$ Bezeichnenderweise richtete sich der Aufsatz nicht gegen Autoren der Kunstgeschichte oder Archäologie, die »ohnedis mehr dem Gebiete der Wissenschaft an[gehören]«, sondern gegen Kunstliebhaber und deren Beurteilung des künstlerischen Wertes von Kunstobjekten. ${ }^{54}$ In

tern nur eingesetzt. Ich möchte aber wohl wissen ob Koch u Catel von einander Belehrung, Satz, Urtheil annehmen möchten oder Rohden u Reinhardt? Ferner ob das Urtheil dieser Künstler über einander, nicht vielleicht noch einseitiger ausfallen möchte, als das eines Mannes, dessen Geist die Richtung gewonnen hat, das auf Begriffe u Ideen zurückzuführen, was die Kunst in Anschauungen und anschaulich zusammenfasst. Ferner sollten diese Künstler doch nicht vergessen, was sie den Schriften des Fernow, Wackenröder, Tiek, Spät [Balthasar Speth - AR] u Schorn schuldig sind, denn ohne diese u ohne dass Philosophen u Dichter die Welt durch ihre Werke zum Genuß der Kunst vorbereiteten, hätten diese Künstler schwerlich Eingang gefunden, da durch die Wissenschaft der Kunst die Lantze gebrochen wird.« Undatierter Brief an Schnorr [März/August 1826], in: SLUB, Mscr. Dresd. n Inv. 15, Bd. 31, fol. 132r. S. a. Noack 1907, S. 214.

54 AZ 1826, Beilage Nr. 119, S. 473. 1833 erschien eine ähnliche Schrift von Reinhart: »Drei Schreiben aus Rom gegen Kunstschreiberei in Deutschland «, Dessau 1833; Stolzenburg 2012, S. 84; Kat. Hamburg/ München 2012, Kat. Nr. 245, S. 354. S. a. Prange 2004, S. 28-29. 
der Tat war Quandt nie an einer Bildungsinstitution als Wissenschaftler tätig oder unterrichtete an einer höheren Schule Kunstgeschichte - ausgenommen eine interimistische Vorlesung über Ästhetik an der Dresdener Kunstakademie im Jahr $1843 .{ }^{55}$ Seine privat betriebene Bildung und Forschung war der fortdauernden Wertschätzung seiner Arbeit sicherlich abträglich.

Ein weiterer Faktor, der zu einem Vergessen von Quandts kunsthistorischen Errungenschaften geführt haben könnte, lag wohl in seiner auf finanziellem Reichtum begründeten Unabhängigkeit. Der Kauf des Rittergutes in Dittersbach 1830 ist dafür bezeichnend. Hier konnte er sich in kleinem Rahmen mit Land und Leuten, Kultur und Arbeit beschäftigen. Über die Einrichtung des Landschaftsparks hinaus lag sein Fokus auf der ökonomischen und sozialen Entwicklung des Landgutes. Dies erforderte viel Zeit, die ihm für eine regelmäßige Arbeit als Kunstgelehrter fehlte. Quandts Unabhängigkeit ermöglichte es ihm, nur das zu tun, was ihn interessierte. Dies führte zu einer gewissen Verzettelung, was er selber feststellte: »[...] Literarische Arbeiten forderten Zeit und Fleiß u dabei wollte ich auch das Leben genießen, bauen, reisen, meine Güter verwalten u außerdem noch meine Pflichten gegen die Academie erfüllen. Durch diese zersplitterte Thätigkeit habe ich mehr unterlaßen als gethan. ${ }^{5^{6}}$ Quandt konnte es sich leisten, Kunstgelehrter zu sein, ohne einem Einkommen nachgehen zu müssen. Dadurch musste er nie ein Amt übernehmen oder einen Beruf ausüben und konnte sich in den Dresdener Museen oder in der Kunstakademie zeitlich begrenzt engagieren. So entging ihm aber auch die Möglichkeit, eine Institution kraft seines Amtes und seiner Arbeit nachhaltig zu prägen.
Quandt zählt dennoch zu einer Generation von Kunstgelehrten, die für die junge Disziplin fruchtbar gewirkt haben. Er gehörte zu den umsichtigen Mäzenen der Nazarener in Rom und verhalf ihnen und nahestehenden Künstlern in Sachsen zu einer Plattform. Er glaubte an die Wirkmacht der Kunst und vor allem der Historienmalerei in der Gesellschaft und förderte sie nach Kräften im Sächsischen Kunstverein. Er schrieb als anerkannter Kenner über altdeutsche Kunst und machte sie so bekannt. Im Königlichen Altertumsverein lenkte er den Blick auf die regionale Kunstgeschichte des Mittelalters und schob Maßnahmen zur Erhaltung sächsischer Kunstwerke an. Seine eigene Kunstsammlung präsentierte er einem breiten Publikum noch zu Zeiten, als die öffentlichen Museen Dresdens selten zugänglich waren. Seine mehr als dreitausend Blätter zählende Graphik- und Zeichnungssammlung dienten ihm zum Studium und zur Erläuterung der europäischen Kunstgeschichte. Seine Gemälde präsentierte er gelehrt und kenntnisreich. Als Mitglied der Galeriekommission setzte er sich für die Erhaltung der Königlichen Gemäldesammlung ein, kämpfte an vorderster Front für einen neuen Museumsbau und organisierte einen für die Besucher der Gemäldegalerie anschaulichen und nachvollziehbaren Rundgang durch die Museumssäle. Schließlich war er einer der ersten, der mit der Bemalung des Belvedere in Dittersbach Goethe ein Denkmal setzte. Mit diesem verehrte er weniger den Weimarer Dichter als die Kunst, deren Werke für ihn die Geschichte der menschlichen Vernunft darstellte. Zu seiner eigenen Ehre prangte bereits im Jahr seines Todes ein Relieftondo von Ernst Rietschel an der Fassade der Kunstakademie (Abb. 128) - als Denkmal für einen gebildeten kunstbeflissenen Menschen, für Johann Gottlob von Quandt.57
55 Als Vertretung für den verstorbenen Heinrich Hase, bevor dessen Nachfolger sein Amt antrat. Brief von Quandt an Friedrich Gottlieb Welcker, 20.5.1850, in: Bonn, Universitäts- und Landesbibliothek, Dezernat 5 / Abt. Handschriften und Rara, Autographensammlung, S 685 (NL Welcker), Brief 3. S. a. Quandt 1844 (1).

56 Brief von Quandt an Unbekannt vom 4.3.1843, in: Berlin, SMB, Zentral- archiv, Autographensammlung, Mappe 1133, Quandt, Johann Gottlob von, fol. 19r-2or. Der Brief steht im Kontext einer Anfrage für Beiträge in der Jenaischen Literaturzeitung, für die er zwanzig Jahre zuvor geschrieben, lange aber nichts mehr publiziert hatte. 57 Wilmowsky 2017, WVZ 185.2, S. 767-768. 


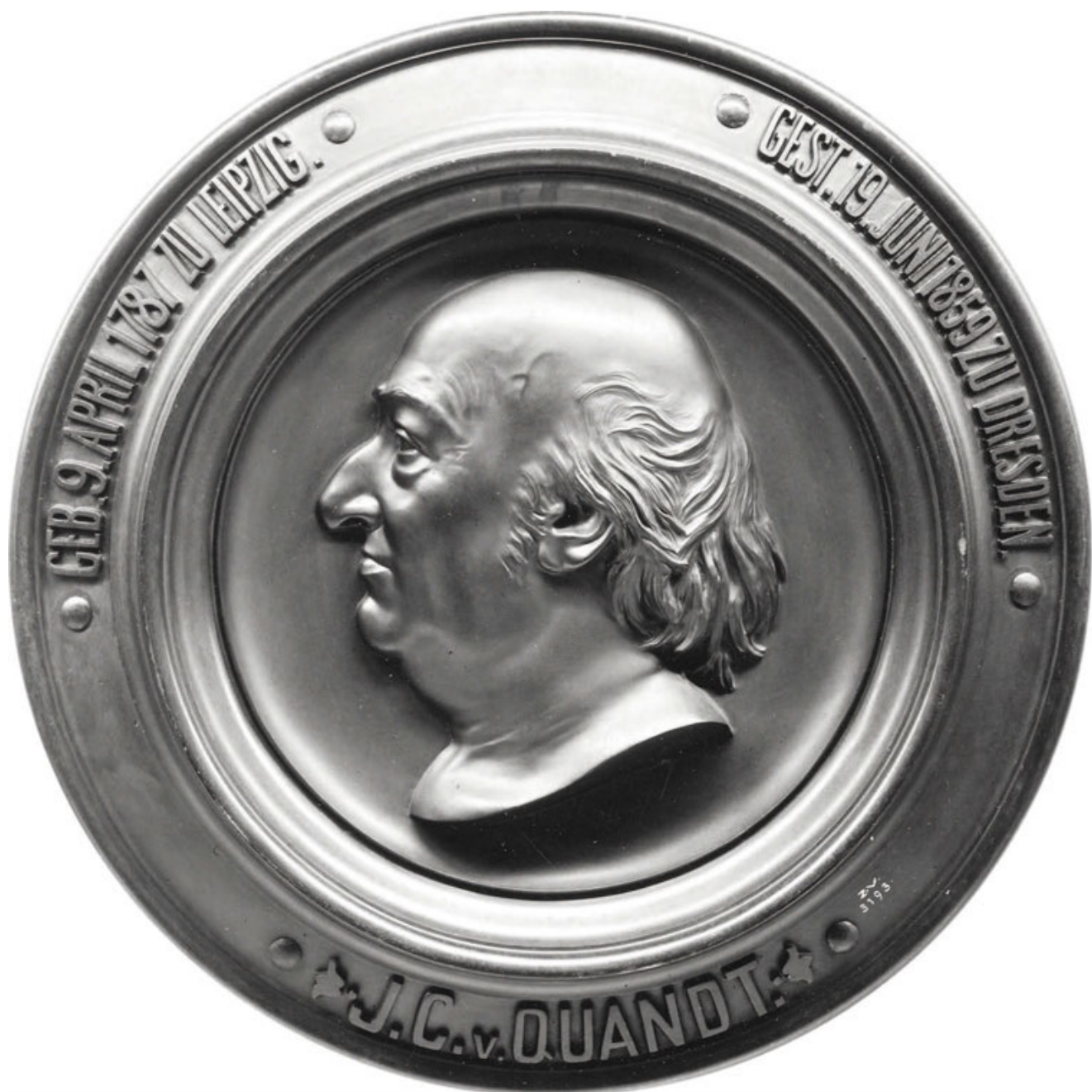

128 Ernst Rietschel, Johann Gottlob von Quandt, 1859, Bronze, Dm: 63,5 T: 8 cm, Dresden, SKD, Skulpturensammlung, Inv.-Nr. ZV 3193 


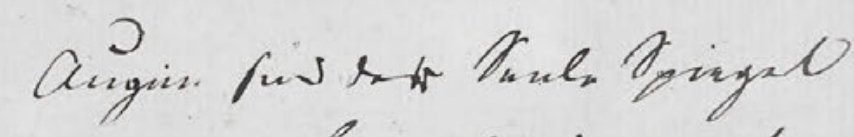

$$
\begin{aligned}
& \text { unot rin tipe Pfsingat viff }
\end{aligned}
$$

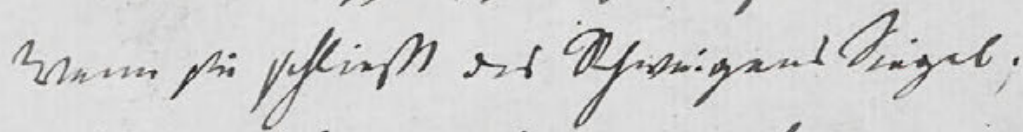

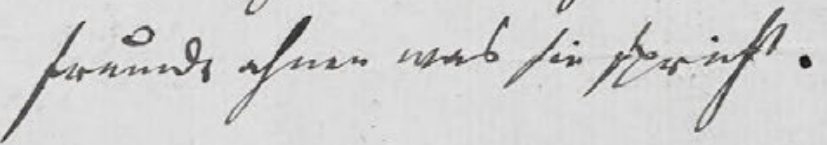

$$
\begin{aligned}
& \text { Alp cats' in intorffaltat }
\end{aligned}
$$

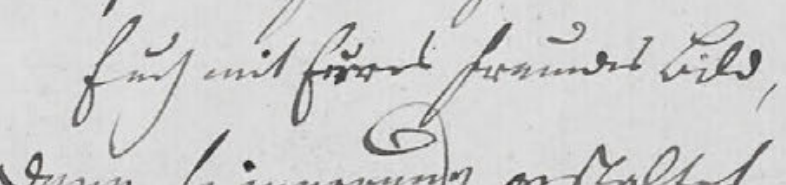

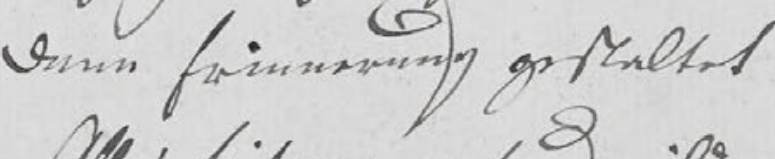

$$
\begin{aligned}
& \text { Alert fistow woy in wills. }
\end{aligned}
$$

$C$

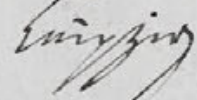

s.3. Anlig

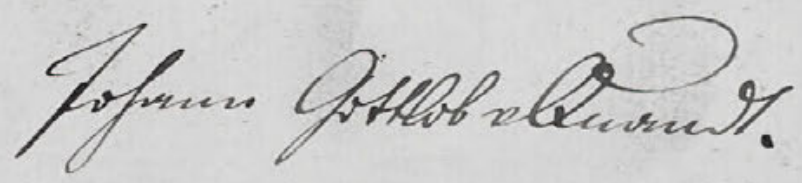

129 Verse von Johann Gottlob von Quandt zu den Porträts von Friedrich Gießmann (s. Abb. 6, 31), 30.7.1829, Feder in Braun, 158 × 187/8 mm, München, Privatbesitz 


\section{Primärquellen und Sekundärliteratur}

\section{Abkürzungen}

\section{ÄGB}

Ästhetische Grundbegriffe. Historisches Wörterbuch in sieben Bänden. Studienausgabe, hrsg. v. Karlheinz Barck et al., Stuttgart/Weimar: c, 2010.

$\mathrm{AZ}$

Allgemeine Zeitung, Augsburg/Stuttgart/

Tübingen: J. G. Cotta, 1798-1925.

FA

Johann Wolfgang von Goethe, Sämtliche Werke. Briefe, Tagebücher und Gespräche. Frankfurter Ausgabe, hrsg. Friedmar Apel et al., 40 Bde., Frankfurt a/M: Deutscher Klassiker Verlag, 1987-1999.

\section{GSA}

Goethe- und Schiller-Archiv, Klassik Stiftung Weimar.

\section{gta Archiv / ETH Zürich}

Archiv des Instituts für Theorie und Geschichte der Architektur, Eidgenössische Technische Hochschule Zürich.

\section{HStADD}

Sächsisches Staatsarchiv, Abteilung Hauptstaatsarchiv Dresden.

\section{JALZ}

Jenaische Allgemeine Literaturzeitung, gegründet von Johann Wolfgang von Goethe und Christian Gottlob Voigt, Jena/Leipzig: Literaturzeitung und Kurfürstlich-Sächsische Zeitungsexpedition, 1804-1841 [Internetressource: Jena, Thüringer Universitäts- und Landesbibliothek Jena, Projekt journals@ UrMEL, zs.thulb.uni-jena.de, letzter Zugriff: 17.9.2018].

KB

Kunst-Blatt. Beilage zum Morgenblatt für gebildete Stände, hrsg. v. Ludwig Schorn, Stuttgart: Cotta, 1816-1849.

\section{MA}

Johann Wolfgang von Goethe, Sämtliche Werke nach Epochen seines Schaffens. Münchner Ausgabe, hrsg. v. Karl Richter in Zusammenarbeit mit Herbert G. Göpfert, Norbert Miller, Gerhard Sauder und Edith Zehm, 21 Bde. [33 Teilbände], München/Wien: Carl Hanser, 1985-1998.

\section{MdbK}

Museum der bildenden Künste, Leipzig, Archiv.
MKL

Metzler Kunsthistoriker Lexikon. 210 Porträts deutschsprachiger Autoren aus vier Jahrhunderten, 2. Aufl. [Erstausgabe: 1999], hrsg. v. Peter Betthausen et al., Stuttgart/Weimar: J. B. Metzler, 2007.

$\mathrm{NL}$

Nachlass.

\section{PrAdK}

Preußische Akademie der Künste, Historisches Archiv der Akademie der Künste, Berlin.

RK

Rüstkammer Dresden.

SKD

Staatliche Kunstsammlungen Dresden.

\section{SLUB, Mscr. Dresd.}

Sächsische Landesbibliothek - Staatsund Universitätsbibliothek Dresden, Handschriftenabteilung.

\section{SMB}

Staatliche Museen zu Berlin.

\section{ThSA, FaL}

Thüringisches Staatsarchiv Altenburg, Familienarchiv Lindenau.

\section{ThULB, HSA}

Thüringer Universitäts- und Landesbibliothek, Jena, Handschriftenabteilung.

\section{Quandt-Autographen in Archiven und Bibliotheken}

Der schriftliche Nachlass von Quandt und seiner Familie gilt als verschollen (siehe Kap. Einführung. Forschungsstand und Quellen). Nachfolgend werden alle Signaturen konsultierter Autographen bis auf Dossierstufe (Mappe, Schachtel, Kapsel, etc.) oder Dokumentenstufe nachgewiesen. Es handelt sich dabei vorwiegend um Archivverweise auf Autographen von Quandt. Einige Bestände enthalten auch Briefe anderer Korrespondenten an Quandt oder solche, die ihn erwähnen. Ebenfalls hier aufgeführt ist die edierte Korrespondenz zwischen Quandt und Goethe. Diese Zusammenstellung entspricht dem aktuellen Stand der Recherchen und ist nicht abschließend.

\section{Briefeditionen}

"Von den herrlichsten Kunstwerken umgeben...". Der Briefwechsel zwischen Johann Wolf- gang von Goethe und Johann Gottlob von Quandt, hrsg. v. Walter Schmitz und Jochen Strobel, Dresden: Thelem Universitätsverlag, 2001.

Hermann Uhde-Bernays, Goethe, Johann Gottlob von Quandt und der Sächsische Kunstverein. Mit bisher ungedruckten Briefen des Dichters, Stuttgart: Verlag der J. G. Cotta'schen Buchhandlung, 1878.

\section{Archive und Bibliotheken}

Altenburg, Thüringisches Staatsarchiv (ThSA) Familienarchiv Lindenau, Nr. 13 Familienarchiv Lindenau, Nr. 15

Berlin, Preußische Akademie der Künste (PrAdK), Historisches Archiv Pers. BK 401 Quandt 118 Gutachten über wissenschaftliche und Kunstgegenstände 136 Ernennung von ordentlichen, außerordentlichen und Ehrenmitgliedern 212a Kunstausstellungen

Berlin, Staatsbibliothek, Handschriftenabteilung Sammlung Adam, NL 141/72, Quandt, Johann Gottlob v.

Sammlung Darmstaedter, Sign. 2b 1821 (8), Ebert, Friedrich Adolf Sammlung Darmstaedter, Sign. 2i 1826 (3), Quandt, Johann Gottlob von Sammlung Härtel, Quandt, (Johann) Gottlob Nachlass Sayn-Wittgenstein, K. 7, Quandt, Johann Gottlob von

Berlin, Staatliche Museen Berlin (SMB), Zentralarchiv, Autographensammlung Mappe 940/2 Mappe 1133, Quandt, Johann Gottlob von Nachlass Rauch XI.3. Briefe von: Böttiger, 1822-1832

Nachlass Johann Gottfried Schadow, NL Sw 182

Bonn, Universitäts- und Landesbibliothek Dezernat 5 / Abt. Handschriften und Rara, Autographensammlung Kiste 86 S 685 (Nachlass Welcker) 
Coburg, Kunstsammlungen der Veste Coburg A. $\mathrm{V}, 1068,(1), 1$

Dortmund, Dortmund, Stadt- und Landesbibliothek

Atg. Nr. 8707

Dresden, Sächsische Landes- und Universitätsbibliothek, Handschriftenabteilung (SLUB,

Mscr. Dresd.)

App. 26

App. 70

App. 130

App. 184

App. 204

App. 232

App. 278

App. 310

App. 393

App. 416, Bd. 12

App. 506

App. 513

App. 1191

App. 1391

App. 2122 Grundlinien zur Bearbeitung der Schönheitslehre als Wissenschaft, angewendet auf Form, Hell und Dunkel, und Farbe: Heft A-I / Johann Gottlob von Quandt [mutmaßl. Verf.], [um 1830].

Aut. 2148

D. 410, I (Sammlung »Briefe an Familie Keil«)

Dd. 209

Depositum Schnorr: Pos.13(2)

e 91, XI, S. 297/98

e $98,1 /$ II

h 20, Seidemanns Korrespondenz, Bd. 7

h 21 Bd. 22, Nr. 134-147

h 33, II, Nr. 198

$\mathrm{H} 37, \mathrm{Bd} .151$

h 41

L 224, Bd. IV, Nr. 11

n Inv. 8, Bd. 1 (Nachlass Schnorr von

Carolsfeld)

n Inv. 8, Bd. 2 (Nachlass Schnorr von

Carolsfeld)

n Inv. 15 Bd. 31 (Nachlass Schnorr von

Carolsfeld)

n Inv. 15, Bd. 32 (Nachlass Schnorr von

Carolsfeld)

n Inv. 77 I, 9, 164, 173 (enthält das Tagebuch

Clara Bianca von Quandt)

R 52 n 189-203

R 140 m (enthält Quandts Testament)

$\mathrm{R} 230 \mathrm{C}$

R 265 b, Bd. 1-3

$\mathrm{S} 1156$

t 2877-2879

u 341

w 84
Dresden, Sächsisches Hauptstaatsarchiv (HStADD)

10025 Geheimes Konsilium, Loc. 4742, Die Oberaufsicht über die Kunst- und wissenschaftlichen Sammlungen betr. 1829 10711 Ministerium des Kgl. Hauses, Loc. 19, Nr. 1

11125 Ministerium des Kultus und öffentlichen Unterrichts 1576-1945, 19243 Historisches Museum 1856-1866

11125 Ministerium des Kultus und öffentlichen Unterrichts, Nachtrag, N 40, Acta die Oberaufsicht über die wissenschaftlichen $u$. Kunst Sammlungen betreffend. 1829-1933

11126 Kunstakademie, Nr. 94

11126 Kunstakademie, Nr. 96

12508 Sächsischer Altertumsverein, Nr. 3 (neu: 755)

12508 Sächsischer Altertumsverein, Nr. 43

12508 Sächsischer Altertumsverein, Nr. 9

(neu: 763 )

12508 Sächsischer Altertumsverein, Nr. 12 (neu: 781)

12509 Sächsischer Kunstverein, Nr. 1

12509 Sächsischer Kunstverein, Nr. 2

12509 Sächsischer Kunstverein, Nr. 3

12881 Genealogica v. Quandt, Nr. 4099

Dresden, Staatliche Kunstsammlungen, Archiv der Rüstkammer (SKD, RK)

HStADD 13458 SKD, RK, O. Nr. [5]

HStADD 13458 SKD, RK, Nr. 6

HStADD 13458 SKD, RK, Nr. 38b

HStADD 13458 SKD, RK, Nr. 46

HStADD 13458 SKD, RK, Lieber-Nr. 77-88, 90, 92-93

Dresden, Staatliche Kunstsammlungen, Archiv der Staatlichen Kunstsammlungen (SKD) HStADD, 13458 SKD, Nachlass Posse, Nr. 27, Nr. 29, Nr. 30 (Abschriften aus den Akten der Generaldirektion der Königlichen Kunstsammlungen, Originale als Kriegsverlust, genaue Hinweise über die ursprünglichen Originalakten in den Fußnoten) HStADD, 13458 SKD, 01/GG Altbestand Gemäldegalerie Dresden 1846-1944 (1968), Nr. 8, Bd. 1 HStADD, Ministerium für Volksbildung, Nr. 18909/1, Acta die Erbauung eines neuen Museums betr. Bd. 1, 1838-1839

Dresden, Stadtarchiv

Acta die Verwaltung der Sparkasse zu Dresden betr., 1824, A. XIII.176c, Vol. III Acta die Tiedge Stiftung betreffend, Vol. I, 1842, B.XIb.24.

Acta die Schillerstiftung betreffend, 1855 , B.XI.b.3, Vol. II
Düsseldorf, Goethe-Museum Inv. o

Frankfurt am Main, Universitätsbibliothek Johann Christian Senckenberg

Nachlass Johann David Passavant, Ms. Ff. J. D.

Passavant, A. II. e, Nr. 581-588

Nachlass Arthur Schopenhauer, Na 50, 193-195

Freiburg im Breisgau, Universitätsbibliothek Schemann NL 12/2588

Hamburg, Staats- und Universitätsbibliothek Carl von Ossietzky

CS 10: Quandt

Heidelberg, Universitätsbibliothek Sign. Heid. Hs. 2751 C85

Jena, Thüringer Universitäts- und Landesbibliothek

HSA, Aut. W. M. v. Goethe, Nr. 1166

Karlsruhe, Badische Landesbibliothek, Autographen

$\mathrm{K} 703$

Krakau, Polen, Biblioteka Jagiellońska [nachfolgende Bestände vor 1945 in der Sammlung Autographa der Preußischen Staatsbibliothek Berlin]

Autographen Sammlung Boisserée Autographen Sammlung Quandt Autographen Sammlung Varnhagen

Leipzig, Museum der bildenden Künste, Archiv (MbdK)

Kunst -1 . Die Bildung eines Vereines der Kunstfreunde in Leipzig [betr.] (Kunstverein Sonnabend-Gesellschaft), 1824-1826 Kunst - 2. Acta die Sonnabends Gesellschaft oder den Verein der hiesigen Kunstfreunde, betr., von Dr. L. Puttrich, 1828-1831 Kunst - 4d. Acta die Direction des Leipziger Kunstvereins betr., 1837

Kunst - 6. Kunstverein. Correspondenz über die Hauptausstellung. 1845

Kunst - 8. Kunstverein und zwar die laufenden Geschäffte betreffend, 18[48] Kunst - 9. Acta des Leipziger Kunstvereins das städtische Museum betr. Sept. 1861-Dec. 1864 Kunst - 10. Acta des Leipziger Kunstvereins Protocolle enthaltend. 1861-1871 Dokumente u. Correspondenz das Verzeichnis der Kunstwerke des städtischen Museums betreffend, [1887]-1896

Leipzig, Stadtarchiv Leipziger Kunstverein (Kunst=Verein. Correspondenz), 1845-1846, Sign. Nr. 118 
Leipzig, Stadtgeschichtliches Museum Handschriftensammlung, Gruppe: Gelehrte, Einzelbezeichnung: Quandt, Joh. Gottlob v. an die Kgl. Bayrische Akademie. Dittersbach, den 10. Sept. 1835

\section{Leipzig, Universitätsbibliothek Hirzel B 556 (Quandt) Liebeskind IV, Quandt, Johann Gottlob von Nachlass 255, C 237, Quandt, von Sondersammlungen 42 215, Quandt, Johann Gottlob von 232, Quandt, Johann Gottlob von 393, Quandt, Johann Gottlob (2) 394, Quandt, von}

\section{Lübeck, Bibliothek der Hansestadt Lübeck Autographensammlung Hennings: Blaue Kartons}

\section{Marbach Deutsches Literaturarchiv Cotta-Archiv (Stiftung der Stuttgarter Zeitung)}

München, Bayerische Staatsbibliothek Autograph Humboldt, Wilhelm von, Nr. 3 Autograph Overbeck, Friedrich Autograph Quandt, Johann Gottlob von Autograph Schnorr von Carolsfeld, Julius E. Petziana V, Quandt, Johann Gottlob von

Nürnberg, Historisches Archiv des Germanischen Nationalmuseums

Autographen Böttiger K. 21

Autographen K. 27

Autographen K. 55

Stanford CA, Stanford University Libraries, Departement of Special Collections Mo475, German Artists, Box I, Folder 32: Quandt

\section{Tartu Ülikool (Universität Tartu, Estland)} Friedrich Ludwig Schardiuse autograafide kollektsioon [3115], Sch 2336 [Internetressource: http://hdl.handle.net/10062/12090, letzter Zugriff: 29.8.2018] Kirjad Karl Morgensternile. 18. kd. [88], F 3 , Mrg CCCXLII, kd.18, I.235-236 [Internetressource: http://hdl.handle.net/10062/22417, letzter Zugriff: 29.8.2018]

Weimar, Goethe- und Schiller-Archiv, Klassik Stiftung Weimar (GSA)

Nachlass Schorn, 85/24,11

\section{Wien, Kunsthandel} Antiquariat Inlibris, Wien, https://inlibris.at/ de.html [letzter Zugriff: 27.8.2018]
Zürich, Eidgenössische Technische Hochschule (ETH), Institut für Geschichte und Theorie der Architektur, Archiv (gta-Archiv)

20-K-1937-9-10

20-K(DD)-1849-07-07:2

20-K-1849-07-11

20-K-1849-07-12

$20-K-1849-07-17(\mathrm{~S})$

20-K-1849(S):1

2O-K-1849(S):2

\section{Kommentierte Bibliographie der publizierten Quandt-Schriften}

Bei nachfolgender Bibliographie der publizierten Schriften Johann Gottlob von Quandts handelt sich um eine Zusammenstellung aller Bücher, Aufsätze und Rezensionen, die eruiert werden konnten. Vor allem in lokalen Zeitungen Dresdens und Leipzigs dürften noch weitere Artikel erschienen sein, wie einige Bemerkungen in den Quellen vermuten lassen. Darüber hinaus sind hier die posthum erschienenen Auktionskataloge seiner Sammlung sowie die nach seinem Tod erschienene, autobiographische Schrift über seine Begegnungen mit Goethe aufgeführt. Wenn mehrere Schriften in einem Jahr erschienen sind, werden diese durch in Klammern gestellte Ziffern hinter den Sigeln identifiziert.

Quandt hat eine Vielzahl von Büchern und Artikeln verfasst. Sie erschienen als selbstständige Publikationen oder als Artikel in bekannten Zeitschriften, unter anderen Ludwig Schorns Kunstblatt, die Zeitschrift für die elegante Welt, der Musenalmanach von Johann Amadeus Wendt, Carl August Böttigers Artistisches Notizenblatt oder das Journal des Luxus und der Moden von Friedrich Johann Justin Bertuch. Quandts Veröffentlichungen werden hier in ihrer thematischen Breite kurz charakterisiert. Um das Verweissystem mit Sigeln in den Anmerkungen der Studie nicht zu verunklären, wird auf eine Einteilung der Quandt-Bibliographie nach Themen verzichtet. Nachfolgend werden den einzelnen Bereichen nur die entsprechenden Sigel in chronologischer Reihenfolge beigegeben, gefolgt von einem kurzen Kommentar. Die vollständigen Literaturangaben sind in der anschließenden, chronologisch geordneten Bibliographie der publizierten Quandt-Schriften erschlossen.

\section{Kunsthistorische Schriften}

Quandt 1811; Quandt 1812; Quandt 1815; Quandt 1816 (2); Quandt 1818 (2); Quandt 1820 (3); Quandt 1822; Anonym [Quandt] 1826; Quandt 1826 (1); Quandt 1826 (2); Quandt 1826 (3); Quandt 1826 (4); Quandt 1829 (4); Quandt 1831 (1); Quandt 1832 (1); Quandt 1830-1833; Quandt 1839 (1); Quandt 1839 (2); Quandt 1840 (2)
Die meisten Publikationen von Quandt entfielen auf Themen zur Kunstgeschichte. Es fällt dabei auf, dass diese in den 1810er bis 1830er Jahren erschienen sind. In den kunsthistorischen Schriften behandelte Quandt größtenteils altdeutsche Kunst und Künstler mit einem wiederholten Fokus auf deren Relikte in Sachsen. Im Sinn seiner Bemühungen um einen Ausgleich der nördlichen und südlichen Kunstschulen sind die Aufsätze über Raffael und die altitalienische Kunst einzuordnen. 1826 erschien zudem sein erfolgreicher Entwurf zu einer Geschichte der Kupferstecherkunst und deren Wechselwirkungen mit anderen bildenden Künsten, mit der Quandt seinen guten Ruf als früher Kunsthistoriker begründete.

\section{Schriften über zeitgenössische Kunst und Künstler}

Quandt 1817; Quandt 1818 (1); Quandt 1820 (1); Quandt 1820 (4); Quandt 1821; -t. [Quandt] 1822; Quandt 1823; Quandt 1824; Quandt 1834 (2); Quandt 1834 (3); Quandt 1838 (1); Quandt 1843 (2); Quandt 1846 (4); Quandt 1848

Quandt schrieb von den späten 1810er bis in die 1840er Jahre wiederholt über zeitgenössische Künstler sowie über die akademischen Kunstausstellungen. Dennoch ist es erstaunlich für einen Förderer seiner Zeitgenossen, wie wenig der Dresdener Kunstgelehrte letztlich über die Kunst seiner Zeit geschrieben hat. Betrachtet man die Themen, so lässt sich ein ausgesprochen selektives Interesse feststellen, dass sich einmal mit Landschaftsbildern, dann wieder mit Historien oder gar mit Dioramen beschäftigt.

\section{Schriften zur Künstlerausbildung}

Quandt 1826 (1); Quandt 1829 (1)

Quandts Interesse an guter, zeitgenössischer Kunst äußerte sich auch darin, dass er zwei Schriften der Künstlerausbildung widmete. Nicht zuletzt deshalb trat er ab 1836 als neues Mitglied im so genannten Akademischen Rat der Dresdener Kunstakademie ein. Der Aufsatz von 1826 wurde sogar ins Niederländische übersetzt.

\section{Schriften zur Konservierung und Restaurierung}

Quandt 1816 (1); Quandt 1820 (2); Quandt 1827 (1); Quandt 1828 (1); Quandt 1842

Während vieler Jahre engagierte sich Quandt für einen Galerieneubau in Dresden. Das alte Stallgebäude am Jüdenhof war für die kostbaren Gemälde nicht mehr geeignet, Hitze, Ruß und Staub belasteten die Kunstwerke. Aus diesen Gründen befasste sich Quandt vertieft mit Restaurierungs- und Konservierungsfragen. Beson- 
ders trat er für die Restaurierung von Raffaels Sixtinischer Madonna durch den Römer Pietro Palmaroli ein.

\section{Museologische Schriften \\ Quandt 1841; Quandt 1846 (1)}

Mit dem Eintritt in die neu gegründete Galeriekommission befasste sich Quandt zunehmend mit Hängungsfragen, so mit den Vorteilen der chronologischen Präsentation. Besonders innovativ ist seine Schrift zu der neuen Gemäldebeschilderung, dank der die Besucher der Gemäldegalerie Künstlernamen und Bildtitel rasch erfassen konnten.

\section{Museums- und Sammlungsführer \\ Kat. Quandt 1824; Quandt 1834 (1); Quandt/ \\ Schulz 1848; Kat. Quandt 1853; Quandt 1856}

Bereits 1824, nicht lange nach seiner Niederlassung in Dresden, veröffentlichte Quandt einen knappen Führer durch seine eigene Sammlung. Es zeigt sich darin sein Anliegen, Kunstwerke interessierten Besuchern zu erläutern. Später folgte ein Führer durch die Privatsammlung altmeisterlicher Kunstwerke von Bernhard August von Lindenau in Altenburg und ein Katalog seiner eigenen graphischen Sammlung mit programmatischer Einführung. Aufgrund von Quandts Aufgaben für die königlichen Museen entstanden Wegleitungen durch die neuen Präsentationen im Historischen Museum und in der neu erbauten Sempergalerie.

\section{Ästhetische und kunsttheoretische Schriften Quandt 1830 (1); Quandt 1844 (1); Quandt 1847; Quandt 1850 (2)}

Quandt schrieb einmal, er habe sich im fortgesetzten Alter zunehmend mit der philosophischen Ästhetik auseinandergesetzt. Dennoch halten sich Bücher und Aufsätze hierüber in überblickbaren Grenzen. Seine ästhetischen Axiome integrierte er vielmehr in verschiedenste Publikationen und stellte sie in den Kontext seiner Kunstbetrachtungen. Dennoch schrieb er zwei Schriften über die Ästhetik: die Briefe aus Italien von 1830 und die Vorträge über Ästhetik für bildende Künstler von 1844. Der konversierende Charakter der Briefe und die aus seinen Vorlesungen an der Akademie der bildenden Künste in Dresden hervorgegangenen Vorträge deuten an, dass der Kunstschriftsteller für seine Ästhetik ein breites Zielpublikum vor Augen hatte.

\section{Buchrezensionen}

Quandt 1827 (2); Quandt 1829 (2); Quandt 1829 (3); Quandt 1830 (3); Quandt 1831 (3); Quandt 1831 (4); Quandt 1832 (2); Quandt
1840 (3); Quandt 1840 (4); Quandt 1843 (3); Quandt 1844 (3); Quandt 1845; Quandt 1846

(3); Quandt 1850 (3); Quandt 1853 (3)

Quandt schrieb von den $1820 e r$ bis in die $1850 e r$ Jahre regelmäßig ausführliche Rezensionen zu neu erschienenen, vorwiegend kunsthistorischen Werken. Die Themen der besprochenen Bücher reichen von der Ölmalerei über Glasgemälde bis hin zur Baukunst. Quandt rezensierte unter anderem Bücher von Aloys Hirt, Karl Friedrich von Rumohr oder Carl Gustav Carus. Von besonderem Interesse für seine Rolle als früher Kunsthistoriker erscheinen seine Buchbesprechungen der ersten kunsthistorischen Überblickswerke von Franz Kugler und Carl Schnaase.

\section{Reiseberichte}

Quandt 1816 (3); Quandt 1819; Quandt 1843

(1); Quandt 1846 (2); Quandt 1850 (1); Quandt 1853 (1); Quandt 1853 (2)

Quandts Reiseberichte unterteilen sich in zwei Phasen. Neben einem kurzen Aufsatz über eine Reise nach Nürnberg veröffentlichte er 1819 seinen dreibändigen Text über die Italienreise von 1813, seiner Grand Tour. In den 1840er Jahren erschienen Beschreibungen seiner Reisen nach Schweden, Südfrankreich und Spanien. Letztere beide wurden anfangs der $1850 e r$ Jahre sogar ein zweites Mal aufgelegt. Während der erste Reisebericht über die Grand Tour noch geprägt von seiner Italienbegeisterung ist, kennzeichnen sich die späteren Reisen durch ein nunmehr breit gefächertes Interesse an anderen Kulturen. Dies zeigt sich auch an den Reisezielen, die in jener Zeit nicht eigentlich zu den Hauptrouten deutscher Kunstreisender zu zählen sind.

\section{Philosophische und politische Schriften}

Quandt 1826 (1); Quandt 1854 (1); Quandt 1857; Quandt 1859 (1)

Basierend auf seiner fortwährenden philosophischen Lektüre erarbeitete Quandt in seinen letzten Lebensjahren Synthesen zu Themen der Politik und Philosophie. Sie sind geprägt vom Versuch, verschiedene Denkschulen miteinander zu vereinen. Ein früher Artikel über die Aufgaben der Kunst in einem Staat, die Quandt 1826 seiner Geschichte der Kupferstecherkunst angefügt hatte, wurde 1828 ins Niederländische übersetzt.

\section{Schriften aus dem Kontext von Quandts Rit- tergut Dittersbach}

Quandt 1836; Quandt 1838 (2); Quandt 1844

(2); Quandt 1846 (5); Quandt 1859 (2)

Der Rittergutsbesitzer Quandt trat als aufgeklärter Bildungsbürger mit Adelstitel auf. Er versuchte nicht nur, ökonomische Prozesse zu optimieren, sondern auch das soziale Wohl und die Bildung seiner Untertanen zu verbessern. Über seine erstaunlich frühen Bemühungen um Sparkassen für die kleinen Leute oder Turnunterricht für Jugendliche hinaus schlugen sich einige seiner Anliegen auch in Publikationen zur Landwirtschaft, zur Sprachbildung oder zur Kinderhilfe nieder.

\section{Gedichte, Reden, Erzählungen}

Quandt 1830 (2); Quandt 1831 (2); Quandt

1833; Quandt 1840 (1); Quandt 1854 (2)

Quandt veröffentlichte einige Gelegenheitsdichtungen zu Kunstwerken alter Meister. Ebenso publizierte er Reden und Gesänge, die er aus Anlass verschiedener Bauten in seinem Rittergut geschrieben hatte. 1854 erschien ein Band mit fiktiven Erzählungen aus dem »Herbarium der Erfahrungen« eines Herrn Kauz, die dieser einer Abendgesellschaft gestandener Herren zum Besten gibt.

\section{Autobiographische Schriften}

Quandt 1828 (2); Quandt 2001 [1870]

Nach der Aufnahme als Ehrenmitglied der Königlichen Akademie der bildenden Künste Berlin schrieb Quandt für das Berliner Kunstblatt seine Biographie nieder. Zu einem unbestimmten Zeitpunkt und aus nicht geklärten Gründen verfasste er zudem eine autobiographische Schrift über seine Begegnungen und sein Verhältnis zu Goethe. Diese wurde posthum veröffentlicht.

\section{Posthume Auktionskataloge zu Quandts Sammlung \\ Kat. Quandt 1860 (1); Kat. Quandt 1860 (2); Kat. Quandt 1868}

Die posthum erschienenen Auktionskataloge erlauben einen Überblick über Quandts umfassende Sammlung an Gemälden, Zeichnungen und Druckgraphiken am Ende seines Lebens und lassen teilweise Rückschlüsse auf ihre Präsentation zu.

\section{Chronologische Bibliographie der publizierten Quandt-Schriften}

\section{Quandt 1811}

»Kunstschätze in der Kirche zu Annaberg im sächsischen Erzgebirge«, in: Zeitung für die elegante Welt, 1811, Jg. 11, Nr. 200, Sp. 1593-1598.

\section{Quandt 1812}

»Einige Vermuthungen, die Bilder in der Kirche zu Annaberg betreffend«, in: Zeitung für die elegante Welt, 1812, Jg. 12, Nr. 11, Sp. 85-86. 


\section{Quandt 1815}

"Über altdeutsche Kunst, in Beziehung auf die in Leipzig aufgefundenen altdeutschen Gemälde, nebst einer Beschreibung derselben«, in: Zeitung für die elegante Welt, 1815, Jg. 15, Nr. 121-126, Sp. 961-1007.

\section{Quandt 1816 (1)}

»Ueber den gegenwärtigen Zustand der Gemäldegallerie in Dresden«, in: Journal für Literatur, Kunst, Luxus und Mode, Dezember 1816, Jg. 31, S. 831-843.

\section{Quandt 1816 (2)}

»Ueber Guido von Fiesole, in Beziehung auf Kunst im Allgemeinen «, in: Kunstblatt, 1816, Nr. 17-20, S. 66-67, 70-72, 80.

\section{Quandt 1816 (3)}

»Über Nuernberg. Bruchstücke aus dem Briefe eines kunstliebenden Reisenden«, in: Journal für Literatur, Kunst, Luxus und Mode, September 1816, S. 553-566.

\section{Quandt 1817}

»Ueber die von Peter Cornelius gezeichneten Scenen aus Göthe's Faust und dem Niebelungenliede«, in: Leipziger Kunstblatt insbesondere für Theater und Musik, 1817, Nr. 34-35, S. 141-143, 145-147.

\section{Quandt 1818 (1)}

»Ueber die diesjährige Kunstausstellung zu Dresden«, in: Zeitung für die elegante Welt, 1818, Jg. 18, Nr. 236-239, Sp. 1901-1904, 1912-1914, 1917-1920, 1926-1930.

\section{Quandt 1818 (2)}

»Ueber das Altdeutsche in der Malerei, in Beziehung auf Heinrich Golzius zwölf neu herausgegebene Kupferstiche«, in: Leipziger Kunstblatt insbesondere für Theater und Musik, 1818, Nr. 64-66, S. 265-266, 269-270, 273-275.

\section{Quandt 1819}

Streifereien im Gebiete der Kunst auf einer Reise von Leipzig nach Italien im Jahr 1813, Leipzig: Brockhaus, 1819.

\section{Quandt 1820 (1)}

»Betrachtungen, durch J. W. v. Rohden's Gemälde einer Ansicht von Tivoli veranlaßt« und »Wanderung durch die Werkstätten deutscher Künstler in Rom«, in: Kunstblatt, 1820, Nr. 55, S. 219-220 und Nr. 66, S. 262-264.

\section{Quandt 1820 (2)}

»Nachricht über das Originalporträt der Fornarina von Raphael«, in: Kunstblatt, 1820, Nr. 12, S. 45.

\section{Quandt 1820 (3)}

»Il Sposalizio. Gemälde von Raphael in der Gallerie alla Brera zu Mailand, gestochen von G. Longhi«, in: Kunstblatt, 1820, Nr. (3), S. 269-271.

\section{Quandt 1820 (4)}

»Über Julius Schnorrs Gemählde, die Verwandlung des Wassers in Wein vorstellend«, in: Archiv für Geographie, Historie, Staatsund Kriegskunst, Nr. 27, 3.3.1820, S. 117-119.

\section{Quandt 1821}

»Nachricht über G. F. Steinkopfs neuere Werke und Rückblick auf eine Recension in Nr. 96 des Kunstblatts 1820«, in: Kunstblatt, 1821, Nr. 30, S. 117-118.

\section{Quandt 1822}

»Raffael's Villa«, in: Die Muse. Monatsschrift für Freunde der Poesie und der mit ihr verschwisterten Künste, hrsg. v. Friedrich Kind, 1822, Jg. 1, Nr. 1, S. 3-24.

\section{-t. [Quandt] 1822}

-t. [Johann Gottlob von Quandt], »Dresden. Ende September 1822«, in: Kunstblatt, 1822, Nr. 93, S. 371-372.

\section{Quandt 1823}

»Einige Worte über Professor Vogel's Malereyen in Pillnitz«, in: Kunstblatt, 1823, Nr. 6, S. 21-22.

\section{Quandt 1824}

»Ueber die dießjährige Kunstausstellung in Dresden«, in: Kunstblatt, 1824, Nr. 92 , S. 364-368.

\section{Kat. Quandt 1824}

Verzeichniss von Gemälden und andern Kunstgegenständen im Hause des J. G. v. Quandt zu Dresden, Dresden: Christian Lebrecht Fürchtegott Ramming, 1824.

\section{Quandt 1825}

»Betrachtungen über die Ausstellung in Dresden im August und September «, in: Artistisches Notizenblatt, September/Oktober 1825 , Nr. 17-20, S. 65-67, 69-76, 81-83.

\section{Quandt 1826 (1)}

Entwurf zu einer Geschichte der Kupferstecherkunst und deren Wechselwirkungen mit anderen bildenden Künsten. Mit zwei Beilagen, Leipzig: F. A. Brockhaus, 1826.

\section{Quandt 1826 (1)}

»Vorschläge zur Verbesserung deutscher Kunst-Akademien und dabei zu berücksichtigende Schwierigkeiten«, in: Quandt 1826 (1), S. 261-291.

[1828 übersetzt ins Niederländische: »Voorslagen ter verbetering der kunstschoolen of kunstacademien met een hartig woordje over de zoogenaamde zich tegen die verbetering kantende bezwaren en moeijelijkheden «, Amsterdam: J. C. van Kesteren, 1828, S. 25-51]

\section{Quandt 1826 (1)}

»Ueber die Stellung der bildenden Künste zum Staate«, in: Quandt 1826 (1), S. 293-312. [1828 übersetzt ins Niederländische: »Over het standpunt, waarin kunsten, handwerken, volkskrachten en nijverheid beschouwd moeten worden met betrekking tot den staat«, Amsterdam: J. C. van Kesteren, 1828, S. 7-24]

\section{Anonym [Quandt] 1826}

Anonym [Johann Gottlob von Quandt], »Die Madonna del Sisto in der königlichen Gallerie zu Dresden«, in: Kunstblatt, 1826, Nr. 30 , S. 118-119.

\section{Quandt 1826 (2)}

»Noch ein Wort über die Johanna von Aragonien « und »Nachtrag zu dem in Nr. 9 gedruckten Aufsatz über die Johanna von Aragonien«, in: Artistisches Notizenblatt, 1826, Nr. 9, S. 33-35, Nr. 10, 38-39.

\section{Quandt 1826 (3)}

"Sollte die Madonna del Sisto wirklich nicht von Raphael seyn?«, in: Artistisches Notizenblatt, 1826, Nr. 1-2, S. 1-7.

\section{Quandt 1826 (4)}

»Ueber die Ausgrabungen in Pompeji und das Museo Borbonico und »Ueber das neue Werk Museo Borbonico«, in: Amalthea oder Museum der Kunstmythologie und bildlichen Alterthumskunde, Bd. 3, hrsg. v. Carl August Böttiger, Leipzig: 1825, S. 332-342.

\section{Quandt 1827 (1)}

»Ueber Palmaroli's Berufung nach Dresden und dessen Arbeiten auf der Königl. Gallerie«, in: Artistisches Notizenblatt, 1827, Nr. 2, S. 5-8, Nr. 3, S. 9-11, Nr. 4, S. 17-20, 53-56.

\section{Quandt 1827 (2)}

Rezension von: »|talienische Forschungen von C. F. von Rumohr. - Erster Theil. 1827.«, in: Allgemeine Literatur-Zeitung, 1827, Nr. 166169, Sp. 481-493, 497-511.

\section{Quandt 1828 (1)}

»Entgegnung auf eine Correspondenznachricht im Berliner Conversations-Blatte No. 18 d. J. über das von Palmaroli restaurirte Gemälde, die Madonna di S. Sisto « und »Restauration«, in: Artistisches Notizenblatt, 1828, Nr. 6, S. 21-23, Nr. 9, S. 33-34.

\section{Quandt 1828 (2)}

»ohann Gottlob von Quandt«, hrsg. v. Ernst Heinrich Toelken, in: Berliner Kunstblatt, 1828, Nr. 5, S. 135-138.

\section{Quandt 1829 (1)}

Ueber Preisaufgaben für bildende Künstler, mit einem Beitrag von Carl August Böttiger, Dresden: Walther, 1829.

\section{Quandt 1829 (2)}

Rezension von: »Neu entdeckte Wandgemäl de in Pompeji, gezeichnet von W. Zahn«, in: Allgemeine Literatur-Zeitung, 1829, Nr. 111, Sp. $245-248$.

\section{Quandt 1829 (3)}

Rezension von: »M. B. L. Bouvier's [...] vollständige Anweisung zur Oehlmalerey für Künstler und Kunstfreunde. Aus dem Französischen übersetzt von Dr. C. F. Prange [...]. Nebst einem Anhang über die geheimnisvolle Kunst, alte Gemälde zu restauriren. Mit sieben Kupfertafeln. 1828. «, in: Allgemeine Literatur-Zeitung, 1829, Nr. 154155 , Sp. 585-600.

\section{Quandt 1829 (4)}

Simon Wagner, Scenen aus dem Leben Albrecht Dürers, nebst Erläuterungen von J. G. Quandt, Dresden: Walther, 1829. 


\section{Quandt 1830 (1)}

Briefe aus Italien über das Geheimnisvolle der Schönheit und die Kunst, Gotha: Heinsius, 1830.

\section{Quandt 1830 (2)}

Drei Gedichte: »An ein Pastellgemälde von Philipp Veith.«, »An die sterbende Maria von Martin Schaffner.«, »An ein Gemälde in der Pommersfelder Gallerie. (Angeblich von Raffael.)«, in: Musenalmanach für das Jahr 1830 hrsg. v. Amadeus Wendt, Leipzig: Weidmannische Buchhandlung, 1830, S. 86-88.

\section{Quandt 1830 (3)}

Rezension von: »Kunstbemerkungen auf einer Reise über Wittenberg und Meißen nach Dresden und Prag von A. Hirt. 1830«, in: Allgemeine Literatur-Zeitung, 1830, Nr. 152-154, Sp. 569-587.

\section{Quandt 1830-1833}

Luigi Lanzi, Geschichte der Malerei in Italien vom Wiederaufleben der Kunst bis Ende des achtzehnten Jahrhunderts, 3 Bde., aus dem Italienischen übersetzt und mit Anmerkungen versehen von Johann Gottlob von Quandt, hrsg. v. Adolph Wagner, Leipzig: Verlag Johann Ambrosius Barth, 1830-1833.

\section{Quandt 1831 (1)}

Hinweisungen auf Kunstwerke aus der Vorzeit. Den Alterthumsfreunden in Sachsen gewidmet von Quandt, Dresden: Walther, 1831.

\section{Quandt 1831 (2)}

Bei Legung des Grundsteins auf Schönhöhe ohnweit Dittersbach am 12. September 1831, [s. I.]: [s. n.], 1831.

\section{Quandt 1831 (3)}

»Erörterungen zu den $>$ Kunstbemerkungen auf einer Reise über Wittenberg und Meißen nach Dresden und Prag von A. Hirt««, in: Kunstblatt, 1831, Nr. 17, S. 65-66.

\section{Quandt 1831 (4)}

Rezension von: „Neun Briefe über Landschaftsmalerey, geschrieben in den Jahren 1815-1824. Zuvor ein Brief von Göthe als Einleitung. Zum Beginn des Jahres 1831 herausgegeben von C. G. Carus. 1831《, in: Allgemeine Literatur-Zeitung, 1831, Nr. 93, S. 97-102.

\section{Quandt 1832 (1)}

Nachträge zu den Hinweisungen auf Kunstwerke aus der Vorzeit, [Dresden]: [s. n.], [1832].

\section{Quandt 1832 (2)}

Rezension von: »Das Leben und die Werke Albrecht Dürers, von Joseph Heller, in drey Bänden. Zweyter Band mit 3 Abbild. 1831《, in: Allgemeine Literatur-Zeitung, Nr. 87, Sp. 49-51.

\section{Quandt 1833}

Bei Einweihung der Burg auf Schönhöhe unweit Dittersbach am 12. September 1833 , [s. I.]: [s. n.], 1833.

\section{Quandt 1834 (1)}

Das historische Museum in Dresden. Andeutungen für Beschauer des historischen Museums, Dresden: Walther, 1834.

\section{Quandt 1834 (2)}

». Thuermer's kuenstlerischer Nachlass«, in: Verzeichniss der Handzeichnungen, Kupferstiche, Kupferwerke und Kunstbuecher aus dem Nachlasse des verstorbenen Herrn Joseph Thuermer, Architekt, Professor ord. der Koenigl. Saechs. Akademie der bildenden Kuenste zu Dresden und Vorsteher der damit verbundenen Bauschule, hrsg. v. Carl Ernst Heinrich, Dresden: Carl Ramming, 1834 , [s.p].

\section{Quandt 1834(3)}

»Diorama des Herrn Daguerre in Paris«, in: Museum. Blätter für bildende Kunst, 1834, Jg. 2, Nr. 49, S. 402-403.

\section{Quandt 1836}

Schützen-Ordnung zu Dittersbach, Dittersbach: [s. n.], 1836.

\section{Quandt 1838 (1)}

»Schönhöhe [...]« in: Kunstblatt, 1838, Nr. 64, S. 253 .

\section{Quandt 1838 (2)}

Kleines $A$-B-C-Buch für Anfänger im Lesen und Schreiben. Synonymen und Homonymen, Leipzig: Brockhaus, 1838.

Quandt 1839 (1)

Die Gemälde des Michel Wohlgemuth in der Frauenkirche zu Zwickau. Im Auftrage des Königlich Sächsischen Alterthumsvereins, Dresden/Leipzig: Rudolph Weigel, 1839.

\section{Quandt 1839 (2)}

Vorwort an die Beschauer der Abgüsse von Bildwerken vom Parthenon, Dresden: [s. n.] 1839.

\section{Quandt 1840 (1)}

Baureden und Festgesänge, Dresden: [s. n.], 1840.

\section{Quandt 1840 (2)}

»Ueber Martin Schongauer als Maler und seine Werke in Colmar«, in: Kunstblatt, 1840, Nr. 76, S. 317-319, Nr. 77, S. 322-324, Nr. 78 , S. 325-326, Nr. 79, S. 329-331.

\section{Quandt 1840 (3)}

Rezension von: »Münchner Jahrbücher für bildende Kunst. Herausgegeben von Dr. Rudolf Marggraff [...]. Erstes u. zweites Heft. $1838 \mathrm{u}$. 1839.", in: Allgemeine Literatur-Zeitung, 1840 Nr. 202-203, Sp. 393-407.

\section{Quandt 1840 (4)}

Rezension von: »Geschichte der Glasmalerei in Deutschland und den Niederlanden, Frank reich, England, der Schweiz, Italien, und Spanien, von ihrem Ursprung bis auf die neueste Zeit. Von M. A. Gessert, Rechtsgelehrten. 1839." in: Allgemeine Literatur-Zeitung, 1840, Nr. $147-148$, S. 561-576

\section{Quandt 1841}

»Über denselben Gegenstand [Über den Vorzug der chronologischen Aufstellung bei großen königlichen und öffentlichen Sammlungen]«, in: Athanasius Graf Raczyński, Geschichte der neueren deutschen Kunst, Bd. 3, Berlin: »auf Kosten des Verfassers", 1841, S. 433-434.

\section{Quandt 1842}

Über den Zustand der königlichen Gemäldegalerie zu Dresden. Für wahre Freunde der Kunst, nebst Belegen und erläuternden Anmerkungen, Leipzig: Weigel, 1842.

\section{Quandt 1843 (1)}

Nippes von einer Reise nach Schweden, Leipzig: Hirschfeld, 1843.

\section{Quandt 1843 (2)}

»Die belgischen Bilder«, in: Kunstblatt, 1843 , Nr. 39/40, S. 165-166, 170-171.

\section{Quandt 1843 (3)}

Rezension von: »Handbuch der Kunstgeschichte von Dr. Franz Kugler, Prof. an der königl. Academie der Künste zu Berlin. 1842.«, in: Allgemeine Literatur-Zeitung, 1843, Nr.3336, Sp. 257-258, 265-28o, 287-288; Nr. 53-54, Sp. 417-420, 425-432, 435-440.

\section{Quandt 1844 (1)}

Vorträge über Ästhetik für bildende Künstler in der Königl. Academie für bildende Künste in Dresden, Leipzig: Verlag von C. L. Hirschfeld, 1844.

\section{Quandt 1844 (2)}

Mittheilungen aus den Papieren des Schönfelder landwirthschaftlichen Vereins, Dresden: [s. n.], 1844.

\section{Quandt 1844 (3)}

Rezension von: »Geschichte der bildenden Künste von Carl Schnaase. Düsseldorf, Buddeus. 1843", in: Allgemeine LiteraturZeitung, 1844, Nr. 87-91, Sp. 689-694, 697728; Nr. 314-317, Sp. 1165-1184, 1189-1192.

\section{Quandt 1845}

Rezension von: "Geschichte der Baukunst von der ältesten Zeit bis auf die Gegenwart. Von J. Andreas Romberg und Friedr. Steger, Leipzig, Romberg. 1844.", in: Allgemeine Literatur-Zeitung, 1845, Nr. 219-220, Sp. 561-568, $575-576$

\section{Quandt 1846 (1)}

»Über die bei der königl. Gemäldegalerie zu Dresden eingeführte Namenangabe«, in: Kunstblatt, 1846, Nr. 9, S. 33-36.

\section{Quandt 1846 (2)}

Beobachtungen und Phantasien über Menschen, Natur und Kunst auf einer Reise in's mittägige Frankreich, Leipzig: Hirschfeld, 1846.

\section{Quandt 1846 (3)}

Rezension von: »1) Geschichte der bildenden Kunst von Dr. Carl Schnaase. 3. Band. Düsseldorf, Buddeus. 1844. 2) Die Basiliken des christlichen Roms nach ihrem Zusam- 
menhange mit Idee und Geschichte der Kirchenbaukunst dargestellt von Dr. Bunsen. München, literar. artist. Anstalt. 1843.«, in: Allgemeine Literatur-Zeitung, 1845, Nr.73-75, Sp. $577-600$.

\section{Quandt 1846 (4)}

»Eduard Bendemann«, in: Sachsens beruehmte Maenner und Frauen der Jetztzeit. Heft 1: Bernhard v. Lindenau. Christ. Fr. v. Ammon. Eduard Bendemann, Leipzig: Wilhelm Schrey, [1846].

\section{Quandt 1846 (5)}

Sendschreiben an den landwirthschaftlichen Verein zu Schönfeld, Dresden: [s. n.], 1846.

\section{Quandt 1847}

»Ueber Gegenstände und Aufgaben der bildenden Kunst« und "Sendschreiben an die Redaction in Betreff unseres Aufsatzes sder Zeitgeist und die Kunst«", in: Einzelne Blätter über bildende Kunst und Kunstvereine im Jahre 1847, hrsg. v. Friedrich Rudolph Meyer, Leipzig: Teubner, 1847, S. 65-72, 134-140.

\section{Quandt 1848}

»Nachrichten über Ludwig Richter in einem Schreiben v. Quandts an Ernst Förster«, in: Kunstblatt, 1848, Nr. 60, S. 239-240.

\section{Quandt/Schulz 1848}

Beschreibung der im neuen Mittelgebäude des Pohlhofs befindlichen Kunst-Gegenstände durch die Herren v. Quandt und Hofrath Schulz mit einem Vorwort des Sammlers. Nebst einer Ansicht und Grundriss des neuen Gebäudes, hrsg. v. Bernhard August von Lindenau, Altenburg: Hofbuchdruckerei, 1848.

\section{Quandt 1850 (1)}

Beobachtungen und Phantasien über Menschen, Natur und Kunst auf einer Reise durch Spanien, Leipzig: C. L. Hirschfeld, 1850.

\section{Quandt 1850 (2)}

»Der Parallelismus zwischen ausübender Kunst und deren Literatur« in: Allgemeine Monatsschrift für Literatur, 1850, S. 60-63.

\section{Quandt 1850 (3)}

»Altdeutsche Baukunst. [Rezension von:] Die Baukunst des Mittelalters, von Franz Mertens. Berlin. 1850.«, in: Allgemeine Monatsschrift für Literatur, 1850, S. 252-256.

\section{Quandt 1853 (1)}

Briefe aus Spanien über Menschen, Natur und Kunst, Leipzig: Hirschfeld, 1853.

\section{Quandt 1853 (2)}

Briefe aus dem mittägigen Frankreich über Menschen, Natur und Kunst, Leipzig: Hirschfeld, 1853.

\section{Quandt 1853 (3)}

Rezension von: »Carus, Carl Gustav, Symbolik der menschlichen Gestalt. Ein Handbuch zur Menschenkenntniss. Mit 150 in den Text ein- gedruckten Figuren. Leipzig. F. A. Brockhaus. 1853. Gr. Oct. $341 \mathrm{~S}$.«, in: Allgemeine Monatsschrift für Literatur, 1853, S. 875-887.

\section{Kat. Quandt 1853}

Verzeichnis meiner Kupferstichsammlung als Leitfaden zur Geschichte der Kupferstecherkunst und Malerei, Leipzig: R. Weigel, 1853.

\section{Quandt 1854 (1)}

Glossen über Politik, Leipzig: Brockhaus, 1854.

\section{Quandt 1854 (2)}

Erzählungen des Herrn Kauz, Dresden: Hermann Burdach, 1854

\section{Quandt 1856}

Der Begleiter durch die Gemälde-Säle des Königlichen Museums zu Dresden, Dresden: Buchdr. Meinhold, 1856.

\section{Quandt 1857}

»Ueber den Einfluß der bildenden Künste auf Volk und Staat«, in: Sächsische Constitutionelle Zeitung, 9.12.1857, Nr. 284, S. 1133-1134.

\section{Quandt 1859 (1)}

Wissen und Seyn. Eine realistische Abhandlung zur Ausgleichung des Spiritualismus und Materialismus, Dresden: Burdach, 1859.

\section{Quandt 1859 (2)}

Über die Rettung hülfloser Kinder. Den Menschenfreunden, welche im Gerichtsamte zu Stolpen sich zur Berathung über Anlegung einer Kindererziehungsanstalt versammelten, gewidmet, Dresden: [s. n.], 1859.

\section{Kat. Quandt 1860 (1)}

Katalog der vortrefflichen KupferstichSammlung und reichen Kunst-Bibliothek des verstorbenen Herrn Johann Gottlob von Quandt [...], welche den 12. Juni 1860 und folgende Tage zu Leipzig [...] öffentlich versteigert werden, hrsg. v. Rudolph Weigel, Leipzig: J. B. Hirschfeld, 1860.

\section{Kat. Quandt 1860 (2)}

Catalog der von Herrn Johann Gottlob von Quandt, Comthur des Königl. Sächsischen Civil-Verdienstordens, hinterlassenen Original-Handzeichnungen alter und neuer Meister [...], welche den 1. October 1860 und folgende Tage Vormittags 10 Uhr zu Dresden an der Frauenkirche Nr. 11 [...] versteigert werden sollen, hrsg. v. Ludwig Gruner, Leipzig: F. A. Brockhaus, 1860.

\section{Kat. Quandt 1868}

Verzeichniss der von Johann Gottlob von Quandt hinterlassenen Gemälde-Sammlung alter und neuer Meister, hrsg. v. Ludwig Gruner, Dresden: E. Blochmann \& Sohn, 1868.

\section{Quandt 2001 [1870]}

»Meine Berührungen mit Goethe«, in: Schmitz/Strobel 2001, S. 230-242 [Erstausgabe: Europa. Chronik der gebildeten Welt, 1870, Sp. 577-582, 625-630].

\section{Quandt in Nachrufen und Lexika}

\section{Nachrufe}

Pastoren Knof, Seidemann und Putzer, Reden und Segenswort, gesprochen am Grabe des Hrn. Johann Gottlob v. Quandt auf Dittersbach, den 22. Juni 1859, Pirna: Diller und Sohn, 1859

Augsburger Allgemeine Zeitung, 23.6.1859, Nr. 174, S. 2843

Deutsche Allgemeine Zeitung, 23.6.1859, Nr. 143, S. 1266.

Neue Würzburger Zeitung, 25.6.1859, Jg. 60, Nr. 174, [s. p.]

Landshuter Zeitung, 26.6.1859, Jg. 11, Nr. 143, S. 576.

Die Dioskuren. Zeitschrift für Kunst, Kunstindustrie und künstlerisches Leben. Hauptorgan der deutschen Kunstvereine, 1859, Jg. 4, Nr. 61, S. 114

Europa. Chronik der gebildeten Welt, 1859, Nr. 28, p. 1001-1002.

Gazette des Beaux-Arts, [Paris] 1859, Bd. 3, S. 191-192.

Journal des Beaux-Arts et de la Littérature, [Brüssel] 1859, Jg. 1, Nr. 13, S. 100.

Männer der Zeit. Biographisches Lexikon der Gegenwart, 1. Serie, Leipzig: Karl. S. Lorck, 1860, Sp. 913.

\section{Lexikoneinträge}

Die Artikel erschienen in zahlreichen Neuauflagen, teilweise bis zu Beginn des 20. Jahrhunderts, beispielsweise im Brockhaus bis in die 14. Auflage von 1892-1896 und deren letzten Nachdruck 1920. Hier sind nur die ersten Einträge zusammengestellt.

Conversations-Lexicon. Neue Folge, 6. Aufl., Leipzig: Brockhaus, 1825, Bd. 12, 1. Abteilung, S. 576-578.

Wigand's Conversations-Lexikon für alle Stände, Leipzig: Wigand, 1850, Bd. 11, S. 294.

Biographie universelle ancienne et moderne, hrsg. v. Louis Gabriel Michaud, 2. Aufl., Paris: Mme. C. Desplaces und M. Michaud, 1854 , S. 598-599.

Herders Conversations-Lexikon, Bd. 4, hrsg. v. Bartholomae Herder, Freiburg i/Br: Herder'sche Verlagshandlung, 1856, S. 645.

Pierer's Universal-Lexikon der Vergangenheit und Gegenwart, hrsg. v. Heinrich August Pierer, 4. Aufl., Altenburg: H. A. Pierer, 1861, S. 736 Meyers Konversationslexikon, 4. Aufl., hrsg. v. Joseph Meyer, Leipzig/Wien: Verlag des Bibliographischen Instituts, 1885-1892, Bd. 13, S. 494 . 


\section{Weitere gedruckte Primärquellen}

\section{Anonym 1825}

Anonym, »Erinnerungen von einem Ausfluge nach Dresden«, in: Zeitung für die elegante Welt, 1825, Jg. 25, Nr. 97-99, 102-107, Sp. 769772, 780-782, 788-791, 811-814, 817-820, $826-828,837-838,845-846,849-852$.

\section{Anonym [Goethe] 1815}

Anonym [Johann Wolfgang von Goethe], »Nachricht von Altdeutschen, in Leipzig entdeckten Kunstschätzen«, in: Morgenblatt für gebildete Stände, 1815, Nr. 15, S. 273-274.

\section{Becker/Frenzel 1826}

»Haus und Garten des Herrn von Quandt, in Neustadt-Dresden« mit einem Kupferstich von Johann Gottfried Abraham Frenzel, in: W. G. Beckers Taschenbuch zum geselligen Vergnügen, Leipzig: Georg J. Göschen, 1826, S. XXVI-XXVIII.

\section{Bendemann 1847}

Der Fries im Thronsaale des Könglichen Schlosses zu Dresden al fresco gemalt von Eduard Bendemann, Leipzig: Wigand, 1847 [Internetressource: Düsseldorf, Heinrich Heine Universität, Digitale Sammlungen, Besondere Sammlungen, Düsseldorfer Malerschule (DFG), Mappenwerke und Künstleralben, http://digital.ub.uni-duesseldorf.de/ dfg/content/structure/1106531, letzter Zugriff: 17.9.2018].

\section{Blümner 1818}

Heinrich Blümner, Geschichte des Theaters in Leipzig von den ersten Spuren bis auf die neueste Zeit, Leipzig: Brockhaus, 1818.

\section{Böttiger 1822}

Carl August Böttiger, »G. v. Quandts Kunstsammlungen«, in: Artistisches Notizenblatt, 15.8.1822, S. 61-62.

\section{Böttiger 1801}

Carl August Böttiger, Archäologisches Museum zur Erläuterung der Abbildungen aus dem classischen Alterthume für Studirende und Kunstfreunde. Erster (sic!) Heft. Ariadne, Weimar: Verlag des Industrie-Comptoirs, 1801

\section{Breuer 1835}

Ludwig Breuer, Gedichte. Nachlass für seine Freunde, Dresden: [s. n.] 1835.

\section{Burckhardt 1843}

Jakob Burckhardt, »Bericht über die Kunstaus stellung zu Berlin im Herbste 1842, in: Kunstblatt, 1843, Jg. 24, Nr. 1-4, S. 1-2, 5-7, 9-15.

\section{Clauss 1869}

C. Clauss, »Der Verkauf der v. Quandt'schen Gemälde-Sammlung in Dresden«, in: Kunstchronik. Beiblatt zur Zeitschrift für bildende Kunst, 1869, Jg. 4, Nr. 6, S. 49-50.

\section{Dürerfest 1828}

Spruch- und Liederkranz zum Albrecht Dürer's=feste, in Dresden am 7ten April 1828, Dresden: Gärtner'sche Hofdruckerei, [1828].

\section{Fechner 1871}

Gustav Theodor Fechner, Ueber die Aechtheitsfrage der Holbein'schen Madonna.

Discussion und Acten, Leipzig: Breitkopf und Härtel, 1871.

\section{Fernow 1806-1808}

Carl Ludwig Fernow, Römische Studien, 3 Bde., Zürich: H. Gessner, 1806-1808.

\section{Fernow 1806}

Carl Ludwig Fernow, »Ueber die Landschaftmalerei«, in: Ders., Römische Studien. Zweiter Theil, Zürich: H. Gessner, 1806, S. 11-130.

\section{Fiorillo 1997 [1798]}

Johann Dominik Fiorillo, Sämtliche Schriften, Bd. 1: Geschichte der zeichnenden Künste von ihrer Wiederauflebung bis auf die neuesten Zeiten [Nachdruck der Ausgabe Göttingen 1798], mit einem Vorwort von Achim Hölter, Hildesheim/Zürich/New York: Georg Olms Verlag, 1997

\section{Förster 1847}

Ernst Förster, Handbuch für Reisende in Deutschland, München: Literarisch-Artistische Anstalt, 1847.

\section{Förster 1846}

Biographische und literarische Skizzen aus dem Leben und der Zeit Karl Förster's, hrsg. v. Luise Förster, Dresden: Gottschalck, 1846.

\section{Förster 1843}

Ernst Förster, »Aus dem gegenwärtigen Kunstleben am Rhein und in den Niederlanden«, in: Kunstblatt, 1843, Jg. 24, Nr. 26/27, S. 109-113, 118-119.

\section{Frenzel 1850}

Friedrich August Frenzel, Der Führer durch das Historische Museum zu Dresden mit Bezug auf Turnier- und Ritterwesen und die Künste des Mittelalters, Leipzig: Rudolf Weigel, 1850.

\section{Friedrich 1999 [1829/33]}

Caspar David Friedrich. Kritische Edition der Schriften des Künstlers und seiner Zeitzeugen I. »Äußerungen bei Betrachtung einer Sammlung von Gemählden von größtentheils noch lebenden und unlängst verstorbenen Künstlern « (Frankfurter Fundamente der Kunstgeschichte, Bd. 16), hrsg. v. Gerhard Eimer, Frankfurt a/M.: Kunstgeschichtliches Institut der Johann Wolfgang Goethe-Universität, 1999

\section{Friedrich 1974}

Caspar David Friedrich, Caspar David Friedrich in Briefen und Bekenntnissen, 2. Aufl. [Erstauflage: 1968], hrsg. v. Sigrid Hinz, München: Rogner und Bernhard, 1974.

\section{Friesen 1838}

Hermann von Friesen, »Flüchtige Bemerkungen über einige Freskogemälde auf der Schönhöhe bei Dittersbach«, in: Kunst-Blatt, 1838, Nr. 64, S. 253-254, Nr. 65, S. 259-260.

\section{Goethe 1827-1842}

Goethe's Werke. Vollständige Ausgabe letzter Hand, 60 Bde., Stuttgart/Tübingen: Cotta,

1827-1842.

\section{Goethe 1816}

Johann Wolfgang von Goethe, »Ruysdael als Dichter«, in: Morgenblatt für gebildete Stände, Nr. 107, 3.5.1816, S. 425-427.

\section{Goethe 1810}

Johann Wolfgang von Goethe, Zur Farbenleh re. Entwurf einer Farbenlehre. Erster, didaktischer Theil, Tübingen: Cotta, 1810.

\section{Goethe 1798}

Johann Wolfgang von Goethe, »Ueber Laokoon«, in: Propyläen. Eine periodische Schrifft, hrsg. v. Johann Wolfgang von Goethe, Tübingen: Cotta, 1798, Bd. 1, Nr. 1, S. 1-19.

\section{Goethe/Rauch 2011}

"Mit vieler Kunst und Anmuth". Goethes Briefwechsel mit dem Bildhauer Christian Daniel Rauch (Ästhetik um 1800, Bd. 8), hrsg. v. Rolf H. Johannsen, Göttingen: Wallstein Verlag, 2011

\section{Grieben 1857}

Theobald Grieben, Zuverlässiger Wegweiser für Dresden, dessen Umgebungen und die Sächsisch-Böhmische Schweiz (Grieben's Reise-Bibliothek, Nr. 4), Berlin: Verlag von Theobald Grieben, 1857

\section{Hegel 1823 [2003]}

Georg Wilhelm Friedrich Hegel, Vorlesungen über die Philosophie der Kunst [1823], hrsg. v. Annemarie Gethmann-Siefert, Darmstadt: Wissenschaftliche Buchgesellschaft, 2003.

\section{Hegel/Hotho 1835}

Georg Wilhelm Friedrich Hegel's Werke. Vollständige Ausgabe. Bd. 10: Georg Wilhelm Friedrich Hegel's Vorlesungen über die Aesthetik, Bd. 1, hrsg. v. Heinrich Gustav Hotho, Berlin: Duncker und Humblot, 1835.

\section{Hilscher 1835/36}

Dresdens Museen, ihre Kunstschätze, Merkwürdigkeiten und Seltenheiten aus sämmtlichen Königl. Sammlungen, hrsg. v. Paul Gottlob Hilscher, 2 Bde., Dresden: C. F. Grimmersche Buchhandlung, 1835/36.

\section{Hirschfeld 1782}

Christian Cay Lorenz Hirschfeld, Theorie der Gartenkunst, Bd. 4, Leipzig: Weidmanns Erben und Reich, 1782.

\section{Hirt 1830}

Aloys Hirt, Kunstbemerkungen auf einer Reise über Wittenberg und Meißen nach Dresden und Prag, Berlin: Duncker und Humblot, 1830 .

Immermann 1833

Karl Immermann, Reisejournal, Düsseldorf: Schaub, 1833

\section{Jean Paul 1804}

Jean Paul, Vorschule der Aesthetik, nebst einigen Vorlesungen in Leipzig über die Par- 
teien der Zeit. Erste Abtheilung, Hamburg: Friedrich Perthes, 1804.

\section{Kant 1790 [2009]}

Immanuel Kant, Kritik der Urteilskraft. Schriften zur Ästhetik und Naturphilosophie. Text und Kommentar, hrsg. v. Manfred Frank und Véronique Zanetti, Frankfurt a/M: Deutscher Klassiker Verlag, 2009.

\section{Kat. Dresden 1856}

Julius Hübner, Verzeichniss der Königlichen Gemälde-Gallerie zu Dresden, Dresden: Liepsch \& Reichardt, 1856.

\section{Kat. Dresden 1843}

Verzeichniss der königlichen Gemälde-Galerie zu Dresden, Dresden: Blochmann, 1843.

\section{Kat. Dresden 1840}

Friedrich Matthäi, Catalog der königlichen Gemaelde-Galerie zu Dresden, Dresden: Blochmann, [1840].

\section{Kat. Dresden 1837}

Friedrich Matthäi, Verzeichniss der Königlich Sächsischen Gemälde-Galerie zu Dresden. Erste Hauptabtheilung. Die Gemälde der äußeren Galerie, Dresden: Gärtner'sche Hofdruckerei, 1837.

\section{Kat. Dresden 1835}

Friedrich Matthäi, Verzeichniss der königlich sächsischen Gemälde-Galerie zu Dresden. Erste Hauptabtheilung. Die Gemälde der äußeren Galerie. I Zweite Hauptabtheilung. Die Gemälde der inneren Galerie, der Abteilung $\mathrm{H}$ der äußeren Galerie und des Pastellcabinets, 2 Bde., Dresden: Gärtner'sche Hofdruckerei, 1835

\section{Kat. Dresden 1833}

Friedrich Matthäi, Neues Sach- und Ortsverzeichniss der königlich sächsischen GemäldeGallerie zu Dresden, Dresden: Gärtner'sche Hofdruckerei, 1833.

\section{Kat. Leipzig 1869}

Leipziger Bücher-Auction, 9. Decbr. 1869. Verzeichniss der von den Herren Geh. Rath Professor Dr. jur. Joh. Ludw. Wilh. Beck, Präsident des k. Sächs. Appellations-Gerichts, Comthur I. Cl. etc. in Leipzig, Professor Dr. theol. u. phil. Karl Heinr. Graf, Oberlehrer an der k. Landesschule zu Meißen und Dr. Ludw. von Jan, Director des k. Gymnasiums zu Erlangen nachgelassenen Bibliotheken, welche nebst andern Büchersammlungen aus allen Wissenschaften, insbesondere einem bedeutenden genealogischen Manuscript (Stammtafeln von gegen 1000 Familien) und einer interessanten Sammlung von andern Manuscripten und literarischen Seltenheiten sowie Kunstartikeln und einige Musikalien von Mittwoch, dem 8. December 1869 an Vormittags von 9 Uhr, Nachmittags von $2 \frac{1}{2}$ Uhr ab durch den verpflichteten Universitäts-Proclamator H. Hartung in Leipzig Goethestraße No. 7. öffentlich gegen baare
Zahlung versteigert werden sollen, Leipzig: Hartung, 1869.

\section{Klemm 1838}

Gustav Klemm, Zur Geschichte der Sammlungen für Wissenschaft und Kunst in Deutschland, 2. Aufl. [Erstausgabe: 1837], Zerbst: G. A. Kummer, 1838.

\section{Klemm 1835}

Gustav Klemm, »Zur Geschichte des Königlich-Sächsischen Alterthumsvereins«, in: Mittheilungen des Königl. Sächs. Vereins für Erforschung und Erhaltung der vaterländischen Alterthümer, 1835, Nr. 1 .

\section{Kügelgen 1959 [1870]}

Wilhelm von Kügelgen, Jugenderinnerungen eines alten Mannes, 6. Aufl. [Erstausgabe: 1870], Leipzig: Koehler \& Amelang, 1959.

\section{Kugler 1845}

Franz Theodor Kugler, »Ueber die beiden Exemplare der Holbeinischen Madonna mit der Familie des Bürgermeisters Meyer, zu Dresden und zu Berlin«, in: Kunstblatt, 1845 , Jg. 26, Nr. 8, S. 29-30.

\section{Kugler 1843}

Franz Theodor Kugler, »Sendschreiben an Herrn Dr. Ernst Förster in München über die beiden Bilder von Gallait und de Biefve«, in: Kunstblatt, 1843, Jg. 24, Nr. 58/59, S. 241-243, 246-248.

\section{Kugler 1842}

Franz Theodor Kugler, Handbuch der Kunstgeschichte, Stuttgart: Ebner \& Seubert, 1842.

\section{Kugler 1838}

Franz Theodor Kugler, Beschreibung der in der Königl. Kunstkammer zu Berlin vorhandenen Kunst-Sammlung, Berlin: Carl Heymann, 1838.

\section{Lessing 1808}

Gotthold Ephraim Lessing, Sämmtliche Schriften. Eilfter (sic!) Theil. Artistische und Antiquarische Schriften, Berlin: Friedrich Nicolai, 1808.

\section{Lessing 1766}

Gotthold Ephraim Lessing, Laokoon: oder über die Grenzen der Mahlerey und Poesie, Berlin: Christian Friedrich Voss, 1766.

\section{Lindau 1845}

Rudolph und Wilhelm Adolph Lindau, Merkwürdigkeiten Dresdens und der Umgegend, 6. erw. Aufl. [Erstausgabe: 1826], hrsg. v. J.G. Wiemann, Dresden/Leipzig: Arnoldische Buchhandlung, 1845.

\section{Lindau 1829}

Rudolph und Wilhelm Adolph Lindau, Merkwürdigkeiten Dresdens und der Umgegend, 2. erw. Aufl. [Erstausgabe: 1826], Dresden/ Leipzig: Arnoldische Buchhandlung, 1829.

\section{Meissner 1884}

Alfred Meissner, Geschichte meines Lebens, 2 Bde., Wien/Teschen: Verlag der königlichkaiserlichen Hofbuchhandlung, 1884

\section{Mengel 1784}

Christian Gottlob Mengel, Leben Johann Gottlob Quandts, Leipzig: Friedrich Gotthold Jacobäer, 1784 .

\section{Meyer/Goethe 1798/99}

Johann Heinrich Meyer und Johann Wolfgang von Goethe, »Von den Gegenständen der bildenden Kunst«, in: Propyläen. Eine periodische Schrifft, hrsg. v. Johann Wolfgang von Goethe, Tübingen: Cotta, 1798/99, Bd. 1, Nr. 1, S. 20-54, Nr. 2, S. 45-81.

\section{Meyer/Goethe 1817 [1999]}

Johann Heinrich Meyer und Johann Wolfgang von Goethe, »Neu-Deutsche Religios-Patriotische Kunst«, in: Ueber Kunst und Alterthum in den Rhein- und Mayn-Gegenden, hrsg. v. Johann Wolfang von Goethe, 1817, Nr. 2 [abgedruckt in: Johann Wolfgang von Goethe. Ästhetische Schriften 1816-1820. Über Kunst und Altertum I-II (Johann Wolfgang von Goethe Sämtliche Werke. Briefe Tagebücher und Gespräche, Bd. 20), hrsg. v. Hendrik Birus, Frankfurt a/M: Deutscher Klassiker Verlag, 1999, S. 103-129].

\section{Mitteilungen Landtag 1846}

Mittheilungen über die Verhandlungen des Landtags im Königreich Sachsen während der Jahre 1845 und 1846, 18.2.1846, Nr. 78.

\section{Mosen 1844}

Julius Mosen, Die Dresdener Gemälde-Galerie in ihren bedeutungsvollen Meisterwerken, Dresden/Leipzig: Arnoldische Buchhandlung, 1844.

Müller/Goethe 1982

Friedrich von Müller, Unterhaltungen mit Goethe, hrsg. v. Renate Grumach, München: Verlag C. H. Beck, 1982.

\section{Nagler 1835-1852}

Georg Kaspar Nagler, Neues Allgemeines Künstler-Lexicon, 22 Bde., München: E.A. Fleischmann, 1835-1852.

\section{Passavant 1849}

Johann David Passavant, „Einige Worte über die Sammlungen des Städel'schen KunstInstitut als Entgegnung auf die Schrift: Das Städel'sche Institut dargestellt und beleuchtet von C[ar]l J[üge]l, Frankfurt a/M: August Osterrieth, 1849

\section{Passavant 1844}

Johann David Passavant, »Ueber die jetzige Historienmalerei in Belgien und Deutschland «, in: Kunstblatt, 1844, Jg. 25, Nrn. 65-69, S. 274-275, 279-280, 282-283, 286-287, 291.

\section{Passavant 1820}

Johann David Passavant, Ansichten über die bildenden Künste und Darstellung des Ganges derselben in der Toscana, zur Bestimmung des Gesichtspunctes, aus welchem die neudeutsche Malerschule zu betrachten ist, Heidelberg/Speyer: August Oswald's Buchhandlung, 1820. 


\section{Quatremère de Quincy 2010}

Antoine Chrysostôme Quatremère de Quincy, »Ueber den nachtheiligen Einfluß der Versetzung der Monumente aus Italien auf Künste und Wissenschaften « [1796], in: Museumsgeschichte. Kommentierte Quellentexte 1750-1950, hrsg. v. Kristina Kratz-Kessemeier, Andrea Meyer und Bénédicte Savoy, Berlin: Reimer, 2010, S. 239-246.

\section{Raczyński 1836-1841}

Athanasius Graf Raczyński, Geschichte der neueren deutschen Kunst, 3 Bde., Berlin: nauf Kosten des Verfassers «, 1836-1841.

\section{Reibisch 1825-1827}

Friedrich Martin Reibisch, Eine Auswahl merkwürdiger Gegenstände aus der Königl. Sächsischen Rüstkammer gezeichnet und beschr. von Friedrich Martin Reibisch, 9 Bde. Dresden: Walther, 1825-27.

\section{Rumohr 1832}

Carl Friedrich von Rumohr, Drey Reisen nach Italien. Erinnerungen, Leipzig: F. A. Brockhaus, 1832

\section{Rumohr 1831}

Carl Friedrich von Rumohr, Italienische Forschungen, Bd. 3, Berlin/Stettin: Nicolai'sche Buchhandlung, 1831.

\section{Schäfer 1860}

Wilhelm Schäfer, Die Königliche GemäldeGallerie im Neuen Museum zu Dresden. Beschreibung und Erläuterung sämmtlicher Gemälde nach der Ordnung der Räume begleitet von kunstgeschichtlichen und kritischen Erinnerungen, 3 Bde., Dresden: $\mathrm{H}$. Klemm's Verlag, 1860.

\section{Schelling 2004}

F. W. J. Schelling. Texte zur Philosophie der Kunst, hrsg. v. Werner Beierwaltes, Stuttgart: Reclam, 2004.

\section{Schiller 2005}

Friedrich Schiller, Ueber die ästhetische Erziehung des Menschen in einer Reihe von Briefen [1795], hrsg. v. Klaus L. Berghahn, Stuttgart: Reclam, 2005.

\section{Schlegel 1996}

August Wilhelm Schlegel, Die Gemählde. Gespräch, hrsg. v. Lothar Müller, Dresden: Verlag der Kunst, 1996.

\section{Schlegel 1980}

Friedrich Schlegel, Die Epoche der Zeitschrift Concordia. 3. Abteilung: Briefe von und an Friedrich und Dorothea Schlegel (Kritische Friedrich-Schlegel-Ausgabe, Bd. 30), hrsg. v. Eugène Susini, Paderborn/Zürich: Verlag Ferdinand Schöning/Thomas-Verlag, 1980.

\section{Schlegel 1805}

Friedrich Schlegel, »Dritter Nachtrag alter Gemählde«, in: Europa. Eine Zeitschrift, 1803, Bd. 2, S. 109-145.

Schlegel 1801/02

August Wilhelm Schlegel, Vorlesungen über schöne Litteratur und Kunst. Gehalten zu Berlin 1801-1802. Unpubliziertes Manuskript, Dresden, SLUB, Mscr. Dresd. e 9o, XXXIV, Bd. 2 [Internetressource: http://digital.slub-dresden. de/id34331245X/1, letzter Zugriff: 17.9.2018].

\section{Schnaase 1843}

Carl Schnaase, Geschichte der bildenden Künste bei den Alten, Bd. 1: Die Völker des Orients. Bd. 2: Griechen und Römer, Düsseldorf: Julius Buddeus, 1843

\section{Schnorr 2000 [1832]}

Veit Hanns Schnorr von Carolsfeld, Meine Lebensgeschichte zugleich als ein sonst und jetzt in einem Zeitraum von 55 Jahren [1832], hrsg. v. Otto Werner Förster, Leipzig: Taurus Verlag, 2000

\section{Schnorr 1886}

Julius Schnorr von Carolsfeld, Briefe aus Italien von Julius Schnorr von Carolsfeld geschrieben in den Jahren 1817 bis 1827. Ein Beitrag zur Geschichte seines Lebens und der Kunstbestrebungen seiner Zeit, hrsg. v. Franz Schnorr von Carolsfeld, Gotha: Friedrich Andreas Perthes, 1886.

\section{Schnorr 1895-1903}

Franz Schnorr von Carolsfeld, »Aus Julius Schnorrs Tagebüchern«, in: Dresdner Geschichtsblätter, 1895-1903, Bd. 1-3 [Internetressource: Digitale Bibliothek der SLUB Dresden, Sign. Hist.Sax.G.0104.m, http:// digital.slub-dresden.de/id257315713/1, letzter Zugriff: 17.9.2018]

\section{Schnorr 1909}

Julius Schnorr von Carolsfeld, »Bericht über mein Leben 1855. Mit einem Anhang biographischer Bemerkungen aus dem Jahr 1847«, in: Künstlerische Wege und Ziele. Schriftstücke aus der Feder des Malers Julius Schnorr von Carolsfeld, hrsg. v. Franz Schnorr von Carolsfeld, Leipzig: Georg Wigand, 1909, S. 5-38.

\section{Seidemann 1860}

Johann Karl Seidemann, Ueberlieferungen zur Geschichte von Eschdorf, Dittersbach und Umgegend, Dresden: Hermann Burdach, 1860.

\section{Solger 1829}

Karl Wilhelm Ferdinand Solger, Vorlesungen über Ästhetik, hrsg. v. Karl Wilhelm Ludwig Heyse, Leipzig: Brockhaus, 1829

\section{Sulzer $1771 / 74$}

Johann George Sulzer, Allgemeine Theorie der Schönen Künste, 2 Bde, Leipzig: M. G. Weidmanns Erben und Reich, 1771/74.

\section{Tieck 1864}

Briefe an Ludwig Tieck, 4 Bde., hrsg. v. Karl von Holtei, Breslau: Eduard Trewendt, 1864.

\section{Tieck 1855}

Ludwig Tieck, Erinnerungen aus dem Leben des Dichters nach dessen mündlichen und schriftlichen Mittheilungen, hrsg. v. Rudolf Köpke, 2 Bde., Leipzig: Brockhaus, 1855.

\section{Tieck 1848 [1828]}

Ludwig Tieck, »Goethe und seine Zeit« (1828), in: Kritische Schriften, Bd. 2, Leipzig: Brockhaus, 1848, S. 171-312.

\section{Tieck 1841}

Ludwig Tieck, Gedichte. Neue Ausgabe, Berlin: Reimer, 1841.

\section{Tieck 1829}

Ludwig Tieck, Schriften, Bd. 13: Märchen. Dramatische Gedichte. Fragmente, Berlin: G. Reimer, 1829.

\section{Vischer 1857}

Friedrich Theodor Vischer, Ästhetik oder Wissenschaft des Schönen. Zum Gebrauche für Vorlesungen. Dritter Theil: Die Kunstlehre. Zweiter Abschnitt: Die Künste. Fünftes Heft: Die Dichtkunst, Stuttgart/Reutlingen: Carl Mäcken, 1857.

\section{Vischer 1844}

Friedrich Theodor Vischer, »Gedanken bei Betrachtung der beiden belgischen Bilder«, in: Jahrbücher der Gegenwart, hrsg. v. Albert Schwegler, Tübingen: Ludwig Friedrich Fues, 1844, S. 46-54.

\section{Vischer 1844 [1841]}

Friedrich Theodor Vischer, »Der Triumph der Religion in den Künsten, von Friedrich Overbeck«, in: Ders., Kritische Gänge, Tübingen: Ludwig Friedrich Fues, 1844, S. 163-206.

\section{Vischer 1837}

Friedrich Theodor Vischer, Ueber das Erhabene und Komische, ein Beitrag zu der Philosophie des Schönen, Stuttgart: Imle \& Krauß, 1837.

\section{Wackenroder/Tieck 2005}

Wilhelm Heinrich Wackenroder und Ludwig Tieck, Herzensergießungen eines kunstliebenden Klosterbruders, hrsg. v. Martin Bollacher, Stuttgart: Reclam, 2005.

\section{Winckelmann 1764}

Johann Joachim Winckelmann, Vorrede zur Geschichte der Kunst des Alterthums, Dresden: Waltherische Buchhandlung, 1764. 


\section{Sekundärliteratur}

\section{Altner 1990}

Manfred Altner, »Die Akademie unter dem Generaldirektorat des Grafen Vitzthum von Eckstaedt [1815-1836]«, in: Dresden. Von der Königlichen Kunstakademie zur Hochschule für Bildende Künste [1764-1989], hrsg. v. der Hochschule für bildende Künste in Dresden, Dresden: Verlag der Kunst, 1990, S. 101-130.

\section{Apel/Greif 1997}

Friedmar Apel und Stefan Greif, »Ueber Kunst und Altertum«, in: Goethe-Handbuch. Bd. 3: Prosaschriften, hrsg. v. Bernd Witte und Peter Schmidt, Stuttgart/Weimar: J. B. Metzler, 1997, S. 619-639.

\section{Apollodor 2005}

Mythographus Apollodorus, Bibliotheke. Götter- und Heldensagen (Sammlung Tusculum), hrsg., übers. u. komm. von Paul Dräger, Düsseldorf: Artemis \& Winkler, 2005.

\section{Assel/Jäger 2005 [2010]}

Jutta Assel und Georg Jäger, Friedrich Overbeck: Der Triumph der Religion in den Künsten. Kommentar und Kritik - eine Dokumentation, 2 Teile, München: Goethezeitportal, 2005 [Internetressource, Teil 1: http://www. goethezeitportal.de/digitale-bibliothek/forschungsbeitraege/autoren-kuenstler-denker/ overbeck-friedrich/jutta-assel-und-georgjaeger-friedrich-overbeck-der-triumph-der-religion-in-den-kuensten-teil-i.html; Teil 2: http:// www.goethezeitportal.de/digitale-bibliothek/ forschungsbeitraege/autoren-kuenstler-denker/overbeck-friedrich/jutta-assel-und-georgjaeger-friedrich-overbeck-der-triumph-der-religion-in-den-kuensten-teil-ii.html, aktualisiert im November 2010, letzter Zugriff: 3.8.2018].

\section{Bader 2013}

Lena Bader, Bild-Prozesse im 19. Jahrhundert. Der Holbein-Streit und die Ursprünge der Kunstgeschichte, Paderborn: Fink, 2013.

\section{Bätschmann 2017}

Oskar Bätschmann, »Der Holbein-Streit 1871: Publikum, Kunsthistoriker, Künstler«, in: Zeitschrift für Archäologie und Kunstgeschichte, 2017, Bd. 74, S. 37-54.

\section{Bätschmann 2005}

Oskar Bätschmann, »Kunstgattungen, Bildgattungen, Schemata«, in: Theorie der Gattungen (Handbuch der musikalischen Gattungen, Bd. 15), hrsg. v. Siegfried Mauser, Laaber: Laaber-Verlag, 2005, S. 34-35.

\section{Bätschmann 2002}

»Carl Gustav Carus (1789-1869): Physician, Naturalist, Painter, and Theoretician of Landscape Painting", in: Carl Gustav Carus, Nine Letters on Landscape Painting, eingeleitet v. Oskar Bätschmann, übersetzt von David Britt, Los Angeles: Getty Research Institute, 2002, S. 1-73.

\section{Bätschmann 1989}

Oskar Bätschmann, Entfernung der Natur. Landschaftsmalerei 1750-1920, Köln: DuMont, 1989.

\section{Bätschmann/Griener 1998}

Oskar Bätschmann und Pascal Griener, Hans

Holbein d. J. Die Darmstädter Madonna.

Original gegen Fälschung, Frankfurt a/M:

Fischer, 1998.

\section{Bäumel 2004}

Jutta Bäumel, Rüstkammer. Führer durch die ständige Ausstellung im Semperbau, Berlin: Deutscher Kunstverlag, 2004.

\section{Baumgärtel 2011}

Bettina Baumgärtel, »Die Düsseldorfer Malerschule und ihre internationale Ausstrahlung ", in: Die Düsseldorfer Malerschule und ihre internationale Ausstrahlung, 1819-1918 [Kat. der Ausstellung: Düsseldorf, Kunstpalast, 24.9.2011-22.1.2012], Bd. 1, hrsg. v. Bettina Baumgärtel, Petersberg: Michael Imhof Verlag, 2011, S. 25-49.

\section{Bemmann 1925}

Rudolf Bemmann, »Aus dem Leben Johann Gottlob von Quandts«, in: Neues Archiv für sächsische Geschichte und Altertumskunde, 1925, Bd. 46, S. 1-45.

\section{Berge 1933}

Rudolf Berge, »Das Schicksal der Dresdner Kunstkammer. Zu Ihrer Auflösung vor hundert Jahren«, in: Wissenschaftliche Beilage des Dresdner Anzeigers, 1933, Jg. 10, Nr. 1, S. 1-3.

\section{Bergmann-Gaadt 2015}

Martina Bergmann-Gaadt, Das Aussehen Christi in der deutschen Bildkunst des 19. Jahrhunderts. Wandlungen des Christusbildes, Diss. Mainz: JohannesGutenberg-Universität, 2015 [Internetressource: https://katalogbeta.slub-dresden. de/id/0014671549/\#detail, letzter Zugriff, 22.6.2018].

\section{Bertsch 2011}

Markus Bertsch, »Wirkung und Rezeption Goethes in der zeitgenössischen Kunst", in: Goethe-Handbuch. Supplemente. Bd. 3: Kunst, hrsg. v. Andreas Beyer und Ernst Osterkamp, Stuttgart/Weimar: J. B. Metzler, 2011, S. 219-264.

\section{Bertsch 2009}

Markus Bertsch, »Keil und die Kunst«, in: Harald Wentzlaff-Eggebert, Weimars Mann in Leipzig. Johann Georg Keil (1781-1857) und sein Anteil am kulturellen Leben der Epoche. Eine dokumentierte Rekonstruktion, Heidelberg: Universitätsverlag Winter, 2009, S. 559-611.

\section{Beyer 2011}

Andreas Beyer, Die Kunst des Klassizismus und der Romantik (C. H. Beck Wissen. Kunstepochen), München: Verlag C. H. Beck, 2011.

\section{Beyer 2010}

Andreas Beyer, »Am Anfang war der Streit. Hans Holbein d. J. und die kunsthistorische Tradition«, in: Konzert und Konkurrenz. Die Künste und ihre Wissenschaften im 19. Jahrhundert, hrsg. v. Christian Scholl, Sandra Richter und Oliver Huck, Göttingen: Universitätsverlag, 2010, S. 201-221.

\section{Beyer/Osterkamp 2011}

Goethe-Handbuch. Supplemente. Bd. 3: Kunst, hrsg. v. Andreas Beyer und Ernst Osterkamp, Stuttgart/Weimar: J. B. Metzler, 2011.

\section{Biedermann 2017}

Heike Biedermann, »Zur Rezeption von Claude Lorrain im 19. Jahrhundert«, in: Dresdener Kunstblätter, 2017, Jg. 61, Nr. 1, S. 22-31.

\section{Biedermann 1875}

Woldemar Freiherrn von Biedermann, Goethe und Dresden, Berlin: Gustav Hempel, 1875.

\section{Bloh 2005}

Jutta Charlotte von Bloh, »Adolph Menzel im Königlichen Historischen Museum Dresden«, in: Menzel in Dresden [Kat. der Ausstellung: Dresden, Residenzschloss, 26.11.200520.2.2006], hrsg. von Petra Kuhlmann-Hodick und Tobias Burg, München: Deutscher Kunstverlag, 2005, S. 58-75.

\section{Bluhm 2004 [2000]}

Lothar Bluhm, »IIn jenen unglücklichen Tagen ..... Goethes Unterhaltungen deutscher Ausgewanderten oder: Die Ambivalenz von Kunst und Gesellschaft (2000)《, in: Goethezeitportal, 12.1.2004 [Internetressource: www. goethezeitportal.de/db/wiss/goethe/unterhaltungen_bluhm.pdf, letzter Zugriff: 29.8.2018].

\section{Blunt/Cooke 1960}

Anthony Blunt und Hereward Lester Cooke, The Roman Drawings of the XVII Q XVIII Centuries in the Collection of Her Majesty the Queen, London: Phaidon Press, 1960.

\section{Börner 2015}

Franziska Börner, Auf der Suche nach Spanien. Reisen deutscher Kunsthistoriker im 19. und beginnenden 20. Jahrhundert, Diss. Barcelona: Universitat de Barcelona, 2015 [Internetressource: http://diposit.ub.edu/dspace/ bitstream/2445/101706/1/B\%C3\%96RNER_ THESIS.pdf, letzter Zugriff: 13.7.2018].

\section{Börsch-Supan 1988}

Helmut Börsch-Supan, Die deutsche Malerei von Anton Graff bis Hans von Marées 17601870, München: Verlag C. H. Beck, 1988.

\section{Börsch-Supan/Jähnig 1973}

Helmut Börsch-Supan und Karl Wilhelm Jähnig, Caspar David Friedrich. Gemälde, Druckgraphik und bildmäßige Zeichnungen, München: Prestel-Verlag, 1973.

\section{Böttger 1910}

Richard Böttger, »Johann Gottlob v. Quandt und Arthur Schopenhauer «, in: Dresdner Anzeiger. Sonntagsbeilage, Okt. 1910, S. 150-152. 


\section{Bolz 1997}

Norbert Bolz, »Die Wahlverwandtschaften«, in: Goethe-Handbuch. Bd. 3: Prosaschriften, hrsg. v. Bernd Witte und Peter Schmidt, Stuttgart/Weimar: J. B. Metzler, 1997, S. 153-186.

\section{Briel 2002}

Cornelia Briel, »Johann Gottlob von Quandt und die Kunstpflege in Sachsen«, in: Luzens 2002, S. 11-17.

\section{Briel 1987 (1)}

Cornelia Briel, »Johann Gottlob von Quandt und der sächsische Kunstverein«, in: Neidhardt et al. 1987, S. 16-25.

\section{Briel 1987 (2)}

Cornelia Briel, „Der Sächsische Kunstverein in den Jahren 1828 bis 1833", in: Dresdner Hefte (Beiträge zur Kulturgeschichte, Bd. 13), 1987, Jg. 5, Nr. 5, S. 13-29.

\section{Briel 1984}

Cornelia Briel, Johann Gottlob von Quandt und der Sächsische Kunstverein. Probleme der Kunstpflege in der ersten Hälfte des 19. Jahrhunderts, Diplomarbeit, Leipzig: KarlMarx-Universität, 1984 [unpubliziert].

\section{Brink 2005}

Claudia Brink, »Der Name des Künstlers. Ein Raffael für Dresden«, in: Raffael. Die Sixtinische Madonna. Geschichte und Mythos eines Meisterwerks, hrsg. v. Claudia Brink und Andreas Henning, Berlin: Deutscher Kunstverlag, 2005, S. 53-92.

\section{Brückle 2015}

Wolfgang Brückle, »Mittelalterliche Werke als Geschichtszeugnis und Kunsterzeugnis « und »Das Mittelalter als Prüfstein der Museumskultur. Szenografische Kontextproduktion seit 1750«, in: Musealisierung mittelalterlicher Kunst. Anlässe, Ansätze, Ansprüche, hrsg. v. Wolfgang Brückle, Pierre Alain Mariaux, Daniela Mondini, Berlin: Deutscher Kunstverlag, 2015, S. 11-29, 149-175.

\section{Brückle 2001}

Wolfang Brückle, »Wege zum Ruhm. Raffael in der Literatur der akademischen Kunstepoche«, in: Raffael und die Folgen. Das Kunstwerk in Zeitaltern seiner graphischen Reproduzierbarkeit [Kat. der Ausstellung: Stuttgart, Graphische Sammlung der Staatsgalerie, 26.5.-22.7.2001], hrsg. v. Corinna Höpfer, Ostfildern-Ruit: Hatje Cantz Verlag, 2001, S. 121-133.

\section{Büsing 2011}

Leander Büsing, Vom Versuch, Kunstwerke zweckmäßig zusammenzustellen. Malerei und Kunstdiskurs im Dresden der Romantik (Studien zur Kunstgeschichte, Bd. 2), hrsg. v. Nils Büttner und Barbara Welzel, Dortmund: Dortmunder Schriften zur Kunst, 2011.

\section{Büttner 2011}

Frank Büttner, »Historische Wahrheit und der Wahrheitsanspruch in der Kunst. Düsseldorf und München in den Auseinandersetzungen um die Geschichtsmalerei im 19. Jahrhundert«, in: Die Düsseldorfer Malerschule und ihre internationale Ausstrahlung, 1819-1918 [Kat. der Ausstellung: Düsseldorf, Kunstpalast, 24.9.2011-22.1.2012], Bd. 1, hrsg. v. Bettina Baumgärtel, Petersberg: Michael Imhof Verlag, 2011, S. 103-113.

\section{Büttner 2002}

Frank Büttner, »Bilder als Manifeste der Freundschaft und der Kunstanschauung zwischen Aufklärung und Romantik in Deutschland«, in: Johann Friedrich Overbeck. Italia und Germania [Kat. der Ausstellung: München, Neue Pinakothek, 20.2.-14.4.2002], hrsg. v. Gisela Scheffler, München: Kulturstiftung der Länder, 2002, S. 15-36.

\section{Büttner 1990}

Frank Büttner, »Bildung des Volkes durch Geschichte. Zu den Anfängen öffentlicher Geschichtsmalerei in Deutschland«, in: Historienmalerei in Europa. Paradigmen in Form, Funktion und Ideologie, hrsg. v. Ekkehard Mai, Mainz: Philipp von Zabern, 1990, S. 77-94.

\section{Büttner 1980/99}

Frank Büttner, Peter Cornelius. Fresken und Freskenprojekte, 2 Bde., Wiesbaden/Stuttgart: Frank Steiner Verlag, 1980/99.

\section{Busch 2003}

Werner Busch, Caspar David Friedrich.

Ästhetik und Religion, München: Verlag

C. H. Beck, 2003.

\section{Busch 1997}

Landschaftsmalerei (Geschichte der klassischen Bildgattungen in Quellentexten und Kommentaren, Bd. 3), hrsg. v. Werner Busch, Berlin: Reimer, 1997.

\section{Busch 1985}

Werner Busch, Die notwendige Arabeske. Wirklichkeitsaneignung und Stilisierung in der deutschen Kunst des 19. Jahrhunderts, Berlin: Gebr. Mann Verlag 1985.

\section{Capitelli 2016}

Giovanna Capitelli, Johann Martin von Rohden and his Nazarene Circle. Watercolours, preparatory drawings and figure studies, übers. v. Sophie Henderson, hrsg. v. Galleria Carlo Virgilio anläßlich der London Art Week 1.-8.7.2016, Rom: Edizioni del Borghetto, 2016.

\section{Cartwright 2010}

David E. Cartwright, Schopenhauer. A Biography, New York: Cambridge University Press, 2010.

\section{Davis 2013}

Charles Davis, Auf den Spuren der Nazarener. Re-reading Vittoria Caldoni: Friedrich Overbeck's »Portrait« in the Neue Pinakothek, hrsg. v. arthistoricum.net, Fachinformationsdienst der Universitätsbibliothek Heidelberg und der SLUB Dresden, Heidelberg/
Dresden: ART-Dok, 2013 [Internetressource: http://archiv.ub.uni-heidelberg.de/artdok/ volltexte/2013/2253, letzter Zugriff: 16.5.2018].

Dehmer/Petri 2018

Andreas Dehmer und Susanne Petri, »Römisches Freundschaftsbild und >kapitolinisches Manifest. Eine allegorische Zeichnung von Julius Schnorr von Carolsfeld (1819) für Johann Gottlob von Quandt«, in: Das Münster. Zeitschrift für christliche Kunst und Kunstwissenschaft, 2018, Jg. 71, Nr. 1, S. 22-31.

\section{Dietzsch 2016}

Steffen Dietzsch, »Bild und Bilden als romantische Praxis. Oder: >Das ächte Denken erscheint, wie ein Machen - und ist auch solches«", in: Praxis und Diskurs der Romantik 1800-1900, hrsg. v. Norman Kaspar und Jochen Strobel, Paderborn: Ferdinand Schöningh, 2016, S. 41-59.

\section{Eberlein 1928}

Kurt Karl Eberlein, »Johann Gottlob von Quandt. Zum Jubiläum des Sächsischen Kunstvereins«, in: Dresdner Kunstbuch. Jahrbuch zur Förderung der Kunstpflege, 1928, Jg. 2, S. 9-21.

\section{Ermisch 1900}

Hubert Ermisch, »Der Königlich Sächsische Altertumsverein. 1825-1900«, in: Festschrift zum fünfundsiebzigjährigen Jubiläum des Königlich Sächsischen Altertumsvereins, Dresden: Wilhelm Baensch, 1900, S. 1-68.

\section{Falser 2008}

Michael Falser, Zwischen Identität und Authentizität. Zur politischen Geschichte der Denkmalpflege in Deutschland, Dresden: Thelem Verlag, 2008.

\section{Fastert 2000}

Sabine Fastert, Die Entdeckung des Mittelalters. Geschichtsrezeption in der nazarenischen Malerei des frühen 19. Jahrhunderts (Kunstwissenschaftliche Studien, Bd. 86), München/Berlin: Deutscher Kunstverlag, 2000.

\section{Frank 1989}

Manfred Frank, Einführung in die frühromantische Ästhetik. Vorlesungen (edition suhrkamp, Bd. 1563), Frankfurt a/M: Suhrkamp Verlag, 1989.

\section{Friesen 1880}

Hermann von Friesen, »Ein Beitrag zur Geschichte der Dresdner Gemälde-Gallerie«, in: Neues Archiv für sächsische Geschichte und Altertumskunde, 1880, Bd. 1, S. 315-333.

\section{Fröhlich 1974}

Martin Fröhlich, Gottfried Semper. Zeichnerischer Nachlass an der ETH Zürich. Kritischer Katalog, Basel/Stuttgart: Birkhäuser Verlag, 1974.

\section{Frommel 1987}

Christoph Luitpold Frommel, »Die Villa Madama, Rom«, in: Raffael. Das architek- 
tonische Werk, hrsg. v. Christoph Luitpold Frommel, Stefano Ray und Manfredo Tafuri, Stuttgart: Deutsche Verlags-Anstalt, 1987, S. 311-356.

\section{Gaehtgens 2002}

Genremalerei (Geschichte der klassischen Bildgattungen in Quellentexten und Kommentaren, Bd. 4), hrsg. v. Barbara Gaehtgens, Berlin: Reimer, 2002.

\section{Gaehtgens 1996}

Thomas W. Gaehtgens, »Historienmalerei.

Zur Geschichte einer klassischen Bildgattung und ihrer Theorie«, in: Historienmalerei (Geschichte der klassischen Bildgattungen in Quellentexten und Kommentaren, Bd. 1), hrsg. v. Thomas W. Gaehtgens und Uwe Fleckner, Berlin: Reimer, 1996, S. 15-76.

\section{Gaehtgens/Fleckner 1996}

Historienmalerei (Geschichte der klassischen Bildgattungen in Quellentexten und Kommentaren, Bd. 1), hrsg. v. Thomas W. Gaehtgens und Uwe Fleckner, Berlin: Reimer, 1996.

\section{Gage 2001}

John Gage, Kulturgeschichte der Farbe von der Antike bis zur Gegenwart, Leipzig: E. A. Seemann Verlag, 2001.

\section{Gallwitz 1977}

Klaus Gallwitz, »Das Städel und die Nazarener«, in: Die Nazarener [Kat. der Ausstellung: Frankfurt a/M, Städtische Galerie im Städelschen Kunstinstitut, 28.4.-28.8.1977], hrsg. v. Klaus Gallwitz, Frankfurt a/M: Städtische Galerie im Städel, 1977, S. 13-17.

\section{Gerstenberg/Rave 1934}

Kurt Gerstenberg und Paul Ortwin Rave, Die Wandgemälde der deutschen Romantiker im Casino Massimo zu Rom, Berlin: Deutscher Verein für Kunstwissenschaft, 1934.

\section{Gethmann-Siefert 2005}

Annemarie Gethmann-Siefert, Einführung in Hegels Ästhetik (UTB 2646), München: Fink, 2005.

\section{Gethmann-Siefert 1995}

Annemarie Gethmann-Siefert, Einführung in die Ästhetik, (UTB 1875), München: Fink, 1995.

\section{Glaser 2002}

Gerhard Glaser, »Das Belvedere auf der Schönen Höhe. Denkmalpflegerische Bemühungen über fünf Jahrzehnte«, in: Luzens 2002, S. 70-72.

\section{Grave 2012}

Johannes Grave, Caspar David Friedrich, München/London/New York: Prestel, 2012.

\section{Grave 2005}

Johannes Grave, »Einblicke in das > Ganzeく der Kunst. Goethes graphische Sammlung«, in: Räume der Kunst. Blicke auf Goethes Sammlungen, hrsg. v. Markus Bertsch und Johannes Grave, Göttingen: Vandenhoeck \& Ruprecht, 2005, S. 255-288

\section{Grave 2003}

Johannes Grave, » Die Gegenwart erhellet die Vorzeitı. Caspar David Friedrich zu Goethes >Ruisdael als Dichter«, in: Jahrbuch des Freien Deutschen Hochstifts, hrsg. v. Anne Bohnenkamp und Christoph Perels, Tübingen: Max Niemeyer Verlag, 2003, S. 208-226.

\section{Grave 2001}

Johannes Grave, Caspar David Friedrich und die Theorie des Erhabenen, Weimar: VDG, 2001.

\section{Grewe 2017}

Cordula Grewe, Wilhelm Schadow. Werkverzeichnis der Gemälde mit einer Auswahl der dazugehörigen Zeichnungen und Druckgraphiken, hrsg. v. Bettina Baumgärtel und Hans Paffrath, Petersberg: Michael Imhof Verlag, 2017.

\section{Grewe 2015}

Cordula Grewe, The Nazarenes. Romantic Avant-Garde and the Art of the Concept, University Park: The Pennsylvania State University Press, 2015.

\section{Grewe 2009}

Cordula Grewe, Painting the Sacred in the Age of Romanticism, Farnham: Ashgate, 2009.

\section{Grewe 2007}

Cordula Grewe, »Historicism and the Symbolic Imagination in Nazarene Art«, in: The Art Bulletin, 2007, Jg. 89, Nr. 1, S. 82-107.

\section{Grewe 2006}

Cordula Grewe, »Italia und Germania. Zur Konstruktion religiöser Seherfahrung in der Kunst der Nazarener«, in: Rom - Europa. Treffpunkt der Kulturen: 1780-1820 (Stiftung für Romantikforschung, Bd. 36), hrsg. v. Paolo Chiarini und Walter Hinderer, Würzburg: Königshausen \& Neumann, 2006, S. 401-425.

\section{Grewe 2005}

Cordula Grewe, »Objektivierte Subjektivität: Identitätsfindung und religiöse Kommunikation im nazarenischen Kunstwerk«, in: Religion Macht Kunst. Die Nazarener [Kat. der Ausstellung: Frankfurt, Schirn Kunsthalle, 15.4.24.7.2005], hrsg. v. Max Hollein und Christa Steinle, Köln: Walther König, 2005, S. 77-99.

\section{Gross 2001}

Reiner Gross, Geschichte Sachsens, Berlin: Edition Leipzig, 2001.

\section{Gross et al. 2005/06}

Geschichte der Stadt Dresden. Vom Ende des Dreißigjährigen Krieges bis zur Reichsgründung, Bd. 2, hrsg. von Reiner Gross et al., Stuttgart: Theiss, 2005/06.

\section{Grosskinsky 2011}

Manfred Grosskinsky, »Zwei Kunststädte im Dialog. Düsseldorfer Maler in Frankfurt am Main und Frankfurter Maler in Düsseldorf in der ersten Hälfte des 19. Jahrhunderts«, in: Die Düsseldorfer Malerschule und ihre internationale Ausstrahlung, 1819-1918 [Kat. der Ausstellung: Düsseldorf, Kunstpalast, 24.9.2011-22.1.2012], Bd. 1, hrsg. v. Bettina Baumgärtel, Petersberg: Michael Imhof Verlag, 2011, S. 151-159.

\section{Grossmann 1925-1928}

Karl Grossmann, »Johann Gottlob von Quandt«, in: Der grosse Garten. 2. Hundert Jahre Sächsischer Kunstverein. JubiläumsFestschrift, hrsg. v. Erich Haenel, Dresden: Verlag Graphische Werke, 1925-1928, S. $134-146$.

\section{Grummt 2011}

Christina Grummt, Caspar David Friedrich. Die Zeichnungen. Das gesamte Werk, 2 Bde., München: Verlag C. H. Beck, 2011.

\section{Hahn/Berding 2010}

Hans-Werner Hahn und Helmut Berding, Reformen, Restauration und Revolution 1806-1848/49 (Gebhardt. Handbuch der deutschen Geschichte, Bd. 14), 10. völlig neu bearbeitete Auflage [Erstausgabe: 1891], Stuttgart: Klett-Cotta, 2010.

\section{Hecht 2012}

Christian Hecht, »Klassiker-Inszenierung im höfischen Kontext. Die Dichterzimmer im Weimarer Schloss«, in: Literatur ausstellen. Museale Inszenierungen der Weimarer Klassik (Jahrbuch der Klassik Stiftung Weimar 2012), Göttingen: Wallstein, 2012, S. 13-30.

\section{Hecht 2000}

Christian Hecht, Der Westflügel des Weimarer Residenzschlosses. Architektur und Ausstattung, Ostfildern-Ruit: Hatje Cantz, 2000.

\section{Heckenbücker 2008}

Silke Heckenbücker, Prometheus, Apollo, Zeus/Jupiter - Goethe-Bilder von 1773 bis 1885 (Maß und Wert. Düsseldorfer Schriften zur deutschen Literatur, Bd. 3), Frankfurt a/M: Peter Lang, 2008.

\section{Heckmann 2003}

Uwe Heckmann, Die Sammlung Boisserée. Konzeption und Rezeptionsgeschichte einer romantischen Kunstsammlung zwischen 1804 und 1827, München 2003.

\section{Heiland 1997}

Susanne Heiland, »Wahrheit und Legende. Die Geschichte des Bilderfundes«, in: Kat. Leipzig 1997, S. 10-18.

\section{Heinrich 2009}

Bernd Heinrich, »Auf den Spuren Gustav von Quandts«, in: Wesenitztaler Landbote, 2009, Jg. 9, Nr. 6, S. 27-29.

\section{Heinrich 2002}

Bernd Heinrich, »Zum Leben Johann Gottlob von Quandt«, »Johann Gottlob von Quandt in Dittersbach« und »Auf den Spuren Quandts in Dittersbach«, in: Luzens 2002, S. 7-10, 43-56, 95-103.

\section{Hempel 2008}

Dirk Hempel, Literarische Vereine in Dresden. Kulturelle Praxis und politische Orientierung 
des Bürgertums im 19. Jahrhundert (Studien und Texte zur Sozialgeschichte der Literatur, Bd. 116), Tübingen: Max Niemeyer Verlag, 2008.

\section{Herding 1991}

Klaus Herding, »)...Woran meine ganze Seele gesogen.... Das Galerieerlebnis - eine verlorene Dimension der Kunstgeschichte?«, in: Kunst und Kunsttheorie 1400-1900 [Akten der Tagung: Wolfenbüttel, Herzog August Bibliothek, 1.-5.12.1987/27.11.-1.12.1988] (Wolfenbütteler Forschungen, Bd. 48.), hrsg. v. Peter Ganz et al., Wiesbaden: Harrassowitz, 1991, S. 257-285

\section{Heres 2006}

Gerald Heres, Dresdener Kunstsammlungen im 18. Jahrhundert, Leipzig: E. A. Seemann Verlag, 2006.

\section{Heres 2005/06}

Gerald Heres, »Die Königlichen Sammlungen«, in: Geschichte der Stadt Dresden. Vom Ende des Dreißigjährigen Krieges bis zur Reichsgründung, Bd. 2, hrsg. von Reiner Gross et al., Stuttgart: Theiss, 2005/06, S. 720-726.

\section{Heres 2004}

Gerald Heres, »Die Königlichen Sammlungen als Hausfideikommiß«, in: Die Dresdner Kunstsammlungen in fünf Jahrhunderten (Dresdner Hefte. Sonderausgabe), hrsg. v. Hans-Peter Lühr, Dresden: Dresdner Geschichtsverein, 2004, S. 48-60.

\section{Heres 1988}

Gerald Heres, »Lindenaus Reform der Dresdener Museen seit 1830«, in: Kunstverhältnisse. Ein Paradigma kunstwissenschaftlicher Forschung, hrsg. v. Michael Franz und Gisold Lammel, Berlin: Akademie der Wissenschaften der DDR, Institut für Aesthetik und Kunstwissenschaften, 1988, S. 66-69.

\section{Heres 1987}

Gerald Heres, »Bernhard August von Lindenau und die Reform der Dresdner Museen«, in: Dresdner Hefte (Beiträge zur Kulturgeschichte, Bd. 19), 1987, Jg. 5, Nr. 5, S. 43-48.

\section{Herrmann 1978}

Wolfgang Herrmann, Gottfried Semper im Exil. Paris London 1849-1855. Zur Entstehung des >Stik 1840-1877 (Schriftenreihe des Instituts für Geschichte und Theorie der Architektur an der Eidgenössischen Technischen Hochschule Zürich, Bd. 19), Basel/ Stuttgart: Birkhäuser Verlag, 1978.

\section{Hertzig 2011}

Stefan Hertzig, Der historische Neustädter Markt zu Dresden. Geschichte und Bauten der inneren Neustadt, Petersberg: Michael Imhof Verlag, 2011.

\section{Hildebrand-Schat 2004}

Viola Hildebrand-Schat, Zeichnung im Dienste der Literaturvermittlung. Moritz Retzschs Illustrationen als Ausdruck bürgerlichen
Kunstverstehens (Epistemata. Würzburger Wissenschaftliche Schriften, Bd. 511), Würzburg: Königshausen \& Neumann, 2004.

\section{Hipp 2007}

Elisabeth Hipp, »Die Kataloge der Galerie«, in: Gemäldegalerie Alte Meister Dresden. Illustriertes Gesamtverzeichnis, 2. ergänzte und korr. Auflage [Erstausgabe: 2005], hrsg. v. Harald Marx und Elisabeth Hipp, Köln: Walther König, 2007, S. 55-78.

\section{Hoch 1981}

Karl-Ludwig Hoch, »Zu Caspar David Friedrichs bedeutendstem Manuskript«, in: Pantheon, 1991, Bd. 34, Nr. 3, S. 229-230.

\section{Hoefer 2007}

Dieter Hoefer, »Gegenstand des Unternehmens ist der Betrieb einer Spar- und Darlehnskasse... Zur Geschichte Dresdner Genossenschaftsbanken«, in: Dresdner Hefte, 2007, Bd. 91, S. 22-31.

\section{Hommel 2000}

Karsten Hommel, Carl Lampe. Ein Leipziger Bildungsbürger, Unternehmer, Förderer von Kunst und Wissenschaft zwischen Romantik und Kaiserreich, Beucha: Sax-Verlag, 2000.

\section{Huse $\mathbf{2 0 0 6}$}

Denkmalpflege. Deutsche Texte aus drei Jahrhunderten, hrsg. und komm. von Norbert Huse, 3. Aufl. [Erstausgabe: 1984], München: Verlag C. H. Beck, 2006.

\section{Jäckel 2002}

Günter Jäckel, »Dresden als Erinnerungsort für Goethe«, in: Goethe-Jahrbuch, 2002, Nr. 119, S. 148-164.

\section{Joachimsthaler 2016}

Jürgen Joachimsthaler, »Romantik als poetische Praxis (in) der Aufklärung«, in: Praxis und Diskurs der Romantik 1800-1900, hrsg. v. Norman Kaspar und Jochen Strobel, Paderborn: Ferdinand Schöningh, 2016, S. 23-39.

\section{John 2001}

Uwe John, »Faszination Vaterländische Geschichte. Prinz Johanns Wirken im Sächsischen Altertumsverein«, in: Zwischen zwei Welten. König Johann von Sachsen [Kat. der Ausstellung: Schloss Weesenstein, 3.5.-28.10.2001], hrsg. v. der Sächsischen Schlösserverwaltung und dem Staatlichen Schlossbetrieb Schloss Weesenstein, Halle/ Saale: Janos Stekovics, 2001, S. 472-475.

\section{Jourdan 2009}

Annie Jourdan, »A national tragedy during the French Restoration: the return of the works of art to their countries (1815)《, in: Napoleon's Legacy. The Rise of National Museums in Europe 1794-1830 (Berliner Schriften zur Museumsforschung, Bd. 27), hrsg. v. Ellinoor Bergvelt et al., Berlin: $\mathrm{G}+\mathrm{H}$ Verlag, 2009, S. 125-135.

\section{Justi 1932}

Ludwig Justi, Von Runge bis Thoma. Deutsche Malkunst im 19. und 20. Jahrhundert. Ein Gang durch die National-Galerie, Berlin: Julius Bard, 1932.

\section{Kaiser 2017}

Uta Kaiser, Sammler, Kenner, Kunstschriftsteller. Studien zur »Geschichte der neueren deutschen Kunst" (1836-1841) des Athanasius Graf Raczyński, Hildesheim/Zürich/New York: Georg OIms Verlag, 2017.

\section{Keiser 1967}

Herbert Wolfgang Keiser, Gemäldegalerie Oldenburg, München: Bruckmann Verlag, 1967.

\section{Karge 2013}

Henrik Karge, »Projecting the Future in German Art Historiography of the Nineteenth Century«, in: Journal of Art Historiography, 2013, Nr. 9, S. 1-26 [Internetressource: https://arthistoriography.files.wordpress. com/2013/12/karge.pdf, letzter Zugriff: 17.9.2018].

\section{Karge 2010 (1)}

Henrik Karge, »Stilgeschichte versus Kulturgeschichte: Zur Entfaltung der kunsthistorischen Methodik in den Jahrzehnten ab 1850«, in: Die Etablierung des Faches Kunstgeschichte in Deutschland, Polen und Mitteleuropa [Akten der Tagung: Krakau, 26.-30.9.2007] (Das Gemeinsame Kulturerbe. Wspòlne Dziedzictwo, Bd. 6), hrsg. v. Wojciech Bałus und Joanna Wolańska, Warszawa: Instytut Sztuki Polskiej Akademii Nauk, 2010, S. 41-58.

\section{Karge 2010 (2)}

Henrik Karge, »Franz Kugler und Karl Schnaase - zwei Projekte zur Etablierung der `Allgemeinen Kunstgeschichte«", in: Franz Theodor Kugler. Deutscher Kunsthistoriker und Berliner Dichter, hrsg. v. Michel Espagne, Bénédic te Savoy und Céline Trautmann-Waller, Berlin: Akademieverlag, 2010, S. 83-104.

\section{Karge 2009}

Henrik Karge, »Die Entfaltung der wissenschaftlichen Kunstgeschichte im 19. Jahrhundert. Biografische und konzeptgeschichtliche Ansätze der Erforschung", in: Kunstgeschichte. Open Peer Reviewed Journal, 2009 [Internetressource: Universität Regensburg, Universitätsbibliothek und Lehrstuhl für Kunstgeschichte, http://www.kunstgeschichte-ejournal.net/17/2/Karge.pdf, letzter Zugriff: 17.9.2018]

\section{Karge 2007}

Henrik Karge, „Ein europäischer Sonderweg? Spanien in der deutschen Kunstgeschichtsschreibung des 19. Jahrhunderts«, in: Spanien und Deutschland. Kulturtransfer im 19. Jahrhundert (Ars Iberica et Americana, Bd. 12), hrsg. v. Karin Hellwig, Frankfurt a/M: Vervuer, 2007, S. 39-55. 


\section{Karge 1998}

Henrik Karge, »Kunst als kulturelles System Karl Schnaase und Jacob Burckhardt«, in: Jacob Burckhardt und die Antike (Kulturgeschichte der antiken Welt, Bd. 85), hrsg. v. Peter Betthausen und Max Kunze, Mainz: Philipp von Zabern, 1998, S. 139-159.

\section{Kat. Bad Muskau 2016}

Italienische Landschaft der Romantik. Malerei und Literatur [Kat. der Ausstellung: Bad Muskau, Neues Schloss, 11.5.-21.8.2016], hrsg. v. Andreas Dehmer, Dresden: Sandstein Verlag, 2016.

\section{Kat. Berlin 2002}

Nationalgalerie Berlin. Das XIX. Jahrhundert, Katalog der ausgestellten Werke, 2. Aufl. [Erstausgabe: 2001], hrsg. v. Angelika Wesenberg et al., Leipzig: E. A. Seemann Verlag, 2002.

\section{Kat. Bonn 2010}

Napoleon und Europa. Traum und Trauma [Kat. der Ausstellung: Bonn, Kunst- und Ausstellungshalle der Bundesrepublik Deutschland, 17.12.2010-25.4.2011], hrsg. v. Bénédicte Savoy, München: Prestel, 2010.

\section{Kat. Dresden 2017}

Italienbilder zwischen Romantik und Realismus. Malerei des 19. Jahrhunderts zwischen Lorrain, Turner und Böcklin [Kat. der Ausstellung: Dresden, Albertinum, 10.2.-28.5.2017], hrsg. v. Heike Biedermann und Andreas Dehmer, Dresden: Sandstein Verlag, 2017.

\section{Kat. Dresden 2012}

Die Sixtinische Madonna. Raffaels Kultbild wird 500 [Kat. der Ausstellung: Dresden, Gemäldegalerie Alte Meister, 26.5.-26.8.2012, hrsg. von Andreas Henning, München: Prestel, 2012

\section{Kat. Dresden 2007}

Gemäldegalerie Alte Meister Dresden. Illustriertes Gesamtverzeichnis, 2. ergänzte und korr. Auflage [Erstausgabe: 2005], hrsg. v. Harald Marx und Elisabeth Hipp, Köln: Walther König, 2007.

\section{Kat. Dresden 2004}

Ernst Rietschel, 1804-1861. Zum 200. Geburtstag des Bildhauers [Kat. der Ausstellung: Dresden, Albertinum, 23.10.20042.5.2005], hrsg. von Bärbel Stephan, München: Deutscher Kunstverlag, 2004.

\section{Kat. Dresden/Lübeck 1997}

Ernst Ferdinand Oehme, 1797-1855. Ein Landschaftsmaler der Romantik [Kat. der Ausstellungen: Dresden, Albertina, 21.4.-29.6.1997 und Lübeck, Behnhaus, 20.7.7.9.1997], hrsg. v. Ulrich Bischoff, Dresden: Neumeister, 1997.

\section{Kat. Dresden/München 2003}

Ludwig Richter - der Maler. Ausstellung zum 200. Geburtstag [Kat. der Ausstellung: Dresden, Gemäldegalerie Neue Meister,
27.9.2003-4.1.2004 und München, Neue Pinakothek, 22.1.2004-25.4.2004], hrsg. von Gerd Spitzer und Ulrich Bischoff, München: Deutscher Kunstverlag, 2003.

\section{Kat. Düsseldorf 2011}

Die Düsseldorfer Malerschule und ihre internationale Ausstrahlung, 1819-1918 [Kat. der Ausstellung: Düsseldorf, Kunstpalast, 24.9.2011-22.1.2012], 2 Bde., hrsg. v. Bettina Baumgärtel, Petersberg: Michael Imhof Verlag, 2011 .

\section{Kat. Frankfurt 2005}

Religion Macht Kunst. Die Nazarener [Kat. der Ausstellung: Frankfurt, Schirn Kunsthalle, 15.4.-24.7.2005], hrsg. v. Max Hollein und Christa Steinle, Köln: Walther König, 2005.

\section{Kat. Frankfurt 1994}

»Von Kunst und Kennerschaft«. Die Graphische Sammlung im Städelschen Kunstinstitut unter Johann David Passavant, 1840 bis 1861 [Kat. der Ausstellung: Frankfurt, Städelsches Kunstinstitut, Graphische Sammlung, 24.11.1994-5.2.1995], hrsg. v. Hildegard Bauereisen und Margret Stuffmann, Frankfurt a/M: Städelsches Kunstinstitut und Städtische Galerie, 1994

\section{Kat. Frankfurt 1977}

Die Nazarener [Kat. der Ausstellung: Frankfurt a/M, Städtische Galerie im Städelschen Kunstinstitut, 28.4.-28.8.1977], hrsg. v. Klaus Gallwitz, Frankfurt a/M: Städtische Galerie im Städel, 1977.

\section{Kat. Göttingen 2015}

Sterbliche Götter. Raffael und Dürer in der Kunst der deutschen Romantik [Kat. der Ausstellung: Göttingen, Kunstsammlung der Universität, 19.4.-19.7.2015], hrsg. v. Michael Thimann und Christine Hübner, Petersberg: Michael Imhof Verlag, 2015.

\section{Kat. Hamburg/München 2012}

Johann Christian Reinhart. Ein deutscher Landschaftsmaler in Rom [Kat. der Ausstellungen: Hamburg, Kunsthalle, 26.10.201227.1.2013 und München, Neue Pinakothek, 21.2.-26.5.2013], hrsg. v. Herbert W. Rott und Andreas Stolzenburg, München: Hirmer, 2012.

\section{Kat. Hamburg/Paris 2016}

Spurenlese. Zeichnungen und Aquarelle aus drei Jahrhunderten [Kat. der Ausstellung: Hamburg, Kunsthalle, Hubertus Wald Forum, 2.9.2016-8.1.2017 und Paris, Fondation Custodia, 4.2.-7.5.2017], hrsg. v. Peter Prange und Andreas Stolzenburg, München: Hirmer, 2016.

\section{Kat. Kassel/Wuppertal 2000}

Johann Martin von Rohden 1778-1868 [Kat. der Ausstellungen: Kassel, Neue Galerie, 22.9.-19.11.2000 und Wuppertal, Von der Heydt-Museum, 3.12.2000-4.2.2001], hrsg. v. Marianne Heinz, Wolfratshausen: Edition Minerva, 2000.

\section{Kat. Leipzig 1997}

Vergessene Altdeutsche Gemälde. 1815 auf dem Dachboden der Leipziger Nikolaikirche gefunden. 1997 anlässlich des 27. Deutschen Evangelischen Kirchentages präsentiert [Kat. der Ausstellung: Leipzig, Museum der bildenden Künste, 19.6.-3.8.1997], hrsg. v. Herwig Guratzsch, Heidelberg: Edition Braus, 1997.

\section{Kat. Leipzig/Bremen 1994}

Julius Schnorr von Carolsfeld 1794-1872 [Kat. der Ausstellungen: Leipzig, Museum der bildenden Künste, 26.3.-23.5.1994 und Bremen, Kunsthalle, 5.6.-31.7. 1994], hrsg. v. Herwig Guratzsch, Leipzig: Museum der bildenden Künste, 1994.

\section{Kat. Lübeck 2010}

Kunst, Küche und Kalkül. Carl Friedrich von Rumohr (1785-1843) und die Entdeckung der Kulturgeschichte [Kat. der Ausstellung: Lübeck, Museum Behnhaus Drägerhaus, 19.9.2010-16.1.2011], hrsg. v. Alexander Bastek und Achatz von Müller, Petersberg: Michael Imhof, 2010.

\section{Kat. Lübeck/Koblenz 2014}

Carl Wilhelm Götzloff (1799-1866). Ein Dresdner Landschaftsmaler am Golf von Neapel [Kat. der Ausstellung: Lübeck, Museum Behnhaus Drägerhaus, 2.5.-20.7.2014 und Koblenz, Mittelrhein-Museum, 8.8.-2.11.2014], hrsg. v. Alexander Bastek und Markus Bertsch, Petersberg: Michael Imhof, 2014.

\section{Kat. München/Dresden 2000}

»...ein Land der Verheißung. Julius Schnorr von Carolsfeld zeichnet Italien [Kat. der Ausstellungen: München, Haus der Kunst, 31.5.-6.8.2000 und Dresden, Albertinum, Kupferstich-Kabinett, 28.1.-1.4.2001], hrsg. v. Staatliche Kunstsammlungen Dresden, Kupferstich-Kabinett, Köln: Wienand, 2000.

\section{Kat. New York 2005}

Fra Angelico [Kat. der Ausstellung: New York, Metropolitan Museum, 26.10.2005-29.1.2006], hrsg. v. Laurence Kanter und Pia Palladino, New Haven/London: Yale University Press, 2005.

\section{Kat. Oslo/Dresden 2014}

Dahl und Friedrich. Romantische Landschaften [Kat. der Ausstellung: Oslo, Nasjonalgalleriet, 10.10.2014-4.1.2015 und Dresden, Albertinum, 6.2.-3.5.2015], hrsg. v. Petra Kuhlmann Hodick et al., Dresden: Sandstein Verlag, 2015.

\section{Kat. Rom 1981}

Die Nazarener in Rom. Ein deutscher Künstlerbund der Romantik [Kat. der Ausstellung: Roma, Galleria Nazionale d'Arte Moderna, 22.1.22.3.1981], hrsg. v. Klaus Gallwitz, München: Prestel, 1981.

\section{Kat. Wartburg-Eisenach 2007}

Elisabeth von Thüringen - eine europäische Heilige [Kat. der Ausstellung: Eisenach, Wartburg, 7.7.-19.11.2007], 2 Bde., hrsg. von Dieter Blume, Petersberg: Imhof, 2007. 


\section{Kat. Wien 1996}

Der Traum vom Glück. Die Kunst des Historismus in Europa [Kat. der Ausstellung: Wien, Akademie der Bildenden Künste, 13.9.19966.1.1997], 2 Bde., hrsg. v. Hermann Fillitz, Wien: Künstlerhaus, 1996.

\section{Klatte 2017}

Gernot Klatte, »Höfische Rüstkammern Waffensammlung, Magazin der Hofausstattung, Museum. Eine Institution des Hofes der frühen Neuzeit am Beispiel Dresden und Berlin«, in: Zeichen und Medien des Militärischen am Fürstenhof in Europa (Schriften zur Residenzkultur, Bd. 10), hrsg. v. Matthias Müller und Peter-Michael Hahn, Berlin: Lukas Verlag, 2017, S. 87-116

\section{Klauss 2001}

Jochen Klauss, Der »Kunschtmeyer«. Johann Heinrich Meyer: Freund und Orakel Goethes, Weimar: Verlag Hermann Böhlaus Nachfolger, 2001

\section{Klecker 1997}

Christina Klecker, »Der Anteil des Adels an Sammlungen und Museumsgründungen in Sachsen«, in: Geschichte des sächsischen Adels, hrsg. v. Kathrin Keller und Joseph Matzerath, Köln/Weimar/Wien: Böhlau, 1997, S. $225-256$.

\section{Kloppenburg/Weber 2000}

Birgit Kloppenburg und Gregor J.M. Weber, La famosissima notte! Correggios Gemälde "Die Heilige Nacht « und seine Wirkungsgeschichte, Emsdetten: Edition Imorde, 2000

\section{Kneschke 1867}

Emil Kneschke, Leipzig seit 100 Jahren. Säcularchronik einer werdenden Großstadt, Leipzig: Selbstverlag des Verfassers, 1867.

\section{Köhler 2002}

Brunhilde Köhler, »Johann Gottlob von Quandt und der Sächsische Kunstverein«, in: Luzens 2002, S. 18-26.

\section{Köhler 1994}

Brunhilde Köhler, Geschichte des Sächsischen Kunstvereins 1828-1945, hrsg. v. Neuer Sächsischer Kunstverein e. V., Dresden: famaVerlagsgesellschaft, 1994

\section{Koeltz 2010}

Ulrike Koeltz, Vittoria Caldoni. Modell und Identifikationsfigur des 19. Jahrhunderts, Frankfurt a/M: Lang, 2010.

\section{Koetschau 1905}

Karl Koetschau, »Vom historischen Museum. Ein Wort pro domo«, in: Dresdner Jahrbuch. Beiträge zur bildenden Kunst, 1905, S. 91-101.

\section{Kolb 2005}

Karin Kolb, »Cranach - Die Gemälde in Dresden und ihre Geschichte« und »Bestandskatalog der Staatlichen Kunstsammlungen Dresden - Cranach-Werke in der Gemäldegalerie und der Rüstkammer «, in: Cranach [Kat. der Ausstellung: Chemnitz, Kunstsamm- lungen, 13.11.2005-12.3.2006], hrsg. v. Harald Marx und Ingrid Mösinger, Köln: Wienand Verlag, 2005, S. 112-173, 199-522.

\section{Koschnik 2010}

Leonore Koschnik, »Kugler als Chronist der Kunst und preußischer Kulturpolitiker«, in: Franz Theodor Kugler. Deutscher Kunsthistoriker und Berliner Dichter, hrsg. v. Michel Espagne, Bénédicte Savoy und Céline Trautmann-Waller, Berlin: Akademieverlag, 2010, S. 1-14.

\section{Kovalevski 2010}

Bärbel Kovalevski, Die Bilder-Chronik des Sächsischen Kunstvereins Dresden 18281836, Frankfurt a/M: H. W. Fichter Kunsthandel, 2010.

\section{Kovalevski 2006}

Bärbel Kovalevski, Louise Seidler 1786-1866. Goethes geschätzte Malerin, Berlin: Dr. Bärbel Kovalevski, 2006.

\section{Kovalevski 1999}

Bärbel Kovalevski, »Johann Wolfgang von Goethe als Mentor von Künstlerinnen«, in: Zwischen Ideal und Wirklichkeit. Künstlerinnen der Goethe-Zeit zwischen 1750 und 1850 [Kat. der Ausstellung: Gotha, Schlossmuseum, 1.4.-18.7.1999 und Konstanz, Rosengartenmuseum, 25.8.-24.10.1999], hrsg. v. Bärbel Kovalev ski, Ostfildern-Ruit: Gerd Hatje, 1999, S. 41-53.

\section{Kramp 2007}

Mario Kramp, »Von Paris nach Dresden: Ein europäischer Horizont. Gottfried Semper als Schüler des rheinischen Architekten Franz Christian Gau«, in: Gottfried Semper - Dresden und Europa. Die moderne Renaissance der Künste [Akten des Kolloquiums: Dresden, Technische Universität, 27.-30.11.2003], hrsg. v. Henrik Karge, München/Berlin: Deutscher Kunstverlag, 2007, S. 101-120.

\section{Krause/Harnisch 2009}

Historische Kulturlandschaft Lieblingstal Dittersbach, hrsg. v. Uwe Krause und Eberhard Harnisch, Dittersbach: Quandt-Verein, 2009 .

\section{Kreutzmann 2010}

Marko Kreutzmann, »Goethe als Gesellschaftskritiker. Zur Symbolisierung sozialen Wandels in den >Wahlverwandtschaften««, in: Goethes »Wahlverwandtschaften«. Werk und Forschung, hrsg. v. Helmut Hühn, Berlin/ Boston: Walter de Gruyter, 2010, S. 327-347.

\section{Kuhlmann-Hodick 2000}

Petra Kuhlmann-Hodick, »Das Landschaftsbuch von Julius Schnorr von Carolsfeld « und »Geschichte und Rezeption des Landschaftsbuches«, in: Kat. München/Dresden 2000, S. $11-63$.

\section{Kultermann 1966}

Udo Kultermann, Geschichte der Kunstgeschichte. Der Weg einer Wissenschaft, Wien/ Düsseldorf: Econ-Verlag, 1966.

\section{Lammel 1998}

Gisold Lammel, Kunst im Aufbruch. Malerei, Graphik und Plastik zur Zeit Goethes, Stuttgart/Weimar: J. B. Metzler, 1998.

\section{Lange 2007}

Justus Lange, »>Bilder, vor denen man knien möchter - Deutsche Kunstgelehrte nehmen die Malerei des Siglo de Oro in den Blick«, in: Spanien und Deutschland. Kulturtransfer im 19. Jahrhundert (Ars Iberica et Americana, Bd. 12), hrsg. v. Karin Hellwig, Frankfurt a/M: Vervuer, 2007, S. 17-36.

\section{Laudel 2007}

Heidrun Laudel, »Bauten und Plätze als >Orte zur Beförderung des Gemeinsinns««, in: Gottfried Semper - Dresden und Europa. Die moderne Renaissance der Künste [Akten des Kolloquiums: Dresden, Technische Universität, 27.-30.11.2003], hrsg. v. Henrik Karge, München/Berlin: Deutscher Kunstverlag, 2007, S. 121-136.

\section{Laudel 2003}

Heidrun Laudel, »Dresden 1834-1849«, in: Gottfried Semper 1803-1879. Architektur und Wissenschaft [Kat. der Ausstellungen: München, Architekturmuseum der TU München in der Pinakothek der Moderne, 4.6.-31.8.2003 und Zürich, Museum für Gestaltung, 1.11.2003-25.1.2004], hrsg. v. Winfried Nerdinger und Werner Oechslin, Zürich: gta Verlag, 2003, S. 125-258.

\section{Locher 2010}

Hubert Locher, »Vorbild und Gegenbild Franz Kuglers Darstellung von Italien und Frankreich in den Handbüchern der Kunstgeschichte«, in: Franz Theodor Kugler. Deutscher Kunsthistoriker und Berliner Dichter, hrsg. v. Michel Espagne, Bénédicte Savoy und Céline Trautmann-Waller, Berlin: Akademieverlag, 2010, S. 69.

\section{Locher 2005}

Hubert Locher, Deutsche Malerei im 19. Jahrhundert, Darmstadt: Wissenschaftliche Buchgesellschaft, 2005 .

\section{Locher 2001}

Hubert Locher, Kunstgeschichte als historische Theorie der Kunst, 1750-1950, München: Wilhelm Fink Verlag, 2001.

\section{Luzens 2002}

Johann Gottlob von Quandt, 1787-1859. Goetheverehrer und Förderer der Künste. Eine Sammlung von Beiträgen, anlässlich der Grundsteinlegung 1831 auf »Schönhöhe" bei Dittersbach vor 170 Jahren und der Wiedereinweihung des restaurierten Fresken saales im Belvedere Schöne Höhe 2001, hrsg. v. Helga Luzens und dem Quandt-Verein, Dittersbach: Quandt-Verein, 2002.

\section{Maaz 2014}

Bernhard Maaz, Hans Holbein d. J. Die Madonnen des Bürgermeisters Jacob Meyer zum 
Hasen in Dresden und Darmstadt: Wahrnehmung, Wahrheitsfindung und -verunklärung, Künzelsau: Swiridoff, 2014

\section{Maaz 2002}

Bernhard Maaz, »Goethe bei Quandt: Die

Fresken auf der Schönen Höhe«, in: Luzens 2002, S. 73-92.

\section{Maaz 1998}

Bernhard Maaz, »Nicht unter Goethe und Raffael. Bezugnahme und Anspruchsformulierungen in Julius Schnorr von Carolsfelds Bildnis der Bianca von Quandt«, in: Jahrbuch der Berliner Museen. Neue Folge, 1998,

Bd. 40, S. 131-144.

\section{Maaz 1989}

Bernhard Maaz, »Johann Gottlob von Quandt. Ein zeichnender Kunstsammler«, in: Dresdener Kunstblätter, 1989, Jg. 33, Nr. 4, S. 115-121.

\section{Maaz 1987 (1)}

Bernhard Maaz, »Die Fresken auf der Schönen Höhe«, in: Neidhardt et al. 1987, S. 44-66.

\section{Maaz 1987 (2)}

Bernhard Maaz, »Die Fresken im Belvedere zu Dittersbach - ein Denkmal für Goethe«, in: Dresdner Hefte (Beiträge zur Kulturgeschichte, Bd. 13), 1987, Jg. 5, Nr. 5, S. 30-42.

\section{Maaz 1986}

Bernhard Maaz, Johann Gottlob Quandt (1787-1859) als Auftraggeber, Mäzen und Kunstsammler, Diplomarbeit, Leipzig: KarlMarx-Universität, 1986 [unpubliziert].

\section{Magirius 2001}

Heinrich Magirius, »Sinn für Schönheit und Reinheit alter Kunst. Johanns Wirken für die Erhaltung und Pflege mittelalterlicher Monumente«, in: Zwischen zwei Welten. König Johann von Sachsen [Kat. der Ausstellung: Schloss Weesenstein, 3.5.-28.10.2001], hrsg. v. der Sächsischen Schlösserverwaltung und dem Staatlichen Schlossbetrieb Schloss Weesenstein, Halle/Saale: Janos Stekovics, 2001, S. $479-483$.

\section{Magirius 1994}

Heinrich Magirius, »Gottfried Semper in Dresden«, in: Zeitschrift für Kunstgeschichte, 1994, Bd. 57, Nr. 3, S. 480-511.

\section{Magirius 1992 (1)}

Heinrich Magirius, »Die bildkünstlerische Ausgestaltung von Gottfried Sempers Gemäldegalerie in Dresden«, in: 100 Jahre Kunsthistorisches Museum. Das Kunsthistorische Museum als Denkmal und Gesamtkunstwerk [Beiträge des Symposiums: Wien, Kunsthistorisches Museum, 17.-19.10.1991] (Jahrbuch der Kunsthistorischen Sammlungen in Wien, Bd. 88), hrsg. v. Gabriele Helke, Wien: Anton Schroll \& Co, 1992, S. 71-87.

Magirius 1992 (2)

Heinrich Magirius, »Die Gemäldegalerie in Dresden. Ein Bau von Gottfried Semper«, in:
Gemäldegalerie Dresden. Die Sammlung Alte Meister. Der Bau Gottfried Sempers, hrsg. v. Harald Marx und Heinrich Magirius, Leipzig: E. A. Seemann Verlag, 1992, S. 29-62.

\section{Magirius 1989}

Heinrich Magirius, Geschichte der Denkmalpflege in Sachsen von den Anfängen bis zum Neubeginn 1945, Berlin: Verlag für Bauwesen, 1989.

\section{Mai 2011}

Ekkehard Mai, „Schadows Erfolgsmodell. Die Düsseldorfer Kunstakademie im Vergleich«, in: Die Düsseldorfer Malerschule und ihre internationale Ausstrahlung, 1819-1918 [Kat. der Ausstellung: Düsseldorf, Kunstpalast, 24.9.2011-22.1.2012], Bd. 1, hrsg. v. Bettina Baumgärtel, Petersberg: Michael Imhof Verlag, 2011, S 51-61.

\section{Mallgrave 2001}

Harry Francis Mallgrave, Gottfried Semper. Ein Architekt des 19. Jahrhunderts, Zürich: gta Verlag, 2001.

\section{Mandelkow 1975-1984}

Goethe im Urteil seiner Kritiker. Dokumente zur Wirkungsgeschichte Goethes in Deutschland, 4 Bde., hrsg. v. Karl Robert Mandelkow, München: Verlag C. H. Beck, 1975-1984.

\section{Marburg 2001}

Silke Marburg, »Adel und Verein in Dresden«, in: Der Schritt in die Moderne. Sächsischer Adel zwischen 1763 und 1918, hrsg. v. Silke Marburg und Josef Matzerath, Köln/Weimar/ Wien: Böhlau, 2001.

\section{Marx 2014 (1)}

Harald Marx, »Die jährlichen Ausstellungen der Kunstakademie in Dresden. Teil III, 1: Die Akademie-Ausstellungen von 1801 bis zum Ende des General-Gouvernements 1815 - sowie vom Sinn und Zweck der Kunstakademien allgemein, vom unterschiedlichen Ort der Unterbringung der Akademie und ihrer Ausstellungen, vom Publikum und von Eintrittspreisen (Materialsammlung und Bemerkungen)《 und Teil III, 2: »Die Akademie-Ausstellungen von 1816 bis zum Jahre 1830; von Fürstenlob und Prüderie bei der Kunstbetrachtung, von Kritiker-Streit und von Ausstellungen, die nicht stattgefunden haben sowie von den jeweiligen Eröffnungsdaten (Materialsammlung und Bemerkungen)«, in: Sächsische Heimatblätter, 2014, Jg. 60, Nr. 2 und Nr. 4, S. 98-111.

\section{Marx 2014 (2)}

Harald Marx, »Das Porträt des Johann Gottlob von Quandt in der Dresdner Galerie Neue Meister - angeblich ein Werk des Carl Christian Vogel von Vogelstein, tatsächlich aber: Ein Meisterbild von Ferdinand Hartmann«, in: Sächsische Heimatblätter, 2014, Jg. 59, Nr. 2, S. 112-121.

\section{Marx 1998}

Harald Marx, »Das Bildnis des Charles de Solier, Sieur de Morette, von Hans Holbein dem Jüngeren«, in: Zeitschrift für schweizerische Archäologie und Kunstgeschichte, 1998, Bd. 55, S. 263-279.

\section{Marx 1992 (1)}

Harald Marx, »Die Dresdener Gemäldegalerie Alte Meister. Gedanken zur Geschichte der Sammlung und zu ihrer musealen Präsentation«, in: 100 Jahre Kunsthistorisches Museum. Das Kunsthistorische Museum als Denkmal und Gesamtkunstwerk [Beiträge des Symposiums: Wien, Kunsthistorisches Museum, 17.-19.10.1991] (Jahrbuch der Kunsthistorischen Sammlungen in Wien, Bd. 88), hrsg. v. Gabriele Helke, Wien: Anton Schroll \& Co, 1992, S. 89-106.

\section{Marx 1992 (2)}

Harald Marx, »Die Dresdener Gemäldegalerie. Geschichte, Ruhm und Wirkung«, in: Gemäldegalerie Dresden. Die Sammlung Alte Meister. Der Bau Gottfried Sempers, hrsg. v. Harald Marx und Heinrich Magirius, Leipzig: E. A. Seemann Verlag, 1992, S. 7-28.

\section{Minning 2012}

Martina Minning, »Die Auflösung der königlich-sächsischen Kunstkammer im Jahr 1832《, in: Die kurfürstlich-sächsische Kunstkammer in Dresden. Geschichte einer Sammlung, hrsg. v. Dirk Syndram und Martina Minning, Dresden: Sandstein, 2012, S. 153-165.

\section{Morat 2011}

Daniel Morat, »Intellektuelle und Intellektuellengeschichte«, in: Docupedia-Zeitgeschichte. Begriffe, Methoden und Debatten der zeithistorischen Forschung, hrsg. v. Jürg Baberowski et al., 20.11.2011 [Internetressource: Zentrum für Zeithistorische Forschung Potsdam, http://docupedia.de/zg/Intellektuelle_ und_Intellektuellengeschichte?oldid=125868, letzter Zugriff: 19.3.2018].

\section{Mütterlein 1913}

Max Mütterlein, »Gottfried Semper und dessen Monumentalbauten am Dresdner Theaterplatz«, in: Neues Archiv für sächsische Geschichte und Altertumskunde, 1913, Bd. 34, S. 299-399.

\section{Nagel 2012}

Christine Nagel, »Professionalität und Liebhaberei: die Kunstkämmerer von 1572 bis 1832, in: Die kurfürstlich-sächsische Kunstkammer in Dresden. Geschichte einer Sammlung, hrsg. v. Dirk Syndram und Martina Minning, Dresden: Sandstein, 2012, S. 361-377.

\section{Naumann 2007}

Martin Naumann, Das römische Haus. Einem verlorenen Kleinod auf der Spur, Leipzig: Pro Leipzig, 2007. 


\section{Neidhardt 2017}

Uta Neidhardt, »The Development Process of the Dresden Triptych. News and Questions «, in: Van Eyck Studies [Akten des Symposiums: Eighteenth symposium for the Study of Underdrawing and Technology in Painting, Brussels, 19.-21.9.2012], hrsg. v. Christina Currie et al., Paris/Leuven/Bristol: Peeters Publishers, 2017, S. 350-366.

\section{Neidhardt 2005 (1)}

Hans Joachim Neidhardt, "Sammler und Mäzene zur Zeit der Romantik in Dresden«, in: Hans Joachim Neidhardt, Caspar David Friedrich und die Malerei der Dresdner Romantik. Aufsätze und Vorträge, Leipzig: E. A. Seemann Verlag, 2005.

\section{Neidhardt 2005 (2)}

Uta Neidhardt, »Jan van Eycks Dresdener Marientriptychon - Entstehung und Funktion«, in: Das Geheimnis des Jan van Eyck [Kat. der Ausstellung: Dresden, Kupferstichkabinett, 13.8.-31.10.2005], hrsg. v. Thomas Ketelsen und Uta Neidhardt, München/Berlin: Deutscher Kunstverlag, 2005, S. 14-21.

\section{Neidhardt 1993}

Hans Joachim Neidhardt, »Gustav Heinrich Naeke. Ein Nazarener aus Sachsen. Beiträge zur Kunst zwischen Romantik und Realismus«, in: Zeitschrift des Deutschen Vereins für Kunstwissenschaft, 1993, Bd. 47, S. 32-48.

\section{Neidhardt 1988}

Hans Joachim Neidhardt, »Gustav Heinrich Naekes > Heilige Elisabeth im Hofe der Wartburg Almosen spendend «", in: Romantik und Gegenwart. Festschrift für Jens Christian Jensen zum 60. Geburtstag, hrsg. v. Ulrich Bischoff, Köln: DuMont, 1988, S. 157-164.

\section{Neidhardt et al. 1987}

Johann Gottlob von Quandt. Eine Sammlung von Beiträgen zum Leben des Kunstmäzens, Förderers der deutschen Romantiker und Vorstand des Sächsischen Kunstvereins anlässlich seines 200. Geburtstages am 9. April 1987, hrsg. v. Hans Joachim Neidhardt et al., Dürröhrsdorf-Dittersbach: Rat der Gemeinde Dürrröhrsdorf-Dittersbach, 1987.

\section{Neidhardt 1976}

Hans-Joachim Neidhardt, Die Malerei der Romantik in Dresden, Leipzig: E. A. Seemann Verlag, 1976.

\section{Neumann 1991/92}

Hartwig Neumann, Das Zeughaus. Die Entwicklung eines Bautyps von der spätmittelalterlichen Rüstkammer zum Arsenal im deutschsprachigen Bereich vom XV. bis XIX. Jahrhundert, 2 Bde., Bonn: Bernard \& Graefe, 1991/92.

Nida-Rümelin/Steinbrenner 2011 Original und Fälschung (Kunst und Philosophie, Bd. 3), hrsg. v. Julian Nida-Rümelin und
Jakob Steinbrenner, Ostfildern: Hatje Cantz Verlag, 2011.

\section{Niehr 1999}

Klaus Niehr, Gotikbilder - Gotiktheorien. Studien zur Wahrnehmung und Erforschung mittelalterlicher Architektur in Deutschland zwischen ca. 1750 und 1850, Berlin: Gebr. Mann Verlag, 1999.

\section{Niehr 1997}

Klaus Niehr, »Ästhetische Norm und nationale Identität. Fiorillo und die Kunst des Hochmittelalters in Deutschland«, in: Johann Dominicus Fiorillo. Kunstgeschichte und die romantische Bewegung um 1800 [Akten des Kolloquiums: Göttingen, Kunstgeschichtliches Seminar und Kunstsammlung der Universität, 11.-13.11.1994], hrsg. v. Antje Middeldorf Kosegarten, Göttingen: Wallstein, 1997, S. 292-305.

\section{Nipperdey 1998}

Thomas Nipperdey, Deutsche Geschichte 1800-1866. Bürgerwelt und starker Staat, Broschierte Sonderausgabe [Erstausgabe: 1983], München: Verlag C. H. Beck, 1998.

\section{Nipperdey 1976}

Thomas Nipperdey, »Die anthropologische Dimension der Geschichtswissenschaft«, in: Thomas Nipperdey, Gesellschaft, Kultur, Theorie. Gesammelte Aufsätze zur neueren Geschichte (Kritische Studien zur Geschichtswissenschaft, Bd. 18), Göttingen: Vandenhoeck \& Ruprecht, 1976, S. 33-58.

Noack 1907

Friedrich Noack, Deutsches Leben in Rom, Berlin/Stuttgart: J. G. Cotta'sche Buchhandlung, 1907 [Nachdruck: Bern: Herbert Lang, 1971].

Palm 2008

Die Parkanlagen am Schloss Dittersbach. Ein Rundgang, 2. Aufl., hrsg. v. Heike Palm, Dresden: Institut für Landschaftsarchitektur der Technischen Universität, 2008.

\section{Pecht 1877}

Friedrich Pecht, Deutsche Künstler des neunzehnten Jahrhunderts. Studien und Erinnerungen. Erste Reihe, Nördlingen: Verlag C. H. Beck, 1877.

\section{Penzel 2007}

Joachim Penzel, Der Betrachter ist im Text. Konversations- und Lesekultur in deutschen Gemäldegalerien zwischen 1700 und 1914 (Politica et Ars, Bd. 13), Berlin: Lit Verlag, 2007.

\section{Pilz 2006}

Katharina Pilz, »Die Gemäldegalerie in Dresden unter Berücksichtigung der Mengsschen Abgusssammlung«, in: Tempel der Kunst. Die Geburt des öffentlichen Museums in Deutschland 1701-1815, hrsg. v. Bénédicte Savoy, Mainz: Philipp von Zabern, 2006, S. 145-174.

\section{Pinnau 1965}

Ruth Pinnau, Johann Martin von Rohden 1778-1868. Leben und Werk, Bielefeld: Broelemann, 1965.

\section{Plagemann 1967}

Volker Plagemann, Das deutsche Kunstmuseum 1790-1870. Lage, Baukörper, Raumorganisation, Bildprogramm, München: PrestelVerlag, 1967.

\section{Prange 2004}

Regine Prange, Die Geburt der Kunstgeschichte. Philosophische Ästhetik und empirische Wissenschaft (Kunst \& Wissen), Köln: Deubner Verlag für Kunst, Theorie \& Praxis, 2004.

\section{Prange/Locher 2007}

Kunstgeschichte 1750-1900. Eine kommentierte Anthologie (Quellen zur Theorie und Geschichte der Kunstgeschichte, Bd. 3), hrsg. v. Regine Prange und Hubert Locher, Darmstadt: Wissenschaftliche Buchgesellschaft, 2007.

\section{Rautmann 1991}

Peter Rautmann, C. D. Friedrich. Das Eismeer. Durch Tod zu neuem Leben, Frankfurt a/M: Fischer Taschenbuch Verlag, 1991.

\section{Reindl 2006}

Isabel Christina Reindl, Georg Lemberger. Ein Künstler der Reformationszeit. Leben und Werk, 2 Bde., Diss. Bamberg: Otto-Friedrich-Universität, 2006 [Internetressource: urn:nbn:de:bvb:473-opus-2538, https://opus4. kobv.de/opus4-bamberg/frontdoor/index/ index/docld/244, letzter Zugriff: 12.7.2018].

\section{Richter $\mathbf{2 0 0 2}$}

Rainer G. Richter, »Die Beziehungen zwischen dem Kunst- und Künstlerfreund Johann Gottlob von Quandt und dem Sächsischen Hofmaler Carl Vogel von Vogelstein«, in: Luzens 2002, S. 27-41.

\section{Richter 1909}

Adrian Ludwig Richter, Lebenserinnerungen eines deutschen Malers. Selbstbiographie nebst Tagebuchniederschriften und Briefen, hrsg. v. Heinrich Richter, Leipzig: Hesse \& Becker, 1909.

\section{Richter/Strobel 2001}

Eckhard Richter und Jochen Strobel, »Der «König der Romantikı und der Adel. Ludwig Tieck in Dresden«, in: Der Schritt in die Moderne. Sächsischer Adel zwischen 1763 und 1918, hrsg. v. Silke Marburg und Josef Matzerath, Köln/Weimar/Wien: Böhlau, 2001, S. 115-168.

\section{Rössler 2017}

Johannes Rössler, Die Kunst zu sehen. Johann Heinrich Meyer und die Bildpraktiken des Klassizismus, Habil. Bern, Universität, 2017 [unpubliziert].

\section{Rössler 2013}

Johannes Rössler, »Gebändigte Gegenwart. Johann Heinrich Meyer als Beiträger für „Ueber Kunst und Alterthum«, in: Johann 
Heinrich Meyer - Kunst und Wissen im klassischen Weimar (Ästhetik um 1800, Bd. 9), hrsg. v. Alexander Rosenbaum, Johannes Rössler und Harald Tausch, Göttingen: Wallstein Verlag, 2013, S. 275-299.

\section{Rössler 2011}

Johannes Rössler, »Über die Gegenstände der bildenden Kunst«, in: Goethe-Handbuch. Supplemente. Bd. 3: Kunst, hrsg. v. Andreas Beyer und Ernst Osterkamp, Stuttgart/Weimar: J. B. Metzler, 2011, S. 343-351.

\section{Rudloff-Hille 1972-1975}

Gertrud Rudloff-Hille, »Goethe und die Dresdner Galerie«, in: Beiträge und Berichte der Staatlichen Kunstsammlungen Dresden, 1972-1975, S. 37-64.

\section{Rüfenacht 2018}

Andreas Rüfenacht, Die Gemäldesammlung des Johann Gottlob von Quandt (1787-1859) in Dresden. Rekonstruktion und tabellarische Übersicht, Oberdorf/Heidelberg: ART-Dok, 2018 [Internetressource: ART-Dok. Volltextserver des Fachinformationsdiensts Kunst arthistoricum.net, urn:nbn:de:bsz:16-artdok-60424, http://archiv.ub.uni-heidelberg.de/artdok/volltexte/2018/6042, letzter Zugriff: 7.8.2018].

\section{Rüfenacht 2017}

Andreas Rüfenacht, »Intellektuelles Wohlgefallen. Johann Gottlob von Quandt (1787-1859) und die zeitgenössische Landschaftsmalerei«, in: Wissenschaft, Sentiment und Geschäftssinn. Landschaft um 1800 (outlines, Bd. 10), hrsg. v. SIK-ISEA, Zürich: Scheidegger \& Spiess, 2017, S. 152-179.

\section{Rüfenacht 2016}

Andreas Rüfenacht, »Johann Gottlob von Quandt und die Gründungsetappen des Leipziger Kunstmuseums«, in: mdbk. Jahrbuch des Museums der bildenden Künste, Leipzig, Jg. 18, 2016, S. 88-99.

\section{Rüfenacht 2012}

Andreas Rüfenacht, »Goethe in Dresden und Dittersbach. Frühe Formen des Dichter-Gedenkens bei Johann Gottlob von Quandt«, in: Literatur ausstellen. Museale Inszenierungen der Weimarer Klassik (Jahrbuch der Klassik Stiftung Weimar 2012), Göttingen: Wallstein, 2012, S. 31-53.

\section{Rüfenacht 2010}

Andreas Rüfenacht, »Zufluchtsorte verstoßener Kunst. Johann Gottlob von Quandts Einrichtung des Historischen Museums Dresden 1832-34«, in: Jahrbuch der Staatlichen Kunstsammlungen Dresden für das Jahr 2010, 2012, Bd. 36, S. 110-119.

\section{Rüfenacht 2009}

Andreas Rüfenacht, Kunst als Gedanke in anschaulicher Form. Die Gemäldesammlung von Johann Gottlob von Quandt (1787-1859) in Dresden, 2 Bde., Lizentiatsarbeit Bern: Universität, 2009 [unpubliziert].

\section{Safranski 2010}

Rüdiger Safranski, Schopenhauer und die wilden Jahre der Philosophie. Eine Biographie, Darmstadt: Wissenschaftliche Buchgesellschaft, 2010.

\section{Sauerlandt 1908}

Max Sauerlandt, Der stille Garten. Deutsche Maler der ersten Hälfte des 19. Jahrhunderts, Düsseldorf/Leipzig: Karl Robert Langewiesche, 1908.

\section{Savoy 2011}

Bénédicte Savoy, Kunstraub. Napoleons Konfiszierungen in Deutschland und die europäischen Folgen. Mit einem Katalog der Kunstwerke aus deutschen Sammlungen im Musée Napoléon, Wien/Köln/Weimar: Böhlau, 2011.

\section{Savoy 2006}

Bénédicte Savoy, »Zum Öffentlichkeitscharakter deutscher Museen im 18. Jahrhundert«, in: Tempel der Kunst. Die Geburt des öffentlichen Museums in Deutschland 1701-1815, hrsg. v. Bénédicte Savoy, Mainz: Philipp von Zabern, 2006, S. 9-26.

\section{Schasler 1872}

Max Schasler, Kritische Geschichte der Aesthetik. Grundlegung für die Aesthetik als Philosophie des Schönen und der Kunst, 2 Bde., Berlin: Nicolaische Verlagsbuchhandlung, 1872.

\section{Schefold 1939}

Max Schefold, »Die Württembergische Künstlerfamilie Steinkopf«, in: Zeitschrift des Deutschen Vereins für Kunstwissenschaft, 1939, Nr. 6, S. 131-161.

\section{Schlink 2002 [1997]}

Wilhelm Schlink, »]acob Burckhardt über das Amt des Kunsthistorikers « [Deutsche OnlineErstveröffentlichung von Wilhelm Schlink, »acob Burckhardt et le srôles de l'historien de l'art«, in: Relire Burckhardt. Textes inédits en français de Jacob Burckhardt, hsrg. v. Maurizio Ghelardi, Paris: Ecole nationale supérieure des Beaux-Arts, 1997, S. 21-53 [Internetressource: Freiburg, Albert-Ludwigs-Universität, Freiburger Dokumentenserver (FreiDok), www.freidok.uni-freiburg.de/volltexte/452/, letzter Zugriff: 17.9.2018].

\section{Schmidt-Burkhardt 2017}

Astrit Schmidt-Burkhardt, Die Kunst der Diagrammatik. Perspektiven eines neuen bildwissenschaftlichen Paradigmas, 2. vollständig überarbeitete und erw. Aufl. [Erstausgabe: 2012], Bielefeld: transcript Verlag, 2017.

\section{Schmidt-Burkhardt 2005}

Astrit Schmidt-Burkhardt, Stammbäume der Kunst. Zur Genealogie der Avantgarde, Berlin: Akademie Verlag, 2005.

\section{Schmidt-Funke 2006}

Julia A. Schmidt-Funke, Karl August Böttiger (1760-1835). Weltmann und Gelehrter, Heidelberg: Universitätsverlag Winter, 2006.

\section{Schmitz 2008}

Walter Schmitz, »Stadtbilder und Funktionen der Stadt: Dresden - Weimar um 1800«, in: Ereignis Weimar-Jena. Gesellschaft und Kultur um 1800 im internationalen Kontext [Akten der Tagung: Jena, Klassik Stiftung Weimar, 2.-5.9.2007], hrsg. v. Lothar Ehrlich et al., Köln: Böhlau, 2008, S. 157-176.

\section{Schmitz 2001}

Thomas Schmitz, Die deutschen Kunstvereine im 19. und frühen 20. Jahrhundert. Ein Beitrag zur Kultur-, Konsum- und Sozialgeschichte der bildenden Kunst im bürgerlichen Zeitalter (Deutsche Hochschuledition, Bd. 125), Neuried: Ars Una, 2001.

\section{Schmitz/Strobel 2001}

"Von den herrlichsten Kunstwerken umgeben...". Der Briefwechsel zwischen Johann Wolfgang von Goethe und Johann Gottlob von Quandt, hrsg. v. Walter Schmitz und Jochen Strobel, Dresden: Thelem Universitätsverlag, 2001.

\section{Schnorr 1888}

Franz Schnorr von Carolsfeld, »Quandt, Gottlob von«, in: Allgemeine Deutsche Biographie $(A D B)$, Bd. 27, Leipzig: Duncker \& Humblot, 1888, S. 11-12 [Internetressource: https:// www.deutsche-biographie.de/pnd104125489. html\#adbcontent, letzter Zugriff: 17.9.2018].

\section{Schölzel 2012}

Christoph Schölzel, Gemäldegalerie Dresden. Bewahrung und Restaurierung der Kunstwerke von den Anfängen der Galerie bis 1876, Görlitz: Gunter Oettel, 2012.

\section{Schölzel 2005 (1)}

Christoph Schölzel, »Die Restaurierungsgeschichte der Sixtinischen Madonna«, in: Raffael. Die Sixtinische Madonna. Geschichte und Mythos eines Meisterwerks, hrsg. v. Claudia Brink und Andreas Henning, Berlin: Deutscher Kunstverlag, 2005, S. 92-114.

\section{Schölzel 2005 (2)}

Christoph Schölzel, »Der Dresdener Galerierahmen. Geschichte, Technik, Restaurierung«, in: Die blendenden Rahmen. Der Dresdener Galerierahmen, hrsg. v. Christoph Schölzel, Worms: Wernersche Verlagsgesellschaft, 2005, S. 13-40.

\section{Schölzel 1994}

Christoph Schölzel, »Das Wirken Pietro Palmarolis in Dresden«, in: Zeitschrift für Kunsttechnologie und Konservierung, 1994, Jg. 8, Nr. 1, S. 1-24.

\section{Scholl 2015}

Christian Scholl, »Raffaels >Poesie< und die Arbeit der Romantiker an den Mediengrenzen«, in: Sterbliche Götter. Raffael und Dürer in der Kunst der deutschen Romantik [Kat. der Ausstellung: Göttingen, Kunstsammlung der Universität, 19.4.-19.7.2015], hrsg. v. Michael Thimann und Christine Hübner, Petersberg: Michael Imhof Verlag, 2015, S. 92-102. 


\section{Scholl 2007}

Christian Scholl, Romantische Malerei als neue Sinnbildkunst, München/Berlin: Deutscher Kunstverlag, 2007.

\section{Schreiner 1973}

Ludwig Schreiner, »Die Villa Raffael in Rom«, in: Niederdeutsche Beiträge zur Kunstgeschichte, 1973, Jg. 12, S. 269-280.

\section{Schröter 1990}

Elisabeth Schröter, »Raffael-Kult und RaffaelForschung. Johann David Passavant und seine Raffael-Monographie im Kontext der Kunst und Kunstgeschichte seiner Zeit«, in: Römisches Jahrbuch der Bibliotheca Hertziana, 1990, Bd. 26, S. 302-397.

\section{Schuckelt 2010}

Holger Schuckelt, Die Türckische Cammer. Sammlung orientalischer Kunst in der kurfürstlich-sächsischen Rüstkammer Dresden, Dresden: Sandstein Verlag, 2010.

\section{Seeliger 1997}

Stephan Seeliger, »uliuus Schnorr von Carolsfeld. Zwei unbekannte Bildnis-Zeichnungen«, in: Weltkunst, 1997, Bd. 67, S. 34-36.

\section{Seidler $\mathbf{2 0 0 3}$}

Louise Seidler, Goethes Malerin. Die Erinnerungen der Louise Seidler, hrsg. v. Sylke Kaufmann, Berlin: Aufbau Taschenbuch Verlag, 2003.

\section{Selbmann 1988}

Rolf Selbmann, Dichterdenkmäler in Deutschland. Literaturgeschichte in Erz und Stein, Stuttgart: J. B. Metzler, 1988.

\section{Simson 1996}

Jutta von Simson, Christian Daniel Rauch. Fuvre-Katalog, Berlin: Gebr. Mann Verlag, 1996.

\section{Skwirblies 2017}

Robert Skwirblies, Altitalienische Malerei als preußisches Kulturgut. Gemäldesammlungen, Kunsthandel und Museumspolitik 1797-1830 (Ars et Scientia. Schriften zur Kunstwissenschaft, Bd. 13), Berlin/Boston: Walter de Gruyter, 2017.

\section{Slive 2001}

Seymor Slive, Jacob van Ruisdael. A Complete Catalogue of His Paintings, Drawings and Etchings, New Haven/London: Yale University Press, 2001

\section{Spitzer 2011}

Gerd Spitzer, m)...wie man etwa den Düsseldorfer Senf auch hier nach dem Rezepte machen kann.< Der Kulturtransfer zwischen der Düsseldorfer und der Dresdner Malerschule«, in: Die Düsseldorfer Malerschule und ihre internationale Ausstrahlung, 1819-1918 [Kat. der Ausstellung: Düsseldorf, Kunstpalast, 24.9.2011-22.1.2012], Bd. 1, hrsg. v. Bettina Baumgärtel, Petersberg: Michael Imhof Verlag, 2011, Bd. 1, S. 141-149.

\section{Spitzer 2010}

Gerd Spitzer, Caspar David Friedrich in der Dresdener Galerie, hrsg. v. Galerie Neue Meister, Staatliche Kunstsammlungen Dresden, Dresden: Sandstein Verlag, 2010

\section{Spitzer 2007}

Gerd Spitzer, Ludwig Richter in der Dresdener Galerie, hrsg. v. Galerie Neue Meister, Staatliche Kunstsammlungen Dresden, Dresden: Sandstein Verlag, 2007.

\section{Stara 2013}

Alexandra Stara, The Museum of French Monuments 1795-1816. »Killing art to make history«, Farnham: Ashgate, 2013.

\section{Stechow 1965}

Wolfgang Stechow, »Caspar David Friedrich und der 'Griper «, in: Festschrift für Herbert von Einem zum 16. Februar 1965, hrsg. v. Gert von der Osten und Georg Kauffmann, Berlin: Mann, 1965, S. 241-246.

\section{Stock 1933}

Friedrich Stock, »Briefe Rumohrs an Otfried Müller und andere Freunde«, in: Jahrbuch der Preußischen Kunstsammlungen, 1933, Beiheft zu Bd. 54, S. 1-44.

\section{Stolzenburg 2012}

Andreas Stolzenburg, »)[...] der redlichste Mann in ganz Rom - fest und unverführbar<. Johann Christian Reinhart und die Künstlerschaft in Rom 1790-1847«, in: Johann Christian Reinhart. Ein deutscher Landschaftsmaler in Rom [Kat. der Ausstellungen: Hamburg, Kunsthalle, 26.10.2012-27.1.2013 und München, Neue Pinakothek, 21.2.-26.5.2013], hrsg. v. Herbert W. Rott und Andreas Stolzenburg, München: Hirmer, 2012, S. 71-90.

\section{Stolzenburg 2007}

Andreas Stolzenburg, Der Landschafts- und Genremaler Franz Ludwig Catel (1778-1856) [Kat. der Ausstellung: Roma, Casa di Goethe, 30.1.-22.4.2007], München: AsKI, 2007.

\section{Suhr 1991}

Norbert Suhr, Philipp Veit (1793-1877). Leben und Werk eines Nazareners. Monographie und Werkverzeichnis, Weinheim: VCH Acta Humaniora, 1991.

\section{Tauber 2011}

Christine Tauber, »Über Kunst und Altertum«, in: Goethe-Handbuch. Supplemente. Bd. 3: Kunst, hrsg. v. Andreas Beyer und Ernst Osterkamp, Stuttgart/Weimar: J. B. Metzler, 2011, S. 414-429.

\section{Tausch 2010}

Harald Tausch, »Das unsichtbare Labyrinth. Zur Parkgestaltung und Architektur in Goethes >Wahlverwandtschaften « in: Goethes ,Wahlverwandtschaftenc. Werk und Forschung, hrsg. v. Helmut Hühn, Berlin/Boston: Walter de Gruyter, 2010, S. 89-136.

\section{Teichmann 2001}

Michael Teichmann, Julius Schnorr von Carolsfeld (1794-1872) und seine Ölgemälde. Monographie und Werkverzeichnis (Europäische Hochschulschriften. Reihe XXVIII. Kunstgeschichte, Bd. 387), Frankfurt a/M et al.: Peter Lang, 2001.

\section{Thimann 2015}

Michael Thimann, »Raffael und Dürer. Ursprung, Wachstum und Verschwinden einer Idee in der Deutschen Romantik«, in: Sterbliche Götter. Raffael und Dürer in der Kunst der deutschen Romantik [Kat. der Ausstellung: Göttingen, Kunstsammlung der Universität, 19.4.-19.7.2015], hrsg. v. Michael Thimann und Christine Hübner, Petersberg: Michael Imhof Verlag, 2015, S. 8-41.

\section{Thimann 2014}

Michael Thimann, Friedrich Overbeck und die Bildkonzepte des 19. Jahrhunderts, Regensburg: Schnell \& Steiner, 2014.

\section{Thimann 2013}

Michael Thimann, »Eine antiklassizistische Programmschrift aus Rom: Johann David Passavants >Ansichten über die bildenden Künste und Darstellung des Ganges derselben in der Toscanar (1820)«, in: Johann Heinrich Meyer - Kunst und Wissen im klassischen Weimar (Ästhetik um 1800, Bd. 9), hrsg. v. Alexander Rosenbaum, Johannes Rössler und Harald Tausch, Göttingen: Wallstein Verlag, 2013, S. 301-324.

\section{Thome 2015}

Markus Thome, »Baukunst im Museum. Mittelalterliche Architekturteile als Anlass für historisierende Ausstellungsräume«, in: Musealisierung mittelalterlicher Kunst. Anlässe, Ansätze, Ansprüche, hrsg. v. Wolfgang Brückle, Pierre Alain Mariaux, Daniela Mondini, Berlin: Deutscher Kunstverlag, 2015, S. 76-96.

\section{Titz-Matuszak 2000}

Ingeborg Titz-Matuszak, Bernhard August von Lindenau (1779-1854), Bd. 1: »Feind der Reaction und der Revolution «. Eine politische Biographie, Bd. 2: Reden, Schriften, Briefe. Eine Auswahl (Veröffentlichungen aus Thüringischen Staatsarchiven, Nr. 5), 2 Bde., Weimar: Verlag Hermann Böhlaus Nachfolger, 2000.

\section{Uhde 1875}

Erinnerungen und Leben der Malerin Louise Seidler, 2. erw. Aufl. [Erstausgabe: 1874], hrsg. v. Hermann Uhde, Berlin: Verlag von Wilhelm Hertz, 1875.

\section{Vasari 2004}

Giorgio Vasari, Kunstgeschichte und Kunsttheorie. Eine Einführung in die Lebensbe schreibungen berühmter Künstler, übers. v. Victoria Lorini, hrsg., eingeleitet und kommentiert von Matteo Burioni und Sabine Feser, Berlin: Verlag Klaus Wagenbach, 2004. 


\section{Vedder 2010}

Ulrike Vedder, »Museum/Ausstellung«, in: Ästhetische Grundbegriffe. Studienausgabe, hg. v. Karlheinz Barck et al., Bd. 7, Stuttgart/ Weimar: J. B. Metzler, 2010

\section{Vieregg 1991}

Hildegard Vieregg, Vorgeschichte der Museumspädagogik dargestellt an der Museumsentwicklung in den Städten, Berlin, Dresden, München und Hamburg bis zum Beginn der Weimarer Republik, Münster/ Hamburg: Lit, 1991.

Vignau-Wilberg 2011

Peter Vignau-Wilberg, Die Lukasbrüder um Johann Friedrich Overbeck und die Erneuerung der Freskomalerei in Rom, Berlin/München: Deutscher Kunstverlag, 2011.

\section{Vötsch 2000}

Jochen Vötsch, »Um Einheit und Erhalt. Die kurfürstlichen Sammlungen als Hausfideikommiß 1737/47«, in: Dresdener Kunstblätter, 2000, Bd. 44, S. 181-185.

\section{Vogel 1999}

Gerd-Helge Vogel, »Bildhafte Sprache und sprechende Bilder: Anmerkungen zum Einfluss der Werke Goethes auf Bildfindungen der Dresdener Romantiker «, in: Anzeiger des Germanischen Nationalmuseums, hrsg. v. Germanischen Nationalmuseum, Nürnberg: Verlag des Germanischen Nationalmuseums, 1999, S. 177-202.

\section{Vogel 1996}

Julius Schnorr von Carolsfeld und die Kunst der Romantik [Akten der VII. Greifswalder Romantikkonferenz: Schneeberg, 30.9.3.10.1994], hrsg. v. Gerd-Helge Vogel, Greifswald: Steinbecker Verlag Rose, 1996.

\section{Waidacher 1993}

Friedrich Waidacher, Handbuch der Allgemeinen Museologie (Mimundus. Wissenschaftliche Reihe des Österreichischen TheaterMuseums, Bd. 3), Wien/Köln/Weimar: Böhlau, 1993.

\section{Weber 1997}

Gregor J.M. Weber, »Wie kommt eine Bäckertochter in den Himmel? Überlegungen zu Oehmes Gemälde >Die Villa Raffaels in Rom «, in: Ernst Ferdinand Oehme, 1797 1855. Ein Landschaftsmaler der Romantik [Kat. der Ausstellungen: Dresden, Albertina, 21.4.-29.6.1997 und Lübeck, Behnhaus, 20.7.7.9.1997], hrsg. v. Ulrich Bischoff, Dresden: Neumeister, 1997, S. 57-63.

\section{Weddigen 2008}

Tristan Weddigen, Die Sammlung als sichtbare Kunstgeschichte. Die Dresdner Gemäldegalerie im 18. und 19. Jahrhundert, Habil. Bern: Universität, 2008 [unpubliziert].

\section{Welich 1996}

Dirk Welich, »Die Fresken der katholischen Kapelle im Schloß Pillnitz«, in: Jahrbuch der Staatlichen Schlösser, Burgen und Gärten in Sachsen, 1996, Jg. 4, S. 112-125.

\section{Weniger 2011}

Matthias Weniger, Sittow, Morros, Juan de Flandes. Drei Maler aus dem Norden am Hof Isabellas der Katholischen, Kiel: Verlag Ludwig, 2011.

\section{Weniger 2003}

Matthias Weniger, „Zur Geschichte von Erwerbung und Präsentation der Sammlung spanischer Gemälde der Dresdener Galerie. Aus Anlass einer Umhängung im zweiten Geschoss des Semperbaus«, in: Dresdener Kunstblätter, 2003, Jg. 47, Nr. 6, S. 338-347.

\section{Wentzlaff-Eggebert 2009}

Harald Wentzlaff-Eggebert, Weimars Mann in Leipzig. Johann Georg Keil (1781-1857) und sein Anteil am kulturellen Leben der Epoche. Eine dokumentierte Rekonstruktion, Heidelberg: Universitätsverlag Winter, 2009.

\section{Wilmowsky 2017}

Monika von Wilmowsky, Ernst Rietschel als Bildhauer mit einem Katalog der Bildwerke. Werkverzeichnis, 2 Bde., Köln: LETTER Stiftung, 2017.

\section{Winzeler 2007}

Marius Winzeler, »Die Architekturausbildung in Dresden vor der Berufung Gottfried Sempers - das Beispiel Heinrich Hermann Bothen (1814-1878)«, in: Gottfried Semper - Dresden und Europa. Die moderne Renaissance der Künste [Akten des Kolloquiums: Dresden, Technische Universität, 27.-30.11.2003], hrsg. v. Henrik Karge, München/Berlin: Deutscher Kunstverlag, 2007, S. 187-202.

\section{Wolf 2002}

Norbert Wolf, Klassizismus und Romantik (Kunst-Epochen, Bd. 9), Stuttgart: Reclam, 2002.

\section{Zirfas 2016}

Jörg Zirfas, »Klassik und Romantik. Das lange 19. Jahrhundert der Ästhetischen Bildung « und »Die Kunst der Selbstverständigung. Hegels Überlegungen zu Bildung, Kunst und Ästhetik«, in: Geschichte der Ästhetischen Bildung. Bd. 3.2: Klassik und Romantik, hrsg. v. Jörg Zirfas et al., Paderborn: Ferdinand Schöningh, 2016, S. 7-32, 128-143.

\section{Zwenger 2003}

Thomas Zwenger, »Universalgeschichte«, in: Handwörterbuch Philosophie, hrsg. v. Wulff D. Rehfus, Göttingen: Vandenhoeck \& Ruprecht, 2003. 